\title{
Eco-hydrology interactions between trees, soil and water in terrestrial and wetland areas: The effect of tree planting on water flow dynamics in Wairarapa Wetlands, New Zealand
}




\section{ABSTRACT}

During the last two decades there has been increasing interest in the role of forests and wetlands as flood mitigating tools due to growing concerns regarding the sustainability of many traditional engineering flood defences such as dykes, sea walls and dams. In forests, the role is facilitated by the interaction between trees, soil and water. Specifically trees reduce surface runoff and prevent flooding through increased evapotranspiration and canopy interception and enhance physical and hydraulic properties of soil that are critical for the absorption and retention of flood waters by the soil. It is increasingly realised that the answer to flood mitigation is not a blanket recommendation to "plant trees". This is because the role of trees varies spatially and temporally as a function of climate, topography, rainfall properties, soil type and condition, catchment scale and geology, among others. For example, where trees are present in wetlands, particularly forested wetlands, the mechanisms by which trees interact with soil and water are similar to that in forests but because of a high water table, the impact of trees may be reduced. Therefore, the mere presence of forests and forested wetlands will not necessarily deliver flood risk management.

The purpose of this study was to explore the effectiveness of trees as flood mitigating tools under various bio-geo climatic factors in forests and forested wetland environments. Three forms of investigation were followed to fulfil this purpose.

A detailed literature review was carried out to assess the role of trees and forests as flood mitigation tools under changing climate, topography, species type, rainfall properties, soil type and condition, catchment scale and geology. A field experiment was carried out to collect data and analyse the effect of trees on soil physical and hydraulic properties that include bulk density, saturated hydraulic conductivity, soil organic carbon, soil moisture content, matric potential and soil moisture retention in a previously forested wetland undergoing restoration in New Zealand. A spatially explicit decision support tool, the Land Use Capability Indicator (LUCI) was then used to determine appropriate areas where intervention can be targeted to optimise the role of trees as flood mitigating tools in previously forested wetlands undergoing restoration.

The detailed review identified a major data gap in the role of trees under hydric conditions (high water table), along with uncertainties on their effectiveness in large catchments ( $\sim 40$ $\mathrm{km}^{2}$ ) and in extreme rainfall events. The field experiment provided the first set of soil hydrology data from an ephemeral wetland in New Zealand showing the benefits of newly established trees in improving hydraulic conductivity of soils. The soil hydrology data is a useful baseline for continuous monitoring of the forested wetlands undergoing restoration. The use of the Land Use Capability Indicator was its first application for the optimisation of flood mitigation in a forested wetland. Its suggested target areas are not necessarily conducive for survival of some tree species, although if suitable species are established, flood risk mitigation could be maximised. Further research on what native species are best for what conditions and in what combinations is recommended, to increase survival in the proposed target areas. 


\section{ACKNOWLEDGEMENTS}

I am grateful to the Victoria University Doctoral Scholarship for funding this research. Special thanks to my supervisors Bethanna Jackson and Stephen Hartley for their immense support, encouragement, valuable suggestions and guidance throughout my PhD.

I have also benefited from the advice and assistance of Ingeborg Kluts, Deborah Maxwell, Nokuthaba Sibanda, Julie Disciple, Tony Silbery and Ian Gunn. Most of the data collection would not have been possible without the generous support of Dez Tessler, Victor Anton, Ryan Evison, and Samwell Warren who drove with me to the site and helped with field work in the uncompromising wetland environment. Many thanks to Jane Chewings, Sabrina Lange, Kosta Tashkoff, Ashley Pocock, Martha Trodahl, Rubianca Benavidez, Shi Cheng, Alex Coles, Charlie Hopkins and Monique Beyer for their assistance in field and laboratory. Big thanks to Jim Law and Don Bell, for providing materials and technical expertise for the field experiment. I am indebted to Dr Hussain Omed (Bangor University), Charity Mundava (Curtin University), Xiaodan Gao and Lizzie Towl (Victoria University) for their wise words of encouragement and belief in me. The bug club and hydrology group provided feedback on presentations and papers. Special thanks to Andy Rae, Stu Easton and Orane Reuland for their assistance in GIS and spatial modelling. To my friends Habte Gabriel and Adrien GasseMarget Rauda, thank you for sharing ideas and helping out in designing powerpoints since our group work during Masters studies right through to my PhD study.

Final thanks to God for the strength to persevere and to my mother for constantly reminding me of some of the important things in life other than the thesis and for goodnaturedly complaining of taking second place to my studies. 


\section{Contents}

ABSTRACT .

ACKNOWLEDGEMENTS

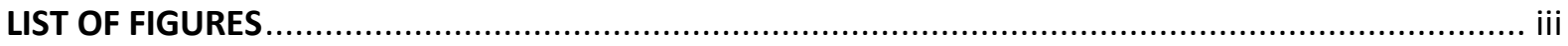

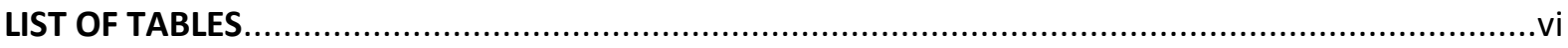

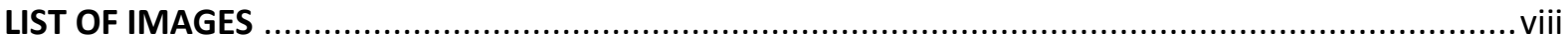

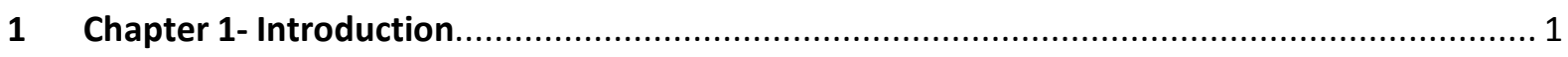

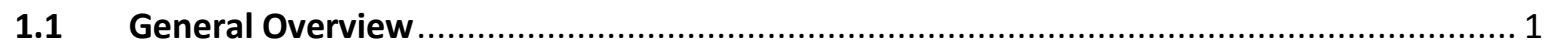

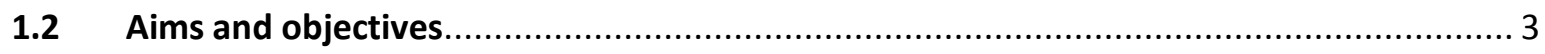

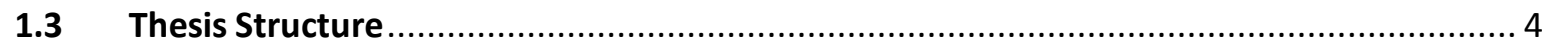

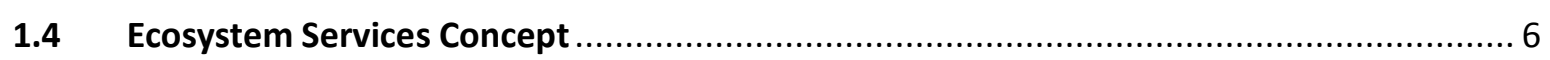

1.4.1 Classification of ecosystem services.............................................................. 7

1.4.2 Application of the ecosystem services concept................................................. 8

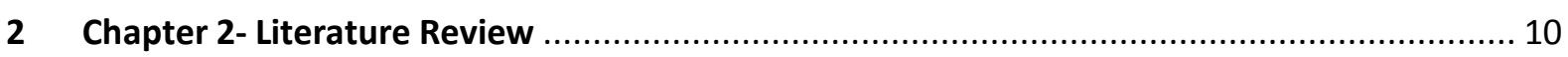

2.1 The role of trees in reducing flood risk-general use/interaction with water, effect of different species, age, position in the landscape, scale, soils and magnitude of rainfall events, geology, climatic conditions and role in other ecosystem types such as wetlands .................... 10

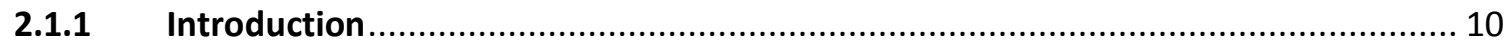

2.1.2 Interaction of trees/forests with water and soil under different climate and

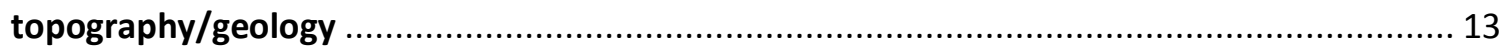

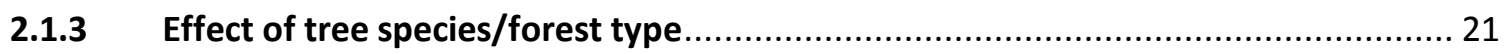

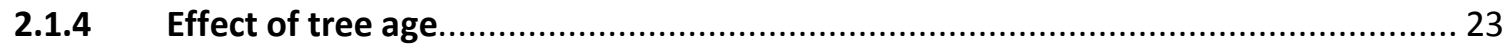

2.1.5 Trees and forests vs. other land use/vegetation types ...................................... 25

2.1.6 Response of trees/forests under different rainfall properties and catchment scale 29

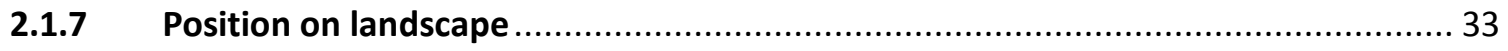

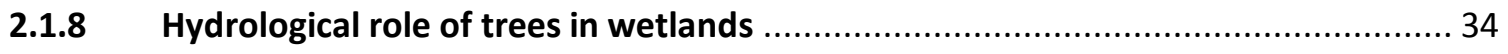

2.1.9 Summary of the main findings of the review and recommendations ..................... 36

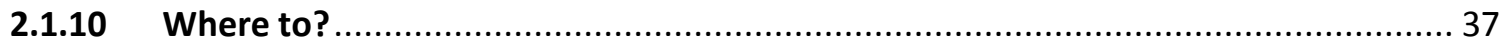

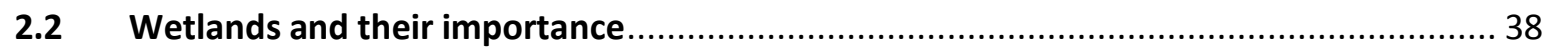

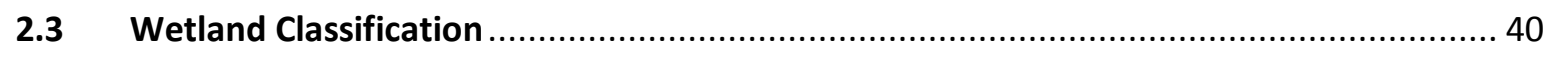

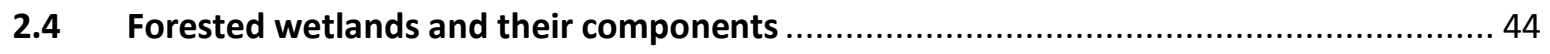

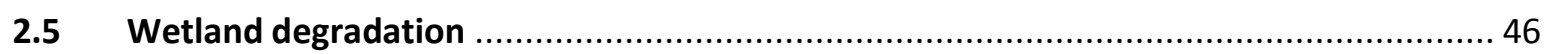

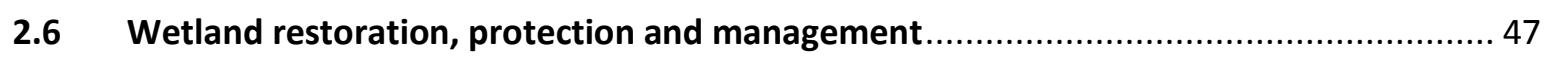

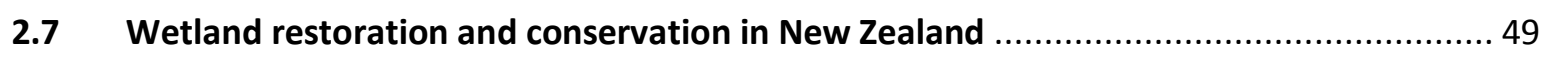

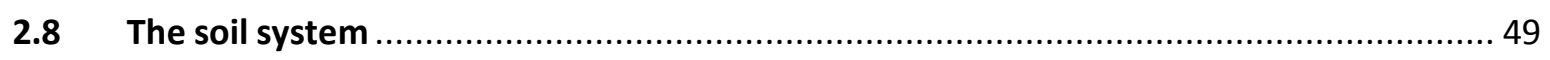

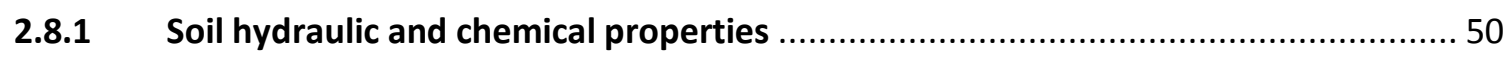




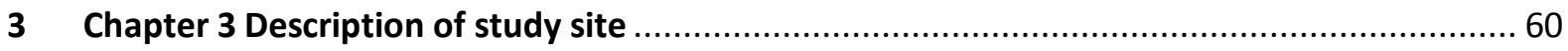

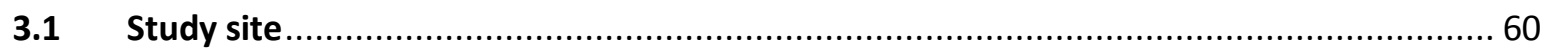

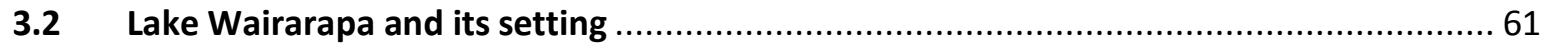

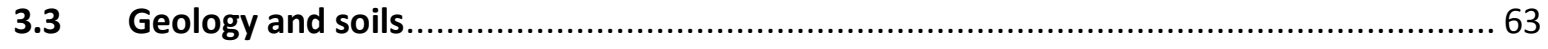

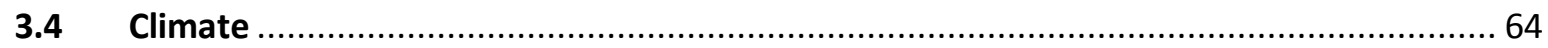

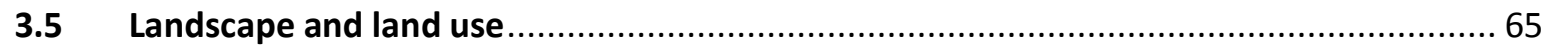

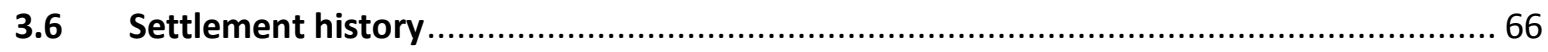

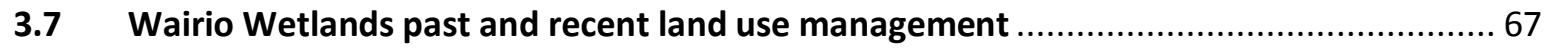

3.8 Characterisation of the established native species at Wairio wetlands ..........................69

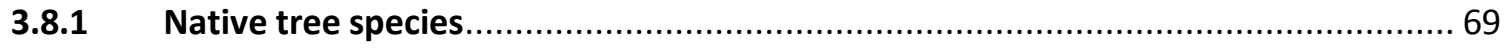

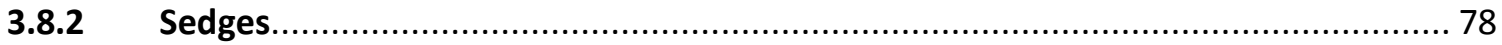

4 Chapter 4- Dynamics of the impact of tree restoration on soil physical, chemical and hydraulic properties of previously forested ephemeral Wairio wetlands. .............................................. 79

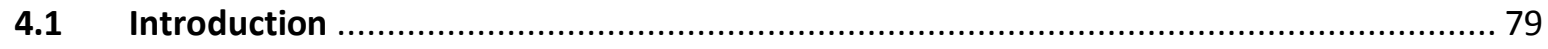

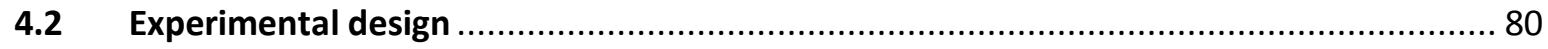

4.3 Quantification of bulk density, saturated hydraulic conductivity, soil organic carbon, soil

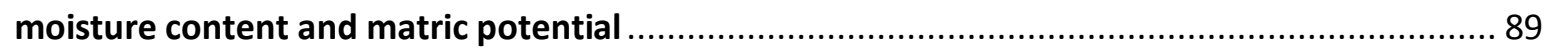

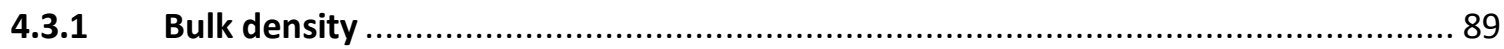

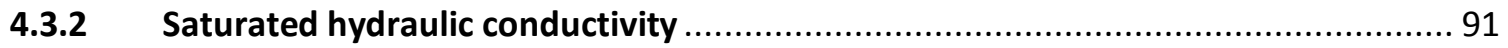

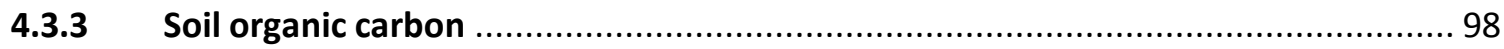

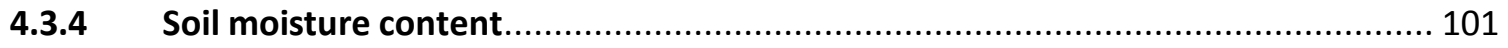

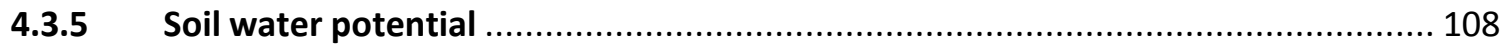

4.3.6 Estimation of an approximate water balance .................................................. 120

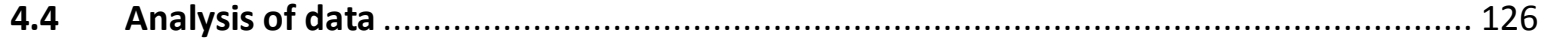

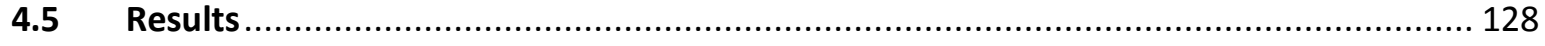

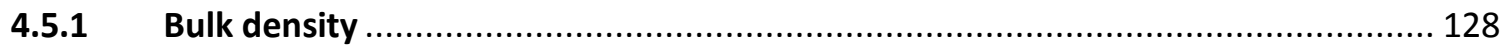

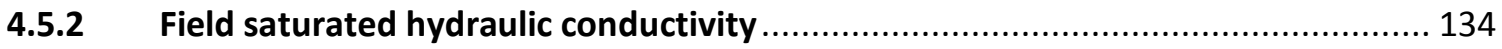

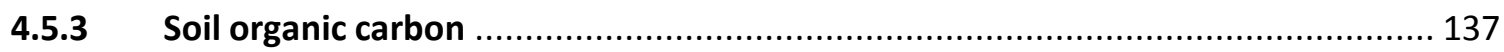

4.5.4 Volumetric soil moisture content (lab derived through gravimetric measurements) ..

4.5.5 Volumetric soil moisture content (field measurements using CS620 moisture

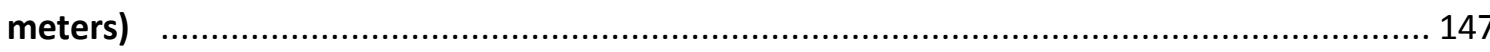

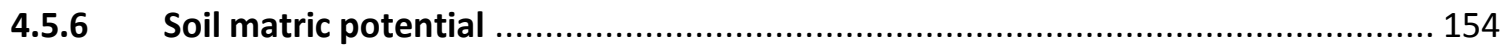

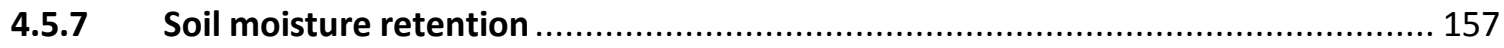

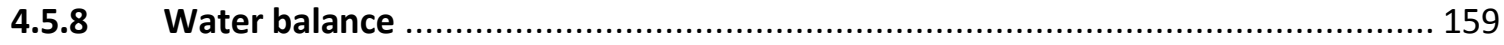

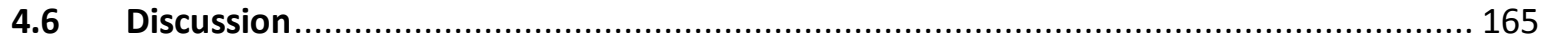




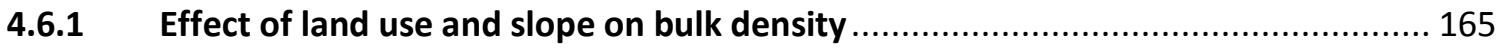

4.6.2 Effect of land use on field saturated hydraulic conductivity ................................ 167

4.6.3 The relationship between land use, slope gradient and soil organic carbon .......... 168

4.6.4 Effect on volumetric soil moisture content (lab derived) ................................... 172

4.6.5 Effect of land use on volumetric soil moisture content (sensor measured) ........... 172

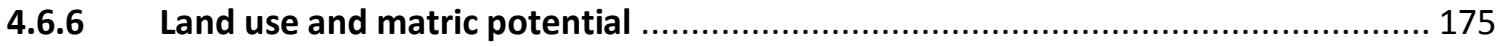

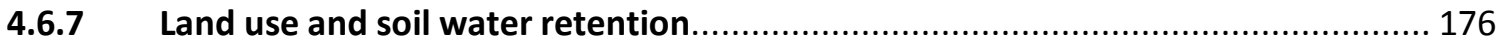

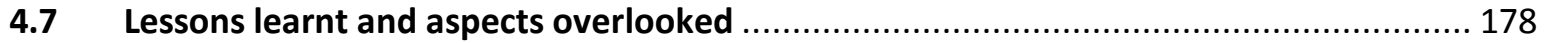

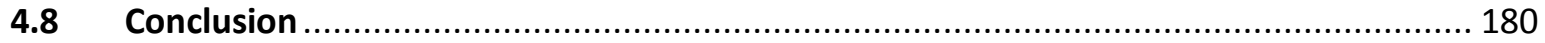

4.9 Aspects that can be considered for the future of this restoration project .................... 181

5 Chapter 5- Strategies to determine appropriate target areas optimise flood runoff mitigation

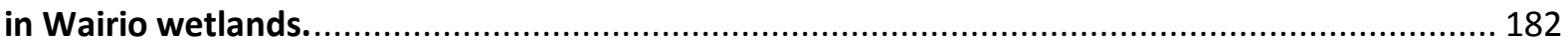

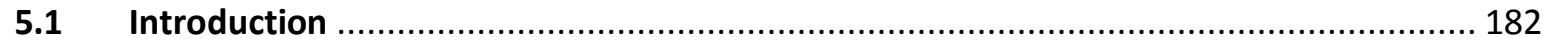

5.2 Description of Land Use Capability Indicator (LUCI) tool .......................................... 183

5.2.1 Description of the flood mitigation component of $\mathrm{LUCl}$ tool used at Wairio wetlands

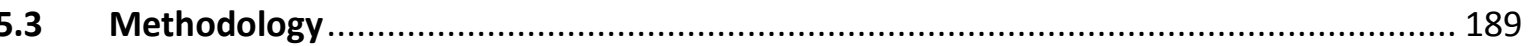

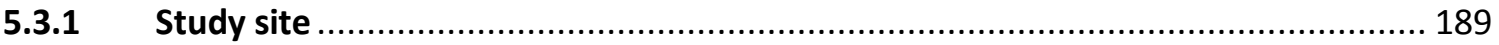

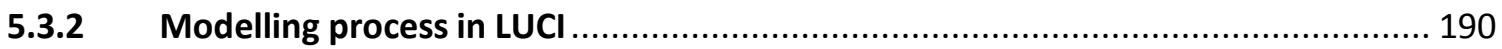

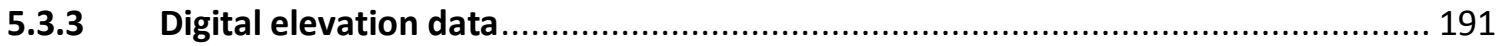

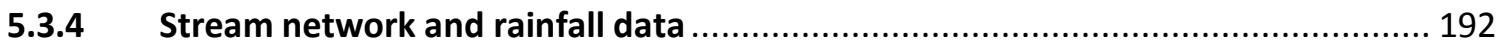

5.3.5 Land cover and soil data for land management scenario generation ..................... 193

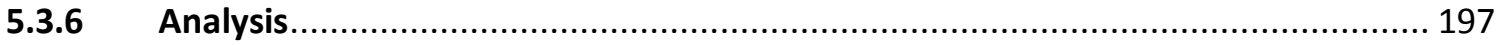

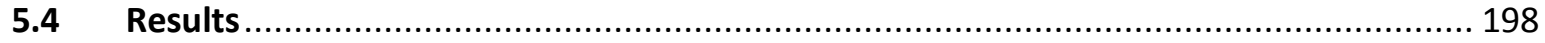

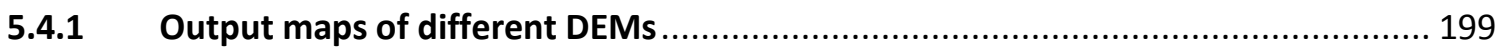

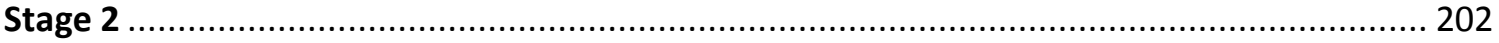

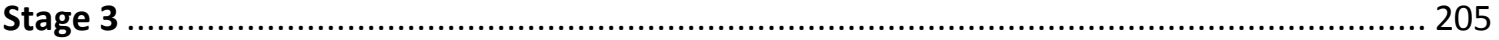

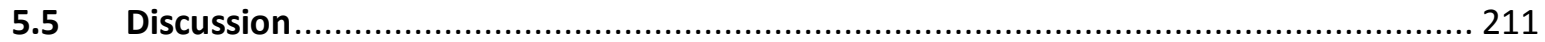

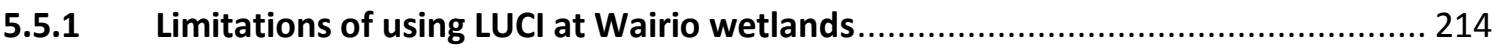

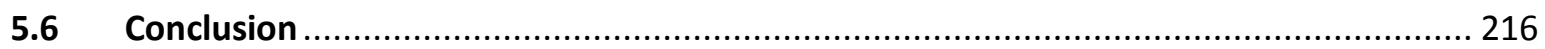

6 Chapter 6- Guidelines for the effective use of trees in forests and forested wetlands for flood

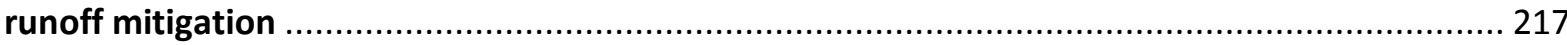

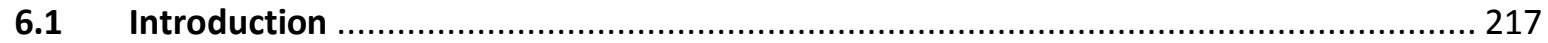

6.2 Under what topography are trees and forests useful? ............................................. 217

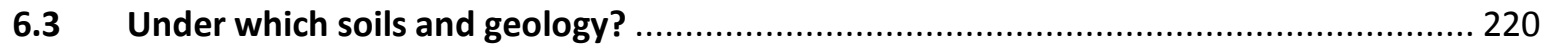

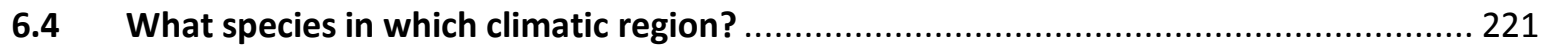




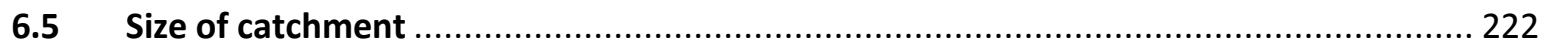

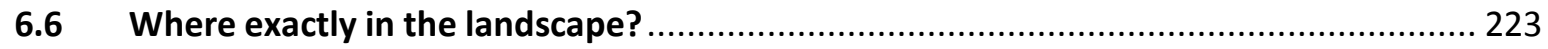

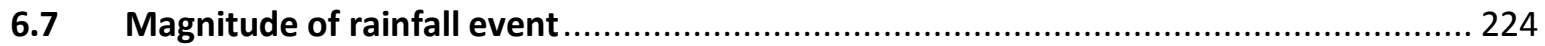

6.8 Guidelines from a holistic perspective for policy makers .......................................... 226

6.9 Guidelines for forested wetlands undergoing restoration ....................................... 231

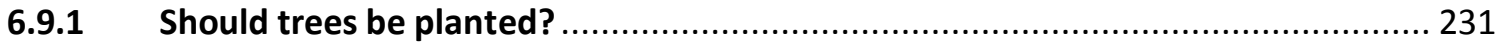

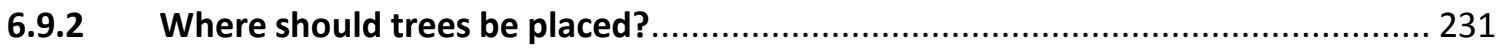

6.9.3 Choice of tree species and sedges that should be planted .................................. 232

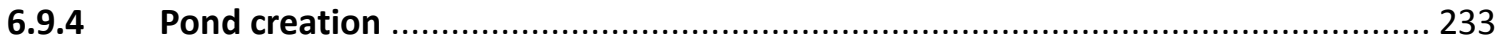

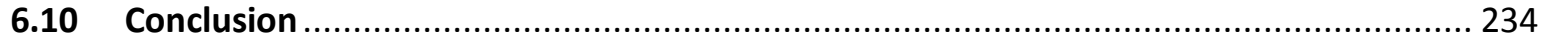

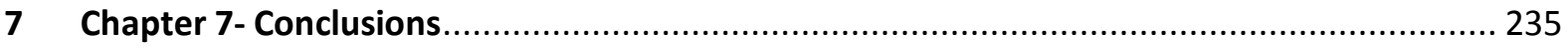

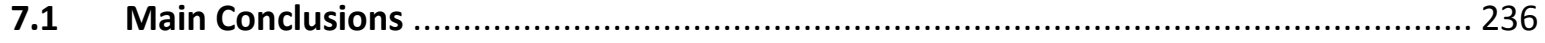

7.1.1 The role of trees and forests as flood mitigation tools under changing climate, topography, species type, rainfall properties, soil type and condition, catchment scale and geology

7.1.2 The role of trees for flood mitigation in previously forested wetlands undergoing restoration.

7.1.3 Delineating appropriate target areas for tree planting to optimise the role of trees as flood mitigating tools in previously forested wetlands undergoing restoration.

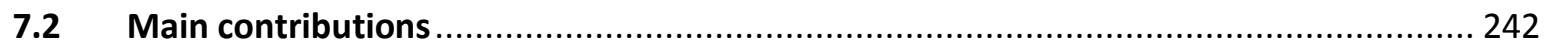

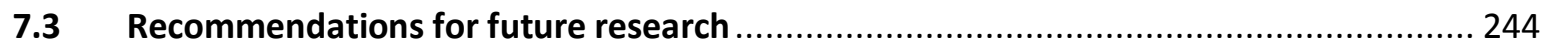

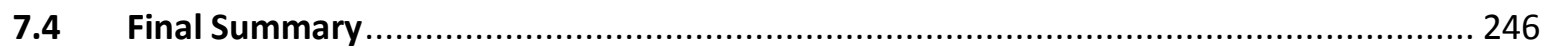

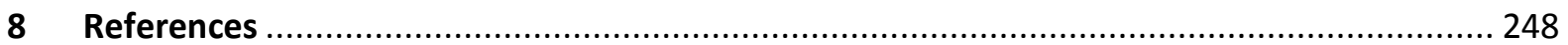

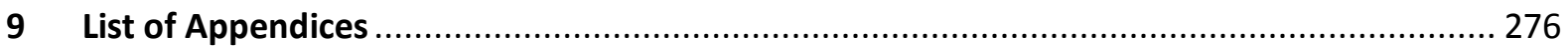




\section{LIST OF FIGURES}

Figure 1. Appropriate positions in the landscape, near the source of runoff or downslope. 34

Figure 2. Plot lay out in stage 3 84

Figure 3. Aerial photo of the sampling locations of soil properties in the plots of Stage 3 85

Figure 4. Plot lay out for stage 2 86

Figure 5. Aerial photo of the sampling locations of soil properties in the plots of Stage 2 ......

Figure 6. Illustration of the relationship between soil water potential components in a soil column with water table at a height of $100 \mathrm{~cm}$. Adapted and modified from Tindall et al. (1999).

Figure 7. Mean (+/- $1 \mathrm{SE}$ ) bulk density of the land use types at different soil depths. Different letters indicate significant differences between land use types within each depth based on LSD posthoc comparisons. 130

Figure 8. Mean (+/- $1 \mathrm{SE}$ ) bulk density of the four land use types at varying slope gradients and soil depths. Different letters indicate significant differences between land use types at varying slopes within each depth based on LSD post-hoc comparisons.

Figure 9. Change in bulk density over time under different land use types at 6 and $18 \mathrm{~cm}$ soil depth

Figure 10. Box plots showing minimum, lower quartile, median, upper quartile and maximum values of decadic log transformed Kfs values of soils under unplanted, planted, cabbage and manuka sites. The dotted line represents the median of all measured values. 136

Figure 11. Mean (+/- $1 \mathrm{SE}$ ) soil organic carbon under four land use types at 6 and $18 \mathrm{~cm}$ soil depths. Different letters indicate significant differences between land use types within each depth based on LSD post-hoc comparisons.

Figure 12. Mean (+/- $1 \mathrm{SE}$ ) soil organic carbon of land use types at varying slope and soil depth. Different letters indicate significant differences between land use types within each depth based on LSD post-hoc comparisons.

Figure 13. Soil organic carbon (SOC) stocks at $6 \mathrm{~cm}$ and $18 \mathrm{~cm}$ depths in four land use types of Wairio wetlands. 140

Figure 14. Box plots showing minimum, lower quartile, median, upper quartile and maximum values of volumetric soil moisture content under unplanted, planted, cabbage and manuka sites. ... 143

Figure 15. Mean volumetric moisture content of four land use types over time 144

Figure 16. Mean (+/- $1 \mathrm{SE})$ soil volumetric moisture content of land use types at varying slope gradients within $6 \mathrm{~cm}$ soil depth. Different letters indicate significant differences between land use types within each depth based on LSD post-hoc comparisons 145 
Figure 17. Mean (+/- $1 \mathrm{SE}$ ) soil volumetric moisture content of land use types at varying slope gradients within $18 \mathrm{~cm}$ soil depth. Different letters indicate significant differences between land use types within each depth based on LSD post-hoc comparisons

Figure 18. Variation in volumetric soil moisture content (\%) across the 2014 season to early 2015 (April 162014 to March 72015 ) at $10 \mathrm{~cm}, 20 \mathrm{~cm}$ and $30 \mathrm{~cm}$ depths for a site planted with a mixture of tree species at $8 \%$ slope gradient in Block 7

Figure 19. Variation in volumetric soil moisture content (\%) across the 2014 season to early 2015 over $10 \mathrm{~cm}, 20 \mathrm{~cm}$ and $30 \mathrm{~cm}$ for an unplanted site at $8 \%$ slope gradient in Block 13

Figure 20. Variation in volumetric soil moisture content (\%) across the 2014 season to early 2015 over $10 \mathrm{~cm}, 20 \mathrm{~cm}$ and $30 \mathrm{~cm}$ for a site planted with a mixture of tree species at $3 \%$ slope gradient in Block 9.

Figure 21. Average soil volumetric soil moisture content at $10 \mathrm{~cm}$ depth under different land use times over time 151

Figure 22. Average soil volumetric soil moisture content at $10 \mathrm{~cm}$ depth under different land use times over time 152

Figure 23. Average soil volumetric soil moisture content at $30 \mathrm{~cm}$ depth under different land use times over time

Figure 24 Matric potential at $10 \mathrm{~cm}$ and $30 \mathrm{~cm}$ in $(\mathrm{a}, \mathrm{b})$ planted and unplanted on high slope, (c) planted on low slope, (d) a zoom of (c) 156

Figure 25. Soil moisture retention curves at $10 \mathrm{~cm}$ depth at three different locations with differing land cover and slopes 157

Figure 26. Soil moisture retention curves at $30 \mathrm{~cm}$ depth of planted and unplanted areas located on $3 \%$ and $8 \%$ slope gradients. 158

Figure 27. Flow chart showing the modelling process in $\mathrm{LUCl}$ 190

Figure 28. Before and after intervention land use permeability modelled at $1 \mathrm{~m}$ DEM (land surveying) 202

Figure 29. Before and after intervention land use permeability modelled at $1 \mathrm{~m}$ DEM (LiDAR). 202

Figure 30. Before and after intervention land use permeability modelled at $5 \mathrm{~m}$ resolution LiDAR 203

Figure 31. Before and after intervention land use permeability modelled at $10 \mathrm{~m}$ resolution DEM (LiDAR) 203

Figure 32. Before and after intervention land use permeability modelled at $15 \mathrm{~m}$ resolution DEM (LiDAR) 204 
Figure 33. Before and after intervention land use permeability modelled at $1 \mathrm{~m}$ DEM resolution (land survey)

Figure 34. Before and after intervention land use permeability modelled at $1 \mathrm{~m}$ DEM (LiDAR)....... 205

Figure 35. Before and after intervention land use permeability modelled at $5 \mathrm{~m}$ DEM resolution (LiDAR).

Figure 36. Before and after intervention land use permeability modelled at $10 \mathrm{~m}$ DEM resolution (LIDAR).

Figure 37. Before and after intervention land use permeability modelled at $15 \mathrm{~m}$ resolution (LiD .. 207

Figure 38. Slope gradient and intervention maps a \& b for stage 2; c \& d for stage 3 210

Figure 39. Demonstration of flood peak discharge of forested and non-forested land uses under varying catchment scales

Figure 40. Magnitude of rainfall event 225

Figure 41. Effectively using trees and forests in as flood mitigation tools at varying soils/geology, catchment scale, rainfall properties and slope in Arid regions.....

Figure 42. Effectively using trees and forests in as flood mitigation tools at varying soils/geology, catchment scale, rainfall properties and slope in Humid regions

Figure 43. Effectively using trees and forests in as flood mitigation tools at varying soils/geology, catchment scale, rainfall properties and slope in Semi-arid regions

Figure 44. Effectively using trees and forests in as flood mitigation tools at varying soils/geology, catchment scale, rainfall properties and slope in Temperate regions 


\section{LIST OF TABLES}

Table 1 Relative magnitudes of water balance components between forested and non-forested areas. Adapted and modified from Cheng et al. (2002)

Table 2 Effect of Trees vs other land use types on flood flow. Adapted, modified and extended from Blaschke et al. (2008) and Ballinger (2009)

Table 3 How the impact of trees and forests changes as rainfall properties and catchment scale change.

Table 4 Summary of a few studies highlighting impact of trees under varying rainfall and landscape scales. 32

Table 5 Hierarchical classification for New Zealand...... 42

Table 6 Hydrogeomorphic classification of forested wetland types .45

Table 7 Landscapes in Wairarapa region 65

Table 8 Land use area in the Wairarapa Catchment 66

Table 9 Summary of the characteristics of cabbage and manuka species. 71

Table 10 Planting dates and initial establishment data for the trees planted in 19 plots across eight blocks. 82

Table 11 Measurement events for bulk density at Wairio wetlands 91

Table 12 Measurement events for field saturated hydraulic conductivity at Wairio wetlands .94

Table 13 Suggested values of $\alpha^{*}$ for different soil types. (Adapted from Elrick \& Reynolds, 1992) .... 97

Table 14 Summary of the methods for determination of soil organic carbon 99

Table 15 Characteristics of sites where CS620 sensors and T4e tensiometers were installed for continuous monitoring of soil mositure levels and matric potential 107

Table 16 Comparison between soil water potential and pore diameter. Adapted and modified from Decagon Devices (2006). 112

Table 17 Fixed effects test of the effect of stage of restoration of the land use types on bulk density..

Table 18 Fixed effects test for the effect of land use, soil depth and slope on bulk density 128

Table 19 Fixed effects test for the effect of land use and slope on saturated hydraulic conductivity

Table 20 Statistical description of saturated hydraulic conductivity $(\mathrm{mm} / \mathrm{hr})$ under different land use types

Table 21 Fixed effects test for the effect of land use, soil depth, slope and stage of restoration on soil organic carbon. 
Table 22 Mean Soil organic carbon (SOC) stocks at different depths along topographical gradient in four land use types of Wairio wetlands

Table 23 Fixed effects test for the effect of land use, soil depth and slope on volumetric soil moisture content.

Table 24 ANOVA for the effect of land use, season and their interaction on the variation in volumetric moisture content at $10 \mathrm{~cm}$ depth 150

Table 25 ANOVA for the effect of land use, season and their interaction on the variation in volumetric moisture content at $20 \mathrm{~cm}$ depth 151

Table 26 ANOVA for the effect of land use, season and their interaction on the variation in volumetric moisture content at $30 \mathrm{~cm}$ depth 153

Table 27 LCBD2 misclassifications 194

Table 28 Soil attributes of the FDL that was used as input for the generation of management scenarios for the LUCI modelling process 195

Table 29 Potential ecological benefits associated with land use interventions before or after restoration. 196

Table 30 Baseline and corrected land use/cover data 198

Table 31 Summary statistics for the difference in elevation between DEMs in Stage 2 . 200

Table 32 Summary statistics for the difference in elevation between DEMs in Stage 3. 200

Table 33. The effect of intervention expressed at various DEM resolutions in stage 2 . 208

Table 34. The effect of intervention expressed at various DEM resolutions in stage 3. 209

Table 35 Effectiveness of trees and forests under varying geology and soils 220

Table 36 Appropriate species for different climatic zones 221

Table 37 Survival rate of species protected by tree guards (grotectors) 233 


\section{LIST OF IMAGES}

Image 1 Cabbage tree (Cordyline australis) a) at 4 years old taken by the author at Wairio (Stage 3, block 10) in September 2014; b cabbage tree at a later stage of growth, adapted from http://www.nzpcn.org.nz/flora_details.aspx?ID=1744 in January 2016 ................................ 70 Image 2 Manuka tree (Leptospermum scoparium) adapted from http://www.nzpcn.org.nz in January 2016

Image 3 Coprosma propinnqua adapted from http://www.nzpen.org.nz in January 2016 72 Image 4 Pittosporum tenufolium adapted from http://www.nzpen.org.nz in January 2016 73 Image 5 Croposma robusta a) adapted from http://www.nzpen.org.nz in January 2016, b) image taken by Stephen Hartley in stage 3 (Block 8) at Wairio wetlands on 19 March 2015 74 Image 6 Olearia virgata adapted from http://www.nzpcn.org.nz in January 2016 .75 Image 7 Podocarpus totara, a) adapted from http://www.nzpcn.org.nz in January 2016; b) Totara at 4 years old, taken by Stephen Hartley in stage 3 at Wairio wetlands on 19 March 2015 .......... 76 Image 8 Kahikatea adapted from http://www.nzpcn.org.nz in January 2016 .................................. 77 Image 9 Carex geminata adapted from http://www.nzpcn.org.nz in January 2016 ........................... 78 Image 10. Lay out of trees in stage 3, Block 12, plot 1, where 15 out of 49 planted trees were protected with grotector tree-guards. Foreground shows cabbage trees, in the distance are planted manuka trees. Photo taken by author in October 2014, 10 months after planting. ...... 88 Image 11. Soil sampling in a plot planted with Cabbage trees in Block 13 using stainless steel core attached to a cross bar, A- Insertion of stainless steel core cup attached to a cross handle, BStainless steel core cup attached to a cross handle, C- Soil sample collected in a stainless steel. Image taken by Author in November 2014. 90 Image 12. Creation of a well (B) using a sharpened auger (A). Image taken by Author in August 2014.

Image 13. Guelph Permeameter mounted over a well on a tripod in a plot planted with a mixture of tree species in Block 1. Image taken by Author in October 2014. 96

Image 14. Tensiometers at 10 and $30 \mathrm{~cm}$ soil depth (a) with refilling tubes, sensor cable and part of the shaft covered with thermal insulation tubes (b) in an unplanted plot of block 13. Image taken by Author in August 2015. 116

Image 15. Tensiometers connected to a CR 1000 data logger powered by a $12 \mathrm{~V}$ battery in an unplanted plot of Block 13. Image taken by Author in August 2014. 


\section{Chapter 1- Introduction}

\subsection{General Overview}

Forests and wetlands are beneficial to both humankind and the wider environment. They play a vital role in flood risk management, carbon sequestration, water quality improvement, recreation and biodiversity provision (Bullock \& Acreman, 2003; Acreman \& Holden, 2013; Archer et al., 2013; Davidson, 2014). Recently there has been increasing interest in their role in flood mitigation, which is the focus of this study. This is because of the growing concern over the sustainability of many traditional engineering flood defences such as dykes, sea walls and dams, and the increase in flood incidences following the removal or destruction of forests (Weber, 2007; Temmerman et al., 2013; Brody et al., 2015). Weber (2007) reported that continuous deforestation for a period of 25 years in Baltimore (USA) resulted in a $19 \%$ increase in storm water runoff that caused floods, and if engineering defences had been used to replace lost storm water retention capacity of trees, the cost would have been approximately US\$ 1 billion. In the Netherlands, it has been estimated that in order to cope with increasing flood risk due to climate change, it would cost 1.6 billion euros per annum by 2050 to maintain appropriate engineering flood defence structures (Kabat et al., 2009; Temmerman et al., 2013). However, restoring wetlands for the same purpose would cost an estimated 600 million euros (Kabat et al., 2009; Temmerman et al., 2013).

The specific role of forests and wetlands in flood mitigation varies temporally and spatially as a function of climate, topography, rainfall properties, soil type and condition, catchment scale and geology, among others (Bullock \& Acreman, 2003; Calder \& Aylward, 2006; Mitsch \& Gosselink, 2007; Archer et al., 2013). Accordingly, the mere presence of forests and wetlands does not necessarily translate to significant flood risk mitigation. There is a need for a better understanding of how and where they can be effectively used for this purpose.

In forests, the flood mitigation role is facilitated by the interaction between trees, soil and water. Specifically trees reduce runoff through evapotranspiration, canopy interception and enhance physical and hydraulic properties of soil that are critical for the absorption and retention of flood waters into the soil sub-surface, compared to other vegetation types such as grasses (Robinson \& Dupeyrat, 2005; Marshall et al., 2009). However, as mentioned 
before, the attenuation of floods varies spatially and temporally according to various climatic, soil, geological and topographical factors, among others. Studies that have investigated the role of forests in reducing flood risk do not fully account for these factors (e.g. Farley et al., 2005; Abe, 2008; Marshall et al., 2009; Archer et al., 2013). Therefore, this research focuses on exploring the hydrological role of trees in reducing the risk of floods across a range of rainfall properties, topography, climates, soil types and conditions, geology and catchment scales that vary spatially and temporally. This role of trees also potentially contributes to the functioning of some wetlands as flood mitigating tools, and this again is of interest to this research as highlighted below.

In wetlands, flood mitigation is thought to generally be facilitated by the soil soaking up and vegetation slowing down excess runoff (Mitsch \& Gosselink, 2007). However, there are a diverse range of wetland types with different vegetation components and soil types (e.g. forested wetlands, peatlands, marshes, fens) (Bullock \& Acreman, 2003), and thus flood mitigation varies depending on each wetland type. This research focuses on understanding the role trees in general, with a specific emphasis on forested wetlands. Forested wetlands are a subset of both forests and wetlands; they are forests as they have trees as the dominant vegetation component, and wetlands because they have hydric soils and a high water table. Hence, trees are the components of primary interest in this research, as they potentially play a vital role in the ability of both terrestrial forests and forested wetlands to mitigate floods. The high water table in forested wetlands, however, reduces the survival of most tree species and the potential sub-surface storage space for excess precipitation compared to terrestrial forests. Therefore, the role of trees in enhancing soil properties for the absorption of large volumes of water in forested wetlands could be less significant to that in typical forests. There is limited research that informs this role of trees in forested wetlands (Lugo et al., 1988; Trettin \& Jurgensen, 2003; Acreman \& Holden, 2013). Most of the forested wetland studies ${ }^{1}$, e.g. Yu et al. (2012), Zhang et al. (2012) carried out in China and Meyer et al. (2008) in the USA were country specific and hence do not fully represent

\footnotetext{
${ }^{1}$ Literature search for terms such as "Forested wetlands"; "Trees" AND "Forested wetlands" AND "Floods"; "Forested wetlands AND Flood control"; "Flood control AND Forested swamps"; "Forested wetlands AND Floods"; "Forested wetlands AND Flood control AND Soils"; "Trees AND Forested wetlands"; "Mangroves"; "Forested wetland restoration"; "Forested wetlands And water retention"; "Forested wetlands AND Hydraulic conductivity"; "Forested wetlands AND Bulk density AND Soil organic carbon". These were carried in databases such as scopus, science direct, JSTOR, ISI Web of Knowledge, Directory of Open Access Journals, Digital Dissertations online
} 
biophysical conditions of a wider range of climatic environments. Yu et al. (2012) quantified the response of one soil property only (soil organic carbon), Meyer et al. (2008) quantified the effects of restoring both trees and other wetland vegetation on two soil properties (soil organic matter content and bulk density) critical for flood mitigation but from the results, it is not possible to disentangle the sole effect of trees. Zhang et al. (2012) quantified the anthropogenic impacts of reforestation on a wide range of soil properties in a wetland but the hydrological implications of the observed results were not discussed.

It is therefore important to clarify the effect of trees across a range of climates and soil properties that vary spatially and temporally in terrestrial (i.e. forests) and semi-terrestrial (i.e. forested wetlands) habitats. Acquiring such information is necessary for facilitating the effective use of trees and forests as flood mitigating tools under a variety of environmental conditions. Since forests ${ }^{2}$ and wetlands ${ }^{3}$ are still being lost to land use change (Junk et al., 2013; Davidson, 2014; FAO, 2015), an understanding of how the hydrological role of trees facilitate their functioning, can also be useful in guiding restoration and promoting their conservation for natural flood management. This form of flood management can be a cost effective and sustainable substitute for or complement to traditionally used engineering flood defense infrastructure such as dams, pipes and sea walls (Temmerman et al., 2013).

To encourage policy formulation for effective natural flood management, quantification of the value of trees in forests and forested wetlands in terms of ecosystem services framework ${ }^{4}$ is helpful (Ming et al., 2007). The ecosystem services framework specifies the functions and attributes that humans can acquire directly or indirectly from these habitats. Decision-making for policy formulation is increasingly based on the ecosystem services concept. It is important that the knowledge of the flood mitigating role of trees is explained in the context of the ecosystem services concept, to be valuable for decision-making.

\subsection{Aims and objectives}

The research outlined in this thesis aims to address the knowledge gap regarding the effectiveness of trees and forests as flood mitigating tools under varying factors (in space and time) in terrestrial and wetland environments. These factors include climate,

\footnotetext{
$230.6 \%$ global loss of forests between 1990 and 2015, as highlighted by FAO (2015)

${ }^{3} 64-71 \%$ global loss of wetlands since $1900 A D$ to present, as highlighted by Davidson (2014)

${ }^{4}$ Discussed in section 1.4
} 
topography, species type, rainfall properties, soil type, geology and catchment scale. This research is the first to carry out a review of the complex relationship between trees and flooding under various geo-climatic and topographical regimes. It identifies a major gap in knowledge of the role of trees under hydric conditions ${ }^{5}$ that are characteristic of forested wetlands. It then provides the first set of detailed soil hydrology data from a previously forested ephemeral wetland in New Zealand undergoing ecological restoration, which will serve as a baseline for long term monitoring to guide conservation and restoration of forested wetlands. Three forms of investigation were followed, based on a literature review, field monitoring and spatial modelling, to achieve the following objectives:

1. To explore the role of trees and forests as flood mitigation tools under changing climate, topography, species type, rainfall properties, soil type and condition, catchment scale and geology via a detailed literature review and careful consideration of processes in order to disentangle confounding factors;

2. Investigate the role of trees for flood mitigation in previously forested wetlands undergoing restoration through literature review, data collection and analysis;

3. Determine appropriate areas where intervention can be targeted to optimise the role of trees as flood mitigating tools in forested wetlands.

\subsection{Thesis Structure}

The next section of Chapter 1 discusses the ecosystem services concept and its application to further explain the importance of this research to humankind. This will provide a basis for use of research outcomes in policy formulation for flood mitigation.

Chapter 2 reviews the hydrological role of trees and forests in reducing the risk of floods under a wide range of environmental variables. The review identifies strategies that can be adopted for more effective natural flood management. In addition, knowledge gaps pertaining to the role of trees in wetlands are identified. In light of the identified knowledge gaps the chapter then explores characteristics of wetlands to identify their components and ecological processes that underpin their flood mitigation role. The current ecological status of global wetlands is reviewed within the context of degradation and on-going restoration efforts. The review identifies New Zealand as one of the regions in which rapid wetland

\footnotetext{
${ }^{5}$ Seasonally or permanently water logged soils in which the water table is high.
} 
degradation has occurred and where restoration is now occurring. It further highlights the need for baseline information on the hydrological role of trees in wetlands to guide restoration in New Zealand and around the world. New generation ecosystem services modelling tools that facilitate guidance by allowing the visualisation of appropriate target areas for optimum functioning of trees are discussed. This provides a foundation for the work in chapter 5 .

Chapter 3 describes the Wairarapa wetland study site in New Zealand, at which evaluation of the role of trees in wetlands was carried out. It characterises the geology, soils, climate, settlement history, land use and vegetation types of the site.

Chapter 4 continues from chapter 3 and elaborates on the research approach, data collection and analysis at the study site. This chapter aims to fulfil the second thesis objective of evaluating the effect of trees on the physical and hydraulic properties of soil critical for the absorption and retention of water (for flood mitigation) in a wetland undergoing restoration. The concepts and approaches of the methods adopted to measure saturated hydraulic conductivity, bulk density, soil moisture content, matric potential, soil organic carbon content and moisture retention are described. Results of the measured properties are presented. A brief overview of the lessons learnt, aspects overlooked and recommendations based on the field work, and analysis of the results are also presented.

Chapter 5 details the rational and research approaches carried out to fulfil the third thesis objective to determine appropriate target areas for planting trees in wetlands to optimise their effectiveness as flood mitigation tools. The spatially explicit modelling tool that was adopted for the research approach is described. Results of specific target areas identified for planting trees in the wetland are presented and discussed.

Chapter 6 presents guidelines for the effective use of trees in terrestrial areas and during restoration of forested wetlands based on the findings from chapters 4 and 5 .

Chapter 7 summarises the findings of the whole research and presents recommendations for further research. 


\subsection{Ecosystem Services Concept}

The ecosystem services concept has become a major focus in the decision-making processes for conservation, management and restoration of ecosystems. The concept demonstrates benefits derived by humans from ecosystems for their well-being. It facilitates the understanding of complex ecosystems by providing an outline of a range of services that people obtain from natural systems. Awareness of this range of services is posited to enable the participation of a broad audience, encouraging responsible resource use without undermining the sustainability of the environment.

Although recently popularised after its adoption in the global assessment of the state of ecosystems by the Millennium Ecosystem Assessment (MEA) of 2005, the concept has implicitly been an important part of societal thinking for many decades. The recognition of the importance of ecosystems can be traced back to the Roman Period where geographical expansion of the Roman Empire resulted in deforestation of the Mediterranean region. During this period, philosophers such as Plato and Cicero understood the significance of the earth's resources to men and recognised the consequences of deforestation in terms of soil erosion and drying up of springs (Mooney \& Ehrlich, 1997). Later on, in the mid-19 ${ }^{\text {th }}$ century, George Perkins Marsh published his concerns over the importance of ecosystems and highlighted the reduction in supply of water from rivers and streams after deforestation (Mooney \& Ehrlich, 1997).

The growing appreciation of the basic foundations of ecosystems and their functions continued with Stephen Forbes (1887), Fair-field Osborn (1948), William Vogt (1948), Aldo Leopold (1949), Odum (1953) and Rachel Carson (1962). These authors showed the robust link between the biotic community and its abiotic environment, the importance of the earth's resources as part of industrial economies, quantified food chains and expressed concern over the environmental risks associated with activities of humankind.

The concept evolved over many decades as ecologists and economists became explicit in describing the role of ecosystems in delivering services to humans. The first description characterised the services as "Environmental services" that deteriorate following a decline in ecosystem functions. A report on the "Man's impact on the global environment" by the Study of Critical Environmental Problems (1970), listed environmental services as: flood 
control, pest control, fisheries, cycling of matter, climate regulation, insect pollination, soil formation, composition of the atmosphere and soil retention.

Holden \& Ehrlich (1974) further evolved "Environmental Services" into "Public Service Functions of the Global Environment", with two extra services added to the list; the maintenance of soil fertility and plant genetic library of the natural environment. Later, they were referred to as "Public Services of the Global Ecosystem" by Ehrlich et al. (1977); "Nature Services" by Westman (1977) and "Ecosystem Services" by Ehrlich \& Ehrlich (1977). The intentions of these researchers were to include the full range of services, tangible and intangible, use and non-use, market and non-market. The principles behind these intentions can be summarised as follows:

- The need to cultivate a culture of establishing sound decisions about environmental management based on the understanding of the relationship between nature and humans.

- An appreciation of the existence of an exchange of goods and services in the daily life of human beings. Services arise from the transformation of resources to forms of value that are useful to humans.

- An establishment of a basis for discussing priorities and actions in environmental decision-making based on delineating the relationship between nature and humans in terms of goods and services.

- A need to make the full range of services known to a broader audience through classification systems that are easy to comprehend.

The concept has since been adopted by various stakeholders around the world including the World Bank, Millennium Ecosystem Assessment, United Nations, Convention on Biological Diversity and World Business Council on Sustainable Development. This has led to the creation of frameworks and classification systems of the services to suit particular projects that manage environmental challenges. Policies that seek to address the challenges have also been formulated.

\subsubsection{Classification of ecosystem services}

Following the rise in awareness of the importance of the ecosystem services approach, different classification schemes for ecosystem services have emerged. Classical examples 
include the MEA (2005), Costanza et al. (1997), Daily (1999) and de Groot et al. (2002), among others (Appendix 19). These classification systems clarified some of the misinterpretations of the concept by distinguishing ecosystem services from ecosystem functions. They highlighted that ecosystem functions (e.g. biophysical processes and properties) interact to produce goods and services (e.g. food and flood mitigation) beneficial for human welfare. They recognised that ecosystem functions depend on each other, interact to produce a service, and a single function can produce more than one service. This enables accurate valuation by preventing double counting (Costanza et al., 1997; Dominati et al., 2010). The classification schemes and underlying concepts are human centric, but the recognition of use and non-use values provides a basis for conservation of the intrinsic value of nature. The classification systems raise awareness of the services, functions and processes (Costanza et al., 1997; de Groot et al., 2002; Dominati et al., 2010), and this research uses this as justification for exploring opportunities to optimise ecosystem service delivery.

\subsubsection{Application of the ecosystem services concept}

There is an increase in use of the ecosystem services concept by various stakeholders as a framework in policy formulation, restoration, conservation and natural resources management to ensure sustainable development. The adoption of the ecosystem services concept in the societal, economic and ecological dimensions, has provided a platform for communicating policies and programmes for natural resource management (Breure et al., 2012). The concept has been applied to address specific issues during policy formulation. These include i) the impact of human action on the wide range of services, ii) the specific ecosystems providing the services, iii) the beneficiaries and how they obtain the services, iv) the role of natural stock and biodiversity in service delivery, v) the interaction of various services with one another, and vi) the appropriate levels of services suitable for human survival. Stakeholder participation has been made possible through the development of decision support tools based on ecosystem processes, functions and flow of services. Some of the tools include bio-physical models such as LUCI (Jackson et al., 2013), ARIES (Villa et al., 2011; Nelson et al., 2009), InVEST (Nelson et al., 2009), Co\$ting Nature (Mulligan et al., 2010), MIMES (Boumans \& Costanza, 2007), EcoAIM (Bagstad et al., 2013), and are reviewed in section 2.9. 
Most of the applications of the concept are discipline focused i.e. soil science (Dominati et al., 2010; Breure et al., 2012; Robinson et al., 2013), hydrology (Koschke et al., 2014) and ecology (Ingram et al., 2012). These context-specific applications provide a hopeful vision of how ecosystem services delivery can be optimised. However, it also means recommendations based on these applications are limited in focus and may not give solutions on a broad spectrum of environmental issues that involve the trade-offs between services. There is still a need for interdisciplinary adoption of the concept to fully address socio-economic and environmental problems.

This study attempts to address this challenge by applying the concept across various disciplines through exploring the eco-hydrology interactions of trees (ecology), soil (soil science) and water (hydrology) for the optimisation of flood mitigation. Embedding the information on the eco-hydrology interactions into the ecosystem services concept creates a bridge for transferability of research outcomes to policy adoption. When policy makers see clearly the flood mitigation benefits resulting from the eco-hydrology interactions, they will have a basis for devising policies that promote restoration and conservation of components (i.e. trees and soil) necessary for these interactions. Another remaining major challenge is the understanding of how the flow of ecosystem services is affected by everchanging drivers such as land use, climate, species composition and nutrient dynamics (Carpenter et al., 2009). Understanding of such dynamics will enable the adoption of interventions that improve ecosystem service provision for the welfare of human beings. The use of ecosystem service modelling tools (as in this study), is one of the ways that can be adopted to enhance the understanding of ecosystem services dynamics and maximise the delivery of the services. 


\section{Chapter 2- Literature Review}

2.1 The role of trees in reducing flood risk- general use/interaction with water, effect of different species, age, position in the landscape, scale, soils and magnitude of rainfall events, geology, climatic conditions and role in other ecosystem types such as wetlands

\subsubsection{Introduction}

The past 200 years have been characterised by an increase in the incidences of flood catastrophes around the world (Zong \& Tooley, 2003; Andréassian, 2004; Blöschl et al., 2015). These have occurred because of natural causes (rainfall patterns), anthropogenic activities (land use and cover change) and large populations settling on flood plains (Andréassian, 2004; Kundzewicz, 2004; FAO-CIFOR, 2005; Blöschl et al., 2015). The negative impact of floods on social wellbeing, economies and natural capital has driven the search for management solutions to increase resilience of vulnerable societies. The management solutions most commonly used are structural engineered defences (traditional methods), flood warnings and land use management (Kundzewicz, 1999; FAO-CIFOR, 2005; Archer et al., 2010).

Traditional methods such as structural engineered defences have been used since ancient times (Kundzewicz 1999; 2004; Vinet, 2008). Nevertheless, there have been rising concerns over their sustainability, cost-effectiveness as sole solutions, and their effects on other environmental, social and economic services (Bana E Costa et al., 2004; Vinet, 2008; Archer et al., 2010). For example, the construction of flood defence structures (retention basins) in Portugal costing approximately 1.6 million Euros had negative effects on ground water quality, nature conservation and public health (Bana E Costa et al., 2004).

Flood warnings and natural land management methods have also been used. Flood warnings are cost effective and can prevent huge loss of lives, but cannot stop floods from occurring. They are also highly dependent on the accuracy of forecasting and may provide short lag time warning depending on peak measurements upstream. Land management solutions that utilize natural assets such as wetlands, coastal systems and forests/trees have been considered as alternative or complementary options (Archer et al., 2010; Department of Heritage Protection, 2012). In particular, forests and trees have attracted interest due to 
the growing evidence ${ }^{6}$ of the decrease in water yield and peak floods after planting and a subsequent increase after tree removal (Andréassian, 2004; Bradshaw et al., 2007).

The link between forests/trees and floods has moved through different eras, from historical recognition, understanding and debate, to scientific controversy (Andréassian, 2004; Neary et al., 2009). An early understanding of a link between forests/trees and floods is indicated by the enactment of forest protection laws as early as 300 BC in China (Neary et al., 2009). Additional evidence comes from France where a law called the 'The Decree of waters' was passed in 1215 (Neary et al., 2009). This was followed by the establishment of the first forest reserve in 1342 by the Swiss, after which an additional 322 were set aside as reserves between 1535 and 1777 (Neary et al., 2009). Italian and French researchers published treaties that recognised the negative impacts of deforestation (e.g. erosion) and the ecohydrology and climate relationships in the early $19^{\text {th }}$ century (Neary et al., 2009).

Huge debates were also part of the process of establishing the hydrological link of forests and floods. The historical debate dates back to the period of antiquity through to the mid$19^{\text {th }}$ century. During this time, ancient historians (i.e. Pliny the Elder), writers (i.e. Kittredge) and foresters inferred that forests and trees had the ability to attract precipitation, feed water to springs and control floods (Andréassian, 2004). These views were however, contrasted by engineers who in this period, were searching for measurable evidence. They concluded that there was no evidence of the effect of forests on rainfall but rather, instead of enhancing water flow to springs, trees are responsible for the reduction of the flow of streams (Andréassian, 2004). Further watershed experiments by engineers and foresters gave the same conclusion of forests reducing the flow of streams.

Consequently in recent decades, there has been a significant increase in hydrological research at field/small catchment scales aiming to provide knowledge on the role played by trees and forests in reducing the risk of flooding. Such research examines the impacts of woodland areas (plantation and native) as well as small strips of trees or shelterbelts on agricultural landscapes (Oyarzun, 1995; FAO-CIFOR, 2005; Eldridge \& Freudenberger, 2005; Bradshaw et al., 2007; Marshall et al., 2009; Archer et al., 2013). Agricultural landscapes have been the centre of attention in many experiments due to the increasing evidence

\footnotetext{
${ }^{6}$ fairly established for forests and less well established for tree belts
} 
showing their capacity to exacerbate surface runoff, which results in flood generation at local scales (O'Connell et al., 2007; Marshall et al., 2009; Archer et al., 2010).

Much emphasis has been placed on trees being heavy users of water through interception loss and high transpiration rates. Moreover, their ability to reduce flood peak by attenuating overland flow through the amelioration of soil properties such as infiltration, hydraulic conductivity and bulk density has been emphasised (Carroll et al., 2004; Eldridge \& Freudenberger, 2005; Nisbet \& Thomas, 2006; Archer et al., 2013). In addition, there are studies that highlight the increase in peak flow discharge following deforestation (Gilmour et al., 1987; Andréassian, 2004; Bradshaw et al., 2007; Archer et al., 2010). A review by Bruijnzeel (2004) reported annual increases in water yields of $140 \mathrm{~mm}$ in Nigeria and 410 $\mathrm{mm}$ in Tanzania following a conversion to agricultural production on land previously occupied by forests. Parallel to this evidence, a decrease in water yield following planting of trees has been reported in studies by Carroll et al. (2004) and Marshall et al. (2009) in the UK, where infiltration rates increased in soils under tree species such as Betula pubescens, Frangula alnus and Betula pendula compared to grazed pastures. Eldridge \& Freudenberger (2005) reported high infiltration rate in soils covered by Eucalyptus albens, Eucalyptus populanea and Eucalyptus melliodora compared to perennial grass and cultivated crop areas in the temperate region of Southern Australia.

This increase in scientific knowledge has resulted in some policy makers promoting land use management strategies such as afforestation in their flood risk management policies. These policies also place restrictions on deforestation (Calder et al., 2003; Nisbet \& Thomas, 2006). Regardless of these efforts, flooding is still occurring in most regions around the world. For example, in the United Kingdom, trees and forests have been included as part of a land management action plan in the flood risk policy agenda for England and Wales for more than a decade. However, devastating floods still occur, the most recent being the 2013 winter floods, which caused losses of more than 5000 homes and businesses in England. This evokes a question of how to use trees and forests effectively as flood risk management tools. To start with, the establishment of trees and forests for flood mitigation occurs in landscapes with varying climate, land cover types, topography, catchment scales, ecosystem types, rainfall properties, soil types and geology. The hydrological signature of trees and forests varies as a function of these environmental variables and according to the age and 
species of the trees (Robinson et al., 2003; Calder et al., 2003; Bruijnzeel, 2004; FAO-CIFOR, 2005). Hence, optimum flood risk management requires knowledge of how trees and forests can be harnessed effectively under changing environmental variables. To fulfil this requirement, there is a need for detailed information on what (and in some cases, if any) tree species or forest types are appropriate based on climate, soil type, antecedent soil moisture conditions (e.g. in wetlands), topography, geology, catchment size and rainfall properties. Partial information can be found in literature, for example, studies on the appropriateness of species type under different topography and climate (Nisbet \& Broadmeadow, 2003; Archer et al., 2013), but this lacks comprehensive evaluation.

This chapter first reviews the relationship between trees or forests and flooding, taking into account their general use and interaction with water and how it is affected by different species, age, position in the landscape, scale, soils and rainfall properties under changing geological and climatic conditions relative to other land use or vegetation types. Their hydrological role is also reviewed under inherently saturated conditions in other ecosystem types such as wetlands, which are mainly controlled by water. Secondly, the chapter will explore the identified research needs pertaining to the role of trees in wetlands.

\subsubsection{Interaction of trees/forests with water and soil under different climate and topography/geology}

This section considers the ecohydrological dynamics affecting the role of trees and forests in flood mitigation. This will highlight where the optimum flood mitigation benefits of using trees and forests can be derived. 


\subsubsection{Vegetation properties that determine the interaction of trees/ forests with water}

The role of forests/trees in regulation of flood risk stems from their inherent ability to utilise large quantities of water, ameliorate soil properties (Figure 1) and reduce water yields compared to many other vegetation types.

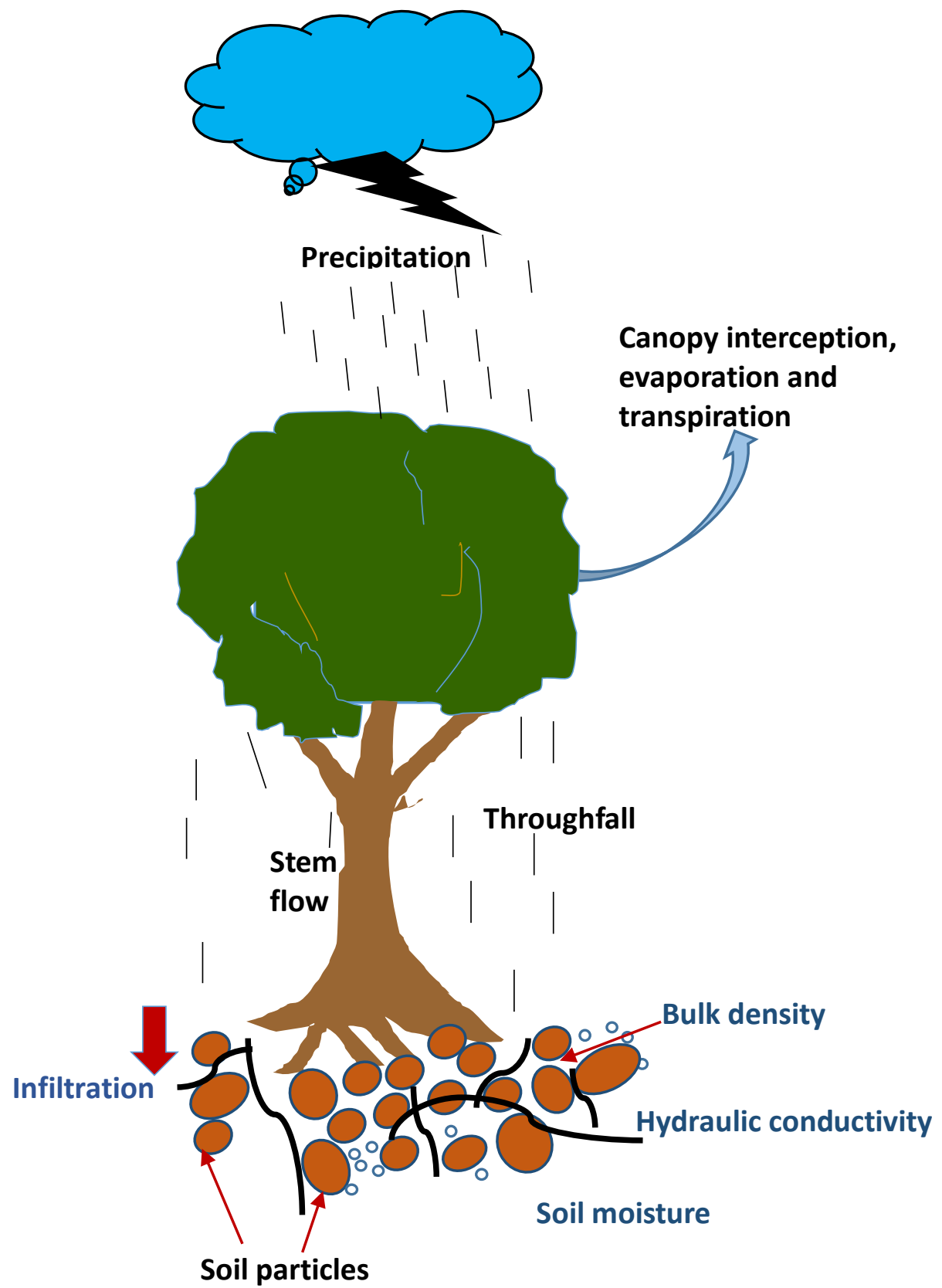

Figure 1 Schematic representation of the interaction between trees, soil and water 
Trees characteristically have high interception ${ }^{7}$ loss (wet leaf evaporation) and transpiration $^{8}$ (dry leaf evaporation) rates relative to short vegetation types such as grasses, (Bruijnzeel, 2001; Eldridge \& Freudenberger, 2005; Nisbet \& Thomas, 2006; O’Donnell et al., 2011; Jobbágy et al., 2012). Trees generally have deeper root systems that access deeper water than grasses and hence are able to transpire more water and reduce antecedent moisture conditions, particularly during dry summer periods (Hall et al., 1996; Nisbet, 2005; Holdo \& Nippert, 2015). It has however, been noted that grasses, rough pasture and arable crops may have higher transpiration rates (400-600 $\mathrm{mm}$ per $1000 \mathrm{~mm}$ annual rainfall) than trees (300-400 mm per $1000 \mathrm{~mm}$ annual rainfall) if water supply is abundant (McNaughton \& Jarvis, 1983; Davie \& Fahey, 2004; Nisbet, 2005). Although transpiration losses from the short vegetation types may exceed that of trees, the management practices such as grazing regime and short crop cycle associated with the vegetation, overall limit their transpiration rates (Nisbet, 2005). Nevertheless, well managed grasslands with good water supply are able to maintain high transpiration rates, therefore when comparing to trees, the major effect of trees on water yield is attributed to high interception loss (Davie \& Fahey, 2004). The range of interception loss of trees varies between $10-45 \%$ of annual rainfall across different species and climatic conditions compared to 14-19\% for grasses (Shiklomanov \& Krestovsky, 1988; Bruijnzeel, 2001; Nisbet \& Thomas, 2006; Abe, 2008). This is attributed to the characteristic dense canopies and high leaf area index of trees. High interception loss reduces the amount of water reaching the surface thereby preventing runoff and flooding.

Through their dense root network and ability to enhance soil meso- fauna activity, trees are able to improve soil structure and hence properties such as infiltration rate ${ }^{9}$, hydraulic conductivity $^{10}$, porosity ${ }^{11}$ and bulk density ${ }^{12}$ (Eldridge \& Freudenberger, 2005; Price et al., 2010) (Figure 1). This increases the amount of water that penetrates and is retained in the soil; reduces the amount of water draining through soil, and diminishes surface runoff which

\footnotetext{
${ }^{7}$ Rainfall is caught/ intercepted by the tree canopy and subsequently evaporated. Rainfall that is not intercepted reaches the ground through stem flow and throughflow (Figure 1).

${ }^{8}$ Water that is absorbed through the roots from the soil is lost though the leaf stomata. This reduces the antecedent soil moisture content and increases the soil storage space for incoming precipitation.

${ }^{9}$ The speed of water moving into the soil.

${ }^{10}$ Transmission of water through the soil under a unit of pressure gradient. Refer to sub-section 2.8 for indepth discussion

${ }^{11}$ The amount of pore spaces between soil particles. The larger the amount, the more water the soil can hold and transport

12 Volume of soil pore spaces per unit mass of soil. The higher the volume of the spaces, the larger the quantity of water the soil can hold or transport. Refer to sub-section 2.8 for in-depth discussion.
} 
is a major source of flooding ( $\mathrm{O}^{\prime}$ Connor \& Costa, 2004; Cosandey et al., 2005; Nisbet \& Thomas, 2006; Archer, 2010). Understanding the interaction of water with trees and forests will help in establishing the optimal age, species, rainfall intensity, catchment scale, position in the landscape, topography, climate, geology and soils where they operate at optimal potential to reduce flood risk.

\subsubsection{Impact of trees and forests under varying soils and geology}

There is increasing experimental evidence that soils under trees and forests are more permeable, retain more water and reduce surface runoff relative to soils under land use systems such as crop/livestock production or shrubland (Cheng et al., 2002; Eldridge \& Freudenberger, 2005; Farley et al., 2005; Vose et al., 2011; Archer et al., 2013). The significance of these differences is impacted by geology. The effectiveness of trees and forests is enhanced on semi-permeable soils overlying semi-permeable or permeable bedrock. It is difficult for trees to establish and grow on impermeable severely degraded soils overlying impermeable bedrock, hence their impact is reduced. On highly permeable soils overlying highly permeable rock, trees will be of little benefit because the soils inherently absorb and retain water.

Some flooding incidences in the UK, Southern Africa and some parts of Northern Europe have been attributed to soil structure degradation as a result of agricultural practices such as harvesting with heavy machinery, growing shallow rooted crops and overstocking, which compact both A and B horizons (Bullock \& Acreman, 2003; Marshall et al., 2009). Planting of trees on such soils improves structure and organic matter content which in turn creates conduits for large volumes of water to flow through (Bruijnzeel, 2004; Sakals et al., 2006; Archer et al., 2013). Shelterbelt research in the Pontbren catchment, mid Wales, UK showed high infiltration rates (up to 60 times) in soils planted with trees compared to grazed pasture soils (Carroll et al., 2004). Complementary to that research, observations by Price et al. (2010) highlighted higher infiltration rates, saturated hydraulic conductivity, moisture content and low bulk density under forest soils compared to non-forested soils (lawn and pasture).

In addition to soil structure, it is vital to take into account the importance of soil depth which determines storage of infiltrated water (Fiorentino \& Lacobellis, 2001). In deep soils, 
if the water table level is low, tree roots extract water from deep horizons and transpire it, thereby creating more storage space (Bruijnzeel, 2004). However, this effect is reduced on shallow soil overlying impermeable bedrock that is resistant to weathering, where root proliferation may be restricted. Bedrock geology also plays an important role in determining the response of forested catchments through its effect on soil depth and permeability which in turn influence water storage. The magnitude at which trees and forests delay or reduce peak flow discharge in catchments is minimised where soils are naturally shallow on impermeable bedrocks and steep areas (Bruijnzeel, 2004). For example, high overland flow rates occur frequently in forested catchments overlaying marlstone and granite rocks that produce shallow soils in tropical and temperate areas (Anderson et al., 1976; Bruijnzeel, 2004; Gaal et al., 2012). Although the impact of trees is very little under shallow soils and impermeable bedrock, it may be better than that of other vegetation types and can improve over time as roots grow and develop more. Bedrock also determines structure and distribution patterns of trees and forests through its effect on nutrient supply which affects growth (Takyu et al., 2002; Fayolle et al., 2012). Parent materials such as sandstone, weather to produce soils with low levels of nutrients, resulting in poor growth of tree species and relatively less effective flood risk management via tree planting (Fayolle et al., 2012). In such cases, the choice of species adapted to such conditions would have an impact on the hydrology for flood risk management. Fundamentally, trees have the greatest impact where they can enhance permeability and storage capacity of the soil.

\subsubsection{Climate}

The way in which trees partition precipitation among interception, infiltration and evapotranspiration varies according to climatic zone as well as the previously discussed soils and geology. In humid climatic zones where precipitation is high and the air is quickly saturated, tree induced infiltration becomes more important than interception loss and evapotranspiration (Jobbágy et al., 2012). In these climatic zones, soils are characteristically moist, vegetation growth is rapid, hydraulic conductivity is high and interception loss (naturally high) is offset by the quickly saturating air, such that partitioning of precipitation through deep drainage becomes a significant hydrological impact of trees. Therefore tree species with deep and dense root systems which create macro-conduits for enhanced infiltration are effective in the humid climatic zones. 
Conversely in sub-humid, semi-arid and arid climates characterised by low rainfall, interception loss becomes more significant in the hydrological role of trees (Jobbágy et al., 2012), although it can be low during intense rainfall events. Soils in most arid regions are subjected to high temperatures, have low moisture levels and are prone to drying up and become hydrophobic (water repellent). While water repellency occurs in other climatic regions (e.g. in humid temperate areas as a result of illuviation), it tends to be more prevalent in arid regions. Water repellency in arid climatic regions persists in coarse textured soils and fire affected terrain, thereby reducing infiltration and increasing overland flow (Doerr et al., 2000). These conditions require establishment of trees that create root channels to provide by-pass routes to enhance infiltration. However, the probability of water scarcity is high in these regions and particular evergreen tree species (e.g. Acacia mearnsii) have been found to be associated with high soil water repellency (Doerr et al., 2000). Hence, the planting of trees for flood control in such regions requires careful consideration involving the establishment of species with high water-use efficiency and low levels of hydrophobic compounds in their litter.

In cool regions, combinations of snow, ice melt and high rainfall in winter can freeze and saturate the soil. The effect of trees and forests on infiltration and runoff generation may be reduced in frozen ground. However, interception and transpiration may still be high and trees can be used to mitigate floods. In temperate areas, floods occur in autumn, spring and summer when soils are not frozen. These floods are often triggered by spring snow melt and high precipitation that saturates the soil, thus the presence of trees and forests would reduce antecedent soil moisture.

Another factor to consider is the likely change in forest water use in different climatic regions in response to the elevated carbon dioxide expected as a result of climate change. Studies have revealed that the expected rise in carbon dioxide levels will induce more stomatal closure, resulting in reduction in transpiration (Curtis \& Wang, 1998; Alkama et al., 2010; Leuzinger \& Körner, 2010; Warren et al., 2011). This may increase antecedent soil moisture and runoff, particularly if the soil reservoir is limited (Alkama et al., 2010; Leuzinger \& Körner, 2010). A question that still remains to be answered is whether the increase in runoff is significant enough to increase flood risk. It is also expected that with elevated levels of atmospheric carbon dioxide there will be an increase in net primary 
production and root biomass, potentially increasing infiltration rates and water holding capacity to offset the runoff (Warren et al., 2011).

\subsubsection{Topography}

Topography plays a fundamental role in influencing soil variability, floods and tree growth. Topographical elements which include elevation, aspect and slope determine the effectiveness of trees in reducing risk of flooding. At higher elevations, the air and soil temperature is low and thus tree growth is reduced in most climatic zones e.g. temperate, boreal and tropical regions (Kronfuss \& Havranek, 1999; Griffiths et al., 2009). At the same time, highly elevated areas often receive high rainfall and contribute more surface runoff. This means the effectiveness of trees or forests in flood mitigation is reduced at such elevations. For example, Anderson et al. (1976) highlighted that forested ridges at high elevation $(1500 \mathrm{~m})$ delivered more runoff $(0.46 \mathrm{~m} / \mathrm{yr})$ compared to forested land at lower elevation $(0.06 \mathrm{~m})$. The thin soils, exposed conditions and limited tree growth and coverage at such elevations may reduce the effectiveness of flood risk regulation via (re-)foresting such areas.

The growth and coverage of trees and forests are also influenced by slope and aspect. Aspect can be categorised as sun-facing, shaded, windward and leeward slopes (Guo et al., 2014). The direction of a slope determines the amount of solar radiation and temperature regime, and consequently evaporation, soil biological and chemical processes to which it is exposed (Seibert et al., 2007). Sun-facing slopes receive higher levels of direct solar radiation and temperatures than shaded slopes. As a result, the growing season tends to be longer, but high temperatures increase moisture evaporation rates and may dry up the sunny-facing slopes, creating xeric conditions. Shaded slopes receive less solar radiation than sunny slopes and may have high soil moisture and organic matter content (Kutiel \& Lavee, 1999; Guo et al., 2014). Leeward slopes generally receive less precipitation than windward slopes (Guo et al., 2014). Depending on how much sunlight energy and water is received on slope aspects, tree growth may be energy or water limited. Therefore tree species that require high availability of soil moisture may be most suitable on shaded windward slopes. Species tolerant to moisture stress but intolerant to inadequate solar energy may be most suitable on sunny leeward slopes. For example, deciduous species have been observed to favour sunny slopes, while evergreens do well on shaded slopes (Armesto 
\& Martinez, 1978). Positioning of trees on aspects where their growth rates are not limited promotes the development of canopy structural properties such as height, stand density and root density which enables rapid forest water use and thus flood risk management (Wenger, 1999).

The gradient of a slope determines the flashiness of flow and consequently flooding. Slope gradient can be categorised into seven classes, i.e. flat (0-2\%), gently sloping (2-5\%), moderately sloping (5-10\%), strongly sloping (10-15\%), moderately steep (15-30\%), steep (30-60 \%) and very steep (> $60 \%$ ) (Wenger, 1999; FAO, 2006). It is worth noting that there is no universal slope gradient classification system, thus the aforementioned classes can be modified to suit particular topography. Steep sloped terrain generates flashy flow compared to gentle and flat topographical surfaces. Establishment of trees on steep terrain increases slope stability through root reinforcement, which in turn increases infiltration and reduces flood risk (Sakals et al., 2006; Ilstedt et al., 2007; Jobbágy et al., 2012). However, flood velocity reduction is often of greater magnitude on gentle to moderately sloping areas where trees have greater access to ground water and are able to grow and achieve high productivity (Jobbágy et al., 2012). On flat areas, runoff rates are reduced, water accumulation is high and the effectiveness of forests and trees in reducing floods is harnessed by establishing species tolerant to waterlogging. The efficiency of trees and forests in controlling runoff flow decreases as slope increases beyond 60 \% (Wenger, 1999), despite trees being one the few land covers that can establish on such slopes. This is because the soils are often shallow and thin, as a result, root reinforcement is reduced.

Along with gradient, the position of slopes and ground surface roughness on which trees and forests are placed plays a fundamental role in reducing flood risk. Generally, the kinetic energy of surface and subsurface water is increased at shoulder, smooth surfaces and back slope positions and decreases at foot slope, rough surfaces and toe slope positions where it entrains to water bodies or eventually accumulates. It is at these low slope positions and rough surfaces, where trees can be most useful for flood risk mitigation especially by preventing damage to infrastructure. 


\subsubsection{Effect of tree species/forest type}

The consideration of specific tree species is slowly becoming a common phenomenon in the use of forests and trees for flood risk mitigation. Different tree species have varying effects on flood risk management in terms of the quantities of water lost through interception, evapotranspiration and magnitude of infiltration rates. Therefore a blanket recommendation to plant, without regard to species type, can sometimes result in adverse effects on the environment or no change.

Generally, broad leaf and coniferous (also referred to as conifers) species have similar impacts on floods because interception loss and infiltration rates are comparable between the species. However, variations exist during winter in temperate regions, between deciduous broadleaves and shallow-rooted, fast-growing conifers. Forest transformation from conifers to deciduous broad leafed species more often increase water yield in temperate regions (Hamilton \& King, 1983; Vose et al., 2011). An annual stream flow increase of $220 \mathrm{~mm}$ was observed after harvesting $60 \%$ of the area occupied by conifers relative to $150 \mathrm{~mm}$ after deciduous broad leaves were harvested (Hamilton \& King, 1983). This is because deciduous broadleaves become dormant and have a leafless canopy in winter which intercepts less water. In contrast, conifers have large surface area needle shaped leaves present throughout the whole year (Bruijnzeel, 2001; Nisbet \& Broadmeadow, 2003; Komatsu et al., 2008; Vose et al., 2011). Coniferous species intercept large amounts of rainfall, thereby reducing water reaching the soil surface by $20-40 \%$ relative to deciduous broad leaves (10-20 \%) (Le Maitre et al., 1999; Nisbet \& Broadmeadow, 2003). However, non-deciduous broadleaves maintain a leafy canopy for interception loss throughout the year just as conifers and may be more ideal for flood mitigation because they have deep root systems for improving infiltration (Nisbet \& Broadmeadow, 2003). Most conifers have shallow root systems and induce surface water repellence and hence may have reduced impact on infiltration compared to broadleaves (Archer et al., 2013).

The effectiveness of coniferous species in reducing the amount of water reaching the soil surface through interception loss may be reduced under humid regions where precipitation and the degree of air saturation are high and evapotranspiration is low. Under such moist conditions, the ability of trees to ameliorate soil properties (infiltration and hydraulic 
conductivity), critical for flood risk mitigation, becomes more significant (Jobbágy et al., 2012). For instance infiltration rates of soil under mixed broadleaf woodland was higher than that of soils supported by Pinus sylvestris $(119 \mathrm{~mm} / \mathrm{hr}$ vs. $42 \mathrm{~mm} / \mathrm{hr}$ ) in humid temperate forest of the boarders of Scotland (Archer et al., 2013).

In semi-arid and arid areas, planting heavy users of water such as some species of the genus Eucalyptus might increase drought-associated risks, particularly on areas where the ground water level is very low. Conversely, in very wet environments or on areas where the ground water table is close to the surface, trees may struggle to establish. In very wet areas, species tolerant to water logging conditions should be used, e.g. Alnus glutinosa (alder) and Salix spp. (willow) in Europe or Dacrycarpus dacrydiodes (kahikatea) in New Zealand. In terms of forest types, natural forests are more effective than plantation forests in most cases and bring with them increases in many other biodiversity values. Nonetheless, plantation forests still reduce flood risk relative to most non-forested land covers.

Underlying geology causes variability in impacts of different species across all climatic regions (Takyu et al., 2002; Fayolle et al., 2012). High infiltration rates can occur under broad leaves if the underlying soils are derived from permeable bedrock. At the same time parent rock material producing soils with low nutrient levels, reduces growth and development of some broadleaved species and limit their ability to increase infiltration rate for flood mitigation (Fayolle et al., 2012). Planting of evergreen coniferous species tolerant to such geological conditions may have a hydrological impact as they are able to grow normally and limit nutrient loss (Fayolle et al., 2012).

Forestation programs in different parts of the world are often biased towards tree species that are of high economic value and fast growing, with less emphasis on environmental implications, particularly where the timber industry is economically viable. In New Zealand, forests planted with exotic species such as Cupresus, Eucalyptus and Pinus radiata contributed about NZD\$ 4.7 billion to the country's exports in 2011 (NZFOA, 2011). In temperate and humid temperate forests of Europe, fast growing coniferous species are popular because their short rotation periods make them economically viable (Archer et al., 2013). In some tropical regions, fast growing Eucalyptus species are commonly grown for timber and construction (Foroughbakhch et al., 2012). However, during the last 10-15 years there has been an increase in the afforestation of other slow growing species for provision 
of environmental services such as biodiversity, water and carbon cycling around the world (Vesterdal et al., 2013). An example is the "near to nature"13 forest management which utilises native slow growing species in countries such as Denmark, Germany and United Kingdom. Given the various preferences towards different tree species and their suitability for different regions around the world, it is necessary to evaluate their effectiveness as natural flood management tools. This will help in creating specific guidelines for decision making regarding the selection of tree species for flood mitigation in different parts of the world.

The important points to take note when assessing tree species for use in flood risk management projects is their water use efficiency, morphology of the root systems, canopy architecture and survival. These characteristics should be prioritised in different climatic regions and under previously discussed soil, topographical and geological conditions.

\subsubsection{Effect of tree age}

Understanding the age of trees and forests is important in choosing the appropriate management technique and when disentangling the effect of other factors such as geology and soil type on runoff generation that causes floods. As trees and forests mature, their ability to increase infiltration and utilise water increases (Bruijnzeel, 2001; Nisbet \& Thomas, 2006). This is ascribed to an increase in the degree of aerodynamic roughness of leaf surfaces and well developed root systems (Bruijnzeel, 2001; Nisbet $\&$ Thomas, 2006). Calder \& Newson (1979) noted that the presence of a mature conifer forest cover would likely reduce the total outflow of water compared to a young one, although the exact age was not mentioned. Over time, trees and forests are able to change impermeable soil to permeable as observed by Archer et al. (2013). However, this ability decreases when they morphologically deteriorate with increase in age (Archer et al., 2013). In such an instance, it may be ideal to maintain a low proportion of old forests in flood prone areas. This can be established by practising uneven aged forest management, for example planting at different time intervals to ensure trees mature at different dates and then selective harvesting of old trees while maintaining ground cover with younger trees .

\footnotetext{
${ }^{13}$ Management of forests to fulfil ecological, economical and societal needs. For example it may integrate timber production, recreation and environmental protection in forest management.
} 
Generally, interception loss in young coniferous trees is low compared to mature trees, for example, young Pinus radiata trees of 8 years old intercept $10 \%$ of rainfall compared to 20 $\%$ at 29 years in temperate zones (Le Maitre et al., 1999). Mature trees have the ability to reduce bulk density and increase porosity due to enhanced decay, which adds more organic matter to the soil (FRMRC, 2008). An increase in infiltration has been observed to correlate with increase in age. A review by Bruijnzeel (2004) stated that soils under mature tropical forests infiltrated between 80 and $95 \%$ of a rainfall event.

A shelterbelt study by Carroll et al. (2004) showed over an order of magnitude increase from $30 \mathrm{~mm} /$ hour to $830 \mathrm{~mm} /$ hour in infiltration in soils under trees as the age increased from 07 years. This is quite a young age range, but such observations can be explained by correlating age and size (area or length) of morphological features (leaves and roots) that interact with water and soils to reduce risk of floods. For instance, some young trees can acquire leaf characteristics that induce high interception loss at magnitudes similar to old trees. In addition, some older trees may have morphological characteristics that resemble those of immature trees. For example, some mature palm tree varieties have small leaf sizes, short height and small root systems that maybe ineffective at minimising floods (Frangi \& Lugo, 1998).

When evaluating the effect of forest age in flood reduction, it is vital to also consider age structure, which has an implication on the levels of resilience and resistance in the face of catastrophes. Even-aged forest stands might have a maximum protective capacity against floods as a result of strength and size, but at the same time their resilience will be low to catastrophic events such as windstorms or disease outbreaks which could wipe out the stands resulting in no protection at all. This has been the case in most even aged Picea abies stands in Nordic countries, where windstorms have wiped out the commonly planted species and reduced the levels of protection against floods (Vodde et al., 2010). Unevenaged stands maintain appropriate levels of protective capacity due to high levels of resistance and resilience brought about by the wide distribution of tree ages (Sakals et al., 2006). 


\subsubsection{Trees and forests vs. other land use/vegetation types}

The hydrological signature of forests and trees becomes stronger as the proportion of the land they occupy relative to other land covers increases. Replacement of trees and forests with grasslands or clear cut increases water yield and flooding in both temperate and tropical regions (Cheng et al., 2002; Costa et al., 2003; Carroll et al., 2004; Eldridge and Freudenberger, 2005; Bradshaw et al., 2007; O’Connell et al., 2007; Germer et al., 2010; Zhang et al., 2012; Archer et al., 2013). This is attributed to changes in components of the water balance particularly reduced interception loss, infiltration, evapotranspiration, and increased soil moisture, annual water yield, storm flow, peak flow and low flow (Table 1) adapted from Cheng et al. (2002). The significant influence of forests on water flow can be demonstrated by the comparison of the relative magnitudes of water balance components in forested and non-forested areas as shown in Table 1 and Table 2. Grasses and cultivated crops have low leaf area index, less aerodynamic roughness, shallow root systems and produce a small quantity of litter compared to trees (Bruijnzeel, 2004; O'Connell et al., 2007). In addition, management activities in such land use types e.g. grazing and use of heavy machinery can compact the soil and induce generation of surface runoff. However, soil conservation techniques such as reduced tillage, use of cover crops, rotational grazing and mulching have been carried out in crop fields and pastures to reduce the risk of floods. Their effectiveness compared to trees is largely dependent on soil type, hence a lot of uncertainties prevail (O'Connell et al., 2007).

It has been noted that the response of grassland catchments can be similar to forest catchments under certain conditions of soil depth and hydrometeorologic extremes. Cosandey et al. (2005) reported reduced discharge in grassland catchments with soils that are intrinsically deep and permeable due to geological reasons in the Mediterranean part of France. They highlighted that when soils are very shallow and impermeable the differences in the impact of forests vs. grassland/other short vegetation types become less significant. However, this is arguable because over time, the ability of trees to produce large quantities of organic matter is likely to increase the depth of shallow soils relative to grasses thus increasing water residence times and reducing risk of floods.

The comparison between land use types has mainly focused on trees and forests vs. grassland because much of our knowledge of the impact of forest cover on floods has been 
derived from catchment studies in which portions of grasslands have been planted with trees, or conversely where trees have been replaced with grassland. 
Table 1 Relative magnitudes of water balance components between forested and non-forested areas. Adapted and modified from Cheng et al. (2002)

Components of water balance

Soil moisture content

Infiltration

Interception loss

Evapotranspiration

Storm flow

Low flow

Peak flow

Annual water yield
Indication of magnitudes between land use types Grassland > Forested land

Forested lands $>$ Grasslands $>$ Clear-cut sites $(40-270 \mathrm{~mm} / \mathrm{hr}) \quad(40-108 \mathrm{~mm} / \mathrm{hr}) \quad(28$ $102 \mathrm{~mm} / \mathrm{hr}$ )

Forested lands $>$ Grasslands $>$ Clear-cut sites $\begin{array}{lll}(24.5 \mathrm{~mm}) & (1 \mathrm{~mm}) \quad(0 \mathrm{~mm})\end{array}$

Forested lands $>$ Grasslands $>$ Clear-cut sites ( $3 \mathrm{~mm} /$ day) $\quad$ (0.4 mm/day)

Clear-cut site $>$ Grasslands $>$ Forested lands

Clear-cut site $>$ Grasslands $>$ Forested lands

Clear-cut site $>$ Grasslands $>$ Forested lands $(158 \mathrm{~mm}) \quad(136 \mathrm{~mm}) \quad(56 \mathrm{~mm})$

Clear-cut site $>$ Grasslands $>$ Forested lands $78 \%$ $20 \%$ 
Table 2 Effect of Trees vs other land use types on flood flow. Adapted, modified and extended from Blaschke et al. (2008) and Ballinger (2009)

\begin{tabular}{|c|c|c|c|}
\hline Source & $\begin{array}{l}\text { Catchment/ } \\
\text { Location }\end{array}$ & $\begin{array}{l}\text { Landuse } \\
\text { comparison }\end{array}$ & Conclusions \\
\hline \multirow[t]{2}{*}{$\begin{array}{l}\text { Archer et al., } \\
2013\end{array}$} & $\begin{array}{l}\text { Eddleston } \\
\text { Catchment, } \\
\text { Scottish } \\
\text { Borders, UK }\end{array}$ & $\begin{array}{l}\text { Broadleaf } \\
\text { woodlands vs } \\
\text { grazed grassland }\end{array}$ & $\begin{array}{l}\text { Near surface field saturated hydraulic } \\
\text { conductivity under broadleaf woodlands } \\
\text { was higher than that under grassland } \\
\text { cover }(152 \mathrm{~mm} / \mathrm{hr} \text { vs } 24 \mathrm{~mm} / \mathrm{hr})\end{array}$ \\
\hline & & $\begin{array}{l}\text { Pines vs grazed } \\
\text { grassland }\end{array}$ & $\begin{array}{l}\text { Saturated hydraulic conductivity was } \\
\text { slightly higher in Pinus sylvestris but not } \\
\text { significantly different to that of grazed } \\
\text { grassland ( } 42 \mathrm{~mm} / \mathrm{hr} \text { vs } 35 \mathrm{~mm} / \mathrm{hr} \text { ) }\end{array}$ \\
\hline $\begin{array}{l}\text { Germer et al., } \\
2010\end{array}$ & $\begin{array}{l}\text { Rondonia } \\
\text { catchment, } \\
\text { Amazon, } \\
\text { Brazil }\end{array}$ & $\begin{array}{l}\text { Open tropical } \\
\text { rainforest vs } \\
\text { pasture }\end{array}$ & $\begin{array}{l}\text { Volume and frequency of storm flow was } \\
17 \text { times and two folds higher under } \\
\text { pasture }\end{array}$ \\
\hline $\begin{array}{l}\text { Carroll et al., } \\
2004\end{array}$ & $\begin{array}{l}\text { Pontbren, } \\
\text { mid Wales, } \\
\text { UK }\end{array}$ & Trees vs pasture & $\begin{array}{l}\text { Infiltration rates were on average up to } 60 \\
\text { times higher under trees relative to grazed } \\
\text { pasture areas }\end{array}$ \\
\hline Dons, 1987 & $\begin{array}{l}\text { Volcanic } \\
\text { plateau, NZ }\end{array}$ & Pines vs pasture & $\begin{array}{l}\text { Average yearly flow yield was reduced } \\
\text { after afforestation using pines by }-52 \%\end{array}$ \\
\hline Duncan, 1995 & $\begin{array}{l}\text { Moutere, } \\
\text { Nelson, NZ }\end{array}$ & Pines vs pasture & $\begin{array}{l}\text { Average yearly flow yield was reduced } \\
\text { after afforestation using pines by }-50 \%\end{array}$ \\
\hline $\begin{array}{l}\text { McKercher, } \\
1980\end{array}$ & $\begin{array}{l}\text { Kikiwa, } \\
\text { Nelson, NZ }\end{array}$ & Pines vs pasture & A low flow yield of $-7 \%$ under pines \\
\hline Smith, 1987 & $\begin{array}{l}\text { Berwick, } \\
\text { Otago, NZ }\end{array}$ & Pines vs pasture & $\begin{array}{l}\text { Average one week annual flow of }-20 \% \\
\text { under pines }\end{array}$ \\
\hline $\begin{array}{l}\text { Fahey and } \\
\text { Jackson, 1997a }\end{array}$ & $\begin{array}{l}\text { Glendu, } \\
\text { Otago, NZ }\end{array}$ & Pines vs tussock & $\begin{array}{l}\text { Average one week annual flow of }-18 \% \\
\text { under pines relative to pastures }\end{array}$ \\
\hline $\begin{array}{l}\text { Claridge, 1980; } \\
\text { Jackson, } 1973\end{array}$ & $\begin{array}{l}\text { Taita, } \\
\text { Wellington, } \\
\text { NZ }\end{array}$ & Pines vs pasture & $\begin{array}{l}\text { Average yearly flow yield was reduced } \\
\text { after afforestation using pines by }-35 \text { to }-80 \\
\%\end{array}$ \\
\hline $\begin{array}{l}\text { Burch et al., } \\
1987\end{array}$ & $\begin{array}{l}\text { Victoria, } \\
\text { Australia }\end{array}$ & $\begin{array}{l}\text { Native forest vs. } \\
\text { Grassland }\end{array}$ & $\begin{array}{l}\text { Grassland site had significantly higher peak } \\
\text { discharge and total runoff due to high } \\
\text { antecedent soil moisture }\end{array}$ \\
\hline $\begin{array}{l}\text { Eldridge \& } \\
\text { Freudenberger, } \\
2005\end{array}$ & $\begin{array}{l}\text { New South } \\
\text { Wales, } \\
\text { Australia }\end{array}$ & $\begin{array}{l}\text { Eucalyptus and } \\
\text { Pines vs. perennial } \\
\text { grassy slope }\end{array}$ & $\begin{array}{l}\text { Infiltration rates were } 5 \text { times higher under } \\
\text { Eucalyptus and pines compared to grassy } \\
\text { slope }\end{array}$ \\
\hline
\end{tabular}




\subsubsection{Response of trees/forests under different rainfall properties and catchment scale}

Characteristics that are important to consider when assessing the impact of changing rainfall properties are intensity, volume and spatial extent. There is growing evidence that trees and forests reduce floods for small events (Eldridge \& Freudenberger, 2005; Bradshaw et al., 2007; Ilstedt et al., 2007; O’ Donnell et al., 2011). These events can be of short duration, high intensity precipitation limited to small areas (convective precipitation) and may cause flash floods. Small events can also be of low intensity, high/low volume and long duration, and are responsible for frequent flooding.

Most research has shown a significant impact of trees for small events occurring in small catchments of less than approximately $40 \mathrm{~km}^{2}$ (Table 3) (Sikka et al., 2003; Alila, 2009; Vose et al., 2011; Ellison et al.,2012). A threshold of $40 \mathrm{~km}^{2}$ has been used because the bulk of research has been carried out in catchments of size ranging from $5-40 \mathrm{~km}^{2}$ so results from these scales can be reported with more confidence. Low intensity precipitation events have been found to correlate to average flood events occurring annually in humid areas (Lavell, 1994; Fiorentino \& lacobellis, 2001). Shelterbelt studies in the Pontbren catchment (UK), acknowledged that field experiments which showed the ability of trees to reduce flood risk were done at what is considered as small events (low intensity, high volume and localised) which may cause small and moderate floods. For instance, $68 \%$ of the total rainfall received during summer fell at a rate less than or equal to $6 \mathrm{~mm} / \mathrm{hr}$ and only $8 \%$ fell at a rate greater than $22 \mathrm{~mm} / \mathrm{hr}$ while in winter $96 \%$ was less than or equal to $6 \mathrm{~mm} / \mathrm{hr}$ (FRMRC, 2008). On the same note, Sikka et al. (2003) indicated that the planting of bluegum Eucalyptus globulus in a grassland watershed reduced both peak and base flows for small rainfall events, although this effect would be insignificant for extreme rainfall events, which cause large floods of up to 100 years return period.

In contrast to small rainfall events, there is still scepticism, limited research and insufficient evidence on the role of trees and forests under large or extreme rainfall events in large catchments $\left(>\sim 40 \mathrm{~km}^{2}\right)$. The effectiveness of trees and forests in mitigating these events is thought by some researchers to be low or negligible for extreme events (Sikka et al., 2003; Bruijnzeel, 2004; FAO-CIFOR, 2005; Calder \& Aylward, 2006; Tran et al., 2010; Bathurst et al., 2011). Extreme events occur less frequently, cover a wide areal extent $\left(>\sim 40 \mathrm{~km}^{2}\right)$, and are of long duration, high volume and either low or high intensity (Table 3). Under these 
events, extreme rainfall outweighs the ability of vegetation to significantly reduce runoff and hence flooding occurs even in the presence of trees and forests (FAO-CIFOR, 2005; Calder \& Aylward, 2006; Bathurst et al., 2011). Modelling based studies by Bathurst et al. (2006; 2011) in four different regions of Latin America (Costa Rica, Chile, Argentina and Ecuador) with different vegetation cover (forest, grasslands and crop lands) simulated effectiveness under extreme rainfall events. The studies concluded that forests and trees do not significantly reduce high flows resulting from extreme rainfall events thus failing to reduce impacts of extreme floods. Moreover, this is exacerbated if the events occur when antecedent soil moisture conditions are high (Bathurst et al., 2011). While such intuition may be plausible, forests can reduce pre-event soil moisture and still reduce the impact of extreme events (Alila, 2009) particularly those of low volume, high or low intensity (Table 3). In large catchments it is also envisaged that the presence of a wide range of land use systems, variability in climate and the presence of forests only on a small proportion of the catchment are likely to mask their effectiveness in reducing flood risk (Robinson et al., 2003; Calder \& Aylward, 2006; Blöschl et al., 2007; O'Connell et al., 2007; Blaschke et al., 2008; Vose et al., 2011). Therefore it is highlighted that the impact of forests cannot be easily distinguished from the aforementioned confounding factors (Vose et al., 2011). However, failure to distinguish confounding factors does not necessarily mean forests or trees do not have an effect. Even in small proportions, appropriately placed and well managed forests may have an effect.

Few studies (e.g. Pearce et al., 1987; Fahey et al., 2004; Siriwardena et al., 2006) have found a significant impact of trees or forests in large catchments (Table 4). Fahey et al. (2004) highlighted a $13 \%$ reduction in water yield which reduces flood risk, after trees were planted on $28 \%$ of a large catchment area $\left(900 \mathrm{~km}^{2}\right)$ in central North Island of New Zealand. Within New Zealand, Pearce et al. (1987) reported a $30 \%$ reduction in water yield following afforestation of $120 \mathrm{~km}^{2}$ of a sub-catchment area. The issue of the appropriate placement position of trees in a landscape becomes relevant in this case.

The impact of forests and trees on extreme rainfall events at large scale is quite complicated and there is need for further field based (catchment experimentation) and modelling studies. 
Table 3 How the impact of trees and forests changes as rainfall properties and catchment scale change

Rainfall intensity, volume and catchment scale

High rainfall intensity,

high volume, large catchment scale $\left(>\sim 40 \mathrm{~km}^{2}\right)$

high volume, small catchment scale $\left(<\sim 40 \mathrm{~km}^{2}\right)$

low volume, large catchment scale $\left(>\sim 40 \mathrm{~km}^{2}\right)$

low volume, small catchment scale $\left(<\sim 40 \mathrm{~km}^{2}\right)$

\section{Low rainfall intensity}

high volume, large catchment scale $\left(>\sim 40 \mathrm{~km}^{2}\right)$

high volume, small catchment scale $\left(<\sim 40 \mathrm{~km}^{2}\right)$

low volume, large catchment scale ( $>\sim 40 \mathrm{~km}^{2}$ )

low volume, small catchment scale $\left(<\sim 40 \mathrm{~km}^{2}\right)$

\section{Potential to reduce flood risk}

High uncertainty, flood impacts could be reduced. Need for more research

Effective

Can be effective

Effective

High uncertainty, flood impacts could be reduced. More research needed.

Effective

Effective

Effective 
Table 4 Summary of a few studies highlighting impact of trees under varying rainfall and landscape scales

\begin{tabular}{|c|c|c|c|c|}
\hline Source & $\begin{array}{l}\text { Catchment/ } \\
\text { Location }\end{array}$ & $\begin{array}{l}\text { Scale of } \\
\text { rainfall }\end{array}$ & $\begin{array}{l}\text { Scale of } \\
\text { catchment }\end{array}$ & Conclusions \& comments \\
\hline $\begin{array}{l}\text { Bradshaw et al., } \\
2007\end{array}$ & $\begin{array}{l}56 \text { countries, } \\
\text { international }\end{array}$ & $\begin{array}{l}\text { Small rainfall } \\
\text { events }\end{array}$ & & $\begin{array}{l}4-28 \% \text { increase in flood } \\
\text { frequency after } 10 \% \text { loss in } \\
\text { native forest cover }\end{array}$ \\
\hline $\begin{array}{l}\text { Bradshaw et al., } \\
2007\end{array}$ & $\begin{array}{l}56 \text { countries, } \\
\text { international }\end{array}$ & $\begin{array}{l}\text { Extreme } \\
\text { rainfall } \\
\text { events }\end{array}$ & & $\begin{array}{l}2.9-25.3 \% \text { increase in flood } \\
\text { frequency as a result of a } 10 \\
\% \text { loss in native forest cover }\end{array}$ \\
\hline $\begin{array}{l}\text { Jackson et al., } \\
2008\end{array}$ & $\begin{array}{l}\text { Pontbren, } \\
\text { United } \\
\text { Kingdom }\end{array}$ & & Field & $\begin{array}{l}\text { Careful placement of small } \\
\text { strips of trees on pasture } \\
\text { hill slope can reduce flood } \\
\text { peaks by } 40 \% \text { at field scale }\end{array}$ \\
\hline $\begin{array}{l}\text { Thomas \& Nisbet } \\
\text { (2006) }\end{array}$ & $\begin{array}{l}\text { England, } \\
\text { United } \\
\text { Kingdom }\end{array}$ & & 40ha catchment & $\begin{array}{l}\text { The effect of planting a } \\
\text { woodland was modelled } \\
\text { and it was concluded that a } \\
\text { delay of a } 1 \% \text { AEP (annual } \\
\text { exceedence probability) } \\
\text { flood by } 1 \text { hour }\end{array}$ \\
\hline $\begin{array}{l}\text { Pearce et al., } \\
1987\end{array}$ & New Zealand & & $\begin{array}{l}\text { Large } \\
\text { catchment area } \\
\left(120 \mathrm{~km}^{2}\right)\end{array}$ & $\begin{array}{l}30 \% \text { reduction in water } \\
\text { yield following afforestation }\end{array}$ \\
\hline Fahey et al., 2004 & $\begin{array}{l}\text { Central North } \\
\text { Island, New } \\
\text { Zealand }\end{array}$ & & $\begin{array}{l}\text { Large } \\
\text { catchment area } \\
\left(900 \mathrm{~km}^{2}\right)\end{array}$ & $\begin{array}{l}13 \% \text { reduction in water } \\
\text { yield after planting } 28 \% \text { of } \\
\text { the catchment with trees }\end{array}$ \\
\hline $\begin{array}{l}\text { Siriwardena et } \\
\text { al., } 2006\end{array}$ & $\begin{array}{l}\text { Queensland, } \\
\text { Australia }\end{array}$ & & $\begin{array}{l}\text { Large } \\
\text { catchment area } \\
\left(16440 \mathrm{~km}^{2}\right)\end{array}$ & $\begin{array}{l}\text { Clearance of natural forest } \\
\text { cover increased runoff by } \\
40 \%\end{array}$ \\
\hline
\end{tabular}




\subsubsection{Position on landscape}

The question of where tree planting can be targeted in landscapes to increase flood risk mitigation has not been adequately explored. Previous studies in England (Somerset) and Wales (Pontbren) have shown that targeting hill slope or upland contributing areas will significantly reduce peak flow and thus flooding (Nisbet \& Broadmeadow, 2003; Marshall et al., 2009). Notwithstanding the paucity of research, the appropriate placement of trees to reduce the risk of floods may be intuitively explored. Areas with high infiltration rates and water storage capacities are less likely to contribute to floods and may not need intervention. In contrast, steep and less permeable areas that intercept large quantities of rainfall are more likely to contribute runoff flow directly to water channels thereby causing floods. Targeting the planting of trees on such high runoff contributing areas can help reduce the risk of floods. For instance in New Zealand, mountainous terrains are catchment headwaters, which intercept large quantities of orographic rainfall and contribute runoff causing floods. Targeted tree planting on the upper Mangatu and Waipao sub-catchments effected a $30 \%$ reduction in annual water yield (Pearce et al., 1987; Blaschke et al., 2008).

In addition to placing trees and forests on runoff contributing areas, benefits could also be realised when they are placed on the lower end of the contributing areas as illustrated in Figure 2. Targeting these positions mitigates a large proportion of runoff cost effectively as opposed to targeting tree placement sorely on contributing areas. This is because a large proportion of runoff is intercepted at the lower end of contributing areas. This conforms to the recommendations proposed by Nisbet \& Broadmeadow (2003), that increasing woodland cover below the upper reaches of Parrett catchment (Somerset, UK) would significantly aid in flood control.

Another potentially effective way to choose the appropriate position in the landscape is to trace the surface flow pathways from sources to receivers. This will enable delineation of zones where water accumulates en-route to channels.

Making decisions on the appropriate position to place trees and forests in a landscape may benefit from the use of decision support tools for assessing, identifying and modelling the flood mitigation service. These tools among others include Integrated Valuation of Ecosystem Services and Tradeoffs (InVest), Land Utilisation and Capability Indicator (LUCI) 
and Artificial Intelligence for Ecosystem Services (ARIES). The use of these tools is a new but developing science which seeks to integrate various stakeholders in decision making regarding the use of natural capital for human well-being.

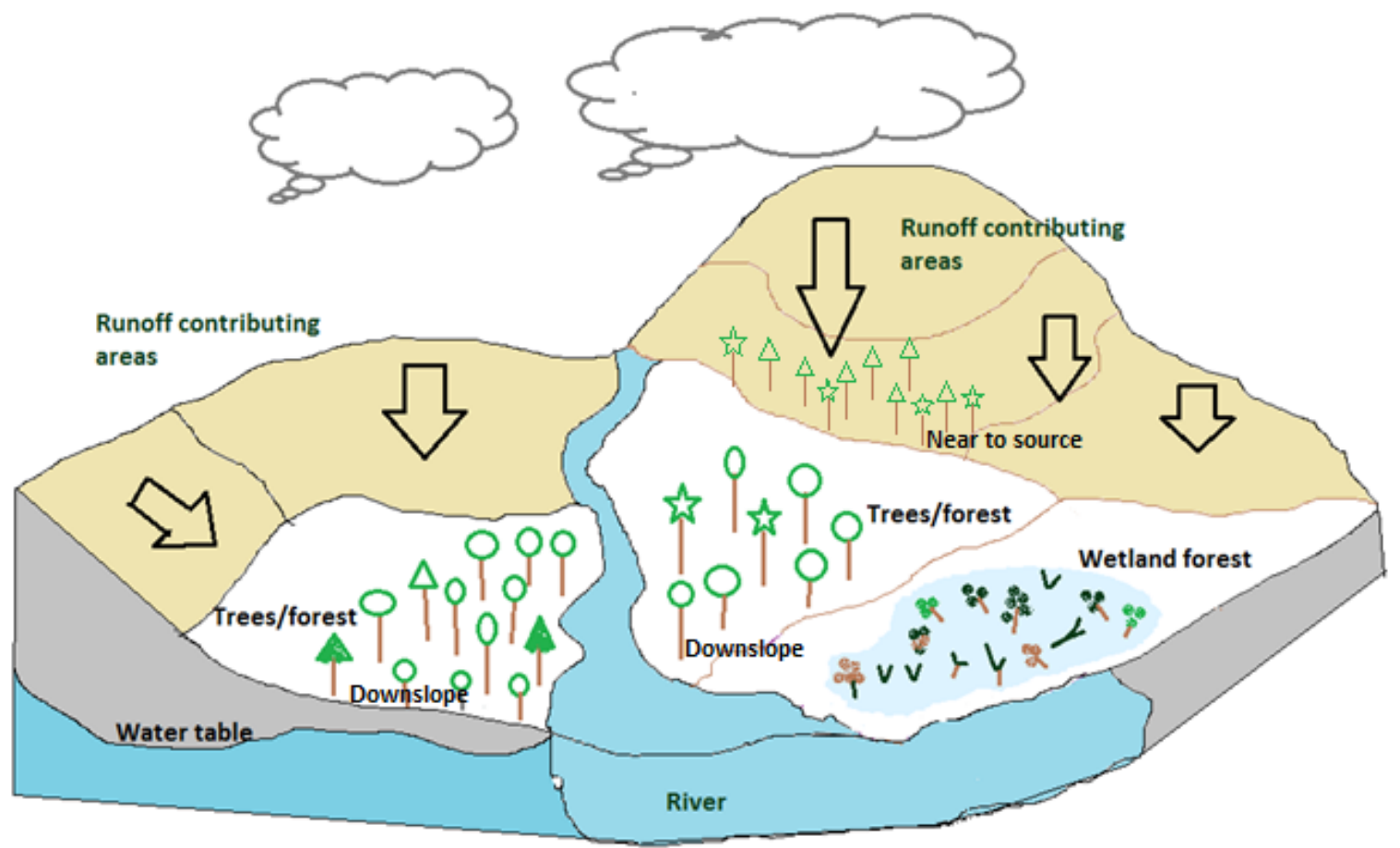

Figure 2. Appropriate positions in the landscape, near the source of runoff or downslope.

\subsubsection{Hydrological role of trees in wetlands}

Research on the impact of trees on water with regards to flood risk management has mainly focused on terrestrial ecosystems characterised by generally unsaturated soils i.e. agricultural lands and forested uplands and lowlands. There is a paucity of studies on their role in other ecosystem types that have permanently or temporarily saturated soils such as wetlands, specifically forested wetlands. Wetlands are good buffers of flood peaks depending on their position in the landscape. Understanding the role of trees in wetlands may also provide a proxy to understand the impact of events coinciding with very high antecedent moisture conditions that occur in terrestrial areas. In these ecosystems, the water table is close to the surface and storage of excess water is limited. Wetlands tend to develop layers of fine textured soils at their bottoms which have low infiltration rates (Jackson, 2006). The use of trees to ameliorate such soils could maximise water storage and increase the effectiveness of wetlands as flood peak buffers. 
Wetlands comprise of three main components i.e. water, vegetation and saturated soils. Water is the main driving component affecting functional processes and spatial distribution of the other components (vegetation and soils) (Mitsch \& Gosselink, 2007). In turn, vegetation and soils also affect water. Vegetation has an impact on the velocity, quantity and residence time of water flowing into a wetland (Jenkins \& Greenway, 2005; Sakals et al., 2006; Mitsch \& Gosselink, 2007).

The hydraulic roughness of vegetation reduces velocity of water and increases the residence time, both of which are useful characteristics of wetlands for flood control, sediment and pollution filtering (Jenkins \& Greenway, 2005; Joyce, 2012). The hydraulic roughness is characterised by geometric properties such as stem density, canopy volume and stiffness (Horn \& Richards, 2007). Trees are able to reduce high velocity flow because they remain firm and upright compared to grasses which are flexible and easily bend (Horn \& Richards, 2006). The ability of trees to increase the residence times of water is an additional benefit for wetland systems as their functions are mainly driven by available water. In these systems, presence of trees may keep soil pores open for more water inflow through infiltration. Studies in riparian areas have indicated that trees lower the level of water table mainly through evapotranspiration which then creates more storage capacity for rain or runoff water (Jenkins et al., 2012). This is not a favourable characteristic in all wetland types, for example in temperate regions the presence of trees in bogs enhances water loss and disrupts ecological functioning (Mitsch \& Gosselink, 2007). The aforementioned traits generally indicate that the role of trees in flood risk management is not only limited to terrestrial ecosystems but may also extend to wetland areas.

The impact of trees on water related soil physical and hydraulic properties critical for flood risk management has not been well established in wetlands. There is limited research that informs this role of trees in wetlands (Lugo et al., 1988; Trettin \& Jurgensen, 2003; Acreman \& Holden, 2013). Some of the few wetland studies include Yu et al. (2012), Zhang et al. (2012) and Meyer et al. (2008). Yu et al. (2012) quantified the response of one soil property only (soil organic carbon). Zhang et al. (2012) reported on the effect of tree planting on a wide range of soil properties in a wetland but the hydrological implications of the observed results were not discussed. Meyer et al. (2008) investigated bulk density and soil carbon as indicators of wetland recovery in forested wetlands. These studies on soil physical and 
hydraulic properties related to trees in wetlands have concluded that the properties vary according to site and it is difficult to generalise. Increases or decreases in bulk density, saturated hydraulic conductivity and infiltration have been observed at different sites following harvesting of trees (e.g. Lockaby et al., 1997; Jackson, 2006). Hence only evapotranspiration can confidently be regarded as an attributing factor to the control of antecedent soil moisture in the presence of trees (Aust \& Lea, 1992; Lockaby et al., 1997). There is therefore a need for more research on the hydrological role of trees in amelioration of soil properties for water retention in wetland systems.

\subsubsection{Summary of the main findings of the review and recommendations}

The potential of use of trees and forests as flood mitigation tools is high in many but not all landscapes. This potential is proven from field scale to $<\sim 40 \mathrm{~km}^{2}$ in many regions around the world, but there is high uncertainty and need for more research above $40 \mathrm{~km}^{2}$ catchment scale. Natural forests are generally more effective than plantation forests but sustainable management and longer rotation periods could improve effectiveness of plantations. Mature trees or forests can effectively reduce flood risk more than young trees up to an age when their resilience to calamities such as windstorms decreases. In flood prone landscapes, functional integration of trees/forests with agricultural land use types may increase the adaptive capacity against floods. The literature review also shows that the effectiveness of trees and forests is in general maximised on gently sloping to moderately steep slopes, and on either deep soils overlying impermeable bedrock, or shallow to moderately deep soils overlying semi-permeable or permeable bedrock. Broad-leafed deep rooting species that facilitate infiltration and interception loss were identified to be ideal flood mitigating tools in humid, semi-arid and temperate climates. However, a combination of coniferous species with deciduous and non-deciduous broadleaves in temperate regions may enable effective reduction of runoff in winter when flood incidences are usually high. In semi-arid and arid regions, caution should also be exercised by avoiding planting of heavy water users, to prevent water depletion during the dry season. Target planting of tree species on low-lying positions of low permeability receiving runoff in the landscape may enhance flood mitigation, but should also consider proximity of the water table to the soil surface so as to select appropriate species. 
The review also shows that the impact of trees is reduced when they are placed on steep to very steep terrains, and on either very shallow, highly degraded impermeable soils overlying impermeable bedrock, or where flat areas coincide with a high water table.

There is need for further research on the effectiveness at large catchment scales and extreme rainfall events. While most research on the hydrological role of trees and forests in flood risk mitigation has been carried out in terrestrial areas (i.e. agricultural landscapes and forests), extensive research is required in other ecosystems such as wetlands. This will allow for the integration of components of different ecosystems as an effective way to reduce flood risk.

\subsubsection{Where to?}

Following the findings of the review, guidelines on the effective use of trees are provided in Chapter 6 for use by policy makers. The remainder of this chapter, explores some of the research needs identified which include the role of trees in wetlands and the use of decision support tools to guide the targeted planting for ecosystem service provision. The following section provides an insight to wetland ecosystems, particularly their importance, classification, historical degradation, restoration, protection and management. This information provides a solid foundation upon which the wetland research was implemented to meet the needs identified in the review. 


\subsection{Wetlands and their importance}

Wetlands are terrestrial ecosystems flooded or saturated by water either permanently or seasonally (Mitsch \& Gosselink, 2007). They consist of a diverse flora and fauna only adapted to such conditions. A habitat is delineated as a wetland if its characteristic components include hydrology (water inflow, outflow, storage, and depth), biota (flora and fauna) and hydric soils. Hydrology, vegetation and soil components are discussed in this section while the fauna components are left out as they are not a focus of this research. Hydrology is the main driving component in the formation, structure and function of wetlands. It determines regular flooding and soil saturation, which are critical for wetland creation and functional stability. It is the cornerstone for functioning of wetland areas (Mitsch \& Gosselink, 2007). Hydrologic variables of wetlands include duration of flooding, flood frequency, period of flooding and depth of flood, which are collectively referred to as the hydroperiod. Water flow into wetlands can be in the form of precipitation, ground water and surface water. As a result, some wetlands can be connected to lakes and streams while others can be isolated. The supply of water into wetlands determines the nutrient and oxygen levels and in turn affects soils and the distribution patterns of flora and fauna (Campbell \& Jackson, 2004; Chui et al., 2011).

Wetland vegetation consists of plants adapted to grow under saturated conditions and commonly referred to as hydrophytes (Mitsch \& Gosselink, 2007). Adaptation strategies to wet conditions include the presence of aerenchyma tissue within root systems for oxygen movement, fibrous root systems which develop horizontally above water, enlarged lenticels above plants for atmospheric gaseous exchange and creation of an oxygenated rhizosphere. There are two categories of wetland plants, i.e. obligatory wetland plants which grow in standing water and saturated soils, and facultative plants which are tolerant to either wet or dry conditions (Mitsch \& Gosselink, 2007). Wetland plants range from sphagnum species to woody tree species present in different wetland types. The occurrence and distribution of wetland vegetation is not only determined by water, but also by the availability and concentration of nutrients. The increase in nutrient levels is correlated to the increase in abundance and richness of wetland vegetation up to a certain limit beyond which a few species begin to dominate (Chow et al., 2012). In some wetland types, for instance bogs, low nutrient levels support the growth of sphagnum species. 
While the wetland physical environment influences vegetation, the vegetation itself has an impact on the soil and water components of the wetland system. Wetland vegetation plays a significant role in controlling nutrient dynamics (carbon, nitrogen and phosphorus cycling), provision of habitat for different groups of organisms and in influencing the water cycle (Bullock \& Acreman, 2003). This is partly achieved through the interaction between vegetation and hydric soils.

Hydric soils develop under saturated conditions and are of poor permeability. The saturated conditions give rise to two types of hydric soils, i.e. organic and mineral soils. Organic soils characteristically comprise of vegetation remains at different levels of decomposition and organic matter levels above 20-35 \% (Mitsch \& Gosselink, 2007). Mineral soils in-turn, have distinct horizons making up a soil profile and less than $20-35 \%$ organic matter (Mitsch \& Gosselink, 2007). Alternating inundation and exposure of mineral wetland soils gives rise to reduction and oxidation (redox) chemical reactions which foster the development of gray and dark reddish brown soil particles respectively. Saturation in wetland soils depletes available oxygen, causing other elements such as sulphur, manganese and iron to be used as electron acceptors by microorganisms during respiration (Mitsch \& Gosselink, 2007). This results in the formation and accumulation of organic materials and redox colour patterns (Vepraskas, 2001). Redox reactions play a critical role in biogeochemical cycles within wetland systems. Understanding these cycles provides knowledge on the role of wetlands in delivering ecosystem services such as carbon sequestration.

Hydric soils also act as a reservoir of nutrients for wetland vegetation, as well as a medium for chemical reactions (Mitsch \& Gosselink, 2007; Kimberley et al., 2012). They are important for the storage of water, pollution control and vegetation distribution in wetland areas. Because soils play an important role in wetland functions, it is essential to explore water related parameters of hydric soils. These include organic carbon, soil physical and hydraulic properties as parameters critical for water movement and storage functions of wetland systems. Such parameters can be used as indicators for success in functionality (Shaffer \& Ernst, 1999; Kimberley et al., 2012) and are discussed in section 2.8.

Interaction of wetland components produces ecological, economic and social benefits that have driven development and sustenance of cultures from ancient times through to the present day. Marsh Arabs (Southern Iraq), Calusa Indians (North America) and Sokaogon 
Chippewa (Wisconsin) have sustainably lived with wetlands for thousands of years and used them for day to day living as sources of food, building material and energy (Mitsch \& Gosselink, 2007).

Benefits of wetlands include flood mitigation, water quality improvement, carbon and nutrient storage, formation of fossil fuels, habitat provision for rare plant and animal species, ground water recharge, grazing and recreation (Davidsson et al., 2000; Zedler \& Kercher, 2004; Wang et al., 2008; Todd et al., 2010; Joyce, 2012; Mitsch et al., 2012). Some wetlands are of direct agricultural value as they are used for livestock production, e.g. in Ireland turlough wetlands are used for grazing (Joyce, 2012; Kimberley et al., 2012). Wetland areas connected to ground water are useful for replenishing ground water supplies through percolation and infiltration of stored water. This is useful under dry conditions when ground water discharge into streams and lakes can help maintain flow levels.

The foundation of this research is based on understanding how these services can be harnessed through management and restoration of wetlands. Since the provision of these services is a factor of wetland type, it is important to explore the different types of wetlands. This enables the understanding of what exactly is being managed. The next section explores wetland classification and highlights the different types of wetlands that are associated with services previously discussed.

\subsection{Wetland Classification}

Assessment of the ecosystem services provided by wetlands requires the exploration of wetland types, because they are not all equally effective in contributing these services. Their utility in service provision is determined by factors such as geomorphic and hydrogeomorphic positions in the landscape. For instance, a wetland located in close proximity to an agricultural point source of pollution is more likely to be useful for water quality improvement compared to one that is isolated (Mitsch \& Gosselink, 2000).

Exploration of wetland types involves analysis of wetland classification systems. The components hydrology, soil and vegetation are useful for identification and classification of wetland types. Wetland classification varies in different parts of the world as countries have adopted the use of terminology specific to their regions. This makes it inevitable to have multiple classification systems. The Ramsar classification system for wetland type (Ramsar, 
2000 ) is used in most parts of the world. In the United States, the hydrogeomorphology (HGM classification) and Cowardin classification of wetlands and deep water habitats (Cowardin et al., 1979) are the commonly used classification systems which in many cases are modified to suit specific regions (Scott \& Jones, 1995; Bernal \& Mitsch, 2012).

The Ramsar classification system created for biodiversity and wildlife is divided into three main categories: Marine/Coastal wetlands, Inland wetlands and Constructed wetlands (Ramsar, 2000). The Cowardin classification comprises of five systems (palustrine, marine, lacustrine, estuarine and riverine), 8 sub-systems and 11 classes (Scott \& Jones, 1995). The forested wetland type that are a focus of this research are classified under the palustrine system in the Cowardin classification.

In New Zealand, wetland classification is primarily based on landforms, substrates and vegetation (Johnson \& Gerbeaux, 2004). An easy system to understand and use is the semi hierarchical classification designed by Johnson \& Gerbeaux (2004) which was adopted and modified from Ward \& Lambie (1999) and Clarkson et al. (2003). It is comprised of six levels; vegetation composition, hydrosystem ${ }^{14}$, wetland class, wetland form, structural form and subsystem (Table 5). Level I constitutes of hydrosystem based on landform setting, temperature, salinity and hydrological setting (Johnson \& Gerbeaux, 2004). The nine hydrosystems include the units Riverine, Esturine, Marine, Nival, Plutonic, Geothermal, Palustrine, Inland saline and Estuarine (Table 5) (Johnson \& Gerbeaux, 2004). Level IA, groups wetlands according to water regime i.e. water flow, period of inundation, water source and drainage while level II comprises of nine wetland classes that are distinguished based on $\mathrm{pH}$, nutrient status and water regime (Table 5). Level II A comprises of forms created and occupied by wetlands and level III has structural classes associated with vegetation structure. Level IV is the lower level of classification in which wetlands are grouped according to one or two dominant vegetation types (Table 5). Forested wetlands are identified in levels II and IV.

The hydrogeomorphic classification system specifically classifies the different forested wetland types based on characteristics related to their functions as demonstrated in section 2.4 .

\footnotetext{
${ }^{14}$ The hydrological and landform setting of wetlands
} 
Table 5. Hierarchical classification for New Zealand

\begin{tabular}{|c|c|c|c|}
\hline & Levels & \multicolumn{2}{|l|}{ Units and their characteristics } \\
\hline \multirow[t]{9}{*}{1} & \multirow{9}{*}{ Hydrosystems } & \multicolumn{2}{|l|}{ Inland Saline } \\
\hline & & \multicolumn{2}{|l|}{ Marine } \\
\hline & & \multicolumn{2}{|l|}{ Geothermal } \\
\hline & & \multicolumn{2}{|l|}{ Riverine } \\
\hline & & \multicolumn{2}{|l|}{ Estuarine } \\
\hline & & \multicolumn{2}{|l|}{ Lacustrine } \\
\hline & & \multicolumn{2}{|l|}{ Palustrine } \\
\hline & & \multicolumn{2}{|l|}{ Plutonic } \\
\hline & & \multicolumn{2}{|l|}{ Nival } \\
\hline $\mathrm{IA}$ & Subsystem & \multicolumn{2}{|c|}{$\begin{array}{l}\text { Water regime; permanently/seasonally wet, fluctuating water table, poor } \\
\text { drainage, slow/moderate/nil water flow, ground water/rain/lake fed }\end{array}$} \\
\hline \multirow[t]{9}{*}{ II } & \multirow[t]{9}{*}{ Wetland class } & \multicolumn{2}{|c|}{$\begin{array}{l}\text { Ephemeral wetlands- source of water is rainfall, adjacent water body and ground } \\
\text { water. They occur in closed depressions that form on tephra, dunes and } \\
\text { moraines. Water accumulates in the depression and cannot flow out. pH in these } \\
\text { wetlands is neutral ranging between 5.5-7 and nutrients levels are moderate. } \\
\text { Rainfall variability causes fluctuation of water table. With high levels above the } \\
\text { ground in winter and spring and lower levels below the ground in summer to the } \\
\text { extent of drying out. }\end{array}$} \\
\hline & & \multicolumn{2}{|c|}{$\begin{array}{l}\text { Bog- rainfall is the only source of water into the wetland system which is } \\
\text { permanently wet with water table close to the surface. Nutrient levels are very } \\
\text { low and pH is acidic, ranging from } 3-4.8 \text {. Occurs on flat ground, terraces and hill } \\
\text { crests and is dominated by peat substrate. }\end{array}$} \\
\hline & & \multicolumn{2}{|c|}{$\begin{array}{l}\text { Fen- fed by rain and ground water, with near permanent saturation and water } \\
\text { table near the surface. Mainly dominated by peat, with nutrient levels slightly } \\
\text { higher than those in bogs and } \mathrm{pH} \text { levels ranging from } 4-6 \text {. Occurs on alluvial fans, } \\
\text { hillslopes and bog margins. }\end{array}$} \\
\hline & & \multicolumn{2}{|c|}{$\begin{array}{l}\text { Swamp- receives water from ground water flow and surface runoff from adjacent } \\
\text { land use. Water table is usually high and above the ground giving rise to } \\
\text { permanent wetness. Nutrient levels are moderate and pH ranges from slightly } \\
\text { acidic to neutral (4.8-6.3). Occurs mainly on valley floors where water flow is } \\
\text { moderate. }\end{array}$} \\
\hline & & \multicolumn{2}{|c|}{$\begin{array}{l}\text { Marsh- source of water is mainly ground water and surface runoff from adjacent } \\
\text { land uses. Occurs on valley margins, riparian zones and gentle sloping areas. } \\
\text { Water table is usually below the surface and there is alternating wetting and } \\
\text { drying. } \mathrm{pH} \text { is neutral (6-7) and nutrient levels range from moderate to high. }\end{array}$} \\
\hline & & \multicolumn{2}{|c|}{$\begin{array}{l}\text { Seepage- occurs on moderate to steep hill slopes where ground water intersects } \\
\text { with the soil surface. Nutrient levels vary from high to low, while pH ranges from } \\
\text { slightly acidic to neutral (4-7). }\end{array}$} \\
\hline & & \multicolumn{2}{|c|}{$\begin{array}{l}\text { Shallow water- shallow water bodies consisting of ponds, lake edges, pools, } \\
\text { streams and lagoons with a water table above the surface and are permanently } \\
\text { wet. Nutrient levels are moderate and ph ranges from slightly acidic to neutral (4- } \\
\text { 7). }\end{array}$} \\
\hline & & \multicolumn{2}{|c|}{$\begin{array}{l}\text { Salt marsh- occurs on coastal platforms and edges of estuaries where the water } \\
\text { source is sea, ground water and brackish water. The soil substrate is mainly } \\
\text { mineral with moderate nutrient levels and pH ranging from 4.9-8. }\end{array}$} \\
\hline & & \multicolumn{2}{|c|}{$\begin{array}{l}\text { Pakihi and gumland- rainfed wetland areas with mineral or peat soils of poor } \\
\text { nutrient status and slightly acidic (4.1-5). Occurs on impermeable soils, sloping } \\
\text { surfaces and deforested land. Water table is below the surface. }\end{array}$} \\
\hline \multirow[t]{5}{*}{ IIA } & \multirow[t]{6}{*}{ Wetland form } & & Basins \\
\hline & & & Hills \\
\hline & & Forms occupied by wetlands slopes & \\
\hline & & & Flats \\
\hline & & & Channels \\
\hline & & & \\
\hline
\end{tabular}




\begin{tabular}{|c|c|c|}
\hline & & C Humock and hollow surface \\
\hline & & Surface channels \\
\hline & & Swamp pool \\
\hline & & Forms created by wetlands Tidal creek \\
\hline & & Gorge \\
\hline & & Alpine tarn \\
\hline & & String mire \\
\hline & & Raised bog \\
\hline III & Structural class & $\begin{array}{l}\text { Shrubland, treeland, rushland, forest, grassland, srub, tussockland, fernland, } \\
\text { cushionfield, reedland, herbfield, Mossfield, sedgeland }\end{array}$ \\
\hline IV & Vegetation Composition & $\begin{array}{l}\text { Domination of } 1 \text { or more vegetation types e.g Prodocarp swamp forest, bog pine, } \\
\text { Juniper wetland, kahikatea/ flax tree swamp, grey willow forest fen, kahikatea } \\
\text { forest ephemeral wetland }\end{array}$ \\
\hline
\end{tabular}




\subsection{Forested wetlands and their components}

When optimising deliverance of wetland ecosystem services it is prudent to classify the targeted wetland types based on characteristics that contribute to their functions. A classification system that identifies forested wetlands based on such characteristics is the hydrogeomorphic (HGM) system. It classifies forested wetlands according to flow patterns, geomorphic setting and source of water. These characteristics are vital to the function and form of forested wetlands. The classification system identifies seven forested wetland types, i.e. depressional, mineral flat, tidal fringe, slope, riverine, lacustrine fringe and organic flat (Brinson, 1999; Smith et al., 1995) (Table 6). Based on this classification system, the Wairio wetlands fall into the depressional type (Table 6). 
Table 6 Hydrogeomorphic classification of forested wetland types

\begin{tabular}{|c|c|c|c|c|}
\hline Type & Form & Hydrology & Soil & $\begin{array}{l}\text { Common name- } \\
\text { Sub types }\end{array}$ \\
\hline Mineral flat & $\begin{array}{l}\text { Large areas of } \\
\text { low relief } \\
\text { occurring on } \\
\text { flood plain } \\
\text { terraces }\end{array}$ & $\begin{array}{l}\text { Influenced by } \\
\text { precipitation if the } \\
\text { wetland is located on } \\
\text { high areas; permeable } \\
\text { soils influence } \\
\text { downward seepage; } \\
\text { ground water input } \\
\text { affects hydrology if } \\
\text { the wetland is } \\
\text { adjacent to upland } \\
\text { areas }\end{array}$ & $\begin{array}{l}\text { Mineral soils } \\
\text { with variable } \\
\text { texture } \\
\text { ranging from } \\
\text { sandy to } \\
\text { organic }\end{array}$ & $\begin{array}{l}\text { Wet hardwood } \\
\text { flats, wet pine } \\
\text { savannah, wet } \\
\text { pine flats }\end{array}$ \\
\hline Depressional & $\begin{array}{l}\text { Build-up of } \\
\text { surface water } \\
\text { in depressions } \\
\text { where channel } \\
\text { inlets and } \\
\text { outlets are } \\
\text { absent. }\end{array}$ & $\begin{array}{l}\text { Precipitation, ground } \\
\text { water discharge and } \\
\text { interflow contribution } \\
\text { from adjacent uplands } \\
\text { influence hydrology }\end{array}$ & Mineral & $\begin{array}{l}\text { Ephemeral } \\
\text { wetlands, } \\
\text { maritime } \\
\text { depressions, } \\
\text { coastal plain } \\
\text { depressions }\end{array}$ \\
\hline $\begin{array}{l}\text { Riverine } \\
\text { wetlands }\end{array}$ & $\begin{array}{l}\text { Common } \\
\text { along stream } \\
\text { channels, } \\
\text { riparian areas } \\
\text { and flood } \\
\text { plains }\end{array}$ & $\begin{array}{l}\text { Interflow from } \\
\text { adjacent uplands and } \\
\text { ground water } \\
\text { discharge influence } \\
\text { hydrology }\end{array}$ & $\begin{array}{l}\text { Mineral and } \\
\text { organic hydric } \\
\text { soils }\end{array}$ & $\begin{array}{l}\text { Muck swamps, } \\
\text { mountain bogs, } \\
\text { wet head water } \\
\text { forests }\end{array}$ \\
\hline Tidal fringe & $\begin{array}{l}\text { Occur on sea } \\
\text { coasts }\end{array}$ & $\begin{array}{l}\text { Wind tides influence } \\
\text { hydrology }\end{array}$ & $\begin{array}{l}\text { Mineral or } \\
\text { organic }\end{array}$ & $\begin{array}{l}\text { Tidal marshes, } \\
\text { tidal hardwoods }\end{array}$ \\
\hline Organic flat & $\begin{array}{l}\text { Occur on } \\
\text { extremely wet } \\
\text { areas of low } \\
\text { relief in } \\
\text { coastal flood } \\
\text { plains }\end{array}$ & $\begin{array}{l}\text { Runoff is the major } \\
\text { hydrological influence }\end{array}$ & $\begin{array}{l}\text { Predominantly } \\
\text { organic }\end{array}$ & $\begin{array}{l}\text { Wet pine flats- } \\
\text { organic, non- } \\
\text { riverine swamp } \\
\text { forest, pocosins }\end{array}$ \\
\hline $\begin{array}{l}\text { Slope } \\
\text { wetlands }\end{array}$ & $\begin{array}{l}\text { Occur on } \\
\text { sloped terrain }\end{array}$ & Surface runoff & Mineral & $\begin{array}{l}\text { Occur in } \\
\text { mountains, } \\
\text { upper coastal } \\
\text { plains }\end{array}$ \\
\hline $\begin{array}{l}\text { Lacustrine } \\
\text { fringe }\end{array}$ & $\begin{array}{l}\text { Occur } \\
\text { adjacent to } \\
\text { lakes }\end{array}$ & $\begin{array}{l}\text { Surface and } \\
\text { subsurface flow from } \\
\text { adjacent lakes and } \\
\text { ground water } \\
\text { discharge }\end{array}$ & $\begin{array}{l}\text { Mineral and } \\
\text { organic }\end{array}$ & $\begin{array}{l}\text { Occurs on } \\
\text { lakes and } \\
\text { ponds }\end{array}$ \\
\hline
\end{tabular}




\subsection{Wetland degradation}

Historically humans had problems with accessing wetlands, endured water-borne diseases and wrath of insects (Junk et al., 2013). As a result, wetlands were considered as value-less waste lands in most ancient times (Mitsch \& Gosselink, 2007). However, the increase in realisation of their functionality as agricultural lands led to their intense colonisation despite the previous antagonistic relationship with human kind. Over the past 10000 years, wetlands have undergone intense degradation and losses globally as a result of anthropogenic causes.

In water scarce regions and densely populated areas, rapid losses or degradation have and are still occurring and may increase for the next few decades (Brinson \& Malvárez, 2002; Junk, 2002; Junk et al., 2013). The situation might even be worse than expected since the extent of wetland areas in some regions e.g. Africa, Russia and South America is not known with accurate precision due to poor inventories (Junk et al., 2013).

Anthropogenic impacts in particular have played a major role in the loss of wetlands. For instance, $80 \%$ have been degraded in highly populated areas of North America, Europe and East Asia (Bobbink et al., 2006), $21.6 \%$ have been lost in China (An et al., 2007) and $90 \%$ in New Zealand and some states such as Ohio and California in the USA (Mitsch \& Gosselink, 2007; McGlone, 2009). Only 8 million square kilometres (6 \%) of the earth's surface remains as wetland area globally (Schultink \& Vliet, 1997; Junk et al., 2013). Anthropogenic induced losses directly alter wetland components i.e. hydrology, soils, flora and fauna. The anthropogenic activities include drainage and diversion for transformation into arable agricultural and urban use, grazing/overgrazing, deforestation, timber harvesting, poaching, mining, peat extraction, construction of hydroelectric dams and dykes, groundwater abstraction, eutrophication, invasive species and intense tourism (Brinson \& Malvarez, 2002; McGlone, 2009; Junk et al., 2013). Population increase has exerted pressure on wetland use for agricultural food production e.g. rice production in China and Africa and beef production for international export in South America (Junk et al., 2013).

Natural factors also contribute to the loss of wetlands. Natural climate change associated with natural variability in precipitation and temperature, particularly increases in temperature and decreases in rainfall, result in the reduction of available water for 
wetlands. Climate change, particularly temperature rise has caused wetlands do dry out, resulting in a loss of $27400 \mathrm{~km}^{2}$ of wetland area in western China (Junk et al., 2013). Some wetlands naturally have short life spans of a few decades for example beaver swamps (Jackson, 2006).

\subsection{Wetland restoration, protection and management}

Based on the greatest level of destruction and loss of wetlands over the past years and their social, economic and ecological significance, efforts have been made to recover their components and ecosystem functions. This has been done through restoration, creation/construction, protection and conservation of wetland systems globally (MorenoMateos et al., 2012). Their loss is an easily recognisable indication of the decrease in water resources and natural areas.

The interest in restoration began after adoption of the Ramsar convention in 1971, a global treaty which provides a framework for sustainable management and conservation of wetlands. About 160 nations had signed up for the treaty in 2011 and 1950 sites have been listed as important, with a large number (971) listed in Europe (Junk et al., 2013). Nations contracted to this convention have delineated important wetland areas and set up policies, management actions and land use planning which has seen an increase in target specific restoration projects over the past 3 decades. In Europe, the European Commission set up a life-Nature programme in 1997 for restoration of inland and coastal wetland areas while in China, 460 reserve parks have been created for wetland protection (Junk et al., 2013).

Wetland area has increased in North America since the passing of legislation for wetland protection in the mid 1970s and 1980s that led to the restoration and creation of more wetlands than had been destroyed (Junk et al., 2013). Prior to the Ramsar convention, the concern for wetlands was evident in the USA where duck stamps manufactured in 1934 were used to generate funds for purchase or lease of wetlands for provision of water fowl habitat (Mitsch \& Gosselink, 2007).

Restoration targets are site specific but the main goal is to help set and harness the natural capacity of wetlands to follow a trajectory that leads to a functional state they exhibited prior to degradation or towards the restorer's desired functionality (Schmitz, 2012). This however, has been met with difficulties as most projects have failed to recover wetlands to 
their pre-existing conditions. One of the main problems identified is that restoration may be created on conditions (soil and hydrology) different from those of the destroyed wetland (Shaffer \& Ernst, 1999) and in such cases, evaluation of restoration activities needs to be done with reference to natural sites. Generally, it takes a minimum of two generations for wetlands to fully recover their functionality and assessments may be carried out earlier and wrongly report restoration failure. Thus more monitoring time is needed before making final conclusions (Schmitz, 2012). However, under warm climates, large, hydrologically interconnected wetland systems recover quickly compared to small and isolated ones in cold climates (Schmitz, 2012). Recovery is based on how close they resemble reference sites, which are pristine wetlands. The only problem with using a reference site is that it is usually at a different stage of development to the restored site and it becomes difficult to relate parameters.

Wetland degradation has been mostly associated with modification of the hydrological regime through drainage, and restoration starts with the assessment of how hydrology has been affected. Restoration of hydrology can be through filling up of constructed drainage ditches, removal of artificial water control structures that impede flow into the system (e.g. drainage pipes, any stop banks, road ways, and tidal barriers), construction of structures such as earth dams that retain water into the system. Restoration of hydrology will in turn affect the distribution and assemblage of vegetation and animal species. For example, in Puerto Rico, the removal of a road way that separated a mangrove wetland area from the sea resulted in the recovery of mangrove vegetation (Turner \& Lewis, 1997).

Wetlands that have had desirable species eliminated are restored by planting of desired or native species, controlling of invasive species and creating conditions suitable for natural regeneration of desired species. In forested wetlands, restoration involves land contouring, planting native species naturally adapted to the site or creation of ecological conditions that favour natural regeneration (Meyer et al., 2008). Since wetland ecosystem services are partly a function of soil processes, restoration practices that target soil parameters and development trajectories and drive them toward the autogenic phase, may improve functional success of restored wetlands. 


\subsection{Wetland restoration and conservation in New Zealand}

Wetland restoration in New Zealand is spear headed by non-governmental organisations and local communities in conjunction with the government (van Roon, 2012). It is carried out to reverse the staggering $90 \%$ loss that has occurred over the past 150 years. The overall aim of various wetland restoration projects in New Zealand is to return the damaged ecosystems to their pristine state or to the level desired by the practitioner based on the current social needs. Over the past 15 years, effort has been put into the establishment and protection of indigenous vegetation, control of invasive species and re-creation of optimum hydrological conditions (van Roon, 2012).

The main challenges to the achievement of these goals have been the lack of adequate knowledge of the pedigree of various wetland sites, absence of data sets describing wetland components, the extreme presence of invasive species (weeds and pests) and difficulties in balancing fulfilment of current social needs and ecological protection (van Roon, 2012). Overcoming some of these challenges requires understanding of the hydrological, soil and nutrient conditions that underpin functions provided for by wetlands. The next section will briefly describe the soil system from where some of the wetland functions are derived. This will give insight to what can be targeted or used as performance indicators during restoration for ecosystem service provision.

\subsection{The soil system}

This section provides a brief insight into the soil system to facilitate the understanding of the significance of soil properties in ecosystem service provision. Soils are a continuously evolving and transforming physical system covering the earth's surface. The soil system is composed of solid components (biological organisms, inorganic and organic materials), liquid components (soil water), gaseous components (air in pore spaces) and energy components (thermal and biomass energy), that are collectively referred to as the soil natural capital stock (Robinson et al., 2009, Dominati et al., 2010, Robinson et al., 2012). The quality of these components defines the soil properties.

Within the soil system, soil properties are interconnected and underpinned by supporting processes (e.g. biological activity, nutrient and water cycling) or degraded through erosion, compaction, salinization and biodiversity loss (Dominati et al., 2010). Natural (climate, 
geology) and anthropogenic (land use management) drivers affect both soil properties and the processes underpinning them for ecosystem service provision. Soil properties can be classified as inherent (static) and dynamic (manageable) (Dominati et al., 2010). Inherent soil properties reflect the pedigree of a site and take a very long time to respond to natural and anthropogenic drivers and include topography, texture and depth, among others. Dynamic soil properties are sensitive to the anthropogenic and climatic forces and are subject to change over a short period of time. These properties include bulk density, macroporosity, $\mathrm{pH}$, carbon stock, organic matter content, soil temperature and moisture content, among others. It is from the soil capital stock that ecosystem services are derived.

The soil capital stock (properties) interacts with the wider environment to produce various benefits such as habitat for biological organisms, substrate for nutrient cycling, retention of flood waters, detoxification of wastes, carbon storage, plant survival and raw materials for fuel, among others (Dominati et al., 2010). Robinson et al. (2012), Dominati et al. (2010), Robinson \& Lebron (2010) emphasise the importance of recognising the soil natural capital stock in ecosystem service delivery. The soil natural capital stock particularly the dynamic soil properties that are sensitive to management, is useful as an indicator of ecosystem function following restoration. A few dynamic soil hydraulic and chemical properties were selected as indicator variables for this research, to evaluate the impact of tree planting as a wetland restoration procedure. These are discussed in the next section.

\subsubsection{Soil hydraulic and chemical properties}

\subsubsection{Saturated hydraulic conductivity}

Saturated hydraulic conductivity $\left(\mathrm{K}_{\mathrm{s}}\right)$ was early recognised as a crucial parameter in the study of permeability, water flow and transport processes in wetland soils (Andersen, 2003; Holden \& Burt, 2003). The speed of the downward entry of water from the surface into wetland soils is determined by its infiltration rate. The transmission of the infiltrating water as driven by a combination of gravitational and pressure potential (hydraulic head) within the soil horizon is referred to as hydraulic conductivity. Hydraulic conductivity is an important indicator of water transport between wetlands and other water bodies and this has an implication on chemical, hydrological and microbiological processes within wetland ecosystems. The volume of water transmitted between wetlands and water bodies through 
the soil is proportional to the hydraulic head and hydraulic conductivity, and can be defined using the Darcy's equation:

$$
Q=-K_{s} A \frac{\Delta h}{l}
$$

Where $Q$ is the volume of discharge $\left(\mathrm{m}^{3}\right)$ through an area $A\left(\mathrm{~m}^{2}\right)$ as a function of the hydraulic conductivity $\left(K_{s}\right)$ of a medium through which water passes through (e.g. soil) driven by the change in hydraulic head with distance travelled by the flow $\left(\frac{\Delta h}{l}\right)$. The volume of discharge varies according to the hydraulic conductivity of the soil.

The shape, distribution and size of soil pores and the volume of water in these pores determine the hydraulic conductivity of a saturated soil (referred to as saturated hydraulic conductivity from here on). Apart from soil texture and structure, biological factors such as earthworms, dead and live vegetation roots and human activity (e.g. land use management) influence hydraulic conductivity. Roots of vegetation have a direct influence on saturated hydraulic conductivity through amelioration of macropores that enhance preferential flow and storage within the subsurface (Burdt, 2003). When the soil is saturated, macropores allow water to by-pass matrix flow thus determining water movement through a large volume of the soil. Halabuk (2006) reported high saturated hydraulic conductivity in reed dominated wetlands compared to cultivated arable land and meadow as a result of high root biomass and low bulk density. Because of the various factors that influence saturated hydraulic conductivity, it exhibits high spatial and temporal variability. Saturated hydraulic conductivity can and will often exhibit a large degree of variability within the same soil type because of macropores (worm holes and root channels) which give high values, and soil swelling (closing of shrinkage cracks) which gives very low values. It will produce different results depending on the time of measurement.

The bulk of wetland research on saturated hydraulic conductivity has focused on peat soils (Boeltar, 1965; Dai \& Sparling, 1973; Andersen, 2003; Holden \& Burt, 2003; Quinton et al., 2008) with less emphasis on wet mineral soils which are a characteristic of forested wetlands. Generally, saturated hydraulic conductivity in mineral soils is high compared to peat soils unless if it is un-decomposed peat (Andersen, 2003). Saturated hydraulic conductivity values vary extensively from a median of $3.6 \times 10^{-1} \mathrm{~mm} / \mathrm{hr}$ in deeply humified sapric peat to $1 \times 10^{4} \mathrm{~mm} / \mathrm{hr}$ in relatively un-decomposed fibric peat (Letts et al., 2000; 
Andersen, 2003). Sandy soils have typical values ranging between $3.4 \times 10^{1}-4.7 \times 10^{3}$ $\mathrm{mm} / \mathrm{hr} ; 0.2-6.8 \mathrm{~mm} / \mathrm{hr}$ for sandy-clay, and between $4.3 \times 10^{-5}-4.3 \times 10^{-6} \mathrm{~mm} / \mathrm{hr}$ for clay (Elci \& Molz, 2009). Halabuk, (2006) observed a median saturated hydraulic conductivity of $167.08 \mathrm{~mm} / \mathrm{hr}$ in alluvial top soils under reeds and sedges in a wetland.

\subsubsection{Bulk density}

Bulk density signifies the dry weight of a soil sample per unit volume, thereby representing the percentage of pore spaces and level of compaction. It influences key ecosystem processes through its effects on soil water holding capacity, porosity, nutrient availability, rooting depth and infiltration.

In hydric soils, it determines the absorbance and percolation of water and the retention of nutrients. It is important for the support of wetland vegetation and transport processes into and across landscapes. Bulk density in wetland mineral soils ranges between 1.0 and 2.0 $\mathrm{gcm}^{-3}$ while in peat soils it can be as low as $0.04 \mathrm{gcm}^{-3}$ (Mitsch \& Gosselink, 2007).

Bulk density has received adequate attention in most studies assessing functional recovery of restored wetlands and it has been concluded that its decrease is closely related with restoration practices that increase organic matter content (Campbell et al., 2002; Bruland et al., 2006; Meyer et al., 2008). The close association between bulk density and organic matter content, infiltration rate, hydraulic conductivity, biological activity makes it a crucial index for soil functioning (Meyer et al., 2008).

Establishing trees on degraded landscapes has been shown to decrease bulk density through root penetration and organic matter build up which in turn increases hydrological connection, water movement and storage. Since bulk density serves as an indicator of mitigation measures, assessing how it is affected by planting trees during wetland restoration will provide information for directing trajectories towards attaining deliverance of ecosystem services.

\subsubsection{Soil moisture content and pressure potential}

Soil moisture is a crucial variable in controlling the hydrological dynamics within forested wetlands. In terms of wetland eco-hydrology, it controls saturation excess runoff and is an 
important component for the transpiration process that occur in vegetation. It is sensitive to anthropogenic induced stress, related to many wetland ecosystem functions (e.g. carbon capture and flood control) and is relevant to all forested wetland types (Rockosh et al., 2009). Macropore flow, water repelling/hydrophilic conditions and biogeochemical processes at different spatial scales are controlled by antecedent soil moisture conditions (Zehe et al., 2010). Soil permeability, climate, vegetation type and basin size among others determine the amount of soil moisture in a wetland. Soil moisture content in forested ephemeral wetlands is high in winter during the rainy season and low in summer in temperate regions. In tropical areas, trees provide shade in wetland areas during summer, thereby preventing evaporation induced soil moisture loss (Bullock \& Acreman, 2003).

In temperate regions, trees create more storage space in the subsurface as water is lost through evapotranspiration (Haskell et al., 2012). Some wetland studies have shown low soil moisture content under permanent grasses in comparison to fallow agricultural land (van der Kamp et al., 2003). The ability of soil to retain and facilitate flow of water is based on the relationship between soil moisture content, pore size and pressure/water potential. At the same time, soil water velocity is directly proportional to gravity and pressure potential.

Application of a suction pressure (negative pressure below atmospheric pressure) results in large pores emptying first. The presence of trees creates suction pressure as a result of drainage through macropores and continuous uptake of water by roots and its subsequent loss through transpiration. Low matric water potential (increased suction) denotes a decrease in moisture content and the subsequent availability of storage space under unsaturated conditions. Under saturated conditions, soil water attains positive hydrostatic pressure higher than atmospheric pressure which represents the potential of water under submerged conditions, typical of flooded areas. The difference between saturated moisture conditions and residual soil moisture conditions represents the proportion of hydraulically active pore spaces that are a dominant pathway for water flow and retention (Campos et al., 2011). Thus to fully describe the flood response of a soil-vegetation system where water release characteristics are dynamic, knowledge about water potential (matric and positive pressure potential) in addition to soil moisture content is important. The ability of trees to create matric suction and subsequent storage space more than other vegetation types has been established in terrestrial uplands (Marshall et al., 2009). However, these effects have 
been rarely quantified for forested wetland areas (Campos et al., 2011). After an extensive research, the author could not find documentation of matrix suction values of restored forested wetlands.

\subsubsection{Soil organic carbon}

Determination of soil organic carbon content is fundamental for characterising the soil quality of ecosystems since it is a characteristic component of biogeochemical cycles. Wetland areas store a large proportion (approximately one-third) of the earth's terrestrial carbon (Trettin \& Jurgensen, 2003; Li et al., 2004; Mitsch \& Gosselink, 2007; Joyce, 2012).

Soil carbon comprises two major carbon pools; soil inorganic carbon and soil organic carbon. Soil inorganic carbon comprises carbonates obtained from rock weathering and direct $\mathrm{CO}_{2}$ absorption by the soil. This carbon pool is considered to be relatively stable and less affected by land use management. Soil organic carbon on the other hand, is derived from decaying plant matter, microbial cells and particulate organic substances, and forms 48-60 $\%$ of the total weight of the organic matter (Rosell et al., 2000; Kayranli et al., 2010). Globally, soil organic matter contains more than double the amount of carbon found in terrestrial vegetation (Schmidt et al., 2011). The balance between organic matter accumulation through primary productivity and its loss through decomposition, determines the soil organic carbon stock. This balance is affected by vegetation type, climate (temperature, moisture content), soil biota and ecosystem types, among other factors. Understanding these factors will help in the management of soil organic carbon stocks for climate change mitigation. Changes in vegetation type for example the replacement of grasslands with tree species, increases the soil organic matter accumulation because of high primary productivity rates. On the contrary, some studies have found that soil organic matter content can decrease (by approximately $10 \%$ ) following land use replacement of grassland vegetation with trees during the first decade, as a result of lower below ground biomass production in humid regions (Berthrong et al., 2011; Ceballos et al., 2013).

In wetlands, the accumulation of soil organic carbon is a function of the balance between organic matter deposition and its loss as a result of hydrological erosion and decomposition (microbial respiration) under either aerobic or anoxic conditions. Anoxic conditions often result in the incomplete decomposition of organic matter. Input of plant residue from 
wetland vegetation, coupled with incomplete decomposition under anoxic conditions, increases organic matter accumulation but can also produce methane. It is estimated that wetlands sequester about 500-750 Pg (20-30 \%) of the earth's soil carbon pool of $2500 \mathrm{Pg}$ but also contribute about $20-25 \%$ of the annual global methane emissions (Whalen, 2005; Lal, 2009; Bloom et. al, 2010), thereby creating a balance between carbon sequestration and methane emissions.

In addition to anoxic conditions, the quality of organic matter, temperature, and topography affect the decomposition rates of organic matter. The quality of soil organic matter is a function of chemical composition which consists of the fresh plant material (labile fraction) and the recalcitrant humic materials (resistant fraction). Organic matter from woody species contains more cellulose, which contributes to the resistant fraction and it is difficult for microbes to decompose and therefore largely accumulates in the soil (Schlesinger, 1997; Bernal, 2008). Therefore, vegetation type determines the quality and affects the accumulation of organic matter.

High temperatures facilitate high primary productivity that increases organic matter accumulation. However, the decomposition rate of organic matter also increases with increasing temperatures. Research has shown that for every $10^{\circ} \mathrm{C}$ rise in temperature, the rate of microbial respiration doubles thereby reducing organic matter accumulation (Albrecht \& Rasmussen, 1995; Schlesinger, 1997; Hartel, 2005). Wetlands in tropical areas both fix and lose more carbon than temperate wetlands but may have a greater net accumulation (Mitsch et al., 2013).

Topography determines soil organic matter accumulation by affecting temperature and soil moisture patterns. Temperature decreases and soil moisture increases from low to high elevations (Bolstad \& Vose, 2001). Therefore, considering the factors affecting organic matter accumulation and decomposition, wetlands with woody vegetation component, occupying high elevation sites in temperate regions may accumulate large quantities of soil organic carbon.

\subsection{The importance of soil organic carbon in wetland dynamics}

Soil organic carbon status is of importance because it delivers, maintains and regulates wetland services. It influences hydraulic properties of the soil by increasing water retention 
and hydraulic conductivity. It is an important component for denitrification which mitigates nitrate movement to water bodies in polluted environments.

Given that conversion of wetlands to other land uses almost always results in significant carbon loss, restoration has received great attention for mitigation of carbon concentration from the atmosphere. Unfortunately there is not much information on the carbon balances of restored forested wetlands, but it is expected that restoration (e.g. planting trees and reestablishing optimum hydrological regimes) should yield a global average estimate of 9-15 $\mathrm{kg} \mathrm{C} \mathrm{m}{ }^{-2}$ soil carbon which is comparable to that of dry land mature forests (Trettin \& Jurgensen, 2003; Gleason et al., 2009). In central Nebraska, Meyer et al. (2008) have reported a $1-1.3 \mathrm{~kg} \mathrm{C} \mathrm{m}^{-2}$ yield in the $0-10 \mathrm{~cm}$ soil fraction after planting a mixture of trees, wetland turfs and shrubs as a form of restoration.

The use of upland forest soil carbon pools as restoration targets may not be representative of the exact wetland conditions, but can be pragmatic under circumstances when there is no data from intact forested wetlands. Restoration in other wetland types such a peat bogs has been observed to yield $23 \%$ less carbon than that of natural undisturbed peat lands even after 100 years (Moreno-Mateos et al., 2012). However, the ability of wetlands to capture carbon varies according to vegetation type, region, time, wetland type disturbance regime and climate (Trettin \& Jurgensen, 2003), thus caution must be taken when prescribing soil carbon response following wetland restoration.

Literature is uncertain on the recovery time of soil organic carbon following restoration of wetlands. Generally soil organic carbon accretion is regarded as a slow process. However, some researchers have observed increases over relatively short periods of time (1-3 years) (Meyer, 2008), while others have suggested it may take up to two full generations to recover soil organic carbon comparable to those of natural undisturbed systems (MorenoMateos et al., 2012). Rather than giving absolute time frames, it might be plausible to consider accumulation in terms of regulatory oversight for example, a 2-4 year monitoring period. This means site, wetland type and species specific studies are critical to widen the knowledge base. 


\subsection{Evaluation of appropriate models to help in optimisation}

The growing interest in quantifying and understanding ecosystem services has led to the development of tools that can provide information on service provision. This section explores some of these ecosystem services tools to facilitate the choice of one that suits this research.

The choice of the appropriate ecosystem service modelling tool for use in this research took into consideration the services of interest, research questions and scale of study. This research focused on the response of spatially and temporally varying water related ecosystem services to restoration at field scale. It is therefore important to consider modelling tools that have been designed to quantify and visualise water related ecosystem services. Water related ecosystems include flood mitigation, natural water filtration and sediment regulation, among others.

Six spatially explicit tools that model water related ecosystem services are reviewed. These include the Integrated Valuation of Ecosystem Services and Tradeoffs (InVEST), Artficial Intelligence for Ecosystem Services (ARIES), Co\$ting Nature, EcoMetrix, Multiscale Intergrated Models of Ecosystem Services (MIMES) and Land Utilisation and Capability Indicator ( $\mathrm{LUCl})$. These tools are generalisable and independently applicable to various spatial scales. InVEST and ARIES are fairly well documented and developed (Bagstad et al., 2013). Co\$ting Nature is partially documented, while EcoMetrix and MIMES are not documented (Bagstad et al., 2013). The initial documentation of LUCI has been fairly established and some of its applicable case studies fairly developed.

InVEST consists of models that estimate the levels and economic values of ecosystem services that vary in response to land use and climate change (Nelson et al., 2009). The models quantify ecosystem services at $30 \mathrm{~m}$ cell sizes and up to $10 \mathrm{~km}$ in areas where data is limited (Vigerstol \& Aukema, 2011). Trade-offs between the ecosystem services are also quantified. InVEST can model flood mitigation, hydropower production, irrigation, water quality, soil conservation, carbon sequestration, pollination, residential property values, tourism, agricultural products, timber and non-timber forest products (Nelson et al., 2009; Vigerstol \& Aukema, 2011). The outputs of the modelled ecosystem services are expressed at each grid cell across the landscape as biophysical levels, GIS maps or in monetary terms 
(Vigerstol \& Aukema, 2011). Based on its principle of operation, InVEST can be potentially useful for achieving the objective of this research, i.e. to assess the impact of restoration in the form of land use/cover change on water related ecosystem services. However, it is largely applicable to landscape or watershed scales with resolutions coarser than that needed for this research and may not explicitly represent the impact of restoration on ecosystem service delivery at field scale.

ARIES is a web based technology designed to assess and valuate ecosystem services (Villa et al., 2011). It simulates the impact of policy scenarios on ecosystem services. ARIES uses probabilistic Bayesian statistical approaches to establish the relationships between inputs (can be in the form of local data) and ecosystem services values (Vigerstol \& Aukema, 2011). It models at $30 \mathrm{~m}$ cell size or more (e.g. $1 \mathrm{~km}$ ) in locations of limited data and evaluates trade-offs between ecosystem services. It identifies the flow of services from the source to the direct beneficiaries. Outputs can be ecosystem services maps showing where ecosystem services are provided, the location of the beneficiaries, and quantitative data. The scale of operation varies according to the ecosystem service being modelled and could occur at local to national scales. ARIES models water supply, flood mitigation, nutrient filtration, sediment regulation, subsistence fisheries, carbon-dioxide mitigation and coastal protection. ARIES can be potentially adapted for use in this research, but the reliance on probabilistic Bayesian approaches to extract relationships between inputs and outputs could require more data than that which is available for this project. This is despite the fact that ARIES generally requires less data than InVEST (Vigerstol \& Aukema, 2011; Bagstad et al., 2013). ARIES has been mostly applied on land scape and watershed scales, thus may not be suitable for the field scale at which this research has been conducted.

Co\$ting Nature is a web based tool that accounts for natural capital, assesses the impact of human interventions and climate on ecosystem services and identifies stake holders who may benefit from these services. It incorporates pre-loaded global data sets at $1 \mathrm{~km}^{2}$ and 1 ha resolutions, scenarios for climate and land use, biophysical and socioeconomic models to quantify ecosystem services (Mulligan et al., 2010; Bagstad et al., 2013). Outputs on the web interface are expressed as maps and can be downloaded in GIS format. Co\$ting Nature models hazard mitigation, water quality, water quantity, nature-based tourism, carbon and 
biodiversity (Mulligan et al., 2010). Based on its principles, Co\$ting Nature can be useful for this research but the scale of operation ( $1 \mathrm{~km}^{2}$ and $\left.1 \mathrm{ha}\right)$ is too coarse.

MIMES is a set of models that produce spatially explicit time series of ecosystem service values for decision making in marine and terrestrial areas (Boumans \& Costanza, 2007). The models assess the impact of land and ocean use scenarios on ecosystem services at local, national and global levels. The modelled ecosystem services include climate regulation, food production, biodiversity, hazard regulation, raw materials and bio-regulation. MIMES is not suitable for the resolution at which ecosystem services should be quantified in this research. EcoMetrix (Parametrix, Inc., Auburn, WA, USA) is a propriety tool that assesses ecosystem services at field or site scale using service specific and non-monetary metrics (Bagstad et al., 2013). The tool has been used for market based trading related to restoration or degradation investment analyses. Being a propriety tool, there are limits to its use for wider participation and experimentation (Nelson \& Daily, 2010), hence cannot be adapted for this research.

LUCI (Jackson et al., 2013) is a GIS toolbox that includes models which consider the impacts of land use on flood regulation, water quality, agricultural productivity, erosion and sediment regulation, habitat connectivity and carbon sequestration. Tradeoffs and synergies among these services are explored and quantified. LUCI models ecosystem services at fine resolutions, 5-10 m cell size at field, watershed and landscape scales. The outputs of the modelled ecosystem services are GIS maps showing areas of the landscape that currently provide services and areas where intervention can enhance or reduce provision of the services (Jackson et al., 2013). This tool is ideal for this research because it models water related ecosystem services at field scale and engages a wide range of stakeholders, all of which are desirable for this research. 


\section{Chapter 3 Description of study site}

\subsection{Study site}

The wetland study was carried out at Wairio wetlands, located on the eastern side of Lake Wairarapa in the lower Northern Island of New Zealand. This 132.3 ha wetland area delineated in red on Map 1 forms part of the 7800 ha Wairarapa- Moana wetland complex. The wetland area is divided into four stages that represent restoration periods. Soil, climate and land use characteristics of the site, are discussed in sections 3.2-3.8.

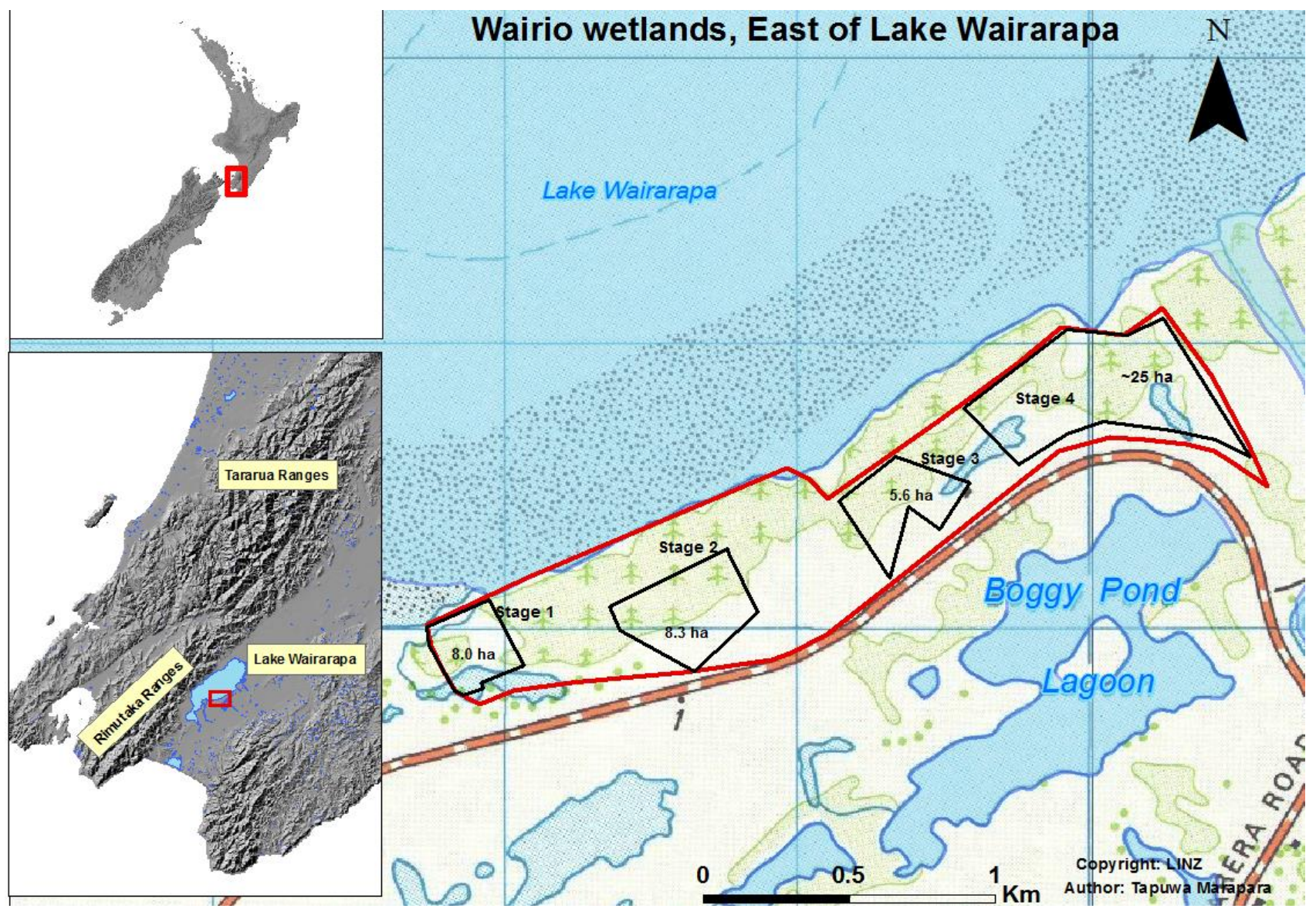

Map 1 Wairio Wetlands 


\subsection{Lake Wairarapa and its setting}

Lake Wairarapa and its wetlands are located in the southern part of Wairarapa Valley. The valley is a broad geological depression situated between Tararua/Ruahine ranges and eastern uplands in the lower south-east part of the Northern Island of New Zealand (Map 1). Tectonically, it lies parallel to the boundary between converging Pacific and Australian plates. Historically, the area had high frequency and magnitude of earthquake activity and is crossed by slip faults on the bottom of axial ranges. The western side of the wetlands is bounded by Rimutaka Ranges while the eastern side is surrounded by farmland.

The wetlands are maintained by shallow ground water which is probably disconnected from the deep ground water. Deep ground water studies in the region show the presence of an aquifer under artesian pressure and no interactions with shallow surface water (Jones \& Gyopari, 2006; Guggenmos, 2010). The wetlands are also fed by rain, surface runoff from adjacent pastures and sub-surface flow from both Lake Wairarapa and the pastures (Figure 3). The wetlands are slowly dried by evapotranspiration (Silbery, 2012), and there is highly unlikely surface outflow to and inflow from Lake Wairarapa because of a high stop bank (Figure 3 Conceptual model of the water flow in and out of the Wairio wetland 


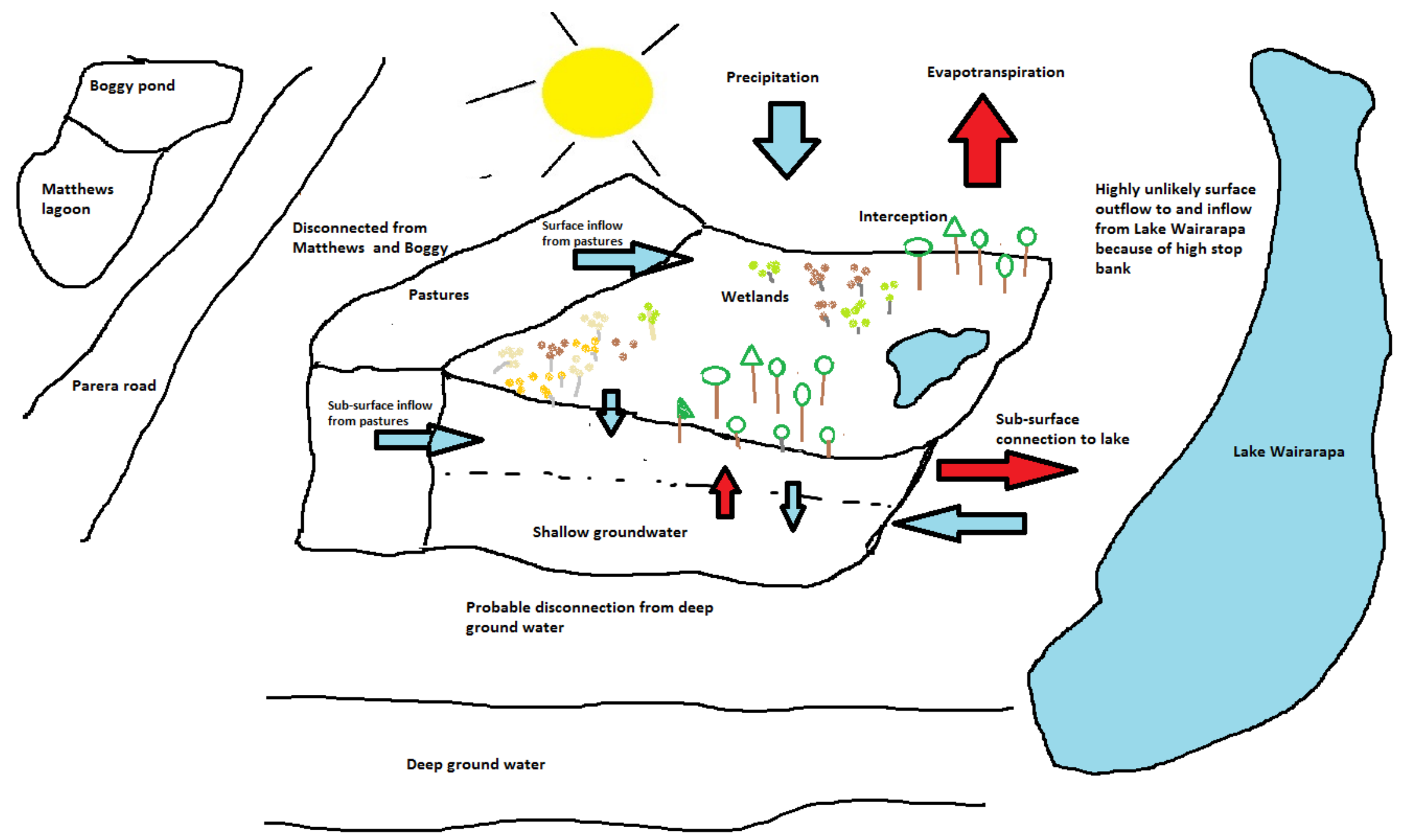

Figure 3 Conceptual model of the water flow in and out of the Wairio wetland (stages 1-4) 


\subsection{Geology and soils}

Alluvial gravel deposits of the Quaternary age are the dominant young material at the study site. They are a result of degradation (during warm periods) and aggradation (during cold periods) which formed alluvial terraces. The alluvial gravels are mixed with course, matrix rich sand and silt particles that are supported by clasts (Jones \& Gyopari, 2005). These particles have very low hydraulic conductivity and regularly compact with depth. Figure 4 shows a sketch of the soil horizons observed from a borehole well (S27/0428W.C.B/Landcorp) located on the land parcel $50 \mathrm{~m}$ south of stage 1 in the wetland.

Older, highly elevated and exposed geological formations such as sand dunes are also found in the study area. Undulating terrain on the eastern part is predominantly comprised of tertiary aged sediments such as karstic limestone which is characterised by low hydraulic conductivity. Also present, is a $20-40 \mathrm{~m}$ thick postglacial estuarine mud formed as a result of sediment deposition during sea level rise at the end of the last glaciation (14000 yrs BP) up to when the present sea levels were attained (6500 yrs BP). Basement greywacke rocks are the oldest rocks (230-120Ma) of the area and form steep axial ranges to the west and the Aorangi ranges on the south-eastern part. They comprise of sandstone and interbedded mudstone from the Aorangi and Rimutaka ranges. These rocks are hard, and have low primary porosity or permeability ${ }^{15}$.

\footnotetext{
${ }^{15}$ Primary porosity or permeability develops during formation of the rocks.
} 


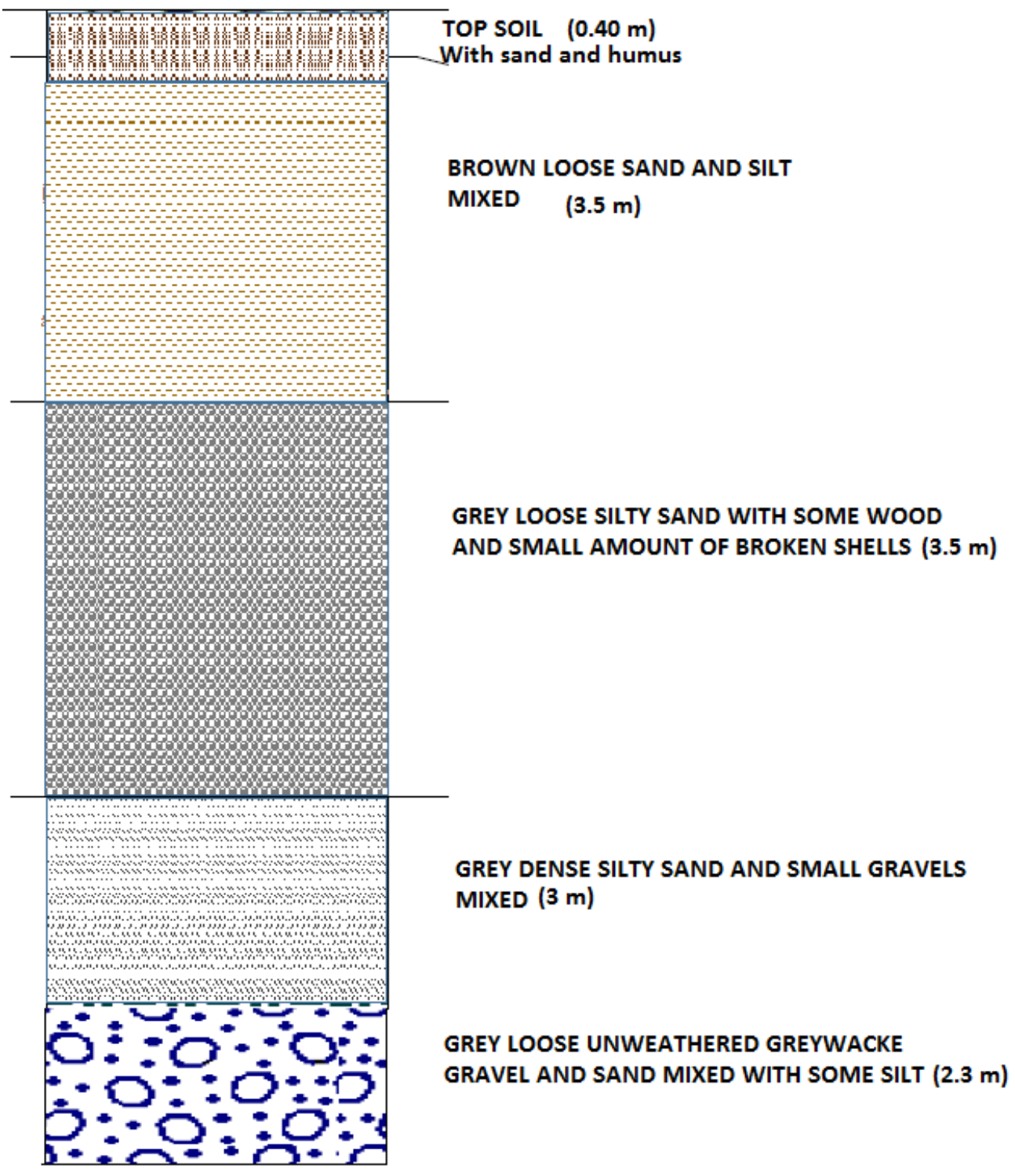

Figure 4 Soil horizons of Wairio wetlands, observed from a borehole well located near stage 1

\subsection{Climate}

Climate is one of the major factors determining water levels of Lake Wairarapa and its wetlands. The area has a warm, dry climate with summer day temperatures ranging between $20-23{ }^{\circ} \mathrm{C}$ and cool mild winters with occasional frosts and a minima of $1-3{ }^{\circ} \mathrm{C}$ night temperature. Mean annual temperature is $12{ }^{\circ} \mathrm{C}$ (Beadel et al., 2000). It receives annual precipitation of $800-1200 \mathrm{~mm}$, with highest rainfall occurring between September and November, increasing the risk of flooding. The rainfall patterns are largely influenced by the Tararua Ranges that are located across the east to west movement of the weather systems. 
The area is exposed to strong westerly and north westerly prevailing winds that can reach a speed of $170 \mathrm{~km} / \mathrm{hr}$ or $11-14$ knots (Beadel et al., 2000; Schrader, 2010). The strong winds can generate a standing wave in Lake Wairarapa, thereby raising water levels to about $1 \mathrm{~m}$ in the Wairio wetlands (Garrick et al., 2007). Dry north-westerlies dominate in summer, while south-easterlies are predominant during winter. South-easterly wind flows and the westerly frontals are the two dominant weather patterns contributing to heavy rainfall and flooding in the area.

The area is prone to drought in spring and summer, having experienced it in 1972-1973, 1997-1998 and 2012-2013 (Korte \& Rhodes, 1993; Beadal et al., 2005; Silbery, 2012).

\subsection{Landscape and land use}

The Wairarapa region comprises of four major landscape types which include ranges, hill country, coastal and plains. The Rimutaka and Tararua ranges cover $14 \%$ of the land area. Aorangi ranges form a defined backdrop on the southern plains and occupy about $6 \%$ of the land area. Together all the ranges occupy a total of $20 \%$ of the Wairarapa land area (Table 7). Hill country is the dominant landscape type, covering $60 \%$ of the land area. Having a wide variation in terms of geology, vegetation, elevation and steepness, the hill country encloses the plains of Wairarapa region. The narrow margin of land along the coastline is occupied by alluvial fans, uplifted marine terraces, sand dunes and steep escarpments. These features are part of the coast landscape type.

Table 7 Landscapes in Wairarapa region

\begin{tabular}{ll}
\hline Landscape & \% coverage of land area \\
\hline Ranges & 20 \\
Hill country & 60 \\
Plains & 20 \\
\hline
\end{tabular}

The main land uses in the Wairarapa catchment are forestry and pastoral farming. Urban areas, horticulture, wetlands and open water occupy a small proportion of the catchment area (Table 8). Indigenous forest occupies $44 \%$ of the catchment area, largely covering the Rimutaka and Tararua ranges. Exotic forest comprising of willow and alder occupy a small proportion ( $0.1 \%)$ of the catchment. Pastoral land (both high and low productive) covers a little over $50 \%$ of the catchment (Table 8). 
Table 8 Land use area in the Wairarapa Catchment

\begin{tabular}{lll}
\hline Land use & Area (ha) & \% catchment \\
\hline Urban & 226 & 0.4 \\
High productive pasture & 24043 & 42 \\
Low productive pasture & 6857 & 12 \\
Exotic forest & 54 & 0.1 \\
Indigenous forest & 25103 & 43.9 \\
Wetland and open water & 490 & 0.9 \\
Horticulture & 136 & 0.2 \\
Other & 335 & 0.6 \\
\hline
\end{tabular}

\subsection{Settlement history}

The wetland is an area of intrinsic cultural and historical significance and was among the first sites settled in New Zealand about 700 years ago. The major attraction that pulled Polynesian settlement creation was the native freshwater eel (tuna) which was largely harvested during migration season. Seasonal settlements for eeling were clustered at the edge of the wetland complexes while permanent settlements were established on surrounding higher forested areas (McIntyre, 2002; McFadgen, 2003).

In the mid-19 $19^{\text {th }}$ century, European sheep farmers arrived in the area and rented land from the Polynesian owners. Renting was made illegal a few years afterwards and the sheep farmers began buying the land. The Polynesians retained most of the wet flood prone areas to continue eel fishing. The outlet to the sea was regularly blocked during eel migration between February and April maximise the quantity harvested. This often resulted in the filling up of wetland areas and caused tension for decades between the fishers and sheep farmers who preferred dry land for pasture. The conflict was resolved following a change of ownership of the water bodies which resulted in land drainage and establishment of stop banks to increase the farming success. This settlement history is what brought about land use management/development activities that degraded the area and ignited this research 
among other studies to assist in the rehabilitation or restoration of the once paradise for flora and fauna.

The following section will give an insight into the land management/development practices that were and are associated with the settlement.

\subsection{Wairio Wetlands past and recent land use management}

The wetland area was originally a podocarp broad leafed swamp forest comprising sedges, harakeke and turfs ${ }^{16}$. The podocarp forest was characterised by Dacrycarpus dacrydioides (kahikatea), Typha orientalis (raupo), Phormium tenax (harakeke) and Prumnopitys taxifolia (matai) in wet areas, and Podocarpus totara (totara) in dry areas (Beadel et al., 2000).

The first arrival of the Polynesians resulted in deforestation of the upland forested areas and subsequent settlement creation (McIntyre, 2002; McFadgen, 2003). The arrival of European sheep farmers in the 1840s resulted in drainage of the wetland for agricultural production, mainly dairy and pastoral farming (McIntyre, 2002; McFadgen, 2003). An earthquake in the Wairarapa valley in 1855 displaced cubic kilometres of rock and uplifted the Wairio wetland block (Rhodes, 2012).

Further drainage and forest clearance occurred in 1963 to ensure flood protection of the productive agricultural lands. In the 1970s, most sheep farms had been converted into intensive and highly profitable dairy production. However, the rise in awareness of the importance of wetlands as ecosystem service providers following an increase in disaster incidences during the 1980s halted further agricultural development, and pioneered restoration of the area.

Between 1987 and 1988, first restoration attempts began by partially flooding the area through construction of an earth dam and digging a channel running from Lake Wairarapa coupled with the construction of a flood gate. These measures were not successful due to damages caused by grazing cattle.

Second and on-going restoration began in 2005 with the objective of creating a large block consisting of permanently flooded areas, ephemeral areas (regular flooding and exposure)

\footnotetext{
16 Tiny plants, often less than $3 \mathrm{~m}$ tall, growing flat along the ground forming a dense carpet. Common on margins of wetlands
} 
comprising of trees, native turf and sedges supporting a wide variety of fauna species. Restoration work so far has created three stages comprising areas of permanent water through pond and dam construction to form permanently wet areas for waterfowl, fish and other water-loving fauna. Native plant species have been planted in these stages.

Stage 1 ( 8 ha) has one repaired, fenced off and protected earth dam with areas bordering it on the north and south planted with eco-sourced trees (kahikatea, cabbage trees), flaxes and sedges. In Stage 2 ( 8.3 ha) a dam was constructed and areas surrounding it were planted with native sedges, flaxes and fenced off. In stage 3 (5.6 ha) (Map 1) two dams were constructed, cattle were excluded prior to planting in the winter of 2011 during which 2500 plants of native woody species were planted: Coprosma robusta, Olearia virgata, Podocarpus totara, Coprosma propinqua, Cordyline australis, Pittosporum tenuifolium, Dacrycarpus dacrydioides and Leptospermum scoparium. The areas surrounding the dams in each stage are ephemeral. Other turf, sedges and grass species present in these wetlands include the rare grass Amphibromus fluitans, the quick growing daisy (Centipeda), Carex geminata and the weed tall fescue. The land parcels between the stages are grazed by cattle.

This research directly focused on the 8.3 ha of stage 2 and 5.6 ha area of stage 3 . The wetlands are not necessarily a perfect example of a site that can be restored to effectively mitigate floods, although they do play a vital role in storing flood waters from Ruamahanga River. The wetland site provided an opportunity to plant new trees as part of on-going restoration, and study them together with the already established trees and other existing vegetation types. The site is more of a convenience to be able to do field scale measurements to demonstrate the processes through which trees can mitigate runoff for flood risk management. 


\subsection{Characterisation of the established native species at Wairio wetlands}

\subsubsection{Native tree species}

\subsubsection{Cabbage tree (Cordyline australis)}

Cordyline australis commonly known as cabbage tree or palm lily, is a fast growing vascular tree species commonly found in a wide range of habitats, from coastal to montane forests and is endemic to New Zealand (NZPCN, 2012). Its characteristic features at maturity include a 1-2 $\mathrm{m}$ diameter trunk with a length of $20 \mathrm{~m}$ and numerous narrow pointed dark to light green long (0.3-1 m) leaves (NZPCN, 2016) (Image 1). The tree flowers from September to January, producing white flowers (source of pollen for bees) which open in early spring and produce ripe fruits in summer (Simpson, 1997). The nutritious fruits are produced in large numbers and are a source of food for native birds such as the New Zealand pigeon, kereru which is a seed disperser for large fruits and is important for regeneration of native forests (Simpson, 1997).

Propagation of the species is through seed and cuttings. Cabbage trees are adapted to a wide range of soil types and have air conducting tissues in the root system which enables survival in water logged/wetland areas. They are pioneer/ early succession species which colonise disturbed areas that may be freshly exposed after erosion, a fire or flood (Simpson, 1997). They form rhizomes that deeply extend vertically, anchoring the tree firmly to the soil. A large number of long, narrow and dense roots develop from the rhizome and dominate a large area of the soil surrounding the tree (Simpson, 1997). After 5 years of growth cabbage trees are reported to have the highest above and below ground biomass (11.3 kg and $2.7 \mathrm{~kg}$ respectively), compared to manuka, karamu and kohuhu (Marden et al., 2005). The main threat to this species is the sudden decline disease, which causes sudden wilt and fresh leaf fall. Long periods of drought also affect this species. 

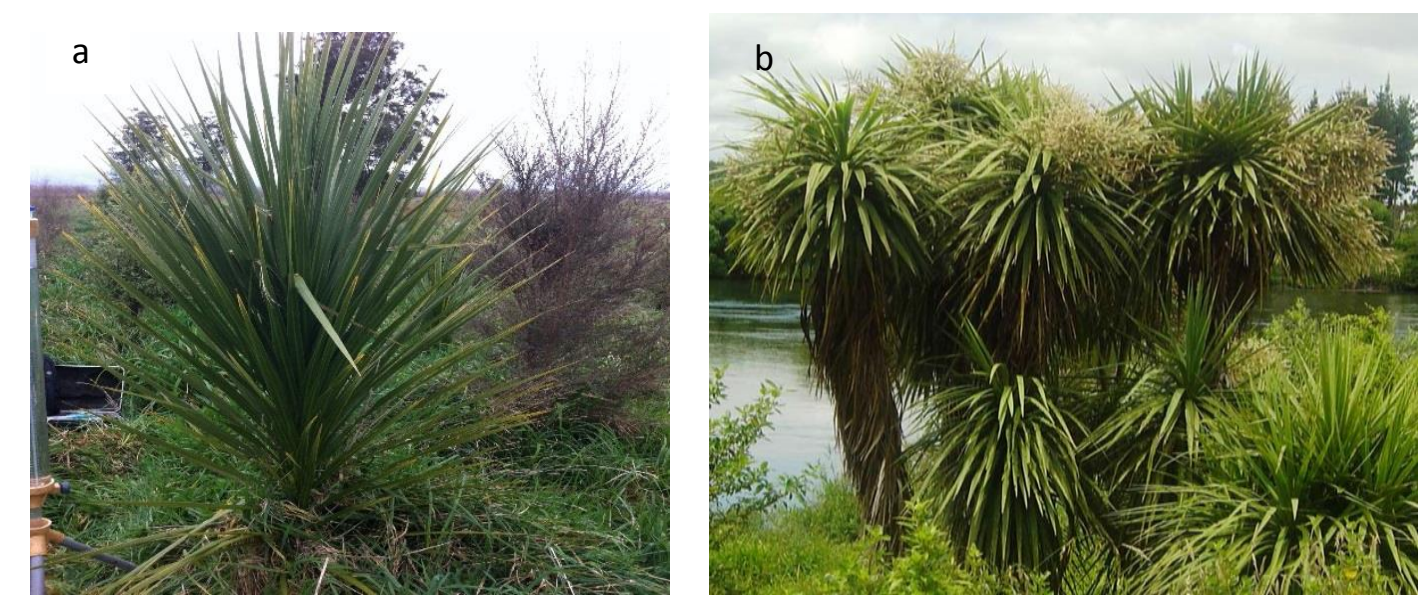

Image 1 Cabbage tree (Cordyline australis) a) at 4 years old taken by the author at Wairio (Stage 3, block 10) in September 2014; b cabbage tree at a later stage of growth, adapted from http://www.nzpcn.org.nz/flora_details.aspx?ID=1744 in January 2016

\subsubsection{Manuka tree (Leptospermum scoparium)}

Leptospermum scoparium commonly known as manuka, tea tree or kahikatoa is a vascular plant of the family Myrtaceae, native to New Zealand and Australia (Image 2). It normally occurs as a shrub of height approximately $5 \mathrm{~m}$ although it can grow into a tree of $10 \mathrm{~m}$ height, with a lot of branches lying flat or erect from the stem base. It has linear rough leaves of 0.01-0.015 $\mathrm{m}$ long and $0.02 \mathrm{~m}$ wide (NZPCN, 2016). Flowering occurs throughout the whole year, producing white, red or pink flowers (Image 2). Its flowers are a common source of food, preferred by various insect pollinators from the orders hymenoptera (honey bee), diptera (fruit flies), coleoptera (beetles) and Lepidoptera (nocturnal moth) (Stephens et al., 2005). It is a light demanding pioneer species characterised by a short life cycle and high fecundity. It is a species of wide ecological amplitude that can tolerate a variety of environmental conditions such as low or high soil moisture content and high acidity. It is normally found in water logged areas and has been reported to tolerate continuous root inundation for up to 272 days (Cook et al., 1980; Stephens et al., 2005). It is recognised for its role in erosion control, carbon sequestration and initiation of a successional sere in

disturbed environments. Manuka is ranked top for above ground biomass production at maturity (Beets et al., 2014). In the juvenile stages (5 years) above ground biomass production is lower than that for cabbage trees, karumu and kohuhu, averaging at $1.8 \mathrm{~kg}$ (Marden et al., 2015). It dominates in harsh environments (infertile, too wet, cold and 

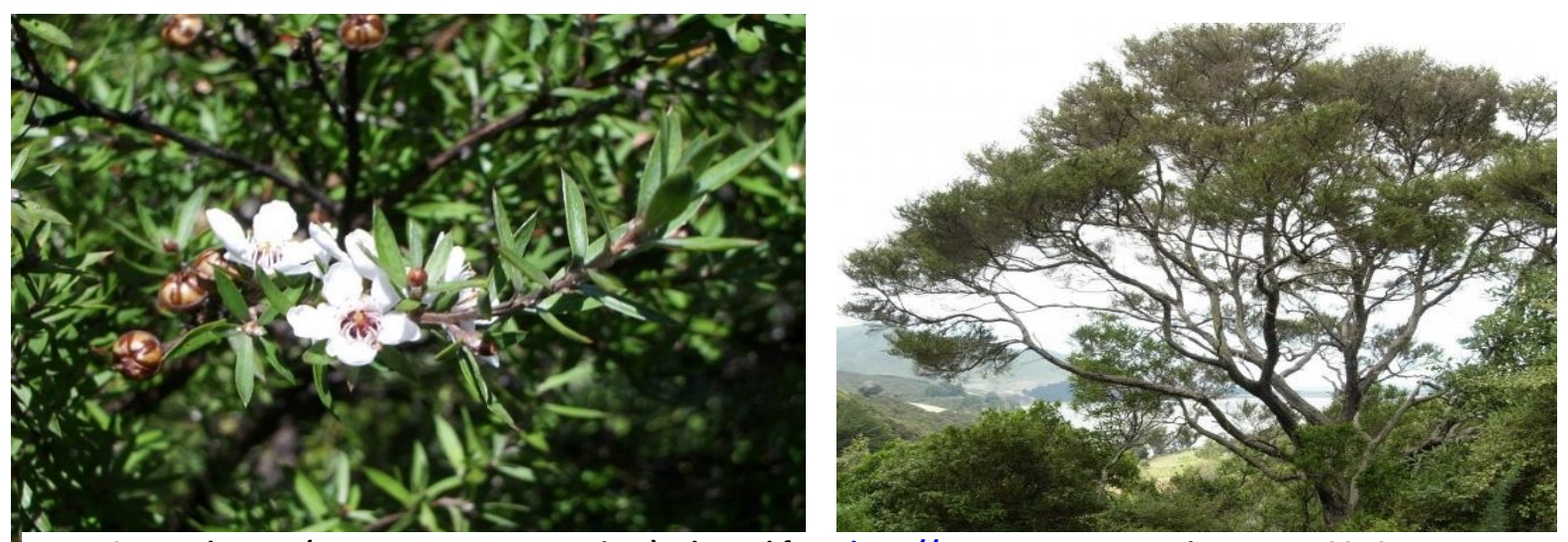

Image 2 Manuka tree (Leptospermum scoparium) adapted from http://www.nzpcn.org.nz in January 2016

exposed) where late successional species may fail to establish and survive. Manuka roots are of high strength, density and extend deep into the soil occupying $5 \%$ volume up to 50 $\mathrm{cm}$ (Prosser, 2011). The choice of cabbage and manuka trees for the experiment was based on their ability to rapidly grow and possibly exert influence on soil properties within a time frame of two years. A summary of the characteristics of the species are presented in Table 9. These tree species were among other six indigenous species which were part of the wetland prior to its degradation. The species include Coprosma propinqua, Pittosporum tenuifolium, Coprosma robusta, Oleria virgate, Podocarpus totara and Dacrycarpus dacrydoides.

Table 9 Summary of the characteristics of cabbage and manuka species

\begin{tabular}{lll}
\hline Common name(s) & Cabbage Tree, palm lily & Manuka, tea tree \\
\hline Botanical name & Cordyline australis & Leptospermum scoparium \\
Morphological features & $\begin{array}{l}\text { Arborescent to } 20 \mathrm{~m} \text {. White } \\
\text { flowers }\end{array}$ & $\begin{array}{l}\text { Arborescent 5- } 10 \mathrm{~m} \text {. Red/pink } \\
\text { flowers }\end{array}$ \\
Habitat & $\begin{array}{l}\text { Alluvial terraces, low land } \\
\text { wetlands, riparian forests, } \\
\text { coastal to montane forests }\end{array}$ & $\begin{array}{l}\text { Coastal areas, low alpine } \\
\text { habitats, edges of wetlands }\end{array}$ \\
Distribution & Endemic to New Zealand. & Indigenous to Australia and \\
& Found in both South and North & New Zealand. \\
Islands & Vascular Native & Vascular Native \\
Flora category & & \\
Fruiting & (December-) January- March & November- December \\
& &
\end{tabular}




\subsubsection{Coprosma propinqua (Mingimingi)}

Coprosma propinqua commonly known as mingimingi is a densely branched tree that grows up to $6 \mathrm{~m}$ high (Image 3). Its leaves are curved sideways, $0.01 \mathrm{~m}$ long and 0.02-0.03 m wide (Image 3) (NZPCN, 2016). It is native to New Zealand and favours a wide range of habitats such as swamp forests, bogs, grasslands and rocky or gravelly places. It prefers moist soils as well as sandy or loamy soils with neutral or acidic $\mathrm{pH}$ and as has moderate tolerance to water logging (Hawke's Bay Regional Council, 2004). Flowering occurs between February and April, forming male and female flowers that are located on different ends of branchlets. It is recognised for its role in carbon sequestration, ranking second at maturity stage, after Manuka (Beets et al., 2014)
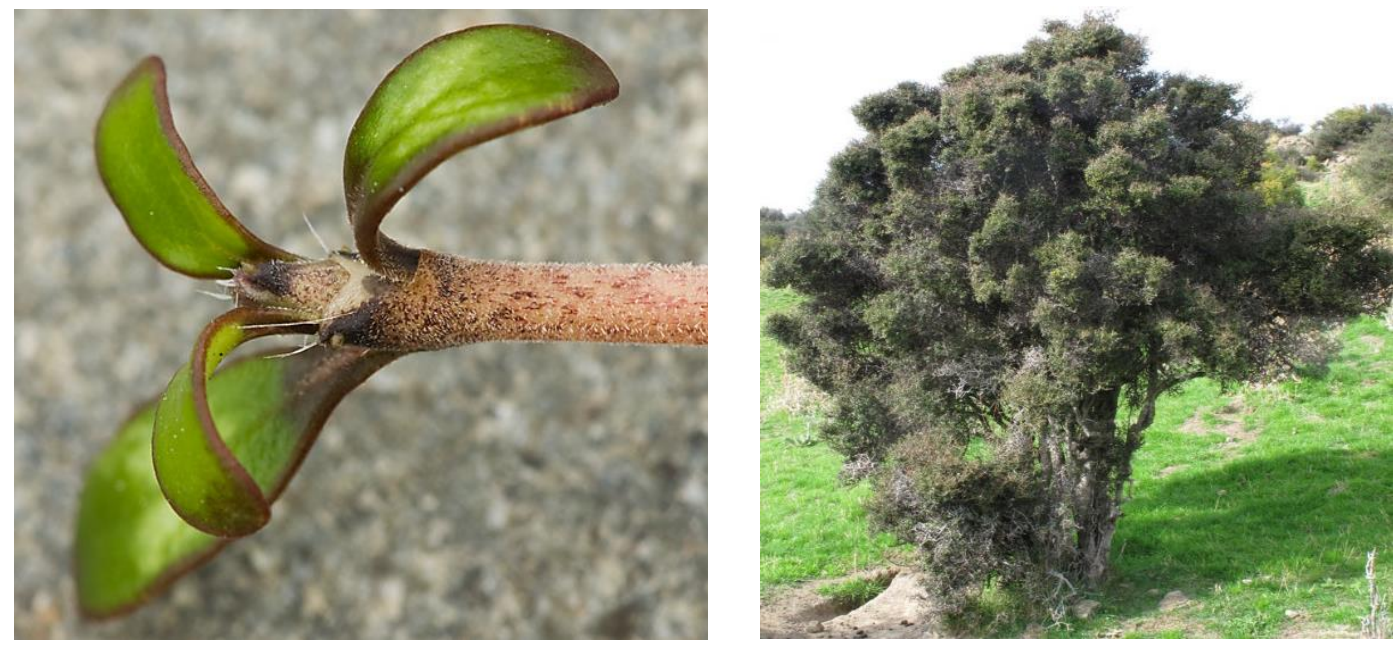

Image 3 Coprosma propinnqua adapted from http://www.nzpen.org.nz in January 2016 


\subsubsection{Pittosporum tenufolium (Kohuhu)}

Commonly known as kohuhu, it is an evergreen tree that grows 5-10 $\mathrm{m}$ high and is native to New Zealand. Flowering occurs in spring, producing small dark brown flowers. Leaves have wavy margins, are glossy, pale green and 0.02-0.04 m long (Image 4) (NZPCN, 2016). It produces an average of $3.9 \mathrm{~kg}$ above ground biomass, five years following establishment (Marden et al ., 2005). It prefers coastal and lower mountain forests as habitat and has low tolerance to water logging. It develops vertically descending roots spreading from the root bole, and an average of $1.2 \mathrm{~kg}$ below ground biomass, five years following establishment (Marden et al., 2005).
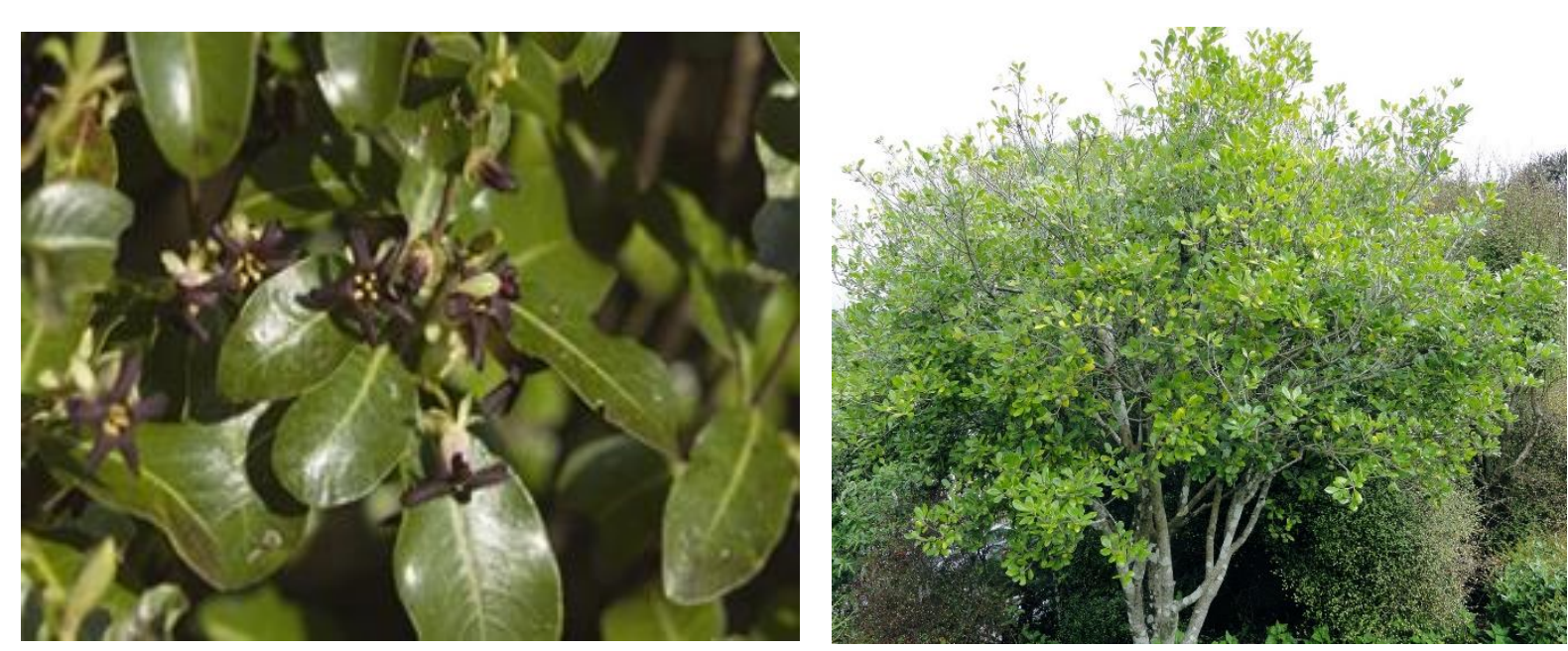

Image 4 Pittosporum tenufolium adapted from http://www.nzpen.org.nz in January 2016 


\subsubsection{Coprosma robusta (Karamu)}

Coprosma robusta thrives in harsh environments of poor soils, swampy areas, windy and cold, and has moderate tolerance to water logging (Hawke's Bay Regional Council, 2004). It grows up to $5 \mathrm{~m}$ high, has dark green medium to large glossy and feathery leaves, about 0.07-0.12m long and 0.04-0.05 m wide (Error! Reference source not found.). Coprosma obusta is likely to have similar patterns of interception as Pittosporum tenufolium because of similarities in leaf morphology (Images 4 \& 5). Having a dense and fibrous heart root system, it is ecologically vital for soil conservation, grows rapidly and is normally used as a nurse plant (Marden et al., 2005). At the age of 5 years, Coprosma robusta was reported to have a mean above ground biomass of $3.9 \mathrm{~kg}$ and below ground biomass of $1 \mathrm{~kg}$ (Marden et al., 2005).

a
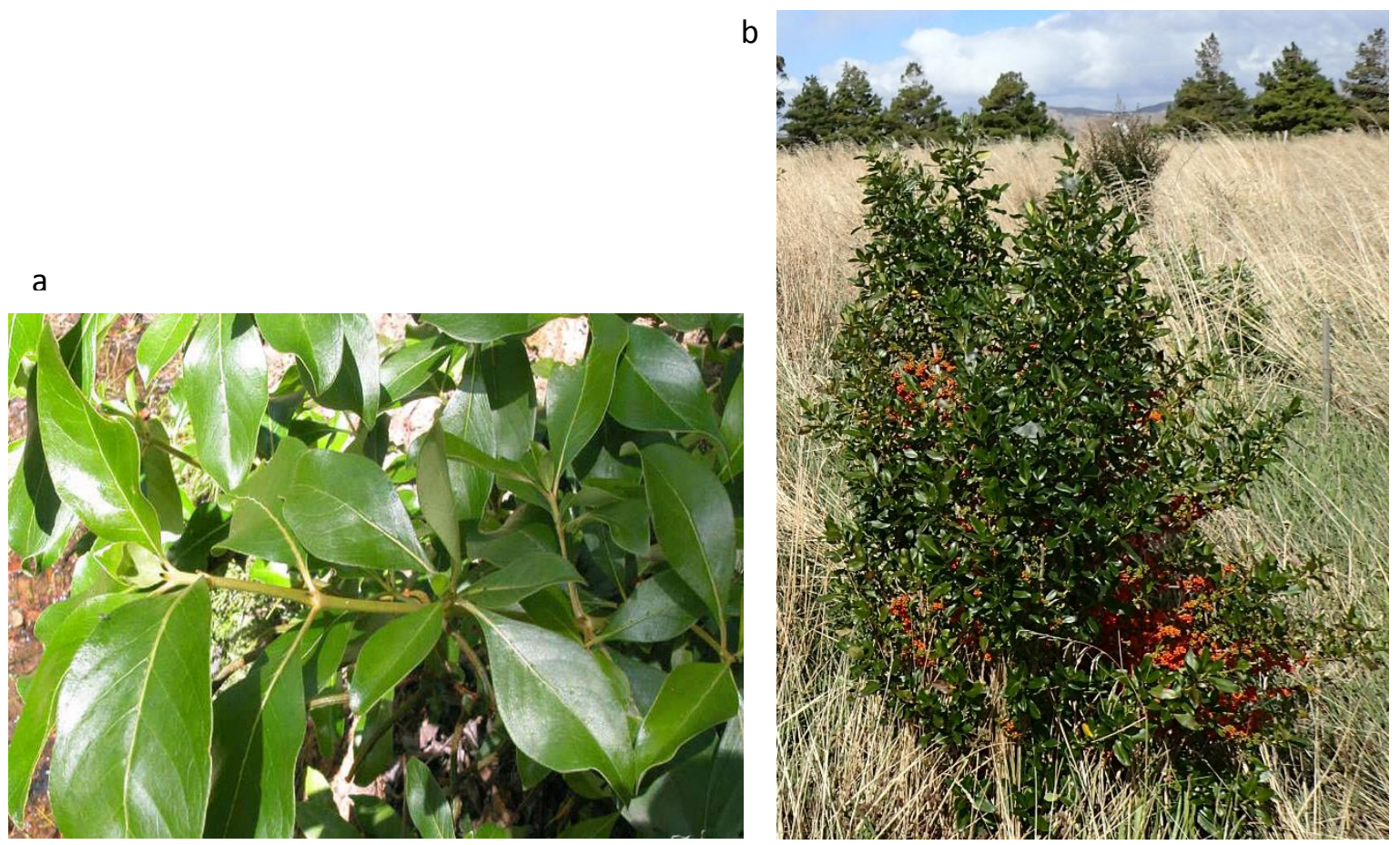

Image 5 Croposma robusta a) adapted from http://www.nzpen.org.nz in January 2016, b) image taken by Stephen Hartley in stage 3 (Block 8) at Wairio wetlands on 19 March 2015 


\subsubsection{Olearia virgata (Twiggy tree daisy)}

It is endemic to New Zealand, grows up to $6 \mathrm{~m}$ height and has small oval pale green obovate leaves (Image 6). During spring to summer, it produces white flowers and short stalks. It prefers wetland valley floors, tussock grasslands, forest margins and has low tolerance to water logged conditions (Heads, 1998; Hawke's Bay Regional Council, 2004). Olearia virgata (0.04 $\mathrm{m}$ by $0.002 \mathrm{~m}$ size) is unlikely to have similar patterns of water interception as Cordyline australis ( $0.3 \mathrm{~m}$ by $1 \mathrm{~m}$ size), Pittosporum tenufolium (0.04 $\mathrm{m}$ long) and Croposma robusta ( $0.2 \mathrm{~m}$ by $0.05 \mathrm{~m}$ size) because of the differences in leaf morphology.
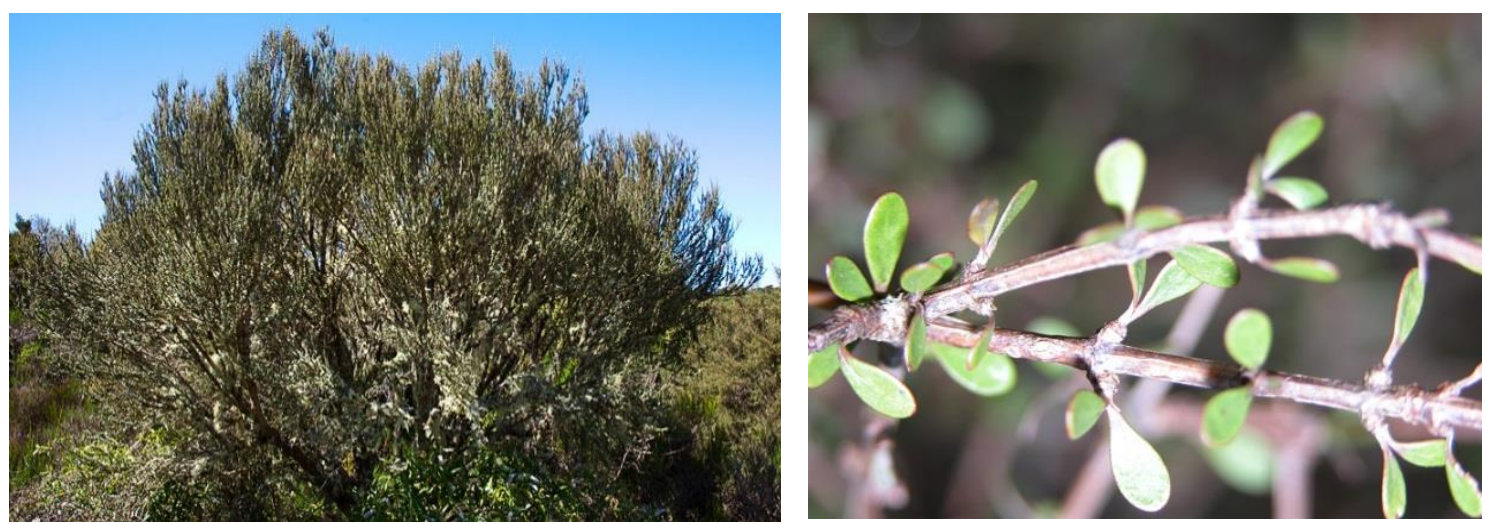

Image 6 Olearia virgata adapted from http://www.nzpen.org.nz in January 2016

\subsubsection{Podocarpus totara (totara)}

It is a slow growing coniferous tree that reaches up to $30 \mathrm{~m}$ in height with flat, sharply pointed brownish green leaves (0.015-0.03 $\mathrm{m}$ long and $0.01 \mathrm{~m}$ wide) that spiral around the stem (NZPCN, 2016) (Image 7). It grows in most regions of New Zealand and is adapted to a wide range of climatic and soil conditions. The root system is characterised by large surface and subsurface laterals extending beyond the crown, descending peg roots and nodulated roots on the surface (Bergin, 2000). It is a species of cultural value, mainly used for carving. 
b

a
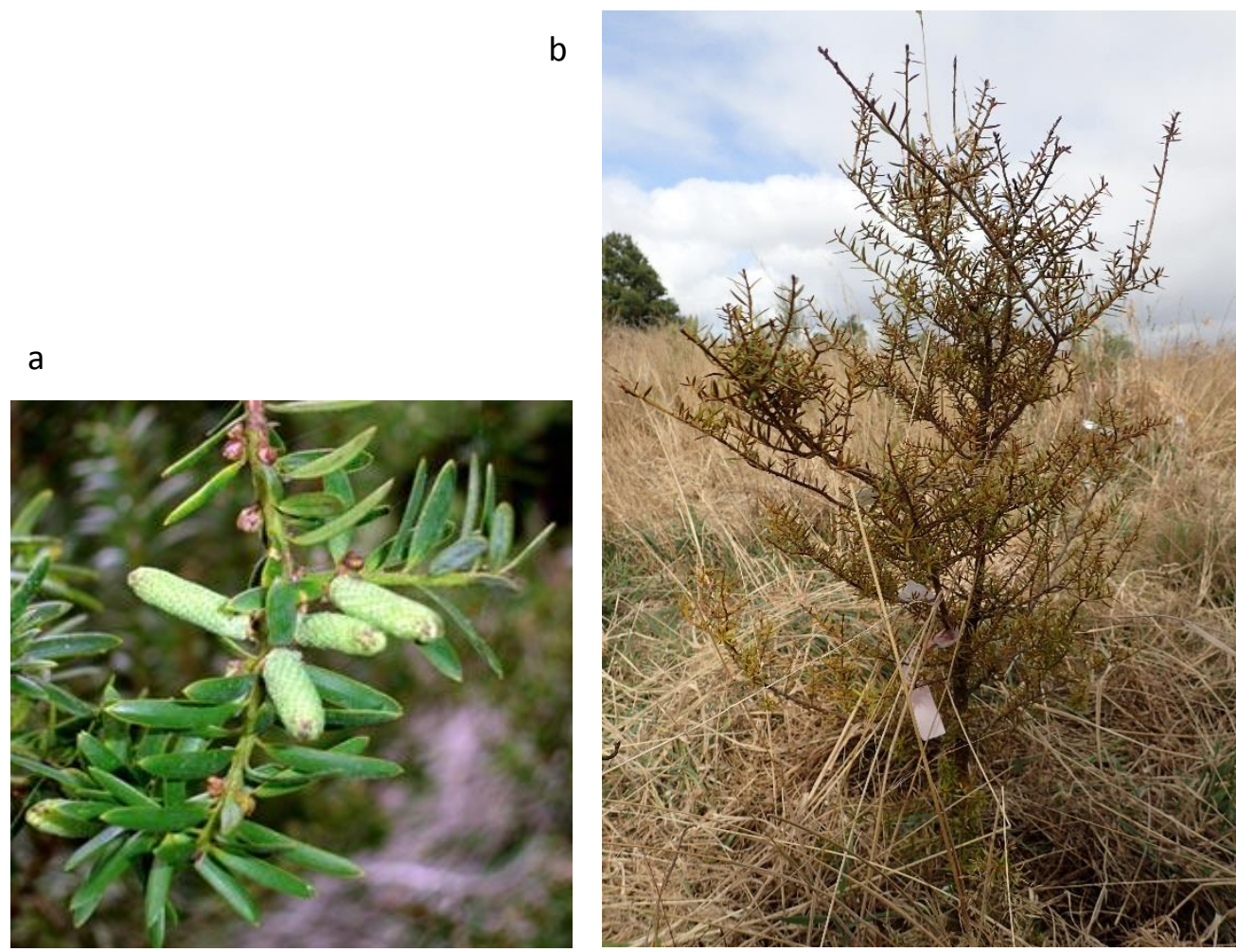

Image 7 Podocarpus totara, a) adapted from http://www.nzpen.org.nz in January 2016; b) Totara at 4 years old, taken by Stephen Hartley in stage 3 at Wairio wetlands on 19 March 2015

\subsubsection{Dacrycarpus dacrydiodes (Kahikatea)}

Native to New Zealand, Dacrycarpus dacrydiodes is a coniferous tree that grows up to $55 \mathrm{~m}$ high with a 2 m diameter trunk, prefers heavy clays to alluvial soils and plains (Smale, 1984). Dacrycarpus dacrydiodes has narrow-linear, subdistichous leaves when in juvenile stages and imbricate 1-2 $\mathrm{mm}$ long, subtrigonous leaves (Image 8) with a broader base at adult phase (NZPCN, 2016). It produces seeds on the terminal on short branchlets and the upper two leaves form a receptacle, become red and succulent when in fruit (NZPCN, 2016). Most birds prefer the fruits produced by Dacrycarpus dacrydiodes and can be a form of dispersal for natural regeneration. It is intolerant of dry soils and occurs on wet areas, hence dominates swampy low lands and hilly areas with an altitude of 700 masl. The tree has high rate of biomass production, reaching an average of $1.23 \mathrm{~kg}$ above ground biomass, $0.37 \mathrm{~kg}$ below ground biomass and a root depth of $0.3 \mathrm{~m}$ at the age of 5 years (Marden \& Phillips, 
2012. Trees may survive up to 500 years and are ecologically useful for stabilising the soil against long term erosion.
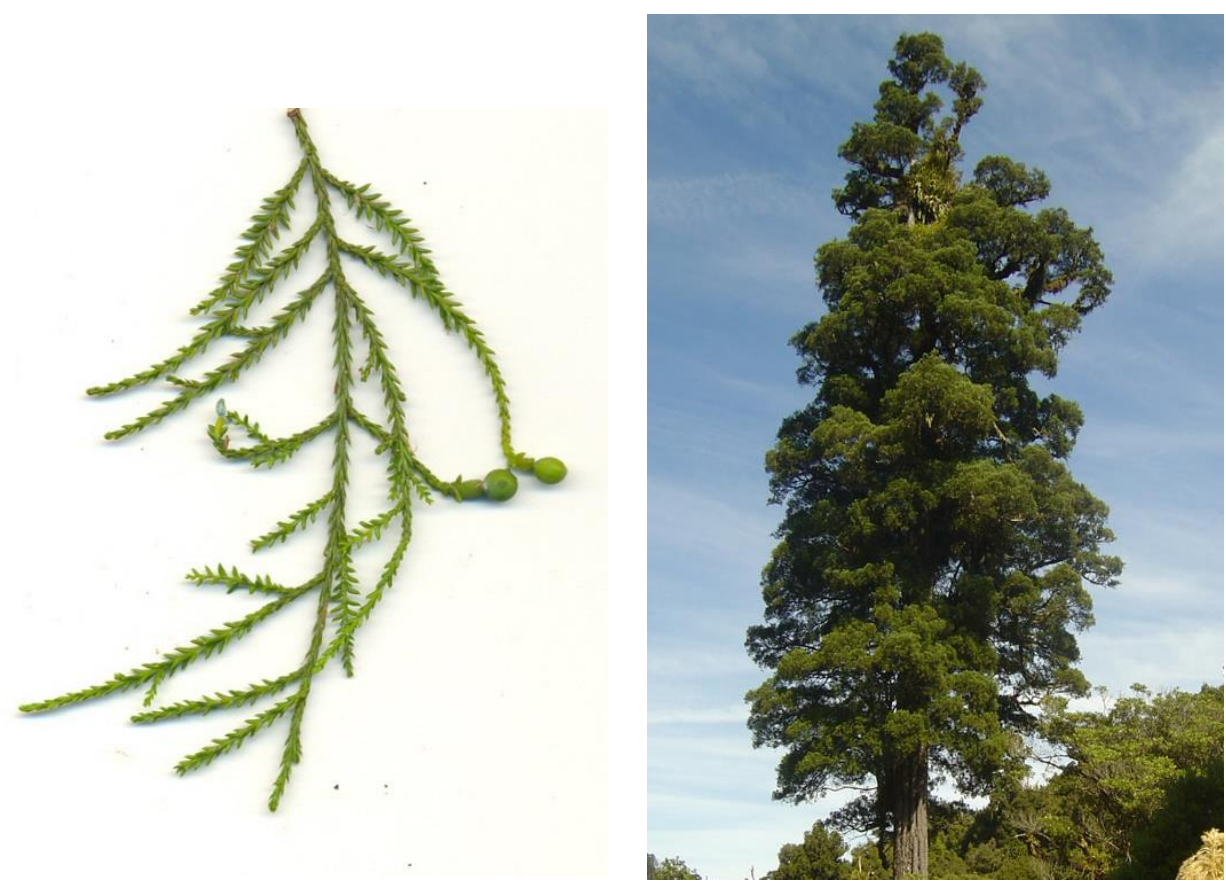

Image 8 Kahikatea adapted from http://www.nzpen.org.nz in January 2016 


\subsubsection{Sedges}

\subsubsection{Carex geminata}

Carex geminata commonly known as cutty grass is one of New Zealand's robust native sedges. It grows abundantly wetland areas up to a height of $2 \mathrm{~m}$, forms large colonies, creeping rhizomes, long sharp edged green leaves (Image 9) (NZPCN, 2016). It is ecologically useful for rehabilitating wetland areas and stream bank stabilisation. It produces flowers between October and November while fruiting occurs between October and March. Carex geminata is likely to intercept more water than a young (5 years) Dacrycarpus dacrydiodes due to longer and wider leaves (Images 8 \& 9).
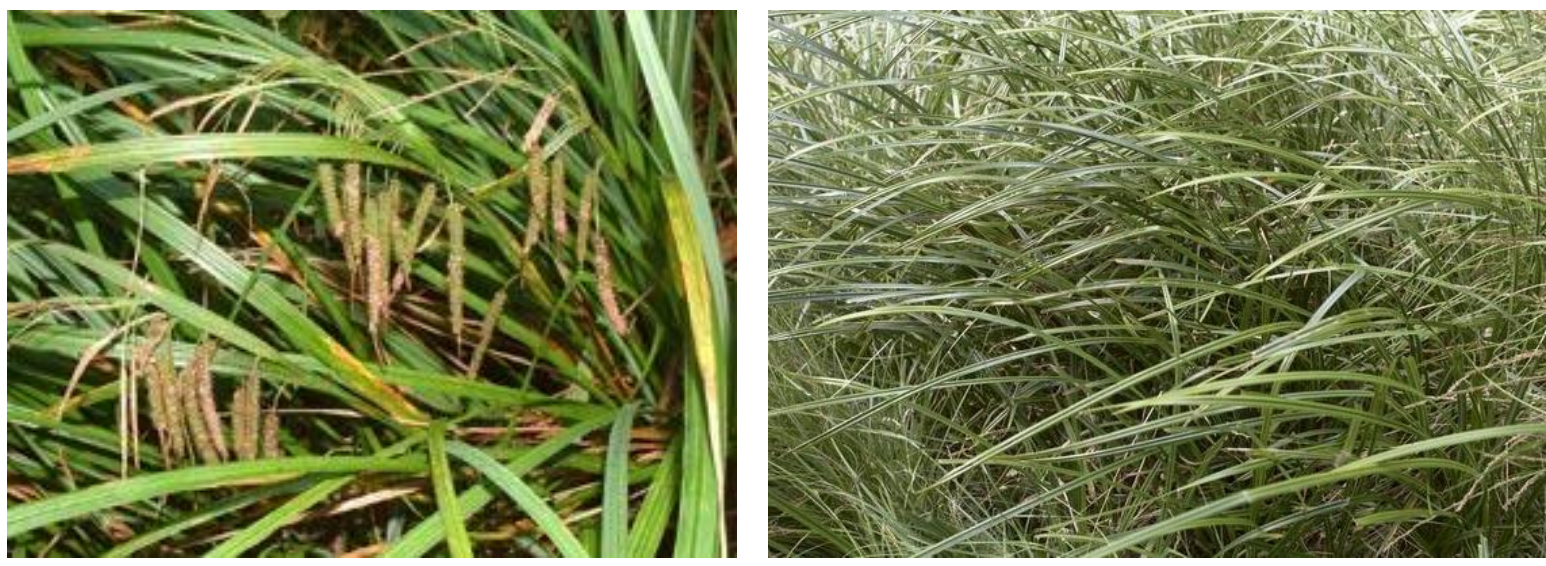

Image 9 Carex geminata adapted from http://www.nzpcn.org.nz in January 2016 


\section{Chapter 4- Dynamics of the impact of tree restoration on soil physical, chemical and hydraulic properties of previously forested ephemeral Wairio wetlands.}

\subsection{Introduction}

As discussed in Chapter 2, trees under certain conditions have a high potential to reduce the risk of floods through changing the soil's physical, chemical and hydraulic properties critical for the absorption and retention of large volumes of water. The reviewed literature suggests that this role varies according to the species and age of trees, slope, bedrock geology, soil type, rainfall properties and size of catchment, among other factors (Carroll et al., 2004; Marshall et al 2009; Bathurst et al., 2011; Gaal et al., 2012; Archer et al., 2013). The literature also notes that other vegetation types such as high producing but deep rooting improved grasses and sedges with high rooting depth can also improve soil properties, but their effectiveness relative to trees will vary according to the aforementioned factors (Cheng et al., 2002; Fayolle et al., 2012; Archer et al., 2013). Information on the hydrological role of trees and grasses in terrestrial habitats is growing (Cheng et al., 2002; Carroll et al., 2004; Jobbágy et al., 2012), but still needs to be established for wetland habitats. By definition, trees are a characteristic vegetation component of forested wetlands. Wetlands play a vital role in mitigating floods (Bullock \& Acreman, 2003; Acreman \& Holden, 2013), but there has not been enough research to quantify the ecological processes underpinning this function, as $64-71 \%$ have been lost globally to land use change in particular, conversion to agriculture (Davidson, 2014).

The demand for information on ecological processes behind wetland functioning to support the successful restoration of lost wetlands has increased (Beissel \& Shear, 1997; Acreman et al., 2007; Meyer et al., 2008). The available information on ecological processes in terrestrial habitats such as forests may not be sufficiently robust for use in guiding restoration of forested wetlands, despite both habitats having some similar vegetative components. This is because wetland habitats have hydric soils with high antecedent soil moisture and the hydrological impact of trees in these habitats may be very different than in terrestrial habitats. It is therefore important to explore the impact of tree vegetation on soil parameters that are important for wetland functioning. 
This chapter describes a field experiment carried out in attempt to meet the research needs identified in the literature review in chapter 2 . The experiment aimed to quantify the effect of tree-planting as a restoration strategy on soil physical and hydraulic properties critical for the absorption of floodwaters in Wairio wetlands of Lake Wairarapa, New Zealand. The experiment compared soil properties in sites planted with various indigenous tree species to unplanted sites comprising of wetland turfs, sedges and high producing grasses. These comparisons were explored across varying micro-topography to account for some of the factors (i.e. topography, species and land use type) that may influence the hydrological role of trees in enhancing absorption and retention of water. The physical, chemical and hydraulic properties of soil measured include bulk density, saturated hydraulic conductivity, soil moisture content (volumetric and gravimetric), soil pressure potential and soil organic carbon. The quantification of soil organic carbon in response to land use change following restoration also provides an opportunity to explore and generate information on the carbon mitigation potential of the wetland. The focus was on the response of soils rather than solely on vegetation because soils are generally less considered during wetland restoration projects (Beissel \& Shear, 1997), yet they are a valuable component contributing to wetland functions.

This study presents the first set of detailed soil hydrology data for an ephemeral wetland in New Zealand. As such, the information from this chapter provides a starting point for more accurate modelling of wetland hydrology and quantifying national budgets of carbon stocks. It can be useful for the development of quantitative assessment methods that are beneficial for the evaluation of the success of forested wetland restoration for ecosystem service provision. This will help to provide design criteria for wetland restoration projects that seek to reach an endpoint characterised by specific forest communities that are self-sustaining, functionally diverse, ecologically stable and adapted to the dynamic environment, including the provision of specific ecosystem services.

\subsection{Experimental design}

The experimental design consisted of eight blocks, six in stage 3 of the wetland and two in stage 2 . This was not to compare the differences between the stages (because they are similar in terms of soil conditions) but because of spatial constraints all eight blocks could not fit in stage 3 . Three of the blocks (numbered $7,9,10$ ) in stage 3 , consist of three planted 
plots in each block established in 2011 (Figure 5). Each of these plots consists of a mixture of pioneer species, nurse species. These species include cabbage trees (Cordyline australis), manuka (Leptospermum scoparium), mingimingi (Coprosma propinqua), kohuhu (Pittosporum tenuifolium), karamu (Coprosma robusta), twiggy tree daisy (Olearia virgate), totara (Podocarpus totara), and kahikatea (Dacrycarpus dacrydoides). Five remaining newly established blocks, three in stage 3 (Figure 5) and two in stage 2 also consist of three plots each (Figure 7). Two plots were planted with cabbage trees and manuka respectively during 2013 at 49 stems/plot and the third plot was unplanted (Table 10). The third unplanted plot consists of a mixture of wetland sedges, turfs and high producing exotic grasses (Figure 5).

Trees in the newly established five blocks were transplanted in winter and summer of 2013, at 1 year old. Ideally, they should have been transplanted at the same time in winter, but there were accessibility issues in some of the plots as the wetland was flooded and transplanting in these plots had to be rescheduled to the beginning of summer. This posed a high risk on the sapling survival rate due to the high chance of the ephemeral wetland completely drying out in summer before substantial growth. The planting dates are shown in Table 10. 
Table 10 Planting dates and establishment data for the trees planted in 19 plots across eight blocks.

\begin{tabular}{|c|c|c|c|c|c|c|c|c|c|c|}
\hline Stage & Block & $\begin{array}{l}\text { Topograph } \\
\text { ic position }\end{array}$ & Plot (s) & $\begin{array}{l}\text { Species } \\
\text { Treatment }\end{array}$ & $\begin{array}{l}\text { Slope } \\
(\%)\end{array}$ & Planting date & $\begin{array}{l}\text { Number } \\
\text { of trees } \\
\text { planted } \\
\text { per plot }\end{array}$ & $\begin{array}{l}\text { Average } \\
\text { height of } \\
\text { trees in } \\
\text { summer } \\
2014 / 15 \\
\text { (m) }\end{array}$ & $\begin{array}{l}\% \\
\text { survival } \\
\text { in } \\
\text { summer } \\
2014 / 1 \\
5\end{array}$ & $\begin{array}{l}\text { Age of } \\
\text { trees at } \\
\text { the end of } \\
\text { study } \\
\text { (years) }^{1}\end{array}$ \\
\hline 2 & 1 & High & 1 & Cabbage & 8 & 25 June 2013 & 49 & 1.17 & 82 & 2 \\
\hline 2 & 1 & High & 2 & Manuka & 8 & 10 July 2013 & 49 & 1.05 & 69 & 2 \\
\hline 2 & 1 & High & 3 & Unplanted & 8 & & & & & \\
\hline 2 & 2 & High & 1 & Cabbage & 8 & 10 July 2013 & 49 & 1.07 & 80 & 2 \\
\hline 2 & 2 & High & 2 & Unplanted & 8 & & & & & \\
\hline 2 & 2 & High & 3 & Manuka & 3 & $\begin{array}{l}5 \text { November } \\
2013\end{array}$ & 49 & 1.16 & 55 & 2 \\
\hline 3 & 11 & Low & 1 & Cabbage & 3 & $\begin{array}{l}20 \text { December } \\
2013\end{array}$ & 49 & 0.70 & 65 & 2 \\
\hline 3 & 11 & Low & 2 & Manuka & 3 & $\begin{array}{l}14 \text { November } \\
2013\end{array}$ & 49 & 1.17 & 82 & 2 \\
\hline 3 & 11 & Low & 3 & Unplanted & 8 & & & & & \\
\hline 3 & 12 & Low & 1 & Cabbage & 3 & $\begin{array}{l}20 \text { December } \\
2013\end{array}$ & 49 & 0.77 & 73 & 2 \\
\hline 3 & 12 & Low & 2 & Manuka & 3 & $\begin{array}{l}20 \text { December } \\
2013\end{array}$ & 49 & 0.71 & 27 & 2 \\
\hline 3 & 12 & Low & 3 & Unplanted & 6 & & & & & \\
\hline 3 & 13 & High & 1 & Cabbage & 8 & 3 July 2013 & 49 & 1.30 & 84 & 2 \\
\hline 3 & 13 & High & 2 & Unplanted & 8 & & & & & \\
\hline 3 & 13 & High & 3 & Manuka & 6 & 3 July 2013 & 49 & 1.40 & 37 & 2 \\
\hline 3 & 7 & High & $\begin{array}{l}1 a, 2 b, \\
3 c\end{array}$ & $\begin{array}{l}\text { Mixture of } \\
\text { species }\end{array}$ & 8 & 23 June 2011 & $64,16,48$ & 2.03 & 82 & 4 \\
\hline 3 & 9 & Low & $\begin{array}{l}1 a, 2 b, \\
3 c\end{array}$ & $\begin{array}{l}\text { Mixture of } \\
\text { species }\end{array}$ & 3 & 23 June 2011 & $64,16,48$ & 1.78 & 62 & 4 \\
\hline 3 & 10 & High & $\begin{array}{l}1 a, 2 b, \\
3 c\end{array}$ & $\begin{array}{l}\text { Mixture of } \\
\text { species }\end{array}$ & 8 & 23 June 2011 & $16,64,48$ & 2.05 & 75 & 4 \\
\hline
\end{tabular}

${ }^{1}$ End of study taken as 2015

The establishment of the five new blocks, containing cabbage trees and manuka in two separate plots allowed for the exploration of the effect of different species on soil properties. The plots were $12 \mathrm{~m} \times 12 \mathrm{~m}$ containing 49 stems at inter and in-row spacing of $1.5 \mathrm{~m}$ between saplings (equivalent to a planting density of 2500 stems per hectare). A minimum distance of $2 \mathrm{~m}$ was left between the plots. Each block was $15 \mathrm{~m} \times 40 \mathrm{~m}$. In each of the planted plots, 15 trees were protected in tree guards (grotectors) (Image 10). Weed mats were also put in the grotectors. The purpose of grotectors was to increase survival rates (Table 38) amidst competition with grass species and weeds, wind problems, herbivory, and to make it easier to identify the plots in situations when grasses have colonised some of the plots. Spot spraying was carried out in some of the plots prior to planting as weed management strategy to increase the survival rates. 
All eight blocks were located on areas of varying micro-topography of approximately $3 \%, 6$ $\%$ and $8 \%$ slope gradients. Slope was nested within plots. Field reconnaissance at the beginning of the project indicated that the location of the already established three blocks (i.e. $7,9,10$ ) in stage 3 (consisting of a mixture of native trees species) was based on where trees might survive best (i.e. on high slope). The location of the remaining five blocks accounted for variability in topography for comparison purposes. However, due to the nature of the wetland environment and accessibility issues on some low slope areas, there was forced relocation of some of the blocks to allow planting. The location on varying microtopography allowed for the exploration of the effect of topography on the ability of trees to change soil properties critical for absorption and storage of water in wetlands.

The research also gathered information on the status of the soil properties before planting. However, due to the wetland flood conditions, some of the plots that were measured for "before planting" data, could not be planted and hence the number of "before-after" comparisons was not as great as initially intended.

The soil physical, chemical and hydraulic properties were quantified by taking three random measurements from each plot on different occasions in the stages 2 and 3 (Figure 6 \& Figure 8) over a 24-month period. 


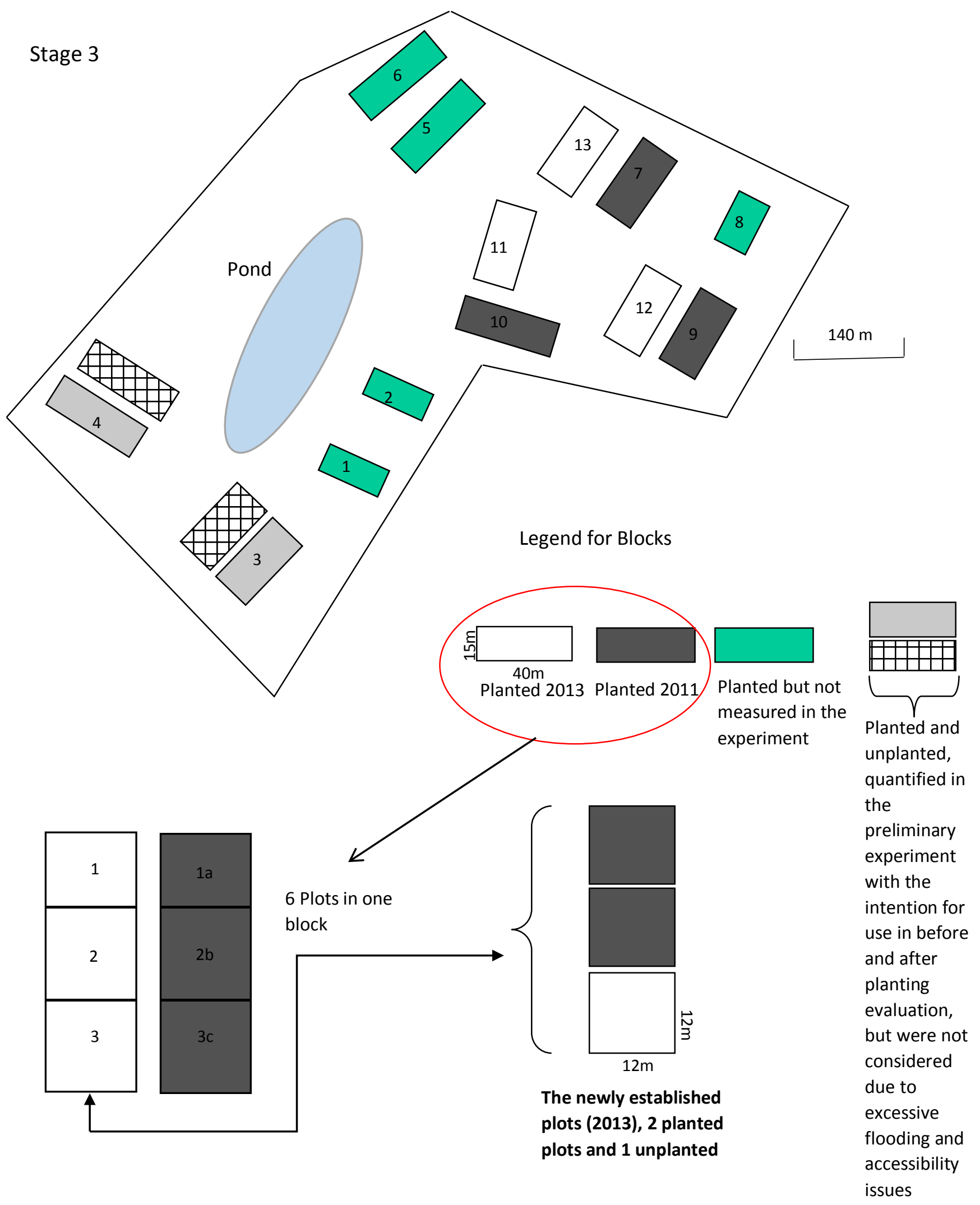

Figure 5. Block and Plot lay out in stage 3 of Wairio wetland 


\section{Stage 3 sampling locations}

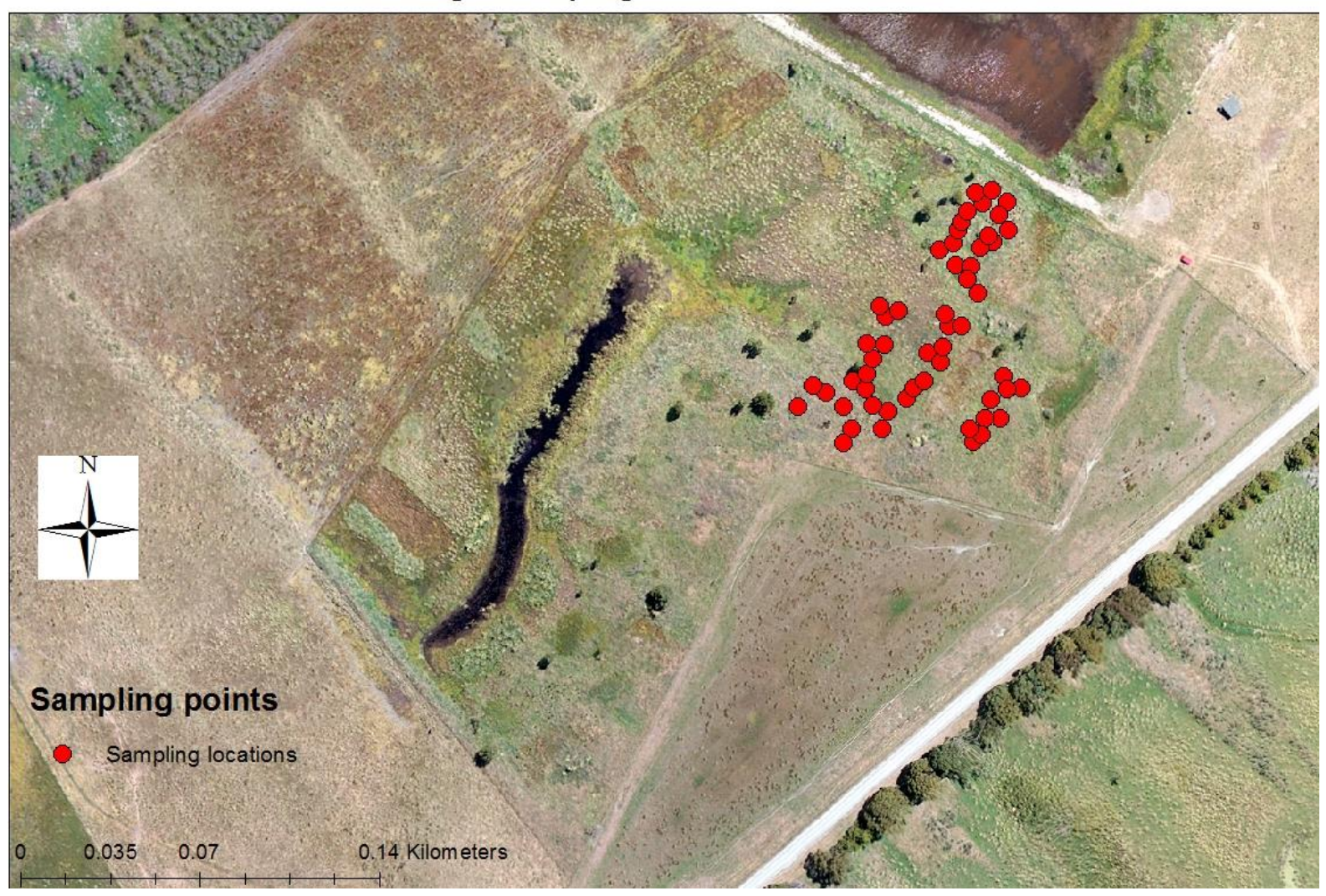

Figure 6. Aerial photo of the sampling locations of soil properties in the plots of Stage 3 (Blocks 7, 9-13) 
Stage 2

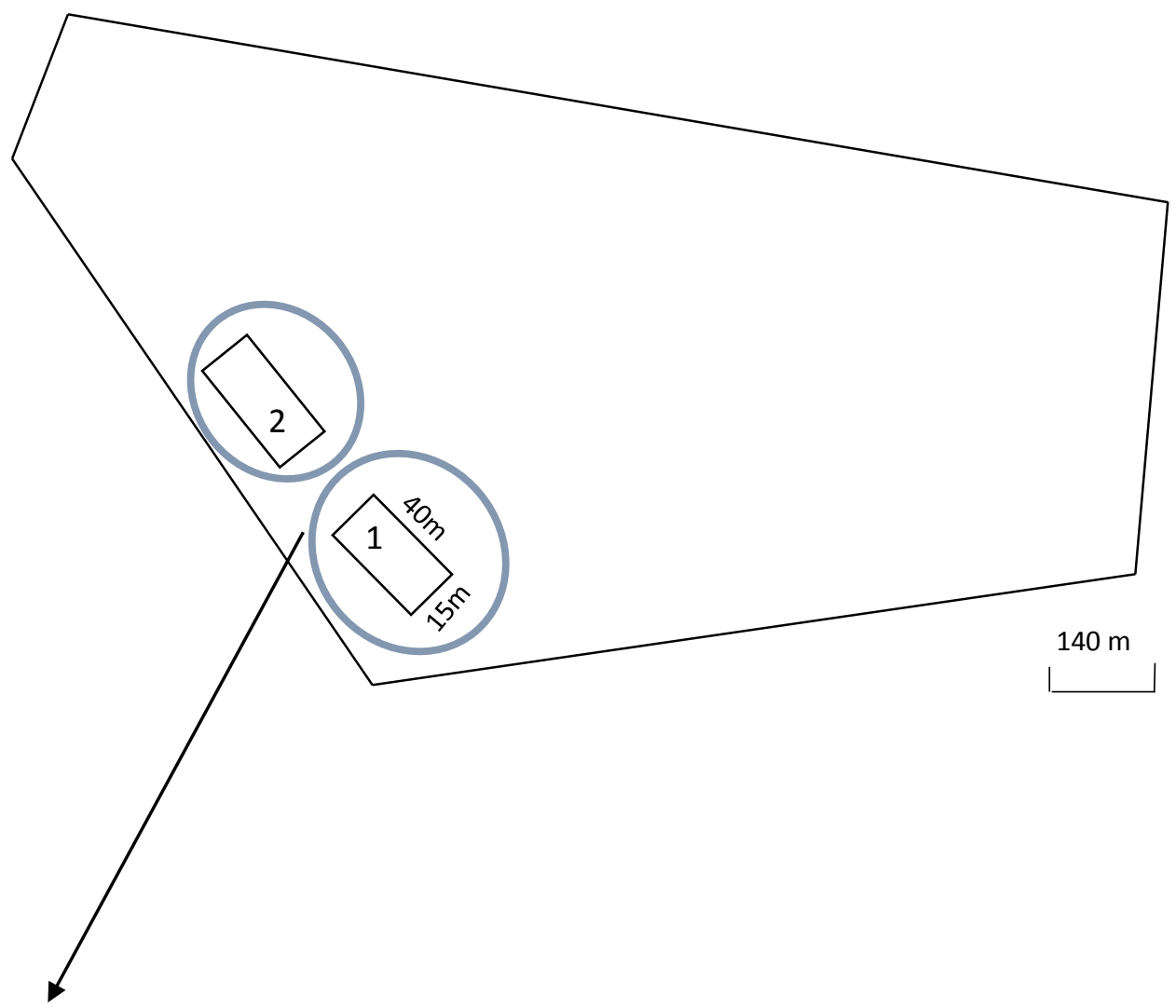

\section{Planted Unplanted}

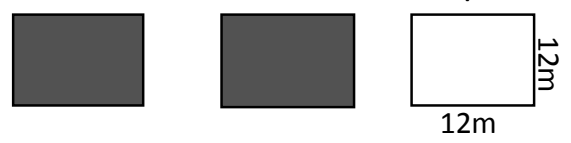

Figure 7. Two blocks $(15 \times 40 \mathrm{~m})$, each containing 3 plots in stage 2 of Wairio wetland 
Stage 2 sampling locations

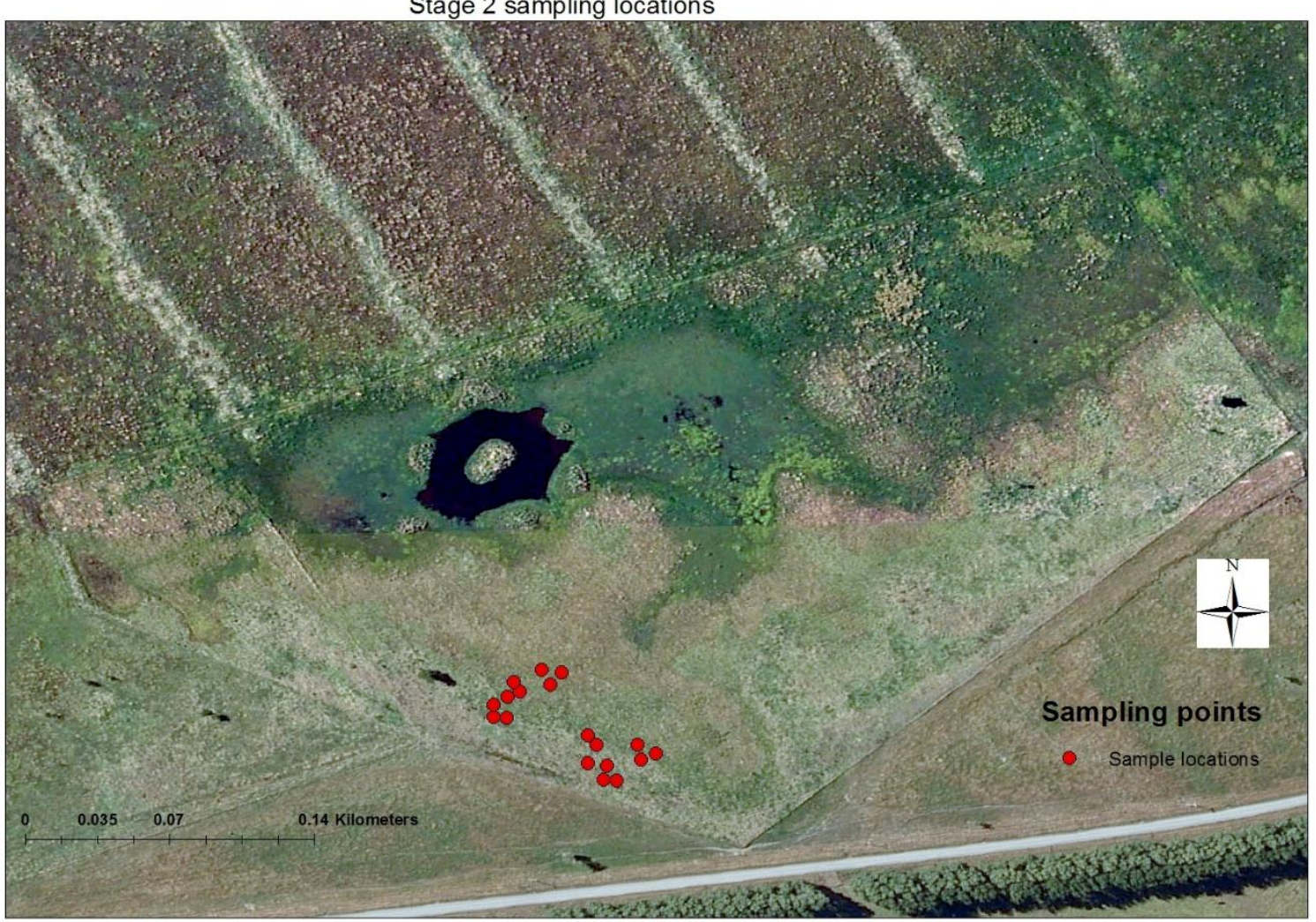

Figure 8. Aerial photo of the sampling locations of soil properties in the plots of Stage 2 


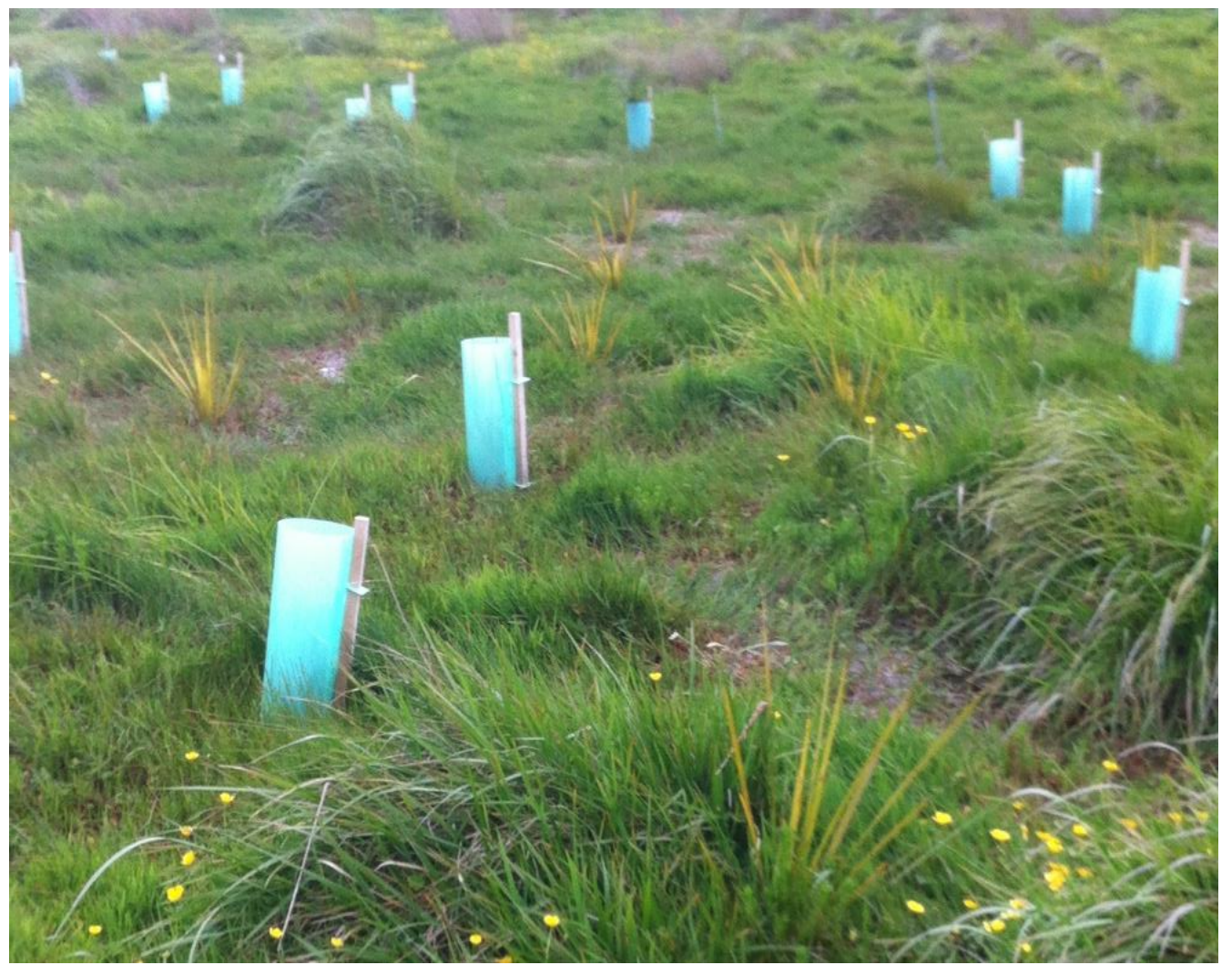

Image 10. Lay out of trees in stage 3, Block 12, plot 1, where 15 out of 49 planted trees were protected with grotector tree-guards. Foreground shows cabbage trees, in the distance are planted manuka trees. Photo taken by author in October 2014, 10 months after planting. 


\subsection{Quantification of bulk density, saturated hydraulic conductivity, soil organic carbon, soil moisture content and matric potential}

\subsubsection{Bulk density}

The majority of published research on bulk density data is derived from field measurements using the standard oven dry method, which makes use of samples collected using different techniques such as core and pit excavation. Soil cores are difficult to use on loose soils and if small, may underestimate bulk density in stony soils by failing to account for large stones with high densities (Reinsch \& Grossman, 1995). The pit excavation technique is regarded as effective in the field however, bulk density is only measured at one level of soil moisture content (Reinsch \& Grossman, 1995). A few studies have used empirical equations based on either a data base with bulk density values or particle size distribution and organic matter content (Lal et al., 2009).

\subsubsection{Measurement of bulk density at Wairio wetlands}

Bulk density was quantified following the international standard soil core procedure described in Belsky et al. (1989), Mordelet et al. (1993) and Young et al. (2009). Soil samples were collected at two fixed depth intervals of $0-6 \mathrm{~cm}$ and $12-18 \mathrm{~cm}$ from each sampling point using $100 \mathrm{~cm}^{3}$ stainless steel cores of $6 \mathrm{~cm}$ length and $4.6 \mathrm{~cm}$ diameter. The reason for measuring at distinct depths is that bulk density generally increases with depth and in this case, we wanted to evaluate the impact of land use on the soil property at deeper depths, where compactness reduces water and nutrient holding capacity of the soil.

Three soil samples were randomly collected in each plot during each of the eleven measurement events (Table 11). To minimise disturbance during sampling, the stainless steel core was fitted with two $1 \mathrm{~cm}$ long cylinders at both ends and placed into a stainless steel core cup. The stainless steel core cup was attached to a cross handle (Image 11) and driven carefully into the soil using a hammer. A total of 209 samples were collected at $6 \mathrm{~cm}$ depth and 190 we collected at $18 \mathrm{~cm}$ depth. 


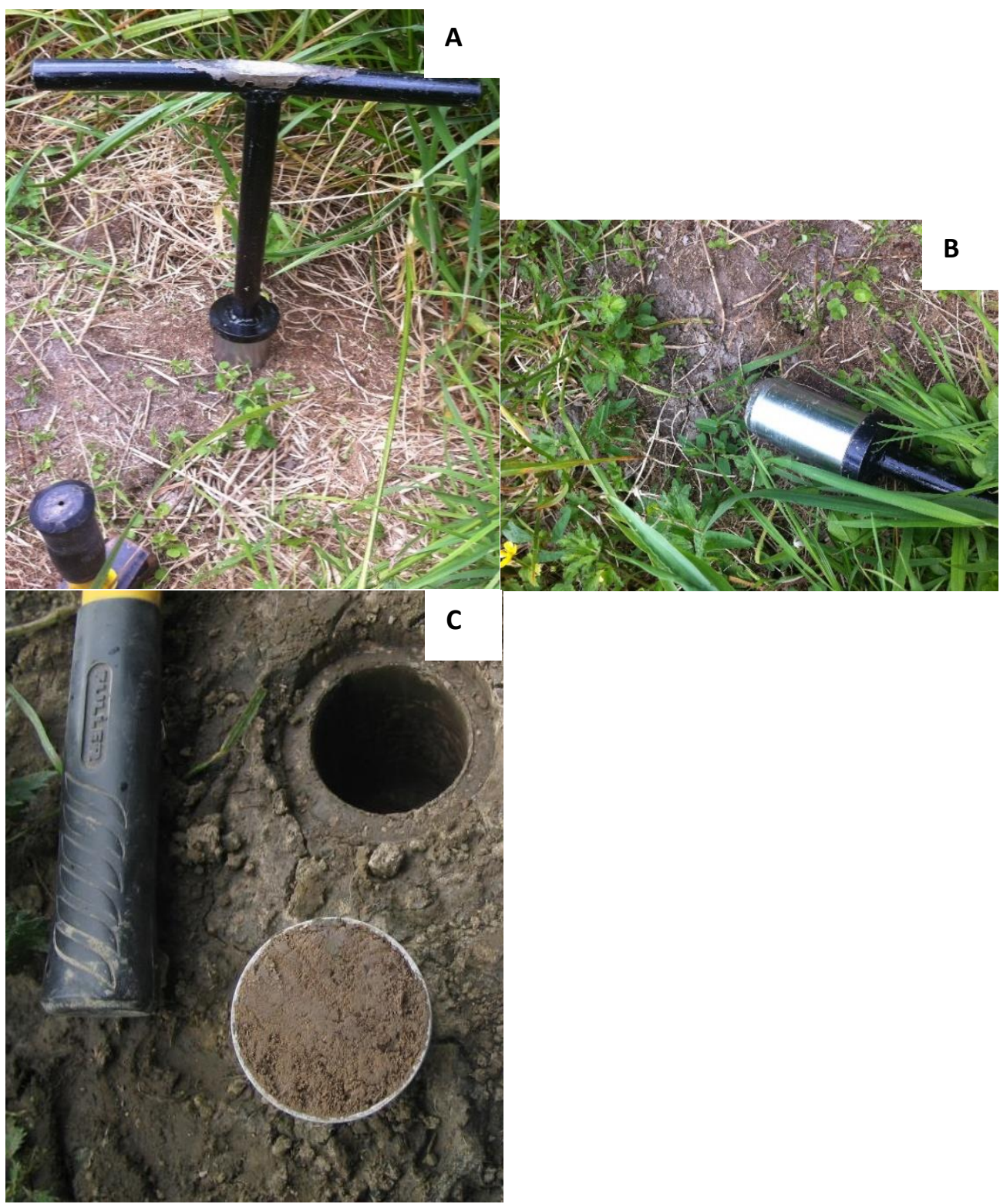

Image 11. Soil sampling in a plot planted with Cabbage trees in Block 13 using stainless steel core attached to a cross bar, A- Insertion of stainless steel core cup attached to a cross handle, B- Stainless steel core cup attached to a cross handle, C- Soil sample collected in a stainless steel. Image taken by Author in November 2014. 
Collected wet samples were weighed in the laboratory, oven dried at $105^{\circ} \mathrm{C}$ for 24 hours and re-weighed to obtain dry mass. Bulk density $\left(\mathrm{g} \mathrm{cm}^{-3}\right)$ of each sample was calculated by dividing the mass of dry soil by the volume of soil core as shown in the equation:

$$
\text { Bulk density }(\rho)=\frac{\text { Mass of soil }(\mathrm{g})}{\text { Volume of core }(\mathrm{cm} 3)}
$$

The bulk density was not corrected for stone content as the soils did not have stones. A few minor setbacks were encountered during soil sampling. Soil core insertion was sometimes restricted by roots and full samples were sometimes difficult to collect on loose dry soils however, soil samples were successfully collected.

Table 11 Measurement events for bulk density at Wairio wetlands

\begin{tabular}{ll}
\hline Blocks & Date of bulk density measurement \\
\hline $7,9,10$ & 16 November 2012 \\
$7,9,10$ & 17 October 2013 \\
$11 \& 13$ & 22 August 2013 \\
$7,9,10,11,12,13$ & 18 January 2014 \\
$1 \& 2$ & 29 January 2014 \\
$7,9,10$ & 4 February 2014 \\
$11 \& 13$ & 12 February 2014 \\
$11,12,13$ & 12 April 2014 \\
$7,9,10$ & 2 May 2014 \\
$1 \& 2$ & 7 May 2014 \\
$1,2,11,12,13$ & 25 November 2014 \\
\hline
\end{tabular}

\subsubsection{Saturated hydraulic conductivity}

Saturated hydraulic conductivity can be quantified using both laboratory and field measurements. Laboratory techniques include consolidation cell, rigid wall permeameter and flexible wall permeameter while field or in situ based measurements make use of porous probes, lysimeter, infiltrometers and borehole tests among others (Kruse et al., 2008; Rosa \& Larocque, 2008).

Field techniques are commonly used for the quantification of saturated hydraulic conductivity as they are considered more representative of the volume of soil explored compared to the small soil core volumes typically measured in the laboratory (Rienzer \& Gandolfi, 2014). As the soil becomes saturated, saturated hydraulic conductivity is likely to be most influenced by a small number of large pores. The small soil cores used in most 
laboratory measurements may not fully represent the network of large pores and can underestimate saturated hydraulic conductivity (Kumar et al., 2010; Rienzer \& Gandolfi, 2014). Laboratory based methods may also overestimate saturated hydraulic conductivity as a result of possible damages during sampling, removal of effective stress, short circuiting of water flow in the interphase of equipment cylinder walls and sample and decomposition in the laboratory (Schlotzhauer \& Price, 1999; Andersen, 2003; Beckwith et al., 2003; Hayashi \& Quinton, 2004).

Among the field techniques used, infiltration-based methods have been found to be robust, effective and viable compared to others (Fallico et al., 2005). In particular, the Guelph Permeameter (Reynolds \& Elrick, 1985, 1989) quantifies field based saturated hydraulic conductivity $\left(\mathrm{K}_{\mathrm{fs}}\right)$ based on infiltration rates and has been used in most wetland studies (Hughes et al., 1998; Holland et al., 2009; Knowles \& Davies, 2009). Its development was established on the borehole permeametry theory. The theory entails the steady state flow of water from a saturated bulb in an augured hole into an infinite amount of unsaturated soil. One of the early proponents of this theory, Glover (1953) used Laplace's equation to show that saturated hydraulic conductivity $\left(K_{s}\right)$ is a function of drainage flux $(Q)$ and a geometric factor $(\mathrm{C})$ in relation to the depth of water in the augured well $(\mathrm{H})$.

$$
K_{S}=\frac{C Q}{2 \pi H^{2}}
$$

This early proposition, however, did not account for capillarity and assumed the sole influence of hydraulic gradient on the flow of water. This assumption can overestimate saturated hydraulic conductivity, especially in soils (e.g. fine textured soils) where matrix flux potential is high (Phillip, 1985). Capillarity is important in determining the size of the saturated bulb in the augured well (Clothier, 2001).

This theory was later improved by Reynolds \& Elrick $(1985,1986)$ who proposed the use of two consecutive pressure head measurements to separate the influence of capillary forces from gravity using analytical solutions based on Richards analysis for measuring water flow from an auger hole above the water table. This solution provided simultaneous equations for calculations of field saturated hydraulic conductivity $\left(\mathrm{K}_{\mathrm{fs}}\right)$ and matric flux potential $\left(\Phi_{\mathrm{m}}\right)$. Matrix flux potential is a measure of soil capillarity and is useful for the characterisation of 
water flow in unsaturated soils and the calculation of multidimensional flow in steep potential gradient conditions (Dirksen, 2001; McKenzie et al., 2002). The method proposed by Reynolds and Elrick, often produces unrealistic negative values of $\mathrm{K}_{\mathrm{fs}}$ and $\Phi_{\mathrm{m}}$ when the soil is heterogeneous (due to the presence of macropores). Elrick et al. (1989) proposed the use of a one head method based on the Richards equation and a parameter $\left(\alpha^{*}\right)$ representing capillarity. The $\left(\alpha^{*}\right)$ parameter can be estimated using soil texture and structure information (Elrick et al., 1989).

$$
\alpha^{*}=K_{f s} / \Phi_{m}
$$

Based on the borehole permeametry theory, the Guelph Permeameter, therefore measures the rate of water absorption by an unsaturated soil from a saturated surface. The rate of water absorption is determined by the hydraulic conductivity of the saturated soil and the capillary absorptive properties of the unsaturated soil.

The Guelph Permeameter measures vertical hydraulic conductivity at deep depths, is not suitable for the quantification of horizontal movement of water, has a short testing period (a few hours), requires low quantities of water and is cheap (Hayasshi \& Quinton, 2004; Knowles \& Davies, 2009; Jačka et al., 2014). However, this method can often underestimate the true value of saturated hydraulic conductivity as a result of compaction of the auger hole during drilling (Jačka et al., 2014). Furthermore, the method is only representative of the point and time at which the measurement is taken. The Guelph Permeameter is effective when the soil is homogeneous and any form of heterogeneity will distort the accuracy of the results (potentially yielding unrealistic negative values) especially when two or multiple head procedures are used during measurement (Rienzer \& Gandolfi, 2014). For that reason, the B horizon in most cases, is considered more appropriate for saturated hydraulic conductivity measurements by the Guelph Permeameter and the single recharge rate from one ponded depth of water in the well (one head, combined reservoir) is adopted to prevent negative values (Chell, 2007).

Whilst acknowledging the aforementioned issues, the Guelph Permeameter was selected for the measurement of saturated hydraulic conductivity at Wairio wetlands. The main reasons for selection were the Guelph Permeameter being portable, water saving, easy to carry and use in a wetland that is far from a clean source of water. 
4.3.2.1 Measuring saturated hydraulic conductivity at Wairio wetlands

Field saturated hydraulic conductivity was measured at 71 point locations during 10 measurement events (Table 12) using the Guelph Permeameter (Soil Moisture Equipment Corp. Santa Barbra, CA, USA). Carrying out multiple measurements over a large area and period of time can help capture a more robust representation of the property and how it changes in space and time.

A well was augured with a sharpened sizing auger (Image 12) at a depth of $20 \mathrm{~cm}$ and radius of $3 \mathrm{~cm}$, and the Guelph Permeameter was mounted over the well on a tripod (Image 13).

Table 12 Measurement events for field saturated hydraulic conductivity at Wairio wetlands

\begin{tabular}{|c|c|c|c|c|}
\hline Event & Start date & End date & $\mathrm{N}$ & Notes \\
\hline 1 & 16 Nov 2012 & 16 Nov 2012 & 6 & Summer, dry soils, very hot, soil temperature $14.9^{\circ} \mathrm{C}$ \\
\hline 2 & 29 Jan 2013 & 29 Jan 2014 & 8 & $\begin{array}{l}\text { Summer, very dry soils, very hot, soil temperature } \\
22^{\circ} \mathrm{C}\end{array}$ \\
\hline 3 & $18 \mathrm{Jul} 2014$ & $18 \mathrm{Jul} 2014$ & 6 & $\begin{array}{l}\text { Winter time, high rainfall, low soil temperature of } \\
10^{\circ} \mathrm{C}\end{array}$ \\
\hline 4 & 18 Aug 2014 & 18 Aug 2014 & 6 & $\begin{array}{l}\text { Winter time, moderate rains during previous days, } \\
\text { low soil temperature of } 6-8^{\circ} \mathrm{C}\end{array}$ \\
\hline 5 & 4 Sep 2014 & 4 Sept 2014 & 6 & $\begin{array}{l}\text { Spring time, moderate rains the previous days. Soil } \\
\text { temperature } 9^{\circ} \mathrm{C}\end{array}$ \\
\hline 6 & 25 Sep 2014 & 25 Sep 2014 & 8 & $\begin{array}{l}\text { Spring time, no rainfall the previous two day, soil } \\
\text { temperature } 10^{\circ} \mathrm{C}\end{array}$ \\
\hline 7 & 7 Oct 2014 & 7 Oct 2014 & 4 & $\begin{array}{l}\text { Spring time. Windy day, wet soils, rain on the } \\
\text { previous days. Soil temperature } 8^{\circ} \mathrm{C}\end{array}$ \\
\hline 8 & 14 Oct 2014 & 14 Oct 2014 & 12 & $\begin{array}{l}\text { Spring time. Slightly windy day, no rain on the } \\
\text { previous days, high soil temperature } 14^{\circ} \mathrm{C}\end{array}$ \\
\hline 9 & 22 Oct 2014 & 23 Oct 2014 & 10 & $\begin{array}{l}\text { Spring time, slightly windy, rain } 3 \text { days before, soil } \\
\text { temperature } 13^{\circ} \mathrm{C}\end{array}$ \\
\hline 10 & 1 Nov 2014 & 1 Nov 2014 & 5 & $\begin{array}{l}\text { Spring time, windy day, no rain, high soil } \\
\text { temperature } 14^{\circ} \mathrm{C}\end{array}$ \\
\hline
\end{tabular}




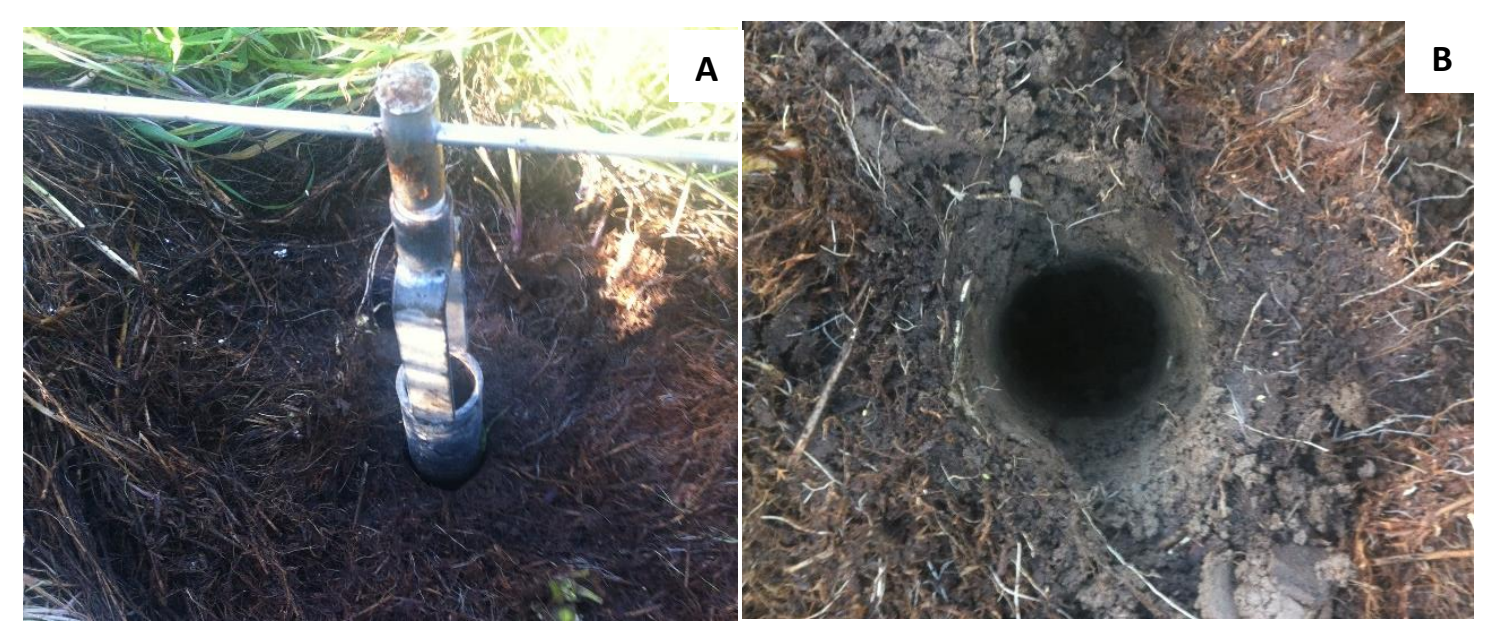

Image 12. Creation of a well (B) using a sharpened auger (A). Image taken by Author in August 2014.

The well was filled with water at a ponded depth of at least $10 \mathrm{~cm}$ to form a saturated bulb, maintained by the constant head of the permeameter. The steady state recharge rate was measured using the one head method. The reading interval for the change in water level ranged from $20 \mathrm{sec}$ to 5 minutes depending on the infiltration rate. The one head method includes the capillarity component $\left(\alpha^{*}\right)$ which represents the flow of water out of the well due to capillary forces (Reynolds \& Elrick, 1985). Accounting for capillarity is important for fine textured soils. 


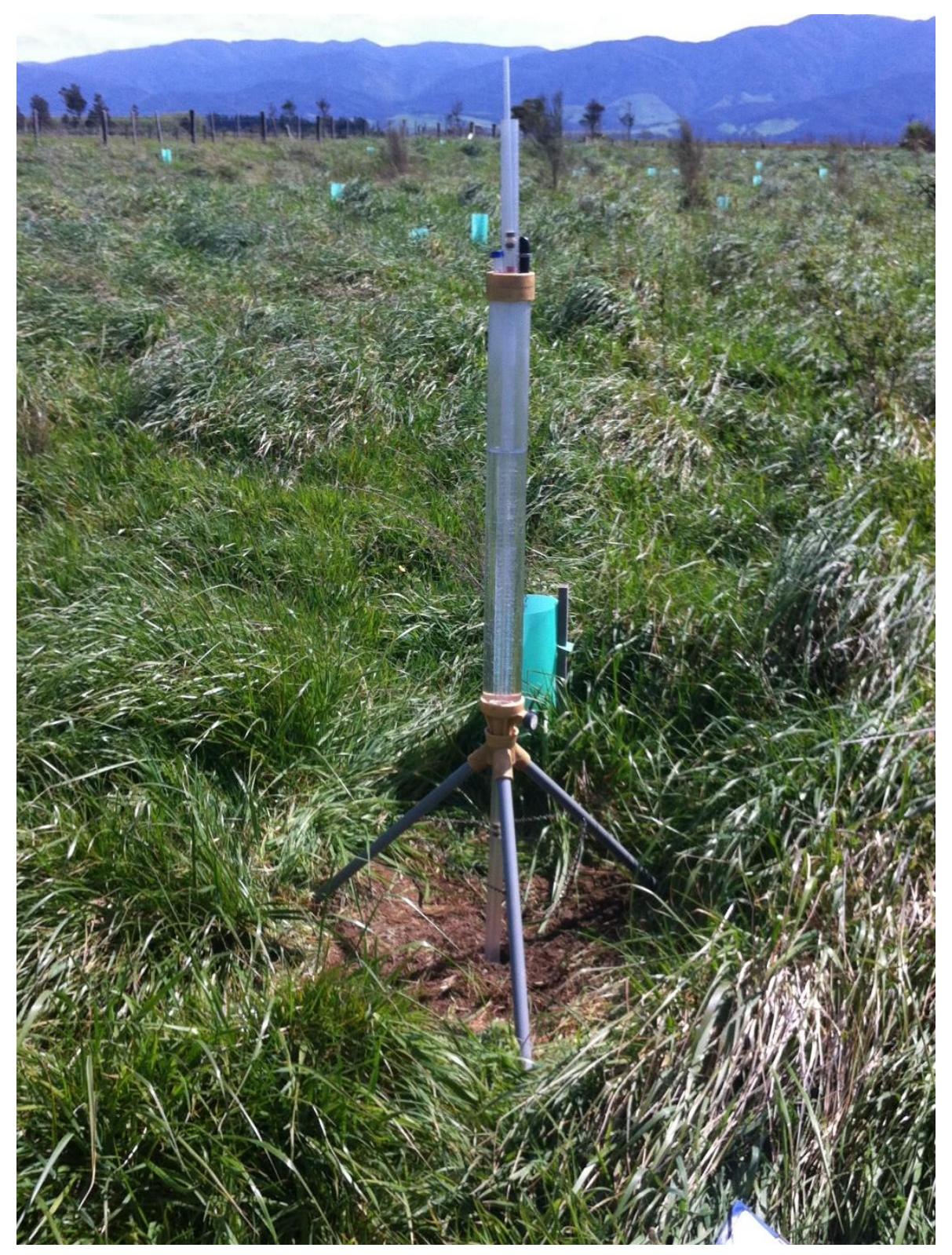

Image 13. Guelph Permeameter mounted over a well on a tripod in a plot planted with a mixture of tree species in Block 1. Image taken by Author in October 2014.

The one head method was used to calculate Kfs using the following equation

$$
K_{f s}=\frac{\mathrm{CQ}}{\left(2 \pi h^{2}\right)+\left(\pi a^{2} C\right)+\left(\frac{2 \pi h}{\alpha^{*}}\right)}
$$

Where,

$K_{f s} \quad=$ Field saturated hydraulic conductivity $(\mathrm{m} / \mathrm{s})$

Q = Steady state recharge $\left(\mathrm{m}^{3} / \mathrm{s}\right)$

$\mathrm{a} \quad=$ well $\operatorname{radius}(\mathrm{m})$ 
$\mathrm{h} \quad=$ steady depth of water in the well $(\mathrm{m})$

$\mathrm{C}=$ dimensionless shape factor (dependent on the ratio $\mathrm{h} / \mathrm{a}$ )

$\alpha^{*} \quad=$ measure of the soils capillarity (ability to absorb water) $\left(\mathrm{m}^{-1}\right)$

The reference value for $\alpha^{*}$ that was used for Wairio wetlands was $12 \mathrm{~m}^{-1}$ as suggested by Elrick \& Reynolds (1992) applicable to agricultural soils, structured clays through loams and unstructured medium and fine sands (Table 13).

Table 13 Suggested values of $\alpha^{*}$ for different soil types. (Adapted from Elrick \& Reynolds, 1992)

\begin{tabular}{ll}
\hline Soil type & $\boldsymbol{\alpha}^{*}\left(\mathbf{m}^{-\mathbf{1}}\right)$ \\
\hline Compacted clays & 1 \\
Most structured soils from clays through loam, unstructured medium and fine sands & 12 \\
Unstructured fine textured soils & 4 \\
Coarse sands and highly structured soils & 36 \\
\hline
\end{tabular}

It was difficult to carry out consistent measurements using the instrument due the uncompromising nature of the wetland environment. The Guelph Permeameter was designed to measure saturated hydraulic conductivity of initially unsaturated soils. However, the regular saturation of the wetland meant that measurements were only possible when soil was dry and thus variability under wet conditions could not be captured.

The double head procedure was first used to quantify the property but it yielded unrealistic negative results and all the data had to be discarded. The double head method assumes homogeneity of soils hence any form of heterogeneity (e.g. macropores) distorts the accuracy of the results. Heterogeneity is characteristic of Wairio wetland soils and hence the single head approach was then adopted. Another challenge was the inconsistency in the time taken to reach a steady state recharge rate. In a single plot, some spots would take less than 30 minutes while for some spatially closer spots, it would take more than 120 minutes. This could have contributed to some of the spurious results obtained.

On windy days, there would be a backflow of water into the instrument, and this would disrupt the measurements. A hole depth of less than $15 \mathrm{~cm}$ did not result in the movement of water from the instrument thus it was adjusted to $20 \mathrm{~cm}$. However, at some spots, this depth would reach the surface of the water table so it would be re-adjusted to $17 \mathrm{~cm}$, and as such, there was no consistency in the depth of hole sampled. 


\subsubsection{Soil organic carbon}

It is challenging to give a blanket amount of carbon fixed for all wetlands because the delicate process is affected by various factors (e.g. temperature, topography, wetland type). For this reason, there is a need to quantify the amount of soil organic carbon accumulation in specific wetland types.

Numerous methods that quantify soil organic carbon can be grouped into quantitative, semi-quantitative and qualitative. These range from destructive dry and wet combustion methods to non-destructive diffuse reflectance spectroscopy technology. Qualitative methods are based on nuclear magnetic resonance (NMR) spectroscopy, diffuse infra-red fourier transform (DIRFT), electron paramagnetic resonance (EPR), ultraviolet-visible (uv-vis) absorption and fluorescence and near infrared (NIR) which require great skill in analysis and interpretation of results as well as a lot of time and funds (Schumacher, 2002; Milori et al., 2011). Quantitative methods make use of combustion techniques or wet chemistry digestion to measure $\mathrm{CO}_{2}$ from organic material. These methods require preparation of samples to remove inorganic substrates and water prior to quantification of carbon. An example is the dry combustion technique, a standard method which measures $\mathrm{CO}_{2}$ emitted from the oxidation of organic carbon and thermal decomposition of carbonate materials (Rahman et al., 2011). This method is highly recommended for accuracy but can be harmful as it produces toxic residues (Schumacher, 2002; Rahman et al., 2011). Semi quantitative methods for carbon estimation are based on organic matter removal and subsequent determination of loss in weight of the sample in soils and these include loss on ignition and hydrogen peroxide digestion. Loss on ignition has been used in many studies characterising soil carbon including in wetlands (e.g. Rahman et al., 2011; Zhang et al., 2012) because it is cost effective, rapid and convenient. However, it can overestimate carbon content if inorganic constituents are lost during heating process, contributing to additional weight loss (Schumacher, 2002; Rahman et al., 2011). This effect can be reduced by baking samples at temperatures not exceeding $400{ }^{\circ} \mathrm{C}$ (Risdon, 2011). A summary of some of the principles, advantages and disadvantages of some of the methods is presented in Table 14. 
Table 14 Summary of the methods for determination of soil organic carbon

\begin{tabular}{|c|c|c|}
\hline Method & Principle & Conclusion \\
\hline $\begin{array}{l}\text { Wet digestion or titrimetric } \\
\text { dichromate redox procedure }\end{array}$ & $\begin{array}{l}\text { Involves oxidation of organic } \\
\text { matter to carbon-dioxide } \\
\text { using a mixture of potassium } \\
\text { dichromate and sulphuric } \\
\text { acid. Unused potassium } \\
\text { dichromate is back- titrated } \\
\text { with ferrous ammonium } \\
\text { sulphate }\end{array}$ & $\begin{array}{l}\text { Useful for handling a large } \\
\text { number of samples, is fairly } \\
\text { cheap and requires less } \\
\text { sophisticated equipment. } \\
\text { Results are fairly accurate but } \\
\text { oxidation factor is needed to } \\
\text { correct for incomplete } \\
\text { oxidation. }\end{array}$ \\
\hline Loss on ignition & $\begin{array}{l}\text { Direct organic matter } \\
\text { estimation. Organic matter is } \\
\text { oxidised by ignition for } 16 \\
\text { hours at } 400 \text { oc and } \\
\text { estimated by weight loss. }\end{array}$ & $\begin{array}{l}\text { Useful for handling a large } \\
\text { number of samples. Sufficiently } \\
\text { accurate for exploratory } \\
\text { purposes and cheap. May } \\
\text { overestimate the amount of } \\
\text { carbon in calcareous soils due } \\
\text { to the loss of } \mathrm{CO}_{2} \text { from } \\
\text { carbonates. Soils with high clay } \\
\text { content may lose structural } \\
\text { water from the clay minerals } \\
\text { thereby contributing to loss on } \\
\text { ignition values. These errors } \\
\text { can be reduced at carefully } \\
\text { controlled low temperatures. }\end{array}$ \\
\hline $\begin{array}{l}\text { Carbon, hydrogen, nitrogen } \\
\text { (CHN) analyser }\end{array}$ & $\begin{array}{l}\text { Involves oxidation of carbon } \\
\text { by } \\
\text { oxygen gases in the presence } \\
\text { of helium. This releases } \mathrm{CO}_{2} \\
\text { which is envisaged to be } \\
\text { directly proportional to the } \\
\text { carbon content in the sample. } \\
\text { The released carbon is } \\
\text { measured by a } \mathrm{CO}_{2} \text { detector } \\
\text { and expressed as a } \\
\text { percentage. }\end{array}$ & $\begin{array}{l}\text { Effective and accurate method } \\
\text { that analyses a large number of } \\
\text { samples efficiently. However, it } \\
\text { is expensive to acquire and } \\
\text { maintain the equipment. }\end{array}$ \\
\hline Diffuse reflectance spectroscopy & $\begin{array}{l}\text { Non-destructive technique } \\
\text { that characterises carbon } \\
\text { content based on reflectance } \\
\text { spectrum of a sample } \\
\text { illuminated with infra-red } \\
\text { light. }\end{array}$ & $\begin{array}{l}\text { Accurate, rapid and high } \\
\text { precision method. A large } \\
\text { number of samples can be } \\
\text { scanned by a single operator } \\
\text { within a short space of time. } \\
\text { Method involves complex data } \\
\text { analysis and requires } \\
\text { calibration for all soil properties } \\
\text { to be quantified in the large } \\
\text { number of samples. It also } \\
\text { requires high expertise and is } \\
\text { expensive to acquire and }\end{array}$ \\
\hline
\end{tabular}


maintain

Combustion train

Van-Slyke-Neil apparatus

Induction furnace

Resistance furnace

Wet oxidation with hydrogen peroxide
Involves combustion and conversion of carbon in a sample to $\mathrm{CO}_{2}$ in a $\mathrm{CO}_{2}$-free air stream using a mixture of potassium dichromate, phosphoric acid and sulphuric acid

The Van-Slyke-Neil apparatus converts organic carbon of a sample heated with mixture of potassium dichromate, phosphoric acid and sulphuric acid into $\mathrm{CO}_{2}$

Involves rapid combustion of a sample at approximately $1650{ }^{\circ} \mathrm{C}$ in an $\mathrm{O}_{2}$ stream. The sample is mixed with copper, iron and tin

Involves rapid heating of a sample mixed with copperoxide at $1500 \stackrel{\circ}{\circ}$ in an $\mathrm{O}_{2}$ stream

Oxidation using $\mathrm{H}_{2} \mathrm{O}_{2}$, drying residue at $110 \circ \mathrm{C}$
Fairly accurate and time consuming procedure

Fairly accurate but expensive

Accurate and expensive procedure

Fairly accurate but time consuming

Incomplete oxidation of organic matter

\subsubsection{Estimation of soil organic carbon concentration at Wairio wetlands}

Soil organic matter and carbon content (\%) were quantified through the Loss on Ignition (LOI) analysis (Nelson \& Sommers, 1996) on the soil samples that were used to calculate bulk density under the four land use types at 6 and $18 \mathrm{~cm}$ depths. There is no standard loss on ignition method for wetland soils, and various studies have used different temperatures and ignition periods. For example, Heiri et al. (2001) ignited at $550{ }^{\circ} \mathrm{C}$ for $4 \mathrm{hrs}$; Nahlik \& Mitsch (2008) ignited at $550{ }^{\circ} \mathrm{C}$ for 3 hours; Cambardela at al. (2001) ignited at $450{ }^{\circ} \mathrm{C}$ for 4 hours; Nelson \& Sommers (1996) and Collins \& Kuehl (2001) ignited at $400{ }^{\circ} \mathrm{C}$ for 16 hours. This research adopted the latter LOI methodology by Nelson \& Sommers (1996) and Collins \& Kuehl (2001) to minimise the oxidation of carbonates and loss of volatile materials. Dried samples were ground, passed through a $2 \mathrm{~mm}$ sieve. Six grams of each of the sieved soil samples were placed in $30 \mathrm{ml}$ crucibles. The samples were weighed and ignited at $400{ }^{\circ} \mathrm{C}$ 
for 16 hours in a muffle furnace. After ignition, the samples were cooled in a desiccator and reweighed. Soil organic matter was expressed as the percentage change in weight following ignition using the following formula:

\section{$\%$ Organic matter $=$}

Weight of oven dry soil at $105^{\circ} \mathrm{C}-$ Weight of soil sample after ignition at $400^{\circ} \mathrm{C}$ Weight of oven dry soil at $105^{\circ} \mathrm{C}$

Estimation of the percentage soil organic carbon was based on the assumption that organic matter contains $50 \%$ carbon. A conversion factor of 2 was used to convert organic matter content to organic carbon content using the following formula:

$$
\% \text { soil organic carbon }=\frac{\% \text { soil organic matter }}{2}
$$

This conversion factor is highly speculative. Literature has published inconsistent conversion factors e.g. Cambardella et al. (2001); Mitsch \& Gosselink (2007); Pribyl (2010), because of the variation in soil organic carbon with vegetation type, climate, soil type, habitat type and degree of decomposition, among other factors. Ideally, conversion factors should be site specific.

\subsubsection{Estimation of soil organic carbon stock (SOC) for Wairio wetlands}

The amount of soil organic carbon under each land use was also quantified per unit area $(\mathrm{kg}$ $\mathrm{C} \mathrm{m}^{-2}$ ) based on the soil depth from where soil samples were collected, the bulk density and organic carbon concentration of the samples. The calculations were performed using the formula:

$\operatorname{SOC}\left(\mathrm{kg} \mathrm{C} \mathrm{m}^{-2}\right)=$ soil bulk density $\left(\mathrm{gcm}^{-3}\right) *$ soil depth $(\mathrm{cm}) * \%$ soil organic carbon

\subsubsection{Soil moisture content}

The quantification of soil moisture content requires taking into account both spatial and temporal variability (Molina et al., 2014). For good accuracy, there is need for a large number of measurements of soil water at field or local scale. Characterisation of spatial 
variability of soil water and its dependence on wetness can be carried out by estimating variance, standard deviation or coefficient of variation (Mittelbach \& Seneviratne, 2012). Geostatistical analysis is also commonly used for estimating spatial variability (Mittelbach \& Seneviratne, 2012; Molina et al., 2014).

Sampling frequency is another important factor to consider when studying water content at plot scale. High temporal resolutions (e.g. 30 minute intervals, hourly) are the commonly used sampling frequencies for accurate soil moisture determination at plot or local scale, depending on data storage capacity of monitoring equipment (Molina et al., 2014). The most recommended is hourly during wetting up periods in ephemeral conditions but can be prolonged to 12 hours if there are data storage constraints (Molina et al., 2014). Daily intervals are recommended during drying periods in ephemeral conditions. This allows a derivation of good quality information from the quantity of data measured. This is made possible through the use of sensors and data loggers that allow continuous monitoring.

According to Zucco et al. (2014), if spatial distribution of soil moisture exhibits temporal variability, it is possible to estimate it over large areas from a limited number of samples.

\subsubsection{Evaluation of moisture measuring techniques}

Methods of quantifying volumetric soil moisture content make use of soil and water properties which include bulk density, water density, electrical conductivity, dielectric properties, volumetric heat capacity, soil thermal conductivity and soil thermal diffusivity (Gardner, 1986; Knight \& Endres, 2005; Robinson et al., 2008). Methods corresponding to these properties include the standard oven dry at $105{ }^{\circ} \mathrm{C}$ (Gardner, 1986), a direct technique, and indirect techniques such as the use of electromagnetic sensors, heat pulse sensors, neutron probes and geophysical methods (Robinson et al., 2008).

\subsection{Direct measurement techniques}

Direct techniques quantify the gravimetric soil moisture content. Gravimetric soil moisture content is the mass of water relative to the mass of dry soil solids. Conventionally, it is reported on a dry basis, though it can also be reported on a wet basis. The gravimetric method is the standard, simple, inexpensive and direct. However, this standard oven dry technique carried out in the laboratory is time consuming (can last up to $24 \mathrm{hrs}$ ), destructs the soil sample and is constrained by the likely loss of organic materials at high 
temperatures which may lead to overestimation of moisture content (Kitić \& CrnojevicBengin, 2013).

\subsection{Indirect techniques}

Indirect methods involve inferring properties of interest from properties already known. These methods measure a property then infer volumetric soil moisture content from that property. Volumetric soil moisture content is the volume of water relative to the total soil volume. In situ methods can only measure volumetric soil moisture content. In the lab, volumetric soil moisture content can be derived from gravimetric soil moisture content by converting using bulk density.

\subsection{Neutron probe}

This is one of the oldest techniques. It contains a small radio-active source which emits epithermal neutrons that interact with hydrogen atoms in the soil. The neutrons are scattered by hydrogen atoms and the magnitude of scatter depends on the amount of hydrogen atoms. Hydrogen atoms are normally associated with water and their interaction with the epithermal neutrons, gives an estimate of the amount of water in the soil. However, in peat soils, hydrogen atoms may be associated with organic matter and this would require calibration of the probe for accurate measurements. Advantages of this probe are that it has the largest volume of influence $(10-20 \mathrm{~cm}$ radius) which can help account for issues of fine-scale spatial variability. It is insensitive to issues of salinity and temperature. Disadvantages are that, it cannot be used for continuous measurements, it is highly regulated and requires a radiation certificate. It is also expensive and difficult to move around.

\subsection{The dual needle heat pulse probe}

The operation of this probe is based on the theory that the heat capacity and storage of the soil is highly dependent on the moisture content. The probe has two needles, one containing a heater and the other containing a temperature measuring device. The first needle passes heat to the soil and the second needle measures the heat pulse as it comes from the first needle. The maximum temperature rise recorded is related to the volumetric water content and the heat capacity of the soil. The needle spacing is crucial to the accuracy of measurement, a needle diffraction can result in a $6 \%$ error. This is a problem in stony 
soils. Advantages include small measurement volume, which is important for location specific (e.g. around growing seed) measurements. Disadvantages include the requirement of specific data loggers with precise temperature measurement. This can be costly. The probe is affected by temperature fluctuations in the soil. They are quite fragile, and there is need for caution when inserting into soil.

\subsection{Geophysical methods}

Geophysical methods such as the ground penetrating radar, electromagnetic induction and direct current resistivity have received interest by researchers quantifying soil moisture mostly in agricultural landscapes (Sheets \& Hendricks, 1995; Knight, 2001; Lesch et al., 2005). A review by Robinson et al. (2008) noted that these methods do not destruct the soil and are useful for determining spatial variability of other properties linked to moisture content. However, since they use properties such as electromagnetic wave propagation time and ground conductivity, there is need for conversion to soil moisture content which requires calibration using other forms of data that may be affected by spatial heterogeneity.

\subsection{Electromagnetic measurements}

These measure the charge storage in soil. The ability to store charge is known as dielectric permittivity. Water has a high dielectric permittivity because it's a polar molecule. Measuring the charge storage of a soil will enable inference of the water content since water stores the bulk of all the charges and it is one of the soil components that changes in concentration. Dielectric sensors are used to measure volumetric moisture content based on dielectric permittivity. Dry soil has a permittivity of 2.5 while that of water is approximately 80 hence presence of water has a significant effect on the permittivity of the soil (Kitić \& Crnojevic-Bengin, 2013).

The highest sensitivity of the sensors is closest to the surface. There are two choices of sensors that can be used to measure dielectric permittivity, these include time domain and frequency domain. The time domain reflectometry (TDR) measures the travel time of a propagated electromagnetic wave over the length of the probe rods. This apparent length increases with an increase on water content. TDR can give good values in all soils if properly calibrated. They are quite expensive, consume more power and are quite complex (requiring expertise to set up). Sensors are sensitive to air gaps. 
To improve on some of these problems, frequency domain or capacitance sensors are used. These measure dielectric permittivity of the soil based on charge time of a capacitor. There is a direct relationship between dielectric permittivity and charging of the capacitor. An example of a frequency domain sensor is the CS-616/ CS-620 (Campbell Scientific, Inc., Logan, UT). These moisture sensors have been used widely in hydrological research and are considered as standard in-situ methods because they simultaneously measure moisture content and bulk electrical conductivity at frequencies that makes it easy to separate the two properties. The CS-620 (Campbell Scientific, Inc., Logan, UT) hand held soil moisture sensor provides a quick, reliable and unlimited quantification of volumetric soil moisture content and has been used in determining moisture variation in restored sites (Haskell et al., 2012). The capacitance sensors are cheap, easy to install, and require low power. Limitations include sensitivity to soil texture and temperature fluctuations, difficult to install down holes, sensitivity to air gaps and electrical conductivity.

\subsubsection{Quantification of soil moisture at Wairio}

Volumetric soil moisture content was measured in the field using CS620 water content reflectometer (Campbell Scientific, Logan, UT, USA) and also quantified from gravimetric measurements carried out in the lab.

\subsection{Indirect measurements using CS620 reflectometers}

Sampling by CS620 reflectometers was carried out at three soil depths, $10 \mathrm{~cm}, 20 \mathrm{~cm}$ and 30 cm (Image 14) continuously for a year (April 2014 to March 2015). Installation at different soil depths was through a $40 \mathrm{~cm}$ (depth) $\times 40 \mathrm{~cm}$ (wide) trench (Image 14). The reflectometers consist of two $30 \mathrm{~cm}$ long stainless steel rods connected to a circuit board that is attached to a four conductor cable which enables power supply and monitoring of the output. The reflectometers were not calibrated. 


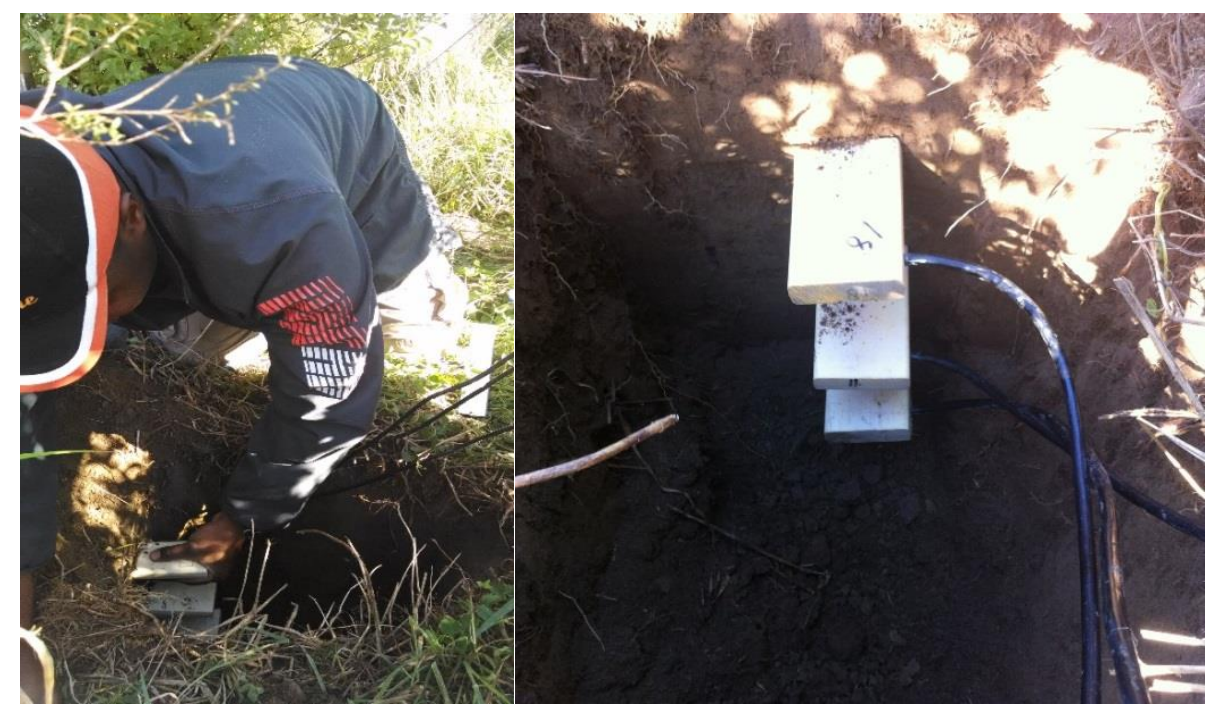

Image 5. Insertion of the CS620 moisture sensors at $10 \mathrm{~cm}, 20 \mathrm{~cm}$ and $30 \mathrm{~cm}$ soil depths in plot 1 of block 7 . Image taken by Dez Tessler in April 2014

The CS620 reflectometers were installed in three plots, two planted (in blocks 7 and 9) and one unplanted (in block 13) located in stage 3 at two different slope gradients (Table 15). Two plots (planted and unplanted) were on an $8 \%$ slope gradient and one planted plot on 3 $\%$ slope gradient. The CS620 reflectometers at each plot were connected to a single ended analog input of CR 1000 data loggers (Campbell Scientific, Logan, UT, USA). The data loggers were powered by a 12 voltage battery (Image 15). The data loggers convert the probe square wave output of the probes to volumetric moisture content using a calibration. The loggers were programmed to collect data every five minutes. A station comprising these accessories was established at each of the three plots (Image 15). The measurements were limited to three plots owing to a limited number of data loggers. 
Table 15 Characteristics of sites where CS620 sensors and T4e tensiometers were installed for continuous monitoring of soil mositure levels and matric potential

\begin{tabular}{|c|c|c|c|c|}
\hline Block & Plot & Land use & Slope (\%) & Equipment \\
\hline 7 & 1 & $\begin{array}{l}\text { Mixture of tree species: Coprosma } \\
\text { robusta, Olearia virgata, } \\
\text { Podocarpus totara, Coprosma } \\
\text { propinqua, Cordyline australis, } \\
\text { Pittosporum tenuifolium, } \\
\text { Dacrycarpus dacrydioides and } \\
\text { Leptospermum scoparium }\end{array}$ & 8 & $\begin{array}{l}\text { Three CS620 reflectometers } \\
\text { installed at } 10,20 \text { and } 30 \\
\mathrm{~cm} \text { depths. Two T4e } \\
\text { tensiometers installed at } 10 \\
\text { and } 20 \mathrm{~cm} \text { depths. } \\
\text { Accessories connected to a } \\
\text { CR } 1000 \text { data logger }\end{array}$ \\
\hline 9 & 1 & $\begin{array}{l}\text { Mixture of tree species: Coprosma } \\
\text { robusta, Olearia virgata, } \\
\text { Podocarpus totara, Coprosma } \\
\text { propinqua, Cordyline australis, } \\
\text { Pittosporum tenuifolium, } \\
\text { Dacrycarpus dacrydioides and } \\
\text { Leptospermum scoparium }\end{array}$ & 3 & $\begin{array}{l}\text { Three CS620 reflectometers } \\
\text { installed at } 10,20 \text { and } 30 \\
\mathrm{~cm} \text { depths. Two T4e } \\
\text { tensiometers installed at } 10 \\
\text { and } 20 \mathrm{~cm} \text { depths. } \\
\text { Accessories connected to a } \\
\text { CR } 1000 \text { data logger }\end{array}$ \\
\hline 13 & 2 & $\begin{array}{l}\text { Sedges, grasses, turfs: Carex } \\
\text { germinata, Agrostis stolonifera, } \\
\text { Dactylis glomerata }\end{array}$ & 8 & $\begin{array}{l}\text { Three CS620 reflectometers } \\
\text { installed at 10, } 20 \text { and } 30 \\
\text { cm depths. Two T4e } \\
\text { tensiometers installed at } 10 \\
\text { and } 20 \mathrm{~cm} \text { depths. } \\
\text { Accessories connected to a } \\
\text { CR } 1000 \text { data logger }\end{array}$ \\
\hline
\end{tabular}
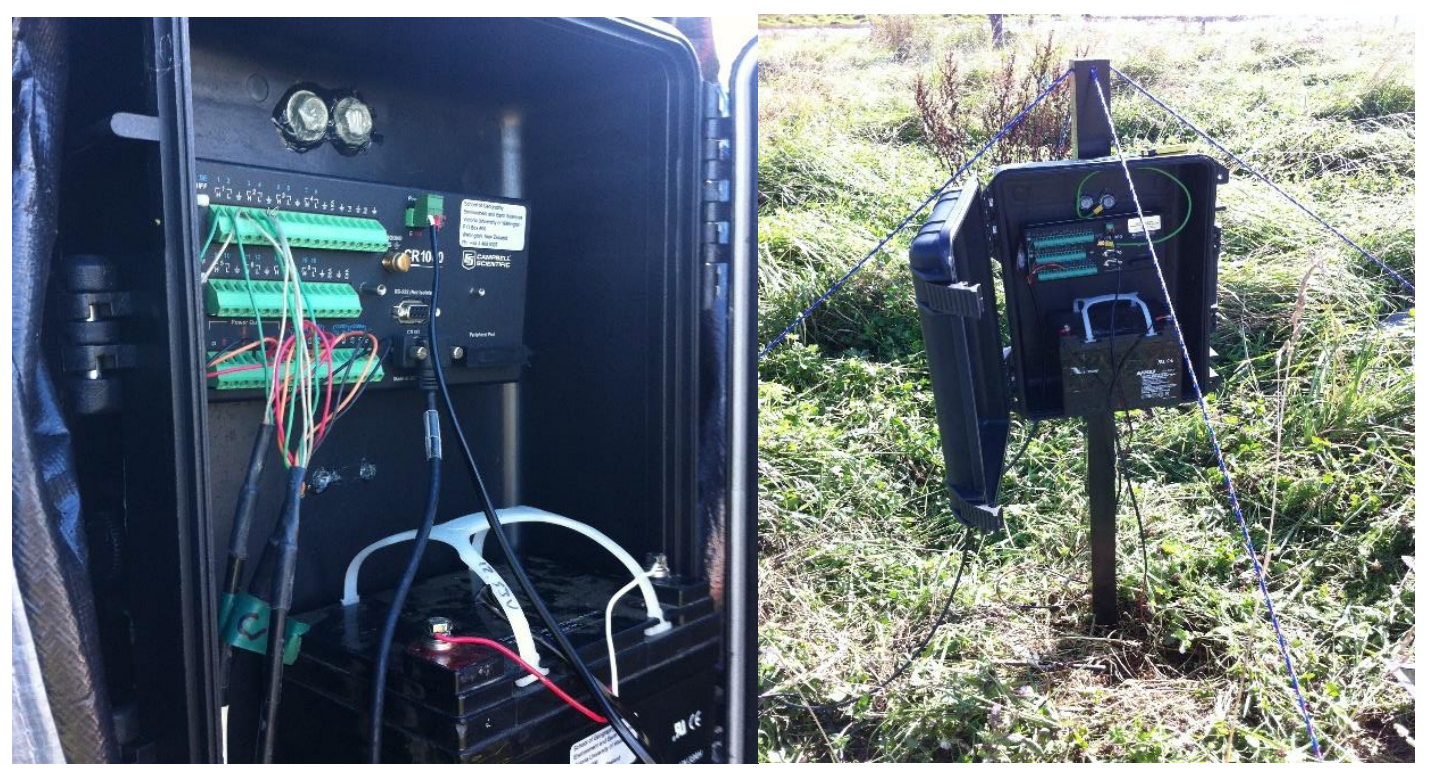

Image 6. CS620 sensors connected to a data logger powered by a 12 voltage battery at a station in an unplanted plot of block 13. Image taken by Author in April 2014. 


\subsection{Direct measurement using gravimetric method}

Samples of known volume $\left(100 \mathrm{~cm}^{3}\right)$ that were collected for bulk density estimation at $6 \mathrm{~cm}$ and $18 \mathrm{~cm}$ soil depths were also used for gravimetric soil moisture estimation. Gravimetric soil moisture was first quantified on a dry weight basis using the formula:

$$
W d(\%)=\frac{\text { Mass of wet soil }(g)-\text { Mass of dry soil }(g)}{\text { Mass of dry soil }(g)} * 100 \%
$$

Conversion of gravimetric soil moisture measurements to volumetric soil moisture measurements was carried out based on the formula:

$$
W v(\%)=\left(W d * \frac{\rho_{b}}{\rho_{w}}\right) * 100 \%
$$

Where;

$\rho_{b}=$ Bulk density $\left(\mathrm{gcm}^{-3}\right)$

$\rho_{w}=$ Density of water $\left(\mathrm{gcm}^{-3}\right)$

\subsubsection{Soil water potential}

Transport of water from the soil surface beyond the root zone down to ground water and vice-versa is governed by the energy state of the soil water. Water moves from places with high potential energy to places with relatively low potential energy and the speed of movement is proportional to the energy gradient between points of different energy levels (Hillel, 1998). This energy is expressed as water potential. It is the force that drives water to flow.

In soils, the water potential expresses the energy status of soil water relative to energy potential of pure water under standard pressure and temperature. It describes the intensity of water and governs its flow and availability. It is a differential property that is bound to surfaces and requires specification of a reference point which is the free water at the soil surface with a potential of zero. Any water that is bound to surfaces or diluted by solutes has a negative water potential less than zero and requires adding energy to move it from 
the bindings back to a pool of free water. Water potential is expressed in units of pressure i.e. megapascals ( $\mathrm{MPa})$, kilopascals $(\mathrm{kPa})$, length of water $\left(\mathrm{m}, \mathrm{cm}, \mathrm{mm} \mathrm{H}_{2} \mathrm{O}\right)$ and bars.

Four component potentials contribute to the energy status of soil water and these include pressure potential energy, gravitational potential energy, solute potential energy and matric potential. Gravitational potential energy of soil water is determined by the position of water in the gravitational force field. It depends on the elevation of the position of water relative to an arbitrary reference level, which in some cases can be at the water table level or soil surface. Thus water at higher elevations within the soil profile has a high gravitational potential than that on the lower end of the profile and moves downwards in the soil profile. Surface water within streams and rivers flows downhill because of gravitational potential energy. Solute potential, also referred to as osmotic potential is a driving force of water movement based on differences in solute concentration between soil solution and free water which then creates a potential energy difference. Water flows from high solute potential regions to low solute potential regions. This is always negative and significantly influences a system if a semi-permeable barrier is present. The barrier allows water to pass through but not the solutes, an example of a barrier would be plant roots. Pressure potential arises from hydrostatic pressure being applied on to water. Pressure potential is always positive below the water table where hydrostatic pressure is greater than atmospheric pressure and zero at the water table. Surface water bodies can have positive pressure potential. Pressure potential can be seen in plant cells, e.g. turgor pressure. In the unsaturated part of the soil, above the free water surface the pressure potential of water can be considered negative and some refer to it as suction or matric potential. In such cases, pressure and matric potentials are coined into a single term based on the assumption of positive values under saturated conditions and negative under unsaturated (Tindall et al., 1999). In this section, pressure and matric potentials are considered separate for operational purposes.

Matric potential is primarily determined by capillary and adsorptive forces that are based on soil matrix properties. The capillary forces arise from the interaction of water and air within the soil pores. Adsorptive forces arise from adhesion of water to most surfaces through short-range London-van der Waals forces and hydrogen bonding. Soil matric potential is always negative when the soil is unsaturated and increases to zero at saturation. It is 
generally the most important component of total water potential as it binds the water to the soil. Research that analyses water flow through soils and groundwater more often focuses on matric potentials and assumes negligible solute potential differences (Whalley et al., 2013). This section will adopt a similar approach, since matric potential is an important component for the determination of the soil water retention properties that are useful for predicting water flow from the surface through the soil to groundwater.

\subsubsection{Matric potential and its relationship with other component potentials}

Matric potential is always negative in the unsaturated zone of the soil because atmospheric pressure is higher. In such conditions, the unsaturated zone acts as a two fluid porous media with both air and water. The negative pressure potential (matric potential, $\psi \mathrm{m}$ ) in this zone is expressed with a negative sign. It results from the interaction of capillary and adsorptive forces between the soil matrix and water. Assuming there is an unsaturated soil column with a particular water table height, the matric potential above the water table would be negative (Figure 9). As the soil wets up, the matric potential increases to zero at the water table level. As the soil gets saturated, the hydrostatic pressure exerted by the water becomes positive and this positive matric potential is also referred to as pressure potential (Figure 9). Pressure potential and matric potential are separated in this discussion because they can be interpreted differently, although they are the same.

Positive pressure potential $(\psi p)$ below the water table also referred to as submergence potential denotes that soil water is at hydrostatic pressure higher than atmospheric pressure (Tindall et al., 1999). The change in positive pressure with depth under the water table is equal and opposite to that of gravitational potential energy. For instance, as pressure increases with depth from zero to positive, the pressure potential is equal but opposite gravitational potential (Figure 9). 


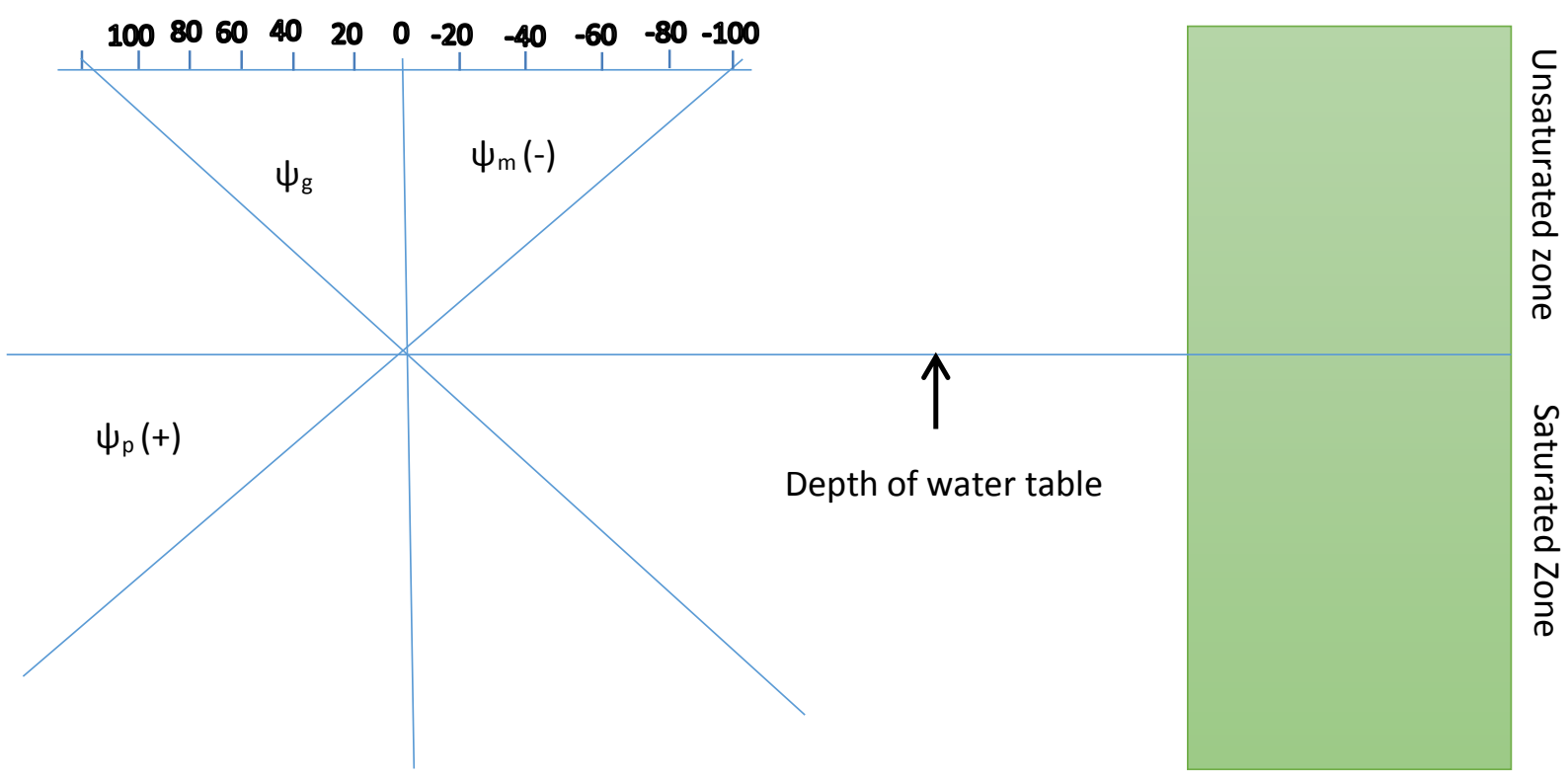

Figure 9. Illustration of the relationship between soil water potential components in a soil column with water table at a height of $100 \mathrm{~cm}$. Adapted and modified from Tindall et al. (1999).

\subsubsection{Relationship between matric potential and soil pore volume}

The level (surface of water table) at which matric potential is equal to zero signifies that the soil is saturated i.e. soil water content is approximately equal to volume of pore spaces in a saturated soil. Application of a suction pressure (negative pressure below atmospheric pressure) results in the soil draining out, with the large pores emptying first. The pressure at which the large pores start draining out is referred to as the air entry suction and in most soils the value is generally $1 \mathrm{kPa}$ or $-10 \mathrm{~cm} \mathrm{H}_{2} \mathrm{O}$ (Loll \& Moldrup, 2000) depending on texture. As suction is continuously applied, large pores that cannot hold water will completely empty out until high suction drains out smaller pores and only very narrow pores retain water at very high suction levels (Loll \& Moldrup, 2000). The remaining moisture at very high suction levels that cannot contribute to water flow in the soil is referred to as residual soil moisture content (e.g. Campos et al., 2011; Martínez et al., 2014).

The difference between residual moisture content and saturated moisture content defines the hydraulically active pore spaces that allow water to flow through the soil (Campos et al., 2011). Since matric potential is a combination of attraction between water and the soil matrix, a decrease in soil pore size will result in the increase in soil surface area and adhesion forces between the soil matrix and water. This means the energy needed to move 
water increases in the presence of smaller pores, resulting in slow movement of water. In an unsaturated soil, the application of a positive pressure results in large pores responding quickly. The relationship between soil suction and pore size distribution determines the amount of water remaining in the soil at equilibrium (Loll \& Moldrup, 2000). Water is held freely in large pores and strongly in smaller pores hence, a high negative water pressure denotes a large proportion of small pores. The relationship is shown in Table 16.

Table 16 Comparison between soil water potential and pore diameter. Adapted and modified from Decagon Devices (2006)

\begin{tabular}{cc}
\hline Water potential $(\mathrm{MPa})$ & Pore diameter $(\mu \mathrm{m})$ \\
\hline-0.001 & 290.08 \\
-0.01 & 29.01 \\
0.00 & 8.79 \\
-0.1 & 2.90 \\
-1.0 & 0.29 \\
-1.5 & 0.19 \\
-10 & 0.03 \\
\hline
\end{tabular}

\subsubsection{Application of matric potential}

Soil moisture retention

Soil moisture retention entails the relationship between water potential and soil moisture content for a given soil. As soil moisture increases, matric suction decreases. This relationship is specifically presented graphically by the moisture retention/ desorption curve. At low suction pressure, the amount of water retained in the soil is determined by soil structure (pore size distribution and capillary effects). At higher suction levels, soil texture strongly influences the amount of water retained. The effect of soil texture on water retention can be graphically presented by comparing retention in sandy vs. clay soils.

A soil containing more moisture content at any given tension has the ability to retain large quantities of water. In sandy soils, less water is adsorbed at high suction pressure than in clay soils. Vegetation has the ability to influence soil moisture retention through its effect on soil pore size and the ability to utilise water through transpiration. Thus, vegetation creates suction pressure in the soil and causes moisture loss. This is important under flooding conditions where more storage space is created for water to flow into the soil instead of water bodies. 


\subsubsection{Quantification of matric potential}

There is no measurement instrument that can accurately measure matric potential within its full range. Measurements involve equilibrating the solid, liquid and vapour with matric potential in the soil. Solid equilibration methods include heat dissipation, electrical resistance and capacitance sensors. The electrical resistance equilibrates a standard solid matrix with the soil and it measures the electrical resistance of some part of that matrix to determine the soil matric potential. Its range of measurement is 0 to $-200 \mathrm{kPa}$. It is a low cost sensor, however, its accuracy and stability can be low when used in high saline soils. Matrix capacitance sensors measure the water content of the matrix by measuring its dielectric constant and use moisture release curve to estimate the matric potential. The measurement is less affected by temperature and saline content, hence is more stable than the electrical resistance sensors. The range of measurement is -10 to $-300 \mathrm{kPa}$. The drawback of the matrix capacitance sensors, is the need to translate soil moisture to matric potential. The heat dissipation sensor measures the moisture in the standard matrix using heat dissipation. The embedded heater and thermistor gives temperature related to water potential. It has very good accuracy if properly calibrated. The range of measurement is quite high, $-10 \mathrm{kPa}$ to $-10 \mathrm{MPa}$. The main drawback is that it requires a high quality data logger, complex programming and temperature corrections to get correct readings.

Liquid equilibration methods include tensiometers and pressure chamber. Tensiometers equilibrate water under tension with soil water and measure the pressure of the water to obtain the matric potential of the soil. The principle of operation involves water movement out of the tensiometer through the porous tip when placed into the soil until equilibrium is reached and the pressure transducer records the pressure potential of soil water. It is the most accurate sensor within its typical measurement range of 0 to $-80 \mathrm{MPa}^{17}$. However, this limited range, reduces measurement accuracy in very dry soil. As the pressure inside the tensiometer approaches zero or beyond, the presence of air bubbles may cause cavitation.

Vapour equilibration methods involve the use of thermocouple psychrometer and dew potentiometer. The thermocouple psychrometer equilibrates samples that are sealed in a chamber and measure the humidity or vapour pressure in the head space of the chamber.

\footnotetext{
${ }^{17}$ N.B. range varies a bit between instruments, can be up to either -90 or $-100 \mathrm{MPa}$
} 
Both solutes and matrix affect the reading, hence the device measures both osmotic and matric potential. The thermocouple psychrometer is mainly used for in-situ measurements. The range of measurement is 0 to $-6 \mathrm{MPa}$. The dew potentiometer operates in a similar way as the psychrometer, where by a sample equilibrates with a headspace in a chamber and the vapour pressure, dew point temperature and sample temperature are measured. The soil water potential is approximately linearly related to the difference between sample temperature and dew point temperature. The measurement range is 0 to $-300 \mathrm{MPa}$ for 515 minutes measurement time and is excellent in dry soils (Dane et al., 2002).

\subsubsection{Measurement of matric potential at Wairio wetlands}

The measurement of matric potential at Wairio wetlands was carried out using UMS T4e tensiometers. The choice of sensors was based on the desired sampling frequency and characteristics of the wetland soil. Wairio wetlands are characteristically ephemeral, i.e. they are flooded in winter and can be very dry in summer. The ephemeral nature of the wetlands meant we had to consider sensors that can optimally operate under very wet (flooded) and dry conditions. The goal of the research was to capture both temporal and spatial variability of matric potential as a factor of land use.

Most sensors (e.g. gypsum blocks, thermal matric sensors, dew point potentiometer) fail to accurately measure matric potential in a very moist range, which are a characteristic of Wairio wetland soils in winter. However, tensiometers have the highest accuracy of any sensor in the wet range. For this reason, the UMS T4e tensiometers custom made (Teflon membrane at the end of a long cable) for inundated conditions were chosen. The T4e tensiometers used for this research comprise of a $40 \mathrm{~cm}$ long a blue acrylic glass shaft attached to a semi-permeable ceramic (Al203) cup. Within the glass shaft, there are two stainless steel capillary tubes extending through to the ceramic cup and a pressure transducer located at the end of the shaft close the ceramic cup. The stainless steel capillary tubes allow refilling of the T4e tensiometers while in the ground.

The choice of these sensors was however made at the expense of the reliability of the measurements during summer. Dry soil conditions that are typical of the summer season 
trigger cavitation ${ }^{18}$ of tensiometers. To assure reliable measurements during the dry period, refilling of the tensiometers was carried out regularly with degased water. The tensiometers work within a range of $+100 \mathrm{kPa}$ (water pressure) to $-85 \mathrm{kPa}$ (suction pressure).

A total of six tensiometers were installed on July $28^{\text {th }} 2014$, in three plots (two tensiometers per plot) (Table 15). Two of the plots were planted with a mixture of tree species (blocks 7 and 9) and one was unplanted (block 13) (Table 15). UMS T4e tensiometers were installed vertically into $2 \mathrm{~cm}$ diameter holes at a $30^{\circ}$ angle and at a depth of 10 and $30 \mathrm{~cm}$ below the soil surface in each of the three plots (Image 14). An angle between $25-65^{\circ}$ is appropriate when vertically installing so as to keep the tensiometer cup free of air for fast response to the changes in tension.

The refilling tubes, part of the acrylic glass shaft and the sensor cable were covered with a thermal insulation tube as a protection measure against UV radiation (Image 14). Solar radiation causes trapped air in the refilling tubes to expand, thereby reducing water tension and causing high variation of readings. Moreover, solar radiation causes discoloration of the refilling tubes.

\footnotetext{
${ }^{18}$ When excess water flows out of the tensiometer, gas bubbles occupy the tensiometer reservoir, causing decrease in pressure and liquid rapture, resulting in malfunctioning of the device.
} 
a. Tensiometers at 10 and $30 \mathrm{~cm}$ depths b. Tensiometers covered with thermal insulation tubes

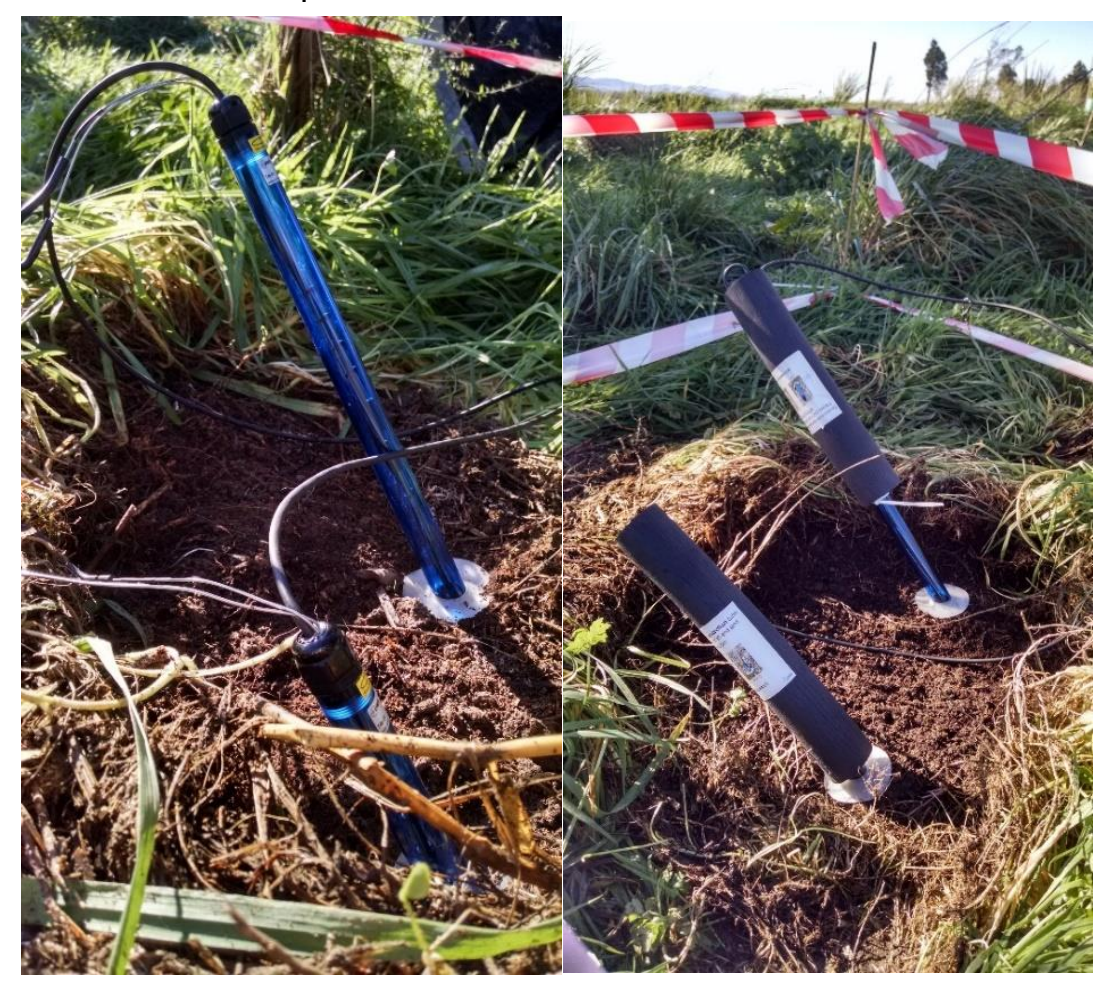

Image 14. Tensiometers at 10 and $30 \mathrm{~cm}$ soil depth (a) with refilling tubes, sensor cable and part of the shaft covered with thermal insulation tubes (b) in an unplanted plot of block 13. Image taken by Author in August 2015. 
Tensiometers at each plot were connected to the CR 1000 data loggers (Campbell Scientific, Logan, UT, USA) powered by a 12 volt battery for continuous measurements (Image 15). The data loggers were programmed to record soil suction pressure at five minute intervals. CR 1000 data loggers read sensor input, transmit through communication peripherals and store the data through storage peripherals. Data was downloaded from the data loggers once every fortnight during which refilling was carried out if the tensiometers were empty. A challenge faced during refilling was that it was difficult to see if bubbles formed inside the blue glass shaft.

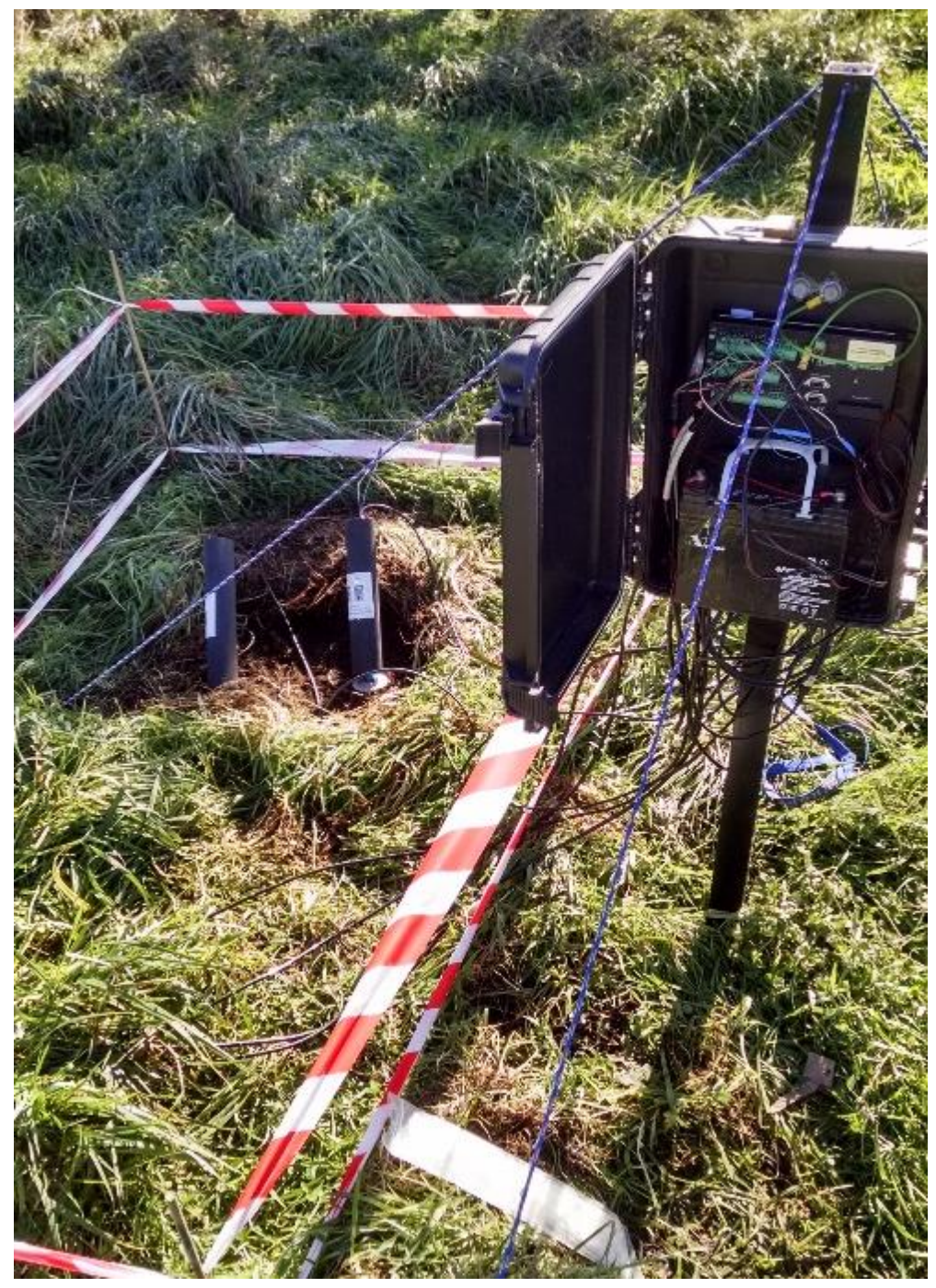

Image 15. Tensiometers connected to a CR 1000 data logger powered by a $12 \mathrm{~V}$ battery in an unplanted plot of Block 13. Image taken by Author in August 2014. 


\subsubsection{Estimation of soil moisture characteristic curves}

The measurement of soil moisture retention can be carried out through direct and indirect determination of soil moisture retention curves. The basic requirement for most direct and indirect methods is paired of soil moisture and matric potential data. Direct methods such as the use of tempe cells, suctions plates, filter paper and soil water plate extractors are labour intensive and time consuming (Wei et al., 2011; Wang et al., 2013). Some indirect methods estimate water retention curves from relating readily available soil data such as bulk density, organic matter content and particle size distribution (commonly known as pedotransfer functions) instead of using matric potential and soil moisture data directly. Various approaches can be used to predict the soil moisture retention curves from pedotransfer functions and measured matric potential and soil moisture data. These include discrete regression methods, functional regression methods and semi-physical approaches (Haverkamp et al., 1999). This section will only discuss the functional regression approach because it is suitable for the matric potential and soil moisture data recorded specifically for the estimation of soil moisture retention in this research. The semi-physical and discrete regression approaches are mostly used on pedotransfer functions (Jauhiainen, 2004).

Functional regression approaches express the soil moisture content as a function of matric potential through fitting models using the least squares approach to give a continuous functional description of the moisture retention curve (Wei et al., 2011). The two most common functional regression approaches are the van Genuchten model (1980) and Brooks and Corey model (1964).

The Brooks and Corey model is denoted as follows:

$$
\theta_{\psi_{m}}=\theta_{r}+\frac{\theta_{s}-\theta_{r}}{\left(\propto . \psi_{m}\right)^{\lambda}}
$$

Where,

$\theta_{\psi_{m}}=$ moisture content at matric potential

$\theta_{r} \quad=$ residual water content (usually fitted to the measured data)

$\theta_{S}=$ saturated water content at zero matric potential 
$\propto \quad$ = fitting parameter related to the inverse of the air entry suction

$\lambda=$ parameter related to the soil pore size distribution

$\psi_{m}=$ matric potential

The Brooks and Corey model assumes that there is a close relationship between the largest soil pores and the air entry suction (matric suction at which air starts to penetrate into the soil). The major drawback of the Brooks and Corey model is that there is discontinuity at the air entry suction and this may result in the inaccurate representation of the moisture curve in the wet range (Jauhiainen, 2004).

The van Genuchten model removes the drawbacks of the Brooks and Corey model by including the $m$ fitting parameter which allows better performance in the wet range. The van Genuchten model is denoted as follows:

$$
\theta_{\psi_{m}}=\theta_{r}+\frac{\theta_{s}-\theta_{r}}{\left(1+\left[\propto . \psi_{m}\right]^{n}\right)^{m}}
$$

$n=$ parameter describing the shape of the curve and is estimated from the measured data $m=$ parameter describing shape of function and can be assumed to be equal to $1-1 / n$ This research adopted the van Genuchten model to relate the measured soil moisture and matric potential data. 


\subsubsection{Estimation of an approximate water balance}

A simple water balance model for Wairio was created to indicate the potential water storage capacity by accounting for water flow in and out of the wetland in relation to the observed temporal variation in soil moisture content. This was carried out using daily rainfall data from the GWRC climate station on the eastern shore of Lake Wairarapa $(1 \mathrm{~km}$ west of Wairio, Map 2Error! Reference source not found.) for the 2014/2015 monitoring period. Daily potential evapotranspiration (PE) estimates were obtained from NIWA's CliFlo database system (http://cliflo.niwa.co.nz). The PE estimates are derived from NIWA's Martinborough climate station (Map 2) and were calculated using the FAO56 PenmanMonteith method based on measured air temperature, wind speed, humidity, radiation and properties of a hypothetical grass 'reference' crop. It is important to highlight that this water balance is an approximation and subject to error. For example, the Martinborough climate station is the closest station to the Wairio wetland (about $35 \mathrm{~km}$ east of Wairio wetland) for which data was available. It has a drier climate than Wairio and thus is not a perfect representation of conditions at the wetland site. The rainfall data from the GWRC climate station is measured using a tipping bucket rain gauge which tends to underestimate the amount of rainfall for heavy events, hence there could be some errors in the data. Another uncertainty can be introduced during estimation of parameters used to quantify components of the water balance. Estimation of model parameters is often sensitive and challenging due to uncertainties associated with determination of parameter values that cannot be obtained straight from the field (Deus et al., 2013). A sensitivity analysis was carried out to test the uncertainty and impact on soil moisture modelling of the estimated sub-surface drainage, drainable water, maximum infiltration rate and maximum soil moisture deficit parameters. The parameters were varied between maximum and minimum values. 


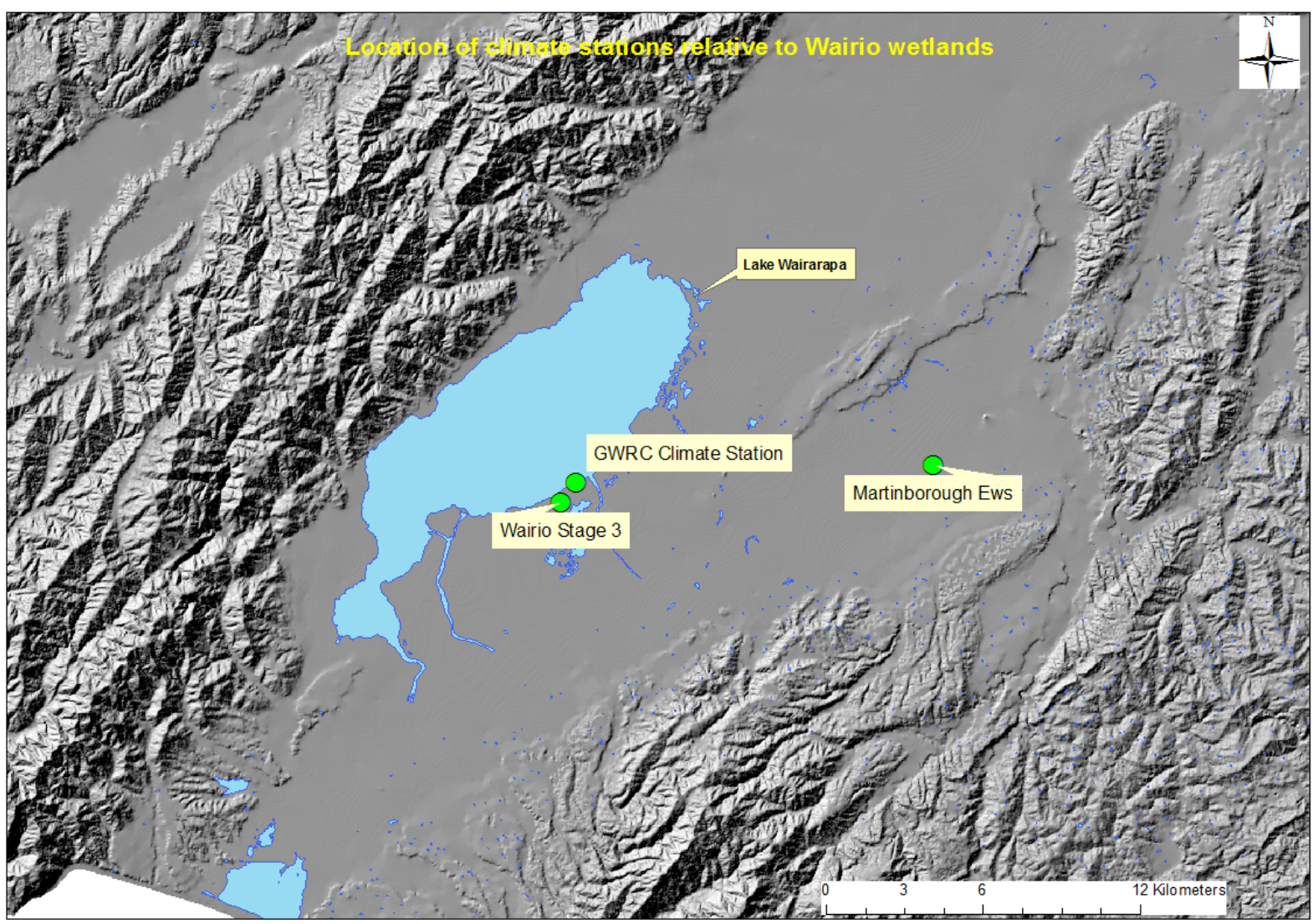

Map 2 Location of GWRC and Martinborough Ews climate stations from where rainfall and evapotranspiration data were derived

A conceptual model of the soil water balance of Wairio is shown in Figure 10. Water can be added to the soil via rainfall or lateral inflow and is lost through transpiration and evaporation (evapotranspiration) or as runoff and sub-surface outflow to streams. The amount of water transpired by plants and lost through evaporation in the presence of abundant water is the potential evapotranspiration. If the amount of water in the system is limited, the actual evapotranspiration is lower than potential evapotranspiration. The simplified water balance equation for the wetland site is represented as:

$$
d S=P+Q \text { in }-(Q o u t+A E+D+R o)
$$

Where:

dS = Changes in wetland water amount

$P \quad=$ Precipitation $(\mathrm{mm})$

Qin = Surface and sub-surface flow to the wetland $(\mathrm{mm})$

Qout = Sub-surface out flow out of the wetland $(\mathrm{mm})$ 


$$
\begin{array}{ll}
A E & =\text { Actual Evapotranspiration }(\mathrm{mm}) \\
D & =\text { Sub-surface drainage }(\mathrm{mm}) \\
R o & =\text { Overland flow (Hortonian flow, Qhort + Saturation excess flow, Qsat) }
\end{array}
$$

For the Wairio water balance, both Qin and Qout are assumed zero. Inference of these components is carried out by analysing components of the water balance and assessing if there are any inconsistences between the modelled and sensor measured soil moisture content. Under the (not necessarily safe) assumption that the input rainfall and evapotranspiration data do not contain significant errors, if the modelled soil moisture is unexpectedly wetter than the sensor measured soil moisture, sub-surface outflow can be inferred. If the sensor measured moisture is unexpectedly higher than the modelled, then sub-surface inflow can be inferred.

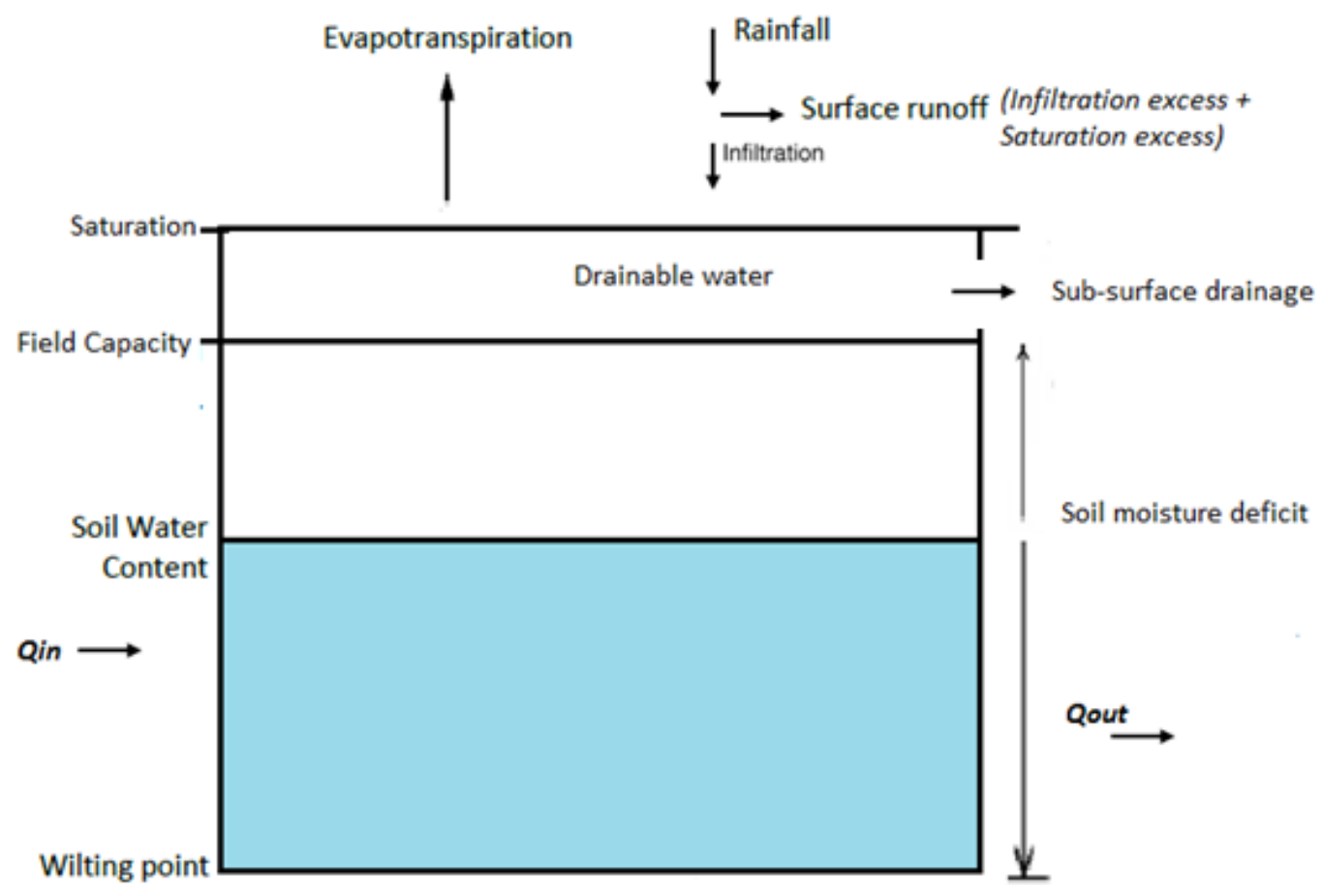

Figure 10 Conceptual model of the inflow and outflow of water through the soil

Precipitation can infiltrate into the soil up to a maximum infiltration rate. The maximum infiltration rate is determined through measured hydraulic conductivity at Wairio and is 
estimated to be between $504-768 \mathrm{~mm} /$ day (Table 17). Any rainfall which exceeds this maximum contributes to infiltration excess overland flow (Hortonian flow, Qhort).

Infiltrated rainfall fills up the soil and determines the amount of soil water available for drainage and actual evapotranspiration. The maximum total plant available water in the soil is represented by the maximum soil moisture deficit $\left(S M D_{\max }\right)$ which is determined from the difference between soil moisture content at field capacity and wilting point down to the rooting depth (Table 17). The rooting depth was taken as $400 \mathrm{~mm}$ for the wetland because roots were observed within this depth and not beyond. Normally, roots access water from 50-100 $\mathrm{mm}$ below the surface.

If soil water is readily available to satisfy the atmospheric demand (potential evapotranspiration), actual evapotranspiration is considered to be equal to potential evapotranspiration. Soil water can satisfy the potential evapotranspiration down to a critical point, below which it becomes difficult to extract. This actual evapotranspiration (AE) is estimated as a function of potential evapotranspiration and the available soil moisture content. This is calculated using the following equation:

$$
A E(i)=P E(i) *\left(\frac{S M D \max -S M D(i)}{S M D \max }\right)
$$

Where:

$A E(i) \quad=$ Actual evapotranspiration at time step $(i)(\mathrm{mm})$

$P E(i) \quad=$ Potential evapotranspiration at time step $(i)(\mathrm{mm})$

$\operatorname{Max} S M D=$ Maximum soil moisture deficit $(\mathrm{mm})$

SMD $(i) \quad=$ Soil moisture deficit at time $\operatorname{step}(i)(\mathrm{mm})$

Soil moisture deficit was estimated using the following equation:

$S M D(i+1)(m m)=\max (S M D(i)+A E(i)-\operatorname{Infil}(i), 0)$

Where:

$\operatorname{SMD}(i+1)(\mathrm{mm}) \quad=$ Soil moisture deficit at a given time step $i+1$

$S M D(i) \quad=$ Soil moisture deficit at the previous time step $(\mathrm{mm})$ 


$$
\begin{array}{ll}
\operatorname{Infil}(i) & =\text { Infiltration at time } \operatorname{step}(i)(\mathrm{mm} / \text { day }) \\
A E(i) & =\text { Actual evapotranspiration at given time }(i)(\mathrm{mm})
\end{array}
$$

This SMD accounts for water in the capillary zone.

Once the soil reaches field capacity, the surplus water between field capacity and saturation point can drain to the subsurface. The amount of drainable water (Dw) varies depending on precipitation, actual evapotranspiration, sub-surface drainage rate (Dsub) and maximum drainable water storage capacity (Dmax). The amount of drainable water is constrained by the maximum drainable water storage capacity of the soil. This constraint is estimated by the difference between the sensor measured moisture content at saturation and moisture content at field capacity (Table 17). How quickly the water drains from this store is represented by the sub-surface drainage rate (Dsub) which is a function of a soil's permeability. Soil permeability is estimated from hydraulic conductivity and values ranging from $1.2-12 \mathrm{~mm} /$ day were used from measurements at Wairio (Table 17). The drainable water is therefore calculated as follows:

$$
D w(i+1)=D w(i)+P(i)-A E(i)-D s(i)
$$

Where,

Dw $\quad$ = Drainable water at the next time step $(\mathrm{mm})$

$D w(i) \quad=$ Drainable water at time step $(i)(\mathrm{mm})$

$P(i) \quad=$ Precipitation at time step $(i)(\mathrm{mm})$

$A E(i) \quad=$ Actual evapotranspiration at time step $(i)(\mathrm{mm})$

$\operatorname{Ds}(i) \quad$ = Sub-surface drainage $(\mathrm{mm})$ (up to a maximum of Dsub)

The drainable water is subject to a constraint such that if Dw $\geq D$ max, any remaining water is lost as saturation excess overland flow (Qsat). 
Therefore total overland flow (Ro) includes both Hortonian and saturation excess overland flows and is estimated as follows:

$$
\operatorname{Ro}(i)=Q \operatorname{hort}(i)+Q \operatorname{sat}(i)
$$

Table 17 Parameters for the water balance

\begin{tabular}{lccc}
\hline & \multicolumn{3}{c}{ Treatment/Land use } \\
\hline Parameters & $\begin{array}{c}\text { Mixed species } \\
\text { (high slope) }\end{array}$ & $\begin{array}{c}\text { Unplanted } \\
\text { (high slope) }\end{array}$ & $\begin{array}{c}\text { Mixed species } \\
\text { (low slope) }\end{array}$ \\
\hline Max SMD (mm) & 90.4 & 88.4 & 53.2 \\
Max Infiltration (mm/day) & 768 & 528 & 504 \\
Sub-surface drainage rate (mm/day) & $1.2-12$ & $1.2-12$ & $1.2-12$ \\
Max drainable water storage $(\mathrm{mm})$ & 14 & 20 & 30 \\
& & & \\
\hline
\end{tabular}

Modelled soil moisture in $(\mathrm{mm})$ at time $(i)$ is estimated by SMD max $-\mathrm{SMD}(i)+\operatorname{Dw}(i)$

To compare the modelled soil moisture content to the sensor measured volumetric soil moisture, the modelled soil moisture was converted to volumetric moisture content using the following equation

$$
\frac{\text { Modelled soil moisture } *(\theta w p+(\theta s-\theta w p)}{S M D \max +D \max }
$$

where,

$\theta w p \quad=$ Moisture content at wilting point

$\theta s \quad=$ Moisture content at saturation 


\subsection{Analysis of data}

Comparative analyses and descriptive statistics were performed using SPSS software version 20 (SPSS Inc., Chicago USA). The data were first checked for normality using the Kolmogorov-Smirnov and Shapiro-Wilk statistical tests. For small sample size data, i.e. saturated hydraulic conductivity, Lilliefors test for normality was used as it is more appropriate (Yazici \& Yolacan, 2007; Rienzner \& Gandolfi, 2014). Homogeneity of variance was tested using the Levene's test to determine whether parametric or non-parametric tests would be suitable for analysis. For the data that did not meet the assumptions of normality, histograms were checked for distributions. If the histograms were fairly normal with a slight skew to the left or right, parametric tests were still used because sample sizes were high (more than 100) for most data sets (Elliot \& Woodward, 2007; Ghasemi \& Zahediasl, 2012). Highly skewed data such as field saturated hydraulic conductivity was normalised through log transformations.

To determine significant differences in soil bulk density, volumetric moisture content, saturated hydraulic conductivity and soil organic carbon under all land use types, ANOVA for linear mixed effects model was used. Linear mixed effects models have the ability to accurately model the contribution of random factors, can analyse data collected at varying time points and fit different variances for each treatment group (Bolker et al., 2008). The mixed effects model is represented as:

$$
y=X \beta+Z u+\epsilon
$$

$y=$ dependent variable

$X=$ the matrix of predictor variables/fixed effects with corresponding regression coefficient vector $\beta$

$Z=$ the random effects design matrix

$u=$ the vector of random effects

$\epsilon=$ the vector of errors 
In this research, data was collected at varying time points and random factors such as block exist, hence linear mixed effects models are suitable for analysis. Block was used as a random effect because only a few blocks were selected from all the available blocks.

Block was used as a random effect in the analysis of the effect of fixed factors (land use, slope gradient, soil depth and stage of restoration) affecting the soil hydraulic and physical properties. The Fisher's LSD test was used for post hoc comparisons when needed.

Water retention was analysed under the different land use types using the van Genuchten model (van Genuchten, 1980). The non-linear least squares approach was used to fit the van Genuchten parameters to the measured soil moisture and matric potential (log transformed) data. The fitting was performed in Microsoft Excel 2013 and the non-linear solver function was used to minimise the sum of squared errors. 


\subsection{Results}

This section presents the outcomes of the analysis of the effect of land use on bulk density, saturated hydraulic conductivity, soil organic carbon, volumetric soil moisture content and matric potential under varying topography and soil depth. Implications of the results are presented in the discussion section 4.6.

\subsubsection{Bulk density}

The compared land use types are located in stages 2 and 3, which are different in terms of when grazing was excluded and trees were planted, but similar in geology and soil type. Stage 2 was fenced off from grazing in 2007 but the older trees are all in stage 3 (the more recently fenced off in 2009). Nevertheless, it was reasonable to investigate the authenticity of the similarities (i.e. geology and soil type) to enhance the understanding of variability in bulk density in response to restoration.

The contribution of the stage of restoration to the variability of bulk density under the four land use types was not significant (Table 18).

Table 18 Fixed effects test of the effect of stage of restoration of the land use types on bulk density

\begin{tabular}{lcccc}
\hline Source & Numerator df & Denominator df & $\mathrm{F}$ & $p$ \\
\hline Intercept & 1 & 7.3 & 1323.28 & $<0.001$ \\
Stage & 1 & 6.1 & 0.553 & 0.485 \\
Land use & 3 & 272.3 & 3.888 & 0.010 \\
Land use * Stage & 2 & 384.100 & 4.729 & 0.09 \\
\hline
\end{tabular}

There was a significant effect of land use on bulk density and the relationship was significantly influenced by differences in soil depth and slope (Table 19). Block was included as a random factor and the syntax for the analysis is shown in Appendix 1.

Table 19 Fixed effects test for the effect of land use, soil depth and slope on bulk density

\begin{tabular}{lcccc}
\hline Source & Numerator df & Denominator df & $\mathrm{F}$ & $p$ \\
\hline Intercept & 1 & 7.3 & 1323.28 & $<0.001$ \\
Land use & 3 & 272.3 & 3.9 & 0.010 \\
Soil depth & 1 & 468.3 & 607.92 & $<0.001$ \\
Slope & 2 & 101.1 & 16.17 & $<0.001$ \\
Land use * Soil depth & 3 & 468.4 & 8.07 & $<0.001$ \\
Land use * Slope & 4 & 328.6 & 2.75 & 0.028 \\
\hline
\end{tabular}


4.5.1.1 Bulk density as a function of soil depth under the different land use types

The general trend for the soil bulk density under the four different land use types ${ }^{19}$ was an increase with depth from 6 to $18 \mathrm{~cm}$ (Figure 11). In the upper $6 \mathrm{~cm}$ depth, the bulk density for all soils under the four different land uses ranged widely from 0.461 to $2.034 \mathrm{gcm}^{-3}$. The average bulk density in unplanted and manuka sites was significantly lower than that in planted and cabbage tree sites (Figure 11; Appendix 2).

At $18 \mathrm{~cm}$ depth, the bulk density for all soils under the four land use types ranged widely from 0.701 to $2.275 \mathrm{gcm}^{-3}$. Soils planted with cabbage trees had significantly higher mean bulk density than soils in unplanted sites (Figure 11; Appendix 2).The average bulk density in unplanted sites was similar to that of planted and manuka sites (Figure 11; Appendix 2).

\footnotetext{
${ }^{19}$ Unplanted- land use comprising of wetland sedges, turfs and grasses Planted- land use planted with a mixture of tree species (16 or 64 or 48 per plot) Cabbage- land use comprising of cabbage trees only at 49 stems per plot Manuka- land use comprising of manuka trees only at 49 stems per plot
} 


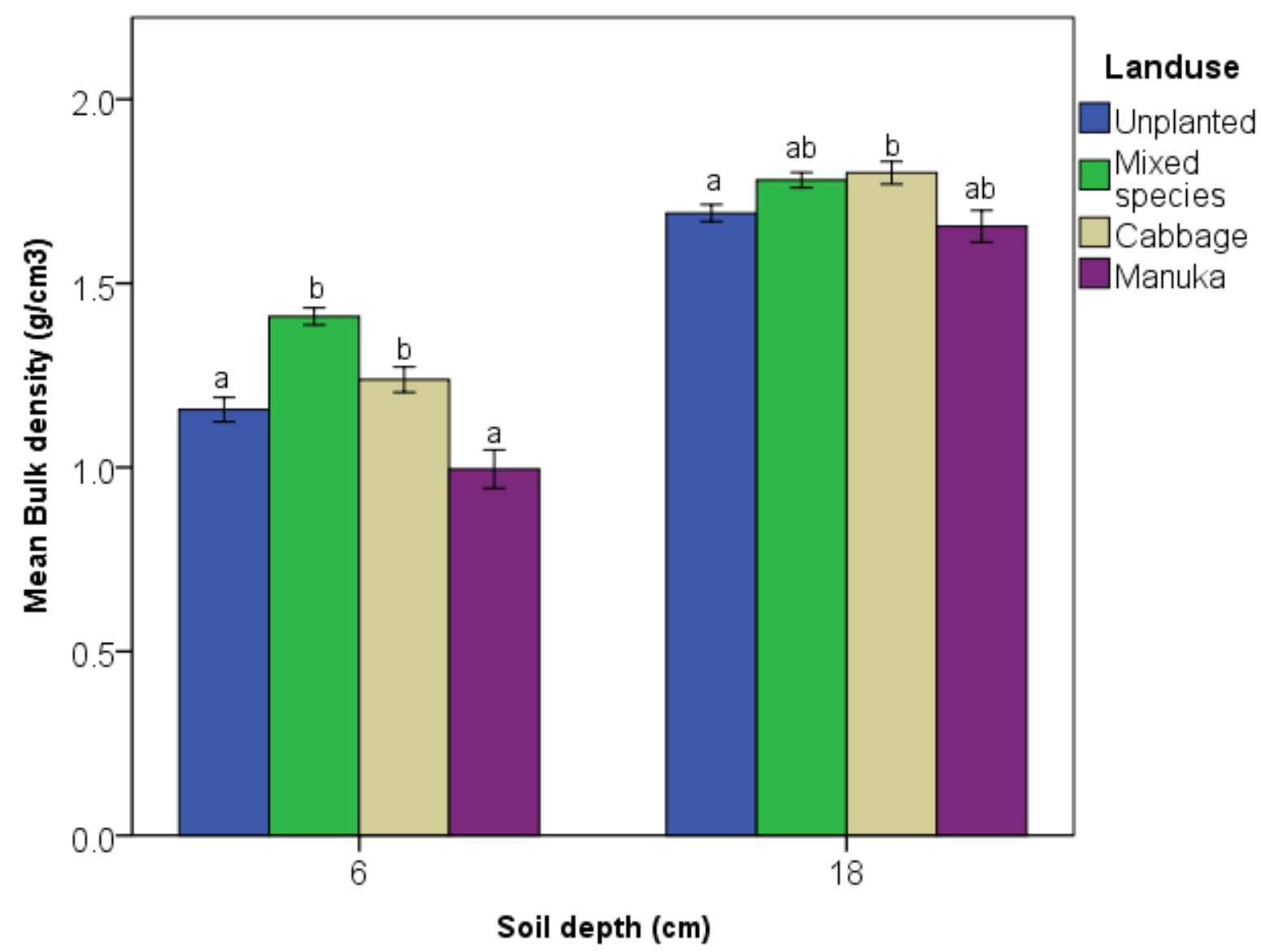

Figure 11. Mean (+/- $\left.1 \mathrm{SE}^{20}\right)$ bulk density of the soil at different depths under the land use types. Different letters indicate significant differences between land use types within each depth based on LSD post-hoc comparisons.

4.5.1.2 Effect of slope gradient on bulk density under the different land use types

All land use types are present on the three slope classes ${ }^{21}$ except at $6 \%$ slope gradient, where only manuka and unplanted sites are present. Therefore, comparisons at $6 \%$ slope gradient were between manuka and unplanted sites.

Pairwise comparisons showed that under $3 \%$ slope, manuka sites had significantly lower bulk density than unplanted, planted and cabbage tree sites at $6 \mathrm{~cm}$ depth (Figure 12; Appendix 3). Unplanted plots and plots with cabbage trees had similar average bulk densities but lower than planted sites at $6 \mathrm{~cm}$ depth (Figure 12; Appendix 3). At $18 \mathrm{~cm}$ depth, the average bulk density under cabbage tree sites was significantly higher than that in unplanted, planted and manuka sites on 3 \% slope (Figure 12; Appendix 3; Appendix 4).

\footnotetext{
${ }^{20}$ The error bars define the interval around the true measure within which $68 \%$ of the measurements fall within $+/-1$ standard error

${ }^{21}$ Slope gradient classes $3 \%$ 
At $6 \%$ slope there were no significant differences in average bulk densities unplanted and manuka sites under both 6 and $18 \mathrm{~cm}$ depths (Figure 12; Appendix 3; Appendix 4). At $8 \%$ slope, unplanted sites had significantly lower average bulk density than planted, cabbage tree and manuka sites within the first $6 \mathrm{~cm}$ soil depth. Soils planted with manuka species had higher bulk density than those planted with cabbage trees and a mixture of tree species, respectively within the $6 \mathrm{~cm}$ depth. There were no significant differences between the four land use types at $18 \mathrm{~cm}$ depth (Figure 12; Appendix 3; Appendix 4). 


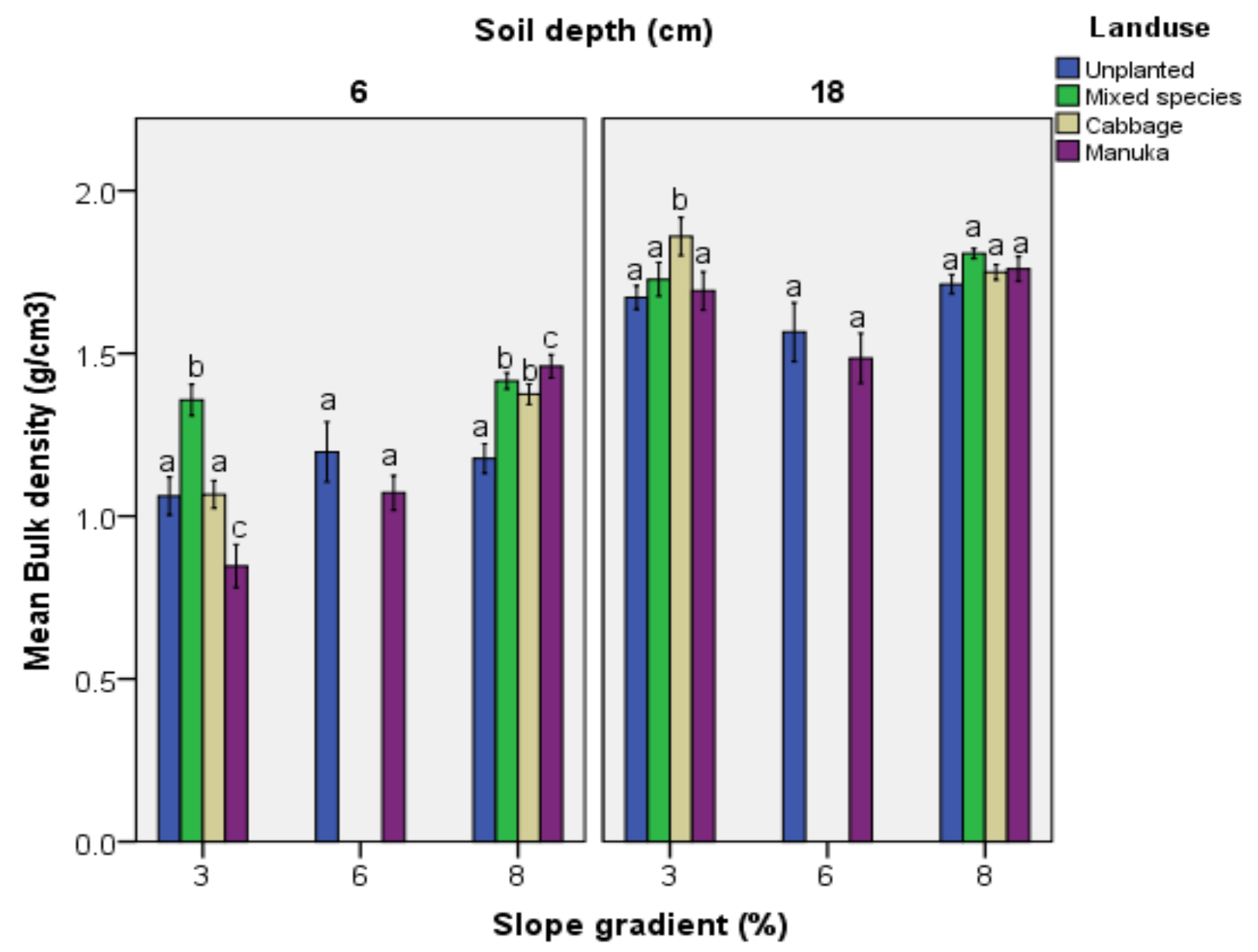

Figure 12. Mean (+/- $1 \mathrm{SE}$ ) bulk density of the four land use types at varying slope gradients and soil depths. Different letters indicate significant differences between land use types at varying slopes within each depth based on LSD posthoc comparisons.

\subsubsection{Effect of the age of land use}

The pairwise comparisons of specific land use types at different ages could not give more information other than that similar to the comparisons between land use types because each land use has a distinctive age. For example, the mean bulk density was lower for established $^{22}$ (unplanted) land use than 1-2 years (cabbage and manuka) and 3-4 years old (mixed tree species) at $6 \mathrm{~cm}$ soil depth.

\subsubsection{Change in bulk density over time under the land use types at 6 and $18 \mathrm{~cm}$ soil depths}

There is no obvious trend in bulk density over time at 6 and $18 \mathrm{~cm}$ soil depths, however, there is a slight decline in the sites planted with a mixture of tree species in block 9 , at $6 \mathrm{~cm}$ depth (Figure 13).

\footnotetext{
${ }^{22}$ Approximately 100 years old
} 
Soil depth (cm)

Block

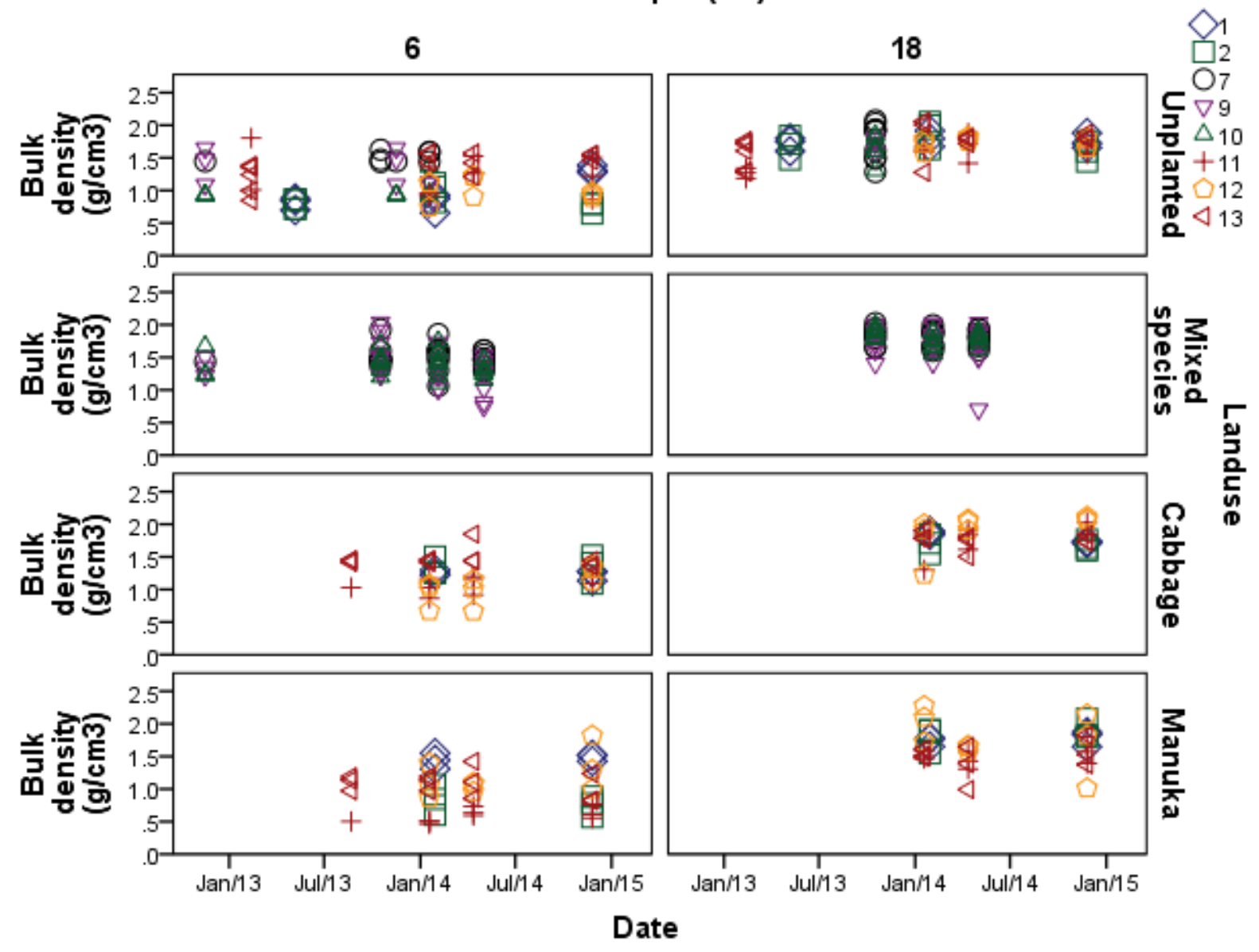

Figure 13. Change in bulk density over time under different land use types at 6 and $18 \mathrm{~cm}$ soil depths 


\subsubsection{Field saturated hydraulic conductivity}

\subsubsection{Characteristics of the saturated hydraulic conductivity data}

A total of 22 measurements of hydraulic conductivity measurements were carried out in unplanted sites, 20 in sites planted with mixed tree species, 15 in sites planted with manuka and 14 in sites planted with cabbage trees. The Lilliefors test for normality showed that with the exception of manuka sites, the data from unplanted, planted and cabbage tree sites was not normally distributed at a significance level of 0.05 . The datasets were log-transformed and the normality test was run again, giving the following results; at unplanted sites, kstat = $0.149, p=0.200$; at planted sites, kstat $=0.222, p=0.011$; at cabbage sites, kstat $=0.149, p=$ 0.200 ; at manuka sites, kstat $=0.113, p=0.200$. The hypothesis for normal distribution of the log-transformed data was not rejected at a significance level of 0.05 for all but the planted land use type. Data from the planted sites that did not pass the normality test were checked for outliers and the legitimate ones were winsorised ${ }^{23}$ (Ghosh \& Vogt, 2012).

4.5.2.2 The effect of land use on saturated hydraulic conductivity of Wairio wetland soils

There was a significant effect of land use on saturated hydraulic conductivity but this effect was not significantly influenced by the change in slope (Table 20; Appendix 5).

Table 20 Fixed effects test for the effect of land use and slope on saturated hydraulic conductivity

\begin{tabular}{lcccc}
\hline Source & Numerator df & Denominator df & $F$ & $p$ \\
\hline Intercept & 1 & 3.4 & 40.94 & 0.005 \\
Land use & 3 & 58.5 & 3.26 & 0.028 \\
Slope & 2 & 6.2 & 1.53 & 0.288 \\
Land use * Slope & 1 & 61.4 & 2.60 & 0.112 \\
\hline
\end{tabular}

The Fisher's Least Significant Difference showed that the differences in the effect of land use were mainly between unplanted and planted areas (Table 21; Figure 14; Appendix 5).

\footnotetext{
${ }^{23}$ A process whereby legitimate outlier values are assigned the next highest or lowest value found in the sample that is not an outlier
} 
Table 21 Statistical description of saturated hydraulic conductivity $(\mathrm{mm} / \mathrm{hr})$ under different land use types

\begin{tabular}{lllll}
\hline Parameters & Unplanted & Planted & Cabbage & Manuka \\
\hline Arithmetic mean & 4.91 & 9.70 & 11.57 & 7.17 \\
Standard deviation & 6.24 & 8.71 & 9.65 & 6.67 \\
Median & 2.28 & 6.84 & 6.77 & 5.80 \\
Minimum & 0.07 & 0.47 & 1.94 & 0.32 \\
Maximum & 22.80 & 22.80 & 31.9 & 21.0 \\
Arithmetic Mean $^{\mathrm{a}}$ & 1.30 & 1.91 & 2.23 & 1.72 \\
Standard Deviation $^{\mathrm{a}}$ & 0.99 & 1.08 & 0.82 & 0.96 \\
Number of samples $^{2}$ & 22 & 20 & 14 & 15 \\
\hline
\end{tabular}

a Parameters for decadic log transformed data sets.

Comparisons using box plots show high median, upper and lower quartiles for soils planted with cabbage trees. Saturated hydraulic conductivity increased from unplanted sites to manuka, planted and cabbage tree sites by 24-42 \% (Table 21; Figure 14). 


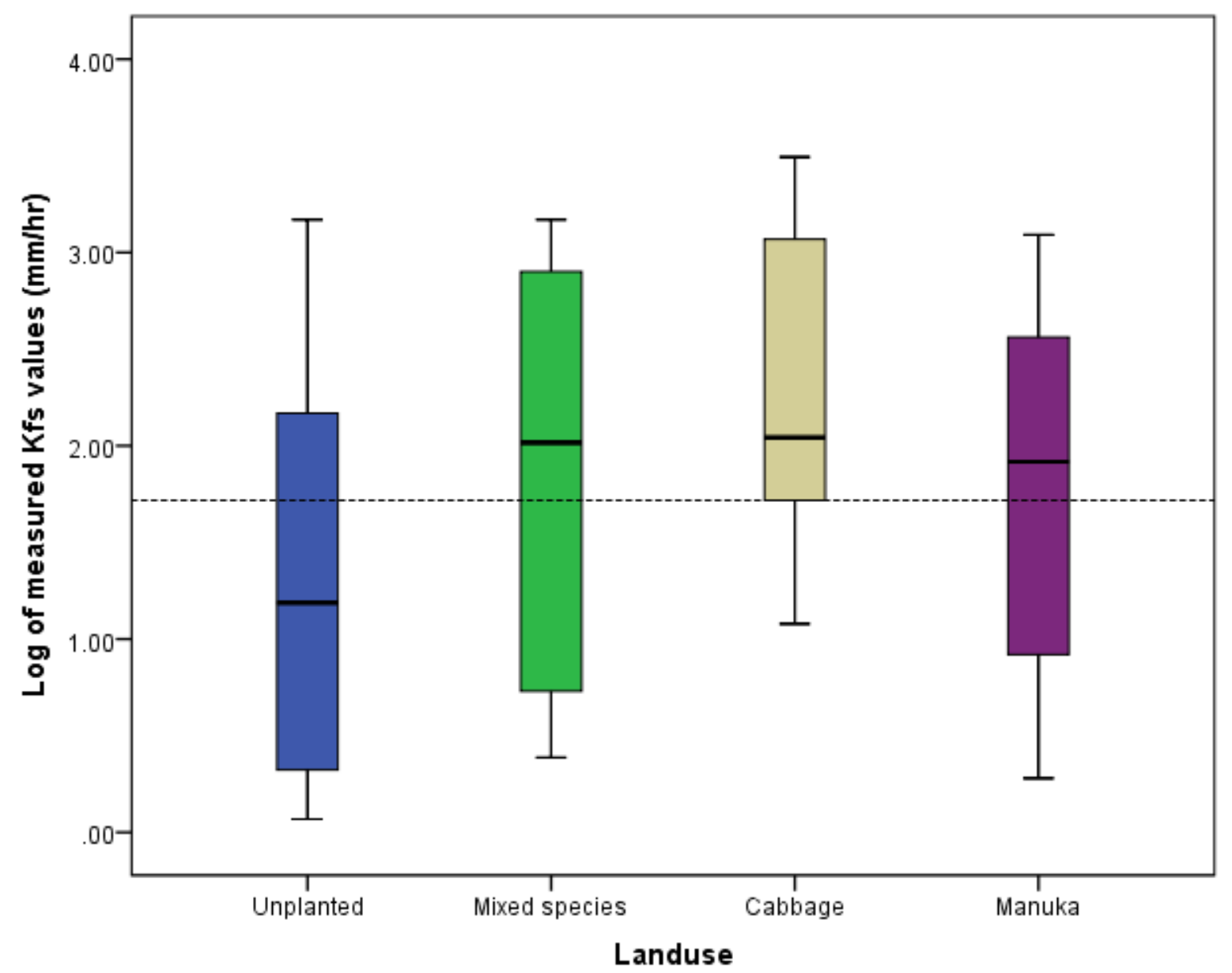

Figure 14. Box plots showing minimum, lower quartile, median, upper quartile and maximum values of decadic log transformed Kfs values of soils under unplanted, planted, cabbage and manuka sites. The dotted line represents the median of all measured values. 


\subsubsection{Soil organic carbon}

Mixed model analysis (syntax, Appendix 7) showed that land use significantly affected soil organic carbon and this effect was significantly influenced by differences in soil depth and slope (Table 22). The stage of restoration in which the land use are placed, did not significantly contribute to the variation in soil organic carbon (Table 22).

Table 22 Fixed effects test for the effect of land use, soil depth, slope and stage of restoration on soil organic carbon

\begin{tabular}{lcccc}
\hline Source & Numerator df & Denominator df & $F$ & $p$ \\
\hline Intercept & 1 & 488 & 907.23 & $<0.001$ \\
Land use & 3 & 488 & 2.61 & 0.051 \\
Soil depth & 1 & 488 & 363.06 & $<0.001$ \\
Slope & 2 & 488 & 9.16 & $<0.001$ \\
Stage & 1 & 488 & 1.47 & 0.226 \\
Land use * Soil depth & 3 & 488 & 7.17 & $<0.001$ \\
Land use * Slope & 4 & 488 & 4.45 & 0.028 \\
Land use * Stage & 2 & 488 & 1.61 & 0.200 \\
\hline
\end{tabular}

4.5.3.1 Soil organic carbon as a function of soil depth under the different land use types

The average percentage of soil organic carbon decreased with the increase in soil depth from 6 to $18 \mathrm{~cm}$ under all four land use types (Figure 15). 


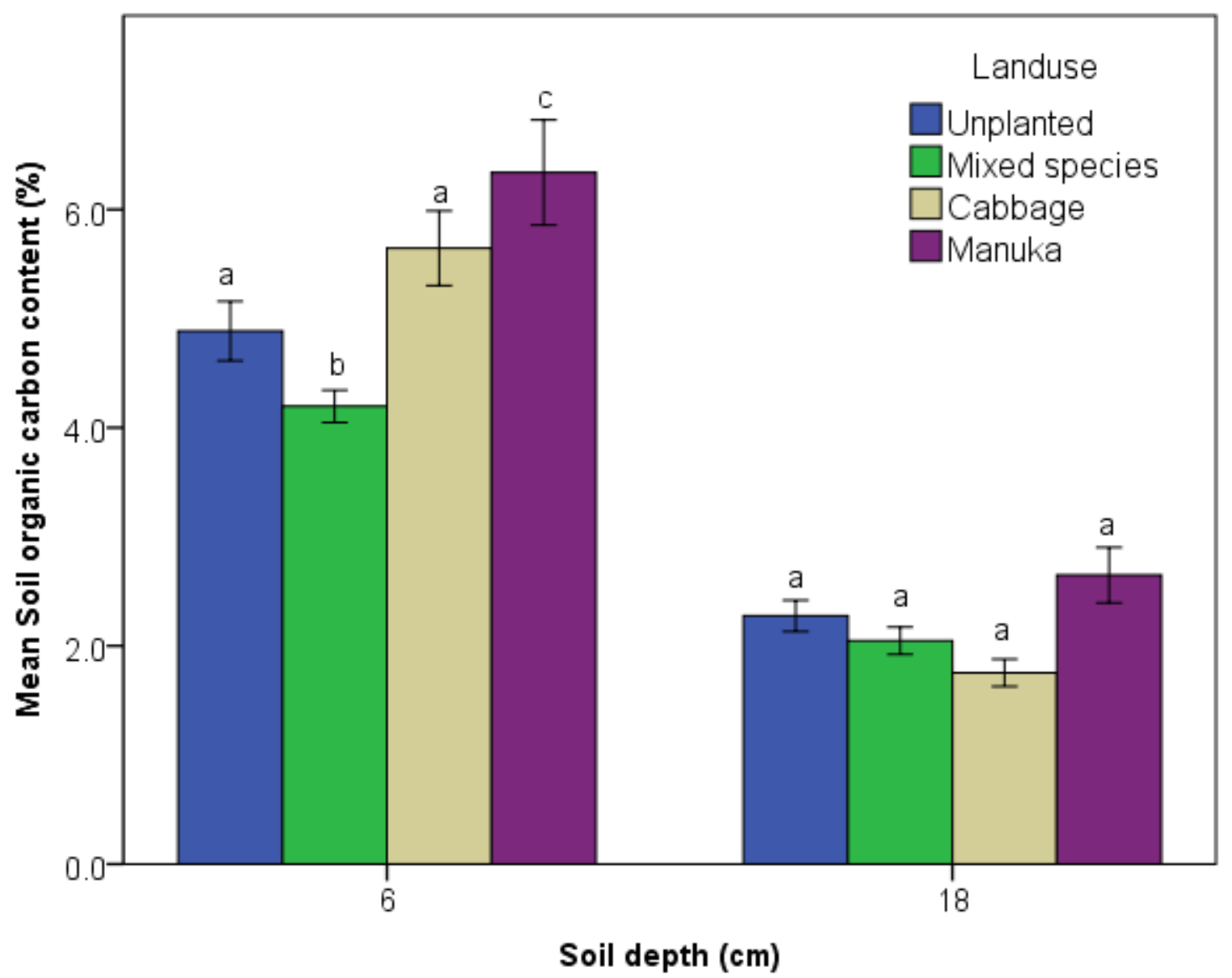

Figure 15. Mean (+/- $1 \mathrm{SE}$ ) soil organic carbon under four land use types at 6 and $18 \mathrm{~cm}$ soil depths. Different letters indicate significant differences between land use types within each depth based on LSD post-hoc comparisons.

Pairwise comparisons showed that soil organic carbon was significantly higher in manuka sites $(6.10 \%)$ than in unplanted $(5.07 \%)$, cabbage tree $(5.64 \%)$ and planted sites $(4.21 \%)$ at $6 \mathrm{~cm}$ depth (Figure 15; Appendix 8). Within $6 \mathrm{~cm}$ depth, unplanted and cabbage tree sites had higher soil organic carbon than planted sites (Figure 15; Appendix 8).

At $18 \mathrm{~cm}$ depth, the average soil organic carbon was similar between all land use types (Figure 15; Appendix 8).

\subsubsection{Effect of slope on soil organic carbon under the different land use types}

The interaction between land use type and slope gradient significantly influenced the soil organic carbon at both 6 and $18 \mathrm{~cm}$ soil depths (Table 22; Figure 16).

At $6 \mathrm{~cm}$ depth, the mean soil organic carbon in unplanted sites was higher at $3 \%$ slope $(5.68$ $\%)$ than at $6 \%(3.80 \%)$ and $8 \%(4.80 \%)$ slope gradients (Figure 16). Similarly, under manuka trees, soil organic carbon was higher at $3 \%$ slope gradient $(7.12 \%)$ than at $6 \%$ slope $(7.04 \%)$ and $8 \%$ slope (3.43\%) (Figure 16). In sites planted with a mixture of tree 
species, the mean soil organic carbon content was lower at $3 \%$ than at $8 \%$ slope gradient (Figure 16). In cabbage tree sites, the average soil organic carbon was higher at $3 \%$ slope than at $8 \%$ (Figure 16$)$.

At $18 \mathrm{~cm}$ depth, the average soil organic carbon decreased with the increase in slope from 3 $\%$ to $8 \%$ under unplanted, planted and manuka sites (Figure 16). In cabbage tree sites, the average soil organic carbon increased with slope from 3 to 8 \% (Figure 16).

Pairwise comparisons between land use types under varying slope gradient within $6 \mathrm{~cm}$ soil depth showed that at $3 \%$ slope gradient, the average soil organic carbon was higher in unplanted sites than in planted sites (Figure 16; Appendix 9). Manuka sites had significantly high soil organic carbon than unplanted and planted sites (Figure 16; Appendix 9).

\section{Soil depth (cm)}

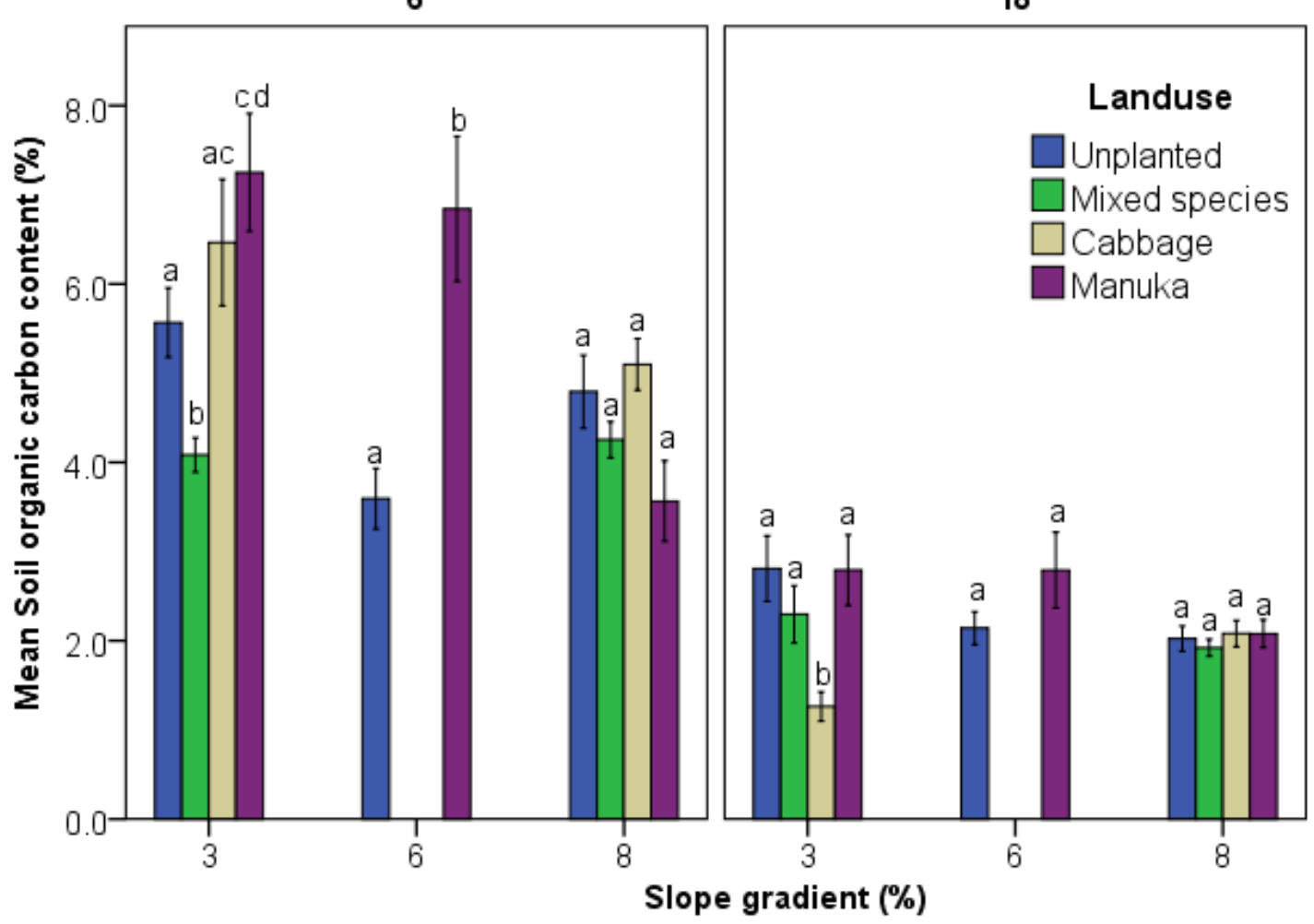

Figure 16. Mean (+/- 1 SE) soil organic carbon of land use types at varying slope and soil depth. Different letters indicate significant differences between land use types within each depth based on LSD post-hoc comparisons.

At $6 \%$ slope, manuka sites had significantly higher mean soil organic carbon than unplanted sites within the first $6 \mathrm{~cm}$ depth (Figure 16; Appendix 9). At $8 \%$ slope the average soil organic carbon was similar under the four land use types (Figure 16; Appendix 9). 
Pairwise comparisons within $18 \mathrm{~cm}$ depth showed that soils under cabbage trees had significantly lower mean organic carbon than unplanted, planted and manuka soils at $3 \%$ slope (Figure 16; Appendix 10). At 6 and $8 \%$ slope gradients, the soil organic carbon was similar between the land use types (Figure 16; Appendix 10).

\subsubsection{Soil organic carbon pools}

Soil organic carbon stocks decreased with increasing soil depth in all the four land use types when averaged across the three slope gradients (Figure 17). The highest soil organic carbon per unit area in the first $6 \mathrm{~cm}$ was observed in cabbage tree sites $\left(0.042 \mathrm{~kg} \mathrm{C} \mathrm{m}^{-2}\right)$, whereas the lowest was observed in unplanted sites $\left(0.031 \mathrm{~kg} \mathrm{C} \mathrm{m}^{-2}\right.$ ) (Figure 17). In 12-18 cm depth, the highest was observed in manuka sites $\left(0.025 \mathrm{~kg} \mathrm{C} \mathrm{m}^{-2}\right)$ and the lowest in cabbage tree sites $\left(0.018 \mathrm{~kg} \mathrm{C} \mathrm{m}^{-2}\right)$.

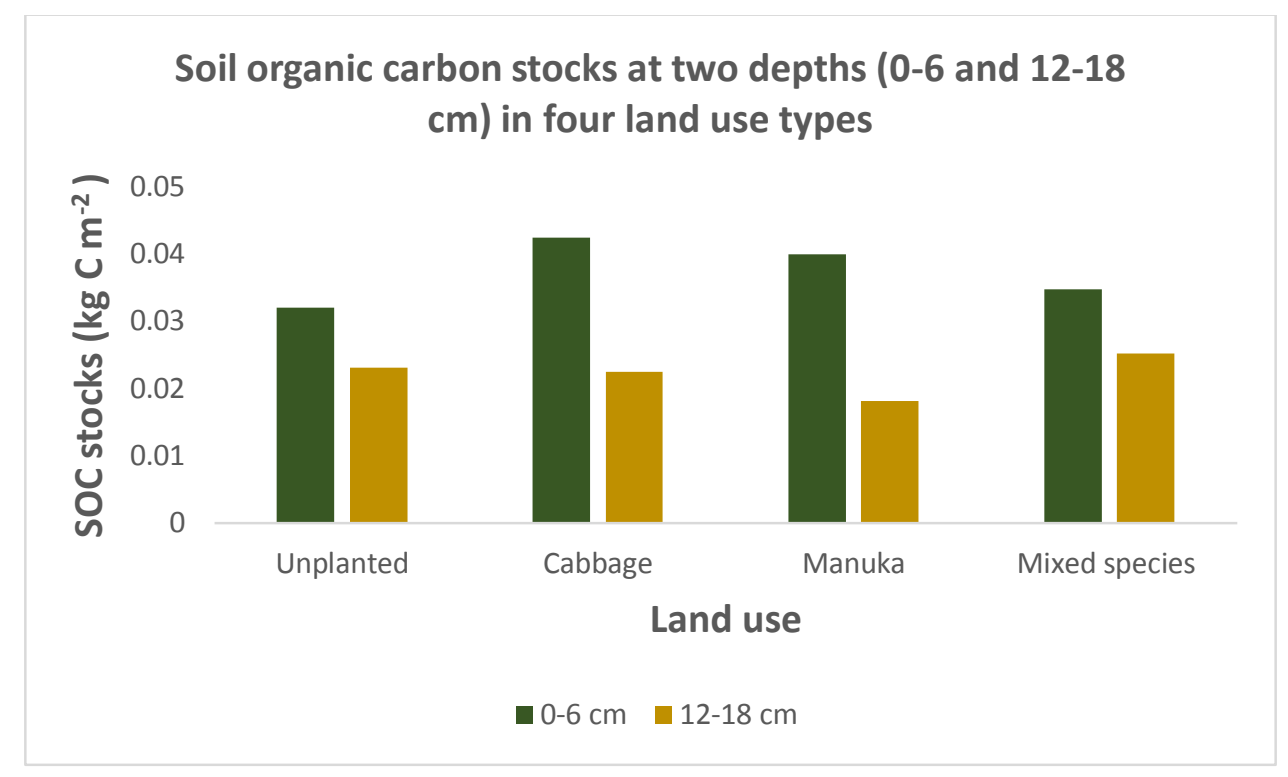

Figure 17. Soil organic carbon (SOC) stocks at $6 \mathrm{~cm}$ and $18 \mathrm{~cm}$ depths in four land use types of Wairio wetlands

Considering the variation in topography, the soil organic carbon per unit area was highest in cabbage tree sites and lowest in sites planted with a mixture of tree species at $3 \%$ slope in 0-6 cm depth (Table 23). At $6 \%$ slope, soil organic carbon stock was higher in manuka sites than unplanted in 0-6 cm depth (Table 23). At $8 \%$ slope, cabbage tree sites had the highest soil organic carbon stocks, whereas unplanted sites had the lowest within the first $6 \mathrm{~cm}$ (Table 23). 
Within 12-18 cm depth, soil organic carbon stocks were highest in manuka and unplanted sites whereas they were lowest in cabbage sites at $3 \%$ slope (Table 23). At $6 \%$ and $8 \%$ slope, manuka sites had the highest stocks and unplanted had the lowest (Table 23).

Table 23 Mean Soil organic carbon (SOC) stocks at different depths along topographical gradient in four land use types of Wairio wetlands

\begin{tabular}{llll}
\hline $\begin{array}{l}\text { Slope } \\
(\%)\end{array}$ & Land use & $\begin{array}{l}\mathrm{SOC}\left(\mathrm{kg} \mathrm{C} \mathrm{m}^{-2}\right) \text { at } \\
0-6 \mathrm{~cm} \mathrm{depth}\end{array}$ & $\begin{array}{l}\mathrm{SOC}\left(\mathrm{kg} \mathrm{C} \mathrm{m}^{-2}\right) \text { at } \\
12-18 \mathrm{~cm} \mathrm{depth}\end{array}$ \\
\hline 3 & Unplanted & 0.035 & 0.028 \\
& Planted & 0.033 & 0.024 \\
& Cabbage & 0.041 & 0.014 \\
& Manuka & 0.037 & 0.028 \\
& & \\
6 & Unplanted & 0.026 & 0.020 \\
& Manuka & 0.044 & 0.025 \\
& & & \\
8 & Unplanted & 0.034 & 0.027 \\
& Planted & 0.036 & 0.028 \\
& Cabbage & 0.042 & 0.022 \\
& Manuka & 0.031 & 0.022 \\
\hline
\end{tabular}


4.5.4 Volumetric soil moisture content (lab derived through gravimetric measurements) The volumetric soil moisture content results presented in this section are a product of gravimetric moisture content and bulk density.

4.5.4.1 Effect of land use type on volumetric soil moisture content under varying slope and depth

There was a significant effect of land use on volumetric soil moisture content and the relationship was significantly influenced by differences in soil depth and slope (Table 24).

Table 24 Fixed effects test for the effect of land use, soil depth and slope on volumetric soil moisture content

\begin{tabular}{lrrrr}
\hline & $\begin{array}{c}\text { Numerator } \\
\text { Source }\end{array}$ & \multicolumn{2}{c}{ Denominator } \\
Intercept & 1 & & \multicolumn{1}{c}{$\mathrm{df}$} & \multicolumn{1}{c}{$p$} \\
Land use & 3 & 224.0 & 17.12 & $<0.001$ \\
Depth & 1 & 517.4 & 4.38 & 0.037 \\
Slope & 2 & 344.1 & 39.83 & $<0.001$ \\
Land use * Depth & 3 & 517.4 & 3.65 & 0.013 \\
Land use * Slope & 4 & 485.4 & 9.87 & $<0.001$ \\
\hline
\end{tabular}

Soil moisture content (expressed as a percentage of dry weight multiplied by bulk density) was highly variable under the different land use types. It ranged from $24.97 \%$ to $49.30 \%$ in unplanted areas, $12.28 \%$ to $45.71 \%$ in areas planted with a mixture of tree species, $24.64 \%$ to $50.29 \%$ in areas planted with cabbage trees, $7.88 \%$ to $54.02 \%$ in areas planted with manuka trees at $6 \mathrm{~cm}$ soil depth (Figure 18). At $18 \mathrm{~cm}$ soil depth, the variability was higher than that at $6 \mathrm{~cm}$, ranging from $15.44 \%$ to $60.38 \%$ in unplanted areas, $7.31 \%$ to $55.04 \%$ in areas planted with a mixture of tree species, $17.85 \%$ to $52.65 \%$ in areas planted with cabbage trees, $6.62 \%$ to $59.36 \%$ in areas planted with manuka trees (Figure 18). 


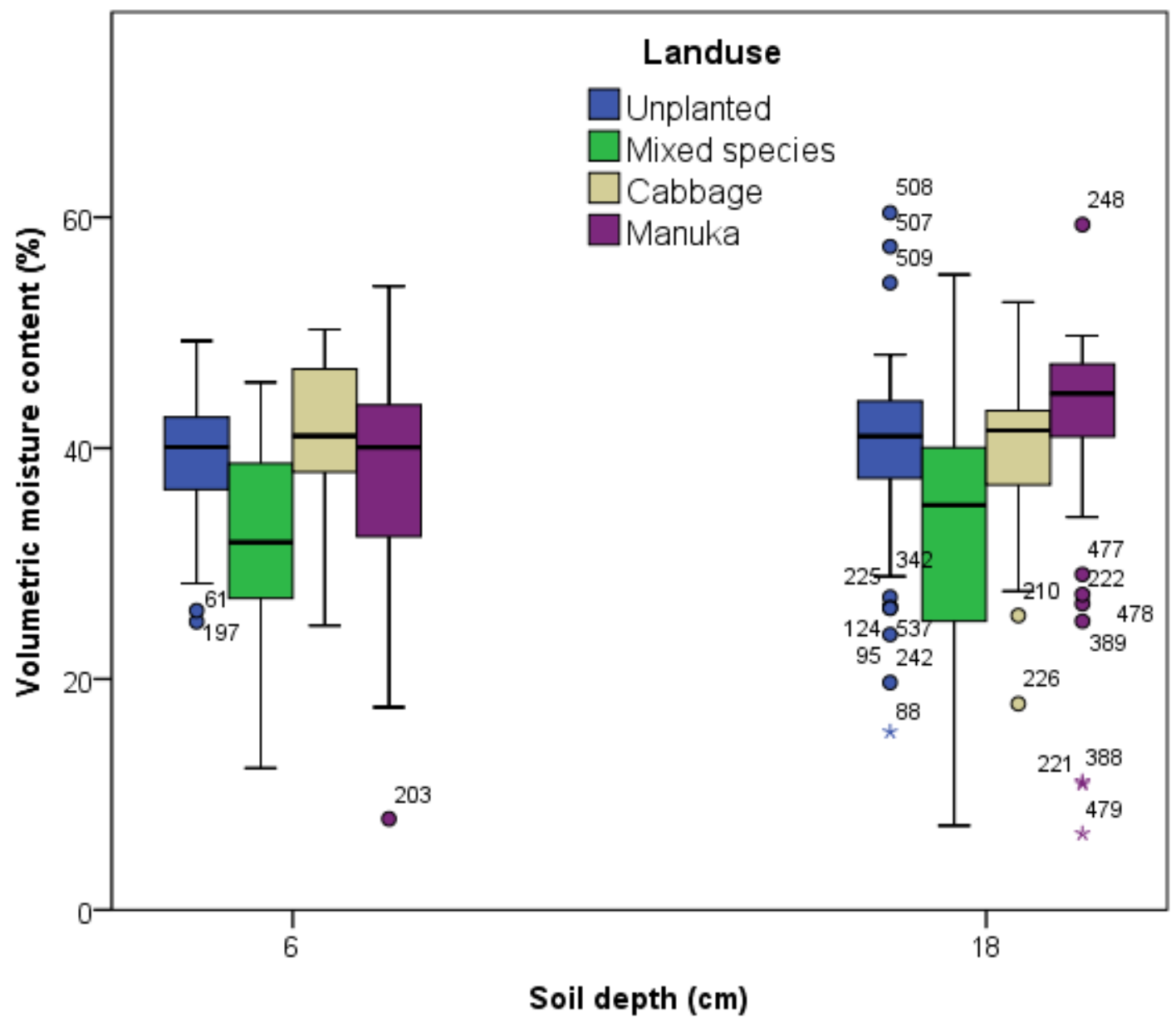

Figure 18. Box plots showing minimum, lower quartile, median, upper quartile and maximum values of volumetric soil moisture content under unplanted, mixed species, cabbage and manuka sites.

Generally, the mixed species reduced soil moisture by $22.5 \%$ at $6 \mathrm{~cm}$ depth and $12.5 \%$ at $18 \mathrm{~cm}$, compared to other vegetation types (Figure 17). The high variability in moisture content shown in the box plot (Figure 18) is a result of the presence of outlier values in unplanted plot of block 11 (very wet), manuka plot of block 1 (dry) and a plot planted with a mixture of tree species in block 10 (dry) (Figure 19). The variability in wet and dry can be explained by the time of sampling, with the dryness being captured during the summer between January and March 2014 (Figure 19). The variability can also be explained by taking into account the slope gradient on which the land use types are located. 


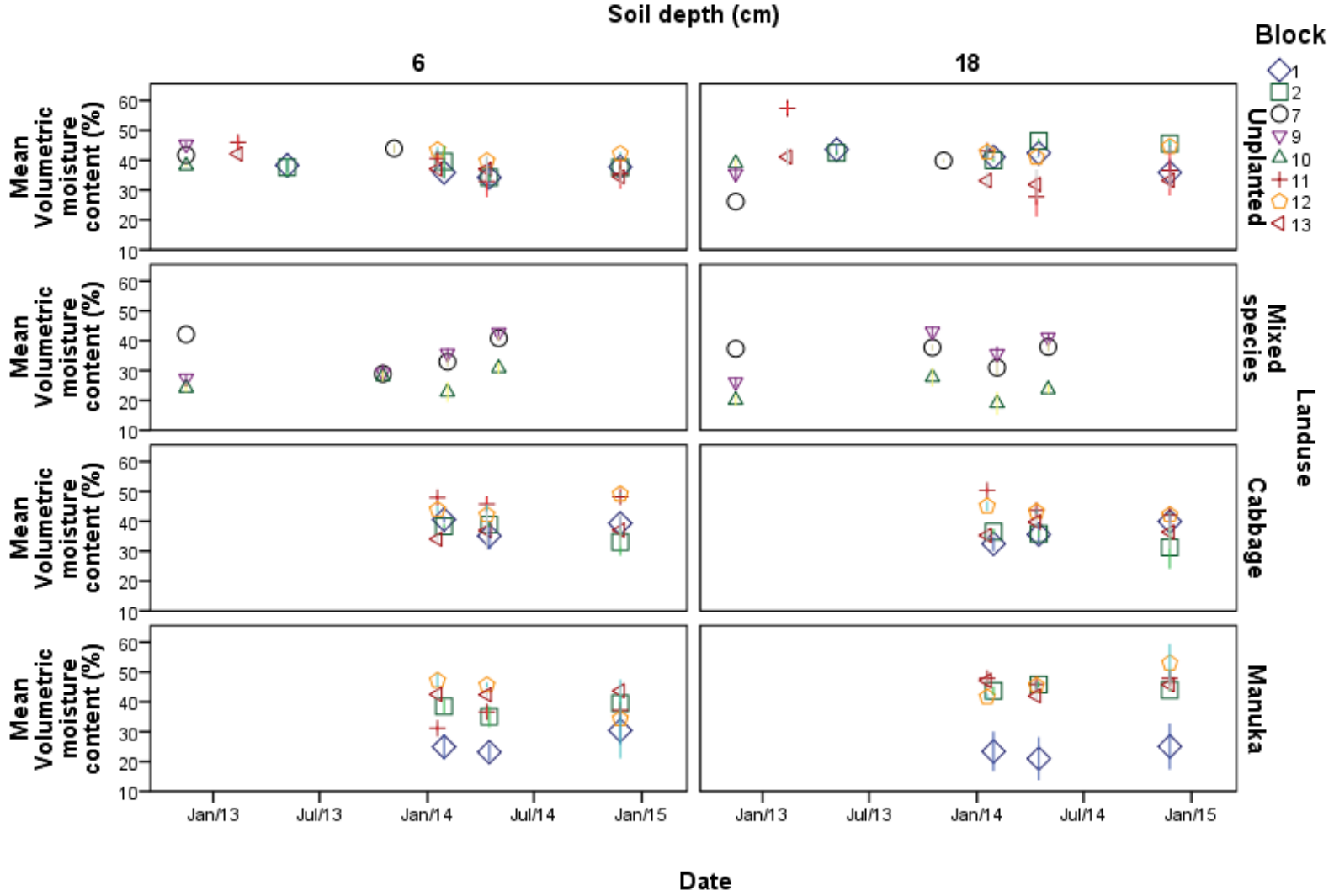

Figure 19. Mean volumetric moisture content of four land use types over time

All three slope classes except for $6 \%$ slope gradient were covered by the four land use types. At $6 \%$ slope gradient, there was only manuka and unplanted land use types.

Pairwise comparisons between land use types showed that at $3 \%$ slope gradient, soils in unplanted sites were significantly wetter than soils planted with a mixture of tree species and cabbage trees respectively within the first $6 \mathrm{~cm}$ (Figure 20; Appendix 11). Similarly, soils under cabbage trees were significantly wetter than soils planted with a mixture of tree species within $6 \mathrm{~cm}$ depth (Figure 20; Appendix 11). Moisture content under manuka was similar to that under unplanted and soils planted with a mixture of tree species but less than that under cabbage tree soils.

At $6 \%$ slope, the soil moisture content in unplanted soils was similar to that in manuka sites, within $6 \mathrm{~cm}$ depth (Figure 20; Appendix 11). 
At $8 \%$ slope, soils in unplanted and cabbage tree sites were significantly wetter than soils in sites planted with a mixture of tree species and manuka respectively at $8 \%$ slope gradient, within $6 \mathrm{~cm}$ depth (Figure 20; Appendix 11).

Overall, soils at $8 \%$ slope gradient were drier than soils at 3 and $6 \%$ slope gradients in all land use types at $6 \mathrm{~cm}$ soil depth (Figure 20; Appendix 11).

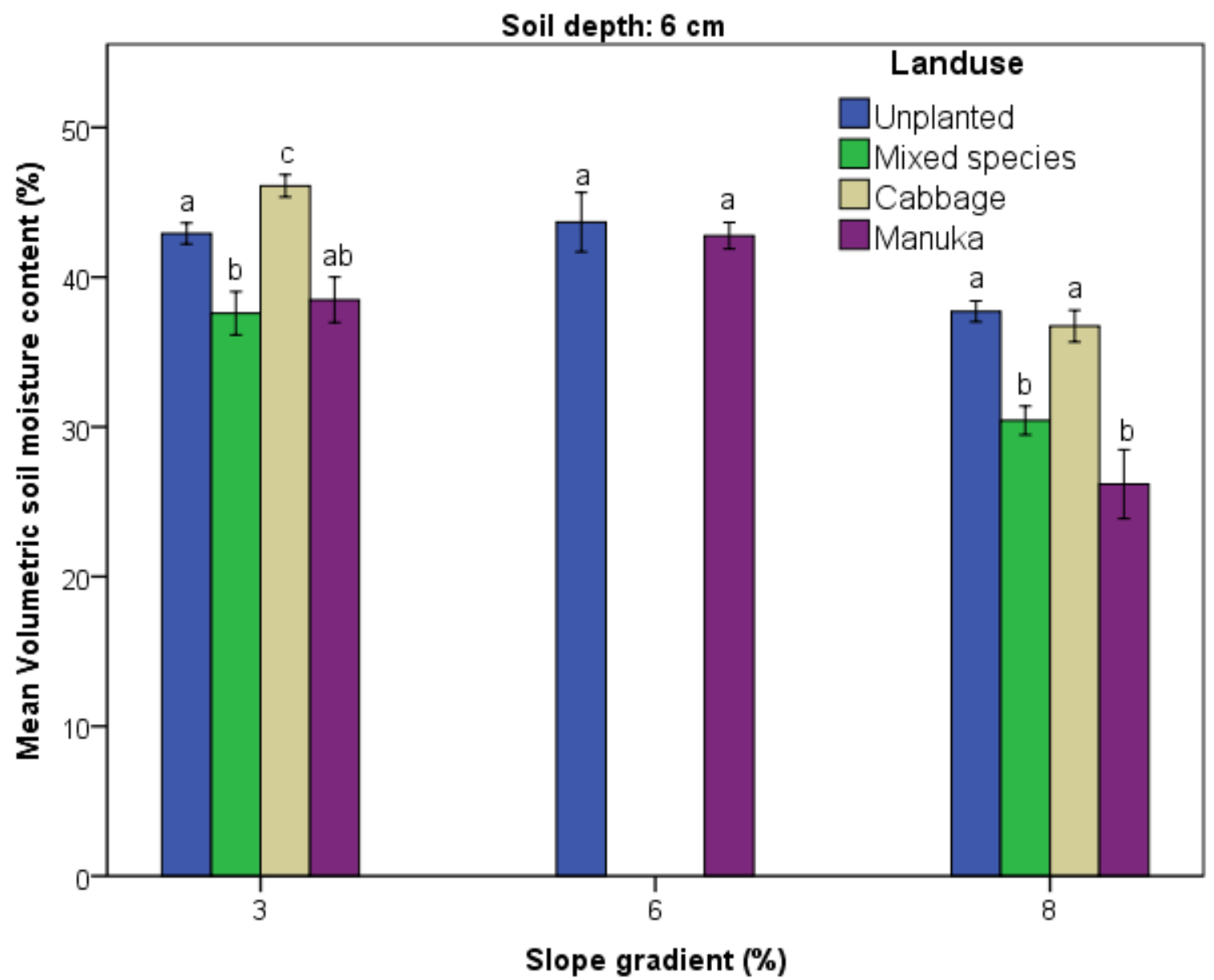

Figure 20. Mean (+/- $1 \mathrm{SE}$ ) soil volumetric moisture content of land use types at varying slope gradients within $6 \mathrm{~cm}$ soil depth. Different letters indicate significant differences between land use types within each depth based on LSD post-hoc comparisons.

At $18 \mathrm{~cm}$ depth, soils in unplanted, manuka and cabbage tree sites were significantly wetter than soils in sites planted with a mixture of tree species at $3 \%$ slope (Figure 21; Appendix 12). At $6 \%$ slope gradient, soils planted with manuka trees had similar quantities of moisture as unplanted soils (Figure 21; Appendix 12). 
At $8 \%$ slope gradient, unplanted sites were significantly wetter than planted and manuka tree sites respectively. Similarly, soils planted with cabbage trees were wetter than soils planted with manuka trees at $18 \mathrm{~cm}$ depth (Figure 21; Appendix 12). Overall, soil moisture content under all land use types, decreased with the increase in slope gradient from $3 \%$ to $8 \%$ (Figure 21).

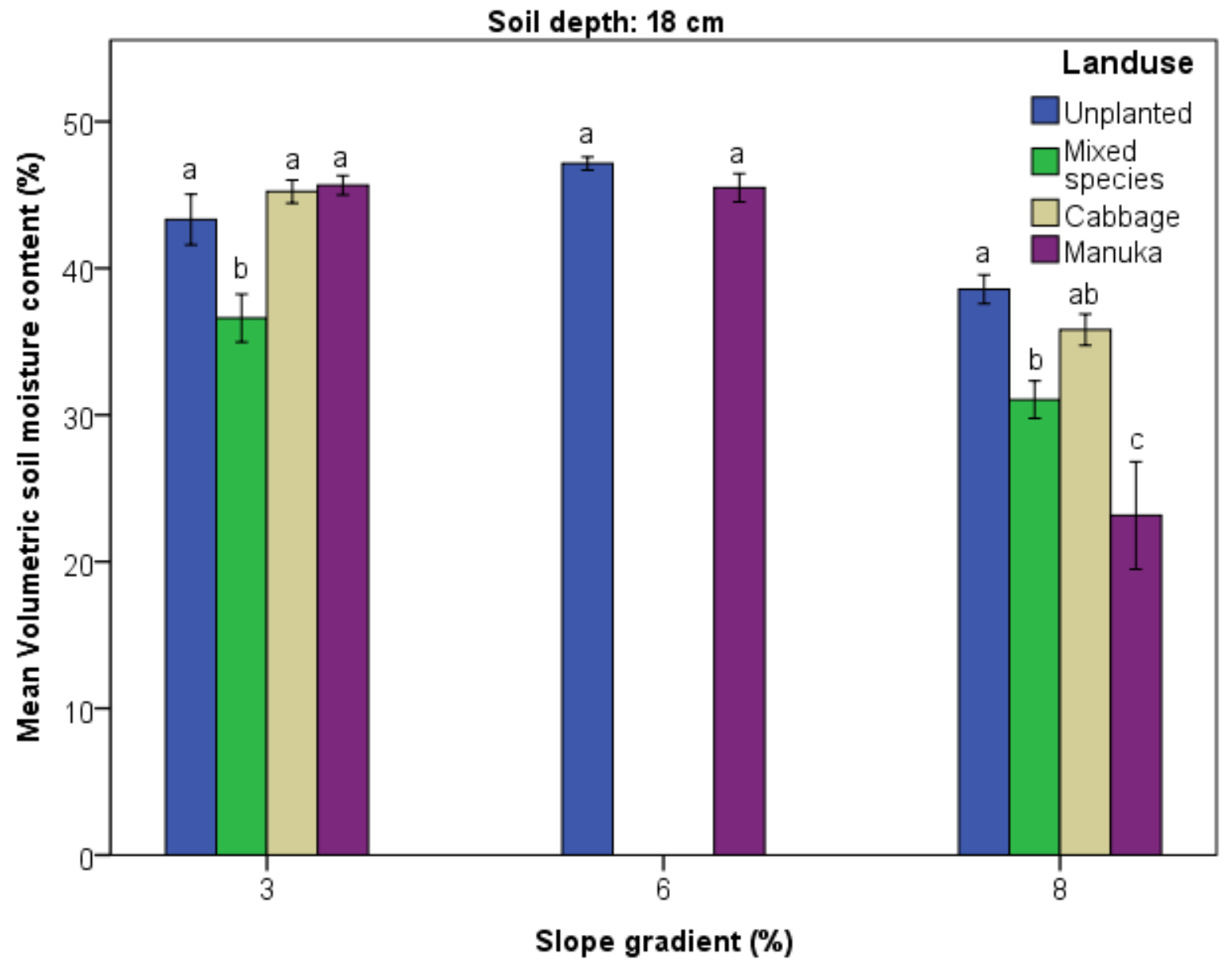

Figure 21. Mean (+/- $1 \mathrm{SE}$ ) soil volumetric moisture content of land use types at varying slope gradients within $18 \mathrm{~cm}$ soil depth. Different letters indicate significant differences between land use types within each depth based on LSD post-hoc comparisons. 


\subsubsection{Volumetric soil moisture content (field measurements using CS620 moisture meters)}

This section presents results of volumetric soil moisture content measured continuously in the field using CS620 moisture meters connected to CR1000 data loggers. Subsection 4.5.5.1 presents results of variation in soil moisture content at 10, 20 and $30 \mathrm{~cm}$ depths under planted or unplanted land use on either high or low slope. Subsection 4.5.5.2 presents the comparison of soil moisture content between the land use types. Implications of the results are discussed in section 4.6.5.

4.5.5.1 Temporal variation in volumetric soil moisture content over three soil depths in unplanted sites and sites planted with a mixture of tree species

Volumetric soil moisture content was higher in mixed species plot on low slope than in the mixed species and unplanted plots on high slope (Figures 21, 22 \& 23). The soil moisture content of the planted plot on high slope was the lowest of the three plots (Figure 22)

The volumetric soil moisture content increased with the increase with depth from 10 to 30 $\mathrm{cm}$ during autumn, winter and spring in the site planted with a mixture of tree species located at $8 \%$ slope (Figure 22) At the beginning of summer, volumetric soil moisture content was higher at $20 \mathrm{~cm}$ depth, after which it decreased to the same level as that at 10 $\mathrm{cm}$ depth during mid-summer, while at $30 \mathrm{~cm}$ soil depth it decreased until the end of summer (Figure 22). Overall, the level of soil moisture content within the three depths, decreased with the decrease in rainfall as the seasons changed from spring to summer (Figure 22). However, in summer (February) of 2015, despite the peak in rainfall, the levels of soil moisture within all three depths remained low (Figure 22).

In the unplanted site located at $8 \%$ slope, volumetric soil moisture content was higher at 10 $\mathrm{cm}$ and $20 \mathrm{~cm}$ depths than at $30 \mathrm{~cm}$ during summer, autumn, winter and spring (Figure 23). Soil moisture content within each soil depth decreased as the rainfall decreased with the change in seasons from spring to summer (Figure 23). However, the soil moisture levels under the three depths responded to the rainfall peak in summer (February) of 2015, despite remaining low (Figure 23). 
In the site planted with a mixture of tree species located on $3 \%$ slope gradient, volumetric soil moisture content was higher within the first $10 \mathrm{~cm}$ soil depth than at $20 \mathrm{~cm}$ and $30 \mathrm{~cm}$ depth where the level of moisture was similar during autumn, winter and spring (Figure 24).

During the summer months, the level of moisture within $30 \mathrm{~cm}$ soil depth was higher than that within $20 \mathrm{~cm}$ but still lower than that within $10 \mathrm{~cm}$ (Figure 24). Overall, soil moisture content decreased in all measured depths with the decrease in rainfall as the seasons changed from spring to summer (Figure 24). The rainfall peak during summer resulted in a sharp increase in soil moisture content at all depths, after which it decreased after the event (Figure 24). 


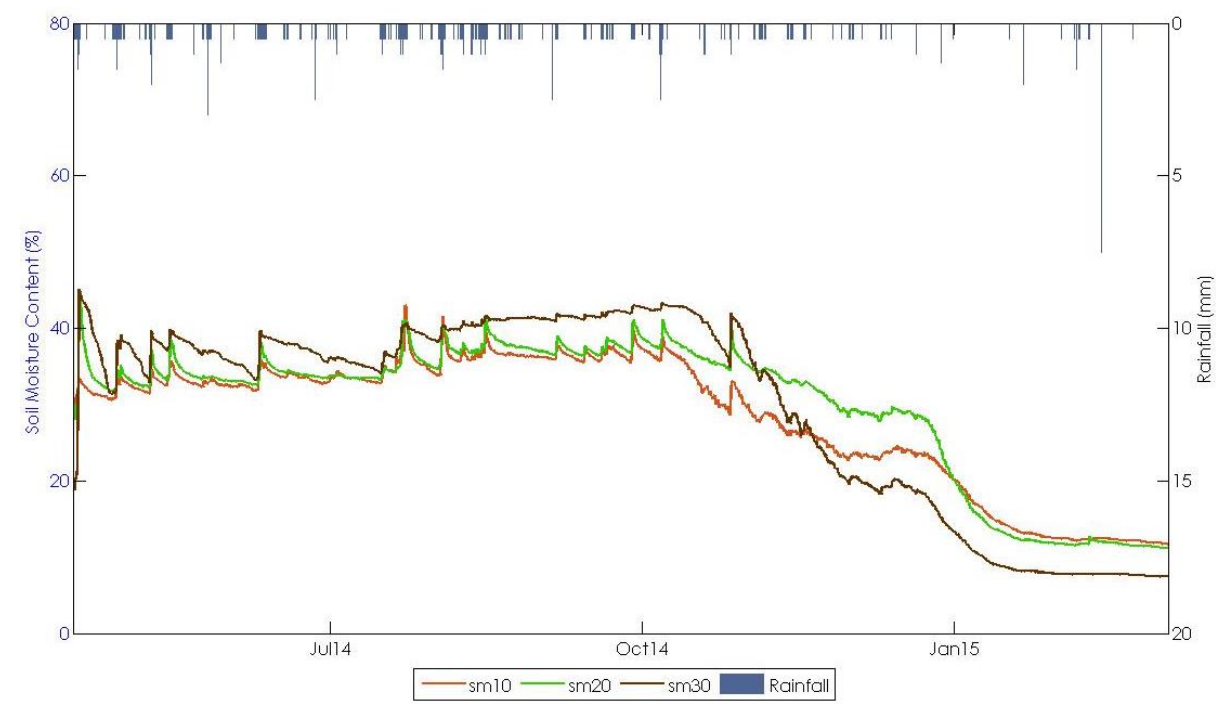

Figure 22. Variation in volumetric soil moisture content (\%) across the 2014 season to early 2015 (April 162014 to March 7 2015) at $10 \mathrm{~cm}, 20 \mathrm{~cm}$ and $30 \mathrm{~cm}$ depths for a site planted with a mixture of tree species at $8 \%$ slope gradient in Plot 1a, Block 7

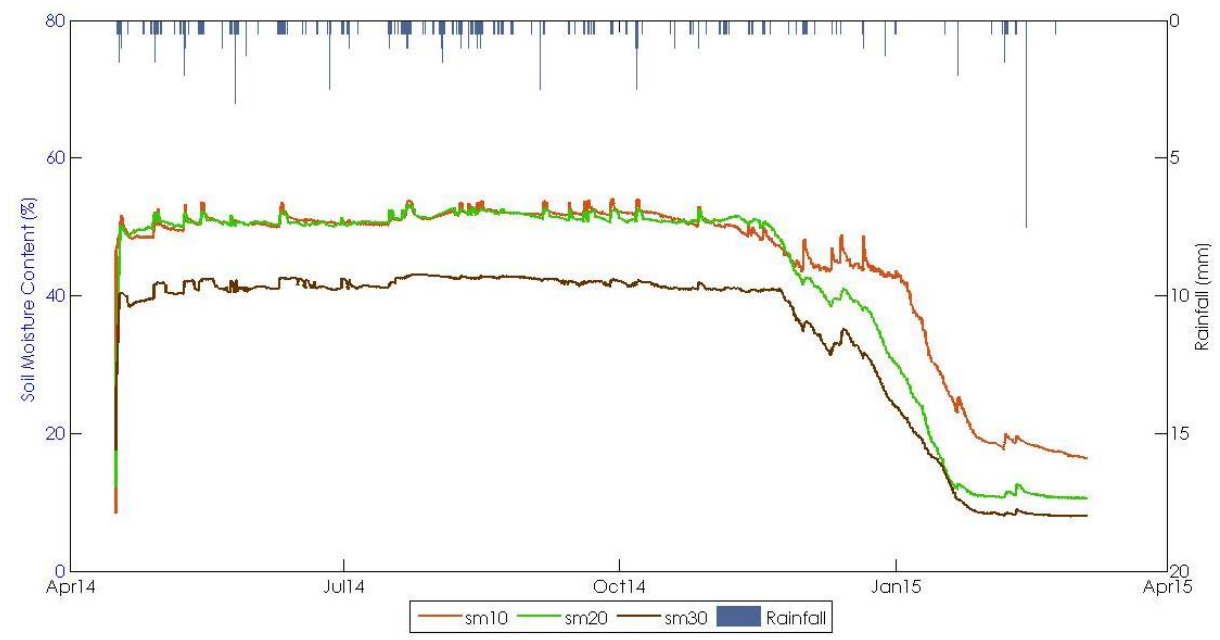

Figure 23. Variation in volumetric soil moisture content (\%) across the 2014 season to early 2015 over $10 \mathrm{~cm}, 20 \mathrm{~cm}$ and $30 \mathrm{~cm}$ depths for an unplanted site at $8 \%$ slope gradient in Plot 2, Block 13

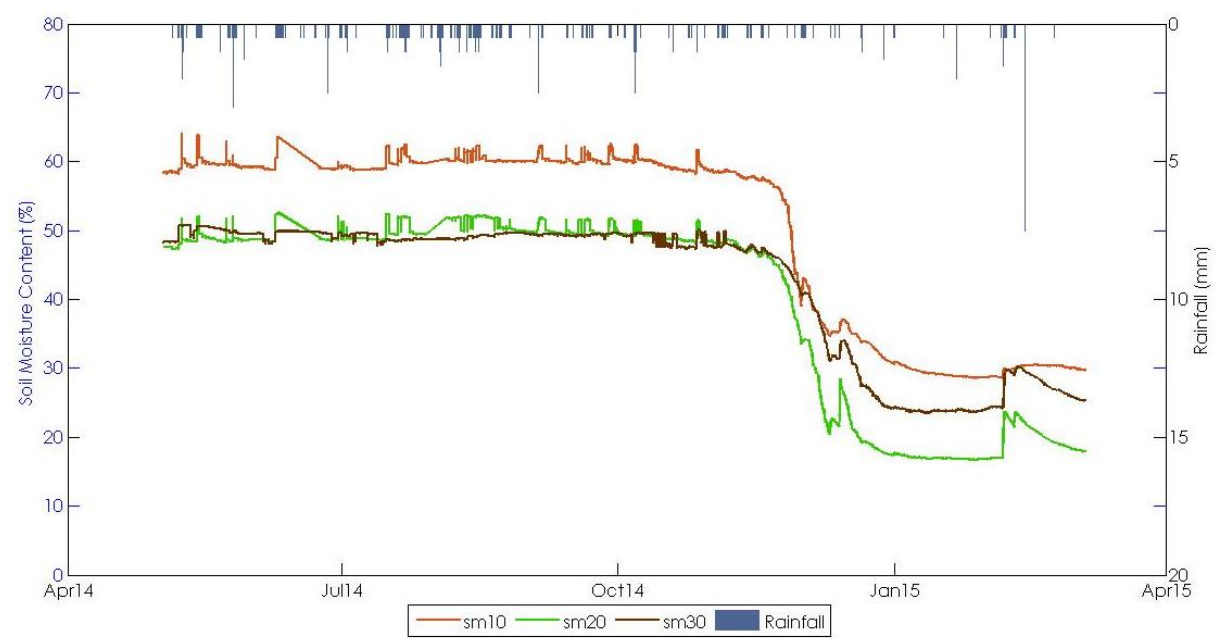

Figure 24. Variation in volumetric soil moisture content (\%) across the 2014 season to early 2015 over $10 \mathrm{~cm}, 20 \mathrm{~cm}$ and $30 \mathrm{~cm}$ depths for a site planted with a mixture of tree species at $3 \%$ slope gradient in Plot 1a, Block 9. 
4.5.5.2 Pairwise comparisons of the spatial-temporal variation of volumetric soil moisture content between land use types

The continuous measurements of volumetric soil moisture content were carried out in three sites (plots), two unplanted and planted located on $8 \%$ slope and one planted located on $3 \%$ slope. Ideally, it would have been more informative to quantify soil moisture from an unplanted site located on $3 \%$ slope for comparative purposes, but due to the costs of equipment, it was not possible. Therefore, slope gradient was not included as factor in pairwise comparisons between land use types, as the land use types alone take into account the slope position. Land use significantly affected volumetric soil moisture content within 10 $\mathrm{cm}$ soil depth and this relationship was significantly influenced by changing seasons (Table 25).

Table 25 ANOVA for the effect of land use, season and their interaction on the variation in volumetric moisture content at $10 \mathrm{~cm}$ depth

\begin{tabular}{|c|c|c|c|c|c|}
\hline Source & $\begin{array}{c}\text { Type III Sum of } \\
\text { Squares }\end{array}$ & $d f$ & Mean Square & $\mathrm{F}$ & $p$ \\
\hline Intercept & 413626894.58 & 1 & 413626894.5 & 12955902.29 & $<0.001$ \\
\hline Seasons & 23781845.48 & 3 & 7927281.83 & 248303.70 & $<0.001$ \\
\hline Land use & 21998318.97 & 2 & 10999159.48 & 344523.14 & $<0.001$ \\
\hline Seasons * Land use & 1141473.90 & 6 & 190245.65 & 5959 & $<0.001$ \\
\hline Error & 8460930.28 & 265019 & 31.93 & & \\
\hline Total & 491639563.16 & 265031 & & & \\
\hline
\end{tabular}

Pairwise comparisons of land use types in autumn, winter and spring showed that the planted site on low slope was significantly wetter than unplanted and planted sites on high slope, within the first $10 \mathrm{~cm}$ soil depth (Figure 25; Appendix 13). The unplanted site was significantly wetter than the planted site on high slope within $10 \mathrm{~cm}$ depth in autumn, winter and spring (Figure 25; Appendix 13). In summer, the planted site on low slope and unplanted site at high slope were significantly wetter than the planted site on high slope (Figure 25; Appendix 13). 


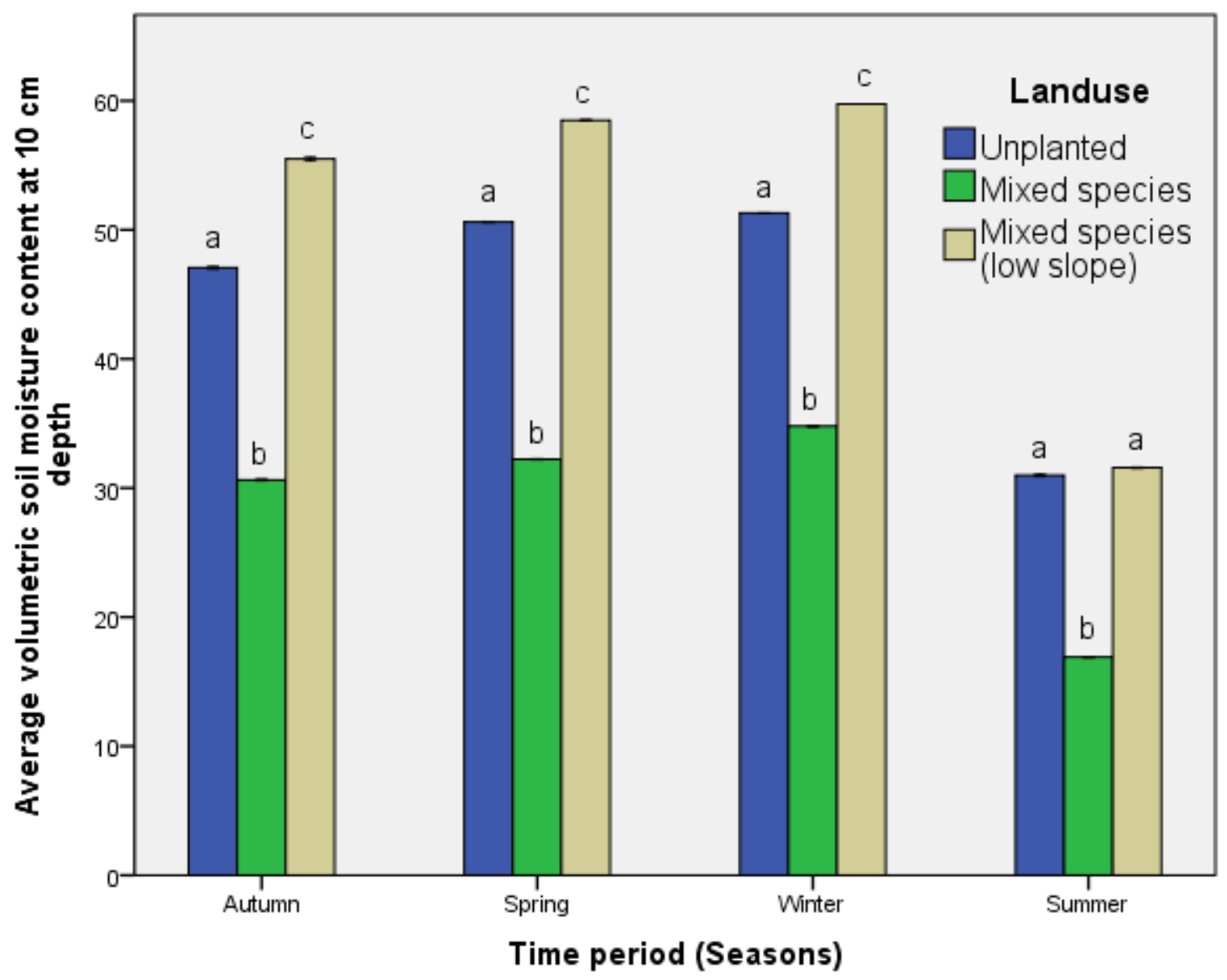

Figure 25. Average soil volumetric soil moisture content at $10 \mathrm{~cm}$ depth under different land use times over time

At $20 \mathrm{~cm}$ soil depth, land use significantly affected volumetric soil moisture content and this relationship was significantly influenced by changing seasons (Table 26).

Table 26 ANOVA for the effect of land use, season and their interaction on the variation in volumetric moisture content at $20 \mathrm{~cm}$ depth

\begin{tabular}{lrrrrr}
\hline & \multicolumn{1}{c}{ Type III Sum of } & & & & \\
Source & \multicolumn{1}{c}{ Squares } & df & Mean Square & \multicolumn{1}{c}{$\mathrm{F}$} & $\mathrm{p}$ \\
\hline Intercept & 342010010.19 & 1 & 342010010.188 & 9020479.988 & $<0.001$ \\
Seasons & 32372006.59 & 3 & 10790668.862 & 284602.818 & $<0.001$ \\
Land use & 7650405.76 & 2 & 3825202.881 & 100889.345 & $<0.001$ \\
Seasons * Land use & 1490008.65 & 6 & 248334.775 & 6549.805 & $<0.001$ \\
Error & 10048151.65 & 265019 & 37.915 & & \\
Total & 413792410.29 & 265031 & & & \\
\hline
\end{tabular}


Pairwise comparisons showed that the planted site on low slope and the unplanted site on high slope were significantly wetter than the planted site on high slope in all seasons (Figure 26; Appendix 14).

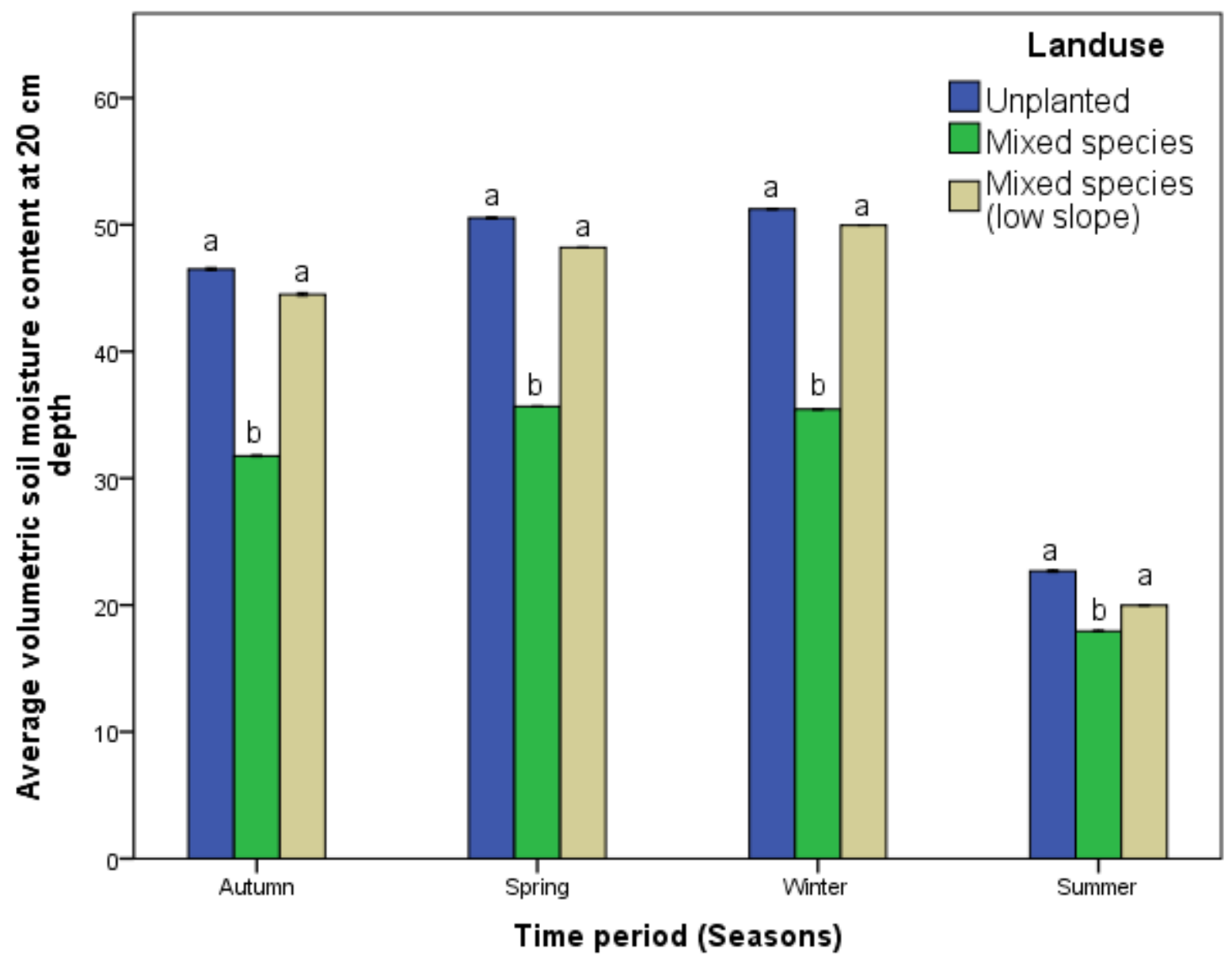

Figure 26. Average soil volumetric soil moisture content at $10 \mathrm{~cm}$ depth under different land use times over time

Similarly, at $30 \mathrm{~cm}$ soil depth, land use significantly affected volumetric soil moisture content and this relationship was significantly influenced by changing seasons (Table 27).

Pairwise comparisons showed that in all seasons, the planted site on low slope was significantly wetter than unplanted and planted sites on high slope (Figure 27; Appendix 15). The unplanted site was also wetter (16-37\% more) than the planted site on high slope, across all seasons (Figure 27; Appendix 15). 
Table 27 ANOVA for the effect of land use, season and their interaction on the variation in volumetric moisture content at $30 \mathrm{~cm}$ depth

\begin{tabular}{|c|c|c|c|c|c|}
\hline Source & $\begin{array}{c}\text { Type III Sum of } \\
\text { Squares }\end{array}$ & $\mathrm{df}$ & Mean Square & $\mathrm{F}$ & Sig. \\
\hline Intercept & 308780629.256 & 1 & 308780629.256 & 9368341.994 & $<0.001$ \\
\hline Seasons & 28329944.999 & 3 & 9443315.000 & 286508.272 & $<0.001$ \\
\hline Land use & 6094614.532 & 2 & 3047307.266 & 92454.688 & $<0.001$ \\
\hline Seasons * Land use & 188183.586 & 6 & 31363.931 & 951.575 & $<0.001$ \\
\hline Error & 8735028.422 & 265019 & 32.960 & & \\
\hline Total & 368651110.680 & 265031 & & & \\
\hline
\end{tabular}

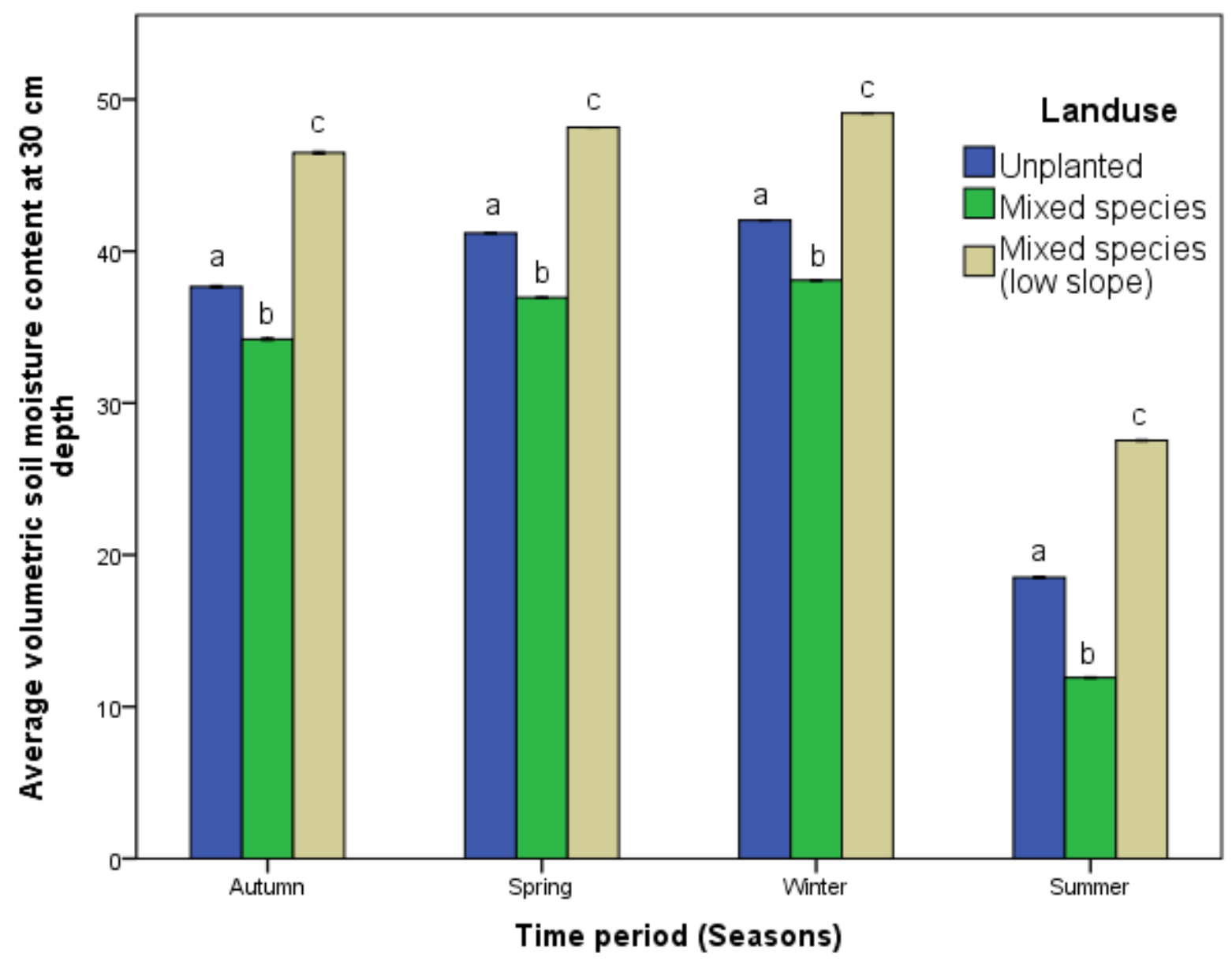

Figure 27. Average soil volumetric soil moisture content at $30 \mathrm{~cm}$ depth under different land use times over time 


\subsubsection{Soil matric potential}

The matric potential results presented here are for three plots, (i.e. two planted with a mixture of tree species on high and low slope, and one unplanted on high slope) for the period starting at the end of winter to the beginning of summer in 2014. It would have been more informative to have a fourth plot of unplanted on low slope, but due to high cost of equipment, it was not possible. Results beyond the beginning of summer are not presented because of tensiometer cavitation problems. Refilling of tensiometers with de-gassed water on various events (Appendix 20) during summer resulted in a temporary increase in pressure, followed by an immediate sharp decrease to less than $0.8 \mathrm{mH}_{2} \mathrm{O}$ in that time. As previously stated under section 4.3.5.4, tensiometers are susceptible to cavitation in the dry range, but were still chosen for this research regardless of this problem because of high accuracy in the wet range (common in wetlands) compared to any sensor. It is within this wet range where surface runoff is likely to be generated due to limited storage capacity of the soil sub-surface hence, it is important to understand water movement.

Changes in pressure of tensiometers installed at 10 and $30 \mathrm{~cm}$ depths mostly occurred in response to rainfall in all the measured sites (Figure 28). There is consistence in the changes in pressure at $30 \mathrm{~cm}$ depth but more variation at $10 \mathrm{~cm}$ (Figure 28). Data shows that the soil starts off slightly dry at the end of winter (matric potential $<0 \mathrm{mH}_{2} \mathrm{O}$ ) but quickly saturates (matric potential $\geq 0 \mathrm{mH}_{2} \mathrm{O}$ ) in response to precipitation in the planted site on high slope (Figure 28a). In spring, the soil stays unsaturated for a long period, with a few occasions of saturation in response to precipitation, after which it dries up from the beginning of summer (Figure 28a). The efficiency of trees in using up water is evident during spring, where despite some periods of rain, the matric potential stays below saturation point. In the unplanted site, the soil starts close to saturation at the end of winter, alternates between wetting and drying during spring, and dries out gradually towards the beginning of summer (Figure 28b).

In the mixed species site on low slope, the soil starts saturated and stays close to saturation until the middle of spring (Figure 28c). A zoom in to these results (Figure 28d), shows during this period, the soil at $30 \mathrm{~cm}$ depth is consistently saturated while at $10 \mathrm{~cm}$ varies between mid- October to November. The rise in pressure above saturation, (i.e. $0.2 \mathrm{mH}_{2} \mathrm{O}$ at $10 \mathrm{~cm}$ depth; $0.4 \mathrm{mH}_{2} \mathrm{O}$ at $30 \mathrm{~cm}$ depth) is an indication of standing water, often in the planted site 
on low slope (Figure 28d) and sometimes in the unplanted site on high slope (Figure 28b). There was no indication of impervious soil layer within the $30 \mathrm{~cm}$ soil profile in all sites as both tensiometers responded to precipitation, as a result water can easily flow through this profile. 
Mixed species, high slope

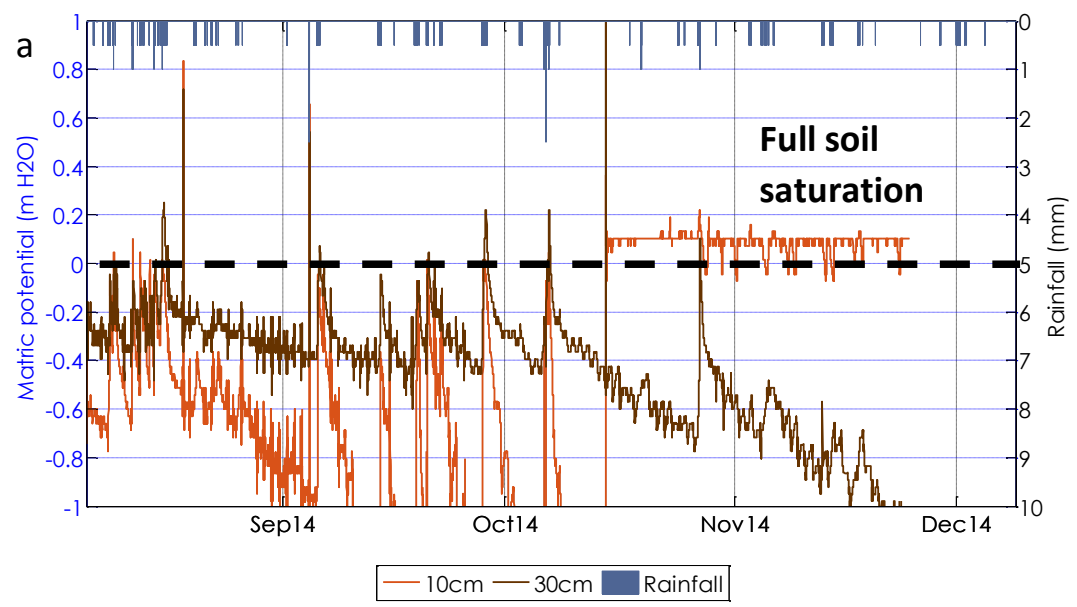

Unplanted, high slope

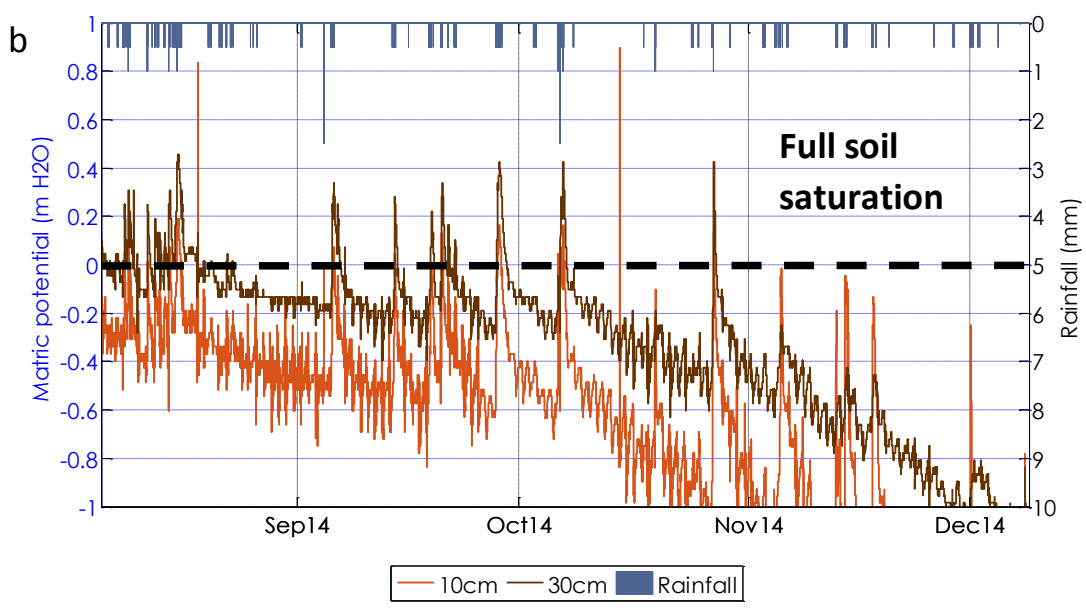

A zoom in of part of the results of the mixed species site on low
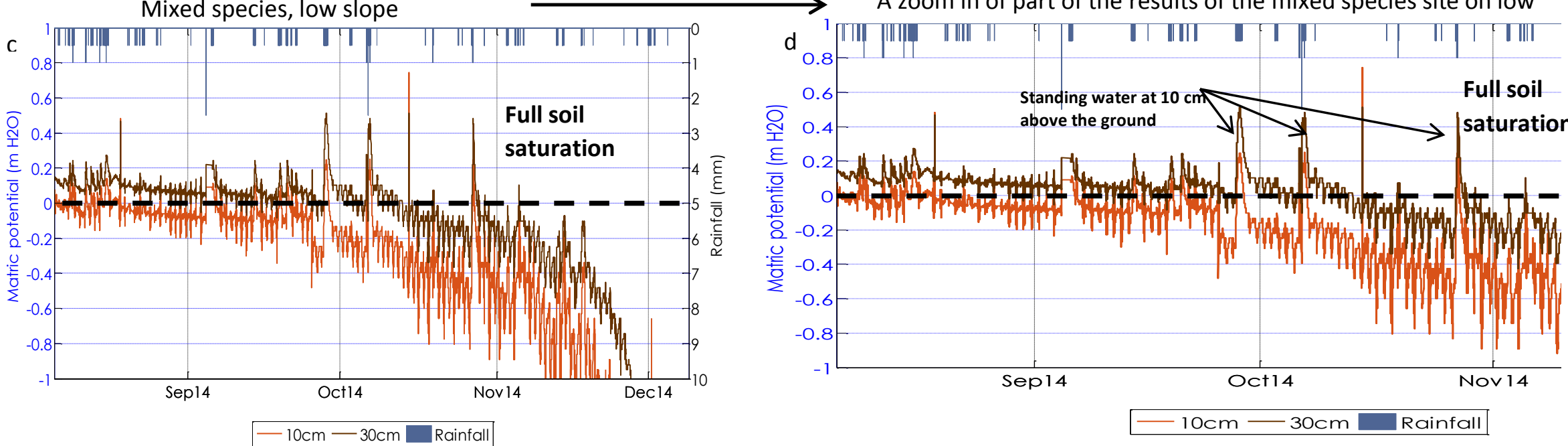

Figure 28 Matric potential at $10 \mathrm{~cm}$ and $30 \mathrm{~cm}$ in (a, b) planted and unplanted on high slope, (c) planted on low slope, (d) a zoom of (c) 


\subsubsection{Soil moisture retention}

Soil moisture content at saturation within the first $10 \mathrm{~cm}$ depth, was higher in the unplanted site $(52 \%)$ than planted site (40\%) at $8 \%$ slope (Figure 29). However, the planted site located at $3 \%$ slope had high moisture content at saturation (60\%) than the unplanted and planted sites on $8 \%$ slope (Figure 29). The residual moisture content was higher under planted site (12\%) than unplanted (3\%) at $8 \%$ slope and planted $(6.9 \%)$ at $3 \%$ slope (Figure 29). The proportion of hydrologically active pores ( $\theta s-\theta r$ ) or effective porosity in which water flow occurs was higher under the unplanted site (49\%) than the planted site (28\%) at $8 \%$ slope. However, the planted site at $3 \%$ slope had higher effective porosity (53 $\%)$ than both planted and unplanted sites at $8 \%$ slope.

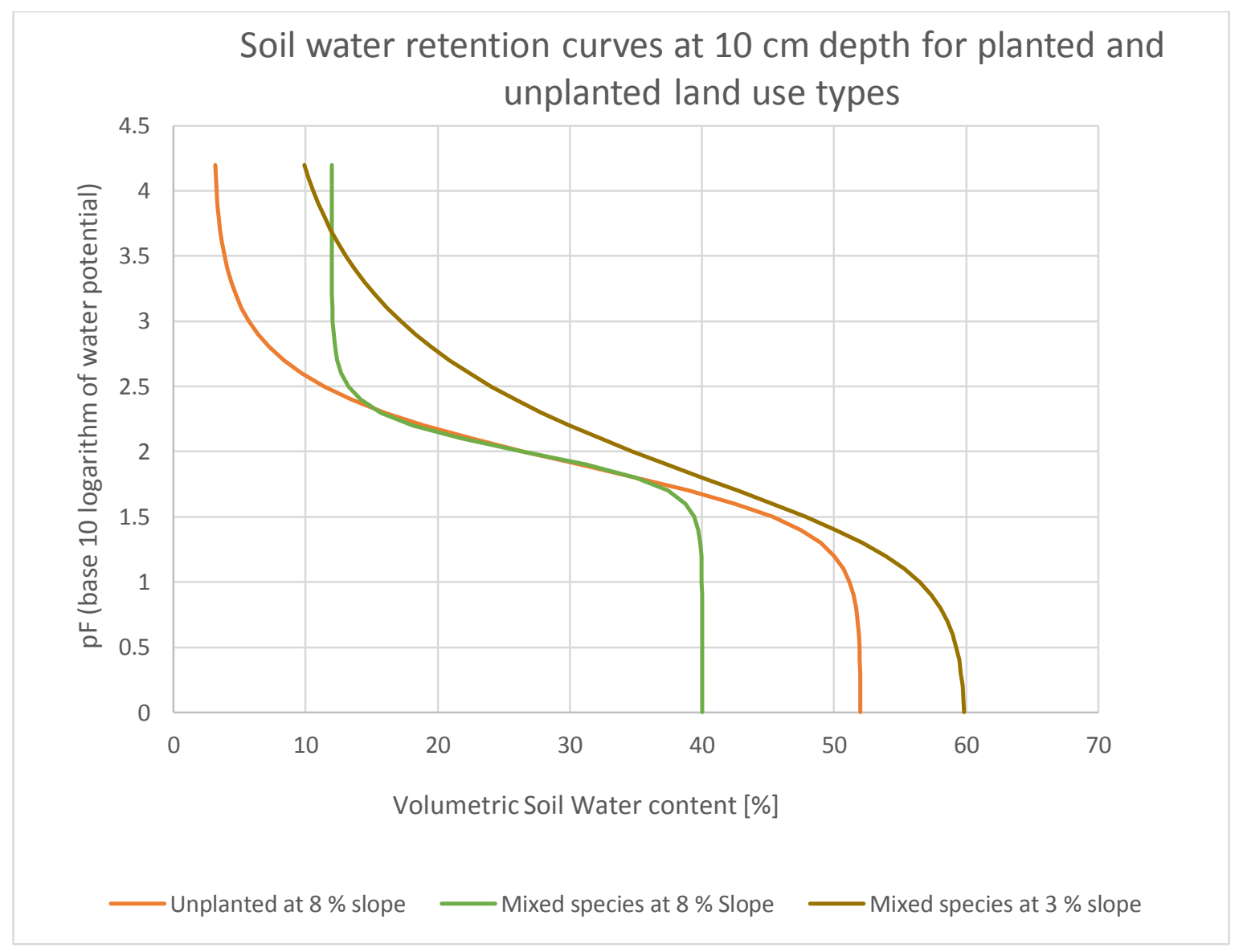

Figure 29. Soil moisture retention curves at $10 \mathrm{~cm}$ depth at three different locations with differing land cover and slopes

At $30 \mathrm{~cm}$ soil depth, planted and unplanted sites on $8 \%$ slope retained similar levels of moisture content (43\%) at saturation, but were less than that retained under planted sites located on $3 \%$ slope (50\%) (Figure 30). The residual soil moisture content was higher 
(7.8\%) under planted and unplanted sites located at $8 \%$ slope than that under planted site (3.1\%) located on $3 \%$ slope (Figure 30 ). The effective porosity was higher under the planted site (47\%) located on $3 \%$ slope than under planted and unplanted sites located on $8 \%$ slope (35\%) (Figure 30).

Overall, the soil moisture at low matric potential (saturation) decreased with the increase in depth under the land use types.

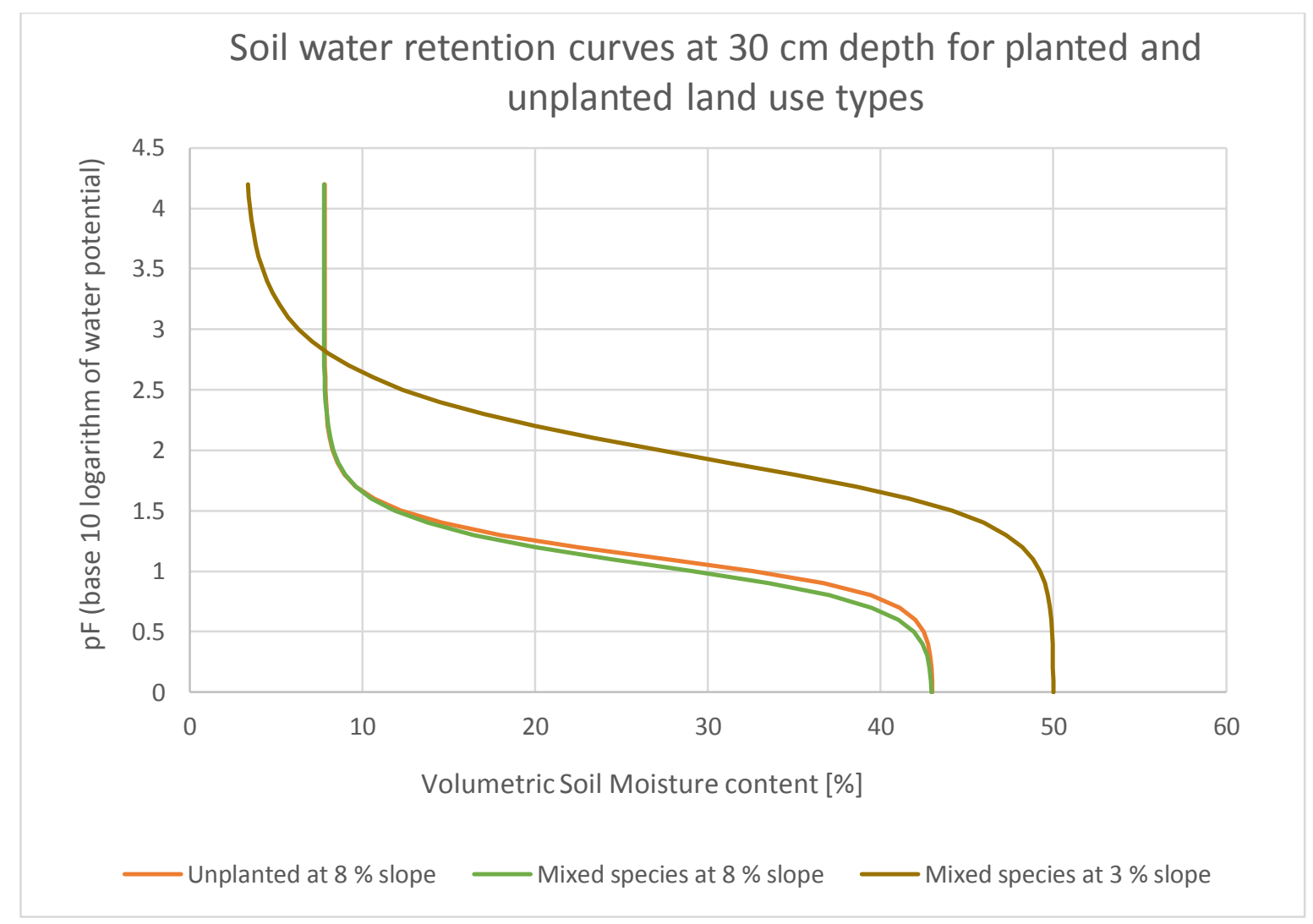

Figure 30. Soil moisture retention curves at $30 \mathrm{~cm}$ depth of planted and unplanted areas located on $3 \%$ and $8 \%$ slope gradients 


\subsubsection{Water balance}

During winter periods when potential and actual evapotranspiration are low, the water balance model suggests there is high runoff and sub-surface drainage (Figure 31). In April to October, precipitation is sufficient to satisfy PE and there is enough water in the soil such that $A E=P E$. The soil is often at saturation so additional rainfall leads to overland flow (in April), and sub-surface drainage (Figure 31). As seasons change to summer, potential and actual evapotranspiration increase with rising temperatures and increased water uptake by plant roots, which dry the soil. This results in negligible overland flow and drainage (Figure 31). The maximum infiltration rate is higher than precipitation, hence no overland flow occurred at any other time besides April when the antecedent moisture conditions are high (as shown in the sensor measured soil moisture data). In general runoff mitigation at Wairio is largely determined by infiltration, evapotranspiration and water retention. 


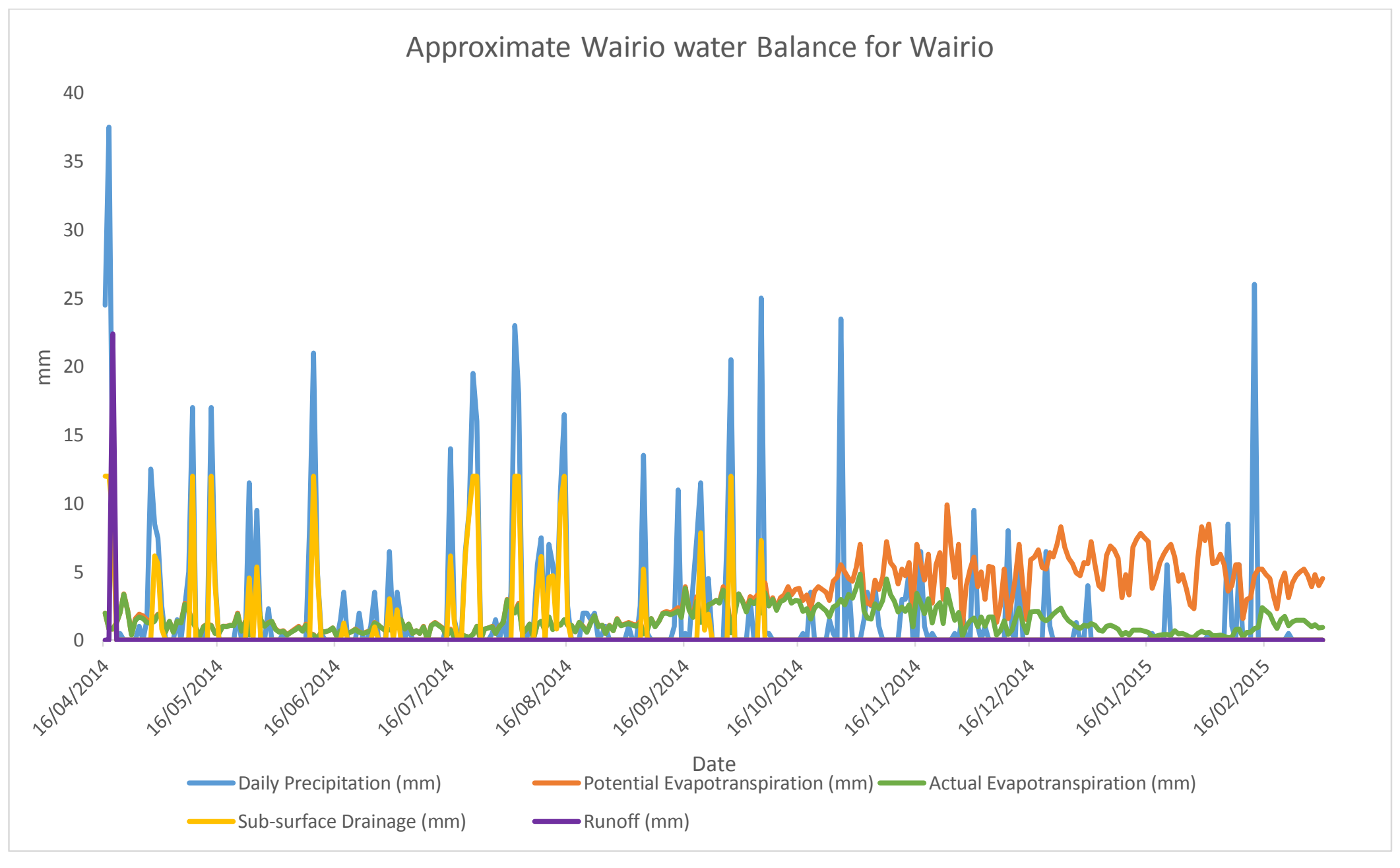

Figure 31 Temporal variation in the components of the water balance at Wairio 
The water balance results show that there is some consistency between the model and sensor observations in tracking changes in soil moisture. Time series plots of the model's soil moisture content and volumetric soil moisture content show that the model predicted similar variation in soil moisture as the sensors in all depths (Figure 32-Figure 34). The model calculates soil water balance over the total upper soil profile, while the measured soil moisture is carried out at the selected depths. Therefore the modelled soil moisture does not always exactly match all sensors, though it tracks the increases and decreases in a similar way (Figure 32-Figure 34). During summer the increase in modelled soil moisture in response to a rainfall event in February is commensurate with those from the sensors, although modelled soil moisture was higher (Figure 32-Figure 34). The modelled soil moisture became wetter than the sensor measured moisture during summer, indicating that lateral outflow may be occurring. In the unplanted site, the modelled soil moisture was below all of the sensor measured soil moisture between October and January (Figure 33). During this period, evapotranspiration is generally high and precipitation is low. However, the low levels of modelled soil moisture could be due to the high evapotranspiration data from the drier climate of Martinborough overestimating the amount of water lost at Wairio. Notwithstanding the effect of evapotranspiration data, the higher levels of sensor measured soil moisture compared to the modelled could also be attributed to some form of water input that could be lateral inflow. Sensitivity analysis of the model parameters was also carried out to determine the extent to which parametric uncertainty accounts for some of the differences between modelled and observed soil moisture.

Generally sensitivity analysis shows that there was some sensitivity of the model (particularly between winter and spring) to the change in the parameters but the consistency in tracking the observed soil moisture was maintained (Appendix 31-Appendix 33). Setting the maximum drainable water storage to a maximum value lowers the modelled soil moisture in winter (Appendix 32). Here the spread between minimum and maximum is distinct but still spans within the range of the observed soil moisture. Between spring and summer, the model is not sensitive to variation in sub-surface drainage and maximum drainable water (Appendix 31Appendix 32). The model was more sensitive to minimum SMD max between winter and spring (Appendix 33). However, since median and maximum SMDmax were used in the actual parameterisation, the model is good enough for soil 
moisture accounting. Overall, the relatively low/no sensitivity of the model to all parameters in summer means that a set of reasonable parameters were used. Accordingly, the assumption of lateral flow and overestimation of evapotranspiration as potential attributing factors to the differences between observed and measured soil moisture could be plausible.

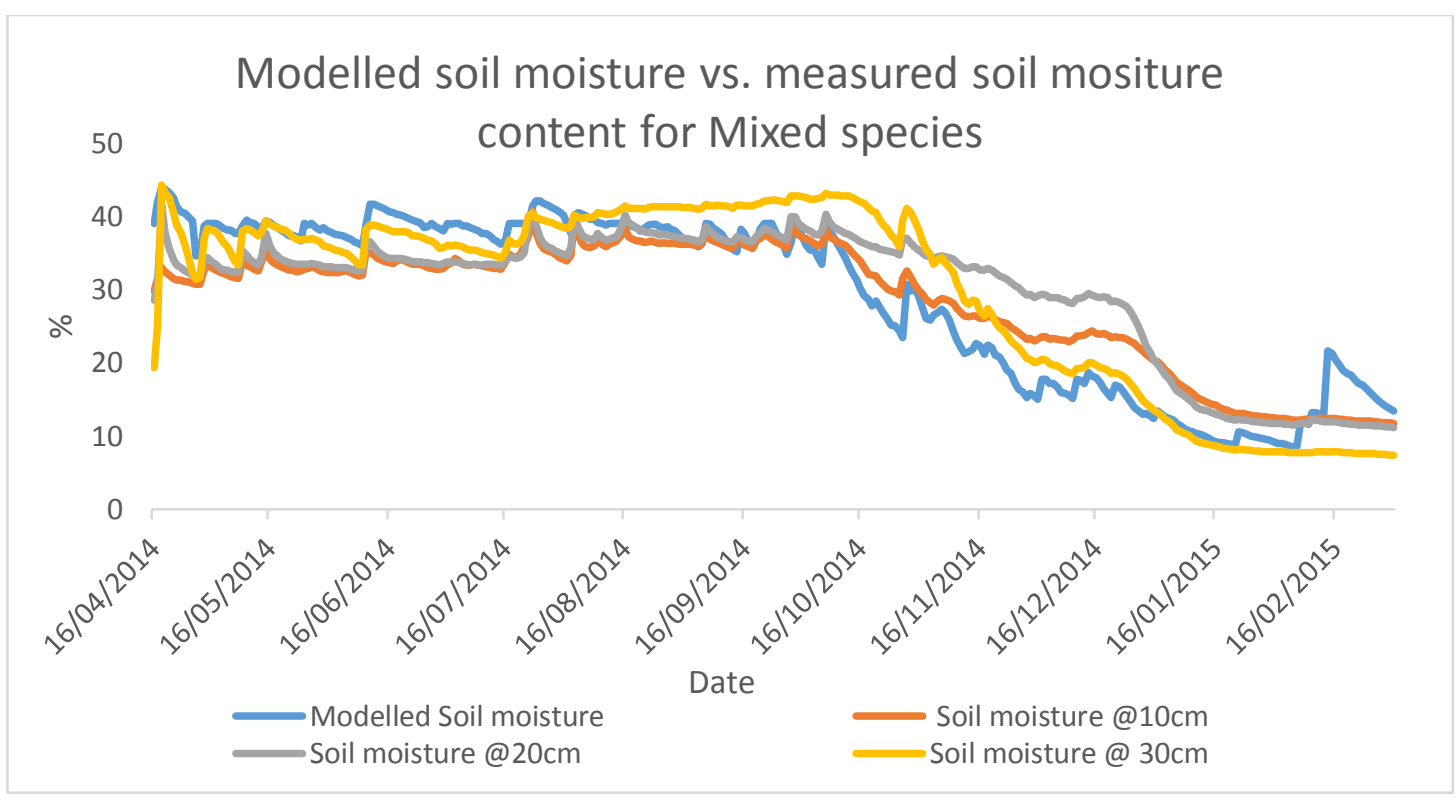

Figure 32 Variation in modelled compared to sensor measured soil moisture in mixed species site on high slope 


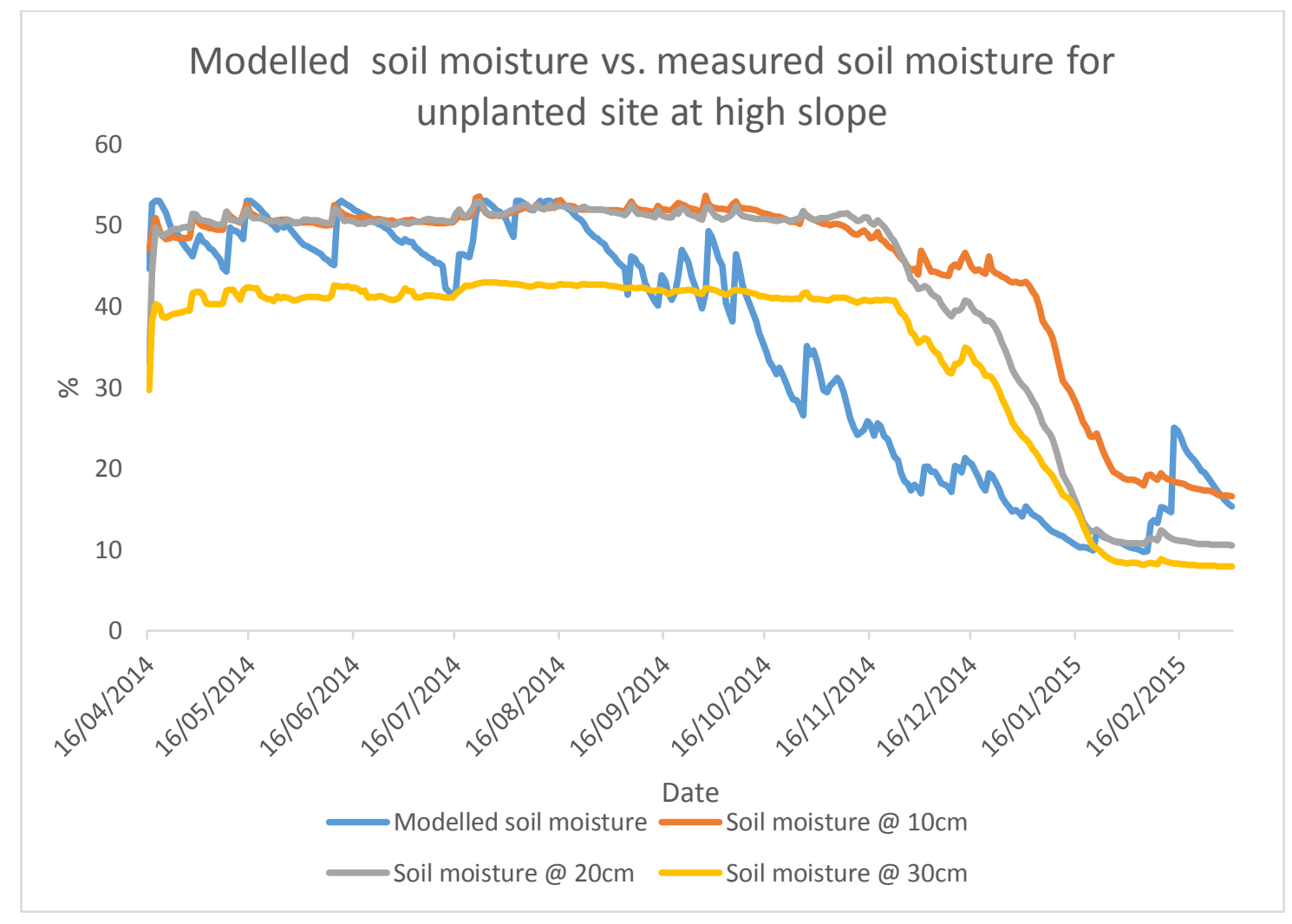

Figure 33 Variation in modelled compared to sensor measured soil moisture in the unplanted site on high slope

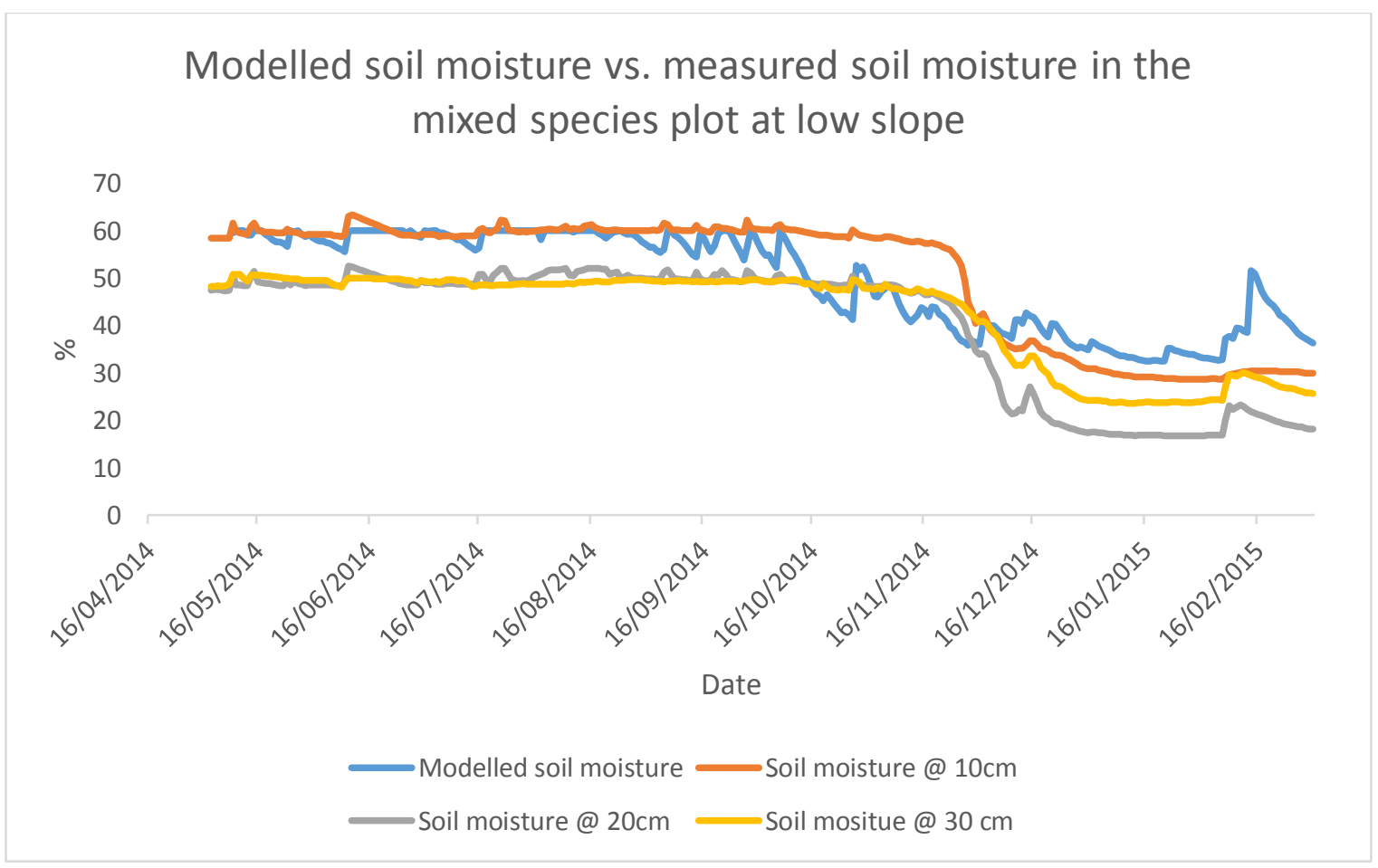

Figure 34 Variation in modelled compared to sensor measured soil moisture in mixed species site on low slope 
Cumulative plots of the water balance components show that during winter, most of the water in the wetland is lost through drainage while in summer it is lost through evapotranspiration (Appendix 25Appendix 27Appendix 29). Cumulative P-AE vs Ro+Dsub plots (Appendix 26Appendix 28 Appendix 30) show that during the wet seasons, the amount of water stored is higher than that is lost to runoff and drainage. In the planted plot on low slope, however, cumulative P-AE is greater than Ro+Dsub all year round meaning there is high water storage on this plot (Appendix 30). This matches the high soil moisture retention results that were reported for this treatment. 


\subsection{Discussion}

\subsubsection{Effect of land use and slope on bulk density}

The range of bulk densities observed at 6 and $18 \mathrm{~cm}$ soil depths at Wairio wetlands (0.4 - 2.3 $\left.\mathrm{gcm}^{-3}\right)$ is consistent with those of wet mineral soils $\left(0.5-2.0 \mathrm{gcm}^{-3}\right)$ from other forested wetlands mentioned in published literature (Trettin \& Jurgensen, 2003; Mitsch \& Gosselink, 2007). Land use change from pasture to trees is known to generally reduce soil bulk density (Carroll et al., 2004). However, at Wairio wetlands, surprisingly, the bulk density was higher in soil under most trees than under grasses, turfs and sedges. This could be due to the initial disturbances associated with planting and human traffic during data collection that may have compacted the soil. However, in the unplanted site, there is no evidence of compaction despite the presence of human traffic associated with data collection. This makes human traffic an unlikely attributing factor to compaction than the planting procedure. Nevertheless, compaction may have confounded the effect of trees on bulk density. Compaction and the effect of trees could not be disentangled within the time frame of this research. Studies by Nisbet \& Thomas (2006) and Archer et al., (2013) show that, once established ( $\sim 5$ years) and with increasing age, trees significantly impact soil properties. Therefore, compaction can be disentangled from the effect of trees over a time frame longer than the monitoring period for this research. However, a research by Carroll et al. (2004) demonstrated the significant influence of young trees of age 0-3 years on soil properties in dry land pastures. Therefore, the saturated soil conditions in Wairio wetlands could have slowed growth of trees and could be another reason why the young trees did not have a significant impact as much the trees in the drier landscape study by Carroll et al. (2004). It is therefore essential to continuously monitor the bulk density of soils under the land uses to fully understand their effects and the time scale over which they become significant.

As expected, bulk density increased with soil depth under both trees and unplanted areas (Figure 11). However, the magnitude of increase was lower under sites planted with a mixture of tree species (22\%) than in unplanted (33.1\%), cabbage tree (31.4\%) and manuka tree sites (38\%). Root penetration and increased biological activity in subsurface layers under tree plantations tend to generate macropores and reduce bulk density (Neary et al., 2009; Ceballos et al., 2013). The low magnitude of increase with depth in sites planted 
with a mixture of tree species however, cannot be sorely attributed to tree root penetration into the subsurface, despite the possibility of this occurring for the 4-year-old trees of $2 \mathrm{~m}$ average height. This is because in general the relative contribution of land use to the change in soil properties decreases with increasing soil depth. Zhang et al. (2012) observed that the impact of anthropogenic intervention on soil properties is generally high in the first $10 \mathrm{~cm}$ depth, while natural factors such as soil series and geology contribute significantly at deeper depths. In wetlands, factors such as ground water level interact with the soil natural factors to influence soil properties at deeper depths. However, for long-term implications, it might be sustainable to reduce bulk density at deeper depth where compaction is high, so trees might serve this purpose as they grow.

Contrary to expectations, soil bulk density under unplanted sites was lower than for sites planted with a mixture of tree species at $3 \%$ slope within $6 \mathrm{~cm}$ depth (Figure 12). Similarly, at $8 \%$ slope the low bulk density under unplanted sites compared to manuka, mixed species and cabbage tree sites within $6 \mathrm{~cm}$ depth was a striking result. This again could be attributed to compaction associated with initial disturbances during planting, the young age of trees, and the low percentage of tree survival at $3 \%$ slope. Despite these results, the potential of trees is highlighted by the low bulk density in soils under the newly established manuka ( 2 years) compared to all other land use types at $3 \%$ slope.

At $18 \mathrm{~cm}$ depth, cabbage tree sites had higher bulk density than the other three land use types at $3 \%$ slope while no differences existed between land use types at both $6 \%$ and $8 \%$ slopes. The decrease in relative impact of land use at this depth, coupled with the young age of trees can be attributed to these results. Soil under the mixed tree species, manuka and cabbage trees might still possess the memory of the characteristics of the previous wetland grasses, sedges and turfs, hence the similarity among the land use types. It is necessary to conduct further investigation on the change in bulk density over time as the trees grow.

Overall, sites planted with manuka, cabbage trees and a mixture of tree species did not consistently have lower bulk density more than unplanted sites under all slope positions. This does not necessarily mean that trees cannot ameliorate bulk density better than wetland grasses, sedges and turfs, but rather over time, as they grow, the effect is easily recognisable. 


\subsubsection{Effect of land use on field saturated hydraulic conductivity}

As expected, soils planted with a mixture of tree species and cabbage trees had higher saturated hydraulic conductivity than those in unplanted sites. These results are in line with several other findings that reported high hydraulic conductivity rates in soils restored with trees, though mostly in terrestrial areas (Marshall et al., 2009; Bonell et al., 2010; GonzalezSosa et al., 2010; Archer et al., 2013). Increased saturated hydraulic conductivity under trees is associated with increased root biomass and fauna activity that increase macropores. Cabbage trees are able to form rhizomes with dense real roots that deeply extend into the soil (Simpson, 1997), and these could be contributing to the creation of conduits for preferential flow. Generally, based on the species description in section 3.8, root biomass would be expected to be high in the mixed species plot due to a combination of various root morphologies. However, there is also a high probability of interspecific competition between species, which reduces the full potential of each individual specie to grow optimally. Therefore cabbage trees may rapidly develop roots when there is no competition from other species.

The saturated hydraulic conductivity findings are however, surprisingly contrasting the high bulk density results in sites with mixed species. It is also surprising that soil under cabbage trees and unplanted areas has similar bulk density but different hydraulic conductivities (lower in the latter). This could be attributed to soil organic matter clogging the soil pores in the unplanted site and disrupting the conduit network that would otherwise increase hydraulic conductivity. The ability of tree roots to create by-pass macro-conduits results increased hydraulic conductivity even if micro-pores are blocked by soil organic matter. The relationship between bulk density and saturated hydraulic conductivity was not analysed in this research, but ideally, bulk density should have been low in the planted sites as it represents an increase in pore size associated with the increase in the ability of the soil to conduct water. However, saturated hydraulic conductivity is more of an indicator of pore continuity in addition to pore size and, may not directly relate to bulk density (Gebhardt et al., 2009). Another possible explanation for the contrasting results could be the difference in sensitivity between bulk density and saturated hydraulic conductivity following land use change over time. In support of this assertion, Hu et al. (2012) observed a more rapid temporal response of saturated hydraulic conductivity than of bulk density. These results 
were derived from four transects with different land use types, i.e. mixed shrubs (unchanged for 50 years), almond (previously farmed and abandoned for 10 years), pea shrubs (abandoned for 30 years) and bunge needle grass (abandoned for 20 years).

Generally, topography and vegetation interactively influence hydraulic conductivity by affecting surface sealing, crusting, soil moisture and organic matter content (Casanova et al., 2000; Mohanty \& Mousli, 2000; Raoof, 2011). Unexpectedly, in this research, the effect of land use was not significantly influenced by the change in slope. This could be due to the small and unequal number of samples between slope categories which are as a result of the challenges encountered during sampling, particularly on flat areas ( $<3 \%$ slope).

Most research on hydraulic conductivity in wetlands has focused on peatland soils (Letts et al., 2000; Andersen, 2003; Mitsch \& Gosselink, 2007) and there is lack of data that can be used as reference for forested wet mineral soils. One available study by Halabuk, (2006) reported a median saturated hydraulic conductivity value of $167.08 \mathrm{~mm} / \mathrm{hr}$ for an alluvial top soil covered by reed and sedge in a wetland in Slovakia. This value could potentially be useful as reference because soils at Wairio have alluvial deposits and some reeds and sedges, though this is not the dominant vegetation type. This means that soils with high median saturated hydraulic conductivity $(11.57 \mathrm{~mm} / \mathrm{hr})$ under cabbage trees in Wairio are $93 \%$ slower at transmitting water than the soils in the reed and sedge dominated wetland in Slovakia (167.08 mm/hr). The low median saturated hydraulic conductivity $(4.91 \mathrm{~mm} / \mathrm{hr})$ in soil under unplanted sites with sedges, turfs and grasses in Wairio is $97 \%$ slower at transmitting water than the soil in the reed and sedge dominated wetland in Slovakia (167.08 $\mathrm{mm} / \mathrm{hr}$ ). This comparison indicates that it might take considerably a long period of time for Wairio wetlands to reach this level (which may not necessarily be a desirable target), but the salient point here is there is potential for improvement in hydraulic conductivity as the trees grow over time.

\subsubsection{The relationship between land use, slope gradient and soil organic carbon}

Average soil organic carbon decreased with increasing soil depth in all land use types as shown in Figure 15. Similar results were reported by Ahamad Dar \& Somaiah (2015); Jobbágy \& Jackson (2000) and Wei et al. (2013). These findings are in line with the observed bulk density results and can be attributed to compaction, coupled with the possibility of 
slow cycling of soil organic carbon and poor root distribution at deeper depths. The relative proportion of slow cycling soil organic carbon pool generally increases with soil depth and is more likely to carry the imprint of previous vegetation for a long time (Paul et al., 1997; Ehleringer et al., 2000; Jobbágy \& Jackson, 2000). Grasses, wetland turfs and sedges were previously the dominant vegetation for a long time at the sites planted with trees at Wairio wetlands. Grasses have shallow root profiles compared to trees (Jackson et al., 1997), and the vertical distribution of soil organic carbon is partly determined by root distribution. Therefore, the decrease in soil organic carbon under trees with depth can be attributed to the soils having the memory of the previous grasses, turfs and sedges. Given that root penetration is expected to contribute to biomass accumulation, over time, soil organic carbon under trees might increase with depth as the trees grow. This is plausible because roots of cabbage trees and manuka at Wairio wetlands were observed at more than $20 \mathrm{~cm}$ depth (Appendix $17 \& 18$ ).

The average soil organic carbon within the $18 \mathrm{~cm}$ soil horizon in all four land use types ranged from $1 \%$ to $7.5 \%$ across the slope gradient. This is about a quarter of the typical soil organic carbon content of an intact wetland mineral soil (less than $12-20 \%$ ) (Mitsch \& Gosselink, 2007). This could be because the recovery of soil organic carbon sometimes requires a long period, i.e. a minimum of 3-10 years (Meyer et al., 2008) and a maximum of up to 100 years (Moreno-Mateos et al., 2012). The re-establishment of trees at Wairio wetlands is still within the minimum carbon recovery period. If soil carbon concentration increases linearly at $3 \%$ per year, it would reach levels of wet mineral soils in just over 5 years.

As expected, soil organic carbon was higher in sites planted with manuka and cabbage respectively than unplanted sites within $6 \mathrm{~cm}$ depth when averaged across all slope gradients. This can partly be explained, by the high net primary production and the accumulation of recalcitrant organic matter of trees that is difficult for microbes to decompose. Species such as manuka have an intricate root system and play a vital role in carbon sequestration through high biomass production (Scott et al., 2000; Stephens et al., 2005). However, similarly, some wetland sedges and turfs are also effective carbon builders (Campbell, 2000; Trettin \& Jurgensen, 2003). 
Soil organic carbon was higher at low slope (3\%) than at high slope (8\%) for unplanted and manuka. These results are consistent with research reported by Lal, (2009) \& Zucco et al. (2014). At lower slope positions, the higher soil moisture content promote anaerobic microbial activity, which results in accumulation of soil organic carbon (Sajedi et al., 2012; Gabarrón-Galeote et al., 2015). In this study, soils at 3 \% slope were observed to be wetter than soils at $6 \%$ and $8 \%$ slope under all vegetation types as discussed in sections 4.6 .4 and 4.6.5.

Pairwise comparisons of land use at varying slope gradients showed similarity in soil organic carbon levels at both 6 and $18 \mathrm{~cm}$ depths under all land use types at $8 \%$ slope. A possible explanation for the observed result is that wetland sedges, grasses and turfs can be as effective as trees in fixing carbon. Trettin \& Jurgensen (2003) and Campbell (2000) reported that sedges, grasses and turfs are major sources of soil organic matter, contributing $14 \%$ of the total net primary production in swamps. Moreover, the sedges, grasses and turfs at Wairio have been present for a long time to contribute significantly to soil organic carbon content. At $6 \%$ slope, soil organic carbon was high under manuka sites than unplanted sites highlighting the possibility of a combination of manuka being a high carbon fixer, together with wetter soils under $6 \%$ compared to $8 \%$ slope.

At $3 \%$ slope, the low soil organic carbon content under sites planted with a mixture of tree species compared to unplanted, manuka and cabbage is an unexpected result. This is because mixed species are older (3-4years) than manuka and cabbage trees (1-2 years). The result could be due to the low vegetation coverage in mixed species sites at the low slope position. Long periods of high soil moisture levels and inundation at the low slope positions were associated with higher mortality in the wetland, despite being favourable for carbon accumulations. Hence, the presence of few trees in these mixed species sites could have contributed to less organic carbon accumulation. Tree species such as kohuhu (Pittosporum tenuifolium) and twiggy tree daisy (Olearia virgate) have low tolerance to water logging compared to species such as cabbage tree (Cordyline australis), kahikatea (Dacrycarpus dacrydiodes) and manuka (Leptospermum scoparium) (Hawke's Bay Regional Council, 2004).

The variation of soil organic carbon with slope and land use is in line with low bulk density observations under unplanted, manuka and cabbage tree compared to mixed species sites 
at $3 \%$ slope gradient. Generally, soil organic carbon is inversely correlated to bulk density; it increases soil stability, reduces compactibility, thereby reducing bulk density.

\subsubsection{Soil organic carbon pool under the different land use types}

Results showed a maximum value of $0.04 \mathrm{~kg} \mathrm{~m}^{-2}$ soil organic carbon pool in the first $6 \mathrm{~cm}$ and $0.03 \mathrm{~kg} \mathrm{~m}^{-2}$ at $18 \mathrm{~cm}$ under cabbage tree sites at 3 and $8 \%$ slope. The same value $(0.04$ $\mathrm{kg} \mathrm{m}^{-2}$ ) was estimated within the first $6 \mathrm{~cm}$ depth in manuka sites at $6 \%$ slope. The soil organic carbon pools between land use types did not differ significantly within the soil horizons but decreased with increasing depth. There is a paucity of research on the values of soil organic carbon pools for forested wetlands and most researchers tend to use values for upland forest soil $\left(9-15 \mathrm{~kg} \mathrm{C} \mathrm{m}^{-2}\right.$ within $0-10 \mathrm{~cm}$ ) as targets for restoration (Trettin \& Jurgensen, 2003; Fissore et al., 2009). Forested wetland soils, however, have a higher potential to store more organic carbon than upland forests because of anaerobic conditions and a higher proportion of active soil organic carbon (Cheng \& Kimble, 2000; Fissore et al., 2009). Among a few of the forested wetland studies, Meyer et al. (2008) reported a $1-1.3 \mathrm{~kg}$ $\mathrm{C} \mathrm{m}^{-2}$ yield in the 0-10 cm soil fraction after planting a mixture of trees, wetland turfs and shrubs as a form of restoration in Nebraska. Yu et al. (2012) reported a maximum of $3.52 \mathrm{~kg}$ $\mathrm{C} \mathrm{m}^{-2}$ in the $0-30 \mathrm{~cm}$ soil fraction of a forested wetland in Yellow river delta, China. This means that, with a maximum of $0.04 \mathrm{~kg} \mathrm{C} \mathrm{m}^{-2}$, Wairio wetlands have approximately $97 \%$ lower organic carbon pool than that of the restored forested wetland in Nebraska and $99 \%$ lower than that in China. It is worth noting the difference in horizon thickness between Wairio $(0-6 \mathrm{~cm})$, Nebraska $(0-10 \mathrm{~cm})$ and China $(0-30 \mathrm{~cm})$ and other factors such as climate, species type and length of time since trees were established that contribute to variation of soil organic carbon. The wetlands in Nebraska were about 8 years old following restoration (Meyer et al., 2008) and the forested wetland in China has been established for a long time (age not specified). Nevertheless, organic carbon pool values from the studies in Nebraska and China depict potentially useful targets. If soil organic carbon per unit area in Wairio wetlands increases at a rate of $0.04 \mathrm{~kg} \mathrm{C} \mathrm{m}^{-2}$ per year, it would take about 29 years to match the levels found in the restored forested wetland in Nebraska. If Wairio wetlands carbon stocks at 6 and $18 \mathrm{~cm}$ depths are combined, the maximum value will be $0.07 \mathrm{~kg} \mathrm{C} \mathrm{m}^{-2}$ under cabbage tree sites. It would take just over 16 years to match the $1-1.3 \mathrm{~kg} \mathrm{C} \mathrm{m}^{-2}$ values of Nebraska and just over 50 years to match the $3.52 \mathrm{~kg} \mathrm{C} \mathrm{m}^{-2}$ of forested wetlands in China. 
This means it may take a long period for the trees at Wairio to significantly enhance the soil organic carbon pool. Continuous monitoring may help in understanding the timescale over which this might happen.

\subsubsection{Effect on volumetric soil moisture content (lab derived)}

This section discusses the results of volumetric soil moisture content derived from gravimetric measurements on samples collected in all four land use types at $6 \mathrm{~cm}$ and $18 \mathrm{~cm}$ depths. Volumetric soil moisture content was more highly variable at $18 \mathrm{~cm}$ soil depth than at $6 \mathrm{~cm}$ under all land use types, indicating the possibility of a highly fluctuating water table. High and or fluctuating water tables that create alternating aerobic and anaerobic conditions are common in wetlands (Sajedi et al., 2012).

Within the upper $6 \mathrm{~cm}$ and the lower $18 \mathrm{~cm}$ soil depths, unplanted sites and cabbage tree sites were wetter than manuka and mixed species sites at $3 \%$ and $8 \%$ slope gradients. It is a plausible result given that soils under cabbage trees are as wet as unplanted soils. This is because cabbage trees are still young and may not be contributing much change to soil conditions yet. At $6 \%$ slope, the similarity in soil moisture levels between manuka and unplanted sites can again be attributed to manuka species being young to effectively contribute much change to soil conditions. Trees generally have higher evapotranspiration rates than grasses and turfs as exhibited in mixed species sites (Figure 18Figure 19). In wetlands the presence of a high water table, signifies that land use alone cannot explain this result. It could be that ground water contributes more to variation since it is a wetland environment.

As expected, the volumetric soil moisture content increased with the decrease in slope under all land use types at both 6 and $18 \mathrm{~cm}$ soil depths. Low slope areas receive water from upslope areas and drain more slowly than upper slope areas, thus are often wetter. This is consistent with previous findings by Qiu et al. (2001); Sajedi et al. (2012) who reported a negative correlation between slope and soil moisture content. These results match with the high soil organic carbon at low slope and low soil organic carbon at high slope.

\subsubsection{Effect of land use on volumetric soil moisture content (sensor measured)}

This section discusses the results of volumetric soil moisture content estimated using CS620 reflectometers connected to data loggers. These were installed at 10, 20 and $30 \mathrm{~cm}$ depths 
in three plots, one planted with a mixture of tree species at high slope (8\%), one unplanted at high slope ( $8 \%)$ and one planted with a mixture of tree species at low slope (3\%).

In general, soil moisture at $10 \mathrm{~cm}, 20 \mathrm{~cm}$ and $30 \mathrm{~cm}$ depths for the land use types correlated with rainfall events, increasing rapidly after precipitation and decreasing during dry periods, although sometimes there was a slight lag in response at $30 \mathrm{~cm}$ depth. This is consistent with the water balance model and the findings in the study by Gao et al. (2014), who observed a positive correlation between precipitation events and surface soil moisture under grasslands, croplands, fallow fields and orchards.

In the site planted with a mixture of tree species at $8 \%$ slope, the increase in average volumetric soil moisture with depth in all seasons except summer indicates the likely presence of conduits created by tree roots that allow water to flow into deeper depths. This conforms to the high rate of saturated hydraulic conductivity observed under planted sites in this study. It is also consistent with Fu et al. (2003) who found that high infiltration rates under woodland areas increased the level of soil moisture. This suggests that high permeability of the $30 \mathrm{~cm}$ soil horizon connects precipitation to shallow ground water causing a rise in water table followed by the response of the soil moisture meter at $30 \mathrm{~cm}$ depth (Figure 22). There could also be sub-surface lateral inflow of water feeding into soil profile. The decrease in soil moisture in all depths in summer is not surprising and can be ascribed to high evapotranspiration as demonstrated by the water balance model (because of high temperatures), low rainfall, surface roughness and reduced ground water level.

In the unplanted site located at $8 \%$ slope, the level of soil moisture was higher at both 10 $\mathrm{cm}$ and $20 \mathrm{~cm}$ depths than at $30 \mathrm{~cm}$ in all seasons. This can be attributed to low interception and reduced evapotranspiration in wetland turfs and grass species, which result in the increase in surface soil moisture. The possibility of shallow roots and increased compaction with increasing depth in this site, means there could be reduced ground water recharge by natural precipitation in deep layers and hence low soil moisture content at $30 \mathrm{~cm}$ depth.

In the planted site located at $3 \%$ slope the soil moisture content was higher at $10 \mathrm{~cm}$ than at $20 \mathrm{~cm}$ and $30 \mathrm{~cm}$ depths. This pattern was different from the planted site on $8 \%$ slope. This represents the controversial relationship between vegetation, water and microtopography. The observed pattern could be ascribed to the low slope position where 
drainage is low compared to high slopes. This low drainage probably limits root growth to surface layers $(0-10 \mathrm{~cm})$ where aerobic conditions regularly prevail, and as such, the pathways for water flow become concentrated here rather than in the $20 \mathrm{~cm}$ and $30 \mathrm{~cm}$ layers. This will increase soil moisture content at shallow depth more so than at deeper depths.

Comparisons of temporal variations of soil water profiles between land use types showed that the unplanted site was wetter than the planted site at $8 \%$ slope. The results were consistent for all seasons and depths. These observations match with lab based volumetric moisture results from this study, which showed that unplanted sites were wetter than planted sites at the same slope under all measured depths $(6$ and $18 \mathrm{~cm})$ in all seasons. This is because trees in the mixed species plot intercept and transpire more water than the short wetland turfs and grasses. The trees present in the mixed species site include Pittosporum tenufolium, Croposma robusta and Cordyline australis that have large leaves (as highlighted in section 3.8.1), hence their combined effect on interception is high. The average height of trees in the mixed species plot was $2.03 \mathrm{~m}$ at $82 \%$ survival rate (Table 10) therefore it is plausible to envisage the significant evapotranspiration and interception influence of trees. This is supported by Mu et al. (2003) and Yang \& Rong (2007) who reported that planting trees reduces soil moisture in the surface soil layers. Conversely, the direct exposure of unplanted sites to solar radiation and the high transpiration rates of grasses in the presence of abundant water (Nisbet, 2005), can result in drier conditions. This explains the commonly observed pattern of high soil moisture content under trees where there is shading compared to grasslands where there is increased exposure to direct solar radiation (Nisbet, 2005; Sajedi et al., 2012).

The mixed species site at the low slope was wetter within 10 and $30 \mathrm{~cm}$ soil layers than both the unplanted and planted sites at the high slope (Figure 25 \& Figure 27). This was consistent in all seasons except for summer where the moisture levels were similar between the unplanted site on high slope and the planted site on low slope within $10 \mathrm{~cm}$ depth. This indicates the possibility of the reduced evapotranspiration impact of trees in autumn, winter and spring at low slope, where drainage of water is low. This also conforms to the review of forests and trees in Chapter 2, and suggestions by Qiu et al. (2001). The persistent water logged and low drainage conditions at low slope, result in poor tree growth, and this is 
evident at the site, where tree survival is $62 \%$ and the average height is $1.78 \mathrm{~m}$ (Table 10). Here the trees are on average, $25 \%$ shorter (height) and $20 \%$ shortfall in survival than the ones in the plot on $8 \%$ slope regardless of the similarity in age and species. In summer, the similarity in the level of moisture content within $10 \mathrm{~cm}$ depth between the planted site on low slope and unplanted on high slope can be ascribed to the reduced impact of trees on low slope. This could also explain the similar results observed at $20 \mathrm{~cm}$ depth in all seasons.

Overall, these results show that planting trees on high slope induces variability and reduces the soil moisture content within $30 \mathrm{~cm}$ compared to unplanted sites at the same slope. This creates space for water flow by reducing antecedent moisture, thereby increasing the ability of the wetland to absorb water for flood mitigation. This effect is however, reduced at low slope where drainage is slow and water table is likely to be close to the surface. These results evoke some questions on whether the presence of trees matters when other variables such as rainfall properties and slope largely contribute to the variation in soil moisture content. Addressing such a question requires the exploration of opportunities for targeting specific areas where the contribution of trees in the presence of other factors is maximised. The use of spatially explicit tools to explore specific target areas for trees in the wetland is discussed in chapter 5 .

\subsubsection{Land use and matric potential}

The quick response of tensiometers to rainfall in all sites suggests that water is able to move quickly through the $30 \mathrm{~cm}$ soil profile either from the soil surface during a rainfall event through some lateral sub-surface flow (as inferred from the water balance), or as the shallow ground water rises in response to precipitation. Therefore, the assumption of subsurface flow in the conceptual hydrology model presented in section 3.2, may be plausible. The fast movement is likely through macro-conduits created by roots and or earthworms since the soils are generally compact (average bulk density range $1.3-1.7 \mathrm{gcm}^{-3}$ ) as has also been observed by Marshall et al. (2009). Earthworms were observed during soil sampling, although their characteristics and population density were not recorded. Tensiometers in the planted site on low slope remained saturated for most of spring indicating the water table is high and close to the surface, thereby limiting drainage. These findings match with soil moisture results because standing water was observed in this site. The high variation of matric potential at $10 \mathrm{~cm}$ depth in all sites can be attributed to water use in the root zone by 
vegetation and slope position (Scanlon et al., 2005). In the planted site on high slope the matric potential was higher (ranging between -0.6 to $-0.8 \mathrm{mH}_{2} \mathrm{O}$ ) than the unplanted site on the high slope $\left(-0.4\right.$ to $\left.-0.6 \mathrm{mH}_{2} \mathrm{O}\right)$ and the planted site on low slope $\left(-0.2\right.$ to $\left.-0.4 \mathrm{mH}_{2} \mathrm{O}\right)$. This means the soil was drier in the planted site on high slope, which is likely to be a reflection of effective removal of water by trees from the root zone through hydraulic lift and transpiration, as well as high drainage on the high slope area. The high matric potential (less negative) at $10 \mathrm{~cm}$ depth in the planted site on low slope position suggests that when the water table is high and close to the soil surface, the effect of trees on reducing soil moisture content through hydraulic lift and transpiration is less significant compared to when they are on high slope areas. The consistent fluctuation of matric potential around saturation at both 10 and $30 \mathrm{~cm}$ depth in the planted site on low slope more than other sites is an indication of the water table being near the soil surface. This is reinforced by the tensiometer readings of $0.2 \mathrm{mH}_{2} \mathrm{O}$ at $10 \mathrm{~cm}$ depth and $0.4 \mathrm{mH}_{2} \mathrm{O}$ at $30 \mathrm{~cm}$ depth indicating standing water of $0.1 \mathrm{~m}$ above the ground.

\subsubsection{Land use and soil water retention}

The high soil moisture at saturation within $10 \mathrm{~cm}$ depth in unplanted sites compared to planted sites at $8 \%$ slope indicates that the unplanted sites can store more water (Figure 29). This may be attributed to the high soil organic carbon content and low bulk density under the unplanted site at high slope gradient. Generally, the higher the organic matter and carbon content, the greater the water storage capacity of the soil (Wang et al., 2013). These results seemingly contrast with the saturated hydraulic conductivity observations (high under planted) and other findings by Wang et al. (2013). Water retention represents pore size distribution and geometry, which in turn have a bearing on saturated hydraulic conductivity (Nasta et al., 2013). Therefore, most studies have found high saturated hydraulic conductivity and water retention capacity in soils planted with trees compared to other vegetation types such as grasses (Meyer et al., 2008; Zhang et al., 2012; Wang et al., 2013). The contrasting observations of high saturated hydraulic conductivity and low soil water retention in the planted site can possibly be due to the presence of a few but highly connected pores that form conduits for water flow. The presence of large and continuous pores increases saturated hydraulic conductivity (Gebhardt et al., 2009; Alaoui et al., 2011). The young tree species might have created a few continuous pathways, hence low storage 
capacity but high hydraulic conductivity. Further research on the soil pore system of the land use types at Wairio would be helpful to understand these results.

The planted site located on low slope retains more water within 10 and $30 \mathrm{~cm}$ depth than both unplanted and planted sites on high slope. These results are also supported by the water balance model (Appendix 30). This is expected since soil organic carbon was high and bulk density was lower at low slope. Here, slope could be contributing more to variation in water storage capacity than variations in vegetation. The significance of vegetation cannot be robustly inferred from this dataset as data from the unplanted site on low slope were not available.

The decrease in water retention with increasing depth under all land use types is consistent with the decrease in soil organic carbon and the increase in compaction with depth. The similarity in water retention in the unplanted and planted sites at $30 \mathrm{~cm}$ soil depth, on $8 \%$ slope could be due to land use having less effect at such depth with other factors such as ground water level and lithology coming into force.

Based on the water balance, it is plausible to highlight that flood runoff mitigation in Wairio wetlands is largely determined by evapotranspiration and water retention. However, for a forested wetland to make a significant dent in the water balance there would be a need to restore a large area. Based on hectarage alone, wetlands may have relatively small effects at large scale but could be beneficial at local scale. Johnston et al. (1990) demonstrated that at least $10 \%$ of a watershed needs to be covered by a wetland for flood flows to be mitigated. 


\subsection{Lessons learnt and aspects overlooked}

\section{Lessons learnt}

- The site presented major difficulties that are commonly faced by researchers studying wetlands. These include limited accessibility to research plots in frequently flooded sites, field equipment not functioning optimally in the uncompromising area, large amounts of time required to finish simple tasks. Sampling strategies had to be altered often and some plots had to be abandoned to overcome the unexpected major difficulties.

- Herbivory on some of the newly planted trees, particularly those not protected by tree guards (grotectors) contributed to the low survival rate (Table 38). This was not anticipated, however, the destruction provided valuable information on the adoption of suitable protection techniques during tree establishment.

- In frequently flooded sites, the unpredictable survival and slow growth of trees and limited accessibility issues made it difficult to conduct before-after type comparisons. Fitting this type of study design for slow growing vegetation (such as trees in a wetland) within the three-year time frame of a PhD is quite challenging. We tried to accommodate this by using some pre-established trees, but of course, we cannot be sure that the unplanted control sites equally represent the previously chosen sites to be planted.

\section{Aspects overlooked}

- The characterisation of carbon content of litter would have provided more information on the role played by vegetation in sequestering carbon. Particularly how much of the carbon is contributed by each vegetation type. Characterisation of biomass data would also act as a quick proxy for the assessment of wetland recovery.

- The characterisation of root architecture and rooting depth of the species in the wetland would have provided supporting information to the observed effect of trees on soil properties. This is however, destructive, time and labour demanding.

- The original intention was for a before-and-after comparison of the 2013 experimental plantings, however the pre-planting data that was collected had to be 
abandoned when the location of the plots was changed due to excessive flooding and lack of access to my original plots. If the abandonment of some of the plots had not occurred, more detailed hydrology and soil data pre-restoration could have provided insight to the degree of disturbance, post-tree planting and also aided to our guidance on the effective restoration strategies.

- The use of a reference site would have provided baseline information for comparison to the results obtained from this research. For example, reference data on soil organic carbon and bulk density would be useful for making reliable estimates of how long it will take for trees to significantly change the soil properties. However, it is worth mentioning that with only $10 \%$ of wetlands remaining in New Zealand, it is quite challenging to find an intact representative reference site that has comparable conditions (i.e. soil morphology, landscape position, vegetation type and hydrological conditions) to those of Wairio wetlands. A potentially suitable reference site for SOC would be Lowe's Bush scenic reserve, near Carterton. 


\subsection{Conclusion}

The data and analysis presented in this chapter from the field experiment conducted at Wairio wetlands between summer 2012 and summer 2014 revealed a number of important insights into the impact of trees, wetland grasses, sedges and turfs on soil physical and hydraulic properties critical for flood runoff mitigation.

There is a potential for the recently established trees to change soil properties for forested wetland flood mitigation. This is shown by the high saturated hydraulic conductivity and soil organic carbon pool under trees compared to wetland grasses, turfs and sedges. Similarly, the wetland grasses, turfs and sedges had a significant impact by increasing the water retention and reducing the bulk density of wetland soils. However, over time, as the trees mature, they may have an even bigger impact on these properties. The age gap between the established tree species ( 2 and 4 years) did not significantly contribute to the observed differences in results. It could be that the age gap at this stage of maturity is too small to warrant significant impact and may be effective as the trees grow older.

The impact of trees and wetland turfs, sedges and grasses varied with the change in topography and soil depth. The differences in the contribution of these land use types to variation in soil properties were more pronounced at high slope and shallow depth of 6-10 $\mathrm{cm}$. Over time, the impact of trees at deeper depths may increase as they develop deep root systems. At low slope, the low tree coverage, reinforced by continuously high moisture conditions that lower survival, particularly of manuka (Leptospermum scoparium), kohuhu (Pittosporum tenuifolium) and twiggy tree daisy (Olearia virgate) species likely contributed to the reduced impact of trees.

The findings from this chapter are derived from spot measurements in some of the accessible areas of the land use types and may not account for detailed spatial variation in topography and soil properties. It would be ideal to obtain knowledge on the extent to which the current tree plantings have contributed to the change in properties on the whole wetland scale. This knowledge will in turn reveal information on specific target areas where if trees are placed, their contribution to the amelioration of soil properties for flood mitigation at wetland scale is maximised. The identification of strategic target areas for planting trees is discussed in chapter 5 . 


\subsection{Aspects that can be considered for the future of this restoration project}

Periodic monitoring of the wetlands will be beneficial to the maximisation of the information provided by this research as way to continuously evaluate ecosystem function in the restored habitat. Specifically the continuous monitoring of soil moisture content, matric potential, bulk density and soil organic carbon to assess whether soil moisture retention improves and compaction decreases with time as the trees grow. These can be carried out cost effectively by adopting telemetry techniques, particularly for soil moisture content and matric potential. Thorough field reconnaissance prior to collecting soil samples for bulk density and organic carbon can guide in choosing sites that are less vulnerable to standing water, thereby reducing travelling time and cost to collect the data.

Construction of precise and detailed water budgets for the use in conjunction with information generated from this research would be an effective guideline for restoration of forested wetlands, especially with the likely increase in wetland restoration projects. This would require the establishment of a climate station at Wairio wetlands to monitor components of water budget such as rainfall, evapotranspiration, wind speed and radiation. It would also be useful to collect data on leaf area index of vegetation at the wetland as a complement to water budgets to explain spatial and temporal variation in evapotranspiration in plots for soil moisture accounting. Time and cost constrains are however, the majors factors that hinder the availability of detailed water budgets and leaf area index data (Beissel \& Shear, 1997).

Given the influence of invasive grasses, wind exposure and herbivory on the survival of newly established plants, it may be necessary to use protective material such as grotectors to increase the chances of survival of trees. It is worth noting that, the use of grotectors is an additional cost of tree re-establishment but in the long-run it will not only offer protection from herbivory, but also reduce competition from wetland grass species. The increase in survival rate may justify the additional cost. 


\section{Chapter 5-Strategies to determine appropriate target areas optimise flood runoff mitigation in Wairio wetlands.}

\subsection{Introduction}

Where there is spatial variability in both ecological processes and soil properties, there are opportunities for optimising the delivery of ecosystem services if interventions are specifically targeted on areas where they are most beneficial (e.g. O'Connell et al., 2007; Wade et al., 2008; Jackson et al., 2013). The study discussed in chapter 4, provides a foundation for informing decisions on the use of trees as flood mitigating tools in wetlands. The study showed the effect of trees on areas where they currently stand but it is not sufficient for the identification of specific target areas where if the trees are placed, their effect or benefit is maximised. Spatially explicit information is crucial for the identification of target areas for the placement of trees during restoration in order to maximise their benefits. There is lack of research that explores target areas for placing trees in wetlands in order to optimise flood risk mitigation and this chapter seeks to address that research gap.

Typically, the establishment of trees during wetland restoration is targeted on areas where they are likely to survive (Casanova \& Brock, 2000; Frieswyk \& Zedler, 2007; Johnson, 2012). However, this does not necessarily mean trees will have a significant ecological impact in these areas. For example, trees may be planted on well-drained soils of high permeability and high nutrient levels with the primary goal of ensuring survival for the secondary goal of contribution to flood management. These soils are, however, inherently permeable so already absorb and retain large volumes of water. Therefore, the benefit of trees as flood mitigating tools would not be maximised and placing them on these areas would be an inefficient use of resources. Conversely, poorly drained soils of low permeability are unlikely to be optimal for the survival and rapid growth of most trees. However, particular tree species with characteristics that raise their chances of survival on such areas could make a significant impact in improving the permeability and absorption capacity of these soils. This evokes question of where to strategically target tree planting to maximise benefits (i.e. flood mitigation) and what approaches can be adopted to enhance their growth and survival in the target areas? Turning the focus from where trees can easily survive to where they 
might best enhance flood mitigation or other outcomes is important for guiding the effective use of trees.

Exploration of the strategic areas for targeting interventions is a new, developing and challenging research area, which is increasingly adopted as scientific research shifts more towards the generation of policy-relevant information. The generation of policy-relevant information requires that ecosystem components and processes driving the provision of ecosystem services are quantified (Nelson \& Daily, 2010) (e.g. as in chapter 4), and that areas where optimal delivery of the services occurs (i.e. flood risk management, in this case) are spatially delineated and visualised (Nisbet \& Thomas, 2003; Robinson et al., 2013).

Tools enabling the spatial delineation and visualisation of areas suitable for interventions optimising ecosystem service provision facilitate the use of information by a wide range of stakeholders involved in decision-making on resource management for sustainable development. However, they are new and at this stage, still need significant further development (Bagstad et al., 2013; Jackson et al., 2013) as discussed in section 2.9. This chapter demonstrates the application of one of such tools, the Land Use Capability Indicator (LUCI) (Jackson et al., 2013). LUCI is applied to determine areas where interventions (i.e. planting trees) can be targeted to improve permeability and storage for maximisation of the absorption and retention of water for flood mitigation in Wairio wetlands. Limitations associated with the quality of digital elevation models representing topography in the applicability of LUCI to wetland conditions are revealed as a contribution to the tool's continued development for use in optimisation of ecosystem service delivery. Findings from this chapter can be useful for decision-making on the effective use of trees as flood mitigating tools in forested wetlands. Furthermore, wetland restoration projects aiming to re-establish trees for ecosystem service provision in New Zealand and around the world can benefit from use of this information. Guidelines based on this information are provided in chapter 6.

\subsection{Description of Land Use Capability Indicator (LUCI) tool}

LUCI is an ecosystem services support framework extended from the Polyscape framework (Jackson et al., 2013). It is a GIS-based negotiation tool that explores and indicates the capability of a landscape to deliver ecosystem services which vary as a result of changes in 
land management. Services considered include flood risk management, carbon sequestration, erosion management, agricultural production and biodiversity conservation through habitat connectivity. LUCI enables the visualisation of impacts that different decisions have on the delivery of the ecosystem services. It identifies areas of high existing value in terms of ecosystem service provision, areas where maximum benefits can be achieved following certain interventions and areas where intervention could reduce optimum delivery of services. Conceptually, the tool explores ecosystem services trade-offs and synergies at field, watershed and landscape spatial scales. Interventions for ecosystem service delivery are prioritised based on the area they affect as a whole, not just the areas directly modified. Practically it is fast running (offers exploration of scenarios in real time), can incorporate or be incorporated into other tools such as INVEST, and can be run using nationally available data.

The current version has both Tier 1 and Tier 2 tools. Tier 1 tools explore ecosystem services individually or in batches, their trade-offs and synergies. Tier 2 tools explore time series operations and use the cascading approach to connect hydrological response units in the landscape. Exploration of the ecosystem services is made possible by the presence of fourteen algorithms. Eleven of the algorithms evaluate the recent and likely impacts of land management change on the supply of ecosystem services. These ecosystem services include agricultural productivity, flood mitigation, habitat suitability, habitat connectivity, methane emissions, nitrous oxide emissions, river flow estimation, nitrogen loading, erosion and sediment delivery and carbon stocks and fluxes, and phosphorus loading. The twelfth algorithm computes the trade-offs and synergies among the ecosystem services. The thirteenth algorithm pre-processes the inputs and generates scenarios. The fourteenth algorithm allows stakeholders to input their views and modify any data flaws based on their knowledge of the landscape under consideration. These algorithms work with a digital elevation model with soil and land cover data as inputs. The ideal resolution of the digital elevation model is generally considered to be 5-10 m pixels in the $x$, y plane (Jackson et al., 2013). The algorithms quantify and classify the performance of ecosystem services for each grid of the elevation data hence adherence to the recommended DEM resolution is necessary. The modelling process of the tool is illustrated in Figure 35. 
The primary outputs of LUCI are GIS "traffic light" coded maps showing areas where management decisions are likely, or not likely, to provide the intended outcomes of ecosystem services supply. The traffic light system symbolises the opportunities to intervene on locations and these can be negotiated among stakeholders. For instance, green colours indicate or give the right to proceed with interventions on stated locations, yellow colours indicate that interventions on locations should be carried out with caution and red colours indicate that resource managers should stop and think through before making decisions to intervene on areas highlighted as ecosystem provision in these areas is already high. This visualisation system is based on the classification of pixels in the landscape (from here on referred to as landscape features) into five categories. The five categories indicate the value of the landscape features according to the performance of ecosystem services supply, i.e. 1) low or marginal value as is and low potential to improve, 2) high existing value, 3) very high existing value, 4) high opportunity for increase value, and 5) very high opportunity to increase value. The output shows the red colour on areas of high and very high existing values to warn stakeholders to stop and think before placing an intervention that would otherwise reduce the already existing optimal supply of ecosystem services. The output shows the green colour for areas of high and very high opportunities for change to encourage stakeholders to intervene to improve the supply of ecosystem services under consideration. For locations of low or marginal value, and little opportunity for increase, the yellow colour is shown to warn stakeholders that intervention should be carried out with caution as these locations may not effectively supply the ecosystem services to the desired level. The same principle applies for the trade-offs. The classification and visualisation system makes communication easier among different stakeholders and increases transparency.

The design of the tool facilitates spatially explicit policy implementation, the participation of a wide range of stakeholders and the implementation policy across a wide range of sectors that include forestry, water, biodiversity and agriculture (Jackson et al., 2013).

$\mathrm{LUCl}$ can be useful for a wide range of stakeholder groups, including policy makers, researchers, local land owners, environmental managers, conservation organisations and anyone whose interests are vested in exploring the impacts of land use management on ecosystem service provision. It has been applied to a variety of land management scenarios 
all over Wales (UK), Bassenthwaite catchment in England (UK), Ghana, Kenya, Greece and New Zealand (Hawkes Bay, Bay of Plenty and East Coast) for that purpose (Jackson et al., 2013). For example, in the Pontbren catchment in Wales (UK), the tool was used to explore the response of flood risk, productivity and biodiversity to various tree and pond placement scenarios in farmlands. In Bassenthwaite catchment, it was used to delineate areas where agri-environmental interventions can be effectively applied to optimise carbon sequestration, conserve biodiversity, improve water quality and flow while at the same time maintaining productivity in farmlands.

The tool is ideal in data deficient areas, where it incorporates local knowledge to fill in the data gaps. Since LUCI models at small field scale, landowners can highly benefit from using it, as they mostly own and manage small parcels of land. This is important because most decision support tools are applicable to landscape scales and may not be of high utility to stakeholders interested in managing small areas.

The tool is a reflection of the shift of research from a solely academic focus to the generation of policy relevant information. It is however, important to note that having GIS knowledge is relevant for the use of LUCI. Local stakeholders might benefit from gaining skills in GIS to reduce the time required to run the tool. Limitations of the current version of LUCI are the lack of economic estimates and quantification of uncertainty is partly due to the difficulty of computing spatial uncertainty. The lack of quantification of uncertainty can be attributed to limited approaches that can be adopted within the GIS context (Stein et al., 2009). However, development of the tool is on-going, with plans to quantify uncertainty based on digital elevation data and to create new algorithms for water quality and visualisation of cultural and tourism amenity. In addition the environment to which the tool is applied has been broadened to include semi-terrestrial areas such as wetlands and freshwater environments. This research forms part of an on-going development of the LUCI tool, by testing its utility in the design of wetland restoration strategies for ecosystem services provision.

\subsubsection{Description of the flood mitigation component of LUCI tool used at Wairio wetlands}

The occurrence of floods in landscapes is a function of climate, topography, soil type, geology, area of water bodies, land use and land cover type among others. A combination of 
impermeable compacted soils, high rainfall, uphill runoff contributing areas and impermeable bedrock geology results in high incidence of fast moving overland flow and rapid throughflow to the surface water bodies, raising the risk of floods. On the contrary, permeable soils overlying permeable bedrock and, receiving flow from uphill areas have the capacity to absorb and store much of this fast moving overland flow and reduce flood risk. On impermeable soils, flood mitigation can be achieved by practising land use management strategies such as establishing forests that ameliorate soil properties for better water storage. The flood tool evaluates flood mitigation potential based on physical principles of hillslope flow. The tool requires a digital elevation model, stream network data, gridded rainfall data, land use and soil data as inputs. It derives information on permeability and storage capacity of elements within the landscape from soil and land use data. Flood mitigation is interpreted as a reduction in the flow reaching surface water bodies during large rainfall events. This reduction is mostly interpreted as a reduced flood peak, although other measures such as reduced overall flood volume may be appropriate, particularly as catchment size increases (Bethanna Jackson, Personal Communication on 04/03/2016).

Based on the permeability and storage information, LUCI considers volumetric constraints on readily and total available plant water, infiltration capacity, maximum drainage rate, and drainable water holding capacity (the capacity of soil to hold water between field capacity and complete saturation). $\mathrm{LUCl}$ then discretises units within the landscape according to similarity of their hydraulic properties and spatially explicit topographical routing. Using gridded annual or flood duration rainfall and evaporation data inputs, $\mathrm{LUCl}$ then calculates the average annual flow rates, or average flood flow rates ( $\mathrm{LUCl}$ tools help document, www.lucitools.org). Alternatively, stream network data can be used if rainfall data is unavailable. This water is routed through the landscape using a bespoke algorithm that considers the aforementioned volumetric constraints on infiltration, drainage and available water. The direction of this routing is enabled by hydrologically conditioning ${ }^{24}$ the digital elevation model of the landscape. In this simple form, ignoring temporal variations in flow, all land use or soil types that absorb water, provide significant mitigation and are treated as of high existing value (sinks), and areas that are intercepted by these features are

\footnotetext{
${ }^{24}$ A process whereby a DEM is adjusted to enable initiation of stream flow pathways. The DEM is usually smoothed by removing or filling up depressions that would otherwise prevent continuous flow of water following stream initiation.
} 
considered to be mitigated (Jackson et al., 2013). Impermeable areas where a large amount of unmitigated flow directly routes to water bodies are flagged as target areas for change (Jackson et al., 2013). Parameters to define thresholds for the "corrected" flow accumulation values are used to categorise priority areas for targeting change (Jackson et al., 2013). The default parameters were used in this application, assuming that landscape areas accumulating more than five times more water than was provided directly to them by rain are a priority for change, while areas accumulating more than 20 times the rainfall are high priority for change (LUCI help document, www.lucitools.org).

A more sophisticated version of the bespoke algorithm can be applied to study the temporal response of the landscape under different meteorological or climatic events (e.g. flood return period rainfall events, droughts), cascading water through hydrological response units discretized in the landscape using a "fill and spill" approach and accounting for changes in plant available and drainable soil moisture over time (Bethanna Jackson, Personal Communication on 04/03/2016). 


\subsection{Methodology}

\subsubsection{Study site}

The modelling process was carried out for stages 2 and 3 of Wairio wetlands located on the eastern side of Lake Wairarapa. In this section, a brief description of the sites is given for the purpose of contextualising the research described in this chapter. For comprehensive description of the study site, please refer to previous sections 3.7 and 4.2.

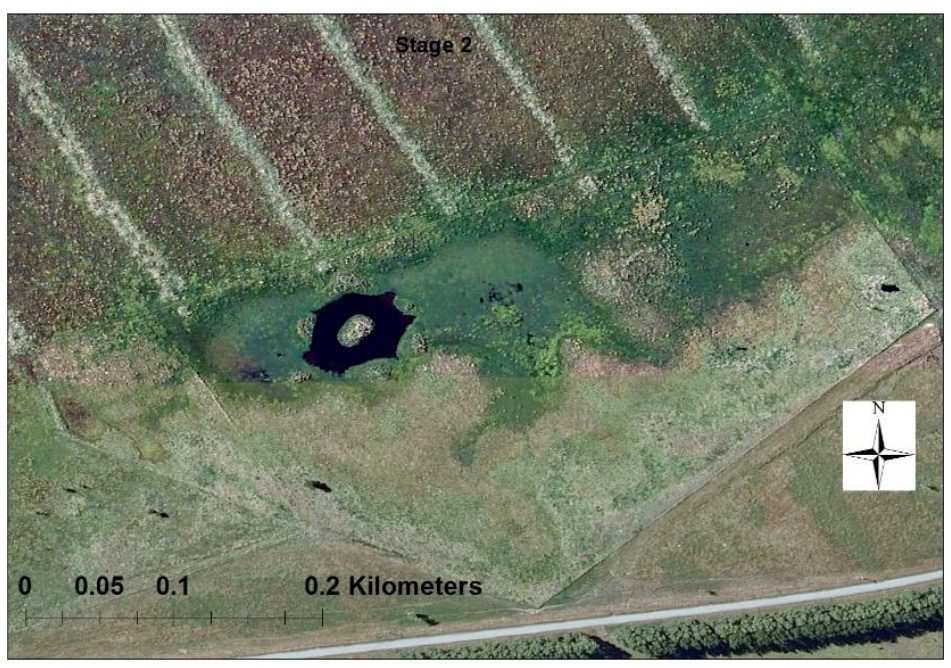

Stage 2 is a fenced off 8.3 ha wetland area comprising of wetland sedges, flaxes, grasses and turfs, an earth dam and indigenous trees species. The trees and flax were re-established and an earth dam constructed as part of restoration which began in 2005 . Before restoration, the area was grazed and dominated by wetland sedges, grasses and turfs.

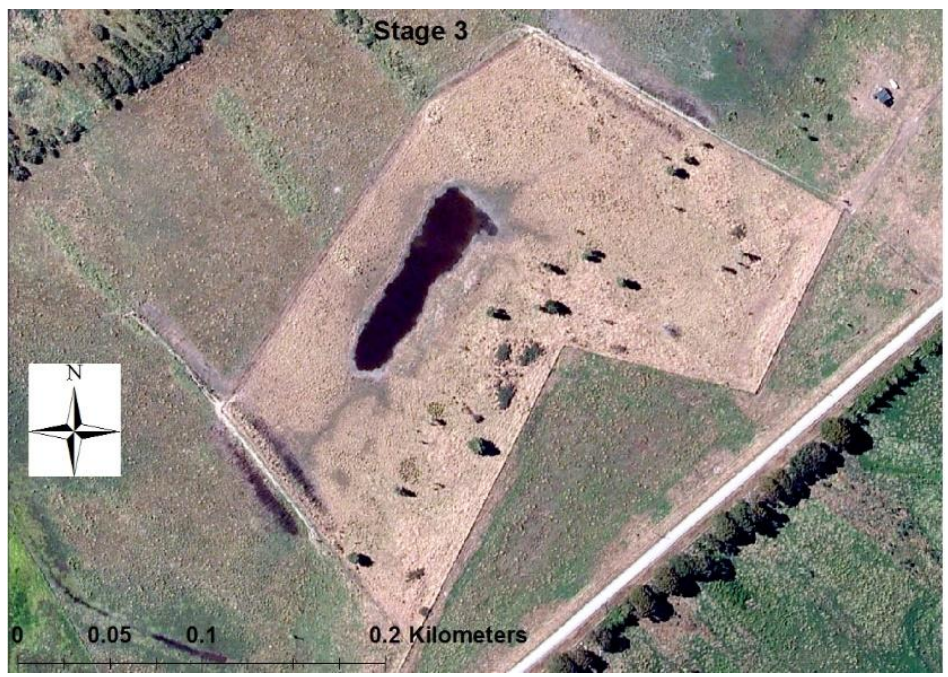

Stage 3 is a 5.6 ha area with a mixture of indigenous tree species and wetland herbaceous vegetation (sedges, grasses, turfs) being the dominant vegetation type. Indigenous trees were reestablished as part of restoration that began in 2005, with an exception of a few remnant of

Kahikatea and Totara trees (about 25) scattered around the wetland. There are more trees in stage 3 than in stage 2 . The change in land cover following restoration in both stages was used to generate scenarios for delineating areas where restoration improved the flood mitigating ability of the wetland and where there is still opportunity for change. 


\subsubsection{Modelling process in $\mathrm{LUCl}$}

The modelling process (also explained in section 5.2) that was followed in LUCl is presented in the flow chart below (Figure 35). The quantification of ecosystem services performance was based on land management scenarios and hydrologically consistent DEM (hyd-topo) outputs. The land management scenarios were generated from land use/ cover and soil data while the hydrologically consistent DEM (hyd-topo) output was generated from DEMs and stream network data. An overview of the generation of inputs used in the modelling process is given in sections 5.3.3, 5.3.4 and 5.3.5.

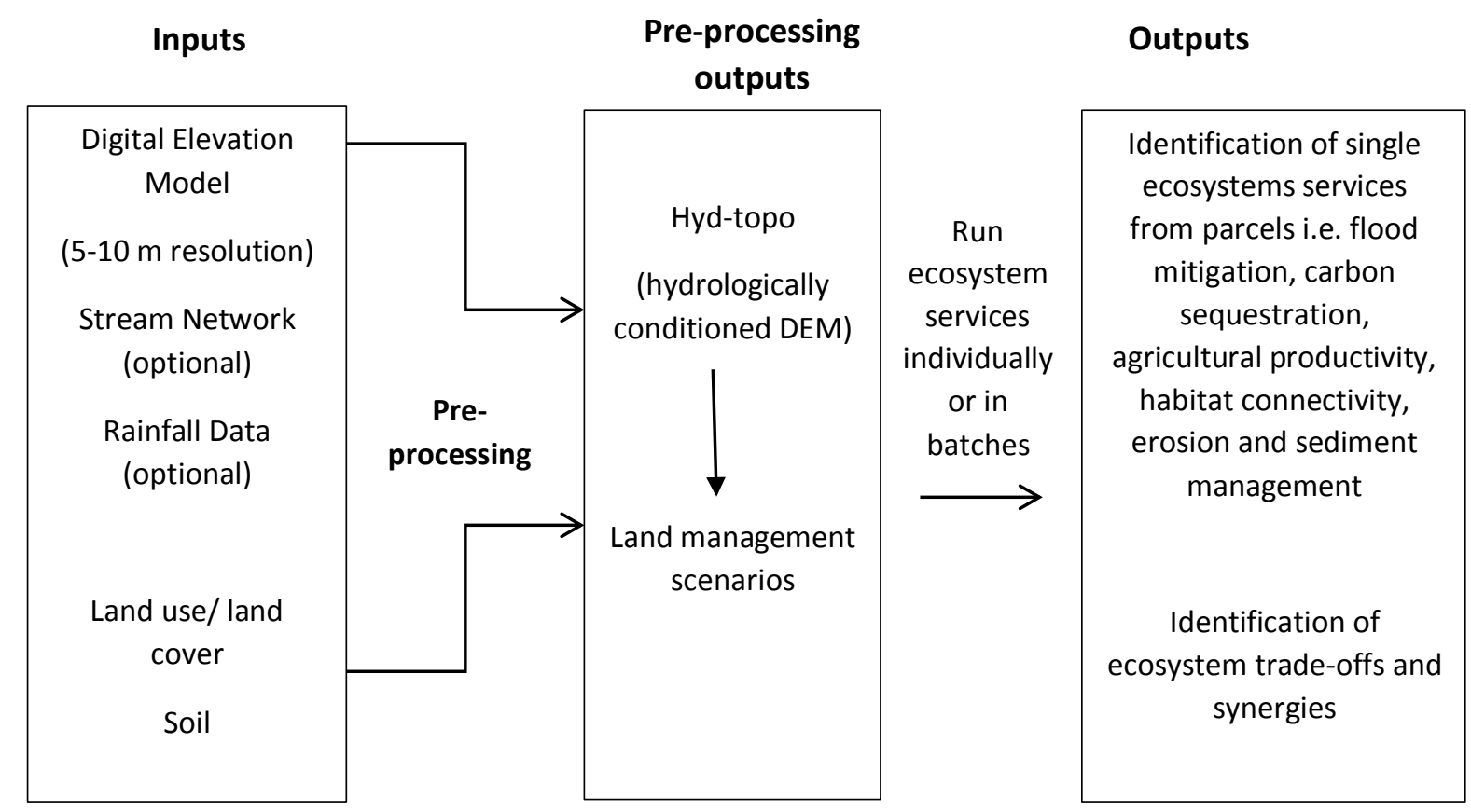

Figure 35. Flow chart showing the modelling process in LUCI

- Input data covering the extent of the modelled area was gathered. This included digital elevation model, stream network, land use or cover and soil data

- Stream network data and digital elevation model was reconciled to form a hydrologically consistent DEM with topographical routing information

- Land management scenarios (i.e. before and after restoration of trees) were generated using the hydrologically consistent DEM, baseline and corrected soil and land use/cover data

- The flow mitigation tool was run using the hydrologically consistent DEM and land management scenarios as inputs to produce maps and quantifications 
- Tables showing the comparison between scenarios were presented.

\subsubsection{Digital elevation data}

Topographical attributes such as elevation and slope affect the interaction of trees, soil and water for flood mitigation, as highlighted in chapters 2 and 4. Specifically the attributes influence the speed and direction of water flow, root growth and proliferation. When modelling water flow and accumulation, these attributes can be represented by a DEM. Therefore, precise representation of the ecosystem services performance is influenced by the quality of the DEM. The quality of the DEM is in turn determined by the resolution (horizontal and vertical) at which the data is presented, the source or procedure used for measuring elevation, interpolation method, topography of the represented landscape, density and location of sampling points (Thompson et al., 2001). These factors are critical for modelling on gentle sloping or flat surfaces of wetlands, where low resolution or otherwise inaccurate DEMs may inaccurately represent hydrological parameters, e.g. cause a reduction in the number and length of channels per area or otherwise misrepresent flow directions in the landscape (Thieken et al., 1999; Thompson et al., 2001).

This research presents the first application of $\mathrm{LUCl}$ in very flat conditions. Algorithm calculations in LUCI are produced at the resolution of a DEM, therefore it is important to explore the effect of different DEM sources of varying grid sizes to determine the accurate representation of the flat topography. Moreover, using elevation data acquired from different sources is critical for determining the reliability of the data sources and for exploring the accurate representation of the surface especially in landscapes where thick vegetation might interfere with the capture of true ground elevation. Aerial surveying using Optech ALTM 3100 LiDAR system is often associated with errors caused by vegetation cover, particularly the penetration of thick vegetation is limited when using this system (Greater Wellington Regional Council, 2015).

To investigate the influence of DEM resolution and sampling density/method on model outputs, five gridded digital elevation data sets of contrasting horizontal resolutions and sources were used as inputs to the model. Four of the elevation data sets were acquired, processed and provided by the Greater Wellington Regional Council, (NZ). These were 
acquired through LiDAR and provided at horizontal resolutions of $1 \mathrm{~m}, 5 \mathrm{~m}, 10 \mathrm{~m}$ and $15 \mathrm{~m}$ and vertical precision of $+/-0.1$ to $0.15 \mathrm{~m}$. The LiDAR data points ( 28 million, over the Wairarapa region) were collected through airborne laser scanning (using Optech ALTM 3100 device) covering an area of 17137 ha in 2003/2004 (AAMHATCH, 2003; 2004). Processing of the points was carried out using Sorted Pulse Data Library software to produce rasters of varying resolution (AAMHATCH, 2003; 2004). From these LiDAR derived rasters $(1 \mathrm{~m}, 5 \mathrm{~m}$, $10 \mathrm{~m}, 15 \mathrm{~m}$ ), 13.9 ha raster sets of Wairio wetlands ( 8.3 ha, stage 2 and 5.6 ha, stage 3 ) were clipped for use in this research.

The fifth elevation data set was acquired through field surveying by the researcher at $1 \mathrm{~m}$ horizontal resolution and vertical precision of 0.01 to $0.05 \mathrm{~m}$. Land surveying for digital elevation data was carried out in stages 2 and 3 of Wairio wetlands using a Trimble R8 GNSS system equipped with Trimble 360 receiver technology during summer in February of 2013. Traversing of the entire study area was carried out with a comprehensive walking route, collecting spot heights with the differential GPS at evenly distributed $10 \mathrm{~m}$ ground sampling distance. A total of 1452 elevation points were sampled in stage 3 and 972 in stage 2 . Collected elevation data was first checked for quality by assessing availability of clumped points and unsampled grid cells were interpolated using Inverse Distance Weight (IDW) at $1 \mathrm{~m}$ resolution. IDW was used as an interpolator as it is suitable for a large number of evenly distributed elevation points and is simple to use than other methods such as kriging and spline (Burrough \& Mcdonell, 1998; Johnston et al., 2001).

Since LUCI quantifies the performance of a landscape to deliver ecosystem services at each individual DEM grid cell, elevation data of medium resolution (5 m and $10 \mathrm{~m}$ ) is generally considered to be ideal, as recommended for the model (Figure 35). However, on very gentle sloping or flat landscapes such as wetlands, digital elevation data of finer resolutions may be useful for the accurate quantification of ecosystem services performance.

\subsubsection{Stream network and rainfall data}

$\mathrm{LUCl}$ automatically generated a raster of stream network based on the calculation of flow direction and accumulation on the filled DEM. For rainfall data, average annual values were used. It is reasonable to assume uniform rainfall at the small scale of tens of hectares. 


\subsubsection{Land cover and soil data for land management scenario generation}

Baseline land cover/use and soil data sets for Wairio wetlands were derived from the New Zealand Land Cover Database 2 (LCDB2) and the New Zealand Land Resource Inventory data base (NZLRI) respectively. The LCDB2 is based on a remote sensing satellite imagery acquired in 2001-2002, a period before restoration began. The minimum map unit for LCDB2 is 1 ha (Thompson et al., 2003; Davies et al., 2013). LCDB2 shows the presence of high producing grasslands, herbaceous freshwater vegetation and ponds in Wairio wetlands.

It is important to highlight that there are significant uncertainties associated with LCDB2. The process through which it was developed (remote sensing, field verification and ancillary data) may misclassify the actual land use/cover depending on interpretation, scale and image quality (Davies et al., 2013). Davies et al. (2013) reported the failure of LCDB2 to distinguish between some land cover types, particularly in wetlands (Table 28).

Verification of the accurate representation of Wairio wetlands vegetation by LCDB2 was carried out by conformation through personal communication (Tony Silbery), ground truthing and the use of aerial images. Where aerial images could not easily distinguish herbaceous wetland vegetation from high producing grasses, confirmation was made using personal communication (Tony Silbery) for the prior to restoration data, and ground truthing for the current data. There were some minor inconsistences between the LCDB2 and the vegetation at Wairio wetlands. Some areas with herbaceous vegetation, sedges and turfs were misclassified as high producing exotic grassland, and these were corrected. To account for restoration and changes in vegetation over time, the LCDB2 was updated and this is discussed later in this section. 


\begin{tabular}{ll}
\hline Actual Land cover & LCDB2 classification \\
\hline Herbaceous wetland vegetation, flax, open water & High-producing exotic grassland \\
Pasture, exotic grassland, deciduous hardwoods & Herbaceous freshwater vegetation \\
Raupo and coprosma scrub & Urban parkland and open space \\
Herbaceous wetland vegetation with manuka & Broadleaves indigenous hardwoods \\
Open water and emergent wetland vegetation & Gorse or broom \\
Swamp and manuka/kanuka & Deciduous hardwoods \\
Pine trees & Lake or pond \\
Urban parkland and open space & Manuka/kanuka \\
Open water, deciduous hardwoods & Closed canopy pine forest \\
\hline
\end{tabular}

Adapted and modified from Davies et al. (2013)

The NZLRI data base comprises of the fundamental soil layers (FSL) which contain soil attributes of the various land parcels in New Zealand. The soil attributes include drainage parameters, soil moisture properties, chemical properties, soil physical characteristics and environment parameters (Newsome et al., 2008) as highlighted in Table 29. These attributes are important for the determination of water flow and retention in a landscape. The soil data shows that the parent material is alluvium and the fine earth originates from hard sand stone rock. Poorly drained, sandy and mottled sandy soils are the characteristic soil types of the wetland. Permeability of the soil is moderate to slow, while the depth to gravel/rock is greater than $100 \mathrm{~cm}$. The potential rooting depth ranges from 70 to $100 \mathrm{~cm}$ but anoxic conditions may limit root proliferation. 
Table 29 Soil attributes of the FDL that were used as input for the generation of management scenarios for the LUCI modelling process

\begin{tabular}{ll}
\hline Soil Attribute & Characteristics \\
\hline Chemical & $\mathrm{pH}$, salinity, total carbon, cation-exchange \\
& capacity, phosphorus retention \\
Physical & Top soil gravel content, rock outcrops, surface \\
& boulders, particle size \\
Drainage & Rooting depth, soil permeability, depth to slowly \\
& permeable horizon, internal soil drainage \\
Moisture & Profile total available water, macroporosity (0- \\
& $100 \mathrm{~cm})$, profile readily available water \\
Environment parameters & Flood return interval, soil temperature regime
\end{tabular}

The baseline data were used as a land management scenario for the quantification of flood mitigation performance of the wetlands before restoration (Appendix 21 \& Appendix 22). The baseline land use/cover was then updated to represent the current (2013/15) vegetation status incorporating restoration procedures such as retirement from grazing and tree planting which began in 2005 and 2008 respectively. The update involved substituting the high-producing grasses and herbaceous freshwater vegetation with indigenous forests on areas that were planted as part of the wetland restoration. In areas that were not planted, the original baseline land cover/land use was not substituted (Appendix 21 \& Appendix 22). In stage 3, a pond that was artificially created during the restoration process was digitised as part of the updated land use (Appendix 22). The updated land management scenario was used for the quantification of flood mitigation performance following restoration and natural change of the wetland over time. A summary of the potential ecological benefits resulting from the management interventions at Wairio are presented in Table 30. 
Table 30 Potential ecological benefits associated with land use interventions before or after restoration at Wairio

\begin{tabular}{llll}
\hline Land use or management & Benefits & Challenges & Mitigating the challenges
\end{tabular}
intervention

\begin{tabular}{|c|c|c|c|}
\hline $\begin{array}{l}\text { Maintaining high } \\
\text { producing exotic }\end{array}$ & $\begin{array}{l}\text { Provides habitat for some } \\
\text { fauna }\end{array}$ & $\begin{array}{l}\text { Some species such as tall } \\
\text { fescue (Festuca }\end{array}$ & $\begin{array}{l}\text { Control invasive species } \\
\text { through use of herbicides }\end{array}$ \\
\hline grasslands & & $\begin{array}{l}\text { arundinacea ) are } \\
\text { invasive and dominate } \\
\text { herbaceous wetland } \\
\text { vegetation }\end{array}$ & $\begin{array}{l}\text { or plant indigenous } \\
\text { woody species which } \\
\text { over time will } \\
\text { outcompete and replace } \\
\text { the invasive exotic } \\
\text { grasses. }\end{array}$ \\
\hline $\begin{array}{l}\text { Establishing indigenous } \\
\text { forest/scrub }\end{array}$ & $\begin{array}{l}\text { Trees increase water } \\
\text { infiltration, sequester } \\
\text { carbon into the wetland } \\
\text { and trap polluting } \\
\text { nutrients better than high } \\
\text { producing grasslands. } \\
\text { Provides habitat for some } \\
\text { fauna }\end{array}$ & $\begin{array}{l}\text { Realisation of benefits } \\
\text { may take long. It may be } \\
\text { difficult to establish trees } \\
\text { in saturated soils where } \\
\text { the water table is } \\
\text { continuously high. High } \\
\text { transpiration rates may } \\
\text { alter the wetland water } \\
\text { balance in summer. }\end{array}$ & $\begin{array}{l}\text { Establish fast growing } \\
\text { species that are tolerant } \\
\text { to water logged } \\
\text { conditions. }\end{array}$ \\
\hline $\begin{array}{l}\text { Maintaining herbaceous } \\
\text { freshwater vegetation }\end{array}$ & $\begin{array}{l}\text { May store more carbon } \\
\text { than exotic grasslands. } \\
\text { May sequester carbon in } \\
\text { quantities comparable to } \\
\text { indigenous forests/scrub. } \\
\text { Reduces the flow of } \\
\text { water out of the wetland. }\end{array}$ & $\begin{array}{l}\text { Can be dominated by } \\
\text { exotic grasses such as tall } \\
\text { fescue }\end{array}$ & $\begin{array}{l}\text { Control of exotic grasses } \\
\text { using herbicides or } \\
\text { introduce some woody } \\
\text { species for competition } \\
\text { to facilitate succession. }\end{array}$ \\
\hline $\begin{array}{l}\text { Creating and maintaining } \\
\text { ponds }\end{array}$ & $\begin{array}{l}\text { Increases the residence } \\
\text { time of water flowing } \\
\text { into the wetlands. } \\
\text { Provides habitat for flora } \\
\text { and fauna. Nutrient } \\
\text { cycling }\end{array}$ & $\begin{array}{l}\text { Deterioration of water } \\
\text { quality indicated by the } \\
\text { presence of } \\
\text { cyanobacteria blooms } \\
\text { and hypoxic blackwater. }\end{array}$ & \\
\hline
\end{tabular}




\subsubsection{Analysis}

Summary statistics of the differences in elevation between five DEMS were calculated using the raster calculator in ESRI's ArcGIS. The statistics calculated include number of cells $(n)$, mean, maximum, minimum and standard deviation.

The raster calculator in ArcGIS was also used to calculate the percentage area covered by land use types before and after intervention. Data on percentage coverage of areas modified, areas receiving benefits as a result of the modification and areas that still need change after intervention was derived from attribute tables of the output maps. This data was used to explain results of the output maps. 


\subsection{Results}

Restoration increased the area of indigenous forest cover from zero to $1.64 \%$ and $3.98 \%$ in stages 2 and 3 respectively (Table 31, Appendix $21 \&$ Appendix 22). The area of ponds in stage 3 increased from $1.4 \%$ to $3.64 \%$ following restoration (Table 31). This increase, coupled with the re-establishment of trees, resulted in the decrease in percentage coverage of high producing exotic grassland and herbaceous freshwater vegetation from $98.6 \%$ to $92.38 \%$ in stage 3 (Table 31). The decrease in pond coverage from $11.57 \%$ to $2.02 \%$ in stage 2 resulted in the increase in area covered by high producing exotic grassland and herbaceous freshwater vegetation ( $88.43 \%$ to $96.33 \%$ ) through natural succession (Table 31, Appendix 21 \& Appendix 22).

Table 31 Baseline and corrected land use/cover data

\begin{tabular}{|c|c|c|c|}
\hline Stage & Land cover/use data & $\begin{array}{l}\% \text { coverage pre- } \\
\text { restoration, based } \\
\text { on LCBD2 } \\
(2001 / 2002)\end{array}$ & $\begin{array}{l}\text { \% coverage change over } \\
\text { time and after restoration } \\
(2013 / 2015)\end{array}$ \\
\hline \multirow[t]{3}{*}{2} & $\begin{array}{l}\text { High producing exotic } \\
\text { grassland, herbaceous } \\
\text { freshwater vegetation }\end{array}$ & 88.43 & 96.33 \\
\hline & Indigenous forest & 0 & 1.64 \\
\hline & Pond & 11.57 & 2.02 \\
\hline \multirow[t]{3}{*}{3} & Indigenous forest & 0 & 3.98 \\
\hline & Pond & 1.4 & 3.64 \\
\hline & $\begin{array}{l}\text { High producing exotic } \\
\text { grassland, herbaceous } \\
\text { freshwater vegetation }\end{array}$ & 98.6 & 92.38 \\
\hline
\end{tabular}




\subsubsection{Output maps of different DEMs}

The $1 \mathrm{~m}$ field survey and LiDAR derived DEMs had closely matched elevation values, with a difference in means of $0.113 \mathrm{~m}$ in stage 2 and $0.118 \mathrm{~m}$ in stage 3 (Tables $31 \& 32$ ). Specific point density for LiDAR over the Wairio site cannot be provided as there was only a raster for the whole Wairarapa region, from which stages 2 and 3 were clipped. All LiDAR DEMs are however from the same point density.

The output maps show the flood mitigation (as indicated by permeability status) of stages 2 and 3. The maps are based on baseline (before intervention), improved land use layer (after intervention) and hydrological DEMs of different resolutions; $1 \mathrm{~m}, 5 \mathrm{~m}, 10 \mathrm{~m}, 15 \mathrm{~m}$ (LiDAR) and $1 \mathrm{~m}$ (field survey) (Figures 28-37). The land management scenarios for the before intervention outputs for both stages 2 and 3 are based on 2001-2002 land use data derived from LCDB2. Land management scenarios for the after intervention output maps are based on updated land use data following restoration, which includes pond creation in stage 3. After intervention maps also show the natural change in wetland structure over time. 
Table 32 Summary statistics for the difference in elevation between DEMs in Stage 2

\begin{tabular}{llllll}
\hline Statistics & $\begin{array}{l}\text { Field survey } \\
(1 \mathrm{~m})\end{array}$ & LiDAR $(1 \mathrm{~m})$ & LiDAR $(5 \mathrm{~m})$ & LiDAR $(10 \mathrm{~m})$ & LiDAR $(15 \mathrm{~m})$ \\
\hline $\begin{array}{l}\text { Count }(\mathbf{n}) \\
\begin{array}{l}\text { Data density } \\
\left.\text { (points } / \mathbf{m}^{2}\right)\end{array}\end{array}$ & 0.012 & 143869 & 5915 & 1450 & 682 \\
Mean (m) & 1.962 & 1.849 & 1.553 & 0.984 & 0.405 \\
Maximum (m) & 23.342 & 4.304 & 13.526 & 6.500 & 0.791 \\
Minimum (m) & 0.005 & 0.361 & 0.016 & 0.006 & 0.002 \\
Std dev. (m) & 0.596 & 0.579 & 1.888 & 1.042 & 0.226 \\
\hline
\end{tabular}

Table 33 Summary statistics for the difference in elevation between DEMs in Stage 3

\begin{tabular}{llllll}
\hline Statistics & $\begin{array}{l}\text { Field survey } \\
(1 \mathrm{~m})\end{array}$ & LiDAR $(1 \mathrm{~m})$ & LiDAR $(5 \mathrm{~m})$ & $\operatorname{LiDAR}(10 \mathrm{~m})$ & LiDAR $(15 \mathrm{~m})$ \\
\hline $\begin{array}{l}\text { Count }(\mathrm{n}) \\
\begin{array}{l}\text { Data density } \\
\left.\text { (points } / \mathrm{m}^{2}\right)\end{array}\end{array}$ & 0.025 & 109782 & 4485 & 1025 & 528 \\
Mean (m) & 1.974 & 1.856 & 1.137 & 1.149 & 0.702 \\
Maximum (m) & 24.196 & 4.177 & 8.614 & 5.644 & 0.785 \\
Minimum (m) & 0.384 & 0.317 & 0.006 & 0.020 & 0.191 \\
Std dev. (m) & 0.280 & 0.632 & 1.316 & 1.165 & 0.107 \\
\hline
\end{tabular}

Representation of the location of drainage pathways and stream channels differs between LiDAR and field survey based results in both stages (Appendix 23), and so do the target areas that still need intervention to improve permeability for water absorption to mitigate floods (Figure 36-Figure 45). The differences in streams occurred despite using a threshold of 0.5 ha for stream initiation or all DEMs. Using $5 \mathrm{~m}$ and $10 \mathrm{~m}$ LiDAR, drainage pathways and stream channels are located at similar places and represented at high and moderate detail respectively (Appendix 23). However, with the $15 \mathrm{~m}$ LiDAR, the drainage pathways and stream channels (Appendix 23) are represented poorly, suggesting the resolution is too low (Figure 36 -Figure 45). At $1 \mathrm{~m}$ (field survey) and $1 \mathrm{~m}$ (LiDAR), drainage pathways and stream 
channels are represented at very high detail but at different density and locations to those shown in LiDAR (5 m, 10 m, 15 m resolution) derived DEM maps (Figures 28-37; Appendix 23). Visual comparison of the output maps shows that results from the high resolution field surveyed DEM has the highest drainage density and stream channels than high resolution LiDAR derived DEMs (Figures 28-37; Appendix 23) and this could be due to the difference in point density. Since many points were sampled directly from the ground during the field survey, it is likely that the high resolution $(1 \mathrm{~m})$ DEMs may be effective for defining hydrological flow patterns at field scale in wetlands. LiDAR data of high resolution $(1 \mathrm{~m})$ did not pick some of the hydrological pathways in the wetlands. This is not uncommon, and may be related to issues such as swath width, distance to base station, interpolation algorithm and position dilution of precision (PDOP) associated with the generation of LiDAR data (Gong et al., 2000; Kienzle, 2004; Liu et al., unpublished). LiDAR may not be suitable for defining hydrological patterns at field scale in wetlands where vegetation cover is thick and surface ponding is prevalent. Despite the differences in accuracy, all the maps show that at least more than $80 \%$ of the wetland area could benefit from intervention in both stages 2 and 3 following the re-establishment of indigenous trees (Figures 28-37). 


\section{Stage 2}

Before intervention (2001/02).

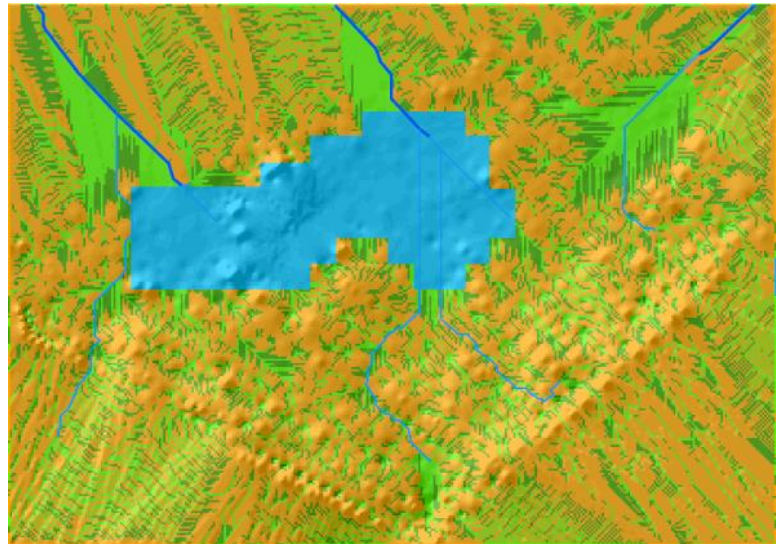

After intervention (2013/14).

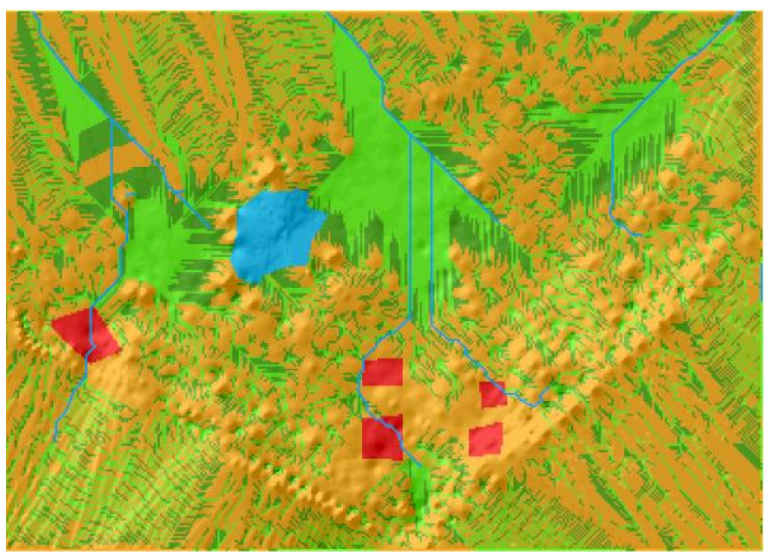

Figure 36. Before and after intervention land use permeability modelled at $1 \mathrm{~m}$ DEM (land surveying)

Before intervention (2001/02).

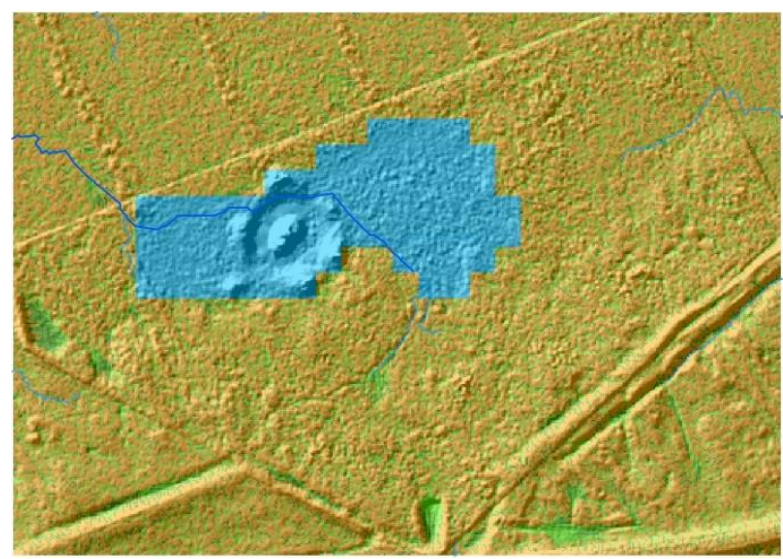

After intervention (2013/14).

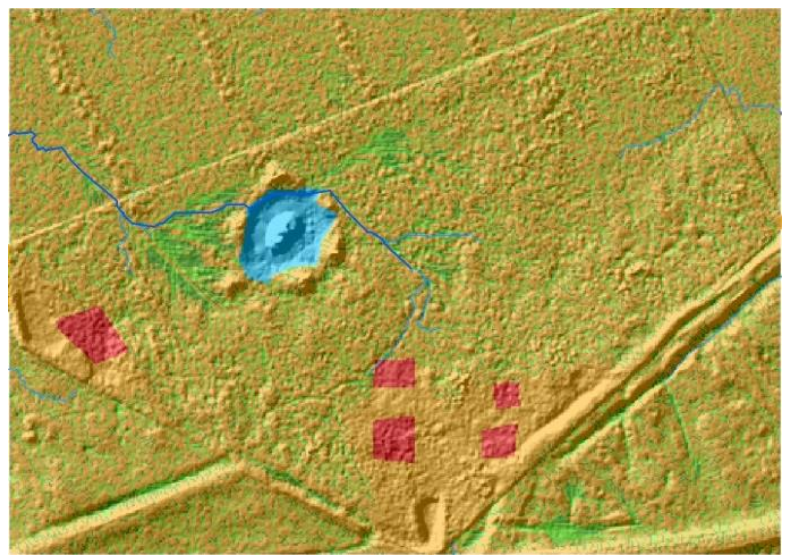

Figure 37. Before and after intervention land use permeability modelled at $1 \mathrm{~m}$ DEM (LiDAR)

Mitigating land use

Minimum opportunity to improve permeability Good opportunity to improve permeability

High opportunity to improve permeability Water bodies

Stream

$\begin{array}{llll}0 & 0.045 & 0.09 & 0.18 \text { Kilometers }\end{array}$


Before intervention (2001/02).
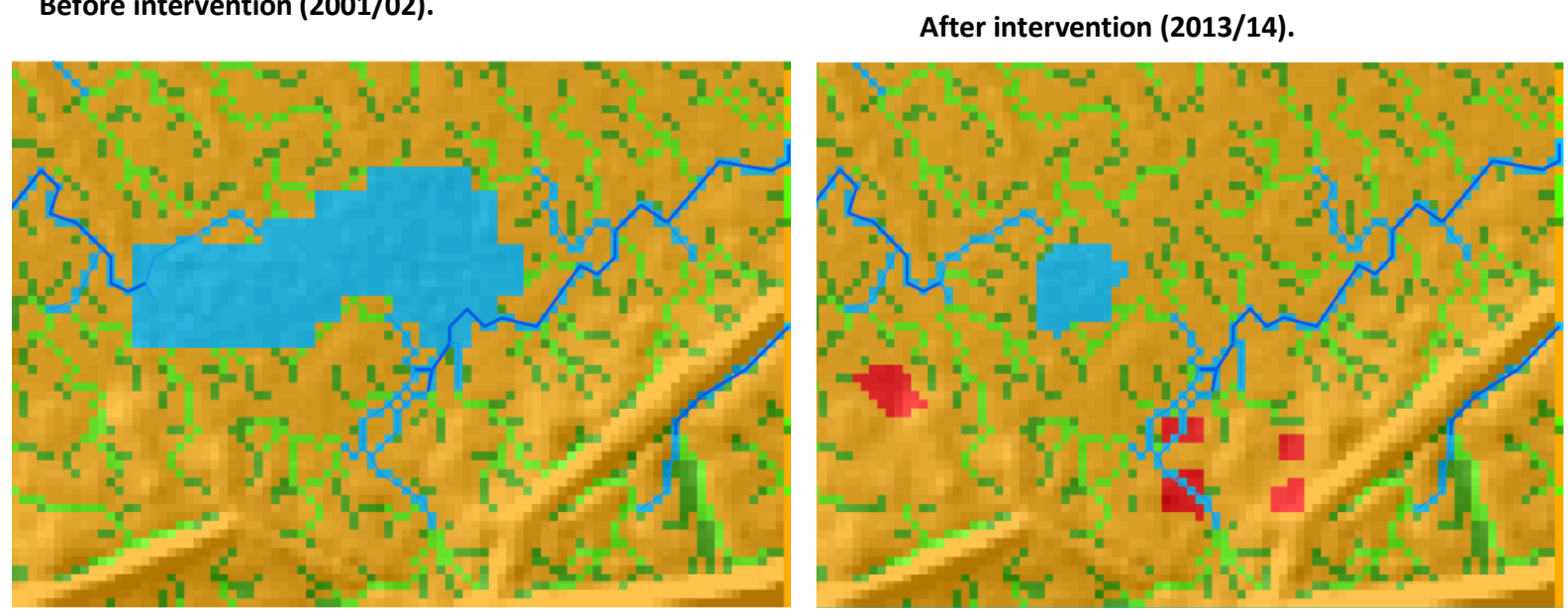

Figure 38. Before and after intervention land use permeability modelled at $5 \mathrm{~m}$ resolution LiDAR

\section{Before intervention (2001/02).}
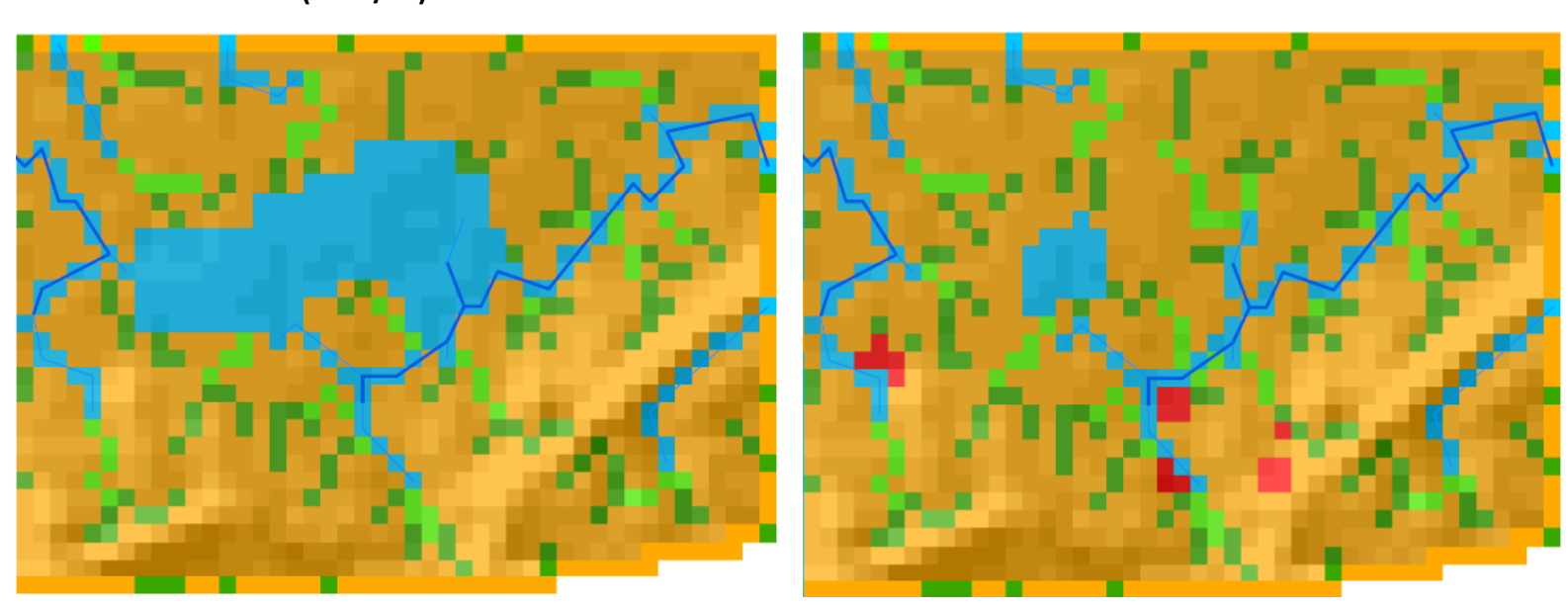

Figure 39. Before and after intervention land use permeability modelled at $10 \mathrm{~m}$ resolution DEM (LiDAR)
Mitigating land use

Minimum opportunity to improve permeability

Good opportunity to improve permeability

High opportunity to improve permeability

Water bodies

Stream

$\begin{array}{lll}0 & 0.045 & 0.09\end{array}$ 0.18 Kilometers
After intervention (2013/14) 
Before intervention (2001/02).
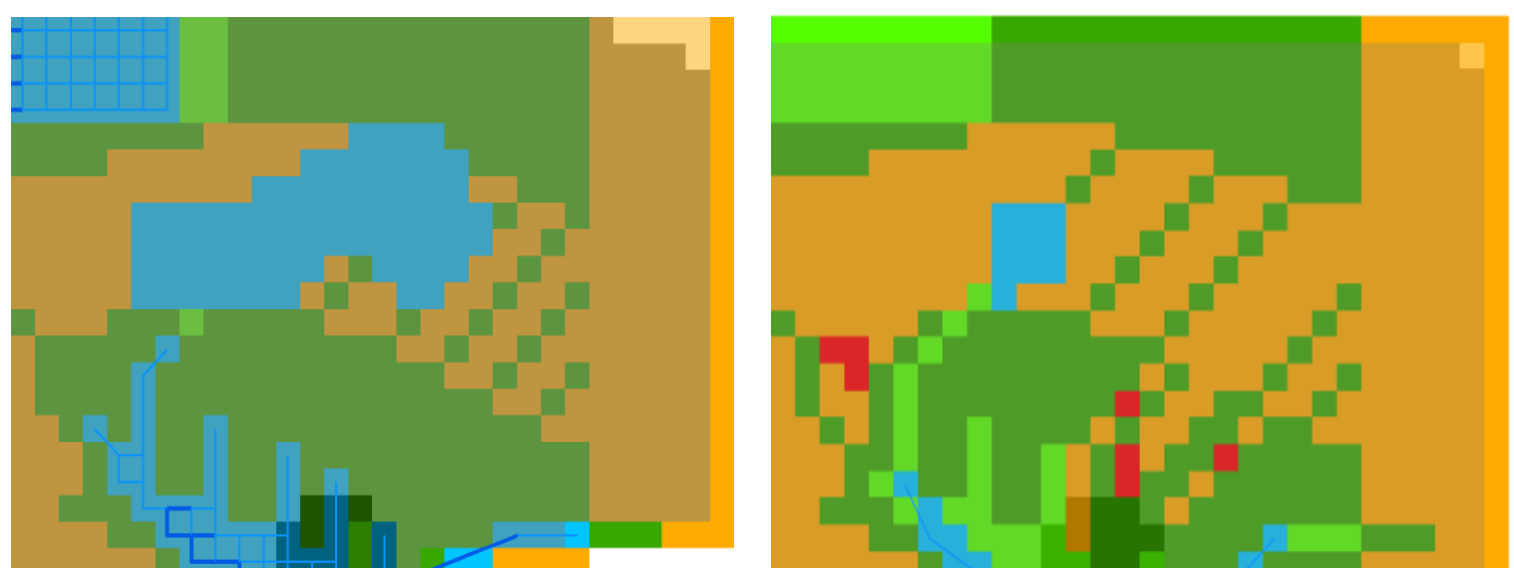

Figure 40. Before and after intervention land use permeability modelled at $15 \mathrm{~m}$ resolution DEM (LiDAR)
After intervention (2013/14).

Mitigating land use
Minimum opportun ity to improve permea bility
Good opportunity to im prove permeability
High opportunity to im prove permeability
Water bodies
Stream

$\begin{array}{lll}0 & 0.045 & 0.09\end{array}$ 0.18 Kilometers 


\section{Stage 3}

Before intervention (2001/02).

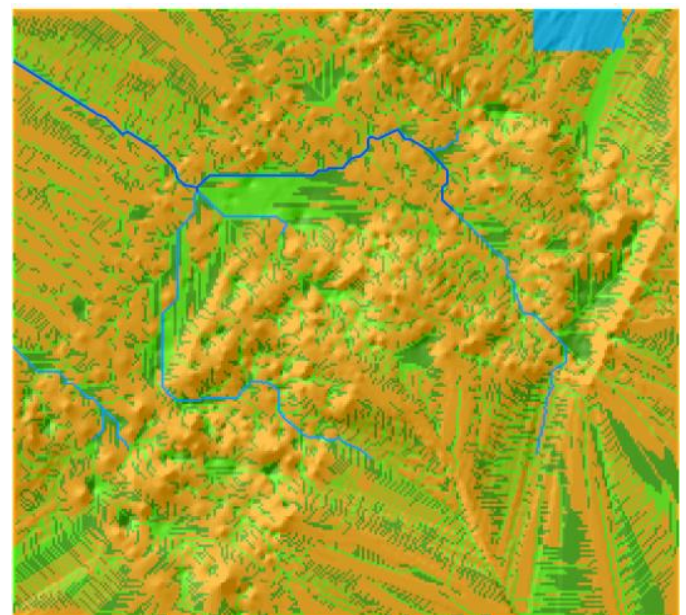

Figure 41. Before and after intervention land use permeability modelled at $1 \mathrm{~m}$ DEM resolution (land survey)

After intervention (2013/14).

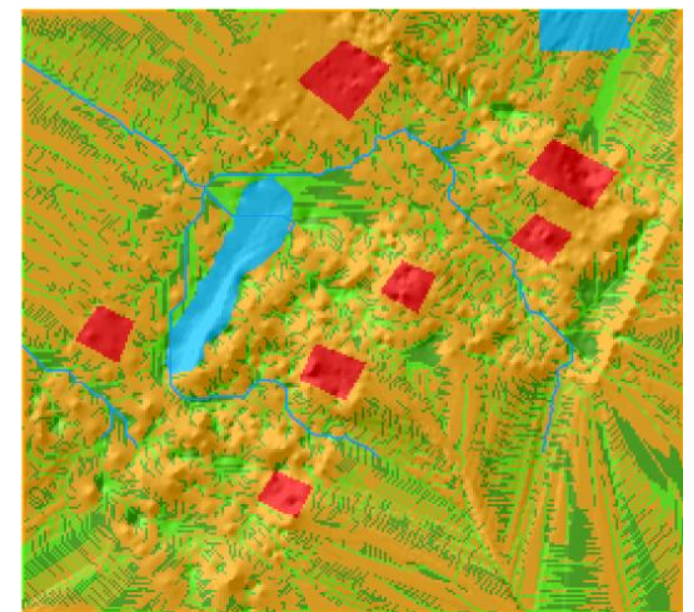

After intervention (2013/14)

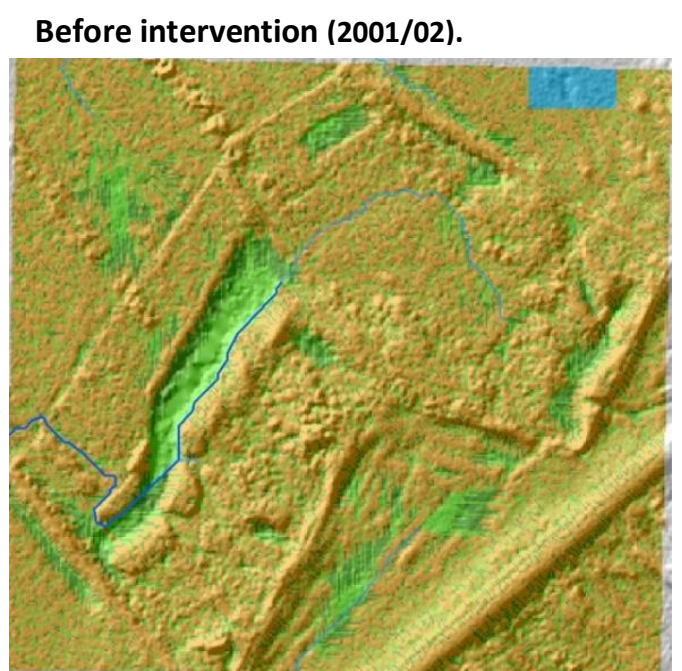

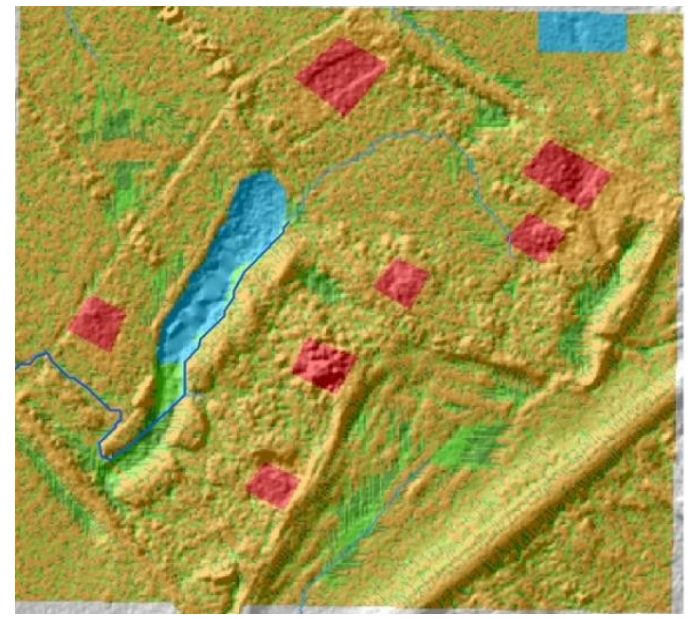

\section{Mitigating land use}

Minimum opportunity to improve permeability Good opportunity to improve permeability High opportunity to improve permeability Water bodies

Stream

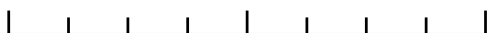

Figure 42. Before and after intervention land use permeability modelled at $1 \mathrm{~m}$ DEM (LiDAR). 
Before intervention (2001/02).

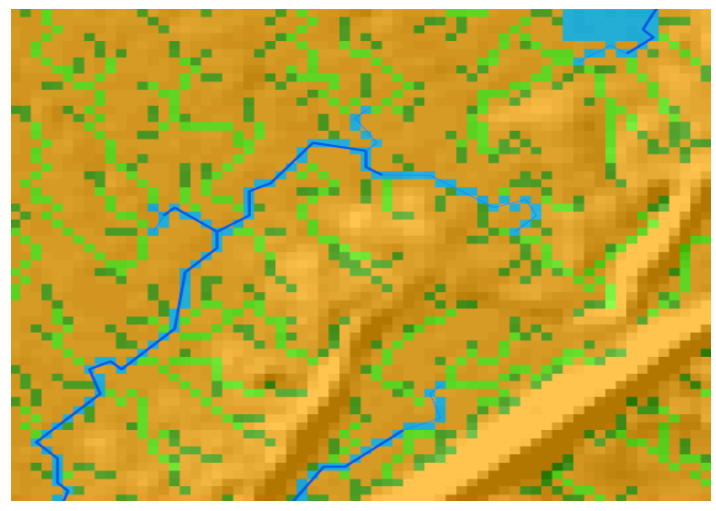

Figure 43. Before and after intervention land use permeability modelled at $5 \mathrm{~m}$ DEM resolution (LiDAR).

\section{Before intervention (2001/02).}

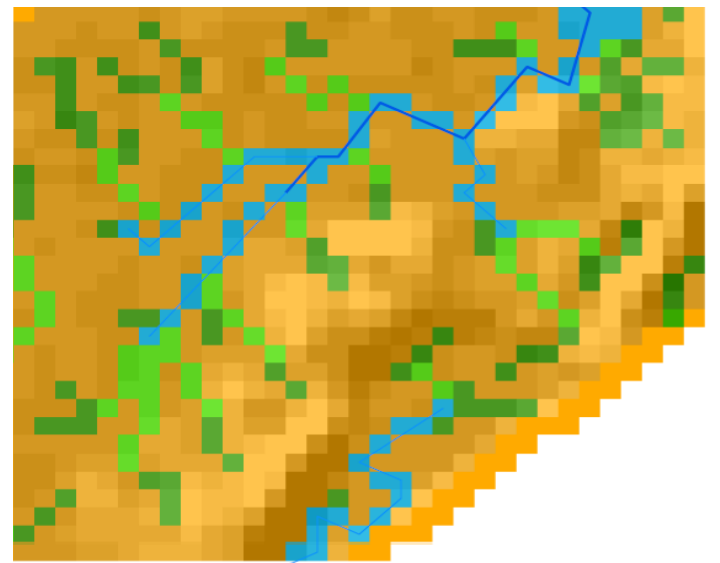

Figure 44. Before and after intervention land use permeability modelled at $10 \mathrm{~m}$ DEM resolution (LiDAR).
After intervention (2013/14).

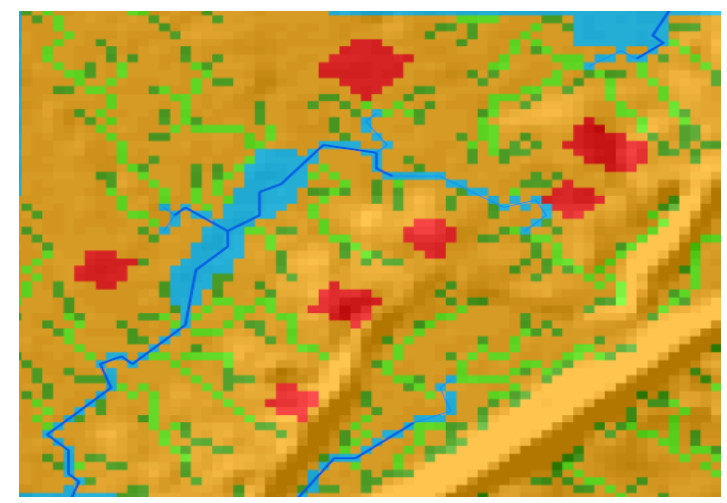

After intervention (2013/14).

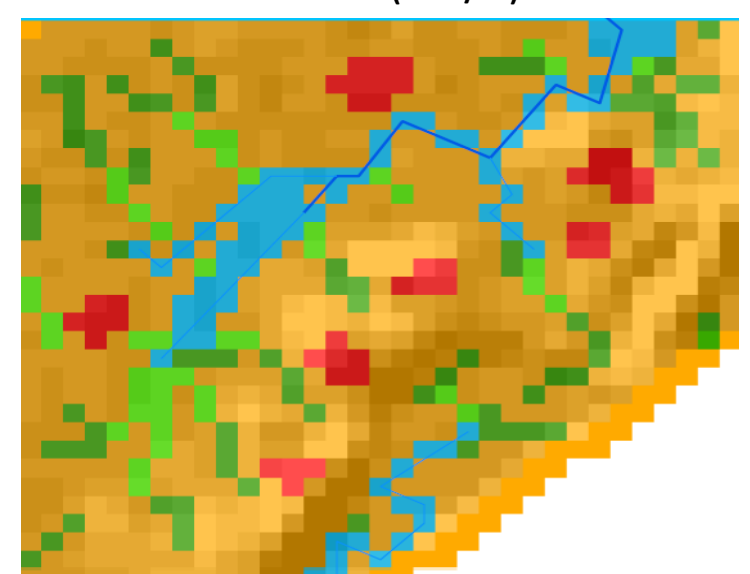

Mitigating land use

Minimum opportunity to improve permeability Good opportunity to improve permeability

High opportunity to improve permeability

Water bodies

Stream

\begin{tabular}{|c|c|}
\hline 0.045 & 0.09 \\
\hline
\end{tabular}


Before intervention (2001/02)

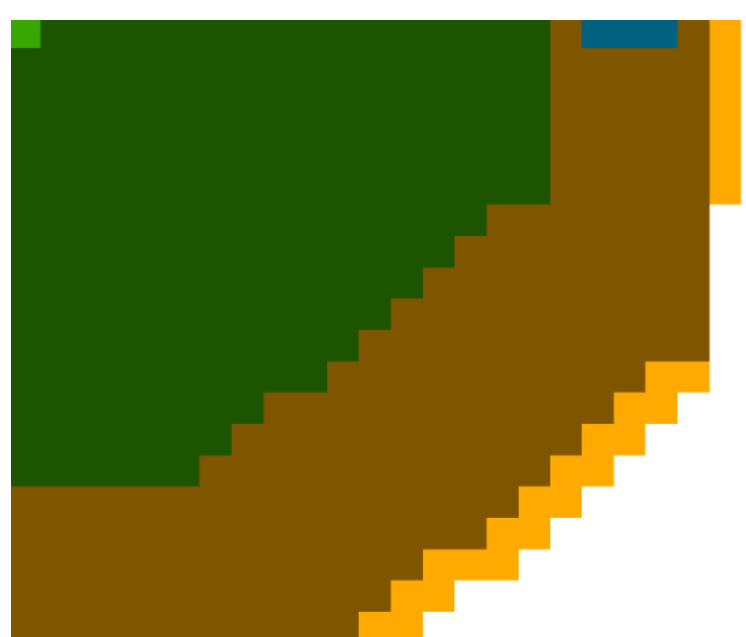

Figure 45. Before and after intervention land use permeability modelled at $15 \mathrm{~m}$ resolution (LiDAR).
After intervention (2013/14)

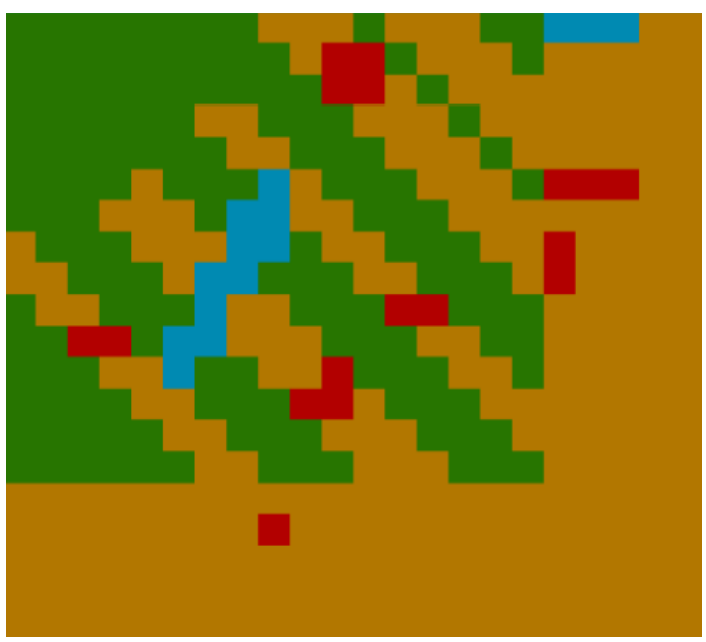

Planting trees increased the proportion of permeable land and reduced the impermeable area in both stages 2 and 3 (Tables 33 \& 34 ). In stage 3 , the impermeable area was estimated to reduce by $9.37-24.77 \%$ depending upon the use of different resolution DEMS as input (Table 35 ). Representation of the change in impermeable area is closely matched under $5 \mathrm{~m}$ and $10 \mathrm{~m}$ resolutions while at $1 \mathrm{~m}$ resolution for both field survey and LiDAR the percentage was different from the other low resolution LiDAR based DEMs. In stage 2, the percentage of impermeable land increased at $10 \mathrm{~m}$ and $1 \mathrm{~m}$ resolutions (for both field survey and LiDAR), following intervention despite an increase in the proportion of permeable area (Table 34). The percentage area covered by water decreased in stage 2 and increased in stage 3 following intervention (Tables $33 \& 34)$. The decrease in stage 2 is attributed to the natural change in wetland structure over time. The increase in stage 3 is as a result of the creation of a pond during restoration. 
Table 34. The effect of intervention expressed at various DEM resolutions in stage 2

\begin{tabular}{|c|c|c|c|c|c|c|c|c|c|c|}
\hline \multicolumn{11}{|c|}{ Stage 2} \\
\hline DEM & \multicolumn{2}{|c|}{5} & \multicolumn{2}{|c|}{10} & \multicolumn{2}{|c|}{15} & \multicolumn{2}{|c|}{1 (field survey) } & \multicolumn{2}{|c|}{1 (LiDAR) } \\
\hline $\begin{array}{l}\text { management } \\
\text { scenario }\end{array}$ & BI & Al & BI & Al & BI & Al & BI & Al & BI & Al \\
\hline $\begin{array}{l}\text { Permeable } \\
\text { land (\%) }\end{array}$ & 0 & 1.49 & 0 & 1.17 & 0 & 1.03 & 0 & 1.58 & 0 & 1.64 \\
\hline $\begin{array}{l}\text { Protected } \\
\text { impermeable } \\
\text { land (\%) }\end{array}$ & 0 & 4.97 & 0 & 0.76 & 0 & 8.5 & 0 & 3.03 & 0 & 7.04 \\
\hline $\begin{array}{l}\text { Impermeable } \\
\text { land (\%) }\end{array}$ & 85.49 & 84.78 & 82.23 & 87.72 & 87.46 & 80.65 & 88.18 & 92.96 & 88.43 & 89.29 \\
\hline Water (\%) & 14.51 & 8.76 & 17.77 & 10.34 & 12.54 & 9.82 & 11.82 & 2.42 & 11.57 & 2.02 \\
\hline
\end{tabular}

BI- Before Intervention, Al- After Intervention 
Table 35. The effect of intervention expressed at various DEM resolutions in stage 3

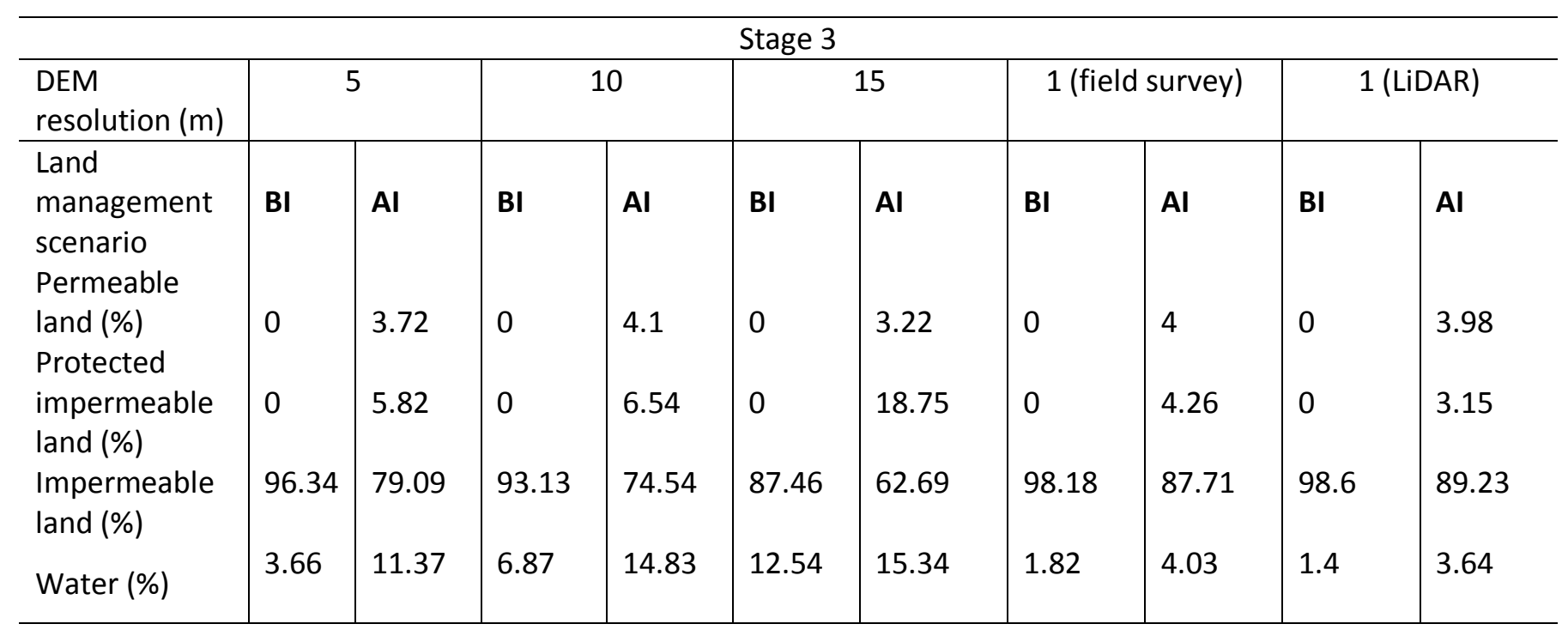

BI- Before Intervention, Al- After Intervention

Assessment of the $1 \mathrm{~m}$ resolution (field survey) output maps for intervention and the slope gradient maps show that most trees are currently planted on gently to moderately sloping (3-8 \%) and on strongly sloping areas (16\%) in both stages 2 and 3 (Figure 46). The degree of saturation on moderate and strong sloping areas is lower compared to flat areas $(<3 \%)$ where the model predicts the need for planting (Figure 46). However, tree planting to date, was targeted on moderate to strongly sloping areas to increase survival. 
a

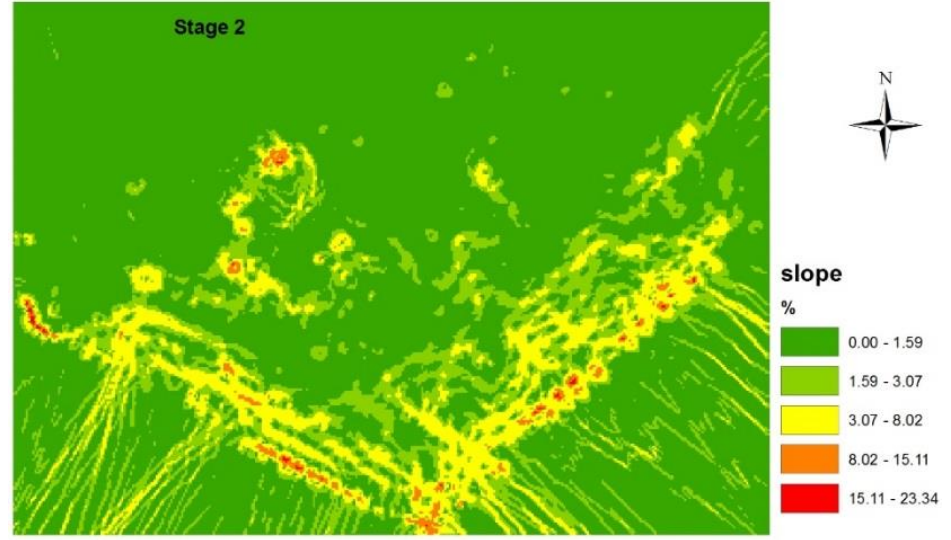

$0 \quad 0.030 .06$ Kilometers

b

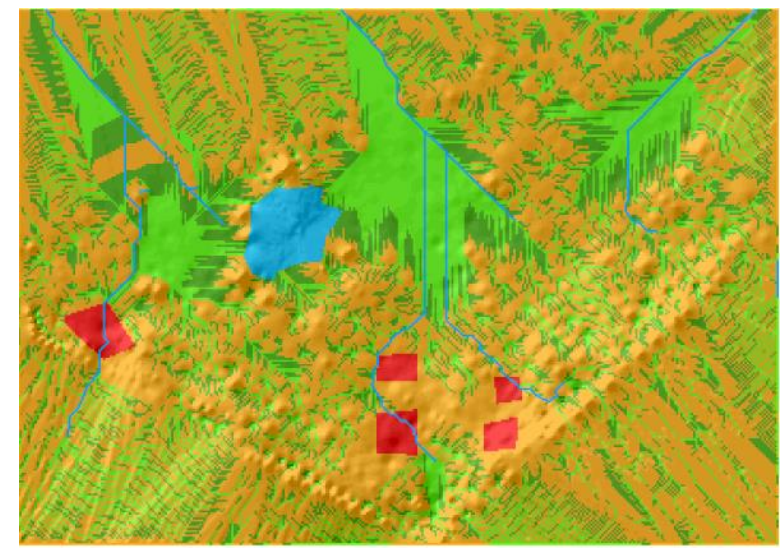

C

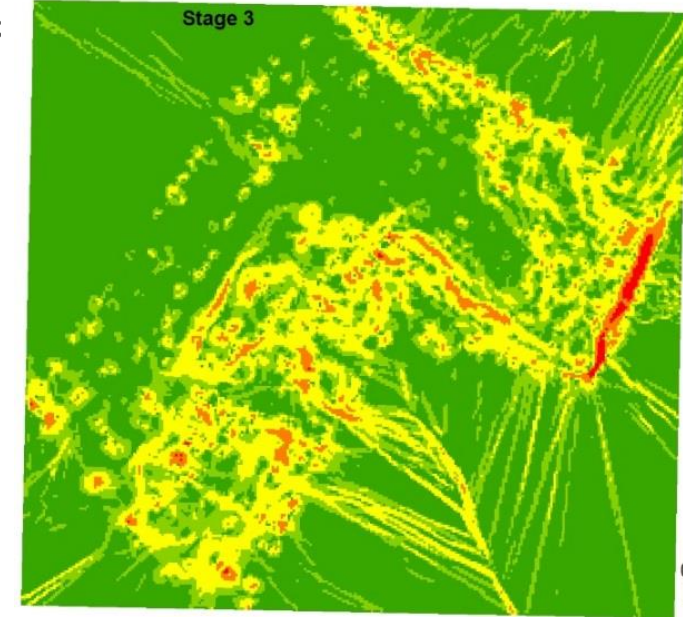

Slope $\%$

$0.00-1.59$

$1.59-3.07$

$3.07-8.02$

$8.02-15.11$

$15.11-24.20$

0.030 .06 Kilometers

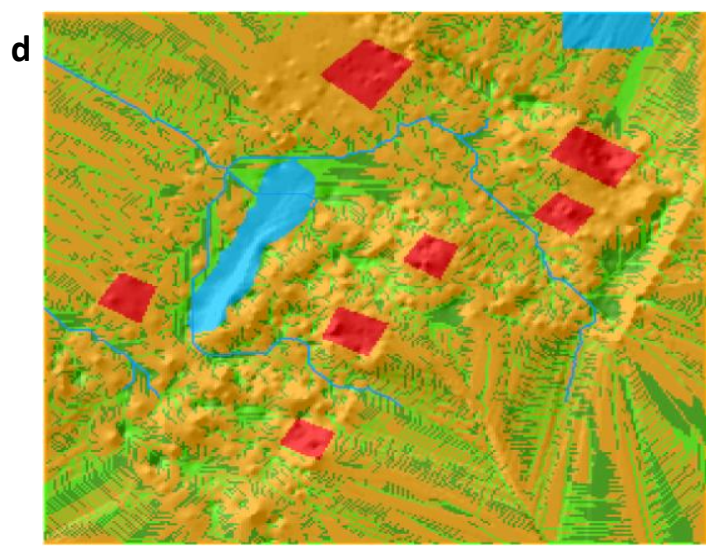

d

Mitigating land use

Minimal opprotunity to improve permeability

Good opportunity to improve permeability

High opportunity to improve permeability

Water bodies

Figure 46. Slope gradient and intervention maps a \& b for stage 2; c \& d for stage 3 (Based on field surveyed DEM at 1m resolution) 


\subsection{Discussion}

This research represents the first application of $\mathrm{LUCl}$ for the identification of target areas where appropriate management at field scale may improve permeability for flood mitigation in wetlands. It is also the first application isolating a small area and applying $\mathrm{LUCl}$ to a very flat region where data issues interfere highly with its topographic routing algorithims. Results from Wairio wetlands indicate that the current restoration practices (i.e. planting trees and creation of ponds) generally have a positive impact on flood mitigation although it is arguably of minor significance and that there is a significant potential for improvement through placement of interventions on specific target areas. However, LUCI is sensitive to the quality of data inputs and therefore the accuracy at which it predicted these target areas in detail is impacted by the quality of DEM (resolution and source) and land cover data.

$\mathrm{LUCl}$ output maps generally indicate that at least $80 \%$ of the wetland areas could still benefit from intervention that improves permeability for flood mitigation. This is a result of the soil data indicating that the wetland soils are characteristically of low permeability status. However, the presence of a high water table may reduce the capacity of the soil to retain large volumes of water. The current proportion of impermeable surface even following restoration is large but in comparison to the previous land use management when the pond and trees were absent in stage 3 , it decreased.

In stage 2 the succession of exotic grasses over time might have contributed to the increase in impermeable surface area. However, the receding of a pond could also have created more soil storage space for water to build up in times of flooding. Ponds are also useful for retaining water and can be regarded as elements of high existing value for flood mitigation just like the established trees (Hassall \& Anderson, 2015; Pearson et al., 2015).

The output maps in general reflect that the majority of the areas that could still benefit from intervention are in the form of land strips. This means single tree planting could be the ideal form of intervention on these strips. However, since the strips cover more than $50 \%$ of the impermeable area, this form of intervention may incur high labour and tree sapling costs. It may be more pragmatic to target large patches, where the established species can act as seed sources for natural regeneration on the land strips. 
Comparison of tree planting to slope gradient maps show that planting of trees during restoration was mainly targeted on elevated and moderately sloping areas, where the soil is reasonably well-drained. These positions are conducive for the survival of trees. Low slope areas susceptible to high degree of saturation and surface ponding were left out due to inaccessibility issues particularly during autumn when the planting is carried out. It is at these low slope areas where the model delineates the need for target planting to optimise absorption and retention of water for flood mitigation. Successful establishment on these areas would require the choice of species combinations highly tolerant to wet conditions for a long period, such as kahikatea and cabbage tree (Gillon, 2014).

LUCI modelling results give a general insight into the benefits of the current restoration procedures, but these results vary according to the quality of inputs used for the generation of land management scenarios. Hydrological parameters (drainage density, flow lengths, areas of water accumulation) are represented differently between output maps derived from LiDAR and field survey DEMs. These differences are as a result of point density and resolution of DEMs. High point density is important for precise height estimation of slopes and accurate depiction of flow routing (Anderson et al., 2005; Sanii \& Student, 2008). Field survey and LiDAR DEMs of similar resolution $(1 \mathrm{~m})$ show differences in drainage densities and flow lengths and this is attributed to point density. The point density for field surveyed DEMs is known (i.e. 0.01 and 0.03 points $/ \mathrm{m}^{2}$ for stages 2 and 3 respectively) while that of LiDAR is not specified. It is likely that field survey DEM more accurately represent terrain features than LiDAR of similar resolution. Field surveys directly measure elevation from the ground, and LiDAR laser airborne scanning may fail to reach the ground especially when there is thick vegetation and standing water (which are typical of Wairio wetlands), therefore field sampled points may accurately represent elevation. LiDAR DEMs of different resolutions were derived from the same point density, although the specific point density is not mentioned. Therefore the differences between them are only attributed to resolution.

The elevation values of low resolution LiDAR derived DEMs were significantly different from elevation values of high resolution field survey and LiDAR. Therefore, low resolution LiDAR derived DEMs inaccurately delineated target areas. As resolution decreases there is likely to be a decrease in total flow and length of streams and drainage density (Shortridge \& Clarke, 1999; Azizian \& Shokoohi, 2014). This decrease in hydrological flow and drainage density 
can be attributed to the decrease in slope associated with the decrease in resolution. Numerous studies (e.g. Shortridge \& Clarke, 1999; Zhang et al., 1999; Azizian \& Shokoohi, 2014) have found that low grid resolution underestimates slopes, while high resolution results in an increase in areas of predicted zones of surface saturation. Generally, the effects of small scale lateral variation in micro-topography cannot be fully captured when DEMs of large cell sizes (low resolution) are used (Parsons et al., 1997). The incomplete representation of micro-topography has implications on flow routing and velocity. While high resolution DEMs are important for accurate feature prediction, they present high volumes of data that require a long time to manage and a high computer memory particularly for large areas (Azizian \& Shokoohi, 2014).

The accuracy at which LUCI predicted target areas was also a factor of the land cover data. The age of indigenous trees/forest land cover is not specified in LCDB2. This has implications on the accurate prediction of the ecosystem service functions because the effectiveness at which trees and forests increase soil permeability and storage capacity varies with age. As discussed in chapter 2 , generally research has shown that mature trees effectively enhance soil permeability compared to young trees (Archer et al., 2013), although this also varies depending on species type. The indigenous species established at Wairio wetlands as part of restoration are of an age range between 2-4 years. Although a few studies have shown that young trees can also increase soil permeability and storage capacity in drier terrestrial areas (e.g. Carroll et al., 2004), it is likely that this may take a longer time frame in wetlands ${ }^{25}$. $\mathrm{LUCl}$ delineated the areas planted with the indigenous species as mitigating because of the presence of mitigating features. While it is accurate that mitigating features (trees) are present, it may not necessarily mean the areas under these trees have become permeable (as highlighted by the results in chapter 4), though over time they will likely become so. Therefore, it is recommended that additional functionality be incorporated into LUCI for better delineation of landscape functions based on land cover age. This also means information on age needs to be added into land cover databases for LUCI to provide robust decision support for interventions. Therefore, it is important to reiterate that because of these uncertainties, the presented results are indicative only.

\footnotetext{
${ }^{25}$ The results in chapter 4 of this thesis support this assertion
} 
By delineating target areas for planting trees, in theory LUCI could also predict habitat suitability for different tree species with different tolerance to flooding. Suitability of tree species to target areas could be added to the optimisation strategy.

Finally, a plausible addition to the spatial modelling would be the consideration of how climate change affects the impact of land use management on flood mitigation in wetlands at field scale. This is a vital consideration, given that climate change is anticipated to result in the increase in rainfall intensity in other regions and reduction in others, and this has implications on water flow regimes in landscapes. This inclusion would benefit policy makers by providing information useful for devising adaptive management strategies in wetland restoration programmes to increase resilience in the face of climate change.

\subsubsection{Limitations of using $\mathrm{LUCl}$ at Wairio wetlands}

As mentioned in the discussion section, the modelling results are only indicative because of various limitations. Sensitivity analysis of LUCI to DEM resolution shows the need for high quality topographical data and robust ground truthing to accurately model flood mitigation in relatively flat wetland areas. This is time and financially demanding and moreover, the ongoing construction of earth dams means that topographical data may need to be continuously updated. The update of DEMs will require collection of more spot height data and presenting it at high resolution.

A large amount of time was invested in collecting soil data for chapter 4 but the data could not be incorporated into the modelling process, as there was insufficient time to do so. Hence there was no correction of the attributes of the New Zealand Fundamental Soils Layer, which may not match what is currently on the ground. This has implications on the accurate representation of soil chemical attributes such as organic carbon which determine the water holding capacity. The correction (ground truthing) of national data was only carried out for some and not all of the land cover, because of flooded conditions in some of the areas.

While LUCI delineates target areas for planting trees, it does not account for the survival suitability of the suggested target areas. This is of particular importance in Wairio and other wetlands where suggested target areas may have saturated soils and standing water that 
limit the survival of most tree species. Research on the optimum growing conditions for tree species in the national data (Land cover data bases 2-4) would be useful in meeting the need.

The current $\mathrm{LUCl}$ version does not incorporate the age of trees into modelling scenarios. While the age of trees does not affect decision-making in terms of establishing trees for flood mitigation in the long run, it clearly affects the current flood mitigation. The trees at the Wairio study site are still young and have not reached their optimal potential to significantly contribute to flood mitigation. Hence, it would be plausible for LUCI modelling to highlight this to avoid underestimation of flood runoff in the case of a flood event occurring at this stage. The data from the study site would be a useful baseline to generate information on tree age for input parametrisation in LUCI. 


\subsection{Conclusion}

This chapter represents the first application of LUCI that attempted to visualise the impact of restoration at field scale in forested wetlands. It was possible to visualise areas where intervention can still be carried out to maximise the ability of Wairio wetlands to absorb water for flood mitigation. These areas constitute at least $80 \%$ of the wetlands and may not necessarily be conducive for the survival of trees if they are to be re-established. Survival of trees can be enhanced by choosing to plant species that can tolerate anoxic conditions for a long period of time. Further research on which species are best for what conditions and in what combinations should be carried out. This is particularly important in wetlands where conditions rapidly change over a short period of time. Results presented in this chapter are only indicative as the quality of inputs, particularly land use data, is poor and the soil data was not corrected to account for what is currently on the ground. The study also demonstrates that $L U C I$ is sensitive to the quality of DEM used as input in wetlands where topography is relatively flat but also highly variable. High quality and high resolution DEMs of $1 \mathrm{~m}$ grid size are appropriate particularly for small areas but can be very time consuming to acquire and may overburden computing resources. It is important that particular attention is focused on the accuracy of elevation data used for the generation of DEMs. 


\section{Chapter 6- Guidelines for the effective use of trees in forests and forested wetlands for flood runoff mitigation}

\subsection{Introduction}

It is apparent that trees are useful for flood moderation in many terrestrial landscapes. However, as discussed in chapter 2, the extent of their usefulness depends on topography, soil type, geology, species type, climatic region, catchment scale, position in landscape, magnitude of rainfall event and the level of soil water table. This chapter provides guidelines for effective use of trees for flood risk mitigation in forests (sections $6.2-6.8$ ) and their subset, forested wetlands (section 6.9) based on the analysis and understanding of the findings from literature review in chapter 2, supplemented by data from the specific forested wetland study in chapters 4 and 5 . The guidelines take into account whether trees should be planted at all, the selection of suitable species, planting date, the importance of other vegetation types and the importance of taking an ecologically holistic approach by considering other ecosystem services in addition to flood mitigation. The forested wetland guidelines are generally applicable to other ephemeral forested wetlands undergoing restoration in New Zealand and other parts of the world but also include some information specific to Wairio wetlands, from where a set of detailed soil hydrology data was derived.

All guidelines are from an ecological perspective based on the eco-hydrological interactions of trees, soil and water under spatially and temporally variable factors such as climate and topography, among others. Social and economic aspects (e.g. values, perceptions and access to resources of vulnerable communities), that are also important in natural flood risk management were not considered. These are recommended for future research.

\subsection{Under what topography are trees and forests useful?}

There are various topographical elements that are important to consider when assessing the topography at which trees and forests are effective in reducing flood risk. These include elevation, aspect, slope gradient, curvature (concave or convex), shape (convergence or divergence) and surface roughness (micro-topography) among others. In most regions, particularly cool climates, the air and soil temperature at higher elevation areas is low and may not favour the growth of most tree species (Griffiths et al., 2009). Moreover, due to 
gravity and sometimes thin soils, high elevation areas generally contribute to fast flowing runoff (if slope is high) during high rainfall events (Anderson et al., 1976), and could benefit from the establishment of specific tree species to combat this. Potentially, some high intercepting coniferous tree species such as Pinus ponderosa (ponderosa pine) and Abies concolor (white fir) that are adapted to high elevation areas can be established to reduce runoff. Knowledge of the tree line ${ }^{26}$ is necessary prior to establishing trees at high elevations. Tree lines vary according to locations, for example in very cold areas such as Scotland and Norway, the tree line is lower (500-800 meters above sea level) while in warm areas such as the Bolivian Andes, the tree line is up to 5000 meters above sea level (Young \& León, 2007). Beyond tree lines, the effectiveness of trees is negligible.

At low elevations, except in cool regions such as the Antarctica, tree growth rate is high, and it is where most forest ecosystems and tree strips are usually located. Here, there is a need to take into account the slope factor, geology, species type, position in landscape, catchment scale, and rainfall event as discussed in sections 6.3-6.9 of this chapter.

Wenger (1999) suggests that trees and forests are often more effective in controlling floods when placed on flat gentle sloping areas (slope gradient $\leq 15 \%$ ). This is because access to groundwater for high productivity is often easily achievable in these areas, except where they are elevated terraces. However, on very flat areas (0-2 \% slope factor) and where there is slope convergence or concavity (Wenger, 1999; Jobbágy, 2012; Gevaert, 2014), the water table is often near the surface, causing persistent water-logging. This may also mean that even if trees can be established, there could be limited capacity to store incoming precipitation even in 'dry' conditions, although this could be severe in the presence of other shallow rooting vegetation types that may be less effective at hydraulic lifting ${ }^{27}$. Nevertheless, choosing to plant anoxic tolerant species such as Alnus glutinosa (alder) may be a plausible intervention.

Moderately steep areas (slope gradient $15-30 \%$ ) generate medium to high velocity flows, while steep terrains (slope gradient $\geq 30 \%$ ) generate high velocity flows and may benefit

\footnotetext{
${ }^{26}$ The boundary at which trees are capable of growing well. Past this boundary, environmental conditions such as lack of moisture or very low temperatures reduce growth and survival

${ }^{27}$ A process by which trees and other vascular plants draw water and nutrients from the soil through their root system.
} 
from tree induced infiltration and slope stability ${ }^{28}$ for flood moderation. However, the effectiveness is reduced above $60 \%$ slope because of a limited soil reservoir and shallow soil depth. These conditions limit the access of trees to water for productivity and reduce their growth (Jobbágy, 2012).

Surface roughness or micro-topographical irregularities, particularly the presence of depressions or hollows, often delay runoff by decreasing flow velocity. Planting trees on rough surfaces will decrease flood flows and enhance flood storage. A combination of the hydraulic roughness of woody trees and ground surface roughness increases frictional resistance and delays runoff initiation (Darboux et al., 2004; Thomas \& Nisbet, 2007).

Planting trees and forests on slope aspects that promote growth and development of canopy and root structural properties would be ideal for effective flood risk management. Both sunlight energy and precipitation are important for growth, however different slope aspects may receive these resources in unbalanced quantities. Depending on how much sunlight energy and water is received on slope aspects, growth of trees may be energy or water limited. Sunny facing slopes receive high sunlight energy but may be deprived of soil moisture due to high evapotranspiration rates, particularly in dry regions. Hence, deciduous species that are tolerant to moisture stress but whose growth is limited by inadequate solar energy may be suitable on these sunny aspects. Shaded aspects may have high soil moisture and less solar energy than sunny slopes. Evergreen species that require high available soil moisture may be most suitable on the shaded aspects. Caution should be taken in arid and semi-arid regions where high temperatures cause moisture deficit on both sunny facing and shaded aspects. Drought tolerant species may be suitable under such circumstances.

\footnotetext{
${ }^{28}$ Strengthens the soil and prevents landslides and mudflows that would otherwise fill up streams and rivers and cause floods
} 


\subsection{Under which soils and geology?}

Soil and geological properties are among the major factors that influence flood generation. The characteristics of soils and geology on which trees are effective for flood mitigation are provided in Table 36.

Table 36 Effectiveness of trees and forests under varying geology and soils

\begin{tabular}{ll}
\hline Geology and soil characteristics & $\begin{array}{l}\text { Utility of trees and forests as flood mitigation } \\
\text { tools }\end{array}$ \\
\hline $\begin{array}{l}\text { Impermeable bedrock. Shallow, impermeable } \\
\text { and highly degraded soils which support less than }\end{array}$ & $\begin{array}{l}\text { Trees and forests probably cannot establish } \\
\text { and hence planting under such conditions } \\
20 \% \text { vegetation cover. }\end{array}$ \\
$\begin{array}{l}\text { Threshold permeability for soil is } 10^{-9} \mathrm{~m} / \mathrm{s}\left(\mathrm{K}_{\mathrm{fs}}\right) \\
\text { However, choice of pioneer species may be } \\
\text { (DIN 18130, 1998). }\end{array}$ & $\begin{array}{l}\text { ideal for rehabilitation of the degraded soils. } \\
\text { Successful rehabilitation occurs over a long } \\
\text { period of time }\end{array}$
\end{tabular}

Impermeable bedrock. Permeable or semipermeable, deep, moderately deep or shallow soils.

Semi-permeable bedrock.

Permeable, semi-permeable or impermeable soils that could be shallow, moderately deep or deep.

Permeable bedrock. Impermeable and semipermeable soil that could be shallow, moderately deep or deep.
Trees and forests are generally useful. They have an opportunity to establish and can reasonably ameliorate permeability and increase depth over a long period of time. If impermeable or semi-permeable bedrock underlies shallow semi-permeable or impermeable soils (less than $1 \mathrm{~m}$ from surface), deep rooting species that create conduits to a deep storage ground water system are ideal. Deep permeable soils ( $>2 \mathrm{~m}$ depth) overlying semi-permeable bedrock have the capacity to store more rainfall, however, dense and deep rooting species can be useful for increasing permeability of bed rock over a long time span.
Highly permeable bedrock and deep, highly permeable soils.

Peat or highly organic soils
These soils are self-mitigating and establishment of forests might be of no benefit. Here, protection of what already exists can be more useful for flood risk reduction

Beware of planting trees on peat soils, as trees may actually reduce organic matter content. There are implications on soil carbon storage, and infiltration and storage capacity may decrease. There is need for careful consideration before intervention. 


\subsection{What species in which climatic region?}

Examples of species that can be used for flood mitigation in various climatic regions are provided in Table 37. This information is based on the review in chapter 2 . In all the climate zones mentioned in Table 37, tree species should be placed below the tree line, on suitable slope aspects, on areas with slope gradient less than $60 \%$ and on semi-permeable soils that allow establishment. Natural forests that are perpetually self-regenerating should be protected if present in the different climatic zones as they are generally more effective than plantation forests that are managed unsustainably, and have additional conservation value for biodiversity (Bradshaw et al., 2007; Wahren et al., 2012).

Table 37 Appropriate species for different climatic zones

\begin{tabular}{ll}
\hline Climatic zones & Appropriate species \\
\hline Arid & Exercise caution with heavy users of water (e.g. Eucalyptus) as they may \\
& deplete water through transpiration during dry seasons and exacerbate \\
& drought in areas where the water table is very low. This reduces stream inflow \\
& and has negative implications for aquatic ecosystems. Choose species with \\
& high water efficiency to conserve water under dry conditions and moderate \\
& floods under wet conditions. In areas where water table is close to the surface, \\
& choose anoxic tolerant species e.g. Populus euphratica (Poplar) in North Africa \\
& (Zhou et al., 2009). Native species may be ideal for the additional benefit of \\
& biodiversity provision.
\end{tabular}

Semi-arid Broad-leafed species, since their deep roots enable high evapotranspiration and reduce antecedent moisture conditions that are responsible for flash floods in these regions. Caution should also be exercised with heavy users of water because in these zones, huge changes in evapotranspiration can result in water shortages (Jobbágy, 2012).

Temperate A combination of deciduous and non-deciduous broad leaves is ideal. This enables runoff reduction through interception loss and high infiltration rates in winter. Coniferous species such as Pseudotsuga menziesii (Douglas fir) can be planted together with broadleaves to trap snow ${ }^{29}$ during winter. The dynamic plasticity of Douglas fir offers resilience to forest ecosystems against the impacts of future climate change (Montwé et al., 2015).

Humid

Deep-rooting broadleafed species are ideal. This is because in humid regions where there are highly seasonal and intense precipitation regimes, infiltration is more important than evapotranspiration in reducing flood risk (Jobbágy, 2012). Conifers may not be appropriate as they sometimes cause illuviation that can induce floods (Doerr et al., 2000).

\footnotetext{
${ }^{29}$ Reduces the amount of snow reaching the ground and prevents the soil from freezing thereby lowering runoff in the case of a rainfall event. If the intercepted snow is also evaporated from the leaves, the amount of water reaching the ground and potentially flowing to rivers is reduced.
} 


\subsection{Size of catchment}

In catchments of any size, it is ideal to establish trees relative to other land-use types such as some pastures and crops to reduce runoff for flood regulation. Figure 47 illustrates this based on the understanding of reviewed literature. There are however, exceptional deep rooting pasture species such as lucerne (Medicago sativa L.) that if managed well, can be effective in reducing runoff as they mature (Zhao et al., 2014). Trees effectively moderate floods in small catchments of less than $\sim 40 \mathrm{~km}^{2}$, as long as the other factors such as topography, climate, rainfall characteristics, soils and geology are conducive for their performance (e.g. Alila, 2009; Vose et al., 2011; Ellison et al., 2012). Currently, we cannot confidently show how trees perform in large catchments $\left(>\sim 40 \mathrm{~km}^{2}\right)$. There are only a few studies (e.g. Fahey et al., 2004; Tran et al., 2010; Bathurst et al., 2011), and they were not able to demonstrate significant effect because of the presence of confounding factors such as rainfall patterns, a wide range of land use and management practices. The studies also highlight the practical challenges (e.g. labour, time and costs) that can be associated with establishing forests and acquiring data at large catchment scale. However, the lack of robust data to support the role of trees and forests in large catchments and the recognised difficulties associated with establishing them at such scales does not mean they are ineffective. In fact, considering the previously discussed hydrological processes (chapter 2 and sections 6.2-6.4), trees are still likely to be beneficial if strategic planning is devised for their use as flood management tools in large catchments. This planning could involve selecting specific target areas that can benefit from the presence of trees to save on costs and improve effectiveness, as discussed in the next section. 


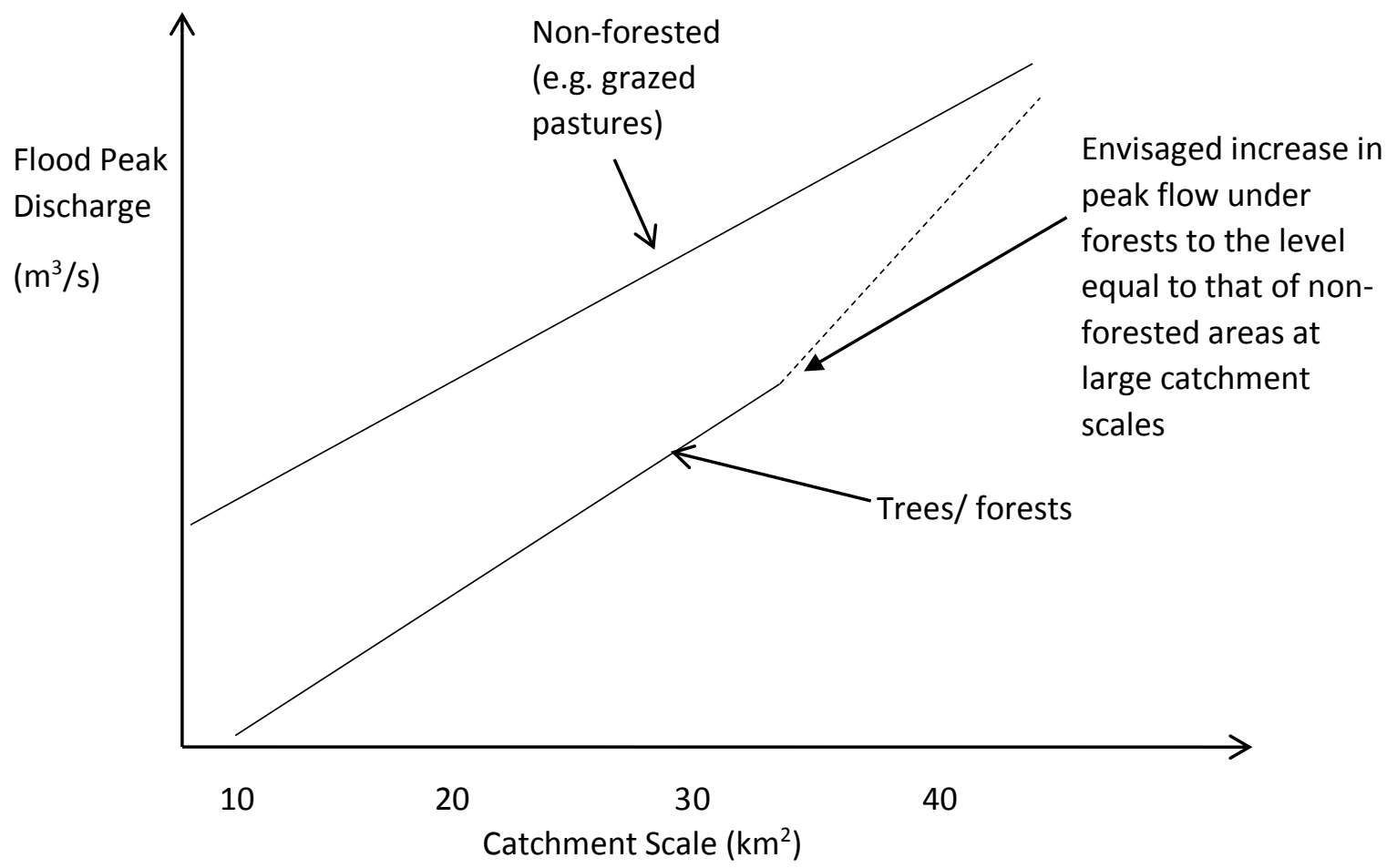

Figure 47. Demonstration of flood peak discharge of forested and non-forested land uses under varying catchment scales

\subsection{Where exactly in the landscape?}

Generally, it is ideal to place trees where they can significantly and positively increase water storage. Upland areas generally receive high rainfall and therefore contribute higher runoff that may cause floods. It may be effective to place interventions (trees) on positions near the source of runoff or downslope where they intercept runoff before it reaches water bodies. However, there may be high potential risk of exacerbating floods in upland areas if rapid recruitment of woody debris clogs bridges and weirs during heavy rainfall events, causing the rise in upstream water levels (Ruis-Villanueva et al., 2014). Planting conifer species with high vegetation resistance (Ruis-Villanueva et al., 2014) would reduce this potential risk. Notwithstanding the risk, woody debris is also beneficial for flood management by enhancing transportation of sediments in river channels, ensuring the river bed elevation does not increase (Kasprak et al., 2011).

On positions where the water table is close to the surface, tree species tolerant to water logged conditions, such as Alnus glutinosa (alder) may be planted, although water storage capacity is limited which means the effectiveness in mitigating floods may also be reduced. 
The positions could be riparian areas or floodplains where trees are beneficial for river bank stabilisation.

\subsection{Magnitude of rainfall event}

Forests and trees may reduce the risk and impacts of floods caused by rainfall events of varying magnitudes compared to land use types such as croplands, compacted grazed pastures and urban areas where much of the land surface is paved. However, the devastating effects that have been noted after rainfall events of extremely high intensity and volume, for example hurricanes (Bathurst et al., 2011), suggest that the benefit of trees and forests is reduced to the level of non-forested land-use types. This is because the high volume and intense rainfall will saturate the soil irrespective of land use, particularly when there are high antecedent soil moisture conditions preceding an extreme rainfall event (Bathurst et al., 2011). This is illustrated in Figure 48 that was created based on the understanding of the literature reviewed. This assertion cannot be made with a high level of confidence, because there are many other factors such as soil type, depth, topography and season that influence the role of forests under extreme events. There is still more research to be carried out. Generally, if other factors are conducive (e.g. topography and soils, climate), high interception and evaporation under forest conditions mean that, there could still be more storage capacity relative to non- forested land use types even if it rains frequently prior to an extreme event. Therefore, the impacts of hurricanes or any other extreme events could be more devastating if forests are not established for flood management. 


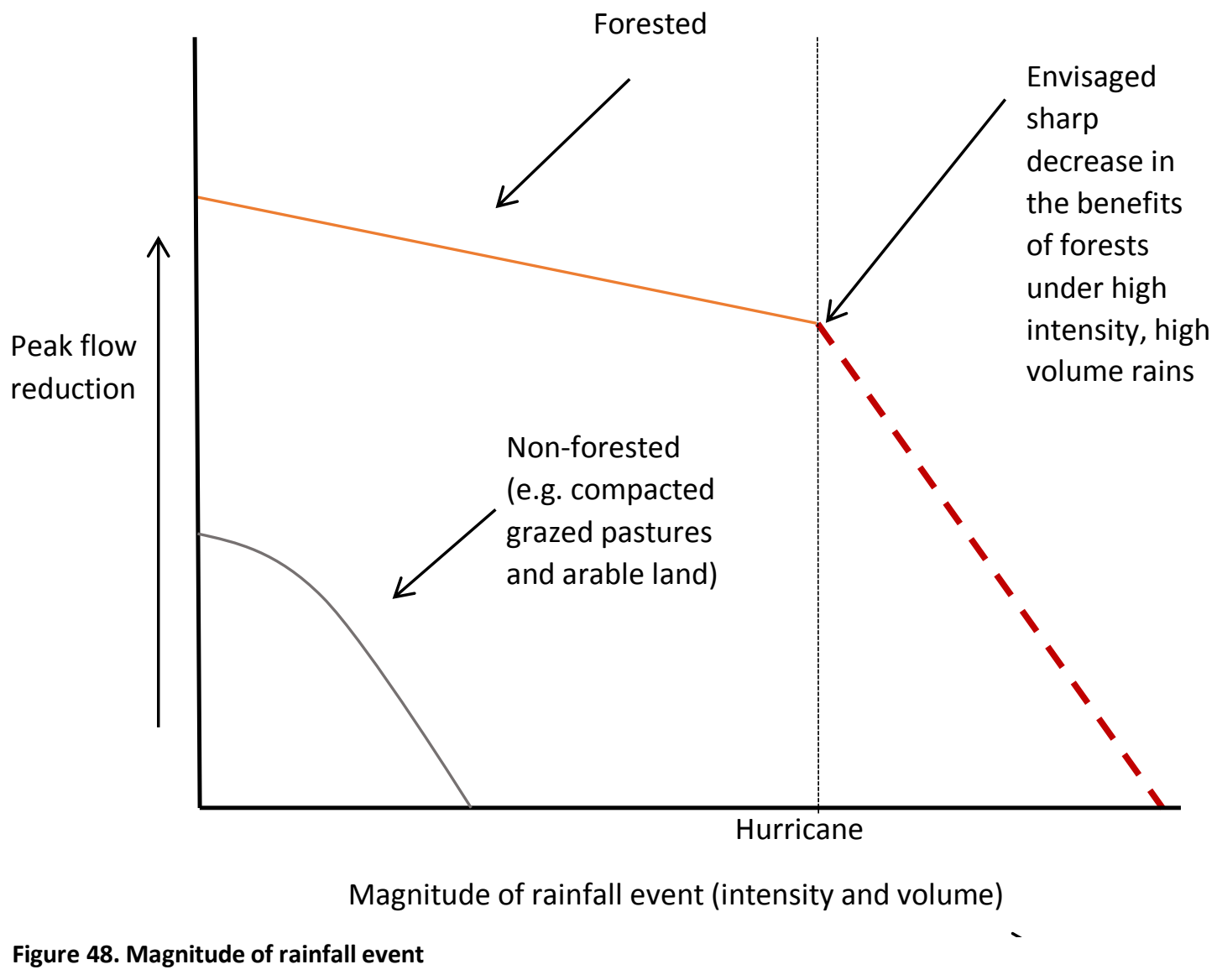




\subsection{Guidelines from a holistic perspective for policy makers}

This section presents guidelines that holistically exploit the synergies between forests/trees and climate, rainfall properties, catchment scale, topography, species, soils and geology for policy makers (with the main points encapsulated within (Figure 49- Figure 52). The proposed guidelines for impermeable, highly permeable and peat soils are similar across four climatic regions (humid, temperate, arid and semi-arid) irrespective of the rainfall property but differ for somewhat permeable, shallow to deep soils. The effectiveness of the proposed guidelines should be treated with caution in large catchment scales $\left(\geq \sim 40 \mathrm{~km}^{2}\right)$ and extreme rainfall events, as there is high uncertainty about the effectiveness of trees under such conditions. 
Impermeable bed rock.

Shallow impermeable

and highly degraded soils
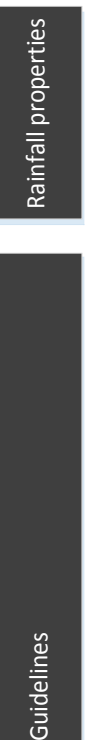

Not effective.

Could rehabilitate using pioneer species

at low to high elevations with moderate to steep slopes in small and large catchments.

1. In large catchments of greater than approximately $40 \mathrm{~km}^{2}$ and extreme rainfall events such as hurricanes, there is high uncertainty on the effectiveness of this solution

Figure 49. Effectively using trees and forests in as flood mitigation tools at varying soils/geology, catchment scale, rainfall properties and slope in Arid regions
Peat/highly organic

soils
Somewhat permeable,

shallow to deep soils

deep soils

mitigating soils by maintaining their inh

state. Establishment of

forests might be of no extra benefit

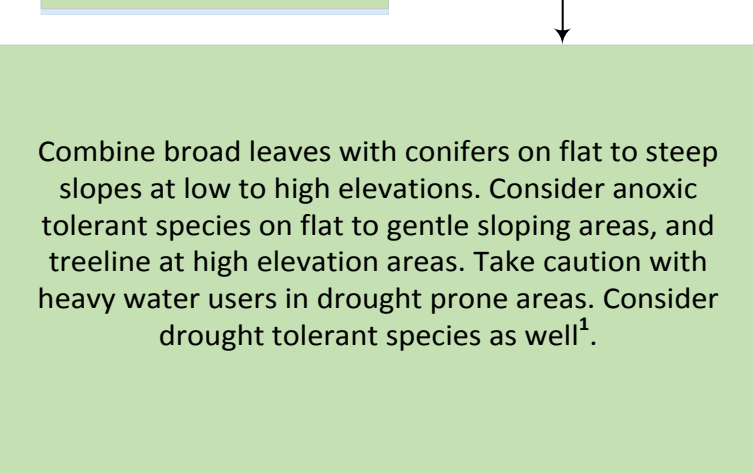

High intensity,

low volume

(high to low

intensity)
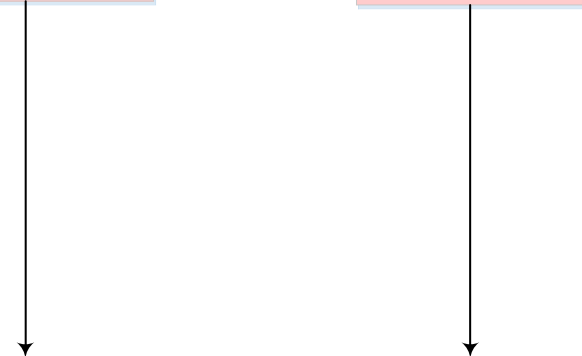

Plant broad leafed species that are good interceptors. These should be established on flat to steep slopes at low to high elevation. Take note of the level of water table on flat to gentle sloping areas and consider anoxic tolerant species. At high elevation, consider tree line. In drought prone areas, plant drought tolerant species and take caution with heavy water users ${ }^{1}$.

Adopt the same solution in regions receiving low intensity and low volume rainfall. 
Impermeable bed rock. Shallow impermeable and highly degraded soils
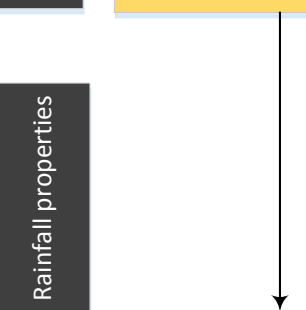

Not effective. Could rehabilitate using pioneer species at low to high elevation areas with gentle to steep slopes in small and large catchments mitigating soils by maintaining their inherent state. Establishment of forests might be of no extra benefit

Plant deep rooting broad leafed species on flat, gentle and steep sloping areas at low, medium and high elevations. Plant anoxic tolerant species on flat and gentle sloping areas. Take caution with conifers as they sometimes induce water repellency. Consider tree line at high elevations ${ }^{1}$.

The strategy may not be highly effective on very

$$
\text { steep slopes. }
$$

Peat/highly organic soils

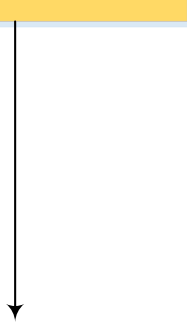

Take caution. Consider not planting because trees may reduce organic matter content and water holding capacity. There are potentially negative implications for carbon storage

Plant deep and dense rooted species. Preferably deciduous and non-deciduous broadleaves tolerant to water logging on flat and gentle sloping areas. Consider treeline at high elevations. Adopt similar strategies in areas receiving low intensity and volume rainfall.

Take caution with conifers as they sometimes induce water repellency ${ }^{1}$.

1. In large catchments of greater than approximately $40 \mathrm{~km}^{2}$ and extreme rainfall events such as hurricanes, there is high uncertainty on the effectiveness of this solution 

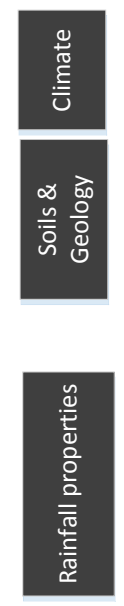

Impermeable bed rock

Shallow impermeable

and highly degraded soils

$\downarrow$

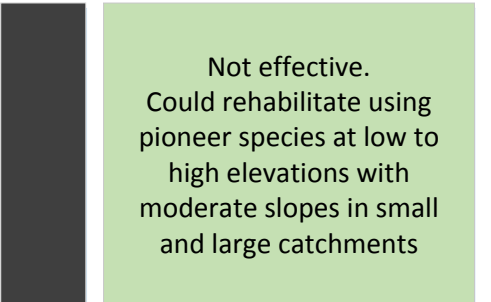

Protect these self-mitigating

Establishment of forests

might be of no extra benefit oils by maintaining their inherent state.

ighly permeable and deep soils

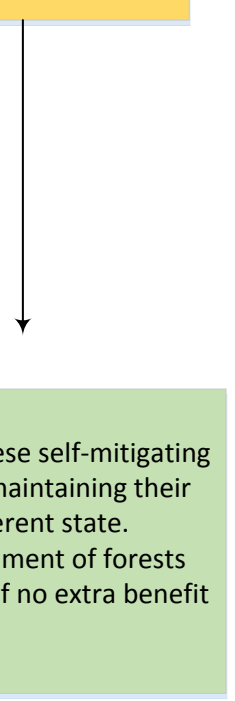

Semi-arid Regions

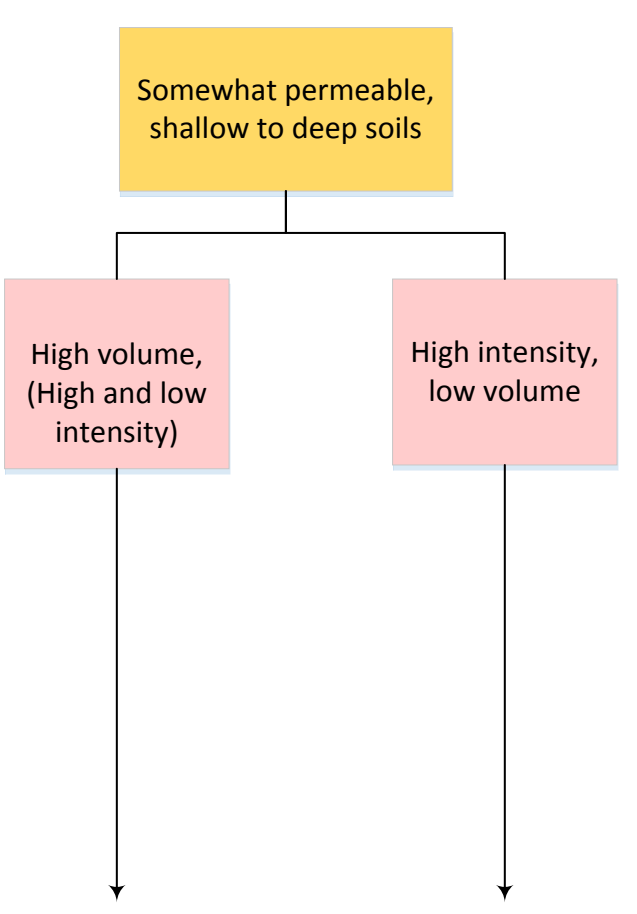

Peat/highly organic soils

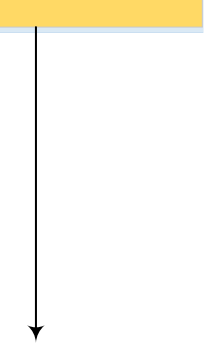

Take caution. Consider not planting because trees may reduce organic matter content and water holding capacity.

There are potentially negative implications for carbon storage

Plant a mixture of broad leaves and conifer species at low to high elevations.

On flat to gentle slopes choose anoxic tolerant species. Take caution with heavy water users in drought prone areas. Consider tree line at high elevation areas ${ }^{1}$.

On very steep slopes, effectiveness could be reduced.
Plant broad leaves at low to high elevations on flat to steep slopes. Choose anoxic tolerant species on flat to gentle slopes. Consider tree line at high elevations.

Take caution with heavy water users in drought prone areas. Adopt similar strategy in areas receiving low intensity and low volume rainfall $^{1}$.

Effectiveness can be reduced on very steep slopes.

1. In large catchments of greater than approximately $40 \mathrm{~km}^{2}$ and extreme rainfall events such as hurricanes, there is high uncertainty on the effectiveness of this solution 
Impermeable bed rock. Shallow impermeable and highly degraded soils
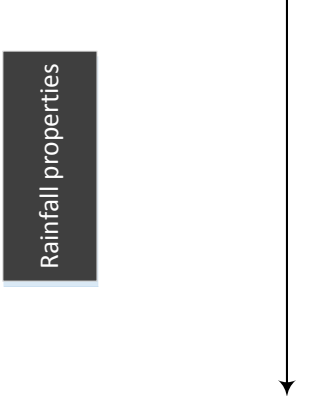

Not effective.

Could rehabilitate using pioneer species at low to

high elevations with

moderate slopes in smal

and large catchments

Temperate Regions

Protect these self-mitigating
soils by maintaining their
inherent state. Establishment
of forests might be of no
extra benefit

extra benefit
Highly permeable and deep soils

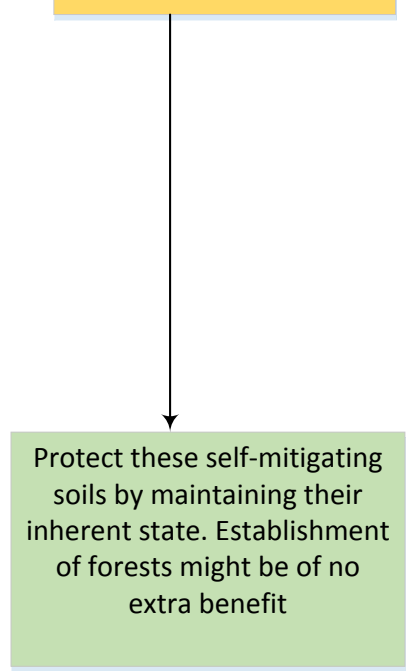

Plant deep rooting broad leaves on flat to steep slopes at low to high elevations. Could also include conifers for interception of snow during winter.

Consider anoxic tolerant species on flat and gentle sloping areas. Take note of tree line at high elevation ${ }^{1}$. Effectiveness of the deep rooting broad leaves could be reduced on very steep slopes.
Peat/highly organic soils

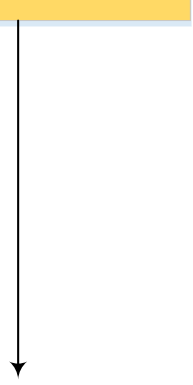

Take caution. Consider not planting because trees may reduce organic matter content and water holding capacity. There are potentially negative implications for carbon storage
Combine deciduous and non-deciduous broad leaves. Also include conifers. Plant these on flat, gentle and steep

slopes at low, medium and high elevations. Consider anoxic tolerant species on flat and gentle sloping areas. Consider tree line at high elevation.

Adopt similar approaches in regions receiving low intensity and low volume rainfall ${ }^{1}$.

The strategy may not be highly effective on very steep slopes.

1. In large catchments of greater than approximately $40 \mathrm{~km}^{2}$ and extreme rainfall events such as hurricanes, there is high uncertainty on the effectiveness of this solution 


\subsection{Guidelines for forested wetlands undergoing restoration}

\subsubsection{Should trees be planted?}

Trees are a typical vegetative component of forested wetlands by definition, and they provide a wide range of benefits such as improved water flow and quality and greater diversity of the habitat and organisms. The answer to whether trees should be planted seems obvious from a forested wetland perspective. One of the objectives for habitat restoration is to maintain ecological structure and function of that habitat. Trees are part of the ecological structure and function of forested wetlands, and therefore should be planted. However, it is also important to note that they may pause potential risks through excessive water consumption, woody debris generation that may increase floods and organics that raise biochemical oxygen demand in water, thereby causing mortality of aquatic life. While planting trees is important for ecological structure and function of wetlands, observations from Wairio wetlands show that the wet antecedent conditions reduce the survival rate of trees and this raises the question of whether trees will establish enough to be beneficial to outcomes such as improved water flow and quality when planted. The survival and ability of trees to provide a wide range of benefits depends crucially on where they are placed and the particular species planted (Gillon, 2014), in addition to other factors such as competition from invasive species and climate.

\subsubsection{Where should trees be placed?}

Observations from Wairio wetlands show that the soils under the recently established trees have high hydraulic conductivity, which over time may potentially enable the wetland to absorb and transmit water in the event of a flood-generating storm. Most of the trees were planted on high slope positions and ridges, where they can optimally survive and grow. On low slope areas, inundation is regular and prolonged during winter such that the survival of trees is reduced. In summer, the low slope areas dry out. It is in these areas where there is a high potential for improvement if trees are planted. This is because the soil sub-surface storage space needs to be enhanced during inundation periods. A combination of two strategies can be adopted to improve the absorption and retention of water on the low slope areas that have a varying degree of wetness. These include the selection of tree species and deep rooting wetland sedges that are highly tolerant to both waterlogging for a 
long period as well as dry conditions in summer, and the creation of ponds for the retention of water in some of the wet areas that are inaccessible for tree planting.

\subsubsection{Choice of tree species and sedges that should be planted}

The selection of appropriate vegetation types for low slope areas should be carried out with the aim of increasing the population size of the site's typical species for maintenance of ecological structure and function. This means survival and other ecological benefits apart from flood management (e.g. nutrient filtration and biodiversity) of selected species are of great importance. Using the studied Wairio wetland as an example, the habitat was originally a podocarp swamp forest with sedges, turfs and flax. The site's typical podocarp species have been re-established as part of restoration and these include Podocarpus totara (totara) and Dacrycarpus dacrydioides (kahikatea). Other native woody species established are Coprosma propinqua (mingimingi), Cordyline australis (cabbage tree), Pittosporum tenuifolium (kohuhu), Leptospermum scoparium (manuka), Coprosma robusta (karamu) and Olearia virgata (Twiggy tree daisy). These species have been planted mostly on areas where they can survive, i.e. on high slope positions. This can be generally applied to other forested wetlands.

Survival rates of most species on low slope areas in Wairio wetlands have been very low, with the exception of cabbage and kahikatea trees that are highly tolerant to water logging. It is therefore plausible to select anoxic tolerant species for very wet areas on low slope, and in this case, kahikatea and cabbage tree species are appropriate. In further support of this proposition, the exploration of Nga Manu nature reserve (Kapiti coast) New Zealand), a remnant of coastal lowland swamp forest showed that kahikatea and cabbage trees were predominantly common on swales, while totara, twiggy tree daisy and manuka preferred the dry tops of dunes. This is also supported by reports from Auckland Regional Council (2001) and Hawkes Bay Regional Council (2004) in New Zealand.

In the very wet areas, non-woody wetland vegetation such as sedges (e.g. Carex geminata) can also be established in combination with the recommended tree species. This sedge occupies some of the very wet areas as observed in stages 2 and 3 of Wairio wetlands.

In general, the planting of tree species in ephemeral wetlands in temperate regions is often carried out in winter when the soil has enough moisture to sustain growth (Deil, 2005). 
However, most low slope areas are often inundated and inaccessible during this period and planting trees becomes challenging. Alternatively, planting dates can be rescheduled to the end of spring or beginning of summer (e.g. as in Wairio wetlands), when some of the low slope areas become accessible. During this time, planted trees can make use of the antecedent soil moisture before it gets diminished in middle of summer. In Wairio wetlands, most of the cabbage trees that were established at the beginning of summer on low slope areas had high survival rates, e.g. in plot 1 of block 12 located on low slope, the survival rate was $73 \%$, by the end of the study (Table 10 ).

The survival and growth of established trees is also affected by competition from invasive species and weeds such as tall fescue, weeds, blackberry, gorse and lupin. Survival can be enhanced by protecting the trees using grotectors and survival rates of the majority of protected trees were over $90 \%$ (Table 38).

Table 38 Survival rate of species protected by tree guards (grotectors)

\begin{tabular}{llllllll}
\hline Stage & Block & Plot & Species & $\begin{array}{l}\text { Number of } \\
\text { trees in } \\
\text { grotectors }\end{array}$ & $\begin{array}{l}\text { Number of } \\
\text { plants that } \\
\text { survived in } \\
\text { grotectors }\end{array}$ & $\begin{array}{l}\text { \% species } \\
\text { surviving in } \\
\text { grotectors } \\
\text { (summer } \\
\text { 2014/15) }\end{array}$ & $\begin{array}{l}\text { \% Survival } \\
\text { of trees } \\
\text { outside } \\
\text { grotectors } \\
\text { (summer } \\
\text { 2014/15) }\end{array}$ \\
\hline 3 & 12 & 1 & Cabbage & 15 & & & 68 \\
3 & 12 & 2 & Manuka & 15 & 13 & 86 & 15 \\
3 & 11 & 1 & Cabbage & 15 & 14 & 53 & 53 \\
3 & 11 & 2 & Manuka & 15 & 14 & 93 & 79 \\
3 & 13 & 1 & Cabbage & 15 & 15 & 93 & 9 \\
3 & 13 & 3 & Manuka & 15 & 15 & 100 & 76 \\
2 & 1 & 1 & Cabbage & 15 & 14 & 93 & 59 \\
2 & 1 & 2 & Manuka & 15 & 14 & 93 & 71 \\
2 & 2 & 1 & Cabbage & 15 & 15 & 100 & 35 \\
\hline
\end{tabular}

On extremely wet areas, where accessibility is reduced even at the beginning of summer, planting of trees or sedges may not be ideal. Ponds however, can be created to retain water on the extremely wet areas.

\subsubsection{Pond creation}

Ponds are generally created on flat and extremely wet areas where ground water is close to the surface. Ponds contribute to the storage of large quantities of water and help reduce 
the risk of floods (Hassall \& Anderson, 2015; Pearson et al., 2015). Modelling in chapter 5 showed that pond creation in stage 3 at Wairio wetlands contributed to the storage of water.

\subsection{Conclusion}

The effectiveness of trees as flood mitigating tools in forests and forested wetlands can be enhanced by understanding various factors that affect their role. These factors include topography, soil type, geology, climate, catchment scale, their position in the landscape and rainfall properties. Precise recommendations vary based on these factors. Effectiveness is maximised if appropriate tree species are planted on flow contributing areas ranging from gentle to moderately steep slopes. On low-lying areas of low permeability where the water table is close to the surface, trees may be of little benefit. Choosing these strategic areas for planting trees prioritises where they are most beneficial and may save costs. Emphasis should also be on the choice of anoxic tolerant species on flat areas where the water table is close to the surface. This particularly applies to forested wetlands where the water table can be near to or even above the ground for a long time and the survival of most species is low. In areas that are too wet, ponds can be created to aid in the retention of water for flood mitigation. 


\section{Chapter 7- Conclusions}

Forests and forested wetlands play a vital role in flood risk mitigation and have recently attracted growing attention as potential substitutes or complements for expensive and sometimes unsustainable traditional engineering flood defences such as dykes, sea walls and dams (Archer et al., 2013; Temmerman et al., 2013). However, the mere presence of forests and forested wetlands does not necessarily mean the risk of flooding is reduced. The flood mitigation role of forests and forested wetlands is a function of the interaction of trees, other present vegetation, soil, water and climate. Trees can often reduce flood risk by lowering throughflow and surface runoff through the enhancement of soil physical and hydraulic properties that are critical for the absorption and retention of flood waters into the soil sub-surface, and through increased evapotranspiration and canopy interception (Robinson \& Dupeyrat, 2005; Marshall et al., 2009). However, this role of trees varies according to climate, topography, species types, rainfall properties, soil type and condition, catchment scale and geology, among other factors (as demonstrated in Chapter 2). Moreover, in forested wetlands the presence of a high water table may reduce the performance of trees in mitigating floods. Therefore, if forests and forested wetlands are to be used effectively as flood mitigating tools, either as substitutes or complements to traditional flood defence systems, it is vital to understand the hydrological role of trees under varying factors.

The main aim of this thesis was to synthesise existing knowledge and generate new empirical information on the eco-hydrological interactions between trees, soil and water under spatially and temporally varying environmental factors in terrestrial and wetland environments, to better understand where trees can be used as flood mitigating tools. Three phases of research were carried out:

- An exploration of the role of trees and forests as flood mitigation tools under changing climate, topography, species type, rainfall properties, soil type and condition, catchment scale and geology: This was carried out via a detailed literature review and careful consideration of processes in order to disentangle confounding factors. Strategies for effective management of flood risk using trees in 
terrestrial areas were identified. Knowledge gaps pertaining to their role under very high soil moisture conditions in wetlands were also identified.

- Investigation of the role of trees for flood mitigation in previously forested wetlands undergoing restoration:

This was carried out via literature review, data collection and analysis to address some of the research needs identified from the literature review mentioned above. Data and information on the effect of trees on saturated hydraulic conductivity, bulk density, soil moisture content, matric potential, soil organic carbon content and moisture retention for an ephemeral wetland in New Zealand were generated. This was the first set of detailed soil hydrology data from a previously forested ephemeral wetland undergoing ecological restoration through re-planting of trees in New Zealand. Findings from this investigation produce a foundation for making better informed decisions on the use of trees as flood mitigating tools in wetlands.

- Determination of appropriate areas where intervention can be targeted to optimise the role of trees as flood mitigating tools in forested wetlands: While investigating the effect of trees on soil properties in wetlands contributes knowledge to their role as flood mitigating tools under various environmental conditions, their effective use is enhanced when strategically placed on specific target areas. The third phase of research involved the application of a spatially explicit modelling tool, the Land Use Capability Indicator (LUCI) to identify specific target areas in a wetland, where if trees are placed their role is optimised.

\subsection{Main Conclusions}

7.1.1 The role of trees and forests as flood mitigation tools under changing climate, topography, species type, rainfall properties, soil type and condition, catchment scale and geology

Evidence from the literature review shows that there is spatial variability in the impact of trees on flood moderation arising from variability in both ecological processes and soil properties (e.g. O'Connell et al., 2007; Jackson et al., 2008; Marshall et al., 2009). Thus a blanket recommendation to 'plant trees' will not optimally enhance their role in flood risk mitigation everywhere. The literature review shows that there is proven potential to 
effectively use trees as flood mitigating tools from field scale to $<\sim 40 \mathrm{~km}^{2}$ in many areas of the world. There is limited research from large catchments $\left(>40 \mathrm{~km}^{2}\right)$ and high uncertainty as a result of the challenges of disentangling the impact of trees from confounding effects such as spatially varying rainfall and geology. From field scale to $<\sim 40 \mathrm{~km}^{2}$, the impact of trees is optimised when they are placed on gently sloping to moderately steep slopes (gradient $\leq 30 \%$ ), and on either shallow to moderately deep soils overlying semi-permeable or permeable bedrock, or deep soils overlying impermeable bedrock. On very deep and highly permeable soils overlying permeable rock, there may be little benefit of planting trees for flood mitigation purposes because the soils already inherently mitigate floods. Caution should be taken before disturbing peat soils, as trees may reduce the accumulation of organic matter through rapid water use, thereby affecting carbon storage and infiltration. Steep terrains (slope gradient 30-60 \%) contribute high velocity flow during high rainfall events and trees may moderate this somewhat, but may not be highly effective due to slow and shallow root development on steep slopes. The impact of trees is reduced on very shallow, highly degraded impermeable soils overlying impermeable bedrock and on very steep slopes (>60\%). This is because it is difficult for trees to grow and survive under these conditions and fundamentally there is a limited soil reservoir and hence limited water storage capacity. Similarly, where flat areas (0-2 \% slope gradient) coincide with a near soil surface water table (such as many wetlands), the growth and survival of most tree species is reduced due to persistent water- logging and the impact of trees is further limited by low soil water storage capacity. Planting anoxic tolerant species increases the survival of trees on the water-logged areas. However, due to the limited soil water storage capacity that is characteristic of these areas, their effectiveness for flood mitigation is likely to be limited.

Targeted planting of tree species on positions near the source of runoff or downslope where they intercept runoff before it reaches water bodies (e.g. low lying positions of low permeability receiving high velocity and high volume flow) is likely to enhance flood mitigation. If the water table is near the soil surface on low lying positions, tree species tolerant to anoxic conditions should be planted. Caution should be exercised with using tree species that consume large quantities of water (e.g. Eucalyptus) particularly in arid and semi-arid regions, as they will exacerbate drought impacts in areas where the water table is very low. Broad-leafed deep rooting species that facilitate infiltration and interception loss 
were identified to be ideal trees for flood mitigation tools in humid, semi-arid and temperate climates. In temperate climates, establishing a combination of coniferous species with deciduous and non-deciduous broadleaves often enables effective reduction of runoff through interception of snow and rainfall, and high infiltration rates in winter when flood incidences are usually high.

In addition, the ability of trees or forests to mitigate floods increases over time as they mature until an age when they morphologically deteriorate and resilience to catastrophic events is reduced. Therefore management practices, such as longer rotation periods, uneven-aged forests and selective harvesting (as is common in parts of Europe) increase the intergenerational effectiveness of trees and forests in flood risk mitigation.

The recommendations from the literature review are of value to flood management around the world. However, there are remaining research needs. Most of the research on the role of forests and trees in flood risk mitigation has been carried out in temperate climates and there is need for additional research in the tropics. There is also a need for more research in large catchments $\left(>\sim 40 \mathrm{~km}^{2}\right)$, under very extreme rainfall events and under the very high antecedent soil moisture conditions that are characteristic of wetlands. The second phase of this thesis addresses the role of trees under high antecedent soil conditions. Outcomes are noted in the next section.

7.1.2 The role of trees for flood mitigation in previously forested wetlands undergoing restoration

An investigation of the role of trees in high antecedent soil moisture conditions was carried out to address one of the research needs identified by the comprehensive review. This involved the collection and analysis of data on the effect of trees on soil hydraulic and physical properties critical for the absorption and retention of water in a previously forested wetland undergoing restoration on the eastern side of Lake Wairarapa in New Zealand. This investigation showed that recently established native tree species increased the saturated hydraulic conductivity of the wetland soil by $24-42 \%$ relative to other vegetation such as sedges, turfs and grasses (section 4.5.2.2). As expected native trees reduced the volumetric soil moisture content (by $16-37 \%$ on average) relative to sedges, turfs and grasses within the top $30 \mathrm{~cm}$ of the soil on areas of high slope in all climatic seasons (section 4.5.5.2). This reduces antecedent soil moisture and creates space for infiltrating water and thus 
mitigating flood runoff. This is supported by the approximate water balance, which showed high rates of evapotranspiration at the wetland. However, their effect on other soil properties such as bulk density, soil organic carbon and moisture retention was not significantly higher or different from that of sedges, turfs and grasses. This could be due to the trees being of young age ( 2 and 4 years) and not yet of sufficient maturity to significantly alter the soil properties. Studies have shown that the impact of trees is likely to increase over time as they grow older (e.g. Bruijnzeel, 2001; Nisbet \& Thomas, 2006; Archer et al., 2013). Nonetheless, in terrestrial areas, young trees (0-3 years) have been shown to significantly improve the soil hydraulic properties in relation to pasture grasses (e.g. Carroll et al., 2004). The high antecedent soil moisture conditions in the wetland area could have slowed growth and could be the reason why the young aged trees did not significantly alter the soil as much as trees of similar age did in the drier terrestrial landscape study by Carroll et al. (2004). The observed increase in bulk density in soil planted with trees indicates the possible effect of disturbances associated with planting that may have compacted the soil. This possibility may be disentangled by further studying over a longer time frame. A rough estimation of the time scale within which soil organic carbon levels of Wairio will closely match that of a restored forested wetland in Nebraska (Meyer et al., 2008) showed that it would require 29 years. This also means continuous monitoring over a long period would be useful for understanding soil organic carbon dynamics as much as soil bulk density.

It is important to highlight, that while useful data was collected, the wetland study site presented some unique difficulties during data collection. These include limited accessibility to some research plots in frequently flooded sites resulting in large amounts of time required to finish simple tasks, failure of field equipment in the uncompromising environment (e.g. the Guelph Permeameter was not always effective), and unpredictable survival and slow growth of trees. Sampling strategies had to be altered and some plots had to be abandoned. Also, given the short time frame of a PhD research (3 years) pre- and posttree planting comparisons could not be fully conducted. Data from these comparisons would have given more insight into the change and recovery of soil properties following the re-establishment of trees, as shown by (e.g. Marshall et al., 2009). This experience has however resulted in the attainment of valuable guidance useful in planning for future data collection in wetland sites and a data set which may be built upon in future years. 
Data on matric potential was useful in determining soil moisture retention and presence of standing water/saturated conditions in sites planted with trees and unplanted sites with sedges, turfs and grasses. The successful quantification of matric potential required making equipment adjustments to adapt to the high standing water conditions that seasonally occurred in the wetland. UMS T4e tensiometers with an air vent membrane at the tip of 1.5 $\mathrm{m}$ long connecting cables (much longer than the standard) were used for the quantification of matric potential. These can be submerged in water so long as the tip of the cable with the air vent is kept above water. The tensiometers were connected to data loggers to allow for continuous monitoring in the event of flooded conditions that hindered accessibility. This indicates the value of adopting telemetry techniques to collect data from inaccessible points in wetland environments. Telemetry equipment is costly to initially establish but in the long run there will be savings on transport and labour costs. We purchased three sets of tensiometers and data loggers (six tensiometers and three data loggers) to continuously measure matric potential in three plots (planted and unplanted on high slope, planted on low slope). Differences in matric potential were observed between the planted $(\psi \mathrm{m}<0$ $\left.\mathrm{mH}_{2} \mathrm{O}\right)$ and unplanted $\left(\psi \mathrm{m} \geq 0 \mathrm{mH}_{2} \mathrm{O}\right)$ plots on high slope at the end of winter (Section 4.5.6). Additional tensiometers in an unplanted plot on low slope for comparison to the planted site on low slope would have increased the value of current data but cost constraints did not permit this.

Characterisation of saturated hydraulic conductivity provided useful information on the capacity of the soil under trees and other wetland vegetation to transmit water. However, the Guelph Permeameter sometimes failed to function optimally, especially in winter and spring when there was high antecedent soil moisture and standing water above the soil surface. If future researchers encounter similar issues in wetland areas, they could alternatively adopt laboratory techniques which are performed in controlled environments. Recently there have been improvements in laboratory based techniques, e.g. the development of UMS Ksat bench top instrument (UMS GMbH, Munich, Germany) which determines saturated hydraulic conductivity at high resolution in a short period of time. This device is precise for a wide range of saturated hydraulic conductivity values ( 0.01 to 400 $\mathrm{mm} / \mathrm{hr}$ ) and can be used repeatedly on the same sample for long term studies (UMS GMbH, 
Munich, Germany, 2013; Schindler et al., 2015). It could be potentially useful for near saturated soils where it is sometimes difficult to use the Guelph Permeameter.

The newly established typically fast growing pioneer trees species (cabbage trees and manuka) are adapted to wetland conditions, however, some of the trees still died. The survival rate for manuka was low in some areas $(27 \%$ in block 12 , plot 2 and $37 \%$, in block 13, plot 3) as shown in section 4.2. This was due to herbivory and persistent water logging, which particularly affected manuka. Low survival in persistently water logged areas provided insight into the consideration of the alternative use of wetland sedges such as Carex geminata on positions that are too wet for the survival of trees. Most of the trees that survived herbivory were covered by a weed mat and enclosed in a translucent green growth tube (grotector / tree guard) that creates a conducive micro-climate for growth and protects against flood debris, wind, animal pests and trespassing livestock.

Despite the aforementioned difficulties encountered during data collection, findings from this investigation are useful as baseline data for continuous monitoring of the role of trees in facilitating flood mitigation in forested wetlands. Wetlands could be the way forward to complement upland areas in flood runoff mitigation.

7.1.3 Delineating appropriate target areas for tree planting to optimise the role of trees as flood mitigating tools in previously forested wetlands undergoing restoration.

This study determined specific areas where intervention should be targeted to optimise the role of trees as flood mitigating tools in the forested wetland under-going restoration on the eastern side of Lake Wairarapa in New Zealand. A spatially explicit modelling tool, the Land Use Capability Indicator (LUCI) (Jackson et al., 2013) was used for this purpose. Five gridded digital elevation data sets of contrasting horizontal resolutions and sources (four derived from LiDAR at $1 \mathrm{~m}, 5 \mathrm{~m}, 10 \mathrm{~m}$ and $15 \mathrm{~m}$ resolutions and one from a field survey at $1 \mathrm{~m}$ resolution), land cover and soil data (for land management scenario generation) were used as inputs to generate output maps showing areas where planting of trees is predicted to enhance soil permeability to maximise the absorption of water in the wetland. The study demonstrates that $\mathrm{LUCI}$ is sensitive to the quality of DEM used as input in wetlands, where topography is relatively flat but also highly variable. High quality and high resolution DEMs of $1 \mathrm{~m}$ grid size are appropriate for small areas (e.g. the modelled 13 ha area of Wairio wetlands), but can be very time consuming to acquire and may overburden computing 
resources. The use of a very coarse resolution DEM results in inaccurate representation of water flow pathways and consequently misrepresentation of areas of water accumulation that may benefit from tree planting.

Findings from the investigation highlighted that at least $80 \%$ of the area in the wetlands could potentially be planted for flood runoff mitigation. These areas are often inundated and have limited sub-surface storage capacity. As such, the areas may not be conducive for the survival of trees because of the regular inundation, as was observed in other already planted areas of similar conditions. The survival and effectiveness of trees under these water logged conditions can be enhanced by choosing to plant flood-tolerant species, such as Dacrycarpus dacrydioides (kahikatea) and Laurelia novae-zelandiae (pukatea). However, on areas that are too wet to establish trees, alternative interventions such as planting nonwoody vegetation with higher tolerance to anoxic conditions (e.g. Carex geminata) and pond creation for water storage can be considered.

Generally, the establishment of trees for ecological functioning in both forests and forested wetlands is typically targeted on areas where they are likely to survive and less attention is given to which areas are the most beneficial and cost-effective for mitigating flood-risk. However, shifting the focus from where trees can easily survive to where they can best enhance flood mitigation is important for guiding the effective use of trees. This shift requires information on which species are best for what conditions and in what combinations. This is not to say the consideration of survival and other biodiversity benefits should be abandoned, but to encourage a multiple-use approach for better win-win solutions and more holistic accounting of the value of trees.

\subsection{Main contributions}

This thesis provided original contributions that are important for natural flood risk management. These include:

\section{- Better understanding of how and where trees can be used effectively as flood} mitigating tools: Although there is vast knowledge about hydrological processes and the relationship between forests and floods, this knowledge is often used to make generalizations that are frequently inaccurate and misleading. There is a propensity 
to rely on simple cause-effect relationships, when in reality natural environments are extremely complex. This thesis is the first to provide a detailed review of the complex relationship between trees and flooding under various geo-climatic and topographical regimes. The review provides key policy relevant information highlighting precisely how, when and where trees can be effectively used to assist in managing the risk of flooding. Conditions under which there is high uncertainty (i.e. large catchments $>40 \mathrm{~km}^{2}$ and extreme rainfall events) regarding their effectiveness were identified.

- Data on the effect of trees on soil properties in forested wetlands: Generally, there is lack of soil hydrology data that highlights the flood runoff mitigation capabilities of forested wetlands. This thesis provides the first set of detailed soil hydrology data from a previously forested ephemeral wetland undergoing ecological restoration in New Zealand was generated. This is valuable baseline information for wetland monitoring, rehabilitation and conservation in New Zealand and around the world.

- Sensitivity analysis of LUCI to DEM quality: This thesis shows the importance of using high quality digital elevation data as inputs to spatially decision support tools to increase precision. This is particularly important in relatively flat areas such as wetlands where it is challenging to capture micro-topographical variations at low resolution. This research is the first application of $\mathrm{LUCl}$ to a wetland area and shows its high performance when high quality digital elevation data is used.

- Update of the New Zealand Land Cover Database 2: The 2001-2002 national land cover data of Wairio wetlands was updated to include the newly established trees and artificially created ponds. Some areas of herbaceous vegetation misclassified as high producing exotic grasslands were corrected. The updated land cover data is useful for guiding management and future research at Wairio wetland.

- Guidelines on the effective use of trees in forests and forested wetlands for flood mitigation: This research provides guidelines as to whether trees should be planted at all in wet antecedent areas where their survival may be reduced, the conditions under which trees are effective, characteristics of species suitable for various climatic, topographical, soil and geological conditions. The guidelines are important for restoration of forests and ephemeral forested wetlands in New Zealand and 
other parts of the world but also include some information specific to Wairio wetlands, from where a set of detailed soil hydrology data was derived.

\subsection{Recommendations for future research}

In light of the outcomes, lessons learnt and aspects omitted in this thesis, the following recommendations are provided for future research:

- Long term monitoring of wetland sites: Forested wetlands are dynamic ecosystems in which ecological processes and components are ever changing. To fully understand these dynamics, it would be of value to continuously monitor the changes in soil hydraulic and physical properties under growing trees and other wetland vegetation for a long time period (e.g. 5-10 years). This would be helpful for improved understanding of the functioning of trees in facilitating flood mitigation in forested wetlands. Furthermore, if future forested wetland restoration projects plan for long term monitoring, the value of obtaining baseline data prior to establishing trees would be high.

- Further data that enhances the understanding of hydraulic properties: Future research may benefit from collecting further data, for example the characterisation of rooting depth, architecture and carbon content of litter to enhance the understanding of hydraulic properties. Carbon content of litter would provide more information on the role played by vegetation in sequestering organic carbon that is important for water retention. Characterisation of how much of soil organic carbon is contributed by the above ground biomass of tree species, wetland turfs, sedges and grasses would be useful because biomass data can be a quick proxy for the assessment of vegetation impacts. This is important given the uncertainty on the rates of accumulation of soil organic carbon, which can be a slow process depending on climatic and soil conditions, among other factors.

The impact of trees and other vegetation types on soil hydraulic properties is associated with the presence of roots, for example coarse roots create macroconduits that enhance soil hydraulic conductivity. Characterisation of root systems of tree species and other wetland vegetation types as part of long term monitoring would be beneficial in maximising the understanding of the information obtained to date. Information on root architecture would also help in selecting vegetation 
suitable for the frequently water-logged areas that may benefit from enhanced water storage.

- Robust field reconnaissance prior to data collection: Accessibility to various sites in ephemeral forested wetlands is highly unpredictable due to intermittent wetting and drying. Sites that may be inaccessible on one event might be accessible on another and vice-versa. Optimal and robust data collection in such unpredictable environments requires thorough field reconnaissance prior to setting up measurements and the use of telemetry techniques with equipment adapted to such conditions. Field reconnaissance will help to choose appropriate sites and to devise strategies how to manoeuvre to the sites in case they become flooded. Adoption of telemetry techniques with specially designed equipment adapted to flooded conditions would be a useful way to collect data from inaccessible spots.

- The quantification of the volume of water flowing in and out of wetlands: The quantification of detailed and precise water budgets for the use in conjunction with information generated from this research would be extremely valuable. Water budgets will help determine the quantity of water flowing in and out of wetlands in the presence of trees thereby aiding in decision-making on how the residence time of water flowing in can be prolonged. These can be supported by collecting data on leaf area index to help explain water budget components such as evapotranspiration. However, it is vital to note that detailed water budgets are costly, time consuming and challenging to obtain (Beissel \& Shear, 1997) and researchers are not always able to quantify them.

- The use of tree guards: Herbivory and high winds had an influence on the survival of the newly established trees, particularly those not protected by tree guards at Wairio wetlands. Future tree planting in wetlands around the world should consider further research on the use of tree guards to enhance the survival of newly established trees.

- Incorporation of additional information into the LUCI model: While LUCI delineates appropriate target areas for planting trees, it does not show the survival suitability of these target areas. It would be of value to incorporate this information to ensure that LUCI predicts where certain tree species will or won't survive. It would also be important to include updated soil data to increase precision of the modelling results. 
- Investigation into the role of trees under extreme rainfall events and at large catchment scale: Findings from this thesis and other studies (e.g. FAO-CIFOR, 2005; Calder \& Aylward, 2006; Tran et al., 2010; Bathurst et al., 2011) highlight the uncertainty (e.g. due to the presence of many confounding factors) and lack of research on the role of trees as flood mitigating tools under extreme rainfall events and at large catchment scale. Investigations on the impact of trees on flood frequency and magnitude at full catchment scale using integrated field and modelling approaches would be helpful in guiding decision-making on afforestation for flood mitigation.

- Investigation of the social and economic aspects important for flood risk management: It is important to adopt a holistic approach towards flood risk management by exploring all factors affecting the achievement of this goal. This thesis provides valuable information on flood risk management mostly from an ecological perspective, i.e. based on the interactions of trees, soil and water in forests and forested wetlands. However, societal and economical aspects related to forests and forested wetland establishment and conservation for flood management are also critical but were outside the scope of this study. These include people's values, perceptions, awareness and access to resources, among others. More research into these aspects will be useful in determining the opportunities of implementing the guidelines provided in this thesis.

- More research on the flood mitigation role of forests in tropical areas: A large body of literature on the hydrological role of trees and forests as flood mitigating tools is available in temperate areas in Europe, tropical regions such as Australia and Spain, but there are limited studies in other tropical regions, particularly in Africa. More research is recommended in these tropical areas to increase the value of existing knowledge on the role played by trees under semi-arid and arid conditions that are typical of the areas.

\subsection{Final Summary}

In conclusion, this thesis achieved its main goal of generating information for the effective use of trees as flood mitigating tools in forests and forested wetlands. Key policy relevant messages highlighting how, when and where trees can be effectively used to assist in 
managing the risk of flooding are given. The review provided substantial evidence that there is potential to effectively use trees or forests as flood mitigating tools when appropriate species are placed on gently sloping to moderately steep sloping areas, on shallow to moderately deep soils overlying semi-permeable and permeable bedrock, or on deep soils overlaying impermeable bedrock. Their effectiveness under these conditions occurs in a range of humid, temperate, arid and semi-arid climates and increases with maturity. In arid and semi-arid regions, caution is emphasised on avoiding the planting of heavy users of water (e.g. Eucalyptus). Caution should also be taken on peat soils. Deep and highly permeable soils overlying permeable rock are self-mitigating and there will be no use of planting trees. The impact of trees is reduced on very shallow highly degraded impermeable soils overlying impermeable bedrock and on very steep slopes.

There is high uncertainty on their role and effectiveness in large catchments $\left(>\sim 40 \mathrm{~km}^{2}\right)$ and under extreme rainfall events such as hurricanes. Further research is necessary to provide substantial evidence. There is substantial scope for further monitoring of the role of trees in Wairio and other forested wetlands undergoing restoration around the world using the baseline data and information that is presented in chapter 4 . Strategic placement of trees to optimise their flood mitigation role in forested wetlands were identified. However, there is scope for improvement of the spatially explicit modelling tool used in the identification of the target areas by incorporating information on survival suitability of species in target areas. 


\section{References}

Abe, T., 2008. Influence of forest type, topography, and understory on infiltration rates in eastern Hokkaido, Japan. Journal of Japanese Forest Society. 90, 84-90.

Acreman, M., Holden, J., 2013. How Wetlands Affect Floods. Wetlands. 33, 773-786.

Acreman, M., Fisher, J., Stratford, C., Mould, D., Mountford, J., 2007. Hydrological science and wetland restoration: some case studies from Europe. Hydrology and Earth System Sciences Discussions. 11, 158-169.

Ahmad Dar, J., Somaiah, S., 2015. Altitudinal variation of soil organic carbon stocks in temperate forests of Kashmir Himalayas, India. Environmental Monitoring and Assessment. 187, 1-15.

Ainsle, W.B., 2002. Forested wetlands. United States Environmental Protection agency.

Albrecht, S.L., Rasmussen, P.E., 1995. Soil quality and soil organic matter. In: Columbia Basin Agricultural Research Annual Report. Spec. Rpt. 946. Oregon State University in cooperation with USDA-Agricultural Research Service, Pendleton, OR.

Alaoui, A., Lipiec, J., Gerke, H., 2011. A review of the changes in the soil pore system due to soil deformation: A hydrodynamic perspective. Soil and Tillage Research. 115, 1-15.

Alila, Y., Kuraś, P.K., Schnorbus, M., Hudson, R., 2009. Forests and floods: A new paradigm sheds light on age-old controversies. Water Resources Research. 45, 8.

Alkama, R., Kageyama, M., Ramstein, G., 2010. Relative contributions of climate change, stomatal closure, and leaf area index changes to 20th and 21st century runoff change: A modelling approach using the Organizing Carbon and Hydrology in Dynamic Ecosystems (ORCHIDEE) land surface model. Journal of Geophysical Research: Atmospheres. 115 (D17).

AAMHATCH, 2004. The Greater Wellington Regional Council Airborne Laser ScanningWairarapa. Vol 81021701NOB.

AAMHATCH, 2003. The Greater Wellington Regional Council Airborne Laser ScanningWairarapa. Vol 210073703NOM.

An, S., Li, H., Guan, B., Zhou, C., Wang, Z., Deng, Z., Zhi, Y., Liu, Y., Xu, C., Fang, S., 2007. China's natural wetlands: past problems, current status, and future challenges. AMBIO: A Journal of the Human Environment. 36, 335-342.

Anderson, H.W., Hoover, M.D., Reinhart, K.G., 1976. Forests and water: effects of forest 
management on floods, sedimentation, and water supply. USDA Forest Sew. Gen. Tech. Rep. PSW-18, 115 p., illus. Pacific Southwest Forest and Range Exp. Stn., Berkeley, Calif.

Andersen, H.E., 2003. Hydrology, nutrient processes and vegetation in floodplain wetlands. PhD thesis. National Environmental Research Institute, Denmark. http://afhandlinger.dmu.dk

Anderson, E. S., Thompson, J. A., and Austin, R.E., 2005. LIDAR density and linear interpolator effects on elevation estimates. International Journal of Remote Sensing. 26, 3889-3900.

Andréassian, V., 2004. Waters and forests: from historical controversy to scientific debate. Journal of Hydrology. 291, 1-27.

Archer, N. A. L., Bonell, M., Coles, N., MacDonald, A. M., Auton, C. A., Stevenson, R., 2013. Soil characteristics and land cover relationships on soil hydraulic conductivity at a hillslope scale: A view towards local flood management. Journal of Hydrology. 497, 208-222.

Archer, D.R., Climent-Soler,D., Holman, I.P., 2010. Changes in discharge rise and fall rates applied to impact assessment of catchment land use. Hydrology Research. 41, 13-26.

Armesto, J. J., Martínez, J. A., 1978. Relations between vegetation structure and slope aspect in the Mediterranean Region of Chile. Journal of Ecology. 66, 881-889.

Auckland Regional Council., 2001. Riparian Zone Management Guidelines TP148.

Aust, W.M., Lea, R., 1992. Comparative effects of aerial and ground logging on soil properties in a tupelo-cypress wetland. Forest Ecology and Management. 50, 57-73.

Azizian, A., Shohoohi, A., 2014. DEM resolution and stream delineation threshold effects on the results of geomorphologic-based rainfall runoff models. Turkish Journal of Engineering \& Environmental Sciences. 38, 64-78.

Bagstad, K. J., Semmens, D. J., Waage, S., \& Winthrop, R., 2013. A comparative assessment of decision-support tools for ecosystem services quantification and valuation. Ecosystem Services. 5, 27-39.

Ballinger, J., 2011. Natural buffer placement and downstream flood mitigation in rural Hawkes Bay, New Zealand, Thesis (MSc). Victoria University of Wellington, New Zealand.

Bana E Costa, C.A., Antão DA Silva., Nunes Correia, F., 2004. Multicriteria evaluation of flood control measures: The case of Ribeira do Livramento. Water Resources Management. 18, 263-283.

Bathurst, J.C., Birkinshaw, S.J., Cisneros, F., Fallas, J., Iroume, A., Iturraspe, R., Gaviño Novillo, M., Urciuolo, A., Alvarado, A., Coello, C., Huber, A., Miranda, M., Ramirez, M., Sarandon, R., 2011. Forest impact on floods due to extreme rainfall and 
snowmelt in four Latin American environments 2: Model analysis. Journal of Hydrology. 400, 292-304.

Beadel, S.M., Bibby, J.C., Perfect, A.J., Rebergen, A., Sawyer, J. 2005. Eastern Wairarapa Ecological District. Survey report of the Protected Natural Areas Programme.

Beadel ,S., Perfect ,A., Rebergen, A., Sawyer, J., 2000. Wairarapa Plains Ecological District: Survey Report for the Protected Natural Areas Programme. Department of Conservation. Wellington, New Zealand.

Beckwith, C. W., Baird, A. J., Heathwaite, A. L., 2003. Anisotropy and depth-related heterogeneity of hydraulic conductivity in a bog peat. I: laboratory measurements. Hydrological Processes. 17, 89-101.

Beets, P., Kimberley, M., Paul, T., Oliver., G, Pearce, S., Buswell, J., 2014. The Inventory of Carbon Stocks in New Zealand's Post-1989 Natural Forest for Reporting under the Kyoto Protocol. Forests. 5, 2230.

Beissel, K., Shear, T., 1997. Comparison of vegetational, hydrologic, and edaphic characteristics of riverine forested wetlands on North Carolina Coastal Plain. Transportation Research Record: Journal of the Transportation Research Board 1601, 42-48.

Belsky, A.J., Amundson, R.G., Duxbury, J.M., Riha, S.J., Ali, A.R., Mwonga, S. M., 1989. The effects of trees on their physical, chemical, and biological environments in a semi-arid savanna in Kenya. Journal of Applied Ecology. 26, 10051024.

Bergin, D.O., 2000. Current knowledge relevant to management of Podocarpus totara for timber. New Zealand Journal of Botany. 38, 343-359.

Bernal, B., Mitsch, W.J., 2012. Comparing carbon sequestration in temperate freshwater wetland communities. Global Change Biology. 18, 1636-1647.

Bernal, B., 2008. Carbon pools and profiles in wetland soils: The effect of climate and wetland type. The Ohio State University.

Berthrong, S. T., Piñeiro, G., Jobbágy, E. G., Jackson, R. B., 2011. Soil C and N changes with afforestation of grasslands across gradients of precipitation and plantation age. Ecological Applications. 22, 76-86.

Blaschke, P., Hicks, D., Meister, A., 2008. Quantification of the flood and erosion reduction benefits, and costs, of climate change mitigation measures in New Zealand. Report prepared by Blaschke and Rutherford Environmental Consultants for MfE. Wellington: Ministry for the Environment. iv $+76 \mathrm{p}$.

Blöschl, G., Gaál, L., Hall, J., Kiss, A., Komma, J., Nester, T., Parajka, J., Perdigão, R.A.P., 
Plavcová, L., Rogger, M., Salinas, J.L., Viglione, A., 2015. Increasing river floods: fiction or reality? Wiley Interdisciplinary Reviews: Water 2, 329-344.

Blöschl, G., Ardoin-Bardin, S., Bonell, M., Dorninger, M., Goodrich, D., Gutknecht, D., Matamoros, D., Merz, B., Shand, P., Szolgay, J., 2007. At what scales do climate variability and land cover change impact on flooding and low flows? Hydrological Processes. 21, 1241-1247.

Bloom, A. A., Palmer, P.I., Fraser, A., Reay,D.S., Frankenberg , C., 2010. Large-scale controls of methanogenesis inferred from methane and gravity spaceborne data, Science. 327, 322-325.

Bobbink, R., Whigham, D.F., Beltman, B., Verhoeven, J.T., 2006. Wetland functioning in relation to biodiversity conservation and restoration, Wetlands: Functioning, Biodiversity Conservation, and Restoration. Springer, pp. 1-12.

Boelter, D. H.,1965. Hydraulic Conductivity of Peats. Soil Science. 100, 227-231.

Bolker, B.M., Brooks, M.E., Clark, C.J., Geange, S.W., Poulsen, J.R., Stevens, M.H.H., White, J.-S.S., 2008. Generalized linear mixed models: a practical guide for ecology and evolution. Trends in Ecology \& Evolution. 24, 127-135.

Bolstad, P.V., Vose, J.M., 2001. The effects of terrain position and elevation on soil $C$ in the Southern Appalachians. In: Lal, R., Kimble, J.M., Follet, R.F \& Stewart, B.A. Assessment Methods for Soil Carbon. Lewis Publishers, Boca Raton, FL.

Bonell, M., Purandara, B. K., Venkatesh, B., Krishnaswamy, J., Acharya, H. A. K., Singh, U. V., Jayakumar, R., Chappell, N., 2010. The impact of forest use and reforestation on soil hydraulic conductivity in the Western Ghats of India: Implications for surface and sub-surface hydrology. Journal of Hydrology. 391, 47-62.

Boumans, R., Costanza, R., 2007. The multiscale integrated Earth Systems model (MIMES): The dynamics, modeling and valuation of ecosystem services, In: Van Bers, C., Petry, D \& Pahl-Wostl., (eds.). Global assessments: Bridging scales and linking to policy. Report on the joint TIAS-GWSP workshop held at the University of Maryland University College, Adelphi, USA, 10 and 11 May, GWSP issues in Global Water System Research, 2, 102-106.

Bradshaw, C.J.A., Sodhi, N., Peh, K.S.H., Brook, B.W., 2007. Global evidence that deforestation amplifies flood risk and severity in the developing world. Global Change Biology. 13, 2379-2395.

Breure, A. M., De Deyn, G. B., Dominati, E., Eglin, T., Hedlund, K., Van Orshoven, J., Posthuma, L., 2012. Ecosystem services: a useful concept for soil policy making! Current Opinion in Environmental Sustainability. 4, 578-585.

Brinson, M.M., Malvárez, A.I., 2002. Temperate freshwater wetlands: types, status, and threats. Environmental Conservation. 29, 115-133. 
Brinson, M.M., 1999. A hydrogeomorphic classification for wetlands. Wetlands Research Program Technical Report WRp-DE-4.

Brody, S.D., Highfield, W.E., Blessing, R., 2015. An Analysis of the Effects of Land Use and Land Cover on Flood Losses along the Gulf of Mexico Coast from 1999 to 2009. JAWRA Journal of the American Water Resources Association.

Brooks, R.H., Corey, C.T., 1964. Hydraulic Properties of Porous Media. Hydrol. Paper. 3. Colorado State University, Fort Collins.

Bruijnzeel, L. A., 2004. Hydrological functions of tropical forests: not seeing the soil for the trees? Agriculture, Ecosystems and Environment. 104,185-228.

Bruijnzeel, L.A., 2001. Forest Hydrology, In: Evans, J., (ed.), The forests handbook. Blackwell Science. 1.

Bruland, G., Richardson, C., Whalen, S., 2006. Spatial variability of denitrification potential and related soil properties in created, restored, and paired natural wetlands. Wetlands. 26, 1042-1056.

Bullock, A., Acreman, M., 2003. The role of wetlands in the hydrological cycle. Hydrology and Earth System Sciences. 7, 358-389.

Burch, G.J, Bath, R.K., Moore, I.D., Loughlin, E.M., 1987. Comparative hydrological behaviour of forested and cleared catchments in south-eastern Australia. Journal of Hydrology. 90,19-42.

Burdt, A.C., 2003. Hydric soil properties as influenced by land-use in Southeast Virginia wet flats.

Burrough, P. A., McDonnell, R.A., 1998. Principles of geographical information systems. Oxford University Press, Oxford. 333pp.

Calder, I.R., Aylward, B., 2006. Forests and floods: Moving to an evidencebased approach to watershed and integrated flood management. International water resources association. Water International. 31, 1-13.

Calder, I.R., Reid, I., Nisbet, T.R., Green, J.C., 2003. Impact of lowland forests in England on water resources: Application of the Hydrological Land Use Change (HYLUC) model. Water Resources Research. 39, 1944-7973.

Calder, I.R., Newson, M.D., 1979. Land-use and upland water resources in Britain - A strategic look1. JAWRA Journal of the American Water Resources Association 15, 1628-1639.

Campbell, D., Jackson, R., 2004. Hydrology of wetlands. In: Harding, J.S., Mosley, M.P., 
Pearson, C.P \& Sorrell, B.K. (eds.) Freshwaters of New Zealand. New Zealand Hydrological Society Inc. Ad New Zealand Limnological Society Inc, Christchurch, New Zealand.

Campbell, C., Vitt, D., Halsey, L., Campbell, I., Thormann, M., Bayley, S., 2000. Net primary production and standing biomass in northern continental wetlands. Information Report-Northern Forestry Centre, Canadian Forest Service.

Campos C, A., Hernández, M.E., Moreno-Casasola, P., Cejudo Espinosa, E., Robledo R, A., Infante Mata, D., 2011. Soil water retention and carbon pools in tropical forested wetlands and marshes of the Gulf of Mexico. Hydrological Sciences Journal 56, 13881406.

Cambardella, C.A., Gajda, A.M., Doran, J.W., Wienhold, B.J., Kettler, T.A., 2001. Estimation of particulate and total organic matter by weight loss on ignition.

Carroll, Z.L., Bird, S.B., Emmett, B.A., Reynolds, B., Sinclair, F.L., 2004. Can tree shelterbelts on agricultural land reduce flood risk? Soil Use and Management. 20, 357-359.

Carson, R., 1962. Silent Spring. Boston: Houghton Mifflin.

Carpenter, S. R., Mooney, H. A., Agard, J., Capistrano, D., DeFries, R. S., Díaz, S., Dietz, T., Duraiappah, A.K., Oteng-Yeboah, A., Pereira, H.M., Perrings, C., Reid, W.V., Sarukhan, J., Scholes, R.J., Whyte, A., 2009. Science for managing ecosystem services: Beyond the Millennium Ecosystem Assessment. Proceedings of the National Academy of Sciences. 106, 1305-1312.

Casanova, M., Messing, I., Joel, A., 2000. Influence of aspect and slope gradient on hydraulic conductivity measured by tension infiltrometer. Hydrological Processes. 14, 155-164.

Casanova, M., Brock, M., 2000. How do depth, duration and frequency of flooding influence the establishment of wetland plant communities? Plant Ecology. 147, 237-250.

Ceballos, D., Frangi, J., Jobbágy, E., 2013. Soil volume and carbon storage shifts in drained and afforested wetlands of the Paraná River Delta. Biogeochemistry. 112, 359-372.

Chell, J., 2007. Measurement of saturated hydraulic of Pontbren soils and preliminary modelling analysis. A Masters Thesis, Imperial college.

Cheng, J. D., Lin, L. L., Lu, H. S., 2002. Influences of forests on water flows from headwater watersheds in Taiwan. Forest Ecology and Management. 165, 11-28.

Cheng, H.H., Kimble, J., 2000. Characterisation of soil organic carbon pool. In: Lal, R., Kimble, J.M., Follet, R.F., Stewart, B.F (eds) Assessment methods for soil carbon. Advances in soil science. CRC Press. 
Chow, A., Dai, J., Conner, W., Hitchcock, D., \& Wang, J.J., 2012. Dissolved organic matter and nutrient dynamics of a coastal freshwater forested wetland in Winyah Bay, South Carolina. Biogeochemistry, 1-17.

Chui, T. F. M., Low, S. Y., Liong, S.Y., 2011. An ecohydrological model for studying groundwater-vegetation interactions in wetlands. Journal of Hydrology. 409, 291304.

Cook, J.M., Mark, A.F., Shore, B.F., 1980. Responses of Leptospermum scoparium and L. ericoides (Myrtaceae) to waterlogging. New Zealand Journal of Botany. 18, 233-246.

Clarkson, B.R., Sorrell, B.K., Reeves, P.N., Champion, P.D., Partridge, T.R., Clarkson, B.D., 2003. Handbook for monitoring wetland condition. Coordinated monitoring of New Zealand wetlands. A Ministry for the Environment SMF funded project. Ministry for the Environment, Wellington.

Claridge, G. 1980. Studies of water quantity and quality at Taita and their possible significance to the Nelson situation. In Proceedings of a seminar on land use in relation to water quantity and quality, Nelson 1979 Nelson Catchment Board.

Clothier, B.E., 2001. Infiltration. In: Smith, K.A. \& Mullins, C.E (eds) Soil and Environmental Analysis-Physical Methods. Marcell Dekker, Inc., New York, 239-280

Cosandey, C., Andréassian, V., Martin, C., Didon-Lescot, J. F., Lavabre, J., Folton, N.,Mathys, N., Richard, D., 2005. The hydrological impact of the mediterranean forest: a review of French research. Journal of Hydrology. 301, 235-249.

Costanza, R., d'Arge, R., De Groot, R., Farber, S., Grasso, M., Hannon, B., Limburg, K., Naeem, S., O'Neill, R. V., Paruelo, J., Raskin, R. G., Sutton, P., Vandenbelt, M.,1997. The value of the world's ecosystem services and natural capital. Nature 387, 253-260.

Collins, M.E.,Kuehl., R.J., 2001. Organic matter accumulation in organic soils. In: Richardson, J.L., Vepraskas, M.J. (eds). Wetland Soils. Genesis, hydrology, landscapes, and classification. Lewis Publishers, CRC Press. Boca Raton, Florida.

Curtis, P.S., Wang, X., 1998. A Meta-Analysis of Elevated $\mathrm{CO}_{2}$ effects on woody plant mass, form, and physiology. Oecologia. 113, 299-313.

DIN 18130., 1998. Foundation ground: Investigation of soil samples; determination of hydraulic conductivity. Part 1, Beuth Verlag GmbH.

Dai, T.S., Sparling, J.H., 1973. Merasurement of hydraulic conductivity of peats. Soil Sci. 53, 21-26. 
Daily, G. C., 1999. Developing a scientific basis for managing Earth's life support systems. Conservation Ecology. 3, 14.

Dane, J.H., Topp, C., Campbell, G.S., Horton, R., Jury, W.A., Nielsen, D.R., van Es, H.M., Wierenga, P.J., Topp, G.C., 2002. Part 4. Physical Methods. Methods of Soil Analysis. Soil Science Society of America, Madison, WI, 1692.

Darboux, F., Reichert, J., Huang, C., 2004. Soil roughness effects on runoff and sediment production. In: Raine, S.R., Biggs, A.J.W., Menzies, N.W., Freebairn, D.M., Tolmie, P.E (eds) Conserving soil and water for society: Sharing solutions, Proc, 13th Int Soil Conservation Organization Conf, Paper, vol., pp 1-6

Davidson, N.C., 2014. How much wetland has the world lost? Long-term and recent trends in global wetland area. Marine and Freshwater Research. 65, 934-941.

Davidsson, T., Kiehl, K., Hoffmann, C.C., 2000. Guidelines for monitoring wetland function. EcoSys Bd. 8, 5-50.

Davie, T.J.A., Fahey, B.D., 2004. Are low flows affected by vegetation change in the same way as annual yield. The Water balance; Proceedings of the NZ Hydrological Society Symposium, Novemeber 2004.

Davis, M., Brown, D., Robertson, H., Chadderton, L., 2013. How well does LCDB2 map wetlands in the Wellington region? DOC Research and Development Series 341.

De Groot, R. S., Wilson, M. A., and Boumans, R. M. J., 2002. A typology for the classification, description and valuation of ecosystem functions, goods and services. Ecological Economics. 41, 393-408.

Deil, U., 2005. A review on habitats, plant traits and vegetation of ephemeral wetlands ; a global perspective. Phytocoenologia. 35, 533-706.

Department of Environment and Heritage Protection., 2012. Natural assets for flood and cyclone resilience: Synthesis of scientific evidence on the role of natural assets to reduce the human impacts of floods and cyclones. The state of Queensland.

Deus, D., Gloaguen, R., Krause, P., 2013. Water balance modeling in a semi-arid environment with limited in situ data using remote sensing in Lake Manyara, East African Rift, Tanzania. Remote Sens. 5, 1651-1680

Dirksen, C., 2001. Unsaturated Hydraulic Conductivity. In: Smith, K.A., Mullins, C.E. (eds) Soil and Environmental Analysis- Physical Methods. Marcell Dekker, Inc., New York, 183-237.

Doerr, S. H., Shakesby, R. A., Walsh, R. P. D., 2000. Soil water repellency: its causes, characteristics and hydro-geomorphological significance. Earth-Science Reviews. 51, 33-65. 
Dominati, E., Patterson, M., Mackay, A., 2010. A framework for classifying and quantifying the natural capital and ecosystem services of soils. Ecological Economics. 69, 1858- 1868.

Dons, A., 1987. Hydrology and sedimentary regime of a pine, native forest and pasture catchment in the central North Island. New Zealand Journal of Forestry. 17, 161-78.

Duncan, M. J. 1995. Hydrological impacts of converting pasture and gorse to pine plantation, and forest harvesting, Nelson, New Zealand. Journal of Hydrology (New Zealand). 34, 15-41.

Ehleringer, J. R., Buchmann, N., Flanagan, L.B., 2000. Carbon isotope ratios in belowground carbon cycle processes. Ecological Applications. 10, 412-422.

Ehrlich, P., Ehrlich, A., and Holdren, J., 1977. 'Ecoscience: Population, resources, environment.' W.H. Freeman: San Francisco, USA.

Eldridge, D. J., Freudenberger, D., 2005. Ecosystem wicks: Woodland trees enhance water infiltration in a fragmented agricultural landscape in eastern Australia. Austral Ecology. 30, 336-347.

Ellison, D., Futter, M. N and Bishop, K., 2012. On the forest cover-water yield debate: From demand- to supply-side thinking. Global Change Biology, 18, 806-820.

Elliott, A.C., Woodward, W.A., 2007. Statistical analysis quick reference guidebook with SPSS examples. 1st ed. London: Sage Publications.

Elrick, D.E., Reynolds, W.D., 1992. Methods for analysing constant head well permeameter data. Soil Sci. Soc. Am. J. 56, 320-323

Elrick, D.E., Reynolds, W.D., Tan, K.A., 1989. Hydraulic conductivity measurements in the unsaturated zone using improved well analyses. Groundwater Monitoring Review. 9, 184-193.

Fallico, C., Migliari, E., Troisi, S., 2005. Characterisation of the field saturated hydraulic conductivity on a hillslope: measurement techniques, data sensitivity analysis and spatial correlation modelling. Hydrol. Earth Sys. Sci. Discuss. 2, 1247-1298.

Farley, K. A., Jobbágy, E. G., Jackson, R. B., 2005. Effects of afforestation on water yield: a global synthesis with implications for policy. Global Change Biology. 11, 1565-1576.

FAO-CIFOR., 2005. Forests and Floods: Drowning in fiction or thriving on facts? ISBN 9793361-64-6.

FAO., 2006. Guidelines for soil description. Fourth edition. Rome 
FAO., 2015. Global Forest Resources Assessment. How are the world's forests changing?

Fayolle, A., Engelbrecht, B., Freycon, V., Mortier, F., Swaine, M., Réjou-Méchain, M., Doucet, L.J., Fauvet, N., Cornu, G., Gourlet-Fleury, S., 2012. Geological Substrates Shape Tree Species and Trait Distributions in African Moist Forests. PLoS ONE. 7 (8).

Fiorentino, M., lacobellis, V., 2001. New insights about the climatic and geologic control on the probability distribution of floods. Water Resour. Res. 37, 721-730.

Fissore, C., Giardina, C. P., Kolka, R. K., Trettin, C. C., 2009. Soil organic carbon quality in forested mineral wetlands at different mean annual temperature. Soil Biology and Biochemistry. 41, 458-466.

Forbes, S.A., 1887. The lake as a microcosm, Reprinted in: Real, L., Brown, J., 1991. Foundations of Ecology. Chicago: University of Chicago Press.

Foroughbakhch, R., Carrillo Parra, A., Hernández Piñero, J.L., Alvarado Vázquez, M.A., Rocha Estrada, A., Cardenas, M.L., 2012. Wood Volume Production and Use of 10 Woody Species in Semiarid Zones of Northeastern Mexico. International Journal of Forestry Research. 7.

FRMRC., 2008. Impacts of upland land management on flood risk: multi-scale modelling methodology and results from the pontbren experiment. FRMRC Research Report UR 16.

Frangi, J.L., Lugo, A.E.,1998. A Flood Plain Palm Forest in the Luquillo Mountains of Puerto Rico Five Years After Hurricane Hugo1. Biotropica. 30, 339-348.

Frieswyk, C.B., Zedler, J.B., 2007. Vegetation Change in Great Lakes Coastal Wetlands: Deviation from the Historical Cycle. Journal of Great Lakes Research. 33, 366-380.

Fu, B., Wang, J., Chen, L., Qiu, Y., 2003. The effects of land use on soil moisture variation in the Danangou catchment of the Loess Plateau, China. CATENA. 54, 197-213.

Gaál, L., Szolgay, J., Kohnová, S., Parajka, J., Merz, R., Viglione, A., Blöschl, G., 2012. Flood timescales: Understanding the interplay of climate and catchment processes through comparative hydrology. Water Resour. Res. 48, W04511.

Gabarrón-Galeote, M.A., Trigalet, S., Wesemael, B.v., 2015. Soil organic carbon evolution after land abandonment along a precipitation gradient in southern Spain. Agriculture, Ecosystems \& Environment. 199, 114-123.

Gao, X., Wu, P., Zhao, X., Wang, J., Shi, Y., 2014. Effects of land use on soil moisture variations in a semi-arid catchment: implications for land and agricultural water management. Land Degradation \& Development. 25, 163-17.

Gardner, W.H., Klute, A., 1986. Water content. Methods of soil analysis. Part 1. Physical and 
mineralogical methods, 493-544.

Garrick, A., Bishop, C., Beadel, S., Rate, S., 2007. Restoration strategy and implementation plan for indigenous vegetation and plant species of the eastern shoreline of Lake Wairarapa: final working draft. Wildlands Consultants Ltd. Rotorua, New Zealand. $66 \mathrm{p}$.

Gebhardt, S., Fleige, H., Horn, R., 2009. Effect of compaction on pore functions of soils in a Saalean moraine landscape in North Germany. Journal of Plant Nutrition and Soil Science. 172, 688-695.

Germer, S., Neill, C., Krusche, A.V., Elsenbeer, H., 2010. Influence of land-use change on near-surface hydrological processes: Undisturbed forest to pasture. Journal of Hydrology. 380, 473-480.

Gevaert, A.I., Teuling, A.J., Uijlenhoet, R., DeLong, S.B., Huxman, T.E., Pangle, L.A., Breshears, D.D., Chorover, J., Pelletier, J.D., Saleska, S.R., Zeng, X., Troch, P.A., 2014. Hillslope-scale experiment demonstrates the role of convergence during two-step saturation. Hydrol. Earth Syst. Sci. 18, 3681-3692.

Ghasemi, A., Zahediasl, S., 2012. Normality Tests for Statistical Analysis: A Guide for NonStatisticians. International Journal of Endocrinology and Metabolism. 10, 486-489.

Gleason, R.A., Tangen, B.A., Browne, B.A., Euliss, N.H., 2009. Greenhouse gas flux from cropland and restored wetlands in the Prairie Pothole Region. Soil Biology and Biochemistry. 41, 2501-2507.

Glover, R.E., 1953. Flow from a test-hole located above groundwater level. In: Zanger, C.N. (ed) Theory and problems of water percolation. US Bur. Reclam. Monogr. 8. Denver, Colorado.

Gonzalez-Sosa, E., Braud, I., Dehotin, J., Lassabatère, L., Angulo-Jaramillo, R., Lagouy, M., Branger, F., Jacqueminet, C., Kermadi, S., Michel, K., 2010. Impact of land use on the hydraulic properties of the topsoil in a small French catchment. Hydrological Processes. 24, 2382-2399.

Gillon, A.K., 2014. Ecological restoration of Wairio wetland, lake Wairarapa: the response of native wetland vegetation to eutrophication and revegetation management strategies. Thesis (MSc) Victoria University of Wellington. 175p.

Griffiths, R. P., Madritch, M. D., Swanson, A. K., 2009. The effects of topography on forest soil characteristics in the Oregon Cascade Mountains (USA): Implications for the effects of climate change on soil properties. Forest Ecology and Management. 25, 17.

Greater Wellington Regional Council, 2015. Catchment management LiDAR use. Powerpoint presentation on July 202015. 
Gong, J., Z. Li, Q. Zhu, H. Shu., Zhou, Y., 2000. Effects of various factors on the accuracy of DEMs: an intensive experimental investigation. Photogrammetric Engineering and Remote Sensing. 66, 1113-1117.

Guggenmos, M., 2010. Groundwater and Surface Water Interaction, Wairarapa Valley, New Zealand. Thesis (MSc) Victoria University of Wellington

Guo, D., Zhang, H.-y., Hou, G.-I., Zhao, J.-j., Liu, D.-y., Guo, X.-y., 2014. Topographic controls on alpine treeline patterns on Changbai Mountain, China. Journal of Mountain Science. 11, 429-441.

Halabuk, A., 2006. Influence of different vegetation types on saturated hydraulic conductivity in alluvial topsoils. Biologia. 61, S266-S269.

Hall, R. L., Allen, S. J., Rosier, P. T. W., Smith, D. M., Hodnett, M. G., Roberts, J. M., Hopkins, R., Davies, H. N., Kinniburgh, D. G., Goody, D. C., 1996. Hydrological effects of short rotation coppice. Institute of Hydrology report to the Energy Technology Support Unit, ETSU, ETSU B/W5/00275/REP.

Hartel, P.G., 2005. The soil habitat. In: Sylvia, D.M., Fuhrmann, J.J, Hartel, P.G \& Zuberer, A. (eds). Principles and Applications of Soil Microbiology. $2^{\text {nd }}$ edition. Pearson Prentice Hall. Upper Saddle River, New Jersey.

Haskell, D.E., Flaspohler, D.J., Webster, C.R., Meyer, M.W., 2012. Variation in soil temperature, moisture, and plant growth with the addition of downed woody material on lakeshore restoration sites. Restoration Ecology. 20, 113-121.

Hamilton, L.S., King, P.N., Center, E.-W., 1983. Tropical forested watersheds: hydrologic and soils response to major uses or conversions. Westview Press Boulder.

Hassall, C., Anderson, S., 2015. Stormwater ponds can contain comparable biodiversity to unmanaged wetlands in urban areas. Hydrobiologia. 745, 137-149.

Haverkamp, R., Bouraoui, F., Zammit, C., Angulo-Jaramillo, R., 1999. Soil properties and moisture movement in the unsaturated zone. In: Delleur, J.W. (ed). The handbook of ground water engineering. CRC Press.

Hawke's Bay Regional Council., 2004. New Zealand native plants for erosion control. Environment Topics Report.

Hayashi, M., Quinton, W. L., 2004. A constant-head well permeameter method for measuring field-saturated hydraulic conductivity above an impermeable layer. Canadian Journal of Soil Science. 84, 255-264.

Heads, M., 1998. Biodiversity in the New Zealand divaricating tree daisies: Olearia sect. nov. (Compositae). Botanical Journal of the Linnean Society. 127, 239-285. 
Heiri, O., Lotter, A.F., Lemcke, G., 2001. Loss on Ignition as a method for estimating organic and carbonate content in sediments: reproductibility and comparability of results. Journal of Paleolimnology. 25, 101-110.

Hillel, D., 1998. Environmental Soil Physics, Academic Press, San Diego.

Holden, J., Burt, T., 2003. Hydraulic conductivity in upland blanket peat: measurement and variability. Hydrological Processes. 17, 1227-1237.

Holdo, R.M., Nippert, J.B., 2015. Transpiration dynamics support resource partitioning in African savanna trees and grasses. Ecology. 96, 1466-1472.

Holland, K. L., Charles, A. H., Jolly, I. D., Overton, I. C., Gehrig, S., Simmons, C. T., 2009. Effectiveness of artificial watering of a semi-arid saline wetland for managing riparian vegetation health. Hydrological Processes. 23, 3474-3484.

Holden, J., Ehrlich, P., 1974. Human population and the global environment. American Scientist. 62.

Horn, R., Richards, J., 2006. Flow-vegetation interactions in restored floodplain environments. Hydroecology and Ecohydrology: Past, Present and Future. 269-294.

Hu, W., Shao, M.A., SI, B.C., 2012. Seasonal changes in surface bulk density and saturated hydraulic conductivity of natural landscapes. European Journal of Soil Science. 63, 820-830.

Hughes, C. E., Binning, P. J., Willgoose, G. R., Hughes, C. E., Binning, P. J., Willgoose, G. R., 1998. Characterisation of the hydrology of an estuarine wetland. Journal of Hydrology. 211, 34-49.

Ilstedt, U., Malmer, A., Verbeeten, E., Murdiyarso, D., 2007. The effect of afforestation on water infiltration in the tropics: A systematic review and meta-analysis. Forest Ecology and Management. 251, 45-51.

Ingram, J.C., Redford, K.H., James E.M., Watson, J.E.M., 2012. Applying Ecosystem Services Approaches for Biodiversity Conservation: Benefits and Challenges, S.A.P.I.EN.S [En ligne], 5.1

Jačka, L., Pavlásek, J., Kuráž, V., Pech, P., 2014. A comparison of three measuring methods for estimating the saturated hydraulic conductivity in the shallow subsurface layer of mountain podzols. Geoderma. 219-220, 82-88.

Jackson, J.L., 1973. Catchment hydrology and some of its problems. In Proceedings soil and plant water symposium, Palmerston North: DSIR Information Series 16.

Jackson, R.B., Mooney, H.A., Schulze, E.D., 1997. A global budget for fine root biomass, 
surface area, and nutrient contents. Proceedings of the National Academy of Sciences of the United States of America. 94, 7362-7366.

Jackson, R.G., 2006. Wetland Hydrology, In: Batzer, D.P and Sharitz, R.R. (Eds,). Ecology of Freshwater and Estuarine Wetlands.

Jackson, B.M., Pagella, T., Sinclair, F., Orellana, B., Henshaw, A., Reynolds, B., Mclntyre, N., Wheater, H., Eycott, A., 2013. Polyscape: a GIS mapping toolbox providing efficient and spatially explicit landscape-scale valuation of multiple ecosystem services. Landscape Urban Plan. 112, 74-88.

Jackson, B.M., Wheater, H.S., Mcintyre, N.R., Chell, J., Francis, O.J., Frogbrook, Z., Marshall, M., Reynolds, B and Solloway, I., 2008. The impact of upland land management on fooding: insights from a multiscale experimental and modelling programme. Flood Risk Management. 1, 71-80.

Jauhiainen, M., 2004. Relationships of particle size distribution curve, soil water retention curve and unsaturated hydraulic conductivity and their implications on water balance of forested and agricultural hillslopes. PhD thesis, Helsinki University of Technology. Water Resources Publications, 165 pp.

Jenkins, G.A., Greenway, M., Polson, C., 2012. The impact of water reuse on the hydrology and ecology of a constructed stormwater wetland and its catchment. Ecological Engineering. 47, 308-315.

Jenkins, G.A., Greenway, M., 2005. The hydraulic efficiency of fringing versus banded vegetation in constructed wetlands. Ecological Engineering. 25, 61-72.

Jobbágy, E.G., Baldi, G., Nosetto, M.D., 2012. Tree plantation in South America and the water cycle: Impacts and Emergent Opportunites, In: Schlichter, T and Montes, L (eds.). Forests in Development: A vital balance.

Jobbágy, E. G., Jackson, R.B., 2000. The vertical distribution of soil organic carbon and its relation to climate and vegetation. Ecological Applications. 10, 423-436.

Johnston, K., J. M. Ver-Hoef, K. Krivoruchko., Lucas, N., 2001. Using ArcGIS Geostatistical Analyst. ESRI. Redlands, 300pp.

Johnston, C.A., Detenbeck, N.E., Niemi, G.J. The cumulative effect of wetlands on stream water quality and quantity. A landscape approach. Biogeochemistry 10, 105-141.

Johnson, B.A., 2012. Ecological restoration of the Wairio Wetland, Lake Wairarapa: Water table relationships and cost-benefit analysis of restoration strategies. Thesis (MSc) Victoria University of Wellington. 124 p.

Johnson, P., Gerbeaux, P., 2004. Wetland Types in New Zealand: Department of Conservation. 
Jones, A., Gyopari, M., 2006. Regional conceptual and numerical modelling of the Wairarapa groundwater basin, Greater Wellington Regional Council, Wellington

Joyce, C., 2012. Preface: Wetland services and management. Hydrobiologia. 692, 1-3

Junk, W.J., An, S., Finlayson, C.M., Gopal, B., Květ, J., Mitchell, S., Mitsch, W., Robarts, R., 2013. Current state of knowledge regarding the world's wetlands and their future under global climate change: a synthesis. Aquatic Sciences. 75, 151-167.

Junk, W.J., 2002. Long-term environmental trends and the future of tropical wetlands. Environmental Conservation. 29, 414-435.

Kabat, P., Fresco, L.O., Stive, M.J.F., Veerman, C.P., van Alphen, J.S.L.J., Parmet, B.W.A.H., Hazeleger, W., Katsman, C.A., 2009. Dutch coasts in transition. Nature Geosci 2, 450452.

Kayranli, B., Scholz, M., Mustafa, A., Hedmark, Å., 2010. Carbon Storage and Fluxes within Freshwater Wetlands: a Critical Review. Wetlands. 30, 111-124.

Kasprak, A., Magilligan, F. J., Nislow, K. H., Snyder, N. P., 2011. A Lidar - Derived Evaluation of Watershed - Scale Large Woody Debris Sources and Recruitment Mechanisms: Coastal Maine, USA. Publications from USDA-ARS / UNL Faculty. Paper 1104.

Kienzle, S., 2004. The effect of DEM raster resolution on first order, second order and compound terrain derivatives. Transactions in GIS, 8(1), 83-111.

Kimberley, S., Naughton, O., Johnston, P., Gill, L., Waldren, S., 2012. The influence of flood duration on the surface soil properties and grazing management of karst wetlands (turloughs) in Ireland. Hydrobiologia. 692, 29-40.

Kitić, G., Crnojević-Bengin, V., 2013. A Sensor for the Measurement of the Moisture of Undisturbed Soil Samples. Sensors. 13, 1692-1705.

Knight, R., Endres, A.L., 2005. An introduction to rock physics principles for near-surface geophysics. In: Butler, D.K (ed.). Near surface geophysics. Investigations in Geophysics 13. Society of Exploration Geophysicists, Tulsa, OK.

Knight, R. 2001. Ground penetrating radar for environmental applications. Annu. Rev. Earth Planet. Sci. 29,229-255.

Knowles, P. R., Davies, P. A., 2009. A method for the in-situ determination of the hydraulic conductivity of gravels as used in constructed wetlands for wastewater treatment. Desalination and Water Treatment. 5, 257-266. 
Korte, C.J.; Rhodes, A.P. 1993. Economics of drought-tolerant pastures for cattle finishing on Hawke's Bayand Wairarapa hill country farms. Proceedings ofthe New Zealand Grassland Association. 55, 45-49.

Koschke, L., Lorz, C., Furst, C., Lehmann, T., Makeschin, F., 2014. Assessing hydrological and provisioning ecosystem services in a case study in Western Central Brazil. Ecological Processes. 3, 2.

Kronfuss, H., Havranek, W.M., 1999. Effects of Elevation and Wind on the Growth of Pinus cembra L. in a Subalpine Afforestation. Eurosilva. 39, 99-106.

Kruse, J., Lennartz, B., Leinweber, P., 2008. A modified method for measuring saturated hydraulic conductivity and anisotropy of fen peat samples. Wetlands. 28, 527-531.

Kutiel, P., Lavee, H., 1999. Effect of slope aspect on soil and vegetation properties along an aridity transect. Israel Journal of Plant Sciences. 47, 169-178.

Kundzewicz, Z. W., 1999. Flood protection-sustainability issues. Hydrol Sci. J. 44, 559-571

Kundzewicz, Z.W., 2004. Floods and Flood Protection: Business-as-Usual? In: Rodda, J.C., Ubertini, L. (eds.). The Basis of Civilization-Water Science? IAHS Publication 286. IAHS Press, Oxfordshire, U.K., 201-209.

Lal, R., 2009. Sequestering carbon in soils of arid ecosystems. Land Degradation \& Development. 20, 441-454.

Le Maitre, DC, Scott, DF., Colvin, C., 1999. Review of information on interactions between vegetation and groundwater. Water SA. 25, 137-152.

Lesch, S.M., Corwin, D.L., Robinson, D.A., 2005. Apparent soil electrical conductivity mapping as an agricultural tool for arid zone soil. Comput. Electron. Agric. 46, 351378.

Letts, M.G., Roulet, N.T., Comer, N.T., Skarupa, M.R., Verseghy, D.L., 2000. Parametrization of peatland hydraulic properties for the Canadian Land Surface Scheme. Atmosphere-Ocean. 38, 141-160.

Leopold, A., 1949. A Sand County Almanac and Sketches from Here and There. New York: Oxford University Press.

Leuzinger, S., Körner, C., 2010. Rainfall distribution is the main driver of runoff under future CO2-concentration in a temperate deciduous forest. Global Change Biology. 16, 246254.

Linderman, R.L., 1942. The trophic dynamic aspect of ecology. Ecology. 23.

Lockaby, B., Stanturf, J., Messina, M., 1997. Effects of silvicultural activity on ecological 
processes in floodplain forests of the southern United States: a review of existing reports. Forest Ecology and Management. 90, 93-100.

Loll, P., Moldrup, P., 2000. Stochastic analyses of field-scale pesticide leaching risk as influenced by spatial variability in physical and biochemical parameters. Water Resources Research. 36, 959-970.

Lugo, A.E., Brown, S., Brinson, M.M., 1988. Forested wetlands in freshwater and salt-water environments. Limnology and Oceanography. 33, 894-909.

Manhique, A.J., Reason, C.J.C., Silinto, B., Zucula, J., Raiva, I., Congolo, F., Mavume, A.F., 2015. Extreme rainfall and floods in southern Africa in January 2013 and associated circulation patterns. Natural Hazards. 77, 679-691.

Marden, M., Phillps, C., 2012. Kahikatea (Dacrycarpus dacrydiodes). Landcare Research, NZ.

Marden, M., Rowan, D., Phillips, C., 2005. Stabilising characteristics of New Zealand indigenous colonising plants. Plant and Soil. 278, 95-105.

Marshall, M.R., Francis, O. J., Frogbrook, Z. L., Jackson, B. M., McIntyre, N., Reynolds,B., Solloway,I., Wheater, H.S., Chell, J., 2009. The impact of upland land management on flooding: results from an improved pasture hillslope. Hydrological. Processes. 23, 464-475.

Martínez, G., Pachepsky, Y.A., Vereecken, H., 2014. Temporal stability of soil water content as affected by climate and soil hydraulic properties: a simulation study. Hydrological Processes 28, 1899-1915.

McEwen, L., Jones, O., Robertson, I., 2014. 'A glorious time?' Some reflections on flooding in the Somerset Levels. The Geographical Journal. 180, 326-337.

McIntyre, R., 2002. The Canoes of Kupe A history of the Martinborough District. Victoria University Press, Wellington.

McKenzie, N., Coughlan, K., Cresswell, H., 2002. Soil Physical Measurement and Interpretation for Land Evaluation. CSIRO Publishing.

McKerchar, A.I., 1980. Hydrological charecteristics of land use catchments in the Nelson area. In Proceedings of a seminar on land use in relation to water quantity and quality, Nelson 1979: Nelson Catchment Board.

McFadgen, B., 2003. Archeology of the Wellington Conservancy: Wairarapa A study in tectonic archaeology. Department of Conservation, Wellington.

McNaughton, K.G., Jarvis, P.G., 1983. Predicting effects of vegetation changes on transpiration and evaporation. In: Kozlowiski, T.T (ed). Water deficit and plant growth. Volume 7. Academic Press.Inc. 
MEA., 2005. Millennium Ecosystem Assessment, Ecosystems and Human Well-being: Synthesis. Island Press, Washington D.C.

Meyer, C., Baer, S., Whiles, M., 2008. Ecosystem Recovery Across a Chronosequence of Restored Wetlands in the Platte River Valley. Ecosystems. 11, 193-208.

Milori D.M.P.B., Segnini, A., da Silva W.T.L., Posadas ,A., Mares, V., Quiroz, R., Martin-Neto, L., 2011.Emerging techniques for soil carbon measurements. CCAFS Working Paper no. 2. CGIAR Research Program on Climate Change, Agriculture and Food Security (CCAFS). Copenhagen,Denmark. www.ccafs.cgiar.org. Accessed on 11 December 2012.

Mittelbach, H., Seneviratne, S., 2012. A new perspective on the spatio-temporal variability of soil moisture: temporal dynamics versus time-invariant contributions. Hydrology and Earth System Sciences. 16, 2169-2179.

Mitsch, W., Bernal, B., Nahlik, A., Mander, Ü., Zhang, L., Anderson, C., Jørgensen, S.E., Brix, H., 2012. Wetlands, carbon, and climate change. Landscape Ecology. 28, 583-597.

Mitsch, W.J., Gosselink, J.G., 2007. Wetlands. New York. John Wiley \& Sons, Inc. 582pp.

Mitsch, W.J., Gosselink, J.G., 2000. The value of wetlands: importance of scale and landscape setting. Ecological Economics. 35, 25-33.

Ming, J., Xian-guo, L., Lin-shu, X., Li-juan, C., Shouzheng, T., 2007. Flood mitigation benefit of wetland soil - A case study in Momoge National Nature Reserve in China. Ecological Economics. 61, 217-223.

Mohanty, B.P., Mousli, Z., 2000. Saturated hydraulic conductivity and soil water retention properties across a soil-slope transition. Water Resources Research. 36, 3311-3324.

Molina, A.J., Latron, J., Rubio, C.M., Gallart, F., Llorens, P. ,2014. Spatio-temporal variability of soil water content on the local scale in a Mediterranean mountain area (Vallcebre, North Eastern Spain). How different spatio-temporal scales reflect mean soil water content. Journal of Hydrology. 516, 182-192.

Montwé, D., Spiecker, H., Hamann, A., 2015. Five decades of growth in a genetic field trial of Douglas-fir reveal trade-offs between productivity and drought tolerance. Tree Genetics \& Genomes. 11, 1-11.

Mordelet, P., Abbadie, L and Menaut, J.C., 1993. Effects of tree clumps on soil characteristics in a humid savanna of West Africa (Lamto, Cote d' Ivoire). Plant and Soil 153, 103-111.

Moreno-Mateos, D., Power, M.E., Comín, F.A., Yockteng, R., 2012. Structural and Functional Loss in Restored Wetland Ecosystems. PLoS Biol. 10(1). 
Mooney, H., Ehrlich, P., 1997. Ecosystems services: a fragmentary history, In: Daily, G, Nature's services: Societal dependence on natural systems. Ed. Island Press, Washington D.C.

Mu, X. M., Xu, X.X., Wang, W.L., Wen, Z.M., Du. F., 2003. Impact of artificial forest on soil moisture of the deep soil layer on Loess Plateau. Acta Pedologica Sinica. 40, 210217.

Mulligan, M., Guerry, A., Arkema,K., Bagstad, K.J., Villa, F., 2010. Capturing and quantifying the flow of ecosystem services, In: Silvestri S., Kershaw F., (eds.). Framing the flow: Innovative Approaches to Understand, Protect and Value Ecosystem Services Across Linked Habitats. UNEP World Conservation Monitoring Centre, Cambridge, UK. ISBN 978-92-807-3065-4.

Nahlik, A.M., Mitsch, W.J., 2008. The effect of river pulsing on sedimentation and nutrients in created riparian wetlands. Journal of Environmental Quality, 37, 1634-1643.

Nasta, P., Assouline, S., Gates, J.B., Hopmans, J.W., Romano, N., 2013. Prediction of Unsaturated Relative Hydraulic Conductivity from Kosugi's Water Retention Function. Procedia Environmental Sciences. 19, 609-617.

Neary, D.G., George, I.G., Rhett, J.C., 2009. Linkages between forest soils and water quality and quantity. Forest Ecology and Management. 258, 2269-2281.

Nelson, D.W., Sommers, L.E., 1996. Total carbon, organic carbon, organic matter. In Sparks DL, (ed). Methods of Soil Analysis. Part 3. Chemical Methods, Soil Science Society of America Book Series, No. 5. Madison, WI.

Nelson, E., Daily, G.C., 2010. Modelling ecosystem services in terrestrial systems. Biol Rep. 2:53.

Nelson, E., Mendoza, G., Regetz, J., Polasky, S., Tallis, H., Cameron, R.D., Chan, K., Daily, G.C., Goldstein, J., Kareiva, P.M., Lonsdorf, E., Naidoo, R., Rickets, T.H., Shaw, R.M., 2009. Modelling multiple ecosystem services, biodiversity, conservation, commodity production and tradeoffs at landscape scales. Front Ecol Environ. 7, 1-11.

Newsome, P.F.J., Wilde, R. H., Willoughby, E. J., 2008. Land resource information system spatial data layers. Technical Report. Landcare Research New Zealand Ltd.

Nisbet, T.R., Thomas, H., 2006. The role of woodland in flood control: a landscape perspective. In: Proceedings of the $14{ }^{\text {th }}$ annual IALE (UK) 2006 conference on Water and the Landscape.

Nisbet, T.R., 2005. Water use by trees. Information note, Forest Commission, UK.

Nisbet, T.R., Broadmeadow, S., 2003. Opportunity mapping for trees and floods. Forest Research, Farnham. 
NZPCN (New Zealand Plant Conservation Network), 2016. Nationally and regionally threatened wetland species. www.nzpcn.org.nz. Accesses on 25 January 2016.

NZPCN (New Zealand Plant Conservation Network), 2012. Nationally and regionally threatened wetland species. www.nzpcn.org.nz. Accessed on 18 July 2012.

O'Connell, P. E., Ewen J., O’Donnell G.M., Quinn, P., 2007. Is there a link between agricultural land use-management and flooding? Hydrol Earth Sys Sci. 11, 96-107.

O'Connor, J.E., E Costa, J.E., 2004. Spatial distribution of the largest rainfall-runoff floods from basins between 2.6 and $26,000 \mathrm{~km}^{2}$ in the United States and Puerto Rico. Water Resources Research. 40, W01107.

O'Donnell, G., Ewen, J., O'Connell, P. E., 2011. Sensitivity maps for impacts of land management on an extreme flood in the Hodder catchment, UK. Physics and Chemistry of the Earth. 36, 630-637.

Odum, E.P., 1953. Fundamentals of Ecology. Philadephia: Saunders.

Osborn, F., 1948. Our Plundered Planted. Boston: Little, Brown and Company.

Oyarzun, C.E., 1995. Landuse, hydrological properties, and soil erodibilities in the bio-bio river basin, Central Chile. Mountain Research and Development. 15, 331-338.

Paige, G., Stone, J., 2000. Measurement methods to identify and quantify spatial variability of infiltration on rangelands. USDA-ARS, SWRC.

Palm, C., Sanchez, P., Ahamed, S., Awiti, A., 2007. Soils: A Contemporary Perspective. Annual Review of Environment and Resources. 32, 99-129.

Parsons, A. J., Wainwright, J., Abrahams, A. D. and Simanton, J. R., 1997. Distributed dynamic modelling of interrill overland flow. Hydrological Processes. 11, 1833-1859.

Paul, E. A., Follet, R. F., Leavitt, S. W., Halvorson, A., Peterson, G. A., Lyon, D.J., 1997. Radiocarbon dating for determination of soil organic pool sizes and dynamics. Soil Science Society of America Journal. 61, 1058-1067.

Pearce, A.J, O'Loughlin, C.L., Jackson, R.J., Zhang, X.B., 1987. Reforestation: on-site effects on hydrology and erosion, eastern Raukumara Range, New Zealand In Proceedings Symposium on Forest Hydrology and Watershed Management.

Pearson, C., Reaney, S., Bracken, L., Butler, L.,2015. Investigating the potential to reduce flood risk through catchment-based land management techniques and interventions in the River Roe catchment, Cumbria, UK, EGU General Assembly Conference Abstracts, p. 1001.

Price, K., Jackson, C.R., Parker, A.J., 2010. Variation of surficial soil hydraulic properties across land uses in the southern Blue Ridge Mountains, North Carolina, USA. Journal of Hydrology. 383, 256-268. 
Prosser, J.A., 2011. Manuka (Leptospemum Scoparium) as a Remediation Species for Biosolids Amended Land, Thesis (MSc). Massey University, Manawatu, New Zealand.

Phillip, J.R., 1985. Reply to "Comments on Steady infiltration from spherical cavities." Soil Sci. Soc.Am J. 49, 788-789.

Qiu, Y., Fu, B., Wang, J., Chen, L., 2001. Spatial variability of soil moisture content and its relation to environmental indices in a semi-arid gully catchment of the Loess Plateau, China. Journal of Arid Environments. 49, 723-750.

Quinton, W. L., Hayashi, M., Carey, S. K., 2008. Peat hydraulic conductivity in cold regions and its relation to pore size and geometry. Hydrological Processes. 22, 2829-2837.

Rahman, M.H., Holmes, A.W., Deurer, M., Saunders, S.J., Mowat, A., Clothier, B.E., 2011. Comparison of three methods to estimate organic carbon in allophanic soils in New Zealand. The Carbon in Orchard Soils Team (COST), Plus Group Ltd.

Raoof, M., 2011. Effect of land slope on some soil physical and hydraulic properties. New Technology of Agricultural Engineering (ICAE), 2011 International Conference.

Reinsch, T., Grossman, R., 1995. A method to predict bulk density of tilled Ap horizons. Soil and Tillage Research. 34, 95-104.

Reynolds, W.D., Elrick, D.E., 1985. In situ measurement in the vadose zone of field saturated hydraulic conductivity, sorptivity and the $\alpha$-parameter using the Guelph Permeameter. Soil Sci. 140, 292-301.

Reynolds, W.D., Elrick, D.E., 1986. A method for simultaneous in-situ measurement in the vadose zone of field saturated hydraulic conductivity, sorptivity and the conductivitypressure head relationship. Groundwater Monitoring Review. 6, 84-95.

Rhodes, J., 2012. The shaping of the Lower Valley, In: Grant, I.F. (ed,). Wairarapa Moana, the Lake and its People. Wairarapa Archive Publishers.

Rienzer, M., Gandolfi, C., 2014. Investigation of spatial and temporal variability of saturated soil hydraulic conductivity at the field-scale. Soil \& Tillage Research. 135, 28-40.

Risdon, B.V., 2011. Gold mining and estuarine evolution. A study of the accelerated sedimentation of Parapara Inlet, Golden Bay, New Zealand. An Msc Thesis, Victoria University of Wellington.

Rokosch, A., Bouchard, V., Fennessy, S., Dick, R., 2009. The use of soil parameters as indicators of quality in forested depressional wetlands. Wetlands. 29, 666-677.

Robinson, M., Dupeyrat, A., 2005. Effects of commercial timber harvesting on streamflow regimes in the Plynlimon catchments, mid-Wales. Hydrological Processes 19, 12131226. 
Robinson, D. A., Jackson, B. M., Clothier, B. E., Dominati, E. J., Marchant, S. C., Cooper, D. M., Bristow, K. L., 2013. Advances in Soil Ecosystem Services: Concepts, Models, and Applications for Earth System Life Support. Gsvadzone. 12, 4.

Robinson, D. A., Hockley, N., Dominati, E., Lebron, I., Scow, K. M., Reynolds, B., Tuller, M., 2012. Natural Capital, Ecosystem Services, and Soil Change: Why Soil Science Must Embrace an Ecosystems Approach. gsvadzone, 11, 1.

Robinson, D. A., Lebron, I., 2010. On the natural capital and ecosystem services of soils. Ecological Economics. 70, 137-138.

Robinson, D. A., Lebron, I., Vereecken, H., 2009. On the Definition of the Natural Capital of Soils: A Framework for Description, Evaluation, and Monitoring. Soil Sci. Soc. Am. J. 73, 1904-1911.

Robinson, D., Campbell, C., Hopmans, J., Hornbuckle, B., Jones, S.B., Knight, R., Ogden, F., Selker, J., Wendroth, O., 2008. Soil moisture measurement for ecological and hydrological watershed-scale observatories: A review. Vadose Zone Journal. 7, 358389.

Robinson, M., Cognard-Plancq, A.L., Cosandey, C., David, J., Durand, P., Fuhrer, H.W., Hall, R., Hendriques, M.O., Marc, V., McCarthy, R., McDonnell, M., Martin, C., Nisbet, T. O'Dea, P., Rodgers, M., Zollne, A., 2003. Studies of the impact of forests on peak flows and baseflows: a European perspective. Forest Ecology and Management. 186, 85-97.

Rokosch, A., Bouchard, V., Fennessy, S., Dick, R., 2009. The use of soil parameters as indicators of quality in forested depressional wetlands. Wetlands. 29, 666-677.

Rosa, E., Larocque, M., 2008. Investigating peat hydrological properties using field and laboratory methods: application to the Lanoraie peatland complex (southern Quebec, Canada). Hydrological Processes. 22, 1866-1875.

Rosell, R., Galantini, J., Suner, L., 2000. Long-term crop rotation effects on organic carbon, nitrogen, and phosphorus in haplustoll soil fractions. Arid Soil Research and Rehabilitation. 14, 309-315.

Ruiz-Villanueva, V., Bladé-Castellet, E., Sánchez-Juny, M., Martí, B., Díez Herrero, A., Bodoque, J.M., 2014. Two dimensional numerical modelling of wood transport. J Hydroinf doi. 10, 2166.

Sakals, M.E., Innes, J.L., Wilford, D.J, Sidle, R.C., Grant, G.E., 2006. The role of forests in reducing hydrogeomorphic hazards. For. Snow Landsc. Res. 80, 11-22.

Sajedi, T., Prescott, C.E., Seely, B., Lavkulich, L.M., 2012. Relationships among soil moisture, aeration and plant communities in natural and harvested coniferous forests in coastal British Columbia, Canada. Journal of Ecology. 100, 605-618.

Sanii, S., Student, M., 2008. Assessing the effect of point density and terrain complexity on the quality of LiDAR-derived DEMs in multiple resolutions. Master on Geographic Information Systems, University of Calgary, Alberta, Canada. 
Scanlon, B.R., Reedy, R.C., Stonestrom, D.A., Prudic, D.E., Dennehy, K.F., 2005. Impact of land use and land cover change on groundwater recharge and quality in the southwestern US. Global Change Biology. 11, 1577-1593.

Schindler, U., von Unold, G., Durner, W., Müller, L., 2015. Recent progress in measuring soil hydraulic properties. International Conference on Environment and Civil Engineering (ICEACE 2015), Pattaya, Thailand.

Schlesinger, W.H., 1997. Biogeochemistry: An Analysis of Global Change. $2^{\text {nd }}$ ed. Academic Press. San Diego, California.

Schlotzhauer, S.M., Price, J.S., 1999. Soil water flow dynamics in a managed cutover peat field, Quebec: Field and laboratory investigations. Water Resources Research. 35, 0043-1397.

Schmidt, M.W., Torn, M.S., Abiven, S., Dittmar, T., Guggenberger, G., Janssens, I.A., Kleber, M., Kogel-Knabner, I., Lehmann, J., Manning, D.A., Nannipieri, P., Rasse, D.P., Weiner, S., Trumbore, S.E., 2011. Persistence of soil organic matter as an ecosystem property. Nature. 478, 49-56.

Schmitz, O.J., 2012. Restoration of ailing wetlands. PLoS-Biology. 10, 16.

Schultink, G., Van Vliet, R., 1997. Wetland Identification and Protection: North American and European Policy Perspectives. Department of Resource Development, Michigan State University. Found at: www.rd.msu.edu/wetlands/wims/wims nort.html.

Schumacher, B.A., 2002. Methods for the determination of total organic carbon in soils and sediments. United States Environmental Protection Agency. EMASC-001.

Schrader, B., 2010. Wairarapa region - Land and climate, Te Ara - the Encyclopedia of New Zealand, updated 1-Apr-10 URL: http://www.TeAra.govt.nz/en/wairarapa-region/3.

Scott, N.A., White, J.D., Townsend, J.A., Whitehead, D., Leathwick, J.R., Hall, G.M., Marden, M., Rogers, G.N., Watson, A.J., Whaley, P.T., 2000. Carbon and nitrogen distribution and accumulation in a New Zealand scrubland ecosystem. Canadian Journal of Forest Research. 30, 1246-1255.

Scott, D., Jones, T., 1995. Classification and inventory of wetlands: A global overview. Vegetatio. 118, 3-16.

Seibert, J., Stendahl, J., Sørensen, R., 2007. Topographical influences on soil properties in boreal forests. Geoderma. 141, 139-148.

Shaffer, P., Ernst, T., 1999. Distribution of soil organic matter in freshwater emergent/open water wetlands in the Portland, Oregon metropolitan area. Wetlands. 19, 505-516.

Sheets, K.R., Hendrickx, J.M.H., 1995. Noninvasive soil-water content measurement using electromagnetic induction. Water Resour. Res.31, 2401-2409. 
Shiklomanov, I.A., Krestovsky, O.I., 1988. The influence of forests and forest reclamation practice on stream flow and water balance, In: Reynolds, E.R.C and Thompson, F.R. (eds,). Forests, Climate and Hydrology: Regional Impacts. United Nations University.

Shortridge, A.M., Clarke, K.C., 1999. On some limitations of square raster cell structures for digital elevation data modelling, In: Lowell, K., Jaton, A., (eds.). Spatial accuracy assessment: land information uncertainty in natural resources. Ann Arbor Press: Ann Arbor, Michigan.

Silbery, T., 2012. The plant life of Wairarapa Moana, In: Grant, I.F., (ed.). Wairarapa Mona, The lake and its people. Wairarapa Archive and Fraser Books.

Sikka, A.K., Samra, J.S., Sharda, V.N., Samraj, P., Lakshmanan, V., 2003. Low flow and high flow responses to converting natural grassland into bluegum (Eucalyptus globulus) in Nilgiris watersheds of South India. Journal of Hydrology. 270, 12-26.

Simpson, P., 1997. Are cabbage trees worth anything? Relating ecological and human values in the cabbage tree, ti kouka. The Journal of New Zealand Studies. 7 (1).

Smale, M.C., 1984. White Pine Bush \& an alluvial kahikatea (Dacrycarpus dacrydioides) forest remnant, eastern Bay of Plenty, New Zealand. New Zealand Journal of Botany. 22, 201-206.

Smith, P.J., 1987. Variation of water yield from catchments under grass and exotic forest, east Otago. New Zealand Journal of Hydrology. 26,175-84.

Smith, R.E., Goodrich, D.C., Woolhiser, D.A., Unkrich, C.A., 1995. KINEROS: a kinematic runoff and erosion model. In: Singh, V.P. (ed.) Computer Models of Watershed Hydrology. Water Resources Publication, Highlands Ranch, 697-732.

Stephens, J.M.C., Molan, P.C., Clarkson, B.D., 2005. A review of Leptospermum scoparium (Myrtaceae) in New Zealand. New Zealand Journal of Botany. 43, 431-449.

Study of Critical Environmental Problems (SCEP)., 1970. Man's Impact on the global Environment.

Takyu, M., Aiba, S.-I., Kitayama, K., 2002. Effects of topography on tropical lower montane forests under different geological conditions on Mount Kinabalu, Borneo. Plant Ecology. 159, 35-49.

Tansely, A.G., 1935. The use and abuse of vegetational concepts and terms. Ecology 16.

Temmerman, S., Meire, P., Bouma, T.J., Herman, P.M.J., Ysebaert, T., De Vriend, H.J., 2013. Ecosystem-based coastal defence in the face of global change. Nature. 504, 79-83. 
Thieken, A.H., Lucke, A., Diekkruger, B \& Richter, O., 1999. Scaling input data by GIS for hydrological modeling. Hydrol. Processes 13, 611-630.

Thomas, H., Nisbet, T.R., 2007. An assessment of the impact of floodplain woodland on flood flows. Water and Environment Journal. 21, 114-126

Thompson, J.A., Bell, J.C \& Butler, C.A., 2001. Digital elevation model resolution: effects on terrain attribute calculation and quantitative soil-landscape modelling. Geoderma 100, 67-89.

Thompson, S., Grüner, I., Gapare, N., 2003. New Zealand Land Cover Database Version 2. Illustrated guide to target classes. Ministry for the Environement, NZ.

Tindall, J.A., Kunkel, J.R., Anderson, D.E., 1999. Unsaturated zone hydrology for scientists and engineers. Prentice Hall Upper Saddle River, NJ.

Todd, M. J., Muneepeerakul, R., Pumo, D., Azaele, S., Miralles-Wilhelm, F., Rinaldo, A., Rodriguez-Iturbe, I., 2010. Hydrological drivers of wetland vegetation community distribution within Everglades National Park, Florida. Advances in Water Resources. 33, 1279-1289.

Tran, P., Marincioni, F., Shaw, R., 2010. Catastrophic flood and forest cover change in the Huong river basin, central Viet Nam: A gap between common perceptions and facts. Journal of Environmental Management. 91, 2186-2200.

Trettin, C. C., Jurgensen, M.F., 2003. Carbon cycling in wetland forest soils: In Kimble,J., Birdsie, R \& Lal, R. (eds), Carbon sequestration in US forests. Lewis Publishers, Boca Raton, Florida.

Turner, R.E., Lewis III, R.,1996. Hydrologic restoration of coastal wetlands. Wetlands Ecology and Management. 4, 65-72.

Van der Kamp, G., Hayashi, M., Gallen, D., 2003. Comapring the hydrology of grassed and cultivated catchments in the semi-arid Canadian prairies. Hydrol. Process. 17, 559575.

van Genuchten, M.Th., 1980. A closed form equation for predicting the hydraulic conductivity of unsaturated soils. Soil Sci. Soc. Am. J. 44, 892-898.

van Roon, M.R., 2012. Wetlands in The Netherlands and New Zealand: Optimising biodiversity and carbon sequestration during urbanisation. Journal of environmental management. 101, 143-150.

Vepraskas, M.J., 2001. Morphological features of seasonally reduced soils, In: Vepraskas, M.J., Craft, C.B., Richardson, J.L. (eds) Wetland soils: Genesis, Hydrology, Landscapes and Classification. CRC web press.

Vesterdal, L., Clarke, N., Sigurdsson, B.D., Gundersen, P., 2013. Do tree species influence soil 
carbon stocks in temperate and boreal forests? Forest Ecology and Management. 309, 4-18.

Vigerstol, K.L., Aukema, J.E., 2011. A comparison of tools for modelling freshwater ecosystem services. Journal of Environmental Management, 92, 2403-2409.

Villa, F., Bagstad, K., Johnson, G., Voigt, B., 2011. Scientific instruments for climate change adaptation : estimating and optimising efficiency of ecosystem services provision. Agricultural and Resource Economics. 11, 83-98.

Vinet, F., 2008. From hazard reduction to integrated risk management: toward adaptive flood prevention in Europe, In: Proverbs, D., Brebbia, C. A. \& Penning-Rowsell, E. (eds.) Flood Recovery, Innovation and Response I. Transactions in Ecology and the Environment, 118. WIT Press, Southampton UK, 113-122.

Vodde, F., Jõgiste, K., Gruson, L., Ilisson, T., Köster, K., Stanturf, J., 2010. Regeneration in windthrow areas in hemiboreal forests: the influence of microsite on the height growths of different tree species. Journal of Forest Research. 15, 55-64.

Vogt, W., 1948. Road to Survival. New York: William Sloan.

Vose, J. M., Sun, G., Ford, C. R., Bredemeier, M., Otsuki, K., Wei, X., Zhang, Z., Zhang, Lu., 2011. Forest ecohydrological research in the 21st century: what are the critical needs? Ecohydrology. 4, 146-158.

Wade, A.J., Jackson, B.M., Butterfield, D., 2008. Overparameterised, uncertain mathematical marionettes - How can we best use catchment water quality models? An example of an 80-year catchment-scale nutrient balance. Science of the Total Environment. 400, $52-74$

Wahren, A., Schwärzel, K., Feger, K.H., 2012. Potentials and limitations of natural flood retention by forested land in headwater catchments: evidence from experimental and model studies. Journal of Flood Risk Management. 5, 321-335.

Wang, C., Zhao, C., Xu, Z., Wang, Y., Peng, H., 2013. Effect of vegetation on soil water retention and storage in a semi-arid alpine forest catchment. Journal of Arid Land. 5, 207-219.

Wang, Y.Z., Hong, W., Wu, C.Z., He, D.J., Lin, S.W., Fan, H.I., 2008. Application of landscape ecology to the research on wetlands. Journal of Forestry Research. 19, 164-170.

Ward, J.C.; Lambie J.S. (Eds) 1999. Monitoring changes in wetland extent: an environmental performance indicator for wetlands. A Ministry for the Environment SMF funded project. Final Report-Project Phase One. Lincoln Environmental, Lincoln University, Canterbury. 
Wardle, D. A., Wiser, S. K., Allen, R. B., Doherty, J. E., Bonner, K. I., Williamson, W. M. 2008. Aboveground and Belowground effects of single-tree removals in New Zealand Rain Forest. Ecology. 89, 1232-1245.

Warren, J.M., Pötzelsberger, E., Wullschleger, S.D., Thornton, P.E., Hasenauer, H., Norby, R.J., 2011. Ecohydrologic impact of reduced stomatal conductance in forests exposed to elevated $\mathrm{CO}_{2}$. Ecohydrology. 4, 196-210.

Weber, T., 2007. Ecosystem services in Cecil County's Green Infrastructure. Technical Report for the Cecil County Green Infrastructure Plan.

Wei, Y., Li, M., Chen, H., Lewis, B. J., Yu, D., Zhou,W., Fang, X., Zhao, W., Dai, L., 2013. Variation in carbon storage and its distribution by stand age and forest type in boreal and temperate forests in Northeast China. PLoS ONE. 8(8).

Wei, Y., He, Y., Nan, L., Chen, A., Liu, G., 2011. The effects of typical vegetation restoration patterns on soil water retention characteristics in Yuanmou Dry-hot valley, China. International Conference on Agricultural and Natural Resources Engineering. Advances in Biomedical Engineering, 3-5.

Wenger, S. 1999. A review of the scientific literature on riparian buffer width, extent and vegetation. Univ. of Georgia, Institute of Ecology, Office of Public Service and Outreach, Athens, GA.

Westman, W. E., 1977. How much are nature's services worth? Science 197, 960964.

Whalen, S.C., 2005. Biogeochemistry of methane exchange between natural wetlands and the atmosphere. Environmental Engineering Science. 22, 73-94.

Whalley, W., Ober, E., Jenkins, M., 2013. Measurement of the matric potential of soil water in the rhizosphere. Journal of experimental botany. 64, 3951-3963.

Yang, G., and L. Y. Rong 2007. Effects of artificial vegetation types on soil moisture, carbon and nitrogen in the hill and gully area of the Loess Plateau. Bulletin of Soil and Water Conservation. 27, 30-33.

Yazici, B., Yolacan, S., 2007. A comparison of various tests of normality. Journal of Statistical Computation and Simulation. 77, 175-183.

Young, K. R., León, B., 2007. Tree-line changes along the Andes: implications of spatial patterns and dynamics. Philosophical Transactions of the Royal Society B: Biological Sciences. 362, 263-272.

Young, M.H., Caldwell, T.G., Meadows, D.G \& Fenstermaker, L.F., 2009. 
Variability of soil physical and hydraulic properties at the Mojave Global Change Facility, Nevada: Implications for water budget and evapotranspiration. Journal of Arid Environments 73, 733-744.

Yu, J., Wang, Y., Li, Y., Dong, H., Zhou, D., Han, G., Wu, H., Wang, G., Mao, P., Gao, Y., 2012. Soil organic carbon storage changes in coastal wetlands of the modern Yellow River Delta from 2000 to 2009. Biogeosciences. 9, 2325-2331.

Zedler, J. B., Kercher, S., 2004. Causes and Consequences of Invasive Plants in Wetlands: Opportunities, Opportunists, and Outcomes. Critical Reviews in Plant Sciences. 23, 431-452.

Zehe, E., Graeff, T., Morgner, M., Bauer, A., Bronstert, A., 2010. Plot and field scale soil moisture dynamics and subsurface wetness control on runoff generation in a headwater in the Ore Mountains. Hydrol Earth Syst Sci. 14, 873-889.

Zhang, X., Drake, N.A., Wainwright, J., Mulligan, M., 1999. Comparison of slope estimates from low resolution DEMs: Scaling issues and a fractal method for their solution. Earth Surface Processes and Landforms 24, 763-779.

Zhang, W., Weindorf, D.C., Zhu, Y., Haggard, B.J., Bakr, N., 2012. Soil series and land use impacts on major soil properties: a quantitative comparison. Soil Research. 50, 390396.

Zhao, X., Huang, J., Wu, P., Gao, X., 2014. The dynamic effects of pastures and crop on runoff and sediments reduction at loess slopes under simulated rainfall conditions. CATENA. 119, 1-7.

Zhou, H., Chen, Y., Li, W., Chen, Y., Fu, L., 2009. Photosynthesis of Populus euphratica and its response to elevated $\mathrm{CO} 2$ concentration in an arid environment. Progress in Natural Science. 19, 443-451.

Zong, Y., Tooley, M., 2003. A Historical Record of Coastal Floods in Britain: Frequencies and Associated Storm Tracks. Natural Hazards. 29, 13-36.

Zucco, G., Brocca, L., Moramarco, T., Morbidelli, R., 2014. Influence of land use on soil moisture spatial-temporal variability and monitoring. Journal of Hydrology. 516, 193-199. 


\section{List of Appendices}

Appendix 1 Syntax created for the analysis of the effect of land use under varying slope gradient, soil depth and block on bulk density

MIXED Bulk_density BY Landuse Soil_depth Slope Block

/FIXED Landuse Soil_depth Slope Landuse*Soil_depth Landuse*Slope|SSTYPE(3)

/RANDOM Block

/METHOD=REML

/EMMEANS=TABLES(OVERALL)

/EMMEANS=TABLES(Landuse) COMPARE ADJ(LSD)

/EMMEANS=TABLES(Slope) COMPARE ADJ(LSD)

/EMMEANS=TABLES(Soil_depth) COMPARE ADJ(LSD)

/EMMEANS=TABLES(Landuse*Soil_depth) COMPARE(Landuse) ADJ(LSD)

/EMMEANS=TABLES(Landuse*Slope) COMPARE(Landuse) ADJ(LSD)

/PRINT SOLUTION TESTCOV. 
Appendix 2 Pairwise LSD comparisons between land use types based on estimated marginal means of bulk density at 6 and $18 \mathrm{~cm}$ soil depth

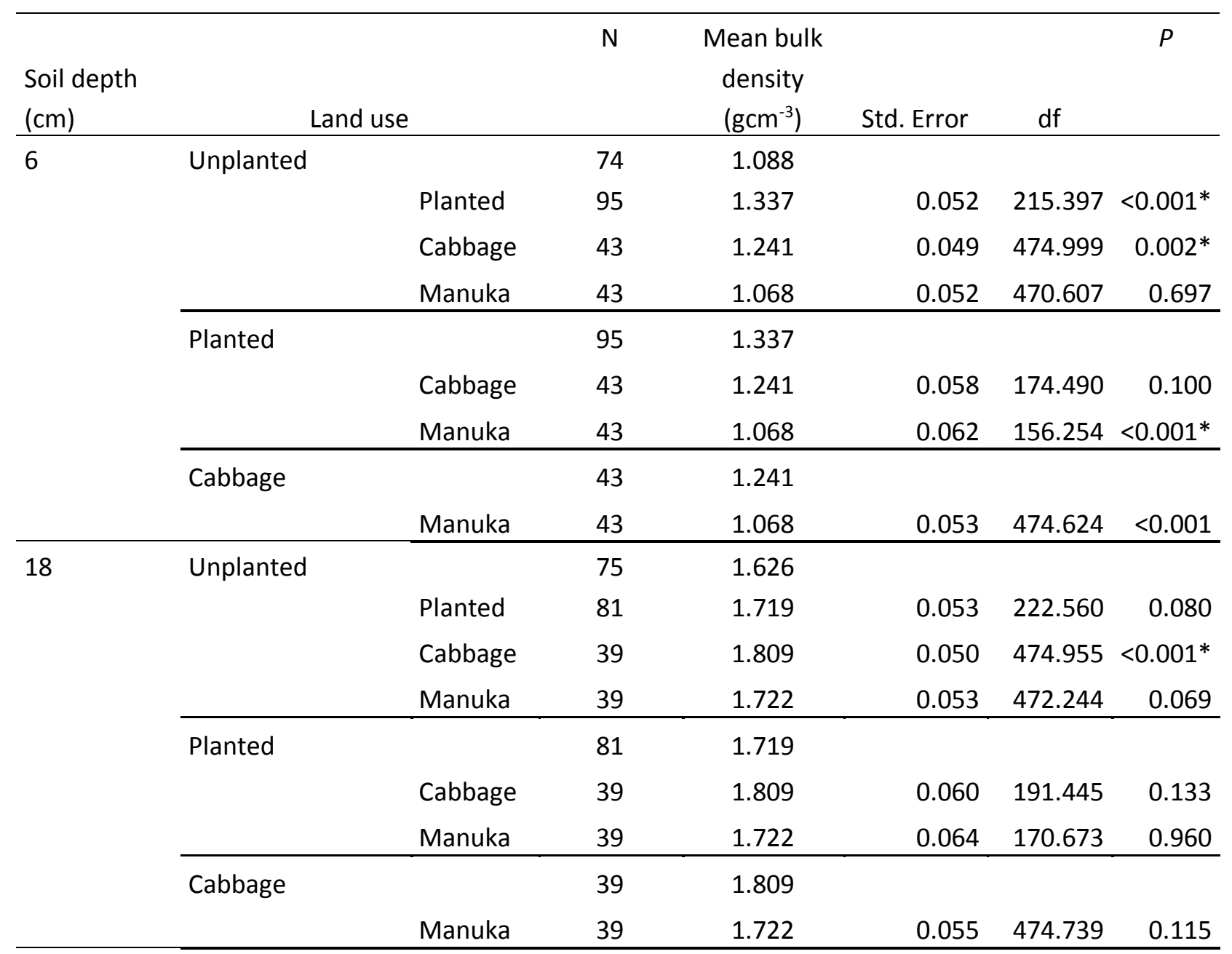

* mean difference is significant at 0.05 level 
Appendix 3 Pairwise LSD comparisons of the effect of land use on bulk density at varying slopes at $6 \mathrm{~cm}$ soil depth

\begin{tabular}{|c|c|c|c|c|c|c|}
\hline Slope (\%) & Land use & & $\begin{array}{c}\text { Mean bulk } \\
\text { density }\left(\mathrm{gcm}^{-3}\right)\end{array}$ & Std. Error & $\mathrm{df}$ & $p$ \\
\hline \multirow[t]{9}{*}{3} & Unplanted & & 1.061 & & & \\
\hline & & Planted & 1.357 & 0.091 & 161.858 & $0.004 *$ \\
\hline & & Cabbage & 1.067 & 0.086 & 228.333 & 0.335 \\
\hline & & Manuka & 0.847 & 0.082 & 215.143 & $0.034 *$ \\
\hline & Planted & & 1.357 & & & \\
\hline & & Cabbage & 1.067 & 0.118 & 93.645 & $0.029 *$ \\
\hline & & Manuka & 0.847 & 0.114 & 81.138 & $0.047^{*}$ \\
\hline & Cabbage & & 1.067 & & & \\
\hline & & Manuka & 0.847 & 0.70 & 240.504 & $0.030^{*}$ \\
\hline \multirow[t]{2}{*}{6} & Unplanted & & 1.069 & & & \\
\hline & & Manuka & 0.944 & 0.112 & 240.504 & $0.014 *$ \\
\hline \multirow[t]{9}{*}{8} & Unplanted & & 1.228 & & & \\
\hline & & Planted & 1.389 & 0.064 & 165.177 & $0.013^{*}$ \\
\hline & & Cabbage & 1.406 & 0.062 & 244.634 & $0.004 *$ \\
\hline & & Manuka & 1.650 & 0.109 & 244.776 & $<0.001^{*}$ \\
\hline & Planted & & 1.389 & & & \\
\hline & & Cabbage & 1.406 & 0.086 & 161.190 & 0.847 \\
\hline & & Manuka & 1.650 & 0.125 & 217.988 & $0.038^{*}$ \\
\hline & Cabbage & & 1.406 & & & \\
\hline & & Manuka & 1.650 & 0.114 & 217.988 & $0.032 *$ \\
\hline
\end{tabular}


Appendix 4 Pairwise LSD comparisons of the effect of land use on bulk density at varying slopes at $18 \mathrm{~cm}$ soil depth

\begin{tabular}{|c|c|c|c|c|c|c|}
\hline Slope (\%) & Land use & & $\begin{array}{c}\text { Mean bulk } \\
\text { density }\left(\mathrm{gcm}^{-3}\right)\end{array}$ & Std. Error & $\mathrm{df}$ & $p$ \\
\hline \multirow[t]{9}{*}{3} & Unplanted & & 1.659 & & & \\
\hline & & Planted & 1.709 & 0.073 & 85.842 & 0.496 \\
\hline & & Cabbage & 1.906 & 0.069 & 203.146 & $<0.001^{*}$ \\
\hline & & Manuka & 1.722 & 0.065 & 186.826 & 0.335 \\
\hline & Planted & & 1.709 & & & \\
\hline & & Cabbage & 1.906 & 0.087 & 39.317 & $0.029 *$ \\
\hline & & Manuka & 1.722 & 0.083 & 32.411 & 0.874 \\
\hline & Cabbage & & 1.906 & & & \\
\hline & & Manuka & 1.722 & 0.062 & 223.216 & $0.003 *$ \\
\hline \multirow[t]{2}{*}{6} & Unplanted & & 1.524 & & & \\
\hline & & Manuka & 1.444 & 0.102 & 218.486 & 0.431 \\
\hline \multirow[t]{9}{*}{8} & Unplanted & & 1.724 & & & \\
\hline & & Planted & 1.817 & 0.049 & 81.083 & 0.060 \\
\hline & & Cabbage & 1.716 & 0.054 & 211.889 & 0.886 \\
\hline & & Manuka & 1.725 & 0.092 & 202.748 & 0.996 \\
\hline & Planted & & 1.817 & & & \\
\hline & & Cabbage & 1.716 & 0.067 & 67.561 & 0.141 \\
\hline & & Manuka & 1.725 & 0.101 & 125.438 & 0.364 \\
\hline & Cabbage & & 1.716 & & & \\
\hline & & Manuka & 1.725 & 0.097 & 216.981 & 0.930 \\
\hline
\end{tabular}


Appendix 5 Pairwise LSD comparisons of the effect of land use on saturated hydraulic conductivity

\begin{tabular}{lccccc}
\hline \multicolumn{7}{c}{ Land use } & $\begin{array}{c}\text { Mean decadic } \\
\text { log Saturated } \\
\text { hydraulic } \\
\text { conductivity }\end{array}$ & Std. Error & df & $p$ \\
\hline \multirow{2}{*}{ Unplanted } & 1.264 & & & & \\
& Planted & 2.118 & 0.296 & 61.388 & 0.005 \\
& Cabbage & 2.094 & 0.425 & 10.576 & 0.078 \\
& Manuka & 1.614 & 0.454 & 9.177 & 0.461 \\
\hline
\end{tabular}

Appendix 6 Syntax created for the analysis of the effect of land use under varying slopes on saturated hydraulic conductivity

MIXED Log Saturated hydraulic conductivity BY Landuse Slope Block

/FIXED Landuse Slope Landuse*Slope|SSTYPE(3)

/RANDOM Block

/METHOD=REML

/EMMEANS=TABLES(OVERALL)

/EMMEANS=TABLES(Landuse) COMPARE ADJ(LSD)

/EMMEANS=TABLES(Slope) COMPARE ADJ(LSD)

/EMMEANS=TABLES(Landuse*Slope) COMPARE(Landuse) ADJ(LSD)

/PRINT SOLUTION TESTCOV. 
Appendix 7 Syntax created for the analysis of the effect of land use under varying slopes, soil depth, stage of restoration on soil organic carbon

MIXED Soil_organiccarbon BY Landuse Depth Slope Stage Block

/FIXED Landuse Depth Slope Stage Landuse*Depth Landuse*Slope Landuse*Stage|SSTYPE(3)

/RANDOM Block

/METHOD=REML

/EMMEANS=TABLES(OVERALL)

/EMMEANS=TABLES(Landuse) COMPARE ADJ(LSD)

/EMMEANS=TABLES(Slope) COMPARE ADJ(LSD)

/EMMEANS=TABLES(Depth) COMPARE ADJ(LSD)

/EMMEANS=TABLES(Stage) COMPARE ADJ(LSD)

/EMMEANS=TABLES(Landuse*Depth) COMPARE(Landuse) ADJ(LSD)

/EMMEANS=TABLES(Landuse*Slope) COMPARE(Landuse) ADJ(LSD)

/EMMEANS=TABLES(Landuse*Stage) COMPARE(Landuse) ADJ(LSD)

/PRINT SOLUTION TESTCOV. 
Appendix 8 Pairwise LSD comparisons of the effect of land use on soil organic carbon at 6 and $18 \mathrm{~cm}$ soil depths

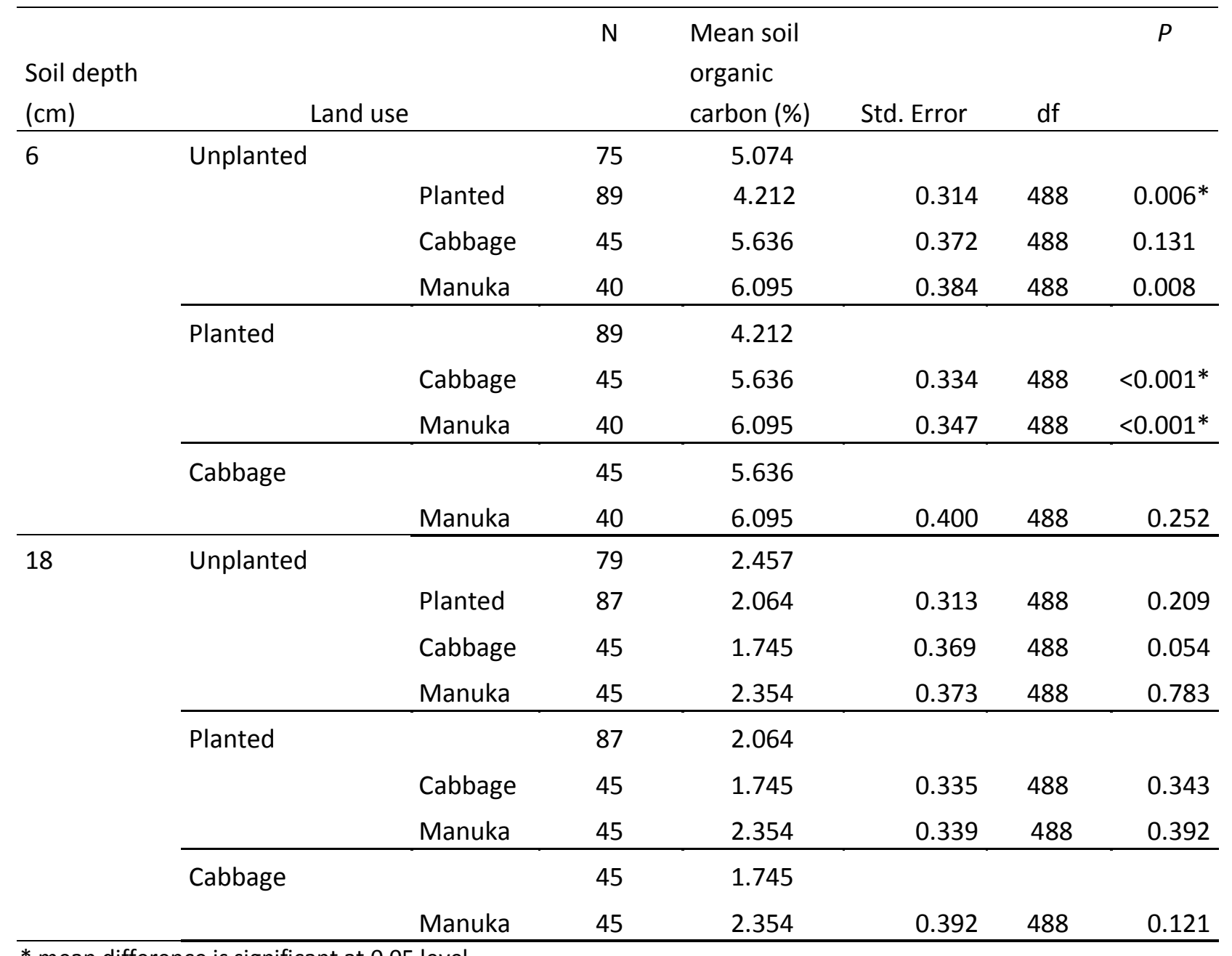

* mean difference is significant at 0.05 level 
Appendix 9 Pairwise LSD comparisons of the effect of land use on soil organic carbon at varying slopes at $6 \mathrm{~cm}$ soil depth

\begin{tabular}{|c|c|c|c|c|c|c|c|}
\hline Slope (\%) & & & $\mathrm{N}$ & $\begin{array}{l}\text { Mean soil } \\
\text { organic } \\
\text { carbon (\%) }\end{array}$ & Std. Error & $d f$ & $P$ \\
\hline \multirow[t]{9}{*}{3} & Unplanted & & 23 & 5.68 & & & \\
\hline & & Planted & 30 & 3.99 & 0.77 & 16.60 & $0.044^{*}$ \\
\hline & & Cabbage & 18 & 6.65 & 0.66 & 238.84 & 0.138 \\
\hline & & Manuka & 23 & 7.12 & 0.62 & 237.36 & $0.020 *$ \\
\hline & Planted & & 30 & 3.99 & & & \\
\hline & & Cabbage & 18 & 6.65 & 0.85 & 15.66 & $0.007^{*}$ \\
\hline & & Manuka & 23 & 7.12 & 0.80 & 13.60 & $0.002^{*}$ \\
\hline & Cabbage & & 18 & 6.65 & & & \\
\hline & & Manuka & 23 & 7.12 & 0.60 & 237.08 & 0.47 \\
\hline \multirow[t]{2}{*}{6} & Unplanted & & 9 & 3.80 & & & \\
\hline & & Manuka & 8 & 7.04 & 0.10 & 234.38 & $0.001^{*}$ \\
\hline \multirow[t]{9}{*}{8} & Unplanted & & 43 & 4.83 & & & \\
\hline & & Planted & 59 & 4.34 & 0.55 & 20.95 & 0.382 \\
\hline & & Cabbage & 27 & 4.95 & 0.52 & 236.61 & 0.823 \\
\hline & & Manuka & 9 & 3.43 & 0.81 & 193.78 & 0.084 \\
\hline & Planted & & 59 & 4.34 & & & \\
\hline & & Cabbage & 27 & 4.95 & 0.64 & 20.68 & 0.356 \\
\hline & & Manuka & 9 & 3.43 & 0.90 & 45.57 & 0.313 \\
\hline & Cabbage & & 27 & 4.95 & & & \\
\hline & & Manuka & 9 & 3.43 & 0.84 & 212.96 & 0.072 \\
\hline
\end{tabular}

*mean difference is significant at 0.05 level 


\begin{tabular}{|c|c|c|c|c|c|c|c|}
\hline Slope (\%) & & & $\mathrm{N}$ & $\begin{array}{l}\text { Mean soil } \\
\text { organic } \\
\text { carbon (\%) }\end{array}$ & Std. Error & df & $P$ \\
\hline \multirow[t]{9}{*}{3} & Unplanted & & 24 & 2.99 & & & \\
\hline & & Planted & 29 & 2.09 & 0.77 & 16.60 & $0.044^{*}$ \\
\hline & & Cabbage & 18 & 1.60 & 0.66 & 238.84 & 0.138 \\
\hline & & Manuka & 27 & 3.00 & 0.62 & 237.36 & $0.020 *$ \\
\hline & Planted & & 29 & 2.09 & & & \\
\hline & & Cabbage & 18 & 1.60 & 0.85 & 15.66 & $0.007^{*}$ \\
\hline & & Manuka & 27 & 3.00 & 0.80 & 13.60 & $0.002^{*}$ \\
\hline & Cabbage & & 18 & 1.60 & & & \\
\hline & & Manuka & 27 & 3.00 & 0.60 & 237.08 & 0.47 \\
\hline \multirow[t]{2}{*}{6} & Unplanted & & 9 & 2.14 & & & \\
\hline & & Manuka & 9 & 2.79 & 0.10 & 234.38 & $0.001^{*}$ \\
\hline \multirow[t]{9}{*}{8} & Unplanted & & 46 & 2.01 & & & \\
\hline & & Planted & 58 & 1.58 & 0.37 & 29.81 & 0.252 \\
\hline & & Cabbage & 27 & 2.15 & 0.30 & 245.64 & 0.647 \\
\hline & & Manuka & 9 & 2.34 & 0.48 & 235.25 & 0.499 \\
\hline & Planted & & 58 & 1.58 & & & \\
\hline & & Cabbage & 27 & 2.15 & 0.43 & 30.94 & 0.199 \\
\hline & & Manuka & 9 & 2.34 & 0.57 & 66.74 & 0.193 \\
\hline & Cabbage & & 27 & 2.15 & & & \\
\hline & & Manuka & 9 & 2.34 & 0.50 & 243.41 & 0.706 \\
\hline
\end{tabular}

* mean difference is significant at 0.05 level 


\begin{tabular}{|c|c|c|c|c|c|c|}
\hline Slope (\%) & Land use & & $\begin{array}{c}\text { Mean } \\
\text { volumetric } \\
\text { moisture } \\
\text { content (\%) }\end{array}$ & Std. Error & df & $p$ \\
\hline \multirow[t]{9}{*}{3} & Unplanted & & 42.460 & & & \\
\hline & & Planted & 34.690 & 2.751 & 97.621 & $0.006^{*}$ \\
\hline & & Cabbage & 46.688 & 1.918 & 263.382 & $0.028 *$ \\
\hline & & Manuka & 39.399 & 1.835 & 264.063 & 0.097 \\
\hline & Planted & & 34.690 & & & \\
\hline & & Cabbage & 46.688 & 2.865 & 78.345 & $<0.001^{*}$ \\
\hline & & Manuka & 39.399 & 2.760 & 69.969 & 0.092 \\
\hline & Cabbage & & 46.688 & & & \\
\hline & & Manuka & 39.399 & 1.606 & 254.019 & $<0.001^{*}$ \\
\hline \multirow[t]{2}{*}{6} & Unplanted & & 42.996 & & & \\
\hline & & Manuka & 45.098 & 4.213 & 210.940 & 0.618 \\
\hline \multirow[t]{9}{*}{8} & Unplanted & & 38.690 & & & \\
\hline & & Planted & 29.007 & 2.075 & 35.130 & $<0.001^{*}$ \\
\hline & & Cabbage & 38.633 & 1.396 & 264.572 & 0.814 \\
\hline & & Manuka & 27.633 & 2.352 & 251.038 & $<0.001^{*}$ \\
\hline & Planted & & 29.007 & & & \\
\hline & & Cabbage & 38.633 & 2.367 & 44.315 & $<0.001^{*}$ \\
\hline & & Manuka & 27.633 & 3.032 & 87.494 & 0.651 \\
\hline & Cabbage & & 38.633 & & & \\
\hline & & Manuka & 27.633 & 2.408 & 252.981 & $<0.001^{*}$ \\
\hline
\end{tabular}

* mean difference is significant at 0.05 level 
Appendix 12 Pairwise LSD comparisons of the effect of land use on volumetric moisture content at varying slopes at 18 cm soil depth

\begin{tabular}{|c|c|c|c|c|c|c|}
\hline Slope (\%) & Land use & & $\begin{array}{c}\text { Mean Volumetric } \\
\text { moisture content } \\
(\%)\end{array}$ & $\begin{array}{l}\text { Std. } \\
\text { Error }\end{array}$ & df & $p$ \\
\hline \multirow[t]{9}{*}{3} & Unplanted & & 42.933 & & & \\
\hline & & Planted & 33.816 & 3.246 & 148.888 & $0.006^{*}$ \\
\hline & & Cabbage & 44.759 & 2.133 & 260.404 & 0.393 \\
\hline & & Manuka & 45.185 & 2.069 & 263.234 & 0.277 \\
\hline & Planted & & 33.816 & & & \\
\hline & & Cabbage & 44.759 & 3.413 & 131.764 & $0.002 *$ \\
\hline & & Manuka & 45.185 & 3.311 & 121.386 & $0.001 *$ \\
\hline & Cabbage & & 44.759 & & & \\
\hline & & Manuka & 45.185 & 1.796 & 252.203 & 0.813 \\
\hline \multirow[t]{2}{*}{6} & Unplanted & & 46.453 & & & \\
\hline & & Manuka & 49.169 & 4.699 & 218.679 & 0.564 \\
\hline \multirow[t]{9}{*}{8} & Unplanted & & 39.141 & & & \\
\hline & & Planted & 31.468 & 2.540 & 56.306 & $0.004 *$ \\
\hline & & Cabbage & 37.162 & 1.557 & 262.719 & 0.205 \\
\hline & & Manuka & 23.108 & 2.638 & 259.879 & $<0.001^{*}$ \\
\hline & Planted & & 31.468 & & & \\
\hline & & Cabbage & 37.162 & 2.878 & 71.904 & 0.052 \\
\hline & & Manuka & 23.108 & 3.586 & 126.073 & $0.021^{*}$ \\
\hline & Cabbage & & 37.162 & & & \\
\hline & & Manuka & 23.108 & 2.686 & 254.632 & $<0.001^{*}$ \\
\hline
\end{tabular}

* mean difference is significant at 0.05 level 
Appendix 13 Pairwise LSD comparisons of the effect of land use on volumetric moisture content under changing seasons at $10 \mathrm{~cm}$ depth

\begin{tabular}{|c|c|c|c|c|c|}
\hline Seasons & Land use & & $\begin{array}{c}\text { Mean volumetric } \\
\text { moisture content } \\
(\%)\end{array}$ & Std. Error & $p$ \\
\hline \multirow[t]{5}{*}{ Autumn } & Unplanted & & 47.07 & & \\
\hline & & Planted & 30.63 & 0.067 & $<0.001^{*}$ \\
\hline & & Planted 2 & 55.50 & 0.075 & $<0.001^{*}$ \\
\hline & Planted & & 30.63 & & \\
\hline & & Planted 2 & 55.50 & 0.075 & $<0.001^{*}$ \\
\hline \multirow[t]{5}{*}{ Spring } & Unplanted & & 50.61 & & \\
\hline & & Planted & 32.23 & 0.049 & $<0.001 *$ \\
\hline & & Planted 2 & 55.50 & 0.050 & $<0.001 *$ \\
\hline & Planted & & 32.23 & & \\
\hline & & Planted 2 & 55.50 & 0.050 & $<0.001 *$ \\
\hline \multirow[t]{5}{*}{ Winter } & Unplanted & & 51.29 & & \\
\hline & & Planted & 34.79 & 0.050 & $<0.001^{*}$ \\
\hline & & Planted 2 & 59.75 & 0.054 & $<0.001 *$ \\
\hline & Planted & & 34.79 & & \\
\hline & & Planted 2 & 59.75 & 0.053 & $<0.001^{*}$ \\
\hline \multirow[t]{3}{*}{ Summer } & Unplanted & & 30.98 & & \\
\hline & & Planted & 16.90 & 0.050 & $<0.001^{*}$ \\
\hline & & Planted 2 & 31.57 & 0.050 & 0.200 \\
\hline
\end{tabular}

* mean difference is significant at 0.05 level 
Appendix 14 Pairwise LSD comparisons of the effect of land use on volumetric moisture content under changing seasons at $20 \mathrm{~cm}$ depth

\begin{tabular}{|c|c|c|c|c|c|}
\hline Seasons & Land use & & $\begin{array}{c}\text { Mean } \\
\text { volumetric } \\
\text { moisture } \\
\text { content (\%) }\end{array}$ & Std. Error & $p$ \\
\hline \multirow[t]{5}{*}{ Autumn } & Unplanted & & 46.50 & & \\
\hline & & Planted & 31.77 & 0.073 & $<0.001 *$ \\
\hline & & Planted 2 & 44.51 & 0.081 & $<0.001^{*}$ \\
\hline & Planted & & 31.77 & & \\
\hline & & Planted 2 & 44.51 & 0.081 & $<0.001^{*}$ \\
\hline \multirow[t]{5}{*}{ Spring } & Unplanted & & 50.54 & & \\
\hline & & Planted & 35.67 & 0.054 & $<0.001^{*}$ \\
\hline & & Planted 2 & 48.21 & 0.054 & $<0.001^{*}$ \\
\hline & Planted & & 35.67 & & \\
\hline & & Planted 2 & 48.21 & .0054 & $<0.001^{*}$ \\
\hline \multirow[t]{5}{*}{ Winter } & Unplanted & & 51.24 & & \\
\hline & & Planted & 35.44 & 0.055 & $<0.001^{*}$ \\
\hline & & Planted 2 & 49.96 & 0.059 & $<0.001^{*}$ \\
\hline & Planted & & 35.44 & & \\
\hline & & Planted 2 & 49.96 & 0.057 & $<0.001^{*}$ \\
\hline \multirow[t]{5}{*}{ Summer } & Unplanted & & 22.68 & & \\
\hline & & Planted & 17.95 & 0.054 & $<0.001^{*}$ \\
\hline & & Planted 2 & 19.98 & 0.054 & $<0.001^{*}$ \\
\hline & Planted & & 22.68 & & \\
\hline & & Planted 2 & 19.98 & 0.054 & $<0.001^{*}$ \\
\hline
\end{tabular}

* mean difference is significant at 0.05 level 
Appendix 15 Pairwise LSD comparisons of the effect of land use on volumetric moisture content under changing seasons at $30 \mathrm{~cm}$ depth

\begin{tabular}{|c|c|c|c|c|c|}
\hline Seasons & Land use & & $\begin{array}{c}\text { Mean volumetric } \\
\text { moisture content } \\
(\%)\end{array}$ & Std. Error & $p$ \\
\hline \multirow[t]{5}{*}{ Autumn } & Unplanted & & 37.66 & & \\
\hline & & Planted & 34.21 & 0.068 & $<0.001 *$ \\
\hline & & Planted 2 & 46.49 & 0.076 & $<0.001^{*}$ \\
\hline & Planted & & 34.21 & & \\
\hline & & Planted 2 & 37.66 & 0.076 & $<0.001^{*}$ \\
\hline \multirow[t]{5}{*}{ Spring } & Unplanted & & 41.20 & & \\
\hline & & Planted & 36.95 & 0.050 & $<0.001^{*}$ \\
\hline & & Planted 2 & 48.15 & 0.050 & $<0.001^{*}$ \\
\hline & Planted & & 36.95 & & \\
\hline & & Planted 2 & 48.15 & 0.050 & $<0.001^{*}$ \\
\hline \multirow[t]{5}{*}{ Winter } & Unplanted & & 42.04 & & \\
\hline & & Planted & 38.08 & 0.051 & $<0.001^{*}$ \\
\hline & & Planted 2 & 49.09 & 0.055 & $<0.001^{*}$ \\
\hline & Planted & & 38.08 & & \\
\hline & & Planted 2 & 49.09 & 0.053 & $<0.001^{*}$ \\
\hline \multirow[t]{5}{*}{ Summer } & Unplanted & & 18.51 & & \\
\hline & & Planted & 11.92 & 0.050 & $<0.001^{*}$ \\
\hline & & Planted 2 & 27.54 & 0.050 & $<0.001^{*}$ \\
\hline & Planted & & 11.92 & & \\
\hline & & Planted 2 & 27.54 & 0.050 & $<0.001^{*}$ \\
\hline
\end{tabular}

* mean difference is significant at 0.05 level 
Appendix 16 Species list of some of the sedges, grasses, turfs at Wairio wetlands

\begin{tabular}{|c|c|c|}
\hline Scientific name & Common name & Status \\
\hline Agrostis capillaris & Browntop & Exotic \\
\hline Agrostis stolonifera & Creeping bent grass & Exotic \\
\hline Amphibromus fluitans & Water brome & Native \\
\hline Bidens frondosa & Beggars tick & Exotic \\
\hline Carex geminata & Wetland cutty grass & Native \\
\hline Dactylis glomerata & Cocksfoot & Exotic \\
\hline Eleocharis acuta & Sharp spike sedge & Native \\
\hline Festuca arundinacea & Tall fescue & Exotic \\
\hline Galium palustre & Marsh bedstraw & Exotic \\
\hline Glyceria fluitans & Floating sweetgrass & Exotic \\
\hline Holcus lanatus & Yorkshire fog & Exotic \\
\hline Isolepis prolifera & - & Native \\
\hline Juncus articulatus & Jointed rush & Exotic \\
\hline Leontodon autumninalis & Autumn hawkbit & Exotic \\
\hline Lotus pedunculatus & Lotus & Exotic \\
\hline Rumex obtusifolius & Broad-leaved dock & Exotic \\
\hline Schoenoplectus pungens & Three square & Native \\
\hline Trifolium fragiferum & Pink clover & Exotic \\
\hline
\end{tabular}


Appendix 17 Root system of a cabbage tree ( 2 year old) in block 13. Photo taken by author on 23/05/2015
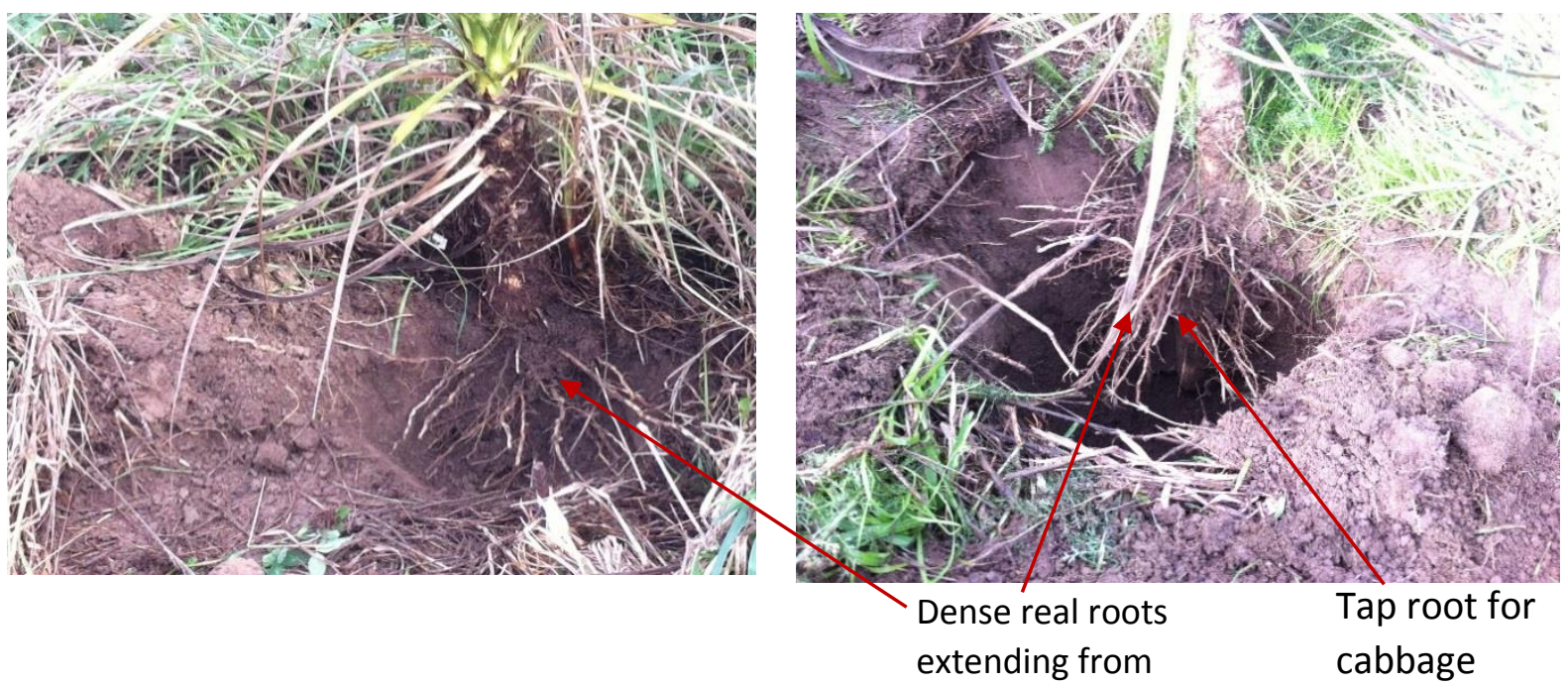

the tap root

Appendix 18 Root system of a manuka tree. Photo taken by author on 23/05/2015

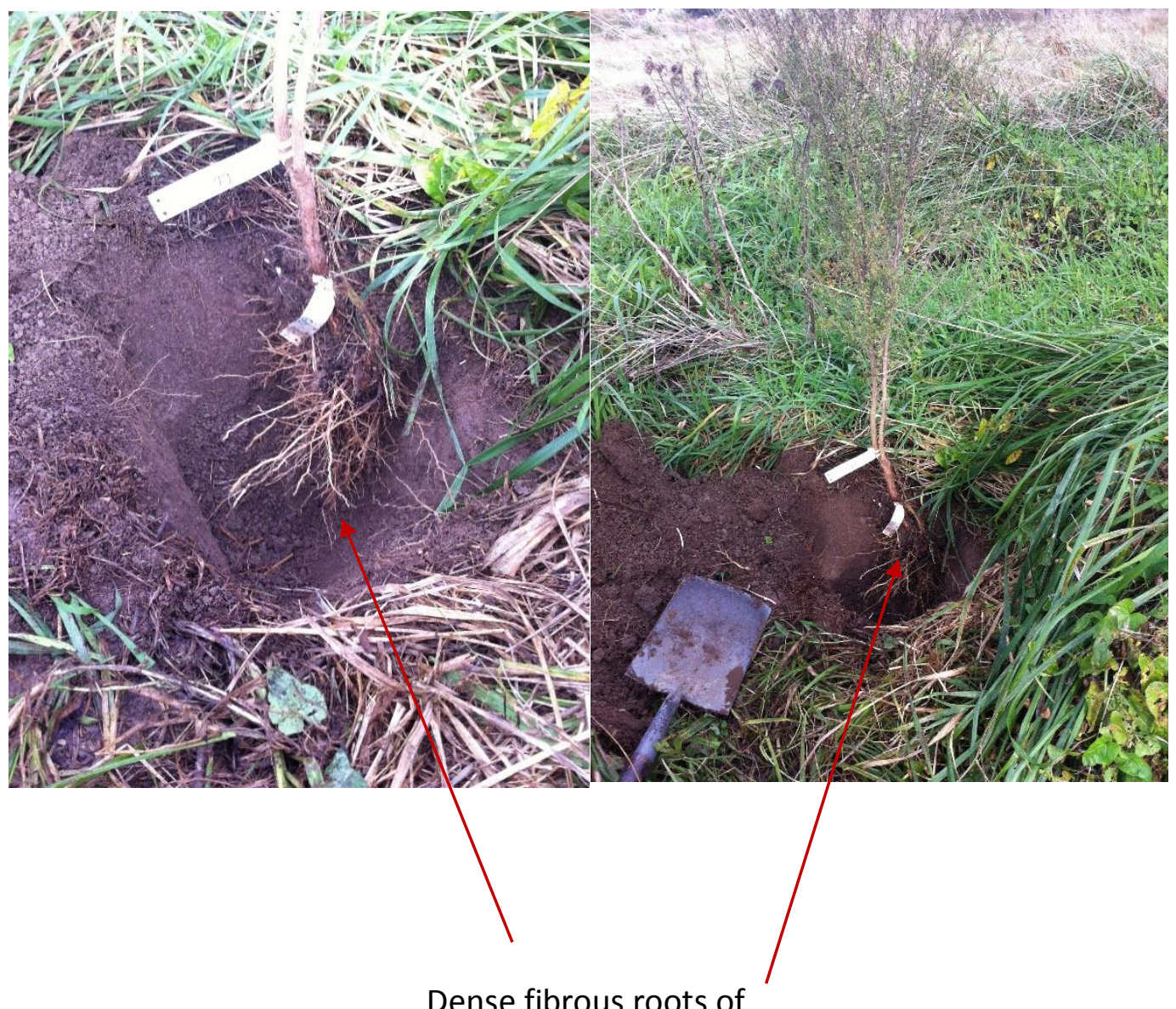

Dense fibrous roots of

manuka extending into the

soil 
Appendix 19: Classical examples of ecosystem services classification

The ecosystem service framework by Daily, (1999) did not distinguish functions from services but like other schemes, it highlighted the roles played by ecosystems. The framework classified ecosystem services into five categories including;

\begin{tabular}{ll}
\hline Services & Examples of benefits \\
\hline Regeneration processes & air and water purification \\
Life fulfilling functions & aesthetic beauty \\
Production of goods & food and medicinal products \\
Preservation of options & conservation of ecosystem components \\
Stabilising processes & $\begin{array}{l}\text { regulation of the hydrological cycle and control } \\
\text { of potential pest species }\end{array}$ \\
\hline
\end{tabular}

Costanza et al., (1997) grouped goods and services into 17 categories as follows:

\begin{tabular}{|c|c|c|}
\hline Service & & Examples of benefits \\
\hline 1. & Gas regulation & $\mathrm{CO}_{2} / \mathrm{O}_{2}$ balance \\
\hline & Climate regulation & $\begin{array}{l}\text { greenhouse gas regulation, DMS production affecting } \\
\text { cloud formation }\end{array}$ \\
\hline & Disturbance regulation & $\begin{array}{l}\text { storm protection, flood control, drought recovery and } \\
\text { other aspects of habitat response to environmental } \\
\text { variability mainly controlled by vegetation structure }\end{array}$ \\
\hline 4. & Water regulation & provisioning of water for agricultural irrigation \\
\hline & Water supply & storage and retention of water \\
\hline & $\begin{array}{l}\text { Erosion control and sediment } \\
\text { retention }\end{array}$ & prevention of loss of soil by wind or runoff \\
\hline & Soil formation & $\begin{array}{l}\text { weathering of rock and the accumulation of organic } \\
\text { material }\end{array}$ \\
\hline & Nutrient cycling & nitrogen fixation \\
\hline & Waste treatment & pollution control and detoxification \\
\hline 10. & Pollination & reproduction of plant populations \\
\hline 11. & Biological control & reduction of herbivory by top predators \\
\hline \multicolumn{3}{|c|}{$\begin{array}{l}\text { 12. Habitat for resident and } \\
\text { transient populations }\end{array}$} \\
\hline 13. & Food production & fish, game, crops, nuts, fruits \\
\hline \multicolumn{3}{|c|}{ 14. Raw materials } \\
\hline 15. & Genetic resources & $\begin{array}{l}\text { medicine, products for materials science, genes for } \\
\text { resistance to plant pathogens and crop pests }\end{array}$ \\
\hline 16. & Recreation & eco-tourism, sport fishing, and other outdoor \\
\hline
\end{tabular}


recreational activities

17. Cultural aesthetic, artistic, educational and spiritual values

During the global assessment of the world's ecosystems, four broad categories of services were identified by the MEA, (2005) and these were:

\begin{tabular}{ll}
\hline Services & Examples of benefits \\
\hline Supporting services & primary production, water cycling, soil formation and \\
& retention \\
Provisioning services & fresh water, genetic resources, food \\
Cultural services & recreation and education \\
Regulating services & climate regulation and erosion control \\
\hline
\end{tabular}

Similarly, the classification scheme by de Groot et al. (2002) identifies 23 services that are grouped into four categories, which include regulation, habitat, production and information functions. 
Appendix 20 Tensiometer refilling events

\begin{tabular}{l|l}
\hline Event & Date \\
\hline 1 & 05 August 2014 \\
2 & 04 September 2014 \\
3 & 18 September 2014 \\
4 & 26 September 2014 \\
5 & 22 October 2014 \\
6 & 24 November 2014 \\
7 & 08 December 2014 \\
9 & 09 January 2015 \\
11 & 27 January 2015 \\
\hline & 05 March 2015 \\
\hline
\end{tabular}


Appendix 21 Land use/cover data used for scenario generation before and after restoration for Stage 2

Baseline Landuse data (2001/02) for Stage 2 before restoration
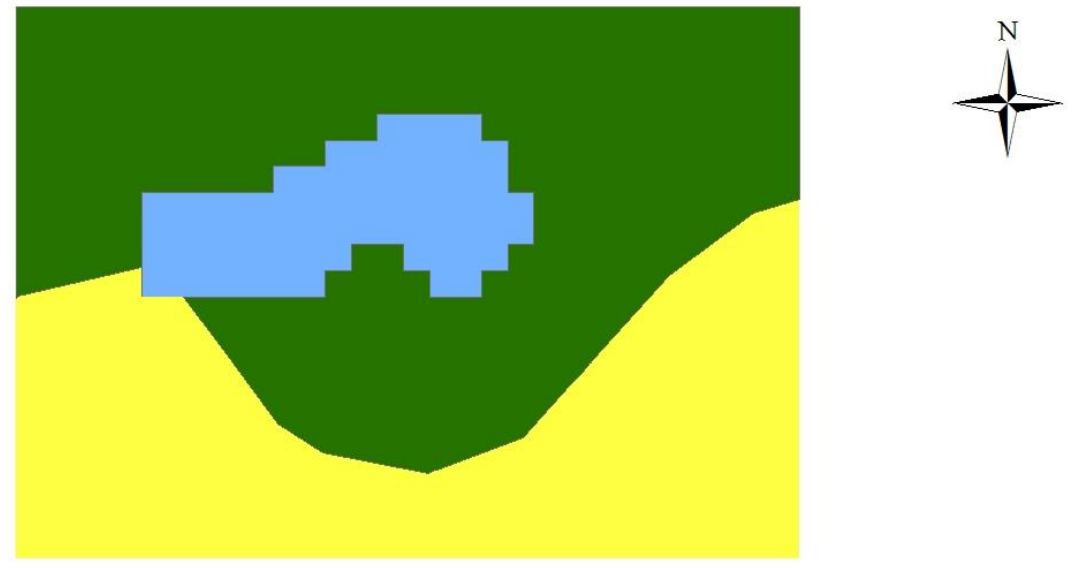

$$
\begin{aligned}
& \text { ludata } \\
& \text { LCDB2CLASS } \\
& \begin{array}{l}
\text { Pond } \\
\text { High producing exotic grassland } \\
\text { Herbaceous freshwater vegetation }
\end{array}
\end{aligned}
$$$$
\begin{array}{llll}
0 & 0.05 & 0.1 & 0.2 \text { Kilometers }
\end{array}
$$

Landuse after restoration and natural change over time for stage 2 (2013/15)

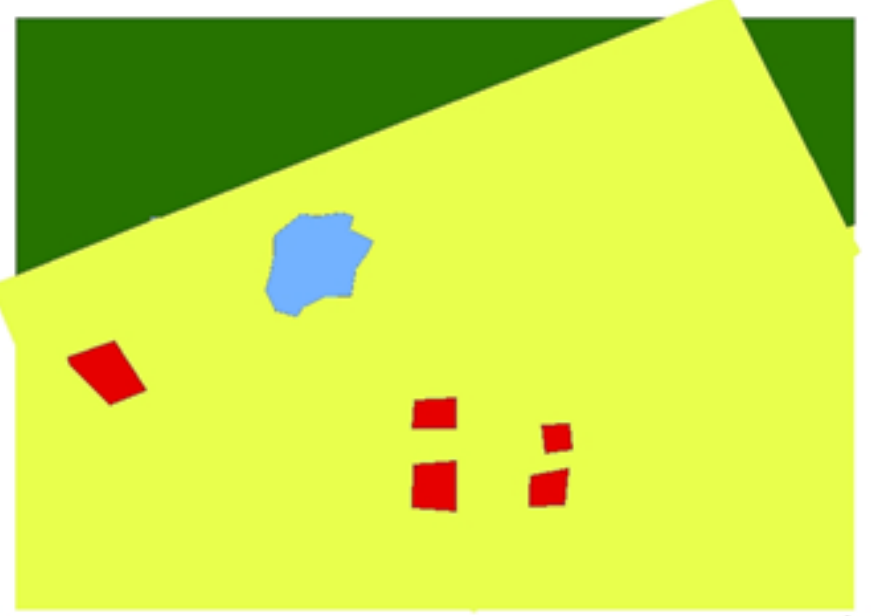

ludata LCDB2CLASS

$\begin{array}{llll}0 & 0.05 & 0.1 & 0.2 \text { Kilometers }\end{array}$

Pond

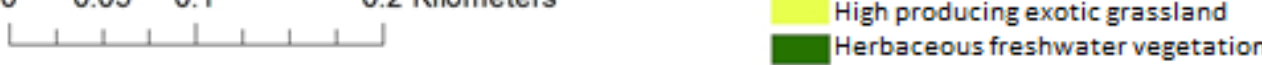
Indigenous forest

Appendix 22 Land use/cover data used for scenario generation before and after restoration for Stage 3 
Baseline Landuse data (2001/02) for Stage 3 before restoration

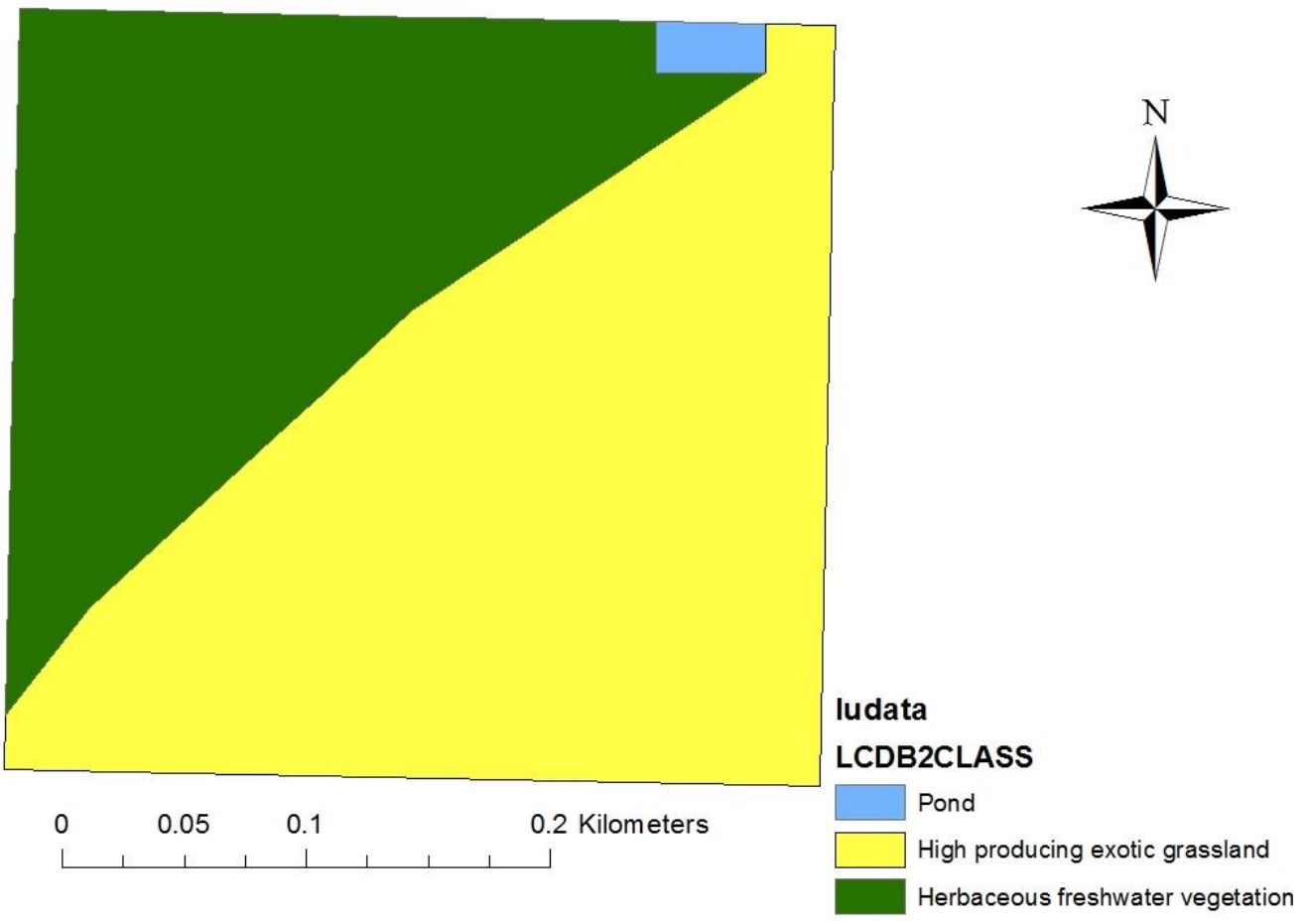

Landuse after restoration and natural succession for Stage 3 (2013/15)

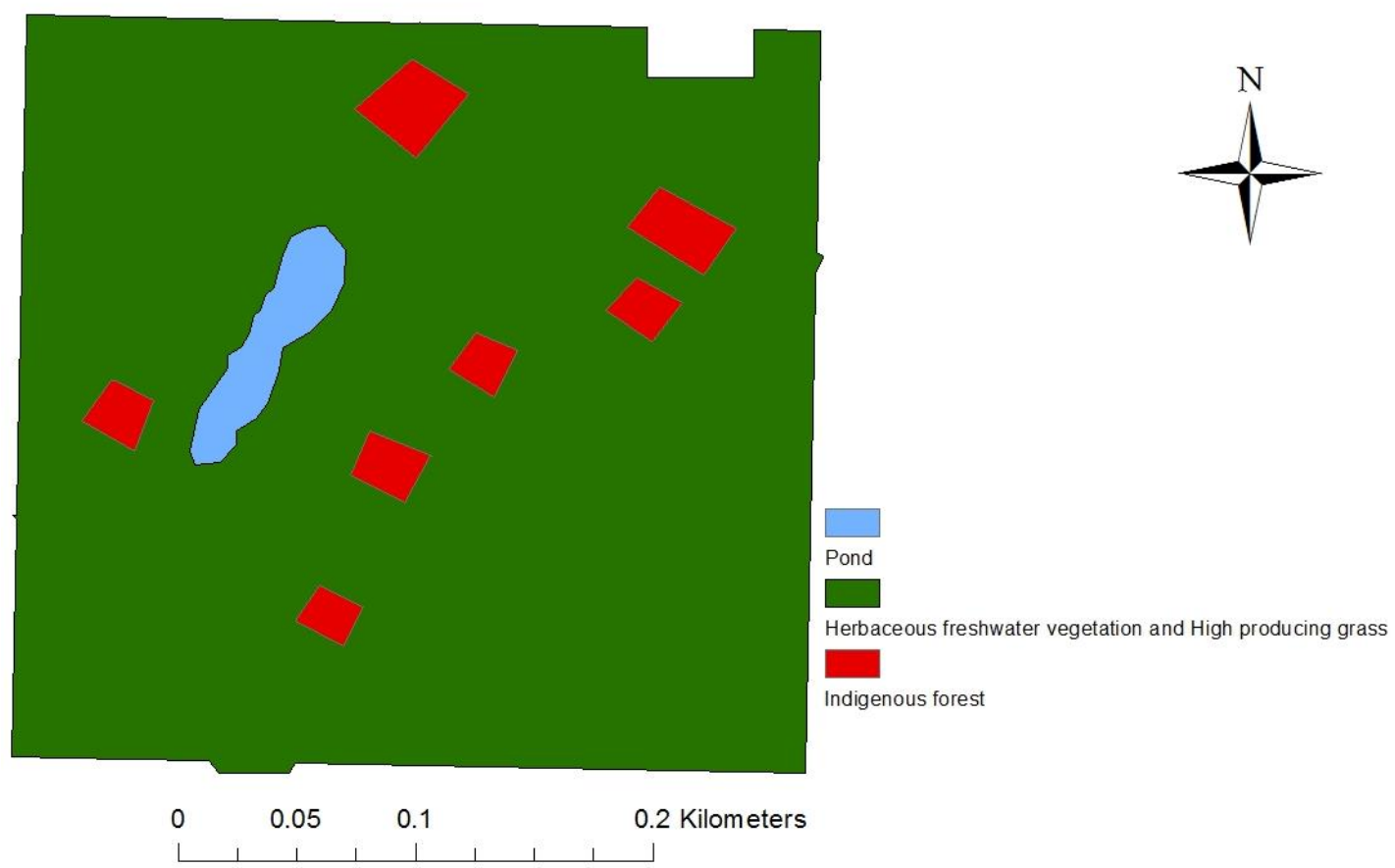

Appendix 23 Drainage density and location of streams at the different DEMS 


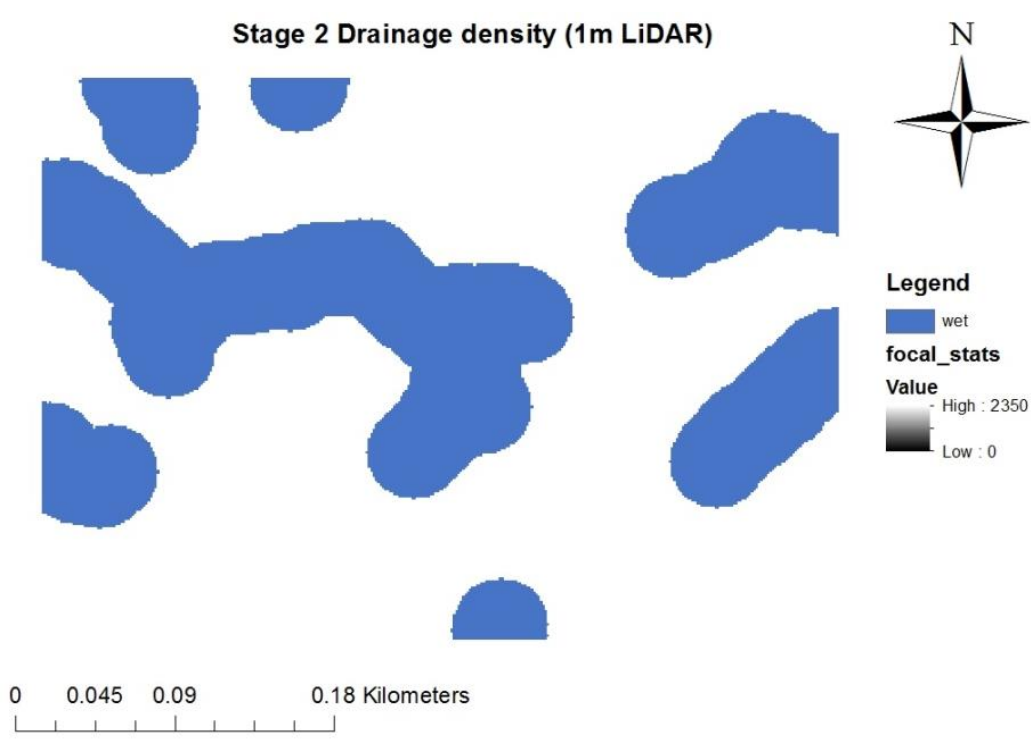

Stage 2 Drainage density ( $1 \mathrm{~m}$ field survey)
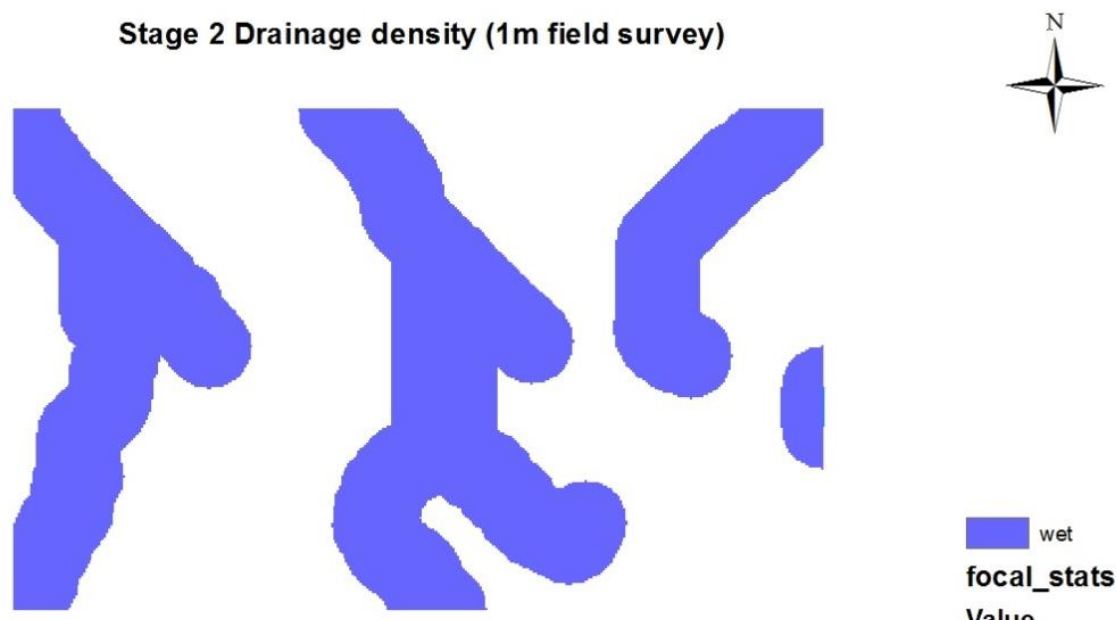

wet

focal_stats

Value

- High : 919

Low : 0

$\begin{array}{lll}0 & 0.045 & 0.09\end{array}$

0.18 Kilometers 


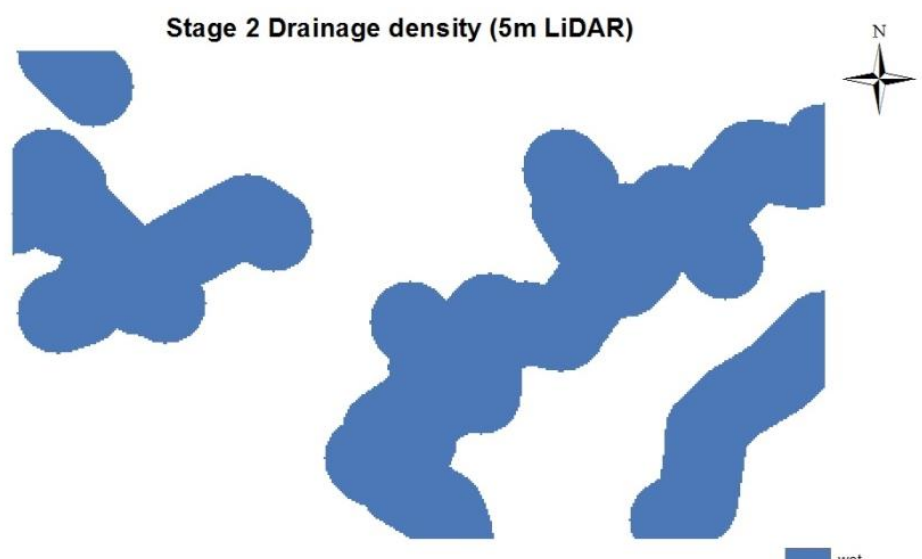

focal_stats

$\begin{array}{lllll}0 & 0.045 & 0.09 & 0.18 \text { Kilometers } \\ + & + & + & +\end{array}$

\begin{tabular}{llll}
0 & 0.045 & 0.09 & 0.18 Kilometers \\
\hline & + & + & +
\end{tabular}

Value
-High : 3646
Low : 0

Stage 2 Drainage density (10m LiDAR)

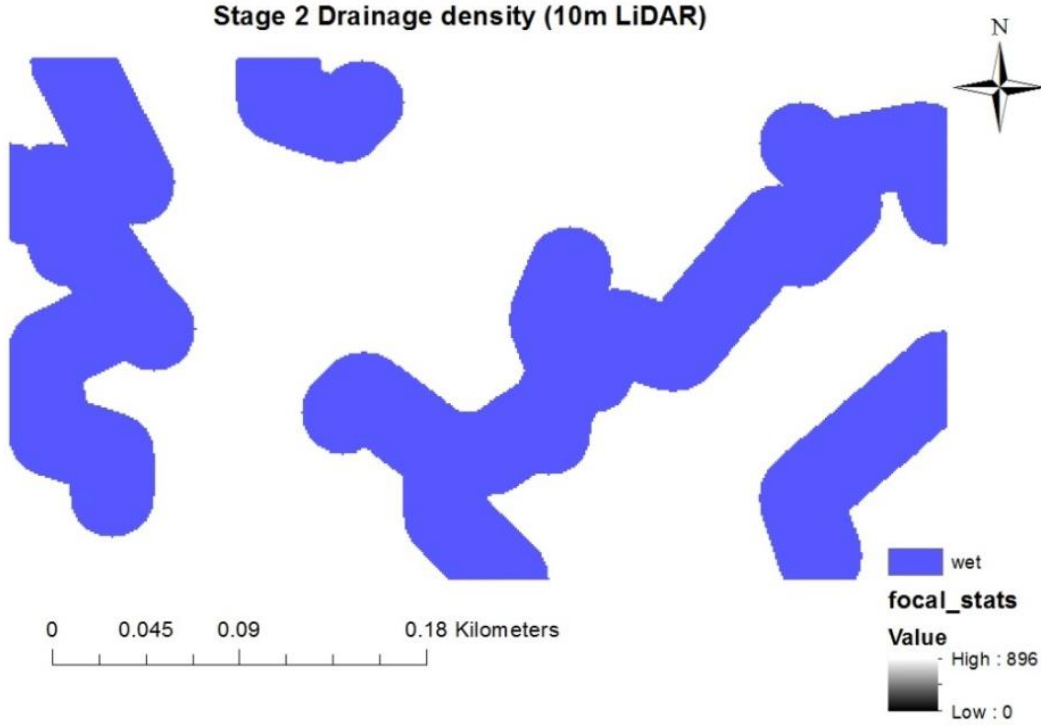

Stage 2 Drainage density (15 m LiDAR)

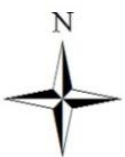

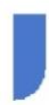

wet

focal_stats

Value

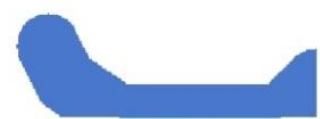

- High : 57

Low : 0 


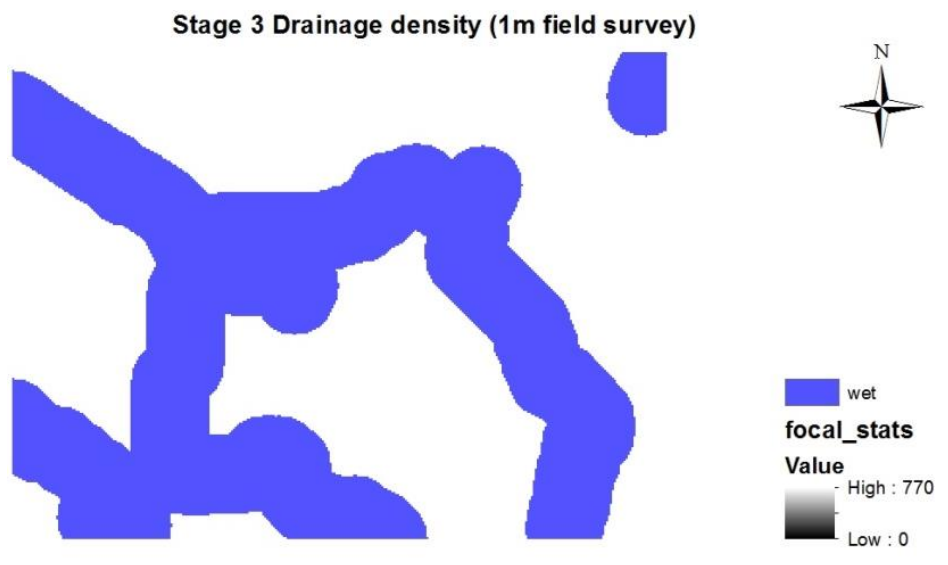

$\begin{array}{llll}0 & 0.045 & 0.09 & 0.18 \text { Kilometers }\end{array}$

Stage 3 Drainage density (1m LiDAR)
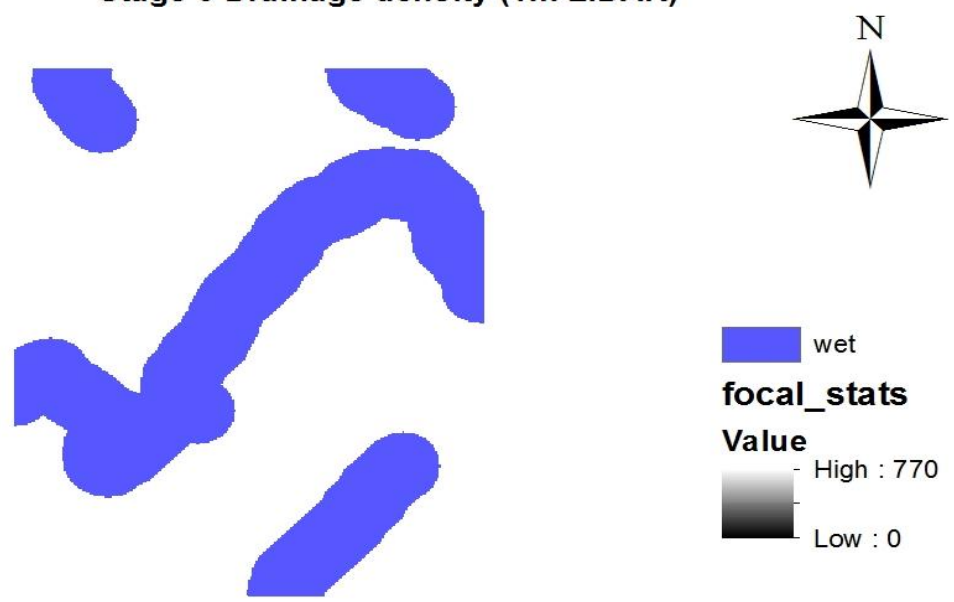

$\begin{array}{lll}0 & 0.045 & 0.09\end{array}$

0.18 Kilometers

Stage 3 Drainage density (5m LiDAR)
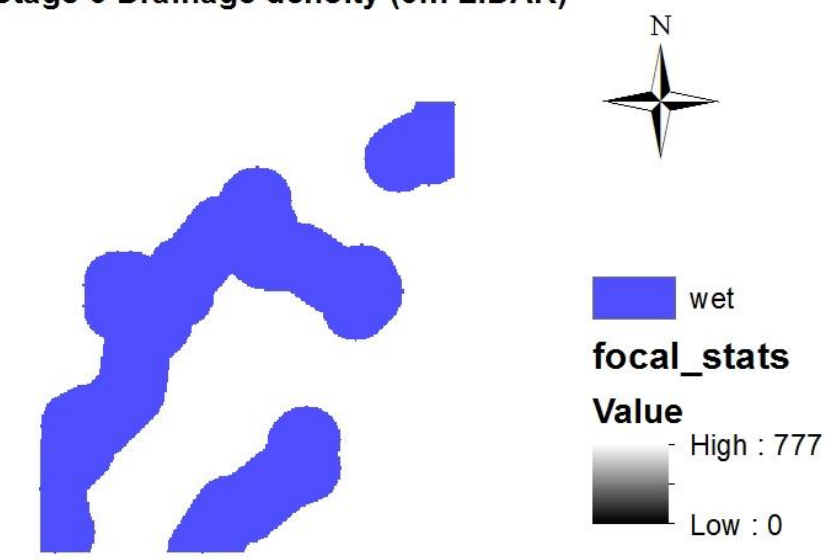

focal_stats

Value

High : 770

Low : 0 


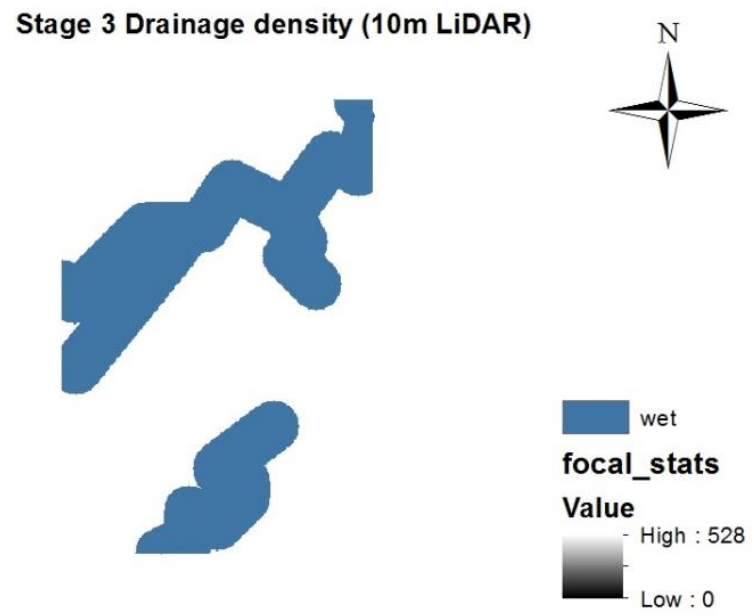

$\begin{array}{lll}0 & 0.0450 .09 & 0.18 \text { Kilometers }\end{array}$ 
Appendix 24 Plots of soil moisture retention raw data
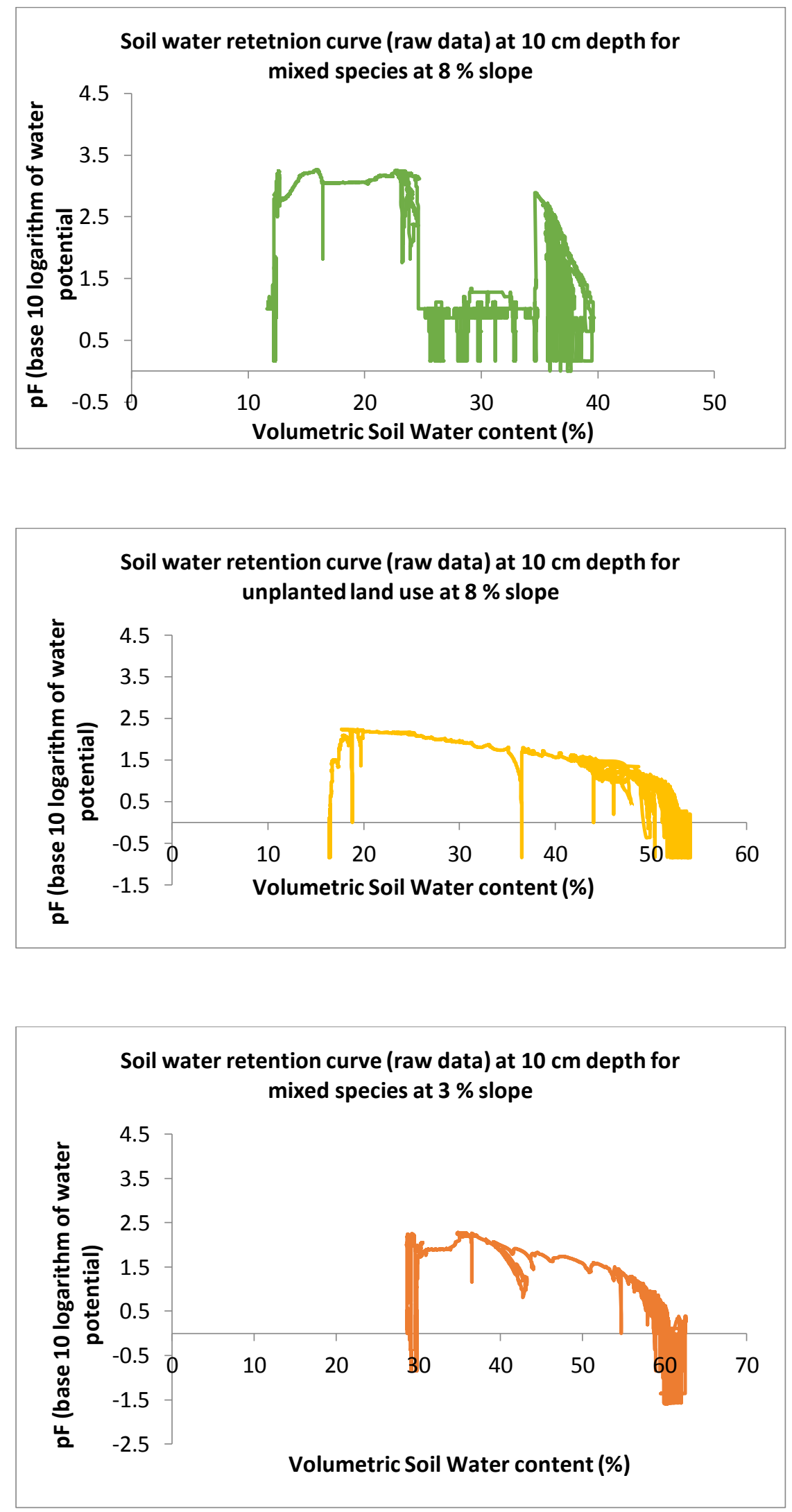

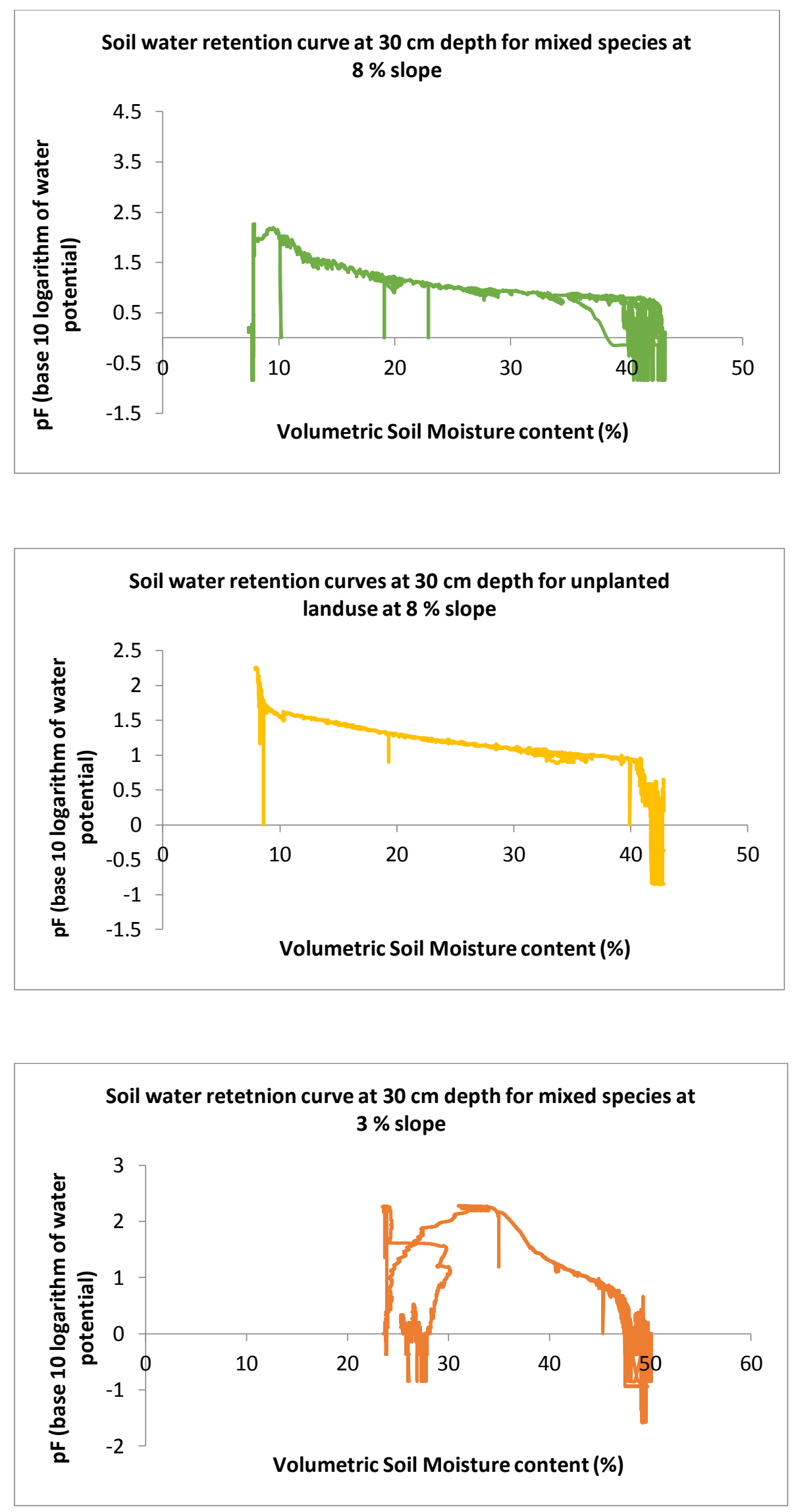


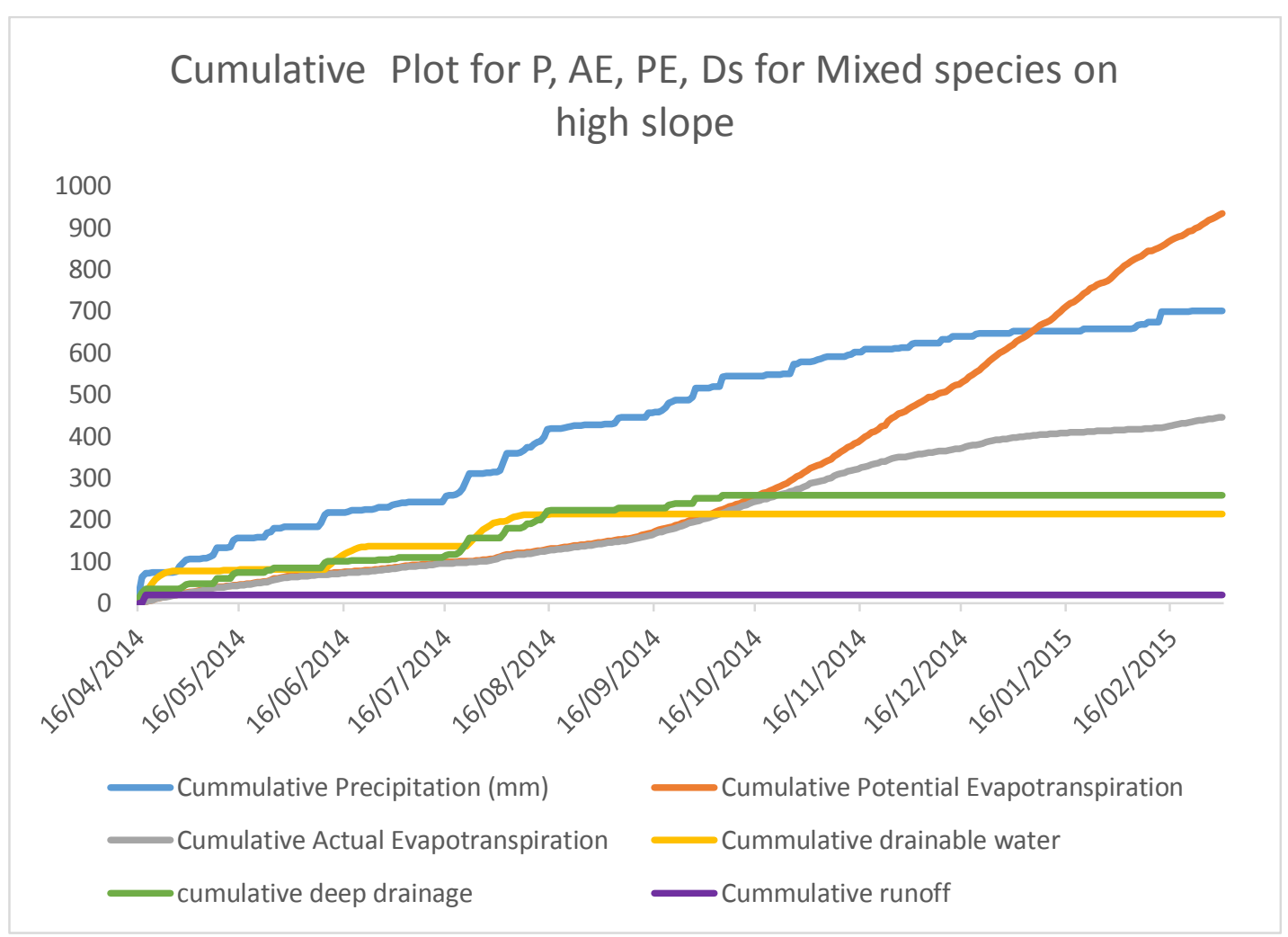

Appendix 26 Cumulative P-AE vs Ro +Ds (mixed species on high slope)

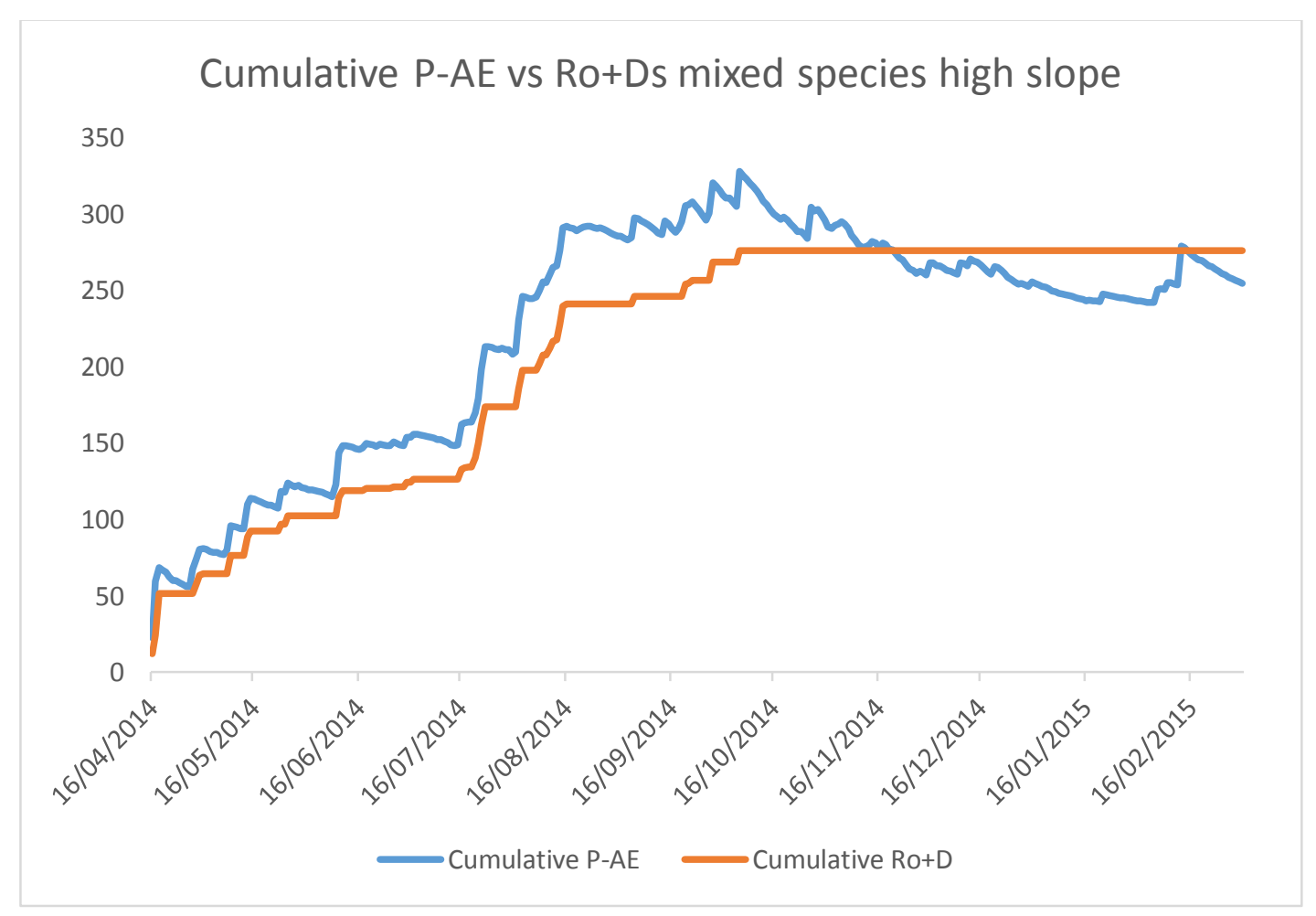




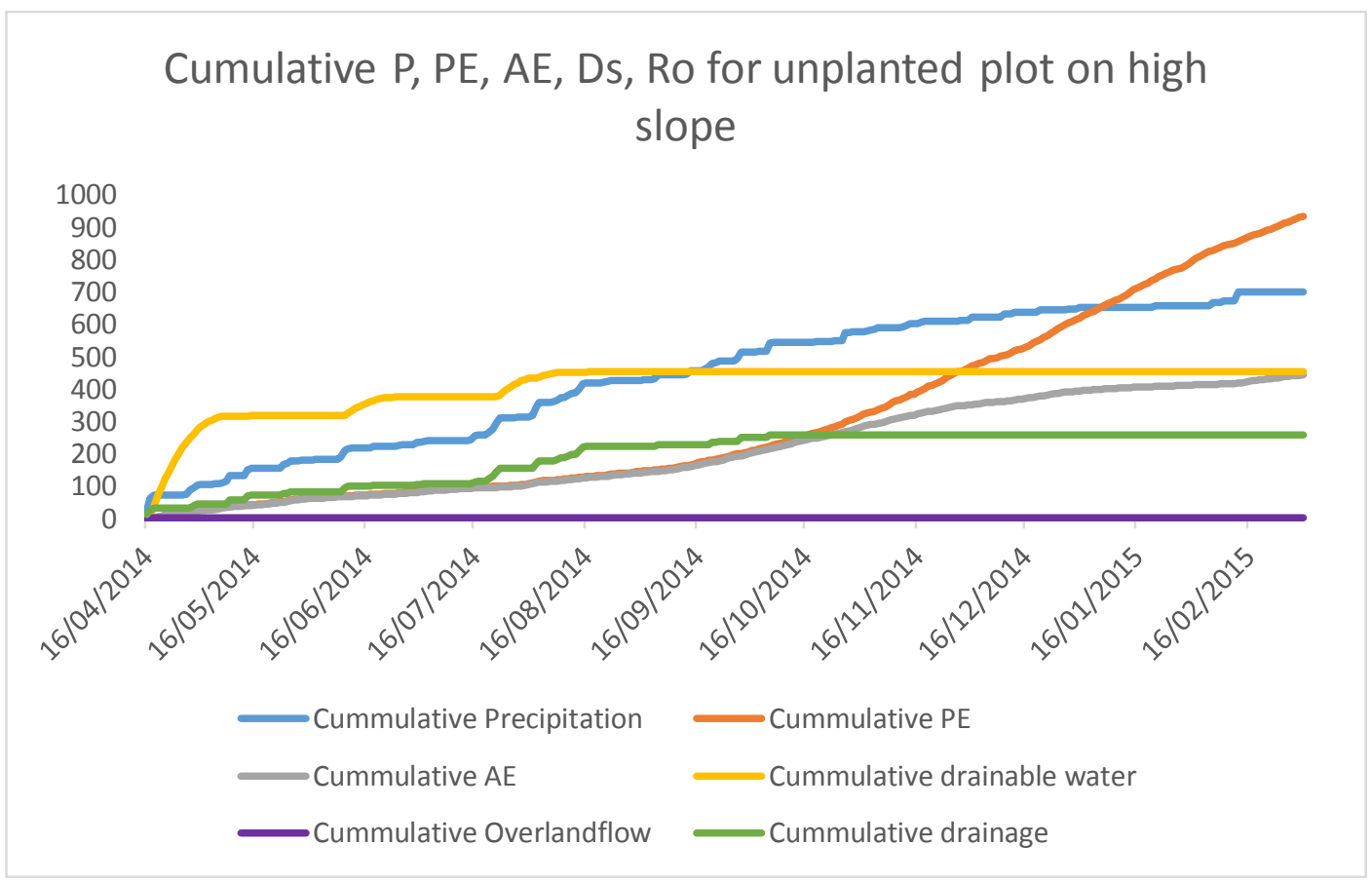

Appendix 28 Cumulative P-AE vs Ds + Ro in unplanted plot in high slope

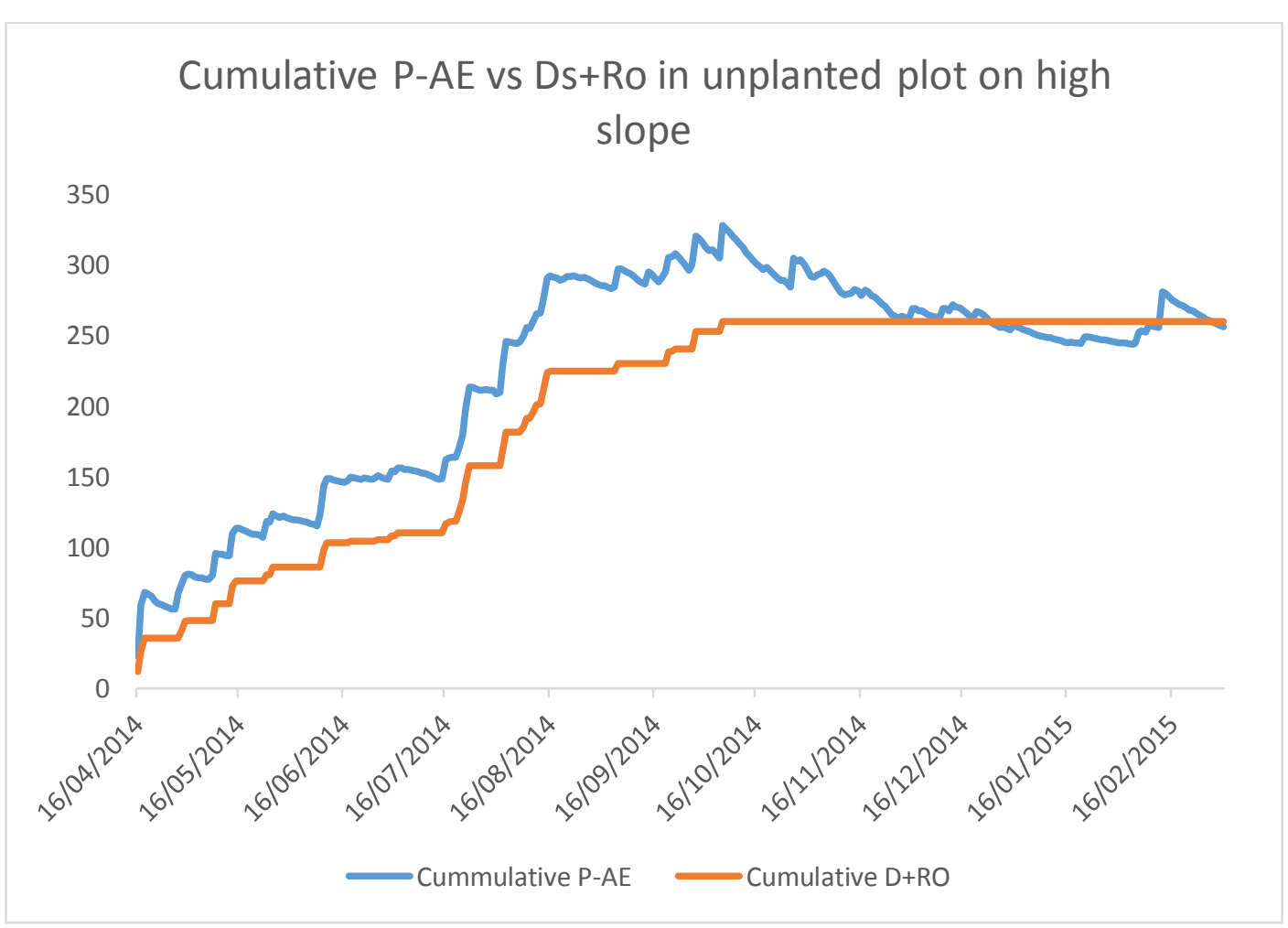




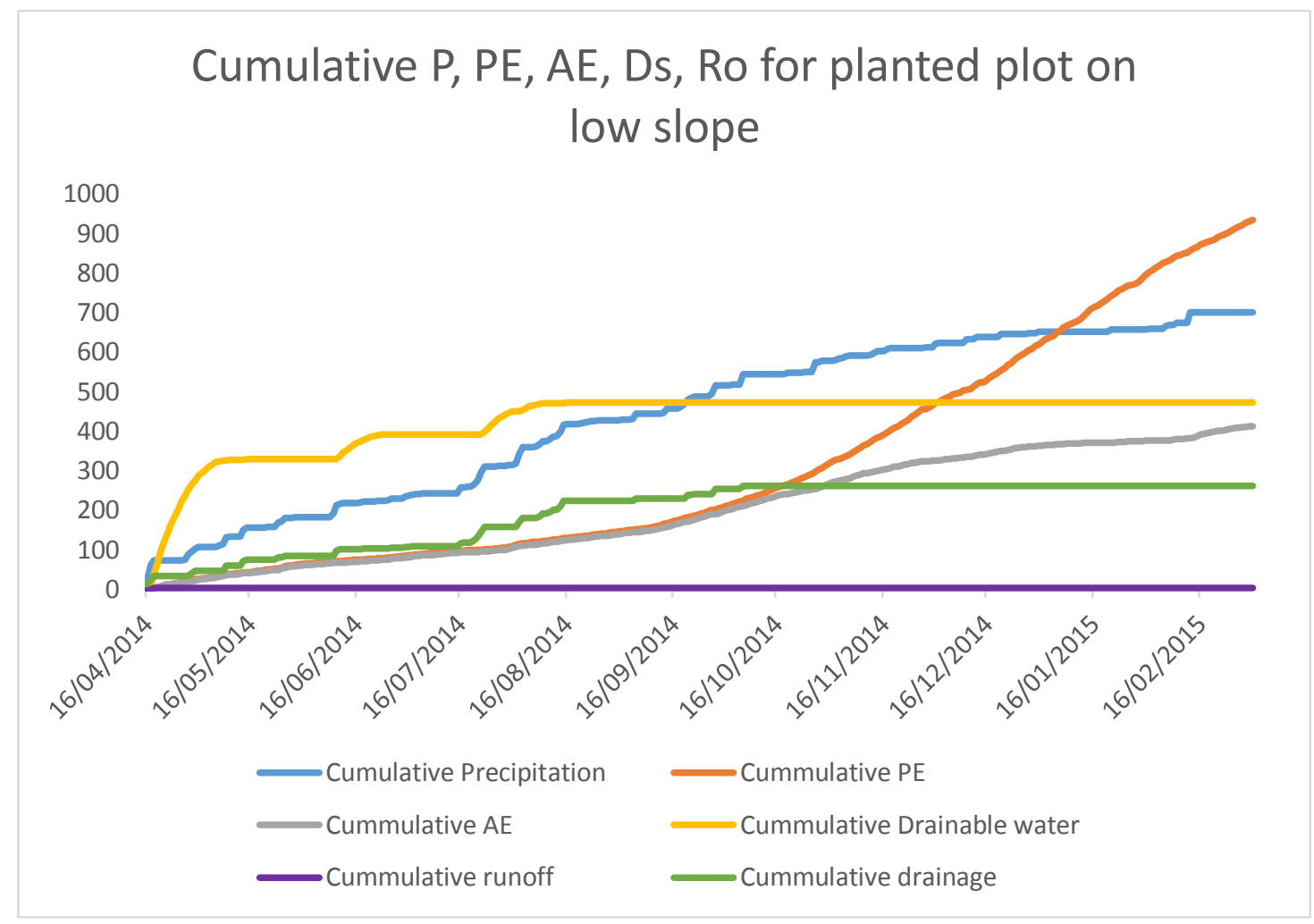

Appendix 30 Cumulative P-AE vs Ds + Ro in mixed species plot on low slope

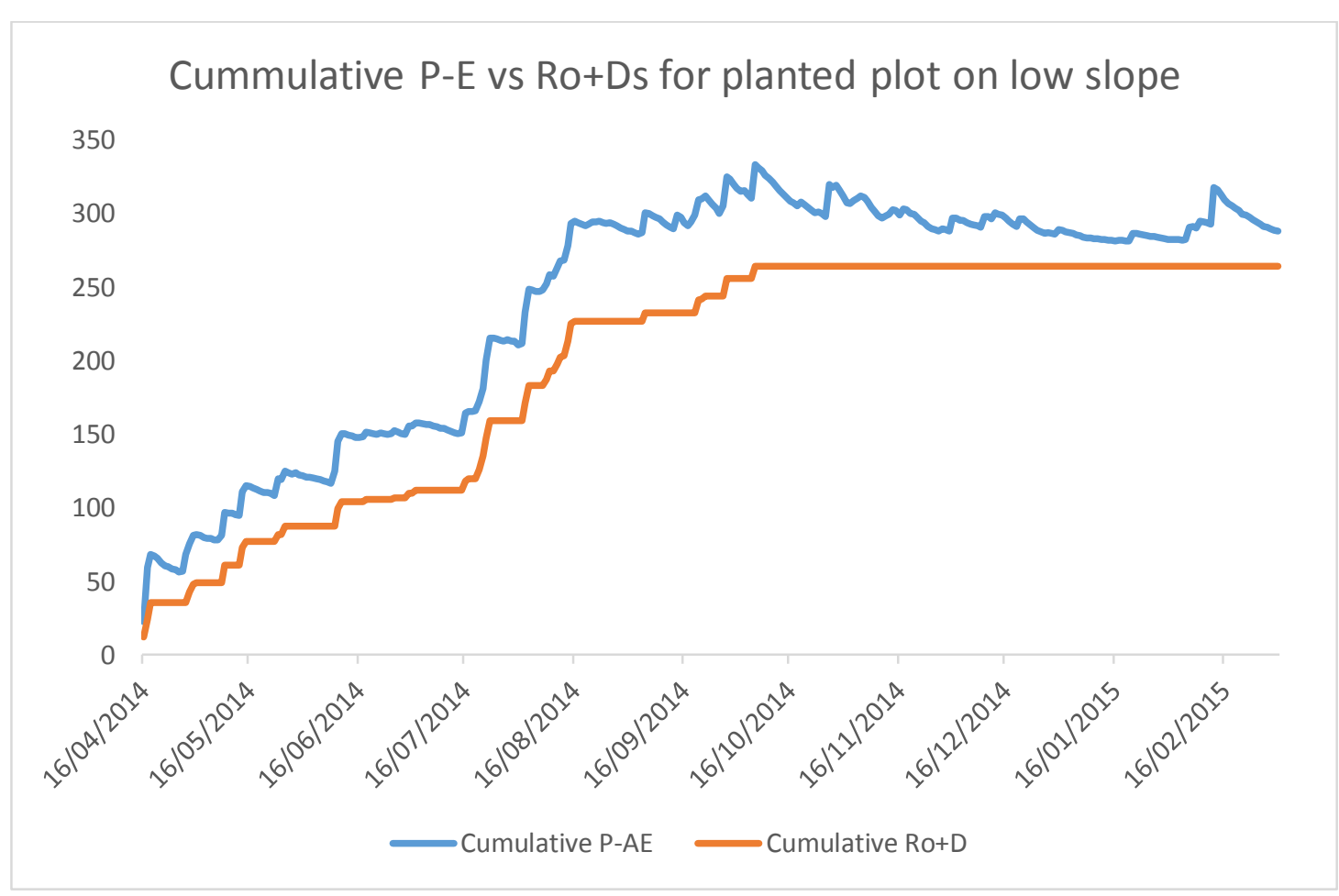




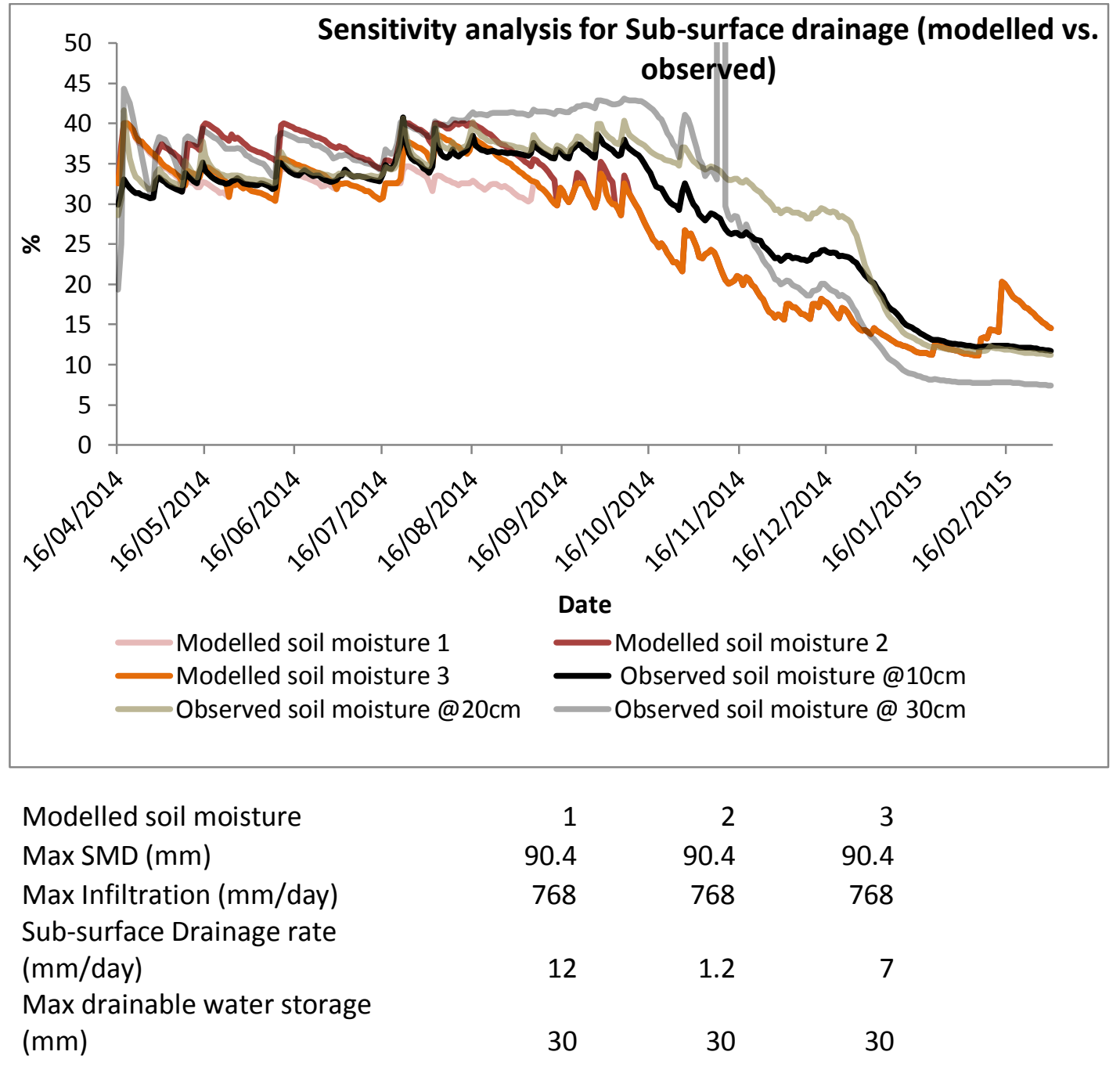




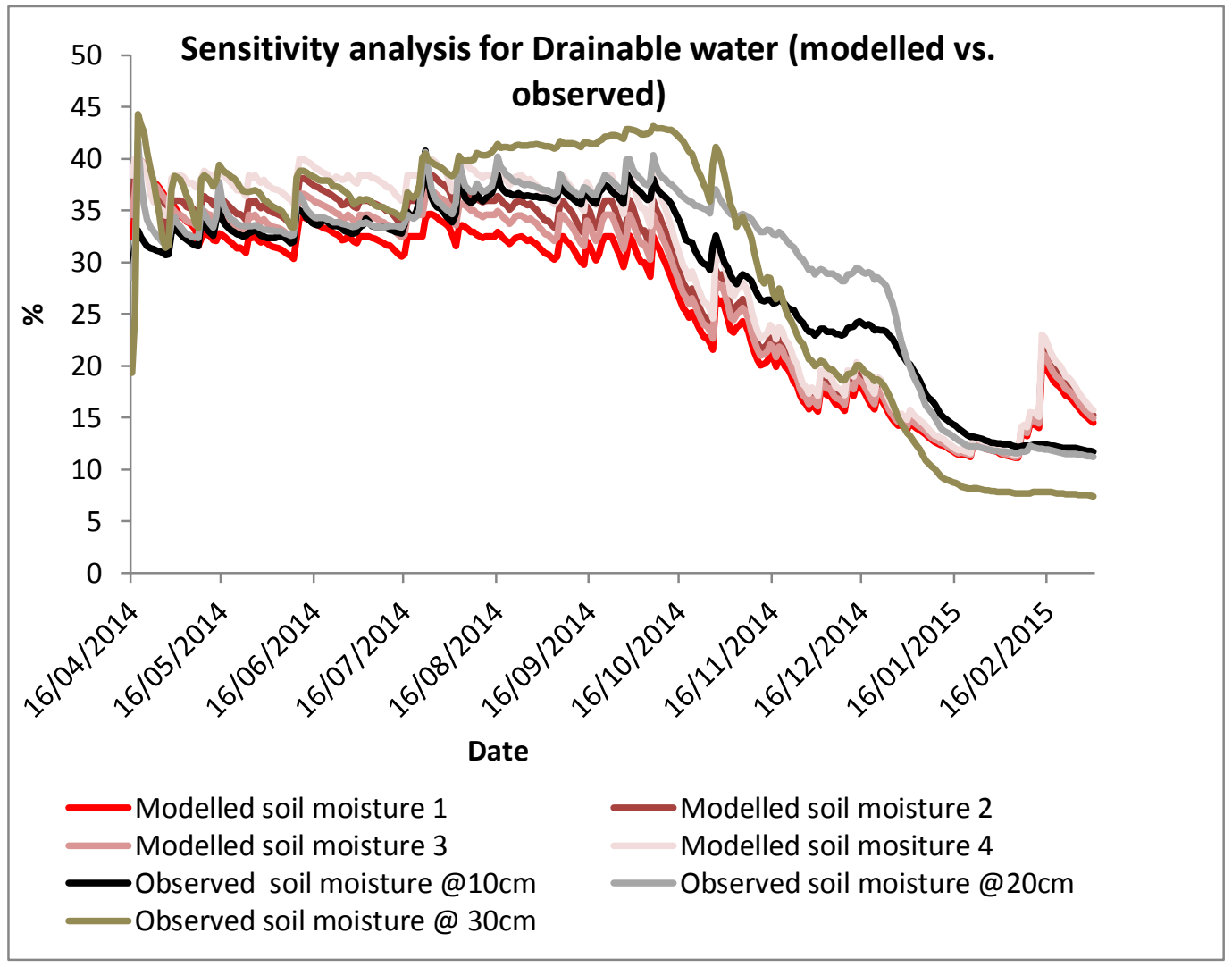

Modelled soil moisture

$\begin{array}{rrrr}1 & 2 & 3 & 4 \\ 90.4 & 90.4 & 90.4 & 90.4 \\ 768 & 768 & 768 & 768\end{array}$

Max Infiltration ( $\mathrm{mm} /$ day)

12

12

12

12

Max drainable water storage $(\mathrm{mm})$

30

14

20

5 


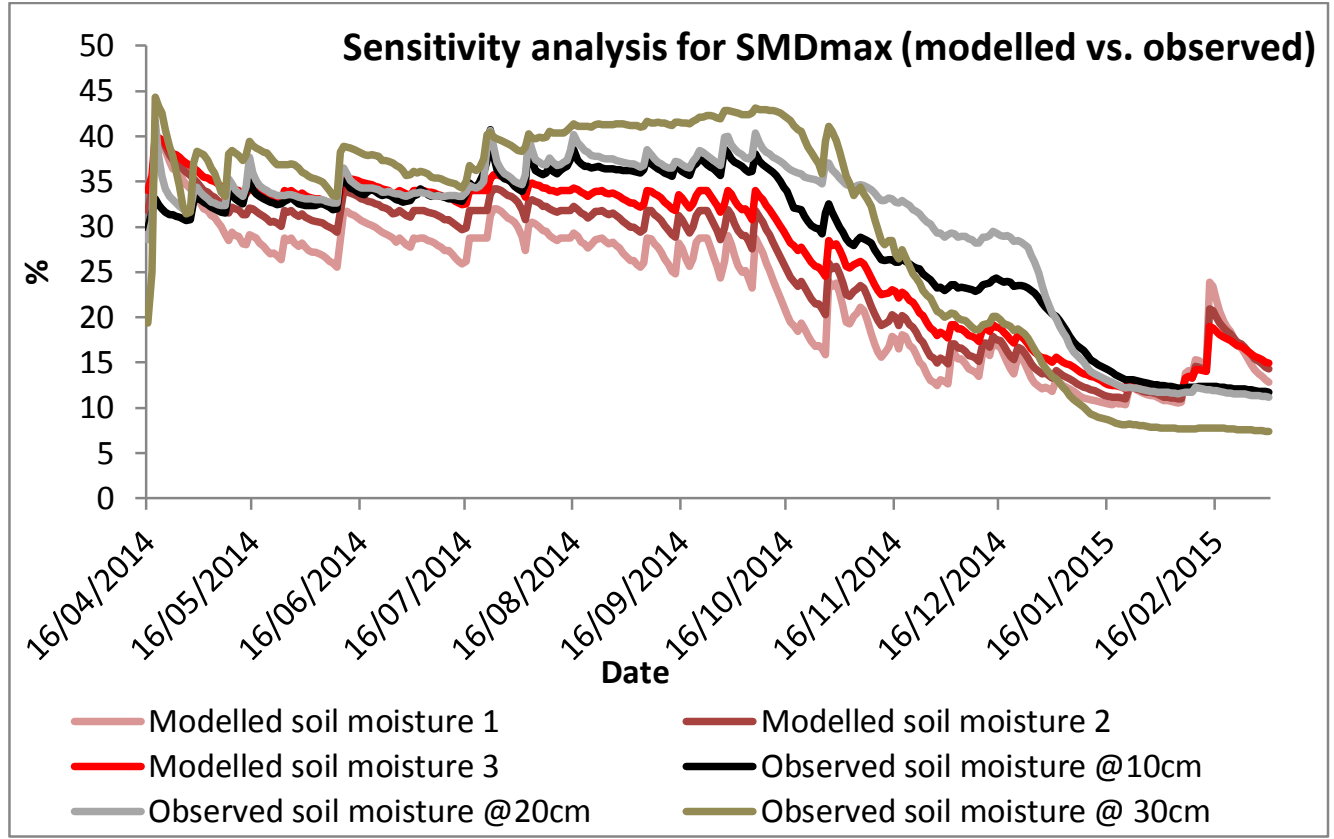

Modelled soil moisture

$\begin{array}{rrr}1 & 2 & 3 \\ 50 & 90.4 & 120 \\ 768 & 768 & 768\end{array}$

Max Infiltration ( $\mathrm{mm} /$ day)

768

Sub-surface Drainage rate

(mm/day)

$12 \quad 12$

12

Max drainable water storage $(\mathrm{mm})$

$30 \quad 30$

30 